\title{
aerospace
}

\section{Civil and Military}

Airworthiness

Recent Developments and

Challenges

Edited by

Kyriakos I. Kourousis

Printed Edition of the Special Issue Published in Aerospace 


\section{Civil and Military Airworthiness}





\section{Civil and Military Airworthiness Recent Developments and Challenges}

Special Issue Editor

Kyriakos I. Kourousis 
Special Issue Editor

Kyriakos I. Kourousis

School of Engineering,

University of Limerick

Ireland

Editorial Office

MDPI

St. Alban-Anlage 66

4052 Basel, Switzerland

This is a reprint of articles from the Special Issue published online in the open access journal Aerospace (ISSN 2226-4310) from 2018 to 2020 (available at: https://www.mdpi.com/journal/aerospace/ special_issues/airworthiness).

For citation purposes, cite each article independently as indicated on the article page online and as indicated below:

LastName, A.A.; LastName, B.B.; LastName, C.C. Article Title. Journal Name Year, Article Number, Page Range.

ISBN 978-3-03928-915-8 (Hbk)

ISBN 978-3-03928-916-5 (PDF)

(C) 2020 by the authors. Articles in this book are Open Access and distributed under the Creative Commons Attribution (CC BY) license, which allows users to download, copy and build upon published articles, as long as the author and publisher are properly credited, which ensures maximum dissemination and a wider impact of our publications.

The book as a whole is distributed by MDPI under the terms and conditions of the Creative Commons license CC BY-NC-ND. 


\section{Contents}

About the Special Issue Editor $\ldots \ldots \ldots \ldots \ldots \ldots \ldots \ldots \ldots$

Kyriakos I. Kourousis

Special Issue: Civil and Military Airworthiness: Recent Developments and Challenges

Reprinted from: Aerospace 2020, 7, 37, doi:10.3390/aerospace7040037 . . . . . . . . . . . . . 1

\section{Anna V. Chatzi}

The Diagnosis of Communication and Trust in Aviation Maintenance (DiCTAM) Model

Reprinted from: Aerospace 2019, 6, 120, doi:10.3390/aerospace6110120 . . . . . . . . . . . . . 3

\section{Jonas Aust and Dirk Pons}

Bowtie Methodology for Risk Analysis of Visual Borescope Inspection during Aircraft Engine Maintenance

Reprinted from: Aerospace 2019, 6, 110, doi:10.3390/aerospace6100110 . . . . . . . . . . . . .

\section{Michail Bozoudis, Ilias Lappas and Angelos Kottas}

Use of Cost-Adjusted Importance Measures for Aircraft System Maintenance Optimization

Reprinted from: Aerospace 2018, 5, 68, doi:10.3390/aerospace5030068 . . . . . . . . . . . . . 59

\section{Dimitrios Chionis and Nektarios Karanikas}

Differences in Risk Perception Factors and Behaviours amongst and within Professionals and Trainees in the Aviation Engineering Domain

Reprinted from: Aerospace 2018, 5, 62, doi:10.3390/aerospace5020062 . . . . . . . . . . . . . 79

\section{Anna V. Chatzi, Wayne Martin, Paul Bates and Patrick Murray}

The Unexplored Link between Communication and Trust in Aviation Maintenance Practice Reprinted from: Aerospace 2019, 6, 66, doi:10.3390/aerospace6060066 . . . . . . . . . . . . . 104

\section{Eranga Batuwangala, Jose Silva and Graham Wild}

The Regulatory Framework for Safety Management Systems in Airworthiness Organisations Reprinted from: Aerospace 2018, 5, 117, doi:10.3390/aerospace5040117 . . . . . . . . . . . . . . 122

\section{Ting Dong and Nam H. Kim}

Cost-Effectiveness of Structural Health Monitoring in Fuselage Maintenance of the Civil Aviation Industry ${ }^{\dagger}$

Reprinted from: Aerospace 2018, 5, 87, doi:10.3390/aerospace5030087 . . . . . . . . . . . 136

\section{Asma Tabassum, Roberto Sabatini and Alessandro Gardi}

Probabilistic Safety Assessment for UAS Separation Assurance and Collision Avoidance Systems

Reprinted from: Aerospace 2019, 6, 19, doi:10.3390/aerospace6020019 . . . . . . . . . . . . . 160

\section{Ilias Lappas and Michail Bozoudis}

The Development of an Ordinary Least Squares Parametric Model to Estimate the Cost Per Flying Hour of 'Unknown' Aircraft Types and a Comparative Application ${ }^{\dagger}$

Reprinted from: Aerospace 2018, 5, 104, doi:10.3390/aerospace5040104 .

Athanasios Iliopoulos, Rhys Jones, John Michopoulos, Nam Phan and R. K. Singh Raman

Crack Growth in a Range of Additively Manufactured Aerospace Structural Materials

Reprinted from: Aerospace 2018, 5, 118, doi:10.3390/aerospace5040118 . . . . . . . . . . . . . . . 201 


\section{Vittorio Memmolo}

Damage Localization in Composite Structures Using a Guided Waves Based Multi-Parameter Approach

Reprinted from: Aerospace 2018, 5, 111, doi:10.3390/aerospace5040111

Oliver Hirling and Florian Holzapfel

EASA's "Open" Category for Military UAS: Opportunities and Limitations in the Field of Airworthiness

Reprinted from: Aerospace 2018, 5, 70, doi:10.3390/aerospace5030070 _ . . . . . . . . . . . 246 


\section{About the Special Issue Editor}

Kyriakos I. Kourousis is a tenured Senior Lecturer (Associate Professor) in the School of Engineering of the University of Limerick in Ireland. He also serves as the Director of the undergraduate and postgraduate airworthiness programs offered by the University of Limerick. Dr. Kourousis holds a B.S. in Aeronautical Engineering from the Hellenic Air Force Academy, and a M.S. and Ph.D. in solid mechanics and metal plasticity, both from the National Technical University of Athens. Dr. Kourousis has 19 years of professional and research experience in the fields of metal plasticity, metal additive manufacturing, and airworthiness, both as an Aeronautical Engineer Officer (Major res.) and university faculty in Ireland and Australia. His professional background includes 12 years in the Hellenic Air Force as a maintenance officer, quality control and assurance manager, and airworthiness manager for the Mirage 2000 fleet. Dr. Kourousis has led various research projects funded by civil and defence companies and state organizations in defence airworthiness, aircraft fatigue, metal plasticity, aviation training, and other areas. To date, he has authored a total of 90 scholarly journal papers, conference papers, and technical and engineering reports in the fields of his research and professional expertise. He is a Chartered Engineer, registered with the United Kingdom Engineering Council, and a Fellow of the Royal Aeronautical Society. 



\title{
Editorial \\ Special Issue: Civil and Military Airworthiness: Recent Developments and Challenges
}

\author{
Kyriakos I. Kourousis \\ School of Engineering, University of Limerick, Limerick V94 T9PX, Ireland; kyriakos.kourousis@ul.ie \\ Received: 27 March 2020; Accepted: 31 March 2020; Published: 1 April 2020
}

Airworthiness, as a field, encompasses all those technical and non-technical activities required to design, certify, produce, maintain and operate safely an aircraft throughout its lifespan. The evolving technology, scientific and engineering methods and, most importantly, aviation regulation, offers new opportunities and creates new challenges for the aviation industry.

This Special Issue assembles a diverse selection of research and review papers on topics of interest to the modern industry practitioners and researchers. These topics span across the initial and continuing airworthiness spectrum, discussing problems in the broader thematic areas of aircraft maintenance [1-7], safety management [6,8], human factors [1,4,5], cost analysis [3,7,9], structures [7,10,11], risk assessment [2,4], unmanned aerial vehicles [8,12] and regulations [6,12].

Reflecting on the list of targeted themes, communicated through the call for papers [13], I was pleased to see that most have been covered in the Special Issue, as indicated with the italic format in Table 1. I trust the readers will enjoy this variety of high-quality research and review papers.

Table 1. Coverage of Special Issue's targeted theme areas, as indicated with the italic format.

\begin{tabular}{|c|c|}
\hline Initial Airworthiness & Continuing Airworthiness \\
\hline $\begin{array}{l}\text { Aircraft and aeronautical components testing } \\
\text { and certification }\end{array}$ & $\begin{array}{l}\text { Safety and risk assessment in aircraft flight and } \\
\text { technical operations }\end{array}$ \\
\hline $\begin{array}{l}\text { Qualification and certification of new technologies, i.e., } \\
\text { supersonic transport aircraft, electric and hybrid } \\
\text { propulsion aircraft, etc. }\end{array}$ & $\begin{array}{l}\text { Reliability analysis of aircraft systems } \\
\text { and components }\end{array}$ \\
\hline Certification of systems specific to military aircraft & $\begin{array}{l}\text { Continuing airworthiness management practice in civil } \\
\text { and military aviation }\end{array}$ \\
\hline $\begin{array}{l}\text { Qualification and certification of additively manufactured } \\
\text { metallic and non-metallic safe/non-safety-critical } \\
\text { aircraft parts }\end{array}$ & $\begin{array}{l}\text { Development and optimization of aircraft } \\
\text { maintenance programmes }\end{array}$ \\
\hline $\begin{array}{l}\text { Advanced testing and computational techniques for } \\
\text { composite aircraft testing and certification }\end{array}$ & $\begin{array}{l}\text { Development and optimization of military aircraft } \\
\text { structural integrity (ASI) management programmes }\end{array}$ \\
\hline $\begin{array}{l}\text { Reliability engineering methodologies and practice in } \\
\text { aircraft design and engineering changes }\end{array}$ & $\begin{array}{l}\text { Effective and efficient inspection and sustainment } \\
\text { techniques for composite aircraft }\end{array}$ \\
\hline $\begin{array}{l}\text { Safety and risk assessment methodologies and practice in } \\
\text { aircraft development }\end{array}$ & Human factors in aircraft maintenance and operations \\
\hline \multirow[t]{3}{*}{ Human factor considerations in aircraft design } & $\begin{array}{l}\text { Safety management effectiveness in flight and } \\
\text { technical operations }\end{array}$ \\
\hline & $\begin{array}{l}\text { Quality management and optimization in aircraft } \\
\text { maintenance organisations }\end{array}$ \\
\hline & $\begin{array}{l}\text { Aircraft technical and non-technical cost analysis and } \\
\text { estimation techniques }\end{array}$ \\
\hline
\end{tabular}


Funding: I have not received external funding.

Acknowledgments: I wish to thank all authors for their contributions.

Conflicts of Interest: I declare no conflict of interest.

\section{References}

1. Chatzi, A.V. The Diagnosis of Communication and Trust in Aviation Maintenance (DiCTAM) Model. Aerospace 2019, 6, 120. [CrossRef]

2. Aust, J.; Pons, D. Bowtie Methodology for Risk Analysis of Visual Borescope Inspection during Aircraft Engine Maintenance. Aerospace 2019, 6, 110. [CrossRef]

3. Bozoudis, M.; Lappas, I.; Kottas, A. Use of Cost-Adjusted Importance Measures for Aircraft System Maintenance Optimization. Aerospace 2018, 5, 68. [CrossRef]

4. Chionis, D.; Karanikas, N. Differences in Risk Perception Factors and Behaviours amongst and within Professionals and Trainees in the Aviation Engineering Domain. Aerospace 2018, 5, 62. [CrossRef]

5. Chatzi, A.V.; Martin, W.; Bates, P.; Murray, P. The Unexplored Link between Communication and Trust in Aviation Maintenance Practice. Aerospace 2019, 6, 66. [CrossRef]

6. Batuwangala, E.; Silva, J.; Wild, G. The Regulatory Framework for Safety Management Systems in Airworthiness Organisations. Aerospace 2018, 5, 117. [CrossRef]

7. Dong, T.; Kim, N.H. Cost-Effectiveness of Structural Health Monitoring in Fuselage Maintenance of the Civil Aviation Industry ${ }^{\dagger}$. Aerospace 2018, 5, 87. [CrossRef]

8. Tabassum, A.; Sabatini, R.; Gardi, A. Probabilistic Safety Assessment for UAS Separation Assurance and Collision Avoidance Systems. Aerospace 2019, 6, 19. [CrossRef]

9. Lappas, I.; Bozoudis, M. The Development of an Ordinary Least Squares Parametric Model to Estimate the Cost Per Flying Hour of 'Unknown' Aircraft Types and a Comparative Application ${ }^{\dagger}$. Aerospace 2018, 5, 104. [CrossRef]

10. Iliopoulos, A.; Jones, R.; Michopoulos, J.; Phan, N.; Singh Raman, R.K. Crack Growth in a Range of Additively Manufactured Aerospace Structural Materials. Aerospace 2018, 5, 118. [CrossRef]

11. Memmolo, V.; Boffa, N.D.; Maio, L.; Monaco, E.; Ricci, F. Damage Localization in Composite Structures Using a Guided Waves Based Multi-Parameter Approach. Aerospace 2018, 5, 111. [CrossRef]

12. Hirling, O.; Holzapfel, F. EASA's "Open" Category for Military UAS: Opportunities and Limitations in the Field of Airworthiness. Aerospace 2018, 5, 70. [CrossRef]

13. Special Issue "Civil and Military Airworthiness: Recent Developments and Challenges". Available online: https://www.mdpi.com/journal/aerospace/special_issues/airworthiness (accessed on 26 March 2020).

(C) 2020 by the author. Licensee MDPI, Basel, Switzerland. This article is an open access article distributed under the terms and conditions of the Creative Commons Attribution (CC BY) license (http://creativecommons.org/licenses/by/4.0/). 
Article

\title{
The Diagnosis of Communication and Trust in Aviation Maintenance (DiCTAM) Model
}

\begin{abstract}
Anna V. Chatzi
School of Commerce, University of Southern Queensland, 37 Sinnathamby Blvd, Springfield Central, Brisbane, QLD 4300, Australia; anna.chatzi@usq.edu.au

Received: 16 September 2019; Accepted: 29 October 2019; Published: 1 November 2019

Abstract: In this research paper a new conceptual model is introduced-the Diagnosis of Communication and Trust in Aviation Maintenance (DiCTAM) model. The purpose of this model is to recognise, measure and predict the relationship between communication and trust in the aviation maintenance field. This model was formed by combining a conceptual cyclical process and two established survey tools, adapted and incorporated in a single question set. The implementation of each phase of the DiCTAM model is performed with the use of qualitative and quantitative research methods. This includes the use of content analyses of accident/incident investigation reports and training material, a survey and a hypothetical case study. The predictive functionality of the DiCTAM model has been investigated through the hypothetical case study. The obtained results indicate a positive relationship between communication and trust according to the aviation maintenance employees' perception and accidents/incidents reports, even though basic training includes communication without direct mention of trust.
\end{abstract}

Keywords: aviation; communication; trust; aviation maintenance; prevention; human factors

\section{Introduction}

Communication can be defined as the transmission of information from one person to another, while trust is the openness to another party, based on the concept of its reliability and competence [1]. Trust is associated with and can contribute to successful communication [2,3]. Thus, a minimum level of trust should be present along with effective communication between two or more counterparts. Past research has shown that effective communication techniques are part of employees' initial and recurrent training and are linked to their on-job safety-related practices [4]. Furthermore, organisational commitment and employees' level of organisational satisfaction is associated with employees' safety-related practices [5-9].

Both communication and trust are fundamental concepts that can influence safe practice in aviation maintenance, especially in the regions exhibiting fast growth [10]. It is well recognised that poor communication is a paramount human factor contributing to errors [11,12]. More specifically, researchers have identified the gap in effective communication between maintenance staff, cabin crew and flight crew, proposing some ways to mitigate this issue [13-16]. Some researchers have acknowledged the need for error-free communication within aviation [14,16], while others have identified poor communication to be an accident causal factor [17-19]. Tools have been developed to proactively detect maintenance failures, such as the Maintenance Operations Safety Survey (MOSS), in which communication and trust are major factors [20]. The relationship between trust and communication, including initial trust levels, among technical staff, have not been adequately investigated and further research could play an important role in aviation maintenance and the advancement of aviation safety [21].

The recognition and measurement of perceptions around communication and trust has been studied extensively in various industries. Various survey-based research tools has been used for that 
purpose, including the Communication Satisfaction Questionnaire (CSQ) and the Trust Constructs and Measures Questionnaire (TCMQ). These are briefly discussed in the following paragraphs.

The CSQ is a tool that was incepted in 1977 [22] and widely used since then in research projects dealing with communication satisfaction in various industries [22-34]. The CSQ has been an efficient tool to extract employees' perceptions of the communication within their organisation $[33,35,36]$. This is a 40-questions questionnaire, with items categorized in eight communicative themes (dimensions). These dimensions vary from interpersonal communication (e.g., an employee's evaluation of the communication with his/her supervisor), to the organization-wide communication climate [32]. This construct has been found to have a test-retest reliability of 0.94 [22]. It has been characterised as "arguably the best measure of communication satisfaction in the organizational arena" ([27], p.6) while Rubin et al. ([34], p.116) agree that "The thoroughness of the construction of this satisfaction measure is apparent. The strategies employed in this study are exemplary."

The TCMQ has been developed by Li, Rong, \& Thatcher [37] and it is in practice a synthesis of various questionnaires developed and used in past research studies [38-44]. The studies performed with the constituent questionnaires have yielded valid and reliable research data and findings, which informed their adoption and adaption from Li et al. [37]. Moreover, the measurement model (reliability scores, construct validity, convergent and discriminant validity) was found to produce statistically significant results [37]. The measurement model results verified that the measurement scales adapted by Li et al. [37] were valid and reliable in their study. Specifically, web capability and reliability were found to be powerfully belief constituent in assessing trust in website. This outcome confirmed that the Information Technology-specific scales, which were adopted by Li et al. [37] were valid in technology trust measurement [37].

This paper introduces a conceptual model, built upon the CSQ and TCMQ tools, which aims to explore and understand the relationship between trust and communication in aviation maintenance. In particular, the objectives of the proposed model are summarised as following:

1. Detect the existence of communication and trust in aviation maintenance practice;

2. Recognise if communication and trust are covered in the aviation maintenance basic training curriculum;

3. Detect and measure the perception of aviation maintenance employees on communication and trust within their working environment;

4. Predict deviations in maintenance practice that can be attributed to communication and trust preconditions.

\section{Model Formulation}

\subsection{Model Foundation: Cyclical Process}

The foundation of the proposed conceptual model is a four-phase cyclical process used for the diagnosis of communication and trust issues in various facets of aviation maintenance. Each phase has been chosen to align with the objectives of the model, as outlined in the Introduction section of this paper. The cyclic process transforms the individual objectives of the model to a structured-interconnected process, following a systems approach. Each phase's tasks are provided below, with the cyclical process illustrated schematically in Figure 1:

1. Phase 1: The two traits, communication and trust, are examined whether they exist or not in aviation maintenance;

2. Phase 2: Aviation maintenance training material is examined to recognise if the aviation maintenance employees are trained for communication and trust and consequently if they have developed awareness and relevant good practices in their work;

3. Phase 3: The aviation maintenance sector is investigated for the detection and measurement of the relation between the communication and trust; 
4. Phase 4: Having completed Phase 1,2 and 3, with all information and data available, one can predict any communication and trust precondition (positive associations), as a possible cause of error in any already established or new maintenance procedure/process/task in the workplace.

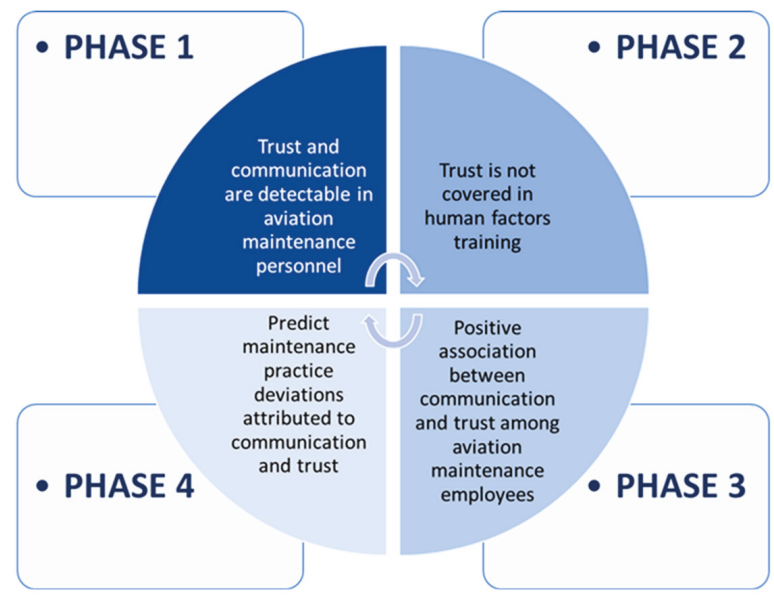

Figure 1. The foundation cyclic process of the proposed conceptual model used.

\subsection{Model Tool: Communication and Trust Question Set}

In order to accomplish the tasks involved in each of the four phases and by extension the objectives of the model, it is necessary to introduce a new tool. For this reason, a dual-use question set is introduced, consisting primarily of the:

- $\quad$ Communication Satisfaction Questionnaire (CSQ) [22];

- $\quad$ Trust Constructs and Measures Questionnaire (TCMQ) [37].

Both the original CSQ and TCMQ $[27,38]$ have been adapted to research communication and trust in an aviation maintenance context. Details on the adaptation of the CSQ and TCMQ are provided in a separate paper, currently under review [45]. These two questionnaires are complemented with demographics and general questions' sections. The complete set is denoted as the Communication and Trust Question Set (CTQS) (Appendix A) and it is comprised of the following sections:

- Section A: Demographic information of the participants;

- Section B: General Questions;

- Sections C, D and E: Communication Satisfaction Questionnaire (Section E is limited to managers);

- Sections F and G: Trust Constructs and Measures Questionnaire (Section G is limited to managers).

The CTQS is common across all phases of the conceptual process (Figure 1) and it is used both as a qualitative tool (having a recognition function) and a quantitative tool (having a diagnosis function). In both cases, the CTQS questions serve either as survey questions for human participants or desk research on primary/secondary data (i.e., when employing content analysis/case study methodologies). For example, as a quantitative tool, the CTQS diagnosis function can be used to explore the perceptions of aviation maintenance professionals about their work (Phase 3 shown in Figure 1). As a qualitative tool, its recognition function can be used to conduct content analysis of accident and incident investigation reports, audit reports and so forth (Phases 1 and 2 shown in Figure 1). Depending on the nature and amount of the body of material available, a quantitative analysis of these data through this function 
is possible. The same approach can be followed for actual or hypothetical scenarios for prediction purposes (Phase 4 shown in Figure 1).

The overall construct and functionalities of the CTQS are illustrated in Figure 2.

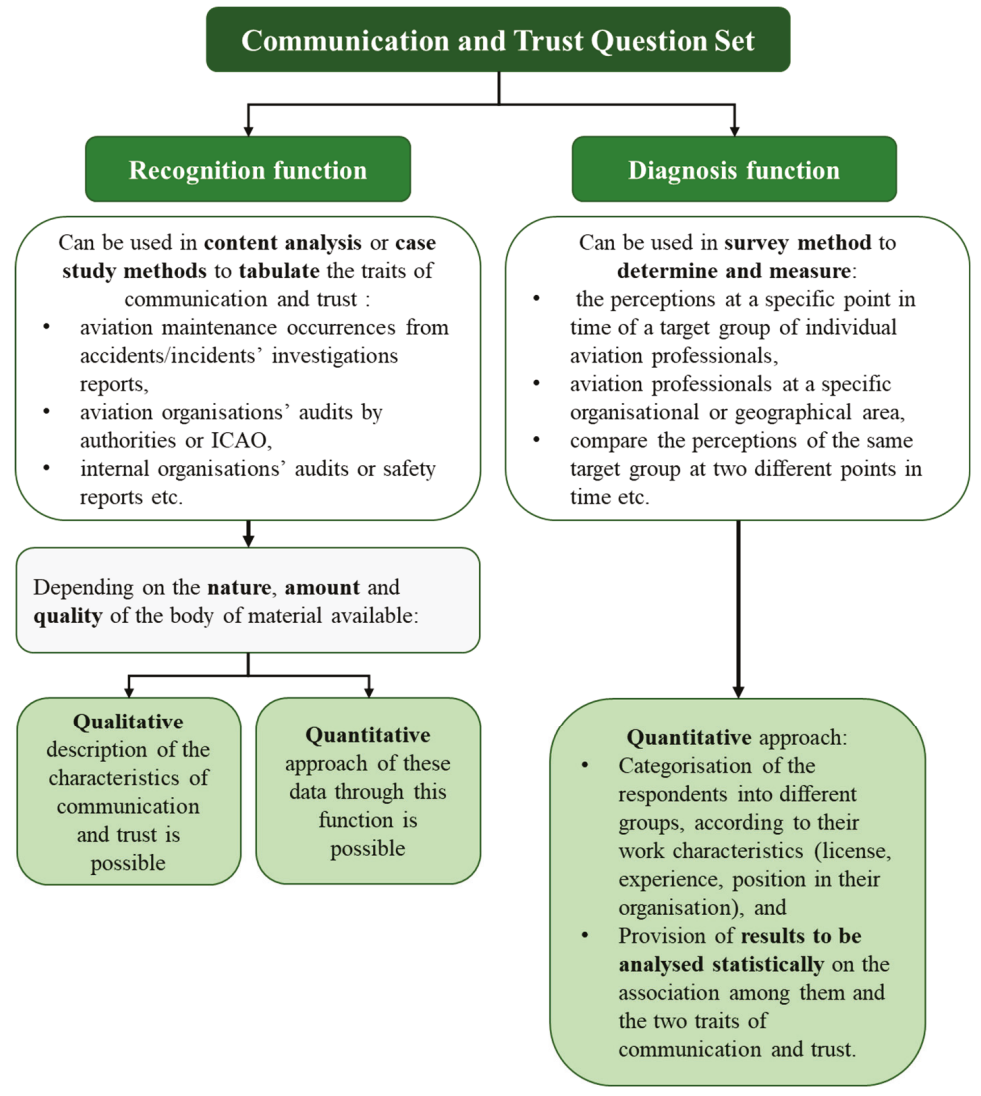

Figure 2. Multifunctional uses of the Communication and Trust Question Set (CTQS).

\subsection{Complete Model: Diagnosis of Communication and Trust in Aviation Maintenance (DiCTAM)}

The merging of the foundation cyclical process with the CTQS (described in Sections 2.1 and 2.2 correspondingly) constitutes the complete model, denoted as the Diagnosis of Communication and Trust in Aviation Maintenance (DiCTAM) model. This is represented schematically in Figure 3, where the different functionalities for each phase are also shown. The implementation of the model and the results obtained is presented in the next section of this paper. 


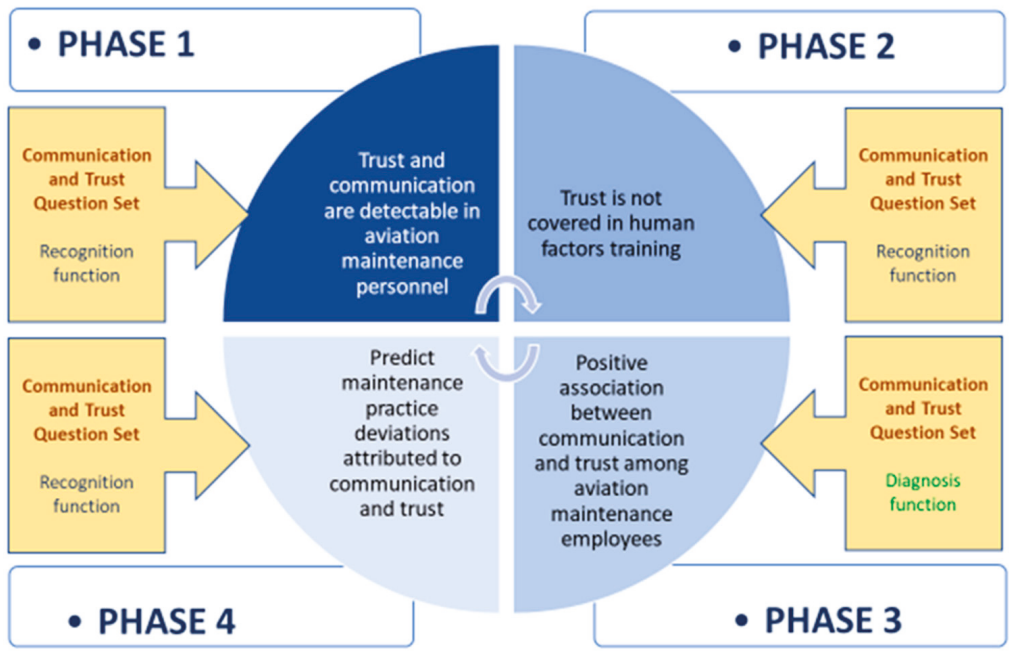

Figure 3. The complete Diagnosis of Communication and Trust in Aviation Maintenance (DiCTAM) model.

\section{Results and Discussion}

The implementation of the DiCTAM model is performed via a selection of different types of data and cases, in order to present its features, operation and the results that can be obtained when used for communication and trust analyses within an aviation maintenance context. Each section corresponds to the phases of the model, discussing in detail in the findings.

\subsection{Phase 1}

The content analysis technique was used in Phase 1 of DiCTAM, chosen for its capability for a thorough investigation of the existence of both communication and trust in real occurrences within aviation maintenance. A selection of accident and incident investigation reports was performed by applying criteria in relation to the language, origin and recency of the report. When applying these criteria, accident and incident investigation authorities/bodies from Indonesia, Ireland, Australia, Netherlands, UK, USA, India, Japan, Portugal and Hong Kong were shortlisted. Initial filtering of the databases of these authorities/bodies was performed with the term 'maintenance,' producing an extensive list of $(100+)$ accidents/incidents. Thus, further shortlisting was necessary, in this case performed by searching in the internet for incidents/accidents considered as 'high profile' (based on their order of appearance in the google search engine results) and for reports containing substantial information (in terms of volume and detail) on the maintenance related causal factors. This shortlisting exercise identified the fifteen representative (for the purposes of this study) accidents/incidents selected for the content analysis. It is noted that further investigation (involving a higher volume of reports) would not add more to the scope of this analysis, as the reports selected were able to reveal the existence of these two traits (communication and trust), reaching their saturation point [46].

Each report was manually scanned for the keywords 'communication' and 'trust' by the author as a Subject Matter Expert (SME) (approved European Union Aviation Safety Agency (EASA) Part 147 maintenance training instructor in Human Factors). In the case that a keyword was found in the report this was mentioned accordingly. From the previous keywords, the only found was 'communication' ('trust' was not found in any report). In this case, the items of the CTQS were used to identify any underlying communication or trust factor. The CSQ items were used to identify underlying 
communication issues while the TCMQ items to locate trust issues. The preconditions for errors identified were mapped against the questionnaire items, with a detailed justification provided.

The summarised results from the analysis of all (fifteen) accident and incident investigation reports are presented in Appendix B. This table offers a quick view of the items of the CTQS identified in these reports. Considering all data obtained from the content analysis (as summarised in Appendix B), it is indicated that both trust and communication are detectable in the aviation maintenance sector. In particular, trust and communication, as they are reported in the accident and incident investigation reports, are identified as distinct preconditions in the vast majority (78\%) of the distinct maintenance errors. In six of the examined distinct maintenance errors (accounting to $14 \%$ of the total 42 ) trust only can be identified as a precondition to maintenance error, while communication is identified in just four distinct maintenance errors (corresponding to $8 \%$ of the errors analysed) (Table 1 ).

Table 1. Absolute number and percentage (\%) of maintenance errors where trust, communication and combination of both identified as preconditions within the accident and incident investigation reports analysed.

\begin{tabular}{|c|c|c|c|}
\hline \multirow{2}{*}{$\begin{array}{l}\text { Total Number of } \\
\text { Distinct Maintenance } \\
\text { Errors Analysed }\end{array}$} & \multicolumn{3}{|c|}{$\begin{array}{l}\text { Number of Distinct Maintenance Errors that Were Identified with } \\
\text { Precondition(s) of: }\end{array}$} \\
\hline & Trust Only & Communication Only & Trust and Communication \\
\hline \multirow{2}{*}{42} & 6 & 4 & 31 \\
\hline & $14 \%$ & $8 \%$ & $78 \%$ \\
\hline
\end{tabular}

Only $22 \%$ (out of the total forty-two errors analysed) included only one (communication or trust) as an error precondition and not both. It is, however, noted that these numerical results are not conclusive, as the investigation reports reflect the accident/incident investigators' exposition of evidence. This means that the investigators were not necessarily looking for 'communication' or 'trust' evidence; therefore, both factors may have not been exhaustively investigated (and subsequently reported).

More specifically about trust, the two types that were investigated in this research were about interpersonal trust and trust towards the company's software used for aviation maintenance purposes. The TCMQ, which includes all trust items, is divided into smaller groups of items, constructs. Each group indicates specific attributes of trust. Therefore, the specific characteristics identified here were trust towards colleagues' competence, integrity and benevolence and trust towards the company software's capability. Regarding the communication satisfaction, there is a similar grouping of items, depending on the theme of each item. Therefore, the groups of items, in relation to satisfaction, are-with the organisation's communication climate, with their superiors, with the organisation's integration, with the media quality, with the general organisational perspective and with the horizontal informal communication. These are the wider groups of the CSQ items, that were initially introduced by Downs and Hazen [22] and can describe categorically the specific issues with communication satisfaction identified in the analysed reports. Nonetheless, the aim of the content analysis here is to identify qualitatively the co-existence of these two factors as maintenance error preconditions.

\subsection{Phase 2}

For the implementation of Phase 2 of the DiCTAM, the data were obtained directly from official/approved aviation maintenance training sources. It is noted that the Federal Aviation Administration (FAA) does not include a distinct module of human factors training in its curriculum (as presented in Appendix B to Part-147-General Curriculum Subjects). Therefore, it is the EASA, Directorate General of Civil Aviation, Government of India (DGCA) and the Civil Aviation Safety Authority of Australia (CASA), from which approved training material can be obtained for review. All three regulatory authorities practically share the same curriculum for their maintenance human 
factors training; thus, the analysis is performed on the EASA Part-66 Category A and B Module 9 'Human Factors' curriculum (Table 2).

Aircraft maintenance training under the EASA framework is highly regulated with provisions of consistency and high quality in the delivered course material by all approved maintenance training organisations (commonly referred as EASA Part-147 organisations, reflecting the applicable regulatory set). Two coursebooks were selected for the content analysis, as very few published and publicly available EASA Part-66 Module 9 'Human Factors' course material exists. These coursebooks were:

- $\quad$ Coursebook 1: 'Module 9-Human Factors' (by C. Strike), published in 2018 by Cardiff and Vale College in the UK [47];

- Coursebook 2: 'Human factors for A level Certification, module 9' by N. Gold, published in 2015 by Aircraft Technical Book Company in the USA [48].

Table 2. Curriculum of the EASA [49] Part-66 Category A and B Module 9 'Human Factors'.

\begin{tabular}{|c|c|c|}
\hline Chapter & Title & Content \\
\hline 9.1 & General & $\begin{array}{l}\text { The need to take human factors into account; } \\
\text { Incidents attributable to human factors/human error, } \\
\text { 'Murphy's' law. }\end{array}$ \\
\hline 9.2 & $\begin{array}{l}\text { Human Performance and } \\
\text { Limitations }\end{array}$ & $\begin{array}{l}\text { Vision; } \\
\text { Hearing; } \\
\text { Information processing; } \\
\text { Attention and perception; } \\
\text { Memory; } \\
\text { Claustrophobia and physical access. }\end{array}$ \\
\hline 9.3 & Social Psychology & $\begin{array}{l}\text { Responsibility: individual and group; } \\
\text { Motivation and de-motivation; } \\
\text { Peer pressure; } \\
\text { 'Culture' issues; } \\
\text { Team working; } \\
\text { Management, supervision and leadership. }\end{array}$ \\
\hline 9.4 & Factors Affecting Performance & $\begin{array}{l}\text { Fitness/health; } \\
\text { Stress: domestic and work related; } \\
\text { Time pressure and deadlines; } \\
\text { Workload: overload and underload; } \\
\text { Sleep and fatigue, shift work; } \\
\text { Alcohol, medication, drug abuse. }\end{array}$ \\
\hline 9.5 & Physical Environment & $\begin{array}{l}\text { Noise and fumes; } \\
\text { Illumination; } \\
\text { Climate and temperature; } \\
\text { Motion and vibration; } \\
\text { Working environment. }\end{array}$ \\
\hline 9.6 & Tasks & $\begin{array}{l}\text { Physical work; } \\
\text { Repetitive tasks; } \\
\text { Visual inspection; } \\
\text { Complex systems. }\end{array}$ \\
\hline 9.7 & Communication & $\begin{array}{l}\text { Within and between teams; } \\
\text { Work logging and recording; } \\
\text { Keeping up to date, currency; } \\
\text { Dissemination of information. }\end{array}$ \\
\hline 9.8 & Human Error & $\begin{array}{l}\text { Error models and theories; } \\
\text { Types of error in maintenance tasks; } \\
\text { Implications of errors (i.e., accidents); } \\
\text { Avoiding and managing errors. }\end{array}$ \\
\hline 9.9 & Hazards in the Workplace & $\begin{array}{l}\text { Recognising and avoiding hazards; } \\
\text { Dealing with emergencies. }\end{array}$ \\
\hline
\end{tabular}


The first examination of these coursebooks determined that both followed the EASA curriculum, as expected. Furthermore, the content of both books was found to cover the curriculum in a similar way, having a comparable structure and content. Therefore, these two coursebooks were the adequate required body of material for using the content analysis technique in Phase 2 of DiCTAM.

The EASA curriculum and the two coursebooks were examined manually by the author as a SME, to locate the words 'communication' and 'trust'. The EASA Part-66 Module 9 'Human Factors' curriculum covers only the chapters and subchapters of the material approved to be taught. In the curriculum, the word 'trust' is not used while the word 'communication' is solely used in chapter seven (Communication) one time in the title of the chapter. The next step was to scan the two EASA Part-66 Module 9 coursebooks for the same words. The results were as follows:

- In Coursebook 1 [47], the word count in Chapter Seven-Communication, for the word 'communication' is 52, while for the word 'trust' is 0 . It is noted that in the whole Chapter Seven-Communication, there is no reference to trust, even though communication is analysed and different communication techniques are presented there.

- In Coursebook 2 [48], the word count in Sub-module 07, Communication, for the word 'communication' is 63 while for the word 'trust' is 1 . Trust towards a message sender is referred one time, in the communication chapter, as a precondition in the effective receipt of a message.

The summary of findings in the curriculum and the coursebooks are shown in Table 3.

Table 3. Word count of 'communication' and 'trust' in the European Union Aviation Safety Agency (EASA) Part-66 Module 9 curriculum and the two coursebooks.

\begin{tabular}{ccc}
\hline EASA Part 66 Module 9 'Human Factors' & \multicolumn{2}{c}{ Word Count } \\
\cline { 2 - 3 } Curriculum and Training Material Examined & Communication & Trust \\
\hline Curriculum & 1 & 0 \\
\hline Coursebook 1 & 52 & 0 \\
\hline Coursebook 2 & 63 & 1 \\
\hline
\end{tabular}

The second stage of this examination continued into the in-depth analysis to identify any concealed elements of communication and trust into the twelve elements of the Dirty Dozen tool. A better understanding of human factors has become imperative within aviation and several models and systems have been introduced and implemented in the continuous attempt to predict and reduce human error. In aviation maintenance, there are twelve factors identified as the principal preconditions or conditions, that contribute to human error, widely known as the Dupont's Dirty Dozen [17,18,50-53]. These elements are dissimilar in nature and appear either on personal, group or organizational performance levels [54]. Communication is among these 12 most frequent causes of human error. These twelve factors are:

1. Lack of communication;

2. Complacency;

3. Lack of knowledge;

4. Distractions;

5. Lack of teamwork;

6. Fatigue;

7. Lack of resources;

8. Pressure;

9. Lack of assertiveness; 
10. Stress;

11. Lack of awareness;

12. Norms.

The Dirty Dozen is one of the most used human factors typologies in aviation maintenance, as it is still used in training and accident and human error analysis in aviation worldwide [18,50-52,55]. These 12 factors are of different nature and quantifiability; nevertheless, each one of them represents a causal failure in the user's judgement and as such, they are treated either individually or in homogeneous groups [52]. In particular, the results of this analysis were obtained by the mapping of the twelve elements of the Dirty Dozen with the use of the CTQS. All Dirty Dozen elements refer to the total population of the aviation maintenance professionals; therefore, all levels of management are included (Sections E and G of the CTQS which are only for supervisors/managers). Ten factors appear to have either the communication or trust elements concealed into their meaning. Two of them, the lack of communication and lack of teamwork, appear to have both communication and trust concealed. For illustrative purposes, the overall mapping of the CTQS items against the Dirty Dozen elements are provided in Appendix C.

The third stage included the manual tabulation of the elements of the Dirty Dozen against the EASA Part-66 Module 9 'Human Factors' course material. This tabulation (using the mapping of the CTQS items against the Dirty Dozen elements) revealed the concealed elements of communication and trust in Coursebook 1 and 2. The summary of the findings is presented in Table 4. From this analysis, it stems that both coursebooks include all factors of the Dirty Dozen and consequently include indirectly and concealed both communication and trust elements in their content.

Considering all data from the content analysis (presented in Table 3) it stems that trust is not considered to be covered sufficiently in the aviation maintenance human factors basic training. In particular, the EASA curriculum has no mention of trust, neither as a separate chapter nor in any other chapters (and most importantly in the communication chapter). In the two examined coursebooks' chapters covering communication, there was only one mention to trust. Therefore, there is neither direct mention nor further explanation/discussion on trust. However, with the assistance of the mapping of the Dirty Dozen factors with the items of CTQS, concealed communication and trust elements were identified into the material of the two coursebooks. The direct absence of the trust factor in the training material may be partially covered by these concealed elements, although this has limited pedagogic value and effectiveness. 
Table 4. Dirty Dozen elements found in the examined EASA Part-66 Module 9 'Human Factors' coursebooks in relation to communication and trust elements.

\begin{tabular}{|c|c|c|c|}
\hline \multirow[t]{2}{*}{ Coursebook } & \multirow{2}{*}{$\begin{array}{l}\text { Dirty Dozen Element Included } \\
\text { in the Coursebook }\end{array}$} & \multicolumn{2}{|c|}{$\begin{array}{l}\text { Preconditions Identified Basec } \\
\text { on the Dirty Dozen Mapping }\end{array}$} \\
\hline & & Communication & Trust \\
\hline \multirow{12}{*}{$\begin{array}{c}\text { Coursebook } 1 \\
\text { (Strike, 2018) }\end{array}$} & 1. Lack of Communication & $x$ & $x$ \\
\hline & 2. Complacency & $x$ & \\
\hline & 3. Lack of knowledge & & $x$ \\
\hline & 4. Distraction & & $x$ \\
\hline & 5. Lack of teamwork & $x$ & $x$ \\
\hline & 6. Fatigue & $x$ & \\
\hline & 7. Lack of resources & $x$ & \\
\hline & 8. Pressure & $x$ & \\
\hline & 9. Lack of assertiveness & $x$ & \\
\hline & 10. Stress & $x$ & \\
\hline & 11. Lack of awareness & $x$ & \\
\hline & 12. Norms & & $x$ \\
\hline \multirow{12}{*}{$\begin{array}{c}\text { Coursebook } 2 \\
\text { (Gold, 2015) }\end{array}$} & 1. Lack of Communication & $x$ & $x$ \\
\hline & 2. Complacency & $x$ & \\
\hline & 3. Lack of knowledge & & $x$ \\
\hline & 4. Distraction & & $x$ \\
\hline & 5. Lack of teamwork & $X$ & $x$ \\
\hline & 6. Fatigue & $x$ & \\
\hline & 7. Lack of resources & $x$ & \\
\hline & 8. Pressure & $x$ & \\
\hline & 9. Lack of assertiveness & $X$ & \\
\hline & 10. Stress & $x$ & \\
\hline & 11. Lack of awareness & $x$ & \\
\hline & 12. Norms & & $x$ \\
\hline
\end{tabular}

\subsection{Phase 3}

In Phase 3 of the DiCTAM model the association among three factors was explored: communication satisfaction, interpersonal trust and trust towards maintenance software used by aviation maintenance companies. To serve this purpose, the CTQS was distributed to diverse set of aviation maintenance professionals working in civil and military organisations. The participants were sent an invitation to participate online (on the web-based tool Limesurvey) through emails. Over the two phases for the recruitment of participants, 501 aviation maintenance professionals were contacted and 259 answered fully to the questionnaire. A quantitative analysis was performed on the data collected, to identify possible interrelations between the three factors examined. For this analysis, a correlational research design was used to prevent any suggestion in any causal relationship among them. For the purposes of this research design, the specific statistical methods used were-Cronbach's alpha, descriptive statistics, correlations between variables, t-tests and analyses of variance (ANOVA) and Harman's one factor, with the help of Statistical Package for Social Sciences (SPSS) Statistics 25.0.0. Further details are provided in a separate paper currently under review [45]. 
The survey results indicated, for managers and subordinates as well as for all employees, that a substantial proportion of their communication satisfaction was explained by their levels of interpersonal trust, giving statistically significant results. Differences in the communication satisfaction and software trust between military and civil aviation maintenance company employees were also observed. The results of civil aviation employees exhibit higher mean scores than that of military for all three factors. Overall, communication satisfaction was found to have a stronger association with interpersonal trust than with software trust. The mean scores of communication satisfaction and interpersonal trust increased across various levels of experience, with the differences between less and more experienced employees being statistically significant. An interesting finding of this research is that aviation maintenance professionals have relatively high levels of trust and communication satisfaction at the start of their current employment. This finding is also consistent with the initial trust levels theory, examined in the past for other industries. The descriptive statistics indicated that the participants of this survey came from many different geographical areas in small numbers. This can limit the results of this survey to be generalised to the global aviation maintenance professionals' population [45].

\subsection{Phase 4}

Following the confirmation of the positive association among those three aspects of the two traits (communication satisfaction, interpersonal trust and software trust), in Phase 4 of the DiCTAM model prediction is attempted. Prediction can form different hypothetical occurrences (possible events and scenarios) by using the survey's results as a guide and can, therefore, contribute to the process of the examination of the two traits. More specifically, Phase 4 includes hypothetical scenarios about possible aviation maintenance deviations that can take place in real life with the use of the case study method. For this purpose, the case study presented next is selected to present the operation of the DiCTAM model, as well as exemplifying its use. A well-known case has been selected, that of the engine fan cowl door losses experienced in the Airbus A320 family fleet in worldwide level [56]. The method of the case study is considered to be suitable method to examine hypothetical scenarios. A suitable application for the prediction exercise is deemed the use of the Fan Cowl Doors (FCDs) maintenance occurrences (after the implementation of the new procedures, provisioned by the latest EASA Airworthiness Directives (ADs)) [56]. The case study methodology assists in the holistic examination of these hypothetical occurrences to unveil concealed elements and identify or even predict future trends or patterns [57].

At this stage the aim is to examine these hypothetical scenarios for the identification of communication and trust elements and then, based on these findings, to predict the possibility of occurrence of each scenario. Seven scenarios, as they were introduced and discussed by Kourousis et al. [56], are examined below for the identification of trust and communication elements. Each scenario is scrutinised against the items of the CTQS by the author as SME, for the identification of a question set's items within the scenario. The seven scenarios are divided in two broader groups, those which are occurring from two different situations:

- The technician retrieves the FCD key from the designated storage area in the cockpit and inserts a logbook entry for the opening/closing of the FCD (Scenarios 1, 2 and 3), presented in Section 3.4.1;

- The technician does not find the FCD key in the designated storage area in the cockpit (Scenarios 4, 5, 6 and 7), presented Section 3.4.2.

\subsubsection{FCD Key in Designated Area}

\section{Scenario 1}

The technician leaves the maintenance task (in the area enclosed by the FCD) for the end of the failure troubleshooting. He/she performs the maintenance task at the end of his/her shift. However, he/she does not dedicate adequate time for the maintenance task, as he/she inadvertently prioritised the FCD task [return of the key, closure of the logbook entry ('FCD closed')], in an effort to avoid the 
FCD is not left open. This poor practice may result in reduced maintenance quality, under stressful or very time constrained situations, since FCD-related tasks are added to the existing workload.

Trust factor identified: Maintenance personnel failed to dedicate the time required for this task, risking the quality of this work. This indicates that the maintenance personnel deviated from an expected good practice in their duties. Specifically, by using the CTQS, the following three items are identified in this failure:

F2-My colleagues perform their duties very well,

F3-Overall, my colleagues are capable and proficient technical staff,

F5-My colleagues act in the best interest of the project.

Items F2 and F3 correspond to the 'construct of trust in colleagues' competence' category while item F5 in the 'construct of trust in colleagues' benevolence' category.

Possible Prevention Measures: Putting more focus on time management techniques and requesting assistance from peer-workers/team leader in stressful/time-pressing situations.

\section{Scenario 2}

The technician performs the maintenance task straight away but leaves the key return and logbook entry closure for later. Since these steps were left for a later time, the technician either forgets completely to return the key/close the logbook entry or gets distracted near that time, having the same result. As a consequence, the aircraft release to service can be delayed, since the involved personnel (flight crew, technical staff) will have to locate the missing key and complete the FCD sign-off in the logbook.

Communication factor identified: Not performing a proper handover, makes the ideal preconditions for errors. This deviation from accurate reporting can result in lack of effective communication between colleagues and can prevent from the proper actions taken to mitigate the errors. Therefore, the communication problems identified here are in relation to items:

D19-The amount of communication was not about right,

D2-The organisation's communication motivates and stimulates an enthusiasm for meeting its goals,

C3-Information about organisational policies and goals,

D8-Personnel receive in time the information needed to do their job,

D6-The organisation's communications are interesting and helpful,

D17-Issues whether the attitudes towards communication in the organisation are healthy,

C7-Information about departmental policies and goals,

D15-Meetings are well organised,

D12-Communication with colleagues within the organisation is accurate and free flowing,

D3-Supervisor listens and pays attention to personnel,

D6-The organisation's communications are interesting and helpful.

Possible Prevention Measures: A dual sign off practice would offer the opportunity for a confirmation check and reduce the possibility of misses and errors.

\section{Scenario 3}

The technician does not perform the maintenance task and has to pass it over to the next shift. Since these steps were left for the next shift, he/she either forgets to return the key/close the logbook entry or gets distracted to do that. In case that the shift handover is not performed properly, the FCD tasks are not completed. As a consequence, similarly to Scenario 2, the aircraft release to service can be delayed, since the missing key has to be located and the logbook signed off.

Communication factor identified: As with Scenario 2, not performing a proper handover, makes the ideal precondition for errors. This deviation from accurate reporting can result in lack of effective communication between colleagues and can prevent from the proper actions taken to mitigate the 
errors. Therefore, the communication problems identified here are in relation to items: D19, D2, C3, D8, D6, D17, C7, D15, D12, D3 and D6.

Possible Prevention Measures: As with Scenario 2, the dual sign off practice can mitigate this issue. Moreover, a thorough (verbal and written) shift handover would be helpful in avoiding communication gaps in relation to the FCD tasks (reducing the possibility for misses and errors).

\subsubsection{FCD Missing from Designated Area}

\section{Scenario 4}

The technician attempts to find the FCD key. He/she prioritises this task over the maintenance task itself. In the case that he/she finds the key, the amount of time spent on the search does not allow him/her to focus on the maintenance task, thus this is not performed adequately.

Trust factor identified: Similar to Scenario 1, maintenance personnel failed to dedicate the time required for this task, risking the quality of this work. This indicates that the maintenance personnel deviated from an expected good practice in their duties. Specifically, following three items are identified in this failure: F2, F3 and F5.

Possible Prevention Measures: Similarly, to Scenario 1, it would be beneficial if better time management techniques were practiced, as well as if the technician requested assistance.

\section{Scenario 5}

The technician attempts to find the FCD key, prioritising the search over the maintenance task (same as in Scenario 4). He/she does not manage to find the key, leaving the maintenance task unaccomplished. In the case that the technician is forgetful or distracted, he/she will not report the missing key, causing more delay, as other personnel in later time will repeat the search process.

Communication factor identified: As with Scenarios 2 and 3, not performing a proper handover, makes the ideal precondition for errors. This deviation from accurate reporting can result in lack of effective communication between colleagues and can prevent from the proper actions taken to mitigate the errors. Therefore, the communication problems identified here are in relation to items: D19, D2, C3, D8, D6, D17, C7, D15, D12, D3 and D6.

Possible Prevention Measures: Similar to other scenarios, the dual sign off in conjunction with a robust handover process could mitigate this miss.

\section{Scenario 6}

The technician attempts to find the FCD key, prioritising the search over the maintenance task (same as in Scenarios 4 and 5). He/she does not manage to find the key, therefore deciding to use his/her own key or the spare key as per the organisation's 'norm and fills in the logbook entry ('open FCD'). After completing the maintenance task, the technician is forgetful/omits or gets distracted and does not report the missing key. As with Scenario 5, this may cause a delay in the future. Moreover, using his/her own key means that this may not have the 'remove before flight' flag attached, increasing the probability of leaving the cowl door open (since this modified visual cue will be missing).

Trust factor identified: Maintenance personnel deliberately chooses to use own key, opposite to the company's policies, which might not include the dedicated visual cue. This indicates that the maintenance personnel deviated from an expected good practice in their duties. Specifically, by using the CTQS, the following four items are identified in this failure:

F2-My colleagues perform their duties very well,

F3-Overall, my colleagues are capable and proficient technical staff,

F4-In general, my colleagues are knowledgeable about our organization,

F5-My colleagues act in the best interest of the project. 
Items F2, F3 and F4 fall in the construct of trust in colleagues' competence while item F5 falls in the construct of trust in colleagues' benevolence.

Communication factor identified: As with Scenarios 2, 3 and 5, not performing a proper handover, makes the ideal precondition for errors. This deviation from accurate reporting can result in lack of effective communication between colleagues and can prevent from the proper actions taken to mitigate the errors. Therefore, the communication problems identified here are in relation to items: D19, D2, C3, D8, D6, D17, C7, D15, D12, D3 and D6.

Possible Prevention Measures: Similar to previous scenarios, the dual sign off in conjunction with a robust handover process could mitigate this. In addition, a change in the organisational culture would be necessary to abolish unsafe practices in relation to established 'norms' outside the standard policies and procedures.

Scenario 7

The technician does not have the required time or attitude to attempt to find the missing key, thus he/she decides not to perform the assigned maintenance task and, for example, to move onto a different task. He/she forgets about the missing FCD key or gets distracted and does not report that. This shall cause delay in the work of the personnel who are then assigned to the maintenance task in the FCD-accessed area (as they will have to search for the missing key).

Communication factor identified: As with Scenarios 2, 3, 5 and 6, not performing a proper handover, makes the ideal precondition for errors. This deviation from accurate reporting can result in lack of effective communication between colleagues and can prevent from the proper actions taken to mitigate the errors. Therefore, the communication problems identified here are in relation to items: D19, D2, C3, D8, D6, D17, C7, D15, D12, D3 and D6.

Possible Prevention Measures: Dual sign off and in-shift/inter-shift handover would be an effective solution to avoid such situations.

\subsubsection{Analysis of Scenarios}

The seven scenarios presented (Scenarios 1 to 7) refer to seven different causal situations in which safety issues, related to the fan cowl doors of modified aircraft of the Airbus 320 family, may arise. These scenarios were investigated against the items of the CTQS. As shown in Table 5, many different trust and/or communication issues corresponded to each one of the scenarios, therefore all scenarios showed communication and trust preconditions. Trust was found present in five scenarios while communication was found present in three. One scenario had communication and trust preconditions present at the same time, while the rest six had solely one precondition present (either trust or communication).

Table 5. Communication and trust items, of the CTQS, identified in Scenarios 1 to 7.

\begin{tabular}{lcc}
\hline Scenario & Trust Factor Items & Communication Factor Items \\
\hline Scenario 1 & F2, F3, F5 & \\
\hline Scenario 2 & & D19, D2, C3, D8, D6, D17, C7, D15, D12, D3, D6 \\
\hline Scenario 3 & & D19, D2, C3, D8, D6, D17, C7, D15, D12, D3, D6 \\
\hline Scenario 4 & F2, F3, F5 & \\
\hline Scenario 5 & & D19, D2, C3, D8, D6, D17, C7, D15, D12, D3, D6 \\
\hline Scenario 6 & F2, F3, F4, F5 & D19, D2, C3, D8, D6, D17, C7, D15, D12, D3, D6 \\
\hline Scenario 7 & & D19, D2, C3, D8, D6, D17, C7, D15, D12, D3, D6 \\
\hline
\end{tabular}

More specifically, the issues identified in relation to trust were about interpersonal trust. The CTQS items are grouped in different constructs, each one indicating specific attributes of trust. Therefore, the specific characteristics identified here were trust towards colleagues' competence and benevolence. 
In relation to the communication satisfaction, issues were identified in relation to the satisfaction with the organisation's communication climate, with the superiors, with the organisation's integration, with the media quality, the general organisational perspective and with the horizontal informal communication. These are the wider groups of the CSQ items, that were initially introduced by Downs and Hazen [22] and can describe categorically the specific issues with communication satisfaction identified in these scenarios.

The communication and trust items identified (listed in Table 5) are not factors that have to exist in combination to contribute to the hypothetical scenario. At least one of these factors (namely, one of the possible items) could suffice in the occurrence of the relevant scenario. The mean value of each item corresponds to the level of communication satisfaction and trust exhibited by the surveyed population. Namely, a high mean score is a positive indicator of high levels of communication satisfaction or trust. For this reason, an item's lower mean score of each scenario was selected as the criterion for the hierarchical categorisation of the scenarios relative to the possibility of occurrence. For example, a scenario with an item having a higher mean is less probable than that of a scenario with an item of a lower mean. Lower mean scores reveal lower communication satisfaction and trust, which subsequently include issues with communication and trust (yielding higher probability of occurrence).

The identification of more probable and less probable scenarios involves the comparison of the means for all scenarios, listed in Table 6. The lower mean score is accounted as to have the higher occurrence probability of the scenario tabulated to this mean score. The least mean score in each scenario, that determined the ranking of the relevant scenario, is shown in Table 6 in bold font and highlighted in grey shade. This process identified two items; whose mean scores categorised the seven scenarios. Therefore, the two mean scores categorised the seven scenarios into two groups: Group A, corresponding to more possible to occur and Group B, to less possible to occur scenarios.

Table 6. Means of the trust and communication factors as identified in Scenarios 1 to 7 . In bold are the minimum means for communication and trust for each scenario.

\begin{tabular}{|c|c|c|c|c|c|c|c|c|}
\hline & & \multicolumn{7}{|c|}{ Scenario } \\
\hline & & 1 & 2 & 3 & 4 & 5 & 6 & 7 \\
\hline \multirow{4}{*}{$\begin{array}{l}\text { Trust Factor } \\
\text { identified }\end{array}$} & F2 & 5.66 & - & - & 5.66 & - & 5.66 & - \\
\hline & F3 & 5.89 & - & - & 5.89 & - & 5.89 & - \\
\hline & F4 & - & - & - & - & - & 5.56 & - \\
\hline & F5 & 5.54 & - & - & 5.54 & - & 5.54 & - \\
\hline \multirow{11}{*}{$\begin{array}{l}\text { Communication } \\
\text { Factor identified }\end{array}$} & D19 & - & 4.45 & 4.45 & - & 4.45 & 4.45 & 4.45 \\
\hline & D2 & - & 4.15 & 4.15 & - & 4.15 & 4.15 & 4.15 \\
\hline & $\mathrm{C} 3$ & - & 4.73 & 4.73 & - & 4.73 & 4.73 & 4.73 \\
\hline & D8 & - & 4.83 & 4.83 & - & 4.83 & 4.83 & 4.83 \\
\hline & D6 & - & 4.51 & 4.51 & - & 4.51 & 4.51 & 4.51 \\
\hline & D17 & - & 4.65 & 4.65 & - & 4.65 & 4.65 & 4.65 \\
\hline & $\mathrm{C} 7$ & - & 4.71 & 4.71 & - & 4.71 & 4.71 & 4.71 \\
\hline & D15 & - & 4.55 & 4.55 & - & 4.55 & 4.55 & 4.55 \\
\hline & D12 & - & 5.27 & 5.27 & - & 5.27 & 5.27 & 5.27 \\
\hline & D3 & - & 5.09 & 5.09 & - & 5.09 & 5.09 & 5.09 \\
\hline & D6 & - & 4.51 & 4.51 & - & 4.51 & 4.51 & 4.51 \\
\hline
\end{tabular}

The output of this exercise summarised the results presented in Table 7, with a two-tier ranking obtained (Groups A and B). Based on this ranking, Scenarios 2, 3, 5, 6 and 7 are more possible to occur that Scenarios 1 and 4 . 
Table 7. Ranking of Scenarios 1 to 7 based on the possibility of occurrence.

\begin{tabular}{lccc}
\hline Possibility of Occurrence & Scenario & M & Trust/Communication Item \\
\hline & Scenario 2 & 4.15 & D2 \\
\cline { 2 - 4 } & Scenario 3 & 4.15 & D2 \\
\cline { 2 - 4 } A. More Possible & Scenario 5 & 4.15 & D2 \\
\cline { 2 - 4 } & Scenario 6 & 4.15 & D2 \\
\cline { 2 - 4 } & Scenario 7 & 4.15 & D2 \\
\hline \multirow{2}{*}{ B. Less Possible } & Scenario 1 & 5.54 & F5 \\
& Scenario 4 & 5.54 & F5 \\
\hline
\end{tabular}

\section{Conclusions}

The novelty of this model lies in the development and utilisation of a dedicated (CTQS) survey/question tool for aviation maintenance, which addresses methodically, for the first time, the association between communication and trust in aviation maintenance. The model can predict hypothetical deviations during maintenance practice attributed to communication and trust preconditions. These preconditions are identified (and can be quantified) based on the target group's perceptions on communication and trust. This model is expected to contribute to the advancement of research in this area, having, in turn, a positive contribution to the promotion of aviation maintenance safety.

In summary, the DiCTAM model is capable to:

1. Detect the traits of communication and trust;

2. Identify, investigating and associating the perceptions of the people involved;

3. Examine in depth the extent of the aviation maintenance employees' exposure to them, through their training;

4. Predict their actions regarding communication and trust preconditions in aviation maintenance.

This process can be expanded to include more preconditions and offer a structured approach applicable to other similar research projects. Thus, the construct of the DiCTAM model would be transferable to other human factors preconditions, which, similarly to communication and trust, are present in aviation maintenance and affect safety.

Funding: This research received no external funding.

Acknowledgments: The financial contribution received from the Research Training Program (RTP) of the Australian Commonwealth Government is acknowledged.

Conflicts of Interest: The author declares no conflict of interest.

\section{Appendix A}

The items of the distributed questionnaire in this research study:

Section A: Demographic information of the participants (Based on [22].).

A1. My current post and duties require me to exercise my aircraft maintenance license privileges.

A2. My company is approved by $\ldots \ldots \ldots \ldots \ldots$ to perform and certify maintenance.

A3. My experience with my current company is

A4. I have a total of ........ years of experience in aviation maintenance. 
Section B: General Questions (Based on [22]).

B1. How satisfied are you with your job?

B2. In the past 6 months, what has happened to your level of satisfaction?

Section C: Communication-My job (Based on [22]).

C1. Information about my progress in my job.

C2. Personnel news.

C3. Information about organisational policies and goals.

C4. Information about how my job compares with others.

C5. Information about how I am being judged.

C6. Recognition of my efforts.

C7. Information about departmental policies and goals.

C8. Information about the requirements of my job.

C9. Information about government action affecting my organisation.

C10. Information about changes in our organisation.

C11. Reports on how problems in my job are being handled.

C12. Information about benefits and pay.

C13. Information about our organisation's financial standing.

C14. Information about accomplishments and/or failures of the organisation.

Section D: Communication-My job and the people I work with (Based on [22]).

D1. My superiors know and understand the problems faced by subordinates.

D2. The organisation's communication motivates and stimulates an enthusiasm for meeting its goals.

D3. My supervisor listens and pays attention to me.

D4. My supervisor offers guidance for solving job related problems.

D5. The organisation's communication makes me identify with it or feel a vital part of it.

D6. The organisation's communications are interesting and helpful.

D7. My supervisor trusts me.

D8. I receive in time the information needed to do my job.

D9. Conflicts are handled appropriately through proper communication channels.

D10. The grapevine (person to person informal communication/gossip) is active in our organisation.

D11. My supervisor is open to new ideas.

D12. Communication with my colleagues within the organisation is accurate and free flowing.

D13. Communication practices are adaptable to emergencies.

D14. My work group is compatible.

D15. Our meetings are well organised.

D16. The amount of supervision given me is about right.

D17. The attitudes towards communication in the organisation are basically healthy.

D18. Informal communication is active and accurate.

D19. The amount of communication in the organisation is about right.

D20. Are you a supervisor/manager? 
Section E: Communication-Only for managers/supervisors (Based on [22]).

E1. My subordinates are responsive to downward directive communication.

E2. My subordinates anticipate my needs for information.

E3. I do not have a communication overload.

E4. My subordinates are receptive to evaluation, suggestions and criticism.

E5. My subordinates feel responsible for initiating accurate upward communication.

Section F: Trust (Adapted from [37]).

F1. My colleagues fulfil my expectations in our collaboration.

F2. My colleagues perform their duties very well.

F3. Overall, my colleagues are capable and proficient technical staff.

F4. In general, my colleagues are knowledgeable about our organisation.

F5. My colleagues act in the best interest of the project.

F6. If I required assistance, my colleagues would do their best to help me.

F7. My colleagues are interested in my professional well-being, not just their own.

F8. My colleagues are truthful in their contact with me by actively exposing the whole truth on any work-related matter.

F9. I would characterize my colleagues as honest by not telling lies.

F10. My colleagues would keep their verbal commitments.

F11. My colleagues are sincere and genuine.

F12. My company's software has the functionality I need.

F13. My company's software has the ability to do what I want it to do.

F14. Overall, my company's software has the capabilities I need.

F15. My company's software is very reliable.

F16. I can depend on the software when I perform/certify maintenance tasks.

F17. This software performs in a predictable way.

F18. Are you a supervisor/manager?

Section G: Trust—Only for managers/supervisors (Adapted from [37]).

G1. My subordinates are effective in assisting and fulfilling my expectations in our collaboration.

G2. My subordinates perform their duties very well.

G3. Overall, my subordinates are capable and proficient technical staff.

G4. In general, my subordinates are knowledgeable about our organisation.

G5. My subordinates act in the best interest of the project.

G6. If I required assistance, my subordinates would do their best to help me.

G7. My subordinates are interested in my professional well-being, not just their own.

G8. My subordinates are truthful in their contact with me by actively exposing the whole truth on a matter.

G9. I would characterize my subordinates as honest by not telling lies. 


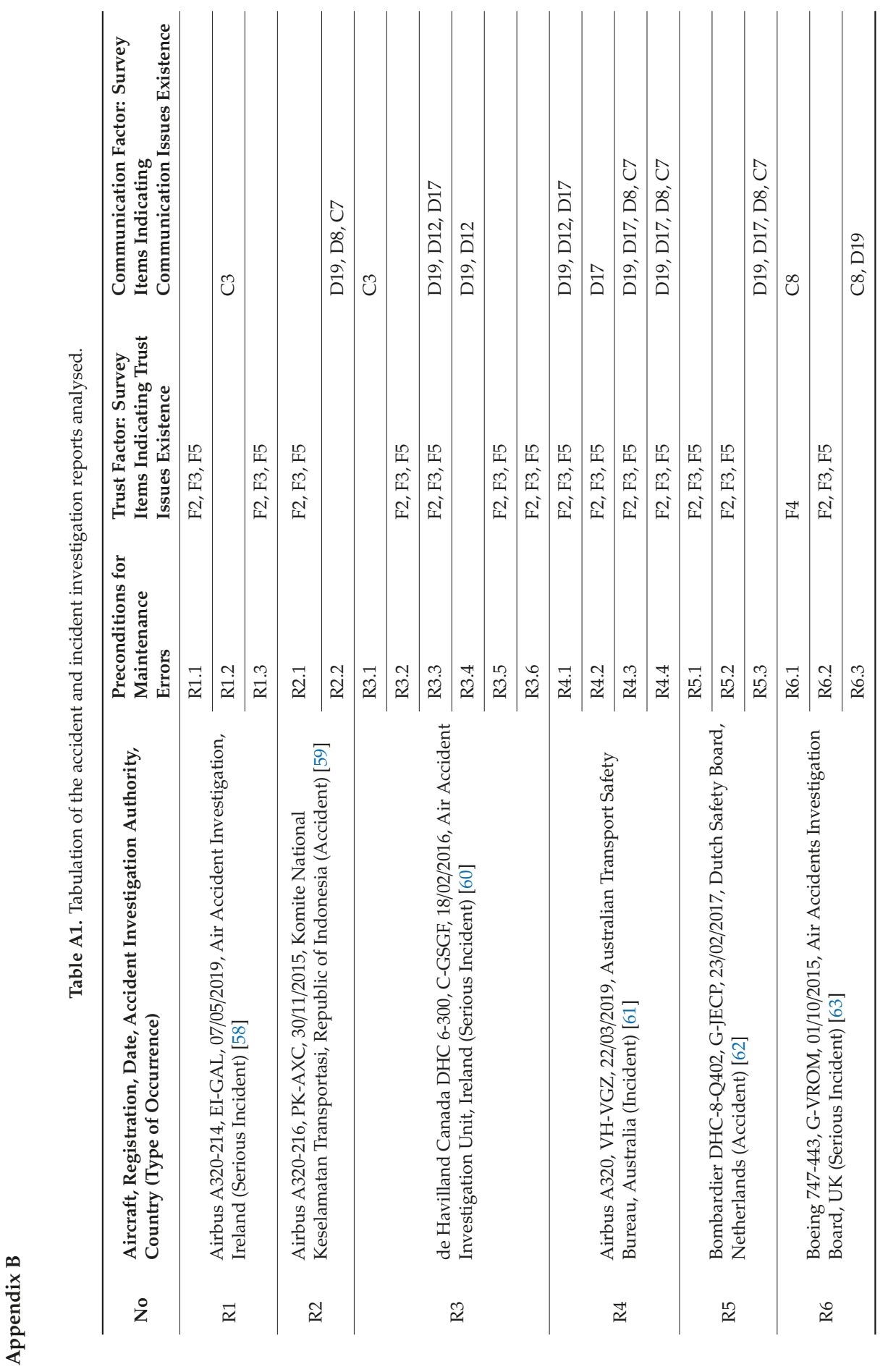




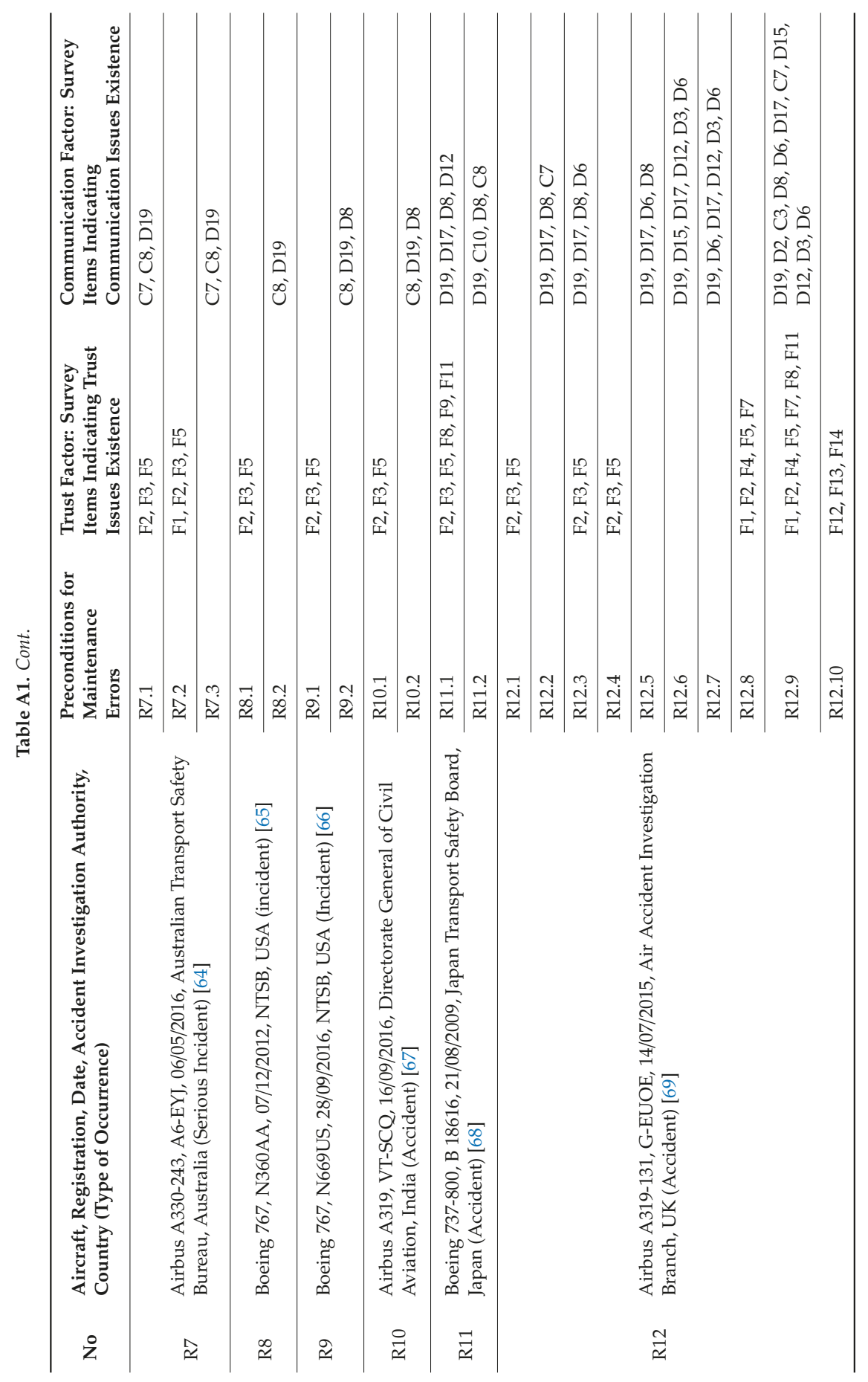




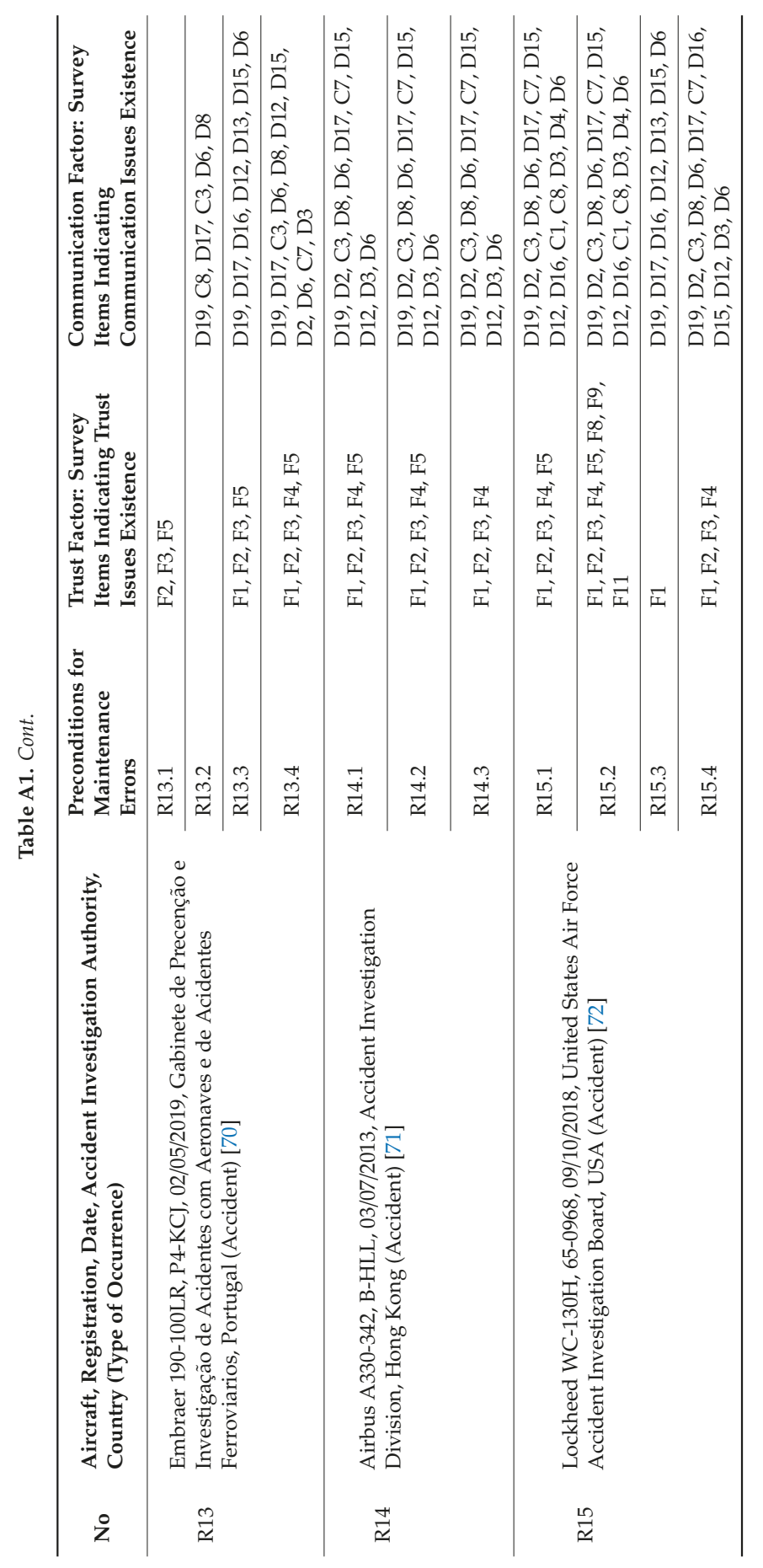


Appendix C

Table A2. Mapping of CTQS items against the Dirty Dozen elements.

\begin{tabular}{|c|c|c|c|c|c|c|c|c|c|c|c|c|c|}
\hline & \multicolumn{13}{|c|}{ Dirty Dozen Element } \\
\hline & & 1 & 2 & 3 & 4 & 5 & 6 & 7 & 8 & 9 & 10 & 11 & 12 \\
\hline & $\mathrm{C} 1$ & $x$ & $\bar{x}$ & & & $x$ & $x$ & $x$ & $x$ & $x$ & $x$ & $x$ & \\
\hline & $\mathrm{C} 2$ & $X$ & $X$ & & & $X$ & $X$ & $x$ & $x$ & $x$ & $x$ & $x$ & \\
\hline & $\mathrm{C} 3$ & $X$ & $x$ & & & $X$ & $X$ & $x$ & $X$ & $x$ & $x$ & $x$ & \\
\hline & $\mathrm{C} 4$ & $x$ & $x$ & & & $x$ & $x$ & $x$ & $x$ & $x$ & $x$ & $x$ & \\
\hline & C5 & $x$ & $x$ & & & $x$ & $x$ & $x$ & $x$ & $x$ & $x$ & $x$ & \\
\hline & C6 & $X$ & $X$ & & & $X$ & $X$ & $x$ & $x$ & $x$ & $x$ & $x$ & \\
\hline & $\mathrm{C} 7$ & $X$ & $x$ & & & $X$ & $x$ & $X$ & $X$ & $X$ & $x$ & $X$ & \\
\hline & C8 & $x$ & $x$ & & & $x$ & $x$ & $X$ & $x$ & $x$ & $x$ & $x$ & \\
\hline & C9 & $X$ & $x$ & & & $x$ & $X$ & $X$ & $X$ & $X$ & $X$ & $x$ & \\
\hline & C10 & $x$ & $x$ & & & $x$ & $x$ & $x$ & $X$ & $x$ & $x$ & $x$ & \\
\hline & C11 & $X$ & $x$ & & & $X$ & $x$ & $X$ & $X$ & $x$ & $x$ & $X$ & \\
\hline & $\mathrm{C} 12$ & $X$ & $x$ & & & $x$ & $x$ & $X$ & $X$ & $X$ & $X$ & $x$ & \\
\hline & $\mathrm{C} 13$ & $X$ & $x$ & & & $x$ & $x$ & $X$ & $X$ & $X$ & $x$ & $x$ & \\
\hline & C14 & $x$ & $x$ & & & $x$ & $x$ & $x$ & $x$ & $x$ & $x$ & $x$ & \\
\hline & D1 & $X$ & $x$ & & & $X$ & $x$ & $X$ & $X$ & $x$ & $x$ & $x$ & \\
\hline \multirow{22}{*}{$\begin{array}{l}\text { Communication and } \\
\text { Trust Question Set } \\
\text { Items }\end{array}$} & D2 & $X$ & $x$ & & & $x$ & $x$ & $X$ & $X$ & $X$ & $x$ & $x$ & \\
\hline & D3 & $x$ & $x$ & & & $x$ & $x$ & $x$ & $x$ & $X$ & $x$ & $x$ & \\
\hline & D4 & $x$ & $x$ & & & $x$ & $x$ & $X$ & $x$ & $x$ & $x$ & $x$ & \\
\hline & D5 & $X$ & $x$ & & & $x$ & $x$ & $x$ & $x$ & $x$ & $x$ & $x$ & \\
\hline & D6 & $x$ & $x$ & & & $x$ & $x$ & $x$ & $x$ & $x$ & $x$ & $x$ & \\
\hline & D7 & $X$ & $x$ & & & $x$ & $x$ & $x$ & $x$ & $x$ & $x$ & $x$ & \\
\hline & D8 & $x$ & $x$ & & & $x$ & $x$ & $x$ & $x$ & $x$ & $x$ & $x$ & \\
\hline & D9 & $x$ & $x$ & & & $x$ & $x$ & $x$ & $x$ & $x$ & $x$ & $x$ & \\
\hline & D11 & $x$ & $x$ & & & $x$ & $x$ & $X$ & $x$ & $x$ & $x$ & $x$ & \\
\hline & D12 & $x$ & $x$ & & & $x$ & $x$ & $x$ & $x$ & $x$ & $x$ & $x$ & \\
\hline & D13 & $X$ & $X$ & & & $X$ & $X$ & $x$ & $x$ & $x$ & $x$ & $x$ & \\
\hline & D14 & $x$ & $x$ & & & $x$ & $x$ & $x$ & $x$ & $x$ & $x$ & $x$ & \\
\hline & D15 & $X$ & $x$ & & & $x$ & $x$ & $X$ & $x$ & $x$ & $x$ & $x$ & \\
\hline & D16 & $X$ & $x$ & & & $X$ & $x$ & $X$ & $X$ & $x$ & $x$ & $x$ & \\
\hline & D17 & $x$ & $X$ & & & $x$ & $x$ & $x$ & $X$ & $X$ & $x$ & $x$ & \\
\hline & D18 & $x$ & $x$ & & & $x$ & $x$ & $x$ & $x$ & $x$ & $x$ & $x$ & \\
\hline & D19 & $X$ & $x$ & & & $X$ & $x$ & $X$ & $X$ & $X$ & $x$ & $x$ & \\
\hline & E1 & $x$ & $x$ & & & $x$ & $x$ & $x$ & $x$ & $x$ & $x$ & $x$ & \\
\hline & E2 & $x$ & $x$ & & & $X$ & $x$ & $x$ & $X$ & $X$ & $x$ & $x$ & \\
\hline & E3 & $X$ & $x$ & & & $x$ & $x$ & $x$ & $x$ & $x$ & $x$ & $x$ & \\
\hline & E4 & $X$ & $x$ & & & $X$ & $x$ & $X$ & $X$ & $X$ & $x$ & $X$ & \\
\hline & E5 & $X$ & $x$ & & & $X$ & $x$ & $x$ & $x$ & $x$ & $x$ & $x$ & \\
\hline
\end{tabular}


Table A2. Cont.

\begin{tabular}{|c|c|c|c|c|c|c|c|c|c|c|c|c|c|}
\hline & \multicolumn{13}{|c|}{ Dirty Dozen Element } \\
\hline & & 1 & 2 & 3 & 4 & 5 & 6 & 7 & 8 & 9 & 10 & 11 & 12 \\
\hline & F1 & $x$ & & $x$ & $x$ & $x$ & & & & & & & $x$ \\
\hline & F2 & $x$ & & $x$ & $x$ & $x$ & & & & & & & $X$ \\
\hline & F3 & $x$ & & $x$ & $x$ & $x$ & & & & & & & $X$ \\
\hline & F4 & $x$ & & $x$ & $x$ & $x$ & & & & & & & $x$ \\
\hline & F5 & $x$ & & $x$ & $x$ & $x$ & & & & & & & $x$ \\
\hline & F6 & $x$ & & $x$ & $x$ & $x$ & & & & & & & $x$ \\
\hline & F7 & $x$ & & $x$ & $x$ & $x$ & & & & & & & $x$ \\
\hline & F8 & $x$ & & $x$ & $x$ & $x$ & & & & & & & $x$ \\
\hline & F9 & $x$ & & $x$ & $x$ & $x$ & & & & & & & $x$ \\
\hline & F10 & $x$ & & $x$ & $x$ & $x$ & & & & & & & $x$ \\
\hline & F11 & $x$ & & $x$ & $x$ & $x$ & & & & & & & $x$ \\
\hline Communication and & F14 & $x$ & & $x$ & $x$ & $x$ & & & & & & & $x$ \\
\hline Trust Question Set & F15 & $x$ & & $x$ & $x$ & $x$ & & & & & & & $x$ \\
\hline Items & F16 & $x$ & & $x$ & $x$ & $x$ & & & & & & & $X$ \\
\hline & F17 & $x$ & & $x$ & $x$ & $x$ & & & & & & & $x$ \\
\hline & G1 & $x$ & & $x$ & $x$ & $x$ & & & & & & & $x$ \\
\hline & G2 & $x$ & & $x$ & $x$ & $x$ & & & & & & & $x$ \\
\hline & G3 & $x$ & & $x$ & $x$ & $x$ & & & & & & & $x$ \\
\hline & G4 & $x$ & & $x$ & $x$ & $x$ & & & & & & & $x$ \\
\hline & G5 & $x$ & & $x$ & $x$ & $x$ & & & & & & & $x$ \\
\hline & G6 & $x$ & & $x$ & $x$ & $x$ & & & & & & & $x$ \\
\hline & G7 & $x$ & & $x$ & $x$ & $x$ & & & & & & & $x$ \\
\hline & G8 & $x$ & & $x$ & $x$ & $x$ & & & & & & & $\mathrm{X}$ \\
\hline & G9 & $x$ & & $x$ & $x$ & $x$ & & & & & & & $x$ \\
\hline & G10 & $x$ & & $x$ & $x$ & $x$ & & & & & & & $X$ \\
\hline & G11 & $x$ & & $x$ & $X$ & $x$ & & & & & & & $X$ \\
\hline
\end{tabular}

\section{References}

1. Silvagni, S.; Napoletano, L.; Graziani, I.; Le Blaye, P.; Rognin, L. Concept for Human Performance Envelope. EU Horizon 2020 Research and Innovation Programme. 2015. Available online: https://ec.europa.eu/ programmes/horizon2020/en (accessed on 8 January 2018).

2. Bachmann, R. The Coordination of Relations Across Organizational Boundaries. Int. Stud. Manag. Organ. 2003, 33, 7-21. [CrossRef]

3. Flin, R. Measuring safety culture in healthcare: A case for accurate diagnosis. Saf. Sci. 2007, 45, $653-667$. [CrossRef]

4. Karanikas, N.; Melis, D.J.; Kourousis, K.I. The Balance Between Safety and Productivity and its Relationship with Human Factors and Safety Awareness and Communication in Aircraft Manufacturing. Saf. Health Work. 2017, 9, 257-264. [CrossRef]

5. Dode, P.; Greig, M.; Zolfaghari, S.; Neumann, W.P. Integrating human factors into discrete event simulation: A proactive approach to simultaneously design for system performance and employees' well being. Int. J. Prod. Res. 2016, 54, 1-13. [CrossRef]

6. Evans, B.; Glendon, A.I.; Creed, P.A. Development and initial validation of an Aviation Safety Climate Scale. J. Saf. Res. 2007, 38, 675-682. [CrossRef] [PubMed]

7. Glendon, A.; Litherland, D. Safety climate factors, group differences and safety behaviour in road construction. Saf. Sci. 2001, 39, 157-188. [CrossRef]

8. Luria, G.; Yagil, D. Safety perception referents of permanent and temporary employees: Safety climate boundaries in the industrial workplace. Accid. Anal. Prev. 2010, 42, 1423-1430. [CrossRef] [PubMed]

9. O'Connor, P. Assessing the Effectiveness of Bridge Resource Management Training. Int. J. Aviat. Psychol. 2011, 21, 357-374. [CrossRef]

10. Kourousis, K.; Comer, A. Indian and Chinese aviation industry: The EASA framework option. Aircr. Eng. Aerosp. Technol. 2018, 90, 246-250. [CrossRef] 
11. Balk, A.D.; Bossenbroek, J.W. Aircraft Ground Handling and Human Factors-A Comparative Study of the Perceptions by Ramp Staff and Management; NLR-CR-2010-125; NLR Air Transport Safety Institute: Amsterdam, The Netherlands, 2010.

12. Bureau of Air Safety Investigation. Human Factors in Airline Maintenance: A Study of Incident Reports. 1997. Available online: https://www.atsb.gov.au/ (accessed on 10 January 2018).

13. Hobbs, A.; Williamson, A. Associations between errors and contributing factors in aircraft maintenance. Hum. Factors 2003, 45, 186-201. [CrossRef]

14. Caldwell, J.A. Fatigue in aviation. Travel Med. Infect. Dis. 2005, 3, 85-96. [CrossRef] [PubMed]

15. Fisher, T.J. Cleared to Disconnect? A Study of the Interaction between Airline Pilots and Line Maintenance Engineers. Ph.D. Thesis, Massey University, Manawatũ, New Zealand, 2016. Available online: http: //hdl.handle.net/10179/11453 (accessed on 1 September 2019).

16. Mattson, M.; Petrin, D.A.; Young, J.P. Integrating safety in the aviation system: Interdepartmental training for pilots and maintenance technicians. J. Air Transp. World Wide 2001, 6, 37-64.

17. Dupont, G. The dirty dozen errors in maintenance. In Proceedings of the 11th Symposium on Human Factors in Maintenance and Inspection: Human Error in Aviation Maintenance, Washington, DC, USA, 12-13 March 1997.

18. Flin, R.; O'Connor, P.; Mearns, K. Crew resource management: Improving team work in high reliability industries. Team Perform. Manag. Int. J. 2002, 8, 68-78. [CrossRef]

19. Weick, K.E. The Vulnerable System: An Analysis of the Tenerife Air Disaster. J. Manag. 1990, 16, 571-593. [CrossRef]

20. Langer, M.; Braithwaite, G.R. The Development and Deployment of a Maintenance Operations Safety Survey. Hum. Factors 2016, 58, 986-1006. [CrossRef]

21. Chatzi, A.V.; Martin, W.; Bates, P.; Murray, P. The unexplored link between communication and trust in aviation maintenance practice. Aerospace 2019, 6, 66. [CrossRef]

22. Downs, C.W.; Hazen, M.D. A Factor Analytic Study of Communication Satisfaction. J. Bus. Commun. 1977, 14, 63-73. [CrossRef]

23. Appelbaum, S.H.; Benyo, C.; Gunkel, H.; Ramadan, S.; Sakkal, F.; Wolff, D. Transferring corporate knowledge via succession planning: Analysis and solutions-Part 2. Ind. Commer. Train. 2012, 44, 379-388. [CrossRef]

24. Brunetto, Y.; Farr-Wharton, R. Does the talk affect your decision to walk: A comparative pilot study examining the effect of communication practices on employee commitment post-managerialism. Manag. Decis. 2004, 42, 579-600. [CrossRef]

25. Carrière, J.; Bourque, $C$. The effects of organizational communication on job satisfaction and organizational commitment in a land ambulance service and the mediating role of communication satisfaction. Career Dev. Int. 2009, 14, 29-49. [CrossRef]

26. Chan, S.H.J.; Lai, H.Y.I. Understanding the link between communication satisfaction, perceived justice and organizational citizenship behavior. J. Bus. Res. 2017, 70, 214-223. [CrossRef]

27. Clampitt, P.G.; Downs, C.W. Employee Perceptions of the Relationship between Communication and Productivity: A Field Study. J. Bus. Commun. 1993, 30, 5-28. [CrossRef]

28. Gochhayat, J.; Giri, V.N.; Suar, D. Multilevel leadership and organizational effectiveness in Indian technical education: The mediating role of communication, power and culture. Int. J. Leadersh. Educ. 2017, 20, 491-505. [CrossRef]

29. Jalalkamali, M.; Ali, A.J.; Hyun, S.S.; Nikbin, D. Relationships between work values, communication satisfaction and employee job performance: The case of international joint ventures in Iran. Manag. Decis. 2016, 54, 796-814. [CrossRef]

30. Mount, D.J.; Back, K.-J. A Factor-Analytic Study of Communication Satisfaction in the Lodging Industry. J. Hosp. Tour. Res. 1999, 23, 401-418. [CrossRef]

31. Pincus, J.D. Communication Satisfaction, Job Satisfaction, and Job Performance. Hum. Commun. Res. 1986, 12, 395-419. [CrossRef]

32. Zwijze-Koning, K.; De Jong, M. Evaluating the Communication Satisfaction Questionnaire as a Communication Audit Tool. Manag. Commun. Q. 2007, 20, 261-282. [CrossRef]

33. Zwijze-Koning, K.H. Auditing Organizational Communication: Evaluating the Methodological Strengths and Weaknesses of the Critical Incident Technique, Network Analysis and the Communication Satisfaction Questionnaire; Universiteit Twente: Enschede, The Netherlands, 2016. 
34. Rubin, R.B.; Palmgreen, P.; Sypher, H.E. Communication Research Measures: A Sourcebook; The Guilford Press: New York, NY, USA, 1994.

35. Gray, J.; Laidlaw, H. Improving the Measurement of Communication Satisfaction. Manag. Commun. Q. 2004, 17, 425-448. [CrossRef]

36. DeWine, S.; James, A.C. Examining the communication audit: Assessment and modification. Manag. Commun. Q. 1988, 2, 144-169. [CrossRef]

37. Li, X.; Rong, G.; Thatcher, J.B. Does technology trust substitute interpersonal trust? Examining technology trust's influence on individual decision-making. J. Organ. End User Comput. 2012, 24, 18-38. [CrossRef]

38. Gefen, D. What Makes an ERP Implementation Relationship Worthwhile: Linking Trust Mechanisms and ERP Usefulness. J. Manag. Inf. Syst. 2004, 21, 263-288. [CrossRef]

39. Lowry, P.B.; Vance, A.; Moody, G.; Beckman, B.; Read, A. Explaining and Predicting the Impact of Branding Alliances and Web Site Quality on Initial Consumer Trust of E-Commerce Web Sites. J. Manag. Inf. Syst. 2008, 24, 199-224. [CrossRef]

40. McKnight, D.H.; Carter, M.; Thatcher, J.B.; Clay, P.F. Trust in a specific technology: An investigation of its components and measures. ACM Trans. Manag. Inf. Syst. 2011, 2, 1-25. [CrossRef]

41. McKnight, D.H.; Kacmar, C.; Choudhury, V. Developing and Validating Trust Measures for e-Commerce: An Integrative Typology. Inf. Syst. Res. 2002, 13, 334-359. [CrossRef]

42. Nicolaou, A.I.; McKnight, D.H. Perceived Information Quality in Data Exchanges: Effects on Risk, Trust, and Intention to Use. Inf. Syst. Res. 2006, 17, 332-351. [CrossRef]

43. Stewart, K.J.; Malaga, R.A. Contrast and Assimilation Effects on Consumers' Trust in Internet Companies. Int. J. Electron. Commer. 2009, 13, 71-94. [CrossRef]

44. Vance, A.; Elie-Dit-Cosaque, C.; Straub, D.W. Examining Trust in Information Technology Artifacts: The Effects of System Quality and Culture. J. Manag. Inf. Syst. 2008, 24, 73-100. [CrossRef]

45. Chatzi, A.V.; Bates, P.; Martin, W. Communication Satisfaction and Trust towards Safe Practice in the Aviation Maintenance Environment. 2019; under review.

46. Vogt, W.P.; Gardner, D.C.; Haeffele, M.L. When to Use What Research Design; Guilford Press: New York, NY, USA, 2012.

47. Strike, C. Module 9-Human Factors; Cardiff and Vale College: Cardiff, UK, 2018.

48. Gold, N. Human Factors for A Level Certification, Module 9; Aircraft Technical Book Company: Tabernash, CO, USA, 2015.

49. European Aviation Safety Agency. Notice of Proposed Amendment (NPA) 2012-05. Available online: https://www.easa.europa.eu/sites/default/files/dfu/NPA\%202012-05.pdf (accessed on 10 June 2019).

50. Blaise, J.-C.; Levrat, E.; Iung, B. Process approach-based methodology for safe maintenance operation: From concepts to SPRIMI software prototype. Saf. Sci. 2014, 70, 99-113. [CrossRef]

51. Chang, Y.-H.; Wang, Y.-C. Significant human risk factors in aircraft maintenance technicians. Saf. Sci. 2010, 48, 54-62. [CrossRef]

52. Marquardt, N.; Gades, R.; Robelski, S. Implicit social cognition and safety culture. Hum. Factors Ergon. Manuf. Serv. Ind. 2012, 22, 213-234. [CrossRef]

53. Wise, J.A.; Hopkin, V.D.; Garland, D.J. Handbook of Aviation Human Factors; CRC Press: Boca Raton, FL, USA, 2010.

54. Reiman, T. Understanding maintenance work in safety-critical organisations-Managing the performance variability. Theor. Issues Ergon. Sci. 2011, 12, 339-366. [CrossRef]

55. Federal Aviation Administration. FAA Aviation Maintenance Technician Handbook-General, Chapter 14, Addendum/Human Factors. In Aviation Maintenance Technical Handbook; Service of the United States Department of Transportation, \& Flight Standards Service: Newcastle, WA, USA, 2011.

56. Kourousis, K.I.; Chatzi, A.V.; Giannopoulos, I.K. The airbus A320 family fan cowl door safety modification: A human factors scenario analysis. Aircr. Eng. Aerosp. Technol. 2018, 90, 967-972. [CrossRef]

57. Leedy, P.D.; Ormrod, J.E. Practical Research: Planning and Design, 10th ed.; Pearson: London, UK, 2013.

58. Air Accident Investigation Unit. Synoptic Report Serious Incident Airbus, A320-214, EI-GAL Cork Airport (2019-004). Available online: http://www.aaiu.ie/reports/aaiu-investigation-reports (accessed on 10 June 2019).

59. Komite National Keselamatan Transportasi. Indonesia Air Asia Airbus A320-216; PK-AXC Karimata Strait Coordinate $3^{\circ} 37^{\prime} 19^{\prime \prime}$ S-109 $42^{\prime} 41^{\prime \prime}$ E (KNKT.14.12.29.04). 2015. Available online: http://knkt.dephub.go.id/ knkt/ntsc_aviation/aaic_case.htm (accessed on 10 June 2019). 
60. Air Accident Investigation Unit. Serious Incident DHC 6-300, C-GSGF Weston Airport, Co. Kildare. 2016. Available online: http://www.aaiu.ie/reports/aaiu-investigation-reports (accessed on 10 June 2019).

61. Australian Transport Safety Bureau. Undetected Engine Thrust Reverser Deactivation Involving Airbus A320, VH-VGZ. 2019. Available online: https://www.atsb.gov.au/ (accessed on 10 June 2019).

62. The Dutch Safety Board. Gear Collapse during Landing. 2018. Available online: https://www.onderzoeksraad. $\mathrm{nl} / \mathrm{en} /$ (accessed on 10 June 2019).

63. Air Accidents Investigation Branch. Boeing 747-443, G-VROM, Damage to Right Wing Landing Gear Door and Strike Board, Near London Gatwick Airport. 2015. Available online: https://www.gov.uk/aaib-reports (accessed on 10 June 2019).

64. Australian Transport Safety Bureau. Air Data System Failure involving Airbus A330-243 A6-EYJ (AO-2013-212). 2016. Available online: https://www.atsb.gov.au/ (accessed on 10 June 2019).

65. National Transportation Safety Board. Aviation Incident Final Report, Boeing 767, N360AA, Incident Report ENG12IA010, 07/12/2012. Available online: https://www.ntsb.gov/investigations/AccidentReports/Pages/ AccidentReports.aspx (accessed on 10 June 2019).

66. National Transportation Safety Board. Aviation Incident Final Report, Boeing 767, N669US, Insident Report ENG14IA027, 28/09/2016. Available online: https://www.ntsb.gov/investigations/AccidentReports/Pages/ AccidentReports.aspx (accessed on 10 June 2019).

67. Directorate General of Civil Aviation. Ground Fatal Accident to Air India Ltd. Airbus A-319 aircraft VT-SCQ. 2016. Available online: http://dgca.nic.in/ (accessed on 10 June 2019).

68. Japan Transport Safety Board. Aircraft Accident Investigation Report China Airlines, Boeing 737-800, B 18616. 2009. Available online: https://www.mlit.go.jp/jtsb/english.html (accessed on 10 June 2019).

69. Air Accidents Investigation Branch. Report on the Accident to Airbus A319-131, G-EUOE London Heathrow Airport on 24 May 2013. Available online: https://www.gov.uk/aaib-reports (accessed on 10 June 2019).

70. Gabinete de Precenção e Investigação de Acidentes com Aeronaves e de Acidentes Ferroviarios. Aircraft Accident Information Notice, Embraer 190-100LR, P4-KCJ, 02/05/2019. Available online: www.gpiaa.gov.pt/ (accessed on 10 June 2019).

71. Accident Investigation Division. Report on the Accident to Airbus A330-342 B-HLL Operated by Cathay Pacific Airways Limited at Hong Kong International Airport, Hong Kong on 13 April 2010. Available online: https://www.thb.gov.hk/aaia/eng/index.htm (accessed on 10 June 2019).

72. United States Air Force Accident Investigation Board. Lockheed WC-130H, T/N 65-0968 1.5 Miles Northeast of Savannah/Hilton Head International Airport, Georgia. 2018. Available online: https://www.afjag.af.mil/ AIB-Reports/ (accessed on 10 June 2019).

(C) 2019 by the author. Licensee MDPI, Basel, Switzerland. This article is an open access article distributed under the terms and conditions of the Creative Commons Attribution (CC BY) license (http://creativecommons.org/licenses/by/4.0/). 
Article

\title{
Bowtie Methodology for Risk Analysis of Visual Borescope Inspection during Aircraft Engine Maintenance
}

\author{
Jonas Aust * and Dirk Pons \\ Department of Mechanical Engineering, University of Canterbury, Christchurch 8041, New Zealand; \\ dirk.pons@canterbury.ac.nz \\ * Correspondence: jonas.aust@pg.canterbury.ac.nz; Tel.: +64-210-241-3591
}

Received: 5 July 2019; Accepted: 24 September 2019; Published: 2 October 2019

\begin{abstract}
Background-The inspection of aircraft parts is critical, as a defective part has many potentially adverse consequences. Faulty parts can initiate a system failure on an aircraft, which can lead to aircraft mishap if not well managed and has the potential to cause fatalities and serious injuries of passengers and crew. Hence, there is value in better understanding the risks in visual inspection during aircraft maintenance. Purpose-This paper identifies the risks inherent in visual inspection tasks during aircraft engine maintenance and how it differs from aircraft operations. Method-A Bowtie analysis was performed, and potential hazards, threats, consequences, and barriers were identified based on semi-structured interviews with industry experts and researchers' insights gained by observation of the inspection activities. Findings-The Bowtie diagram for visual inspection in engine maintenance identifies new consequences in the maintenance context. It provides a new understanding of the importance of certain controls in the workflow. Originality-This work adapts the Bowtie analysis to provide a risk assessment of the borescope inspection activity on aircraft maintenance tasks, which was otherwise not shown in the literature. The consequences for maintenance are also different compared to flight operations, in the way operational economics are included.
\end{abstract}

Keywords: aviation maintenance; borescope inspection; Bowtie analysis; maintenance, repair, and overhaul (MRO); risk assessment; risk management; visual inspection

\section{Introduction}

The inspection of parts is critical to the safety and quality of aerospace hardware. There is value in better understanding the risks of the inspection process itself. The inappropriate diagnosis of part condition may have significant engineering, cost, and safety implications.

Understanding and controlling inspection risks is an important component of the organisational risk management process. A method with particular relevance to procedural risks is the Bowtie analysis. Bowtie analysis was first applied to accident investigation in the oil and gas industry, and was quickly applied to other high-reliability organisations (HROs) including aviation, mining, and nuclear energy $[1,2]$.

The risk assessment approach is named Bowtie, due to the diagram's distinctive shape, reminiscent of the dress bowtie [1]. The diagram is a combination of a fault tree analysis (FTA), event tree analysis (ETA), and barrier analysis (BA) [3]. Hence, the Bowtie is also known as a barrier diagram.

In recent years, Bowtie was increasingly adopted by other industries after the benefits of the method were recognised. Today, Bowtie is applied to several industries including oil and gas [1,4], aviation [5-8], chemical [9,10], defence [11], banking [12], healthcare [2,13], marine [14], mining [1,15], nuclear energy [16], transportation [17,18], and road safety [19]. 
The current paper extends the Bowtie method to visual inspection tasks during aircraft engine maintenance, repair, and overhaul (MRO). This is worth doing because the existing MRO processes tend to be arranged around conventional notions of manufacturing quality such as standardised work procedures. Nonetheless, it is impossible to standardise all processes; there is always an element of personal approach to the work and, hence, variability. This is especially evident where workers are required to exercise judgement in the inspection processes, e.g., deciding whether or not to scrap a turbine blade. There are a variety of human errors that may occur, along the lines of slips, lapses, mistakes, and violations [20]. Consequently, there is a need to find ways to create in workers an awareness of the critical factors that contribute to success and failure of the aerospace hardware. A similar issue arises in other areas of aerospace, especially commercial aircraft operations where standard procedures exist, and are further supplemented by Bowtie analysis for training purposes. In the same way, there is value in developing Bowtie models for $\mathrm{MRO}$, to assist in training workers and sensitising them to the consequences of their work.

Borescope inspection was chosen as the particular situation under examination, as it is one of the main means of defect detection in aircraft engine maintenance. Defects that stay undetected have the potential to cause severe damage to the engine or aircraft, and result in accidents and fatalities [21]. The reliable assessment of part condition is essential. It is crucial to understand risks associated with the inspection process, as well as the barriers that can prevent or recover the outcomes. A better understanding and targeted management of those risks has the potential to contribute towards improved airworthiness and aviation safety.

\section{Review of the Bowtie Method}

\subsection{Historical Origins}

The exact origin of the Bowtie remains to be fully clarified, but it was first mentioned in 1979 in the lecture notes of a hazard analysis class presented by Imperial Chemical Industries at the University of Queensland, Australia [22]. It is accepted that the first company to integrate the Bowtie method as a risk management tool was the Royal Dutch Shell Group in the early 1990s in response to the Piper Alpha oil and gas platform explosion in the North Sea (1988) and after the introduction of the Seveso Directive [23-25]. This new risk analysis and assessment approach was developed as the main component of the "hazard, effect, and management process" (HEMP) and was communicated internally by Shell as a "Bowtie diagram" [25].

The Seveso Directive used a "methodology for the identification of major accident hazards" (MIMAH) to investigate the disaster of accidental toxic dioxin release in Seveso, Italy (1976). Bowtie was used as the basis for the MIMAH methodology. A major achievement of the Seveso Directive includes legislations by the European Union to prevent major accidents and to limit their outcomes $[2,26,27]$.

\subsection{Methodological Parents}

There were different preceding risk assessment methods that provided the context for the Bowtie to emerge, namely, fault tree analysis (FTA), event tree analysis (ETA), cause consequence analysis (CCA), and barrier analysis (BA) [1].

\subsubsection{Fault Tree Analysis}

The fault tree analysis as a method has two applications. Most commonly, it is used during the system design and development stage to predict and prevent future problems. The second application of FTA is for accident investigation, whereby FTA helps to identify and analyse the root-causes contributing through different failure paths to the critical event, which is often referred to as the "top event" (loss of control or failure) [28]. Probabilities can be assigned to the causes, and the top event probability can be computed by employing Boolean logic, which allows the FTA to be quantified $[1,29]$. 
This method was developed by Bell Laboratories in 1962 for the United States (US) Air Force to determine the reliability of the intercontinental Minuteman missile launch control system [30,31]. Later, Boeing adopted, improved, and applied the method for civil aircraft design and for hazard identification. Today the fault tree analysis is used to analyse high-hazard safety systems in nuclear power plants, aerospace, and defence [32].

The key benefit of FTA is the graphical representation of complex relationships between various failure paths and combinations of possible outcomes [33]. The structured and logical approach enables quantification of all possible root-causes. Another benefit of the FTA is that it may be used to predict future failures, and also to diagnose past failures. However, the limitations include the difficulty of quantifying probabilities, inaccuracy in case of scarce or insufficient data, uncertainty in covering all failure modes, and incorporating partial failures, including external environmental effects, and including human behavioural effects (procedures and human error) [33,34].

\subsubsection{Event Tree Analysis}

It is understood that event trees were developed during the WASH-1400 nuclear power plant safety study (around 1974) as a condensed, alternative diagram to fault trees, as using the latter would have led to very large and cumbersome diagrams [35].

While fault trees that start with identifying causes lead to the top event, event trees, in contrast, take a single initial event (top event) and analyse all possible system failure paths leading to consequences caused by the initiating event. A probability can be assigned to each path and, thus, the probability of different consequences can be calculated, which makes the method qualitatively applicable. The risk calculation can be done before an accident to determine possible consequences or after an accident for investigation purposes to identify functional failures of the system. Typical applications of event trees are transportation and nuclear power plants [29,36].

Similar to the FTA, the benefits of the ETA lie in the graphical representation of the failures and the sequence of events. Multiple failure paths can be analysed, and cause-effect relationships can be displayed with their dependencies expressed. Furthermore, it allows probability assessment and detection of insufficient countermeasures [33,37].

A limitation of the ETA is that it analyses only one initiation event at a time. Hence, it is not an effective method when multiple events must occur simultaneously, as it would result in redundant branches. Since the ETA uses binary logic, it is difficult to represent situations with uncertainties such as human or environmental factors. Complex events can be expressed, but they lead to massive and highly complex diagrams. At the same time, simplifying the diagram can lead to missed subtle dependencies $[33,38]$.

\subsubsection{Cause Consequence Analysis}

The cause consequence analysis was developed in 1971 at Riso Laboratories in Denmark, to reveal accidents in complex nuclear installations [39]. It connects the causes and consequences through a so-called "critical or top event", combining two diagrams. Firstly, a cause diagram leading to the top event is a traditional fault tree. Secondly, the consequence diagram is an event sequential diagram that tries to find potential outcomes of the top event [1,39]. The CCA aims to determine the probability of each consequence using FTA logic. It is recognised as the predecessor of the Bowtie method [40].

Among the benefits of the CCA are the visual presentation of complex cause-consequence relationships, the structured method for probability assessment, and the incorporation of system dependencies in the risk evaluation. Furthermore, it enables the representation of time-sequenced events and the analysis of multiple outcomes. A drawback of the CCA is that only one initiating event at a time can be evaluated [41]. Hence, several diagrams are needed when analysing multiple critical events. Since CCA uses a top-down approach, there is the risk that a high-level event or hazard is missed. 


\subsubsection{Barrier Analysis}

Barrier analysis is a system safety assessment method to identify hazards and to evaluate any controls that can prevent the event occurring. The first application of systematic safety barriers was the hazard-barrier-target model developed by Haddon in 1973 [42]. The barrier approach was used to express means of control in systems with a hazardous energy source, which could potentially lead to damage to either equipment or personnel. Later, Reason introduced his Swiss-cheese metaphor (1990) [20]. This concept often has multiple barriers (cheese slices), such that, if one fails, the next one may stop the event. The holes in the slices symbolise the inherent ineffectiveness of the barriers. When the holes of all slices align, it is the moment when all barriers fail and the control of the situation is lost, and undesired consequences may occur $[1,20,33,43]$.

Most recent, Sklet worked on barrier models and came up with a definition widely used by practitioners. He defines safety barriers as "physical and/or non-physical means planned to prevent, control, or mitigate undesired events or accidents" [44].

Even though the barrier concept is mainly qualitative, studies by Duijm and Goossens showed that barriers can be quantified by combining weighted factors and a rating system. Each barrier is then scored based on its safety performance measures, i.e., effectiveness, reliability, consistency, and other criteria [45].

Currently, BA is more broadly used for any process where a controlled state should be maintained, including areas of quality, safety, security, and health.

The BA is simple to understand as it visually represents the barriers that are in place, as well as the absence of any barrier which could have prevented or mitigated an undesired event to occur. The BA directly results in recommendations for where to implement additional barriers or to improve or maintain existing barriers.

A limitation of the original BA is its incomprehensiveness as a sole risk assessment tool, as it does not identify human errors and hardware failures that are not directly associated with hazardous energy sources [46]. However, it can be easily combined with other methods.

The BA may lead to linear thinking and is, therefore, highly subjective, which makes it difficult to reproduce, in particular, for non-obvious and complex causes, as there is a risk of confusing causes and countermeasures (barriers).

\subsection{Principles of Bowtie Analysis}

The Bowtie method combines features of the above methods. It includes a simplified FTA and ETA, without the logic symbols, and combines them based on the CCA approach, through single cause-consequence relationships. The functional blocks of these other methods are replaced with barriers, which are placed on both sides of the diagram to prevent or mitigate any undesired outcomes. The structure is laid out horizontally, whereas those other charts are vertical, and this results in the characteristic shape with the central knot and, hence, the Bowtie name.

There is no standardised terminology for the different elements of a Bowtie, which often causes confusion. The definitions below originate from the United Kingdom Civil Aviation Authority (UK CAA), the European Aviation Safety Agency (EASA), and the Federal Aviation Administration (FAA) [5-7]. This coincides with the terminology used by Shell, where the method was first applied [23].

Hazard: A hazard is defined as condition, object, or activity that can potentially cause harm or damage, including injuries to personnel, damage to equipment, properties, or environment, or reduced ability to perform an action as intended.

Top Event: The top event is the moment when the controlled state of a hazard is lost. It is yet to cause any damage or negative impact, but can lead to undesired outcomes if all prevention barriers fail. The term "top event" is derived from the fault tree analysis, where the critical event is on the top.

Threats: Threats describe initiating events that can potentially cause, through several pathways, the occurrence of the identified top event if all safety barriers fail. There can be one or multiple threats leading to the top event. 
Consequences: Consequences are potential outcomes or a chain of outcomes resulting from the release of the top event, directly resulting in loss of control or damage if all mitigation barriers fail.

Barriers: Barriers, which are also called controls or layers of protection, are measures that prevent or mitigate undesired outcomes or reduce the likelihood of their occurrence, as well as maintaining the desired state. Derived from the fault tree and event tree analysis, the barriers can be categorised based on their location in the Bowtie diagram and their function. Prevention barriers are located on the left side of the Bowtie diagram, between the threat and top event. They eliminate the threat entirely or prevent the top event from occurring and, consequently, they prevent the hazard from being released. When the top event is reached, mitigation barriers become effective and reduce the likelihood of the consequences to occur, or limit the severity of the undesired consequences [10,13,47]. These barriers are located between the top event and the consequences.

Escalation Factors and Escalation Factor Barriers: Safety barriers are not $100 \%$ effective, as well as having inherent and temporary weaknesses. In Bowtie, the conditions influencing the effectiveness are called escalation factors [47], degradation factors [48], or barrier decay mechanisms [49], and are depicted using branches from the main path barrier. Once the escalation factors are determined, the next step is to identify barriers that are in place to manage the escalation factors. Those barriers are called escalation factor barriers or degradation factor safeguards [48]. In the Bowtie diagram, those barriers are placed between the escalation factor and the affected barrier on the main threat path.

Figure 1 shows the schematic structure of a Bowtie diagram with all elements.

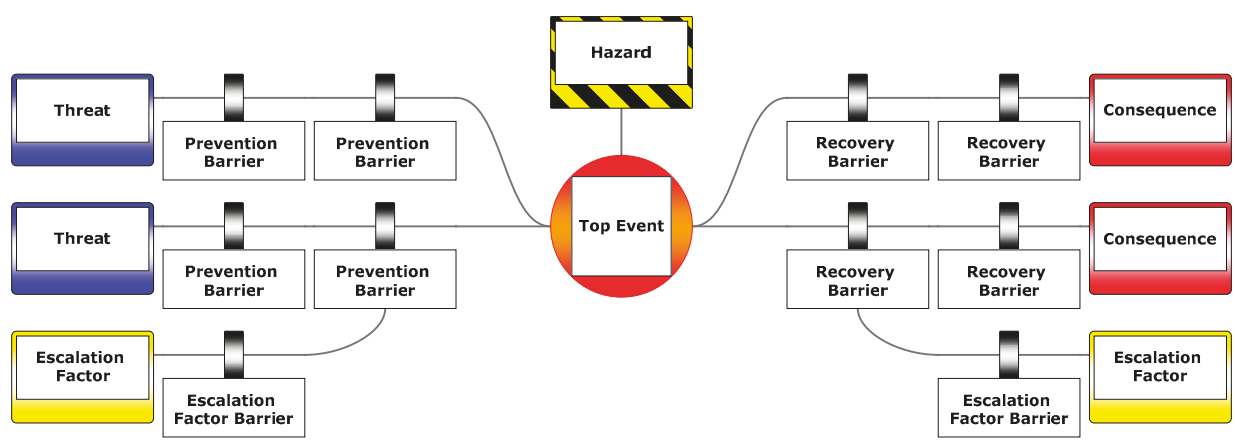

Figure 1. Schematic Bowtie diagram with prevention and recovery barriers.

\section{Methodology}

\subsection{Purpose}

The purpose of this research was to identify the risks occurring in visual inspection tasks during aircraft engine maintenance in an MRO environment. This is a very different situation to aircraft operations, and, while there is substantial literature including Bowtie analysis for operations [5-8], there is a paucity for MRO applications. The questions that arose include how the Bowtie analysis could be used in aviation maintenance, and what the difference of Bowtie is in aircraft operation. In particular, there is a need for understanding the multiple factors that influence the visual inspection and how those can be controlled by prevention. Furthermore, it is crucial to understand the consequences that can occur and how these can be mitigated in the case of the top event release. This goes beyond the most obvious worst-case scenarios, i.e., incidents, accidents, and fatalities.

It should be noted that Bowtie analysis and diagrams vary depending on the area under investigation and the target audience. Where operations are complex, it can be helpful to divide work streams into smaller pieces and perform risk analysis for each individually. Bowtie analysis is typically performed for a specific, usually critical, step in a complex operation chain. However, since all the process steps are linked together, Bowties can also be linked together. In BowtieXP this is realised by 
chaining Bowties to represent the full operation and process chain. In this context, it is important to understand that a Bowtie element can be both a threat and a consequence at the same time, depending on the operational environment the risk analysis is performed. For example, a consequence in the manufacturing environment (e.g., a defective part) can be a threat in the subsequent maintenance Bowtie diagram. A generic Bowtie chain is shown in Figure 2, and the common element is highlighted. In this research, the Bowtie diagrams were created for the MRO environment only and were not chained together.

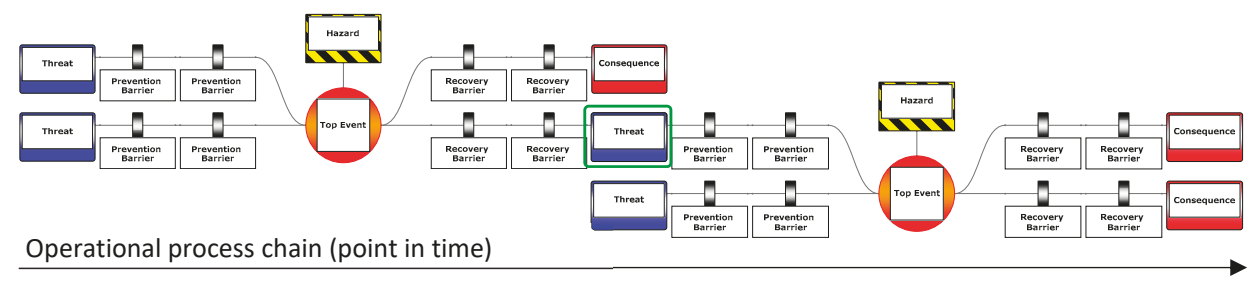

Figure 2. Generic Bowtie chain.

The specific case under examination is borescope inspection, particularly the impact of hardware factors. Borescope inspection is a technique to visually inspect the inside of an aircraft engine, while avoiding a costly tear-down. It enables the evaluation of engine parts for their airworthiness and operability, which is critical for aircraft reliability and safety. The borescope tool is an optical instrument with a built-in camera and light source, which displays the image live on a screen. The borescope inspection occurs either with the engine on the wing, or when the engine is first presented to the MRO. The latter is called an induction inspection. There is also a post-test borescope inspection that occurs after re-assembly and testing as a last step before returning the engine to the aircraft.

\subsection{Approach}

The specific industry under observation was the Christchurch Engine Centre (CHCEC). This is an MRO facility with 470 staff, maintaining over 140 IAE V2500 engines per year. The borescope inspection tasks were not limited to in-house induction and post-test inspection, but also included on-wing inspection at the customer's premises. Hence, inspectors had considerable experience.

Initially, we examined the open literature on Bowties applied to visual inspection and aviation maintenance in general. However, nothing relevant was found; hence, it was necessary to start from scratch. Our approach was based on the "AS9110 Quality Maintenance Systems-Requirements for Maintenance Organizations" standard [50]. Firstly, the hazard and top event were identified. We framed this in terms of the worker perspective, specifically wording it in such a way as to be aligned with the role, and recruiting personal motivation and pride in workmanship. We did this because the primary audience for the Bowtie is the worker. Hence, the top event was "inappropriate diagnosis of part condition".

We then identified the consequences in the MRO environment. These are not identical to the aircraft operation perspective. Next, we constructed the threat branches and added prevention barriers. Subsequently, escalation factors and escalation factor barriers were added.

These constructions were based on discussion with 15 aircraft maintenance technicians (AMTs) and through observation of their activities. Three AMTs had up to 10 years work experience in the field, seven had more than 10 years, and five had more than 20 years. Their certifications ranged from non-destructive testing (NDT) operator to borescope operator and borescope video reviewer. The barriers of the main threat paths and the escalation path were inferred based on engineering knowledge. This part of the process was consistent with the approach suggested by Lewis [51]. Threats and consequences were identified by the individual AMTs, recorded in field notes by the researcher, and 
subsequently grouped into the various categories shown in the results. The Bowties were constructed using BowTieXP software revision 9.2.13 [52].

We then validated the Bowties by discussing them with the most experienced inspection expert at our industry partner (borescope operator with level 2 certification, which is the highest certification available in the field). A consensus was reached on the structure of each Bowtie.

\section{Results}

\subsection{Identification of Top Event}

The top event that was identified in the Bowtie analysis was "inappropriate diagnosis of part condition". For further explanation of the top event, borescope inspection for engine blade defects was used as a specific example. Safety critical defects include cracks, nicks, dents, tears, etc. [21].

There are several scenarios that could lead to an inappropriate diagnosis of the part condition. These include the following:

1. Defect missed: If the inspector misses a defect that exceeds the tolerance limits. In the terminology of the confusion matrix, this is known as a true negative.

2. Defect falsely detected: The inspector finds something and declares it as defective despite it being within the tolerance level or detecting a non-existent defect. This is called a false positive as it was incorrectly rejected. For example, deposit on an airfoil could be incorrectly identified as pitting or corrosion [21].

3. Indication mis-located: Engine blades are divided into multiple areas, so-called airfoil zones. Each zone has a different tolerance level in terms of the size of defect and the number of defects per blade or blade set (stage). A defect that is localised in zone B, which may be acceptable for the zone B tolerance, is not necessarily acceptable for zone A. Consequently, a blade that is incorrectly identified as airworthy could be released to service. In the contrary case, a defect is incorrectly identified as being unairworthy in zone A, while actually located in zone B and, hence, is scraped unnecessarily.

4. Defect forgotten before decision is made: This might happen when the inspector examines the full blade stage in one full run and later revisits the defective blades. If no marker is set or the inspector gets distracted for some reason, he might forget the defect and not go back to check.

It was found that the threats and prevention barriers, as well as the consequences and mitigation barriers, were nearly identical for all those scenarios. Hence, one combined Bowtie was developed instead of four duplicated ones, which only differed in the top event.

\subsection{Consequences}

Consequences are generally characterised by damage. While the Bowtie method is well established, existing applications in the aviation industry are focused on the aircraft operation and the "significant seven". These describe a range of significant safety scenarios, namely, loss of control, runway excursion, controlled flight into terrain, runway incursion, airborne conflict, ground handling, and fire, which were analysed by CAA applying Bowtie [6,53]. The consequences for MRO, however, are somewhat different.

We identified that the consequences in the MRO context include not only the safety of the aircraft passengers and the potential for fatalities, but also the operational economics. These economic damages could affect the MRO service provider, the engine owner, or the airline. The identified economic and technical perspectives include the following:

- Gate returns and air turn-backs;

- Reputation damage;

- Fines and litigations;

- $\quad$ Reduced part lifetime; 
- Shortened cycle time;

- Premature engine shop visit;

- Financial loss;

- Airworthy parts scrapped;

- Release of an unairworthy part to service;

- Severe damage to engine and/or aircraft;

- Fatality, accident, incident.

It was noticed that consequences may appear in a chronological or procedural order and can be divided into immediate, subsequent, or final consequences. In this work, the immediate consequences for "inappropriate diagnosis of the part condition" were the "release of an unairworthy part into service" and "scrapping of an airworthy part" (Figure 3). The latter had only financial loss as a subsequent consequence, whereas the consequences for the release of an unairworthy part were much greater and included the examples shown in the list above. As the work stream under examination was "borescope inspection", we made this the hazard label. This is because borescope can be an activity that can potentially cause harm or damage if not performed properly.

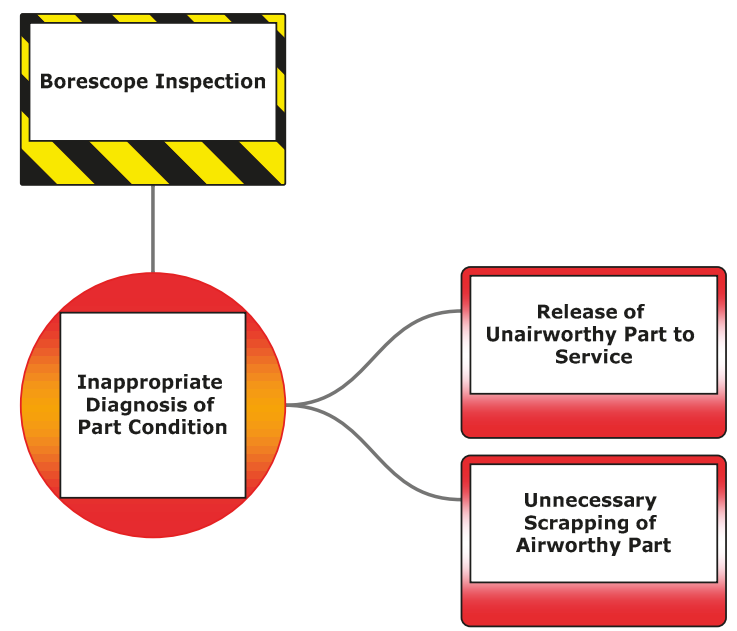

Figure 3. Bowtie diagram for "inappropriate diagnosis of part condition" with immediate consequences.

The Bowtie method cannot express this chronological consequence path and, hence, this could not be visualised with the BowtieXP software. We applied image editing software to modify the Bowtie diagram manually. The result is shown in Figure 4.

\subsection{Threats}

When evaluating the threats of incorrect diagnosis of the part condition, seven main threats arose. The Bowtie software allows one to add a description to each threat. However, this is not displayed in the diagram. Hence, we prepared the list shown in Table 1 below and added a short description with a typical example to each of the threats.

The table represents what we think is the right level of detail for the borescope inspection Bowtie, without detailing each failure mode. Factors that had the same or similar barriers to prevent the top event from occurring were grouped as main treats. 
Table 1. Threat list with descriptions.

\begin{tabular}{|c|c|}
\hline Threat & Description \\
\hline Incorrect tool or setting & $\begin{array}{l}\text { Wrong borescope or borescope tip is being used. This can result in } \\
\text { difficulties obtaining an angle from which the inspected part is seen } \\
\text { properly and is visually assessable. } \\
\text { Incorrect settings in the borescope menu selected include if the contrast } \\
\text { is too high or the brightness of the light source is too low. }\end{array}$ \\
\hline Borescope not working properly & $\begin{array}{l}\text { Borescope is not working properly as required for the inspection task. } \\
\text { This can be a result of inappropriate handling or transportation of the } \\
\text { borescope. }\end{array}$ \\
\hline $\begin{array}{l}\text { Damaged borescope tip or } \\
\text { inappropriate tip condition }\end{array}$ & $\begin{array}{l}\text { Borescope tip is damaged or in an inappropriate condition. This often } \\
\text { happens when borescoping a dirty engine and the fine deposit sticks to } \\
\text { the tip or clogs the opening, which results in a limited, blurry, or } \\
\text { smeared image. }\end{array}$ \\
\hline $\begin{array}{l}\text { Inadequate engine or borescope } \\
\text { knowledge }\end{array}$ & $\begin{array}{l}\text { A lack of knowledge of the engine or borescope inspection such as the } \\
\text { correct manipulation of the borescope can result in inspecting the wrong } \\
\text { parts, revisiting the same parts multiple times, or missing the inspection } \\
\text { on others. }\end{array}$ \\
\hline Correct tool not available & $\begin{array}{l}\text { Borescope tips often get dirty and sometimes appropriate cleaning } \\
\text { material is not available. As a result, the tips get sent to the } \\
\text { manufacturer for cleaning. The same process occurs when the borescope } \\
\text { has a technical issue. Due to the time pressure, the engine cannot wait, } \\
\text { and the inspection process is performed with alternative available tools. }\end{array}$ \\
\hline $\begin{array}{l}\text { Tip lost or left behind after } \\
\text { inspection }\end{array}$ & $\begin{array}{l}\text { An unnoticed left behind or lost tip can cause foreign object damage } \\
\text { (FOD) to the engine once it is running. }\end{array}$ \\
\hline Inappropriate or missing aids & $\begin{array}{l}\text { Aids include insertion tubes, magic arms, hockey arms, etc. If these are } \\
\text { incorrectly installed or missing, borescope inspection can be challenging, } \\
\text { which results in a shifting of focus from the actual inspection and } \\
\text { evaluation of the part condition to the manipulation and handling of the } \\
\text { borescope or aids. }\end{array}$ \\
\hline
\end{tabular}

The threat side of the Bowtie is shown in Figure 5.

\subsection{Barriers and Escalation Factors}

For each threat and consequence branch, barriers were added to the Bowtie diagram. The barriers were a combination of current existing barriers from the MRO site of our industry partner and our own knowledge. Subsequently, escalation factors and escalation factor controls were added, showing the aspects that influence the effectiveness of the main barriers.

Since the main target of risk management is the prevention of the top event, most Bowties focus on the prevention, rather than the recovery side. Hence, we emphasised the prevention side. Nonetheless, the main recovery barriers and its escalation factors, as well as the escalation factor barriers, are presented.

To reduce the complexity of the diagram, only the two immediate consequences are displayed on the right side of the Bowtie diagram. The threat side of the Bowtie is shown in Figure 6, and the consequence side is illustrated in Figure 7. Since the Bowtie diagram could not be adjusted in the BowtieXP software in order to present it in a legible way, we applied manual image processing to split the original Bowtie into its single threat and consequence paths. The full Bowtie with all barriers, escalation factors, and escalation factor barriers can be found in Figures A1-A5 (Appendix A). For a higher- resolution version of those figures, please see Supplementary Materials S1-S5. 


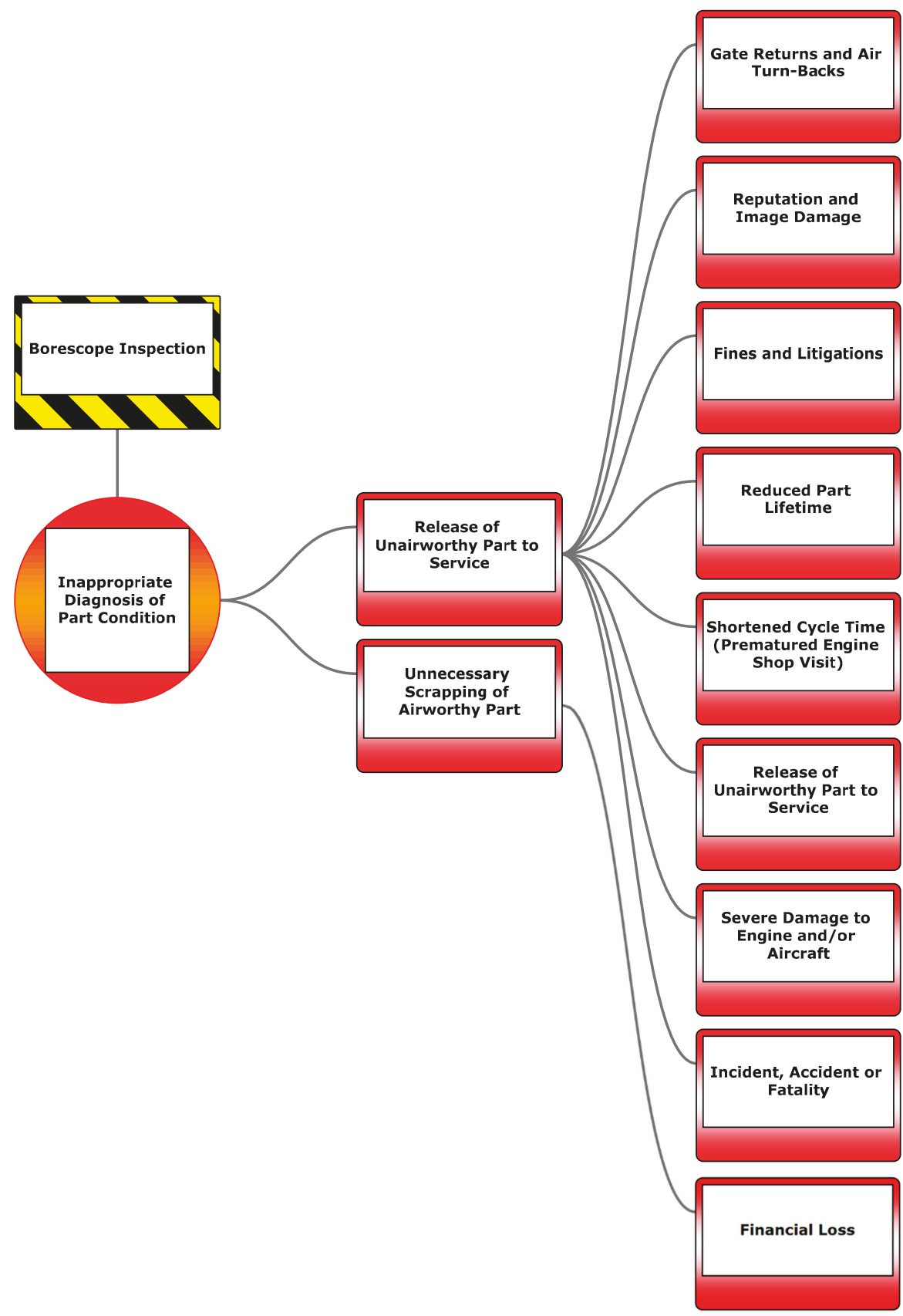

Figure 4. Bowtie diagram for "inappropriate diagnosis of part condition" with immediate and manually added subsequent consequences. 


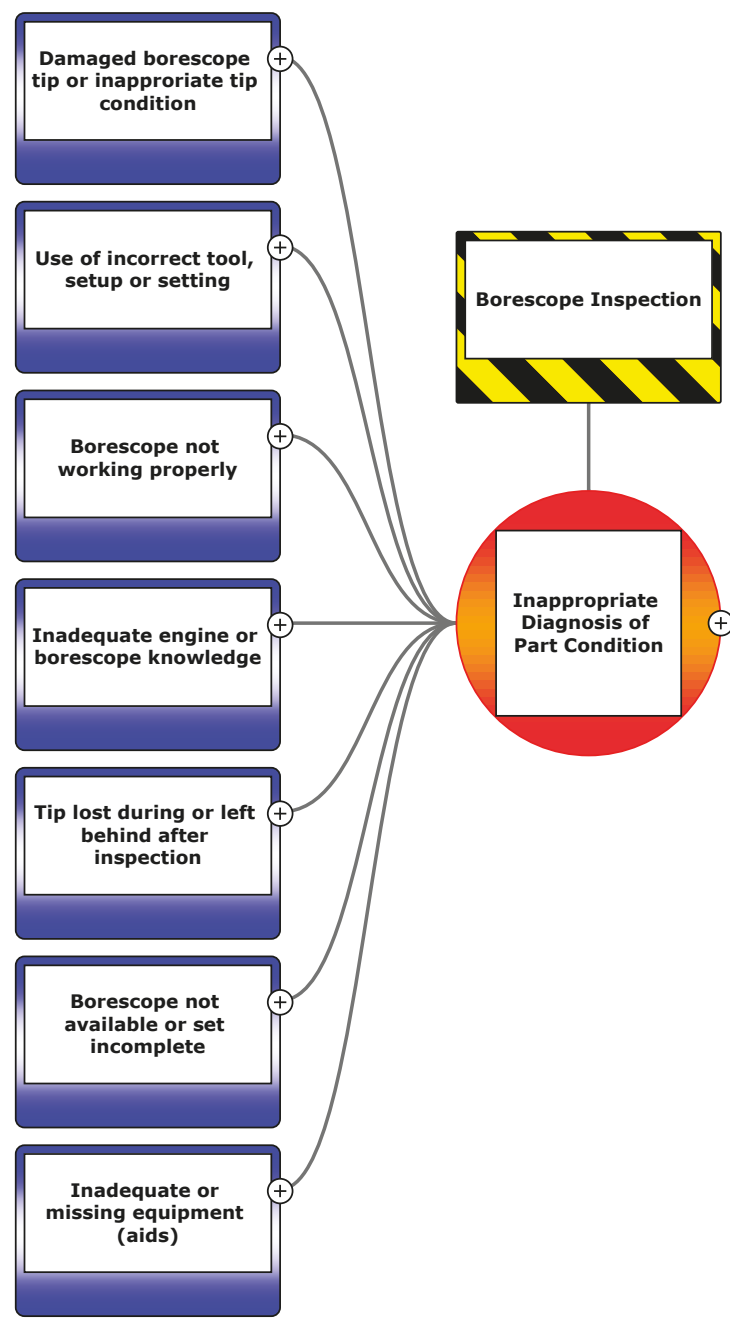

Figure 5. Bowtie diagram for "inappropriate diagnosis of part condition" with threats. 


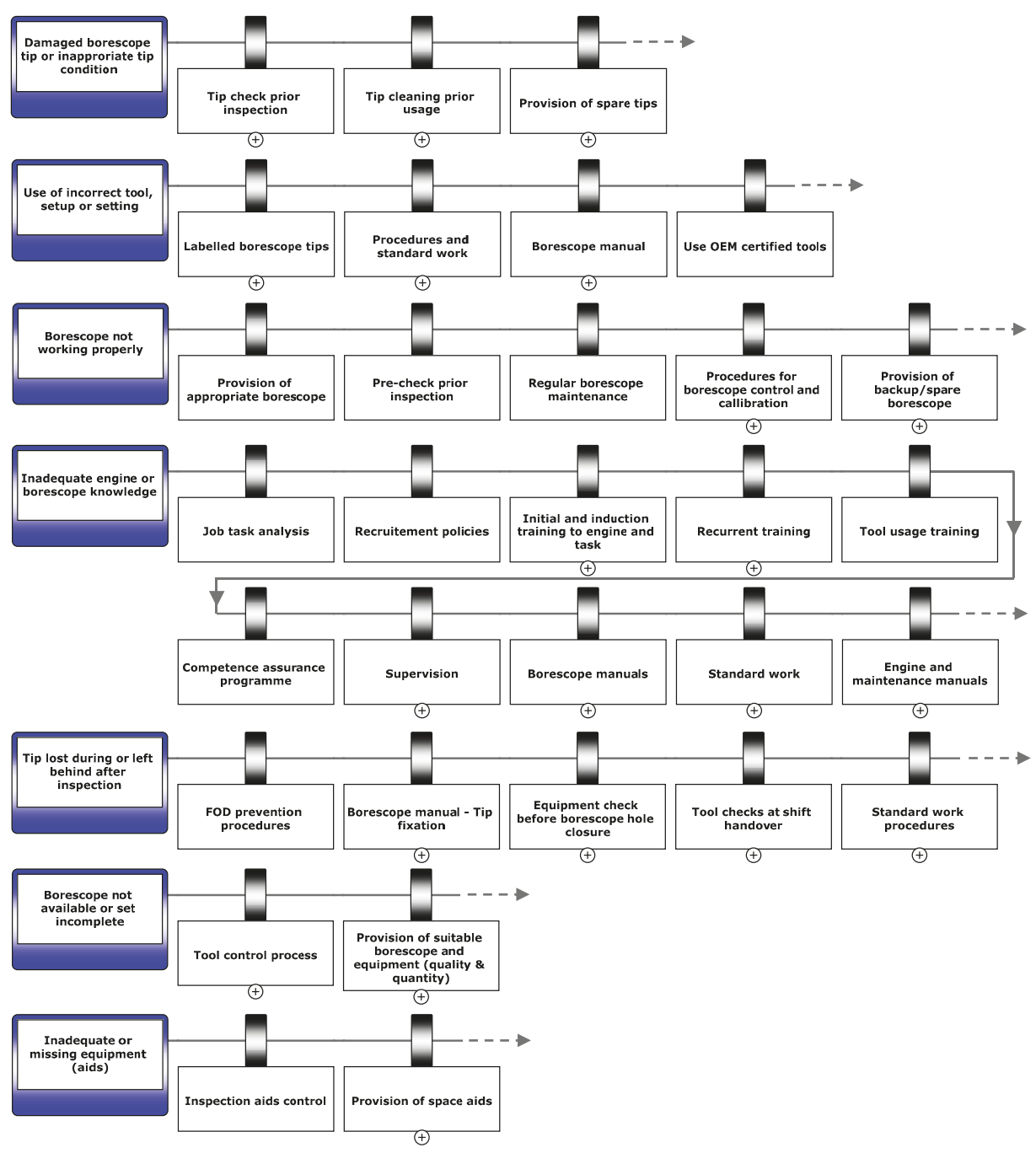

Figure 6. Left half of the Bowtie diagram with threats and prevention barriers. 


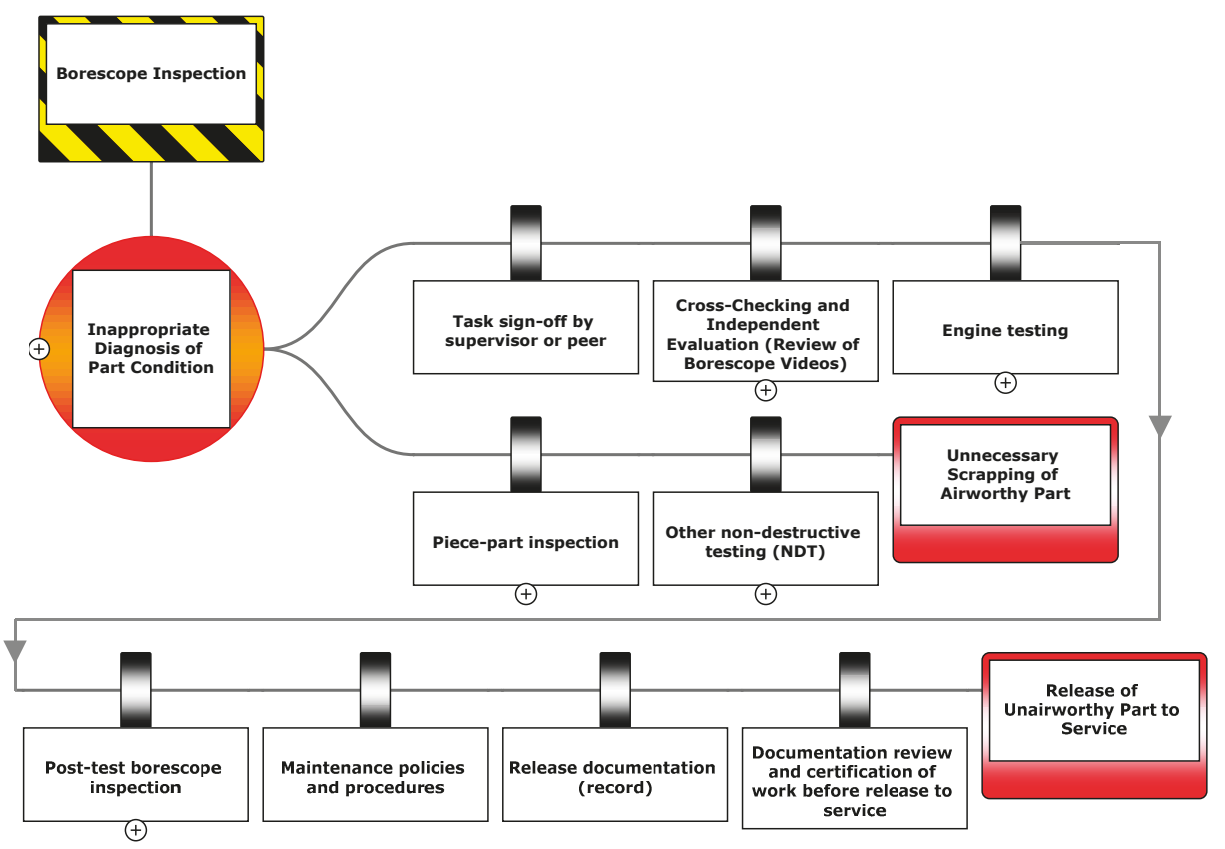

Figure 7. Right half of the Bowtie diagram with consequences and recovery barriers.

\section{Discussion}

\subsection{Summary of Outcomes}

While the Bowtie method is well known in the aviation industry, it is only applied to significant accident scenarios, named the "significant seven". However, there is no mention of the method being applied in other high-risk and error-prone areas of the complex aviation system, such as aircraft and engine maintenance-at least there is nothing published in the research literature. This paper investigated the adaptability of the Bowtie method to the maintenance, repair, and overhaul environments and analysed how it differs in principle from the conventional Bowtie used in aircraft operation.

We showed that it is possible to reconceptualise the consequence component of the Bowtie to include organisational economics and the adverse effects on the organisation in whichever dimensions those occur. We propose that, in general, it could be worthwhile to identify the consequences that are consistent with the organisational purpose-which is evident in vision, value, and mission statements. This is because employees already understand these concepts, at least in the sense that these factors are important for the survival of the organisation. In this way, the Bowtie consequences might be explicitly aligned with the organisational purpose, and in turn this may provide a coherent rationale and motivation to the operator to engage with the quality and safety systems.

\subsection{Implications for Practitioners}

There are several potential uses for the Bowtie, for inspection and for applying Bowtie to aviation maintenance.

Firstly, the presented Bowtie is particularly useful for borescope inspection, which creates awareness of the relevance of visual inspection in aircraft maintenance. It helps the inspectors to understand the risks and how they can be prevented or minimised. Furthermore, it provides a better understanding as to which specific barriers are in place and why it is important to maintain them. 
For example, when training courses are held frequently, workers can visually see their impact and why they are crucial from a risk management perspective. It demonstrates the importance of complying with organisations risk management strategies. Additionally, it enables them to identify missing or ineffective barriers, and demonstrate where resources have the greatest impact and, hence, should be invested. This insight can also be used for investment recommendations to executive management, which applies the aforementioned organisational economics, as implementing and improving barriers is costly and can affect the overall profitability.

Generally speaking, the Bowtie approach can be used for teaching purposes and to create awareness of the importance of risk management, demonstrating the risk strategies of the company, highlighting weaknesses in risk management, and supporting the safety culture of the company.

The Bowtie analysis and the development of the diagram demand a detailed risk and hazard assessment. This process promotes improved understanding and has the possibility to gain new insights, which can be exploited on a company level, in other areas of the engine maintenance process, or even within the broader maintenance industry. It may also be valuable outside the MRO industry for aircraft operators, as it highlights the importance of operational economics and how it can be added into Bowtie analysis.

As originally intended, the Bowtie can be used as a tool for communicating within the different management levels in an organisation. Depending on the required level of detail needed for a specific audience, different levels of a Bowtie can be created to align with the needs of that specific department. It also offers the opportunity to use Bowtie as a tool to express one's concerns for a lacking process and how it could be improved by implementing additional barriers or improving the existing ones.

\subsection{Limitations of the Work}

There are several limitations to the applied Bowtie methodology. Depending on the audience, the Bowtie may have not the right level of detail. Some tend to be too generic, whereas others tend to be too specific. However, both can be valid depending on the audience that the Bowtie addresses. For example, the borescope manufacturer or the inspector requires more specific details compared to the upper management. Therefore, there will always be a struggle in providing the right level of detail, which can only be handled either by developing multiple Bowties for the same top event, which means double the work, or the more detailed paths could potentially be hidden when presenting to a higher audience.

When developing the Bowtie for visual inspection, we realised that some barriers, including their escalation factors and escalation factor barriers, were repeated on nearly every single threat branch. This resulted in a more complex-looking Bowtie diagram, which can lead to the loss of the main purpose of using a Bowtie, which is its effectiveness as a communication tool.

Even though Bowtie generally allows for quantification of the top event and its consequences, we found it challenging because of the scarcity of historical data [54]. While the idea of accumulating data from multiple sources such as audits, accident reports, and statistics over a period of time is attractive [55], it is not altogether certain how this might be achieved, since data for extremely rare events are often not reliable or applicable, making probability and failure rate assignments difficult.

In the case of visual inspection, data were not available and, therefore, we had to ask industry experts for their opinions. When talking to these experts, who were inspectors, they were able to name many factors that they could identify as influential to the inspection result. However, as they are inspectors and not system risk analysts, they were not able to provide us with realistic estimates for the frequency of a threat occurrence and how likely a barrier was to fail. The same problem would occur when calculating the impact of the escalation factors. Even with estimates, a Bowtie does not account for the accuracy and the certainty of those estimates (probability of failure on demand) or the extent of influence that escalation factors have on the barrier. As a result, the presented Bowtie is not quantified, until we can develop a strategy to account for the limitations. 
Borescope inspection is performed at multiple stages in the maintenance process. These stages include on-wing inspection, induction inspection, and post-test inspection. Due to the different environments, engine conditions, and performance at different times, the factors vary between inspection types, despite it all existing under the borescope inspection umbrella. Some mitigation barriers are only present when the Bowtie is used for induction inspection. On the other hand, in the case of a post-test inspection, the same barriers will not be present, since they already passed from a process perspective. These barriers are namely the "engine test" and the "post-test borescope inspection". This paper presented the Bowtie analysis for induction inspection, since this is the inspection where most defects are found, which decides whether or not to strip down the engine. Hence, for on-wing and post-test inspection, the presented Bowties are only partially applicable and need further adjustment.

The strength of using Bowtie lies in its visual representation of threats, barriers, and consequences [56]. Nonetheless, the method has limited possibilities of representing the chronological order of the barriers, i.e., representing barriers that take place simultaneously (from a process point of view) and barriers that are process-wise in series.

Similar to the barriers, it was found that there is a chronological order of consequence. Since BowtieXP only allows one consequence per branch, it was not possible to show the consequence event chain and, hence, only the subsequent or the last event of this chain could be displayed. In practice, it tends to be the most propagated outcome in the consequence path, which is ultimately the worst-case scenario. This is purposely done to create awareness and highlight the level of risk in each task that an aircraft maintenance technician performs, which could potentially lead to severe damage to the engine, aircraft, passengers, airliner, or MRO provider. We bypassed this limitation using image editing to manually sequence the immediate and final consequences for the inappropriate diagnosis of part condition.

Lastly, a Bowtie cannot show sub-interactions and correlations; for example, multiple escalation factors must occur at the same time to degrade the barrier. Furthermore, it does not account for the severity of the top event and consequences if multiple threats release the top event at the same time. This causes a fixed mindset that threats, barriers, and escalation factors are always independent and cannot aggravate each other.

\subsection{Implications for Future Research}

After applying Bowtie to visual inspection in the MRO industry, we identified the need for future research. The first two points address the problem of representing the chronological order of threats, barriers, and consequences, followed by the need for a more structured and standardised Bowtie approach.

Firstly, a Bowtie has no possibility of presenting causational paths of the threat development. Equally, there is no option to present the consequence development path. One way to bypass this limitation is by connecting the Bowties in chronological sequence. In the presented case which used "inappropriate diagnosis of part condition" as the top event, the direct consequence would be the release of an unairworthy part or the scrapping of an airworthy part. Both consequences would form the threats for the subsequent Bowtie, and the new consequences are chronologically subsequent. However, since Bowtie diagrams are viewed individually, the subsequent and ultimate consequences are not visible. Hence, we introduced a new way of representing the consequence chain, which could be used similarly for the threat development path. This could be further investigated and potentially be added as a feature in the software.

Secondly, barriers could be chronologically expressed by adding a second dimension to the barriers. Barriers that prevent the top event at the same point in time could be grouped together. Barriers or barrier groups that prevent the top event at different points in time or in a subsequent process step could be displayed separately. 
A third opportunity for future research could be to address some of the unsystematic aspects of Bowtie creation. Our experiences in constructing the above Bowtie suggested that there is a need for a structured approach for Bowtie construction. Existing methods tend to be ad hoc, and they rely on the existing knowledge of the analyst. Possible ways to address this may include introducing the $6 \mathrm{M}^{\prime} \mathrm{s}$, PEAR, SHELL, or similar risk categorisations to the current Bowtie model.

An obstacle for developing a Bowtie is the lack of a generic structure. While the Bowtie diagram itself has a characteristic shape and common elements, there is still little standardisation in terms of how to identify threats and barriers. There are different ways of performing a Bowtie analysis. The most common one is based on expert knowledge. However, this is subjective and based on the perspective of the risk analysis expert rather than that of the operator. In an accident scenario, the Bowtie is developed by investigators who investigate which barriers are in place, which ones failed, and why. However, when developing a new system or analysing an existing one prior to an incident or accident occurrence, there is no standardised framework provided. As each Bowtie and its top event are unique, the process of Bowtie analysis is ad hoc. This provides potential for further research to develop an approach for systematically developing a Bowtie without fully relying on expert knowledge and availability, and ultimately simplifying the Bowtie method, while reducing the current ad hoc approach.

The development of a Bowtie diagram is time-consuming and strenuous, particularly for top events with many possible threats and long threat branches. Some barriers and their escalation factor sub-branches are often repeated in the threat branches, and this makes the method cumbersome. The focus and energy, however, should be on the critical thinking and analysis process, rather than the drawing of the diagram. Future research could focus on a simplified process of creating Bowtie diagrams, which has the potential to further increase its application across industries.

This could potentially be the solution for another limitation of Bowtie, i.e., the static representation of the specific point in time when the risk analysis was performed and when the Bowtie was created. Bowties lack the adaptability to changes in the system. Changes could include the implementation of additional barriers, barrier efficiency and effectiveness improvements, or organisational changes. Some attempts were made to update and monitor Bowties in real time, enabling a more dynamic risk assessment $[57,58]$. An automated approach for the Bowtie generation would support this approach.

\section{Conclusions}

The purpose of this research was to identify the risks occurring in visual inspection tasks during aircraft engine maintenance in an MRO environment. This work makes several novel contributions towards solving this problem. Firstly, it provides a method for using the Bowtie analysis on aircraft maintenance tasks-this required a reconceptualisation of the consequences, which are different compared to flight operations. They include not only the safety of the aircraft passengers and the potential for fatalities, but also the operational economics. Secondly, it provides a detailed analysis of the risks associated with borescope inspection and the barriers that can prevent or mitigate those risks, which were otherwise not shown in the literature.

Supplementary Materials: The following are available online at http://www.mdpi.com/2226-4310/6/10/110/s1: Figure S1: Threat side of Bowtie with prevention barriers; Figure S2: Threat side of Bowtie with prevention barriers, escalation factors, and escalation factor barriers; Figure S3: Consequence side of Bowtie with recovery barriers; Figure S4: Consequence side of Bowtie with recovery barriers, escalation factors, and escalation factor barriers; Figure S5: Full Bowtie with all components.

Author Contributions: Conceptualization, J.A. and D.P.; methodology, J.A. and D.P.; software, J.A.; validation, J.A. and D.P.; formal analysis, J.A. and D.P.; investigation, J.A.; resources, D.P.; data curation, J.A.; writing-original draft preparation, J.A.; writing-review and editing, J.A. and D.P.; visualization, J.A.; supervision, D.P.; project administration, D.P.; funding acquisition, D.P.

Funding: This research project was funded by the Christchurch Engine Centre (CHCEC), a maintenance, repair, and overhaul (MRO) facility based in Christchurch, and a joint venture between the Pratt and Whitney (PW) division of United Technologies Corporation (UTC) and Air New Zealand (ANZ). 
Acknowledgments: We sincerely thank staff at the Christchurch Engine Centre for their support and providing insights into visual inspection and risk management. In particular, we want to thank Tim Coslett, Marcus Wade, and Paul McMaster.

Conflicts of Interest: J.A. was funded by a PhD scholarship funded by the Christchurch Engine Centre (CHCEC). The authors declare no other conflicts of interest.

\section{Appendix A. Bowtie Analysis for Borescope Induction Inspection}

Figure A1 shows the threat side of the Bowtie diagram with prevention barriers. For a higherresolution version, please see the online Supplementary Materials.

Figure A2 shows the threat side of the Bowtie diagram with prevention barriers, escalation factors, and escalation factor barriers. It is apparent that the disadvantage of Bowtie can be a massive diagram, which is barely legible. Hence, we segmented the diagram into sub-diagrams-one for each threat path.

Figure A2a-g show the extracts from the Bowtie diagram presented in Figure A2.

Figure $\mathrm{A} 3$ shows the consequence side of the Bowtie diagram with recovery barriers.

Figure A4 shows the consequence side of the Bowtie diagram with recovery barriers, escalation factors, and escalation factor barriers.

Figure A5 shows the complete Bowtie result with all elements. This figure only serves the purpose of illustrating the characteristic shape, which may have been lost in the previous diagrams, as these were edited to improve the legibility. For a higher-resolution version, please see the online Supplementary Materials. 


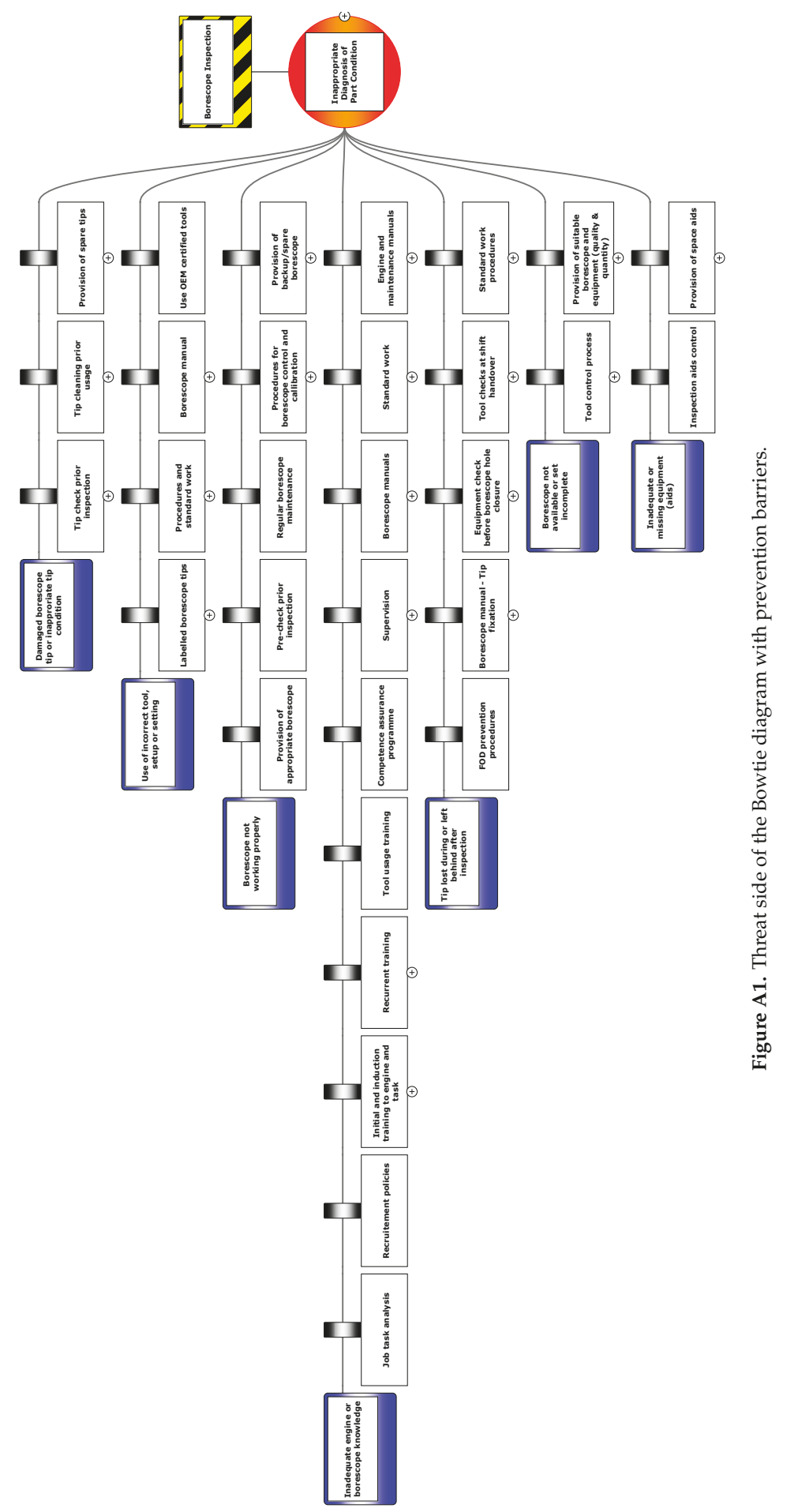




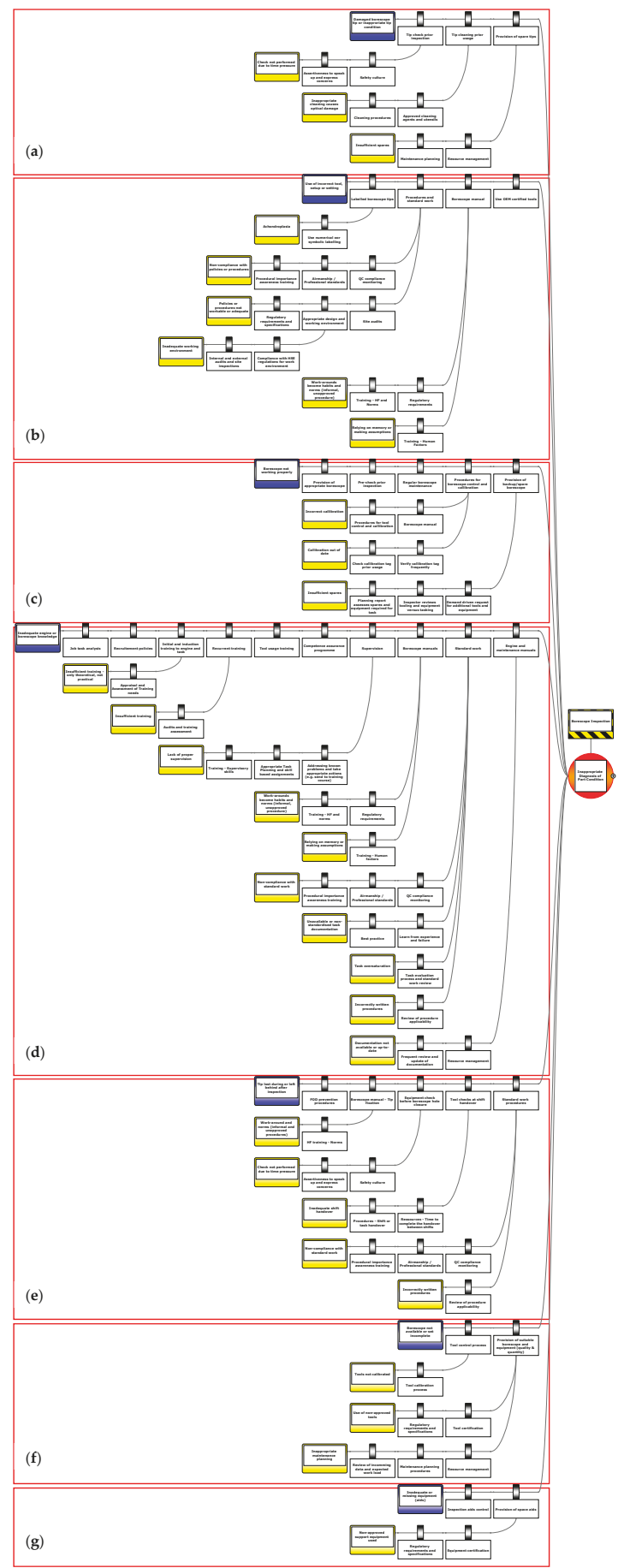

Figure A2. Threat side of the Bowtie diagram with prevention barriers, escalation factors, and escalation factor barriers. 


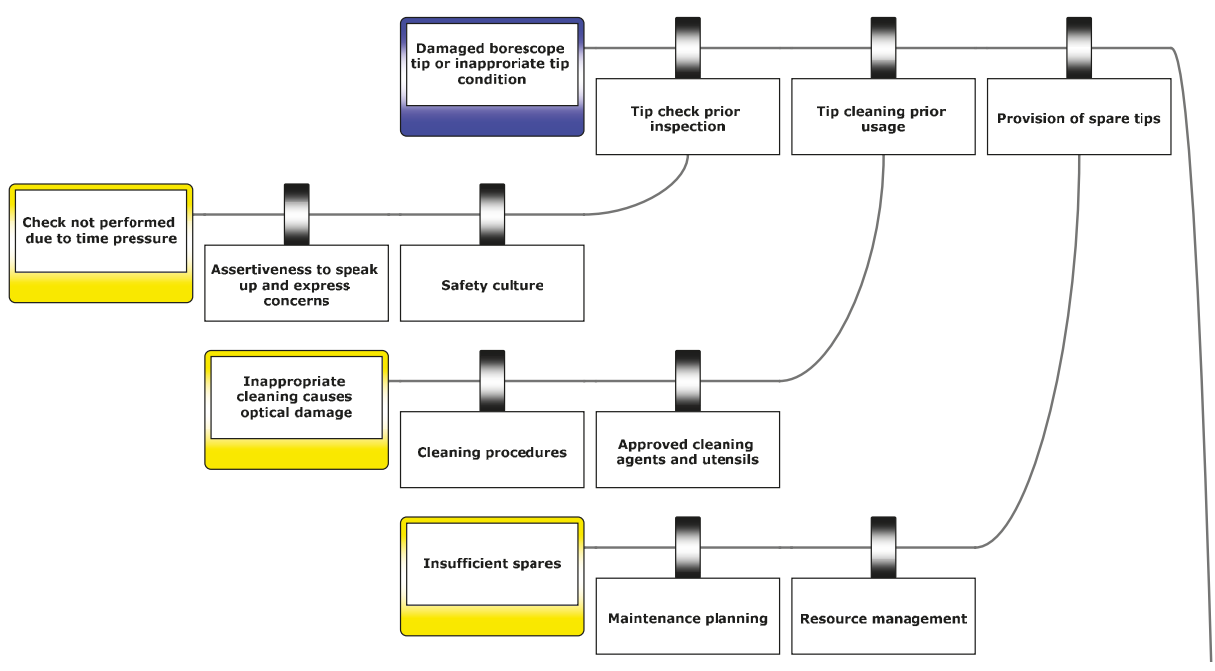

Figure A2a. "Damaged borescope tip or inappropriate tip condition" threat path.

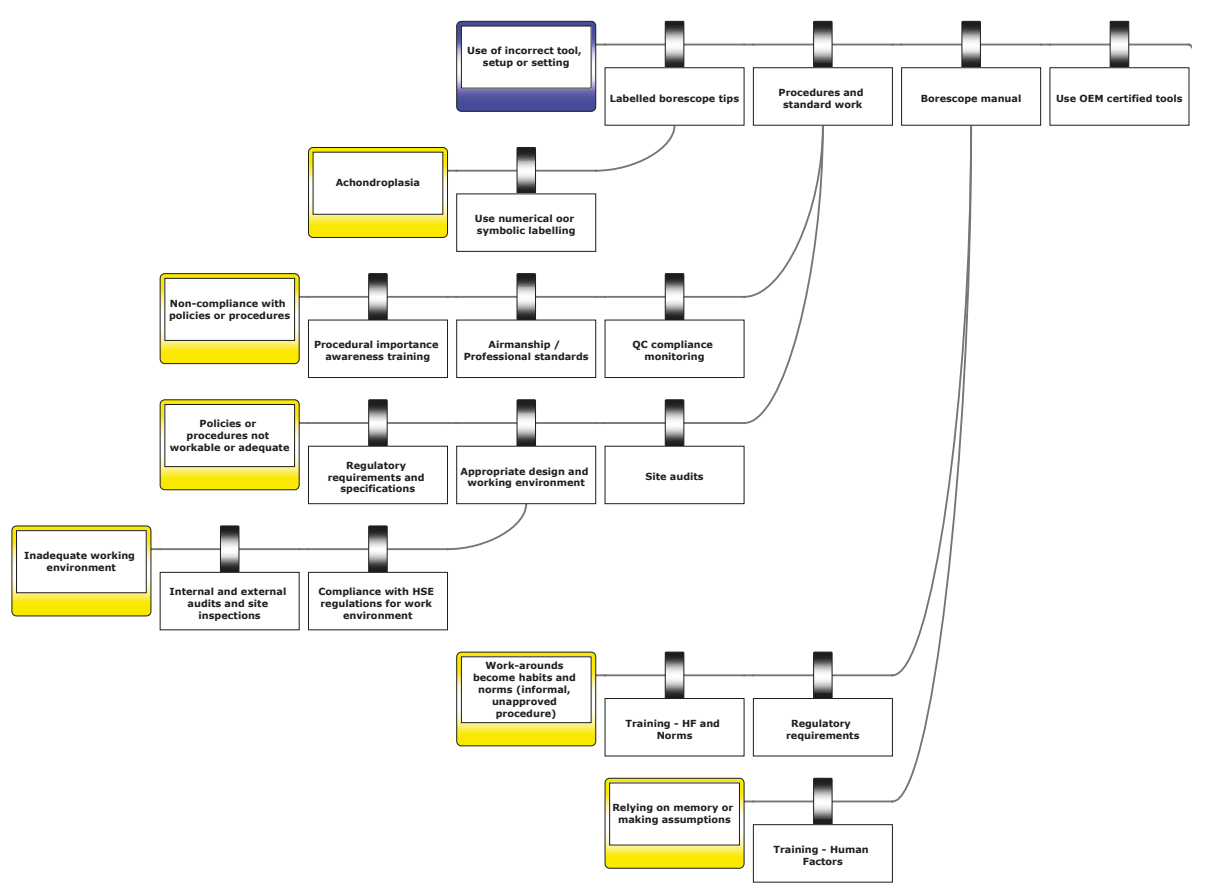

Figure A2b. "Use of incorrect tool, set-up, or setting" threat path. 


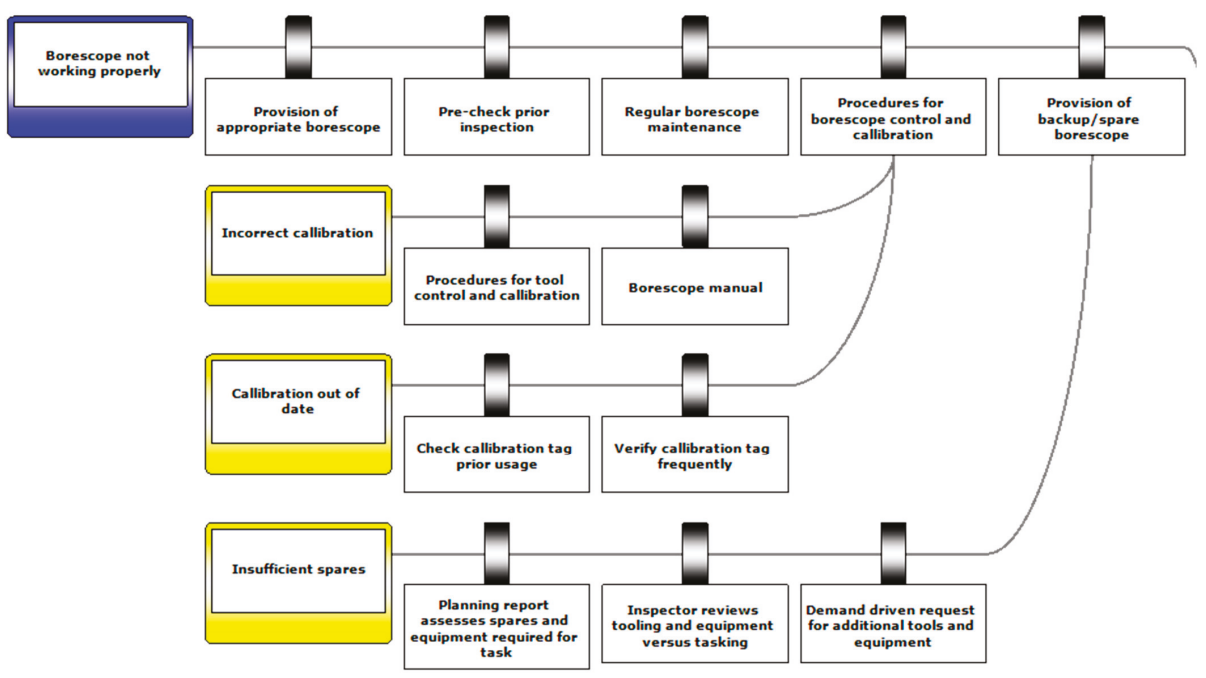

Figure A2c. "Borescope not working properly" threat path. 


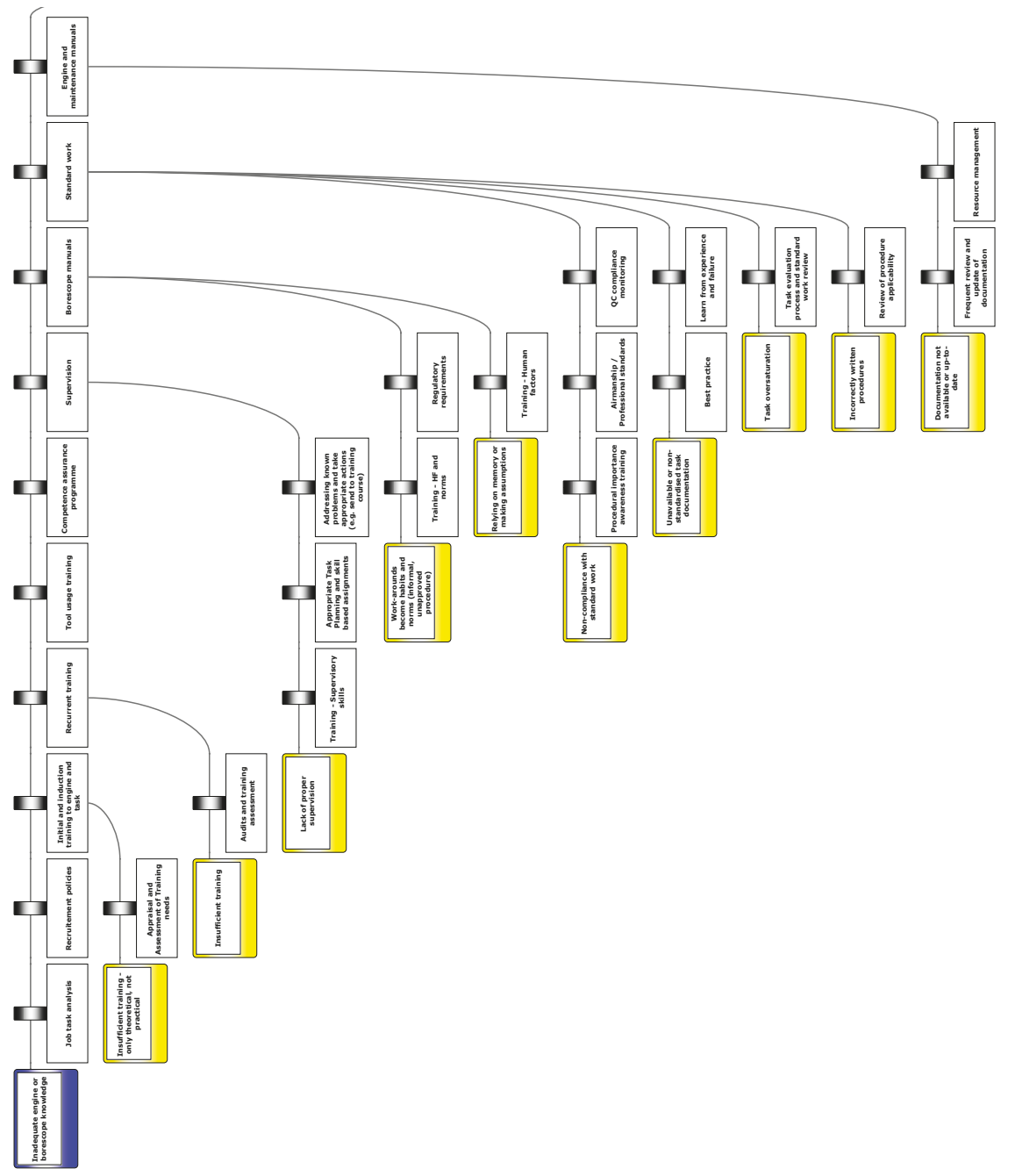

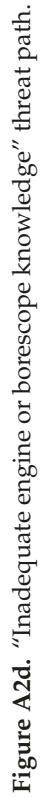




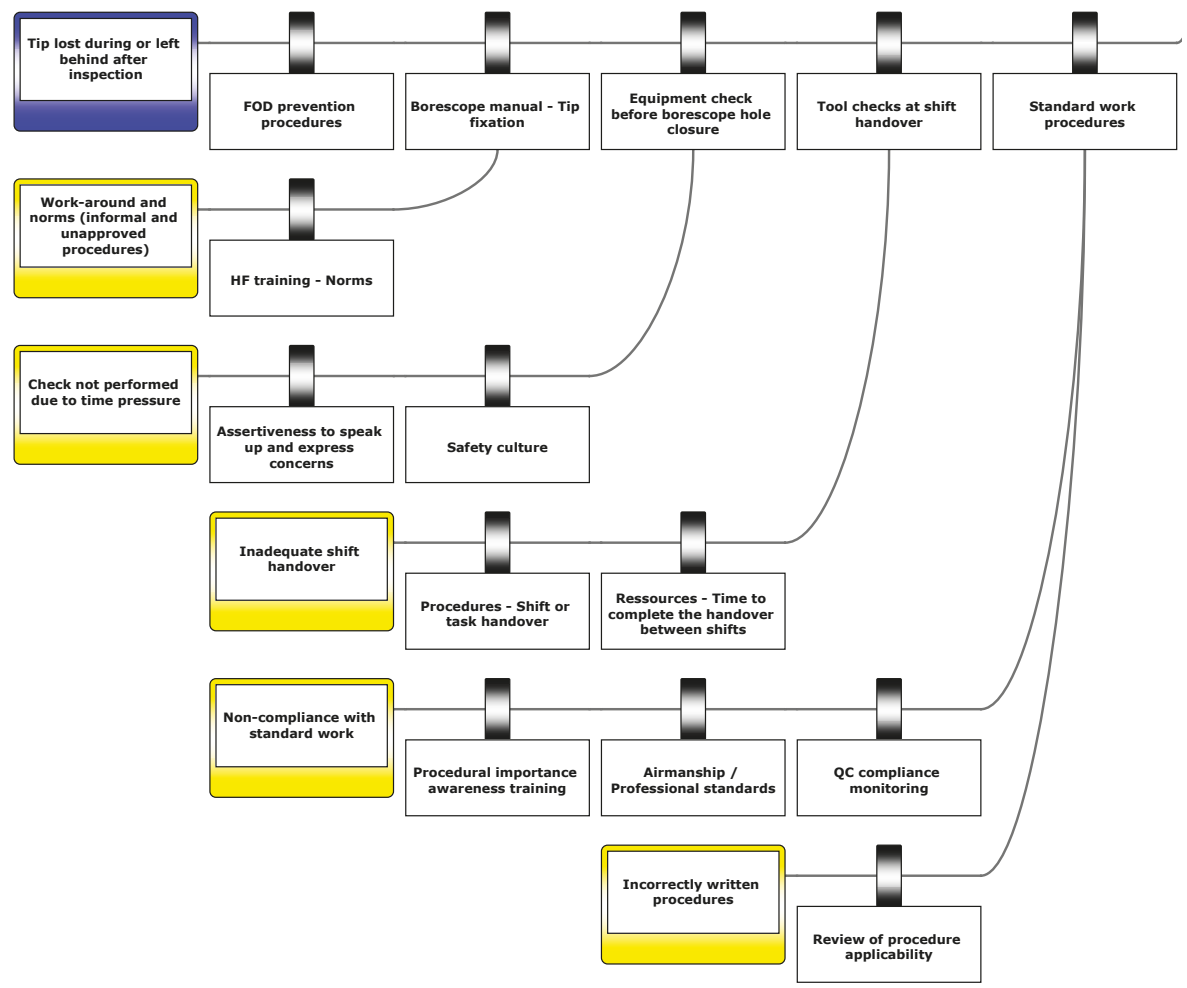

Figure A2e. "Tip lost during or left behind after inspection" threat path.

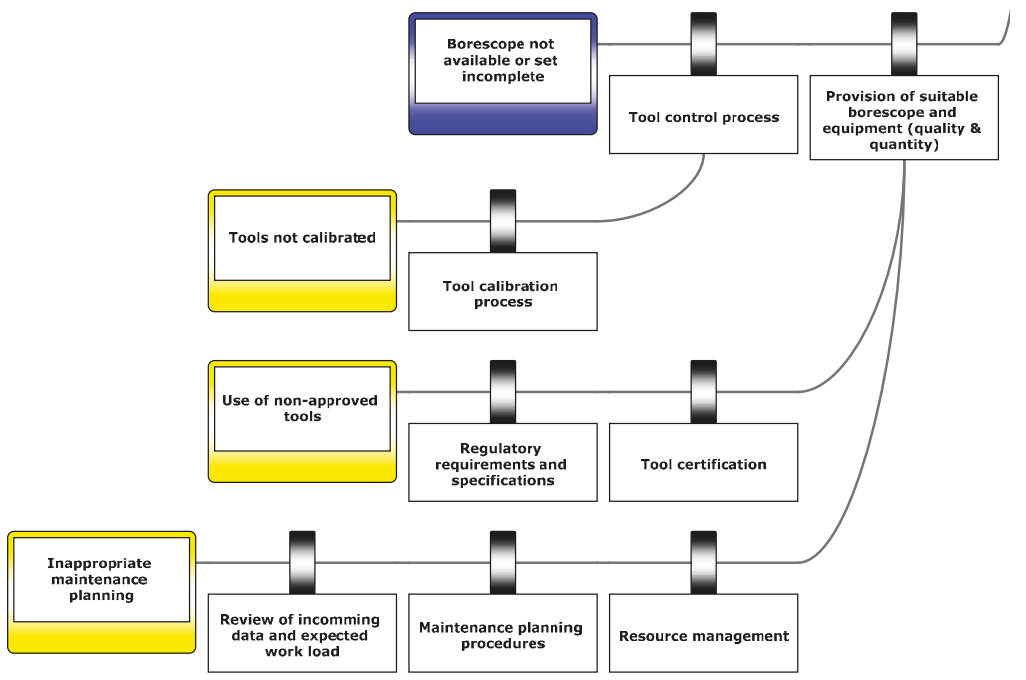

Figure A2f. "Borescope not available or set incomplete" threat paths. 


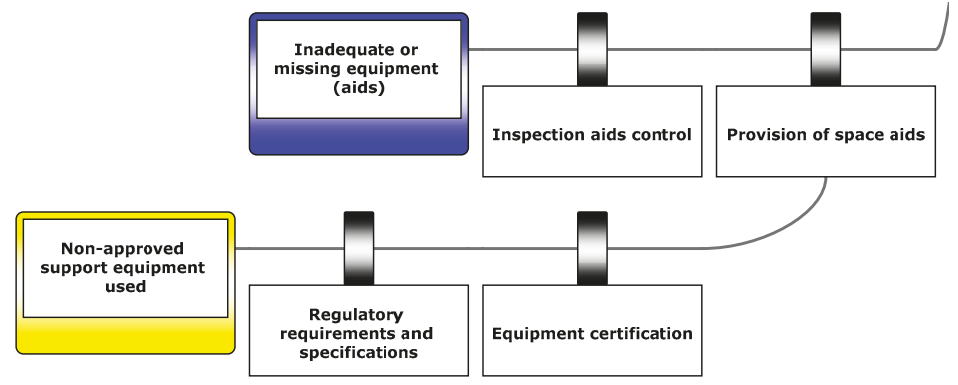

Figure A2g. "Inadequate or missing equipment (aids)" threat paths. 


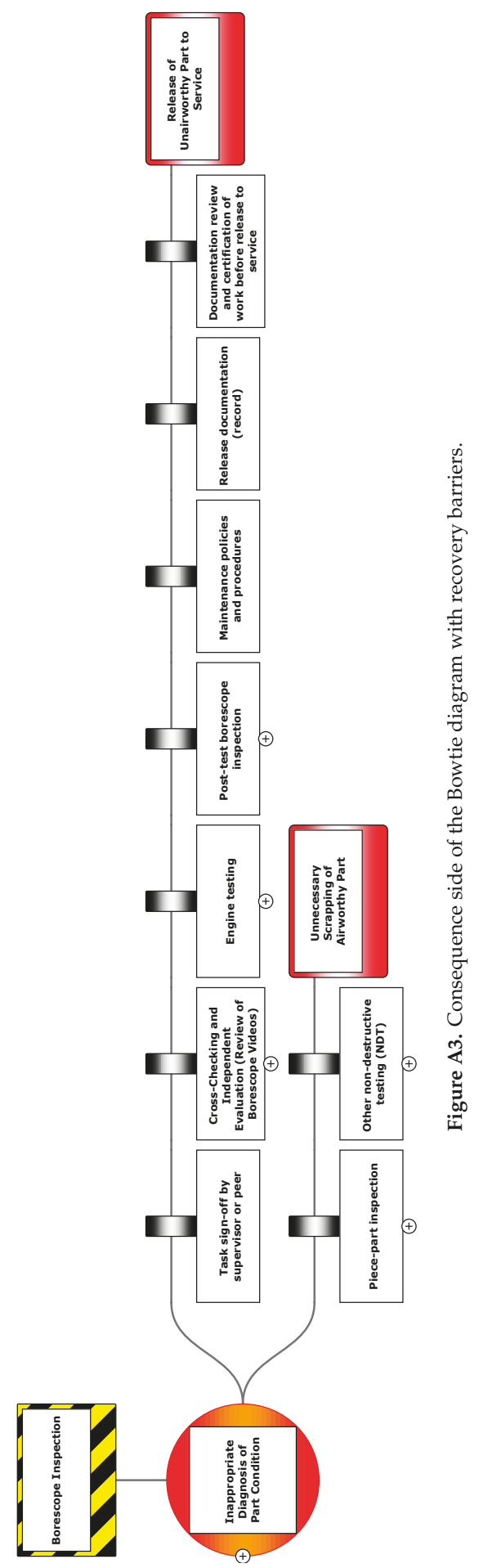




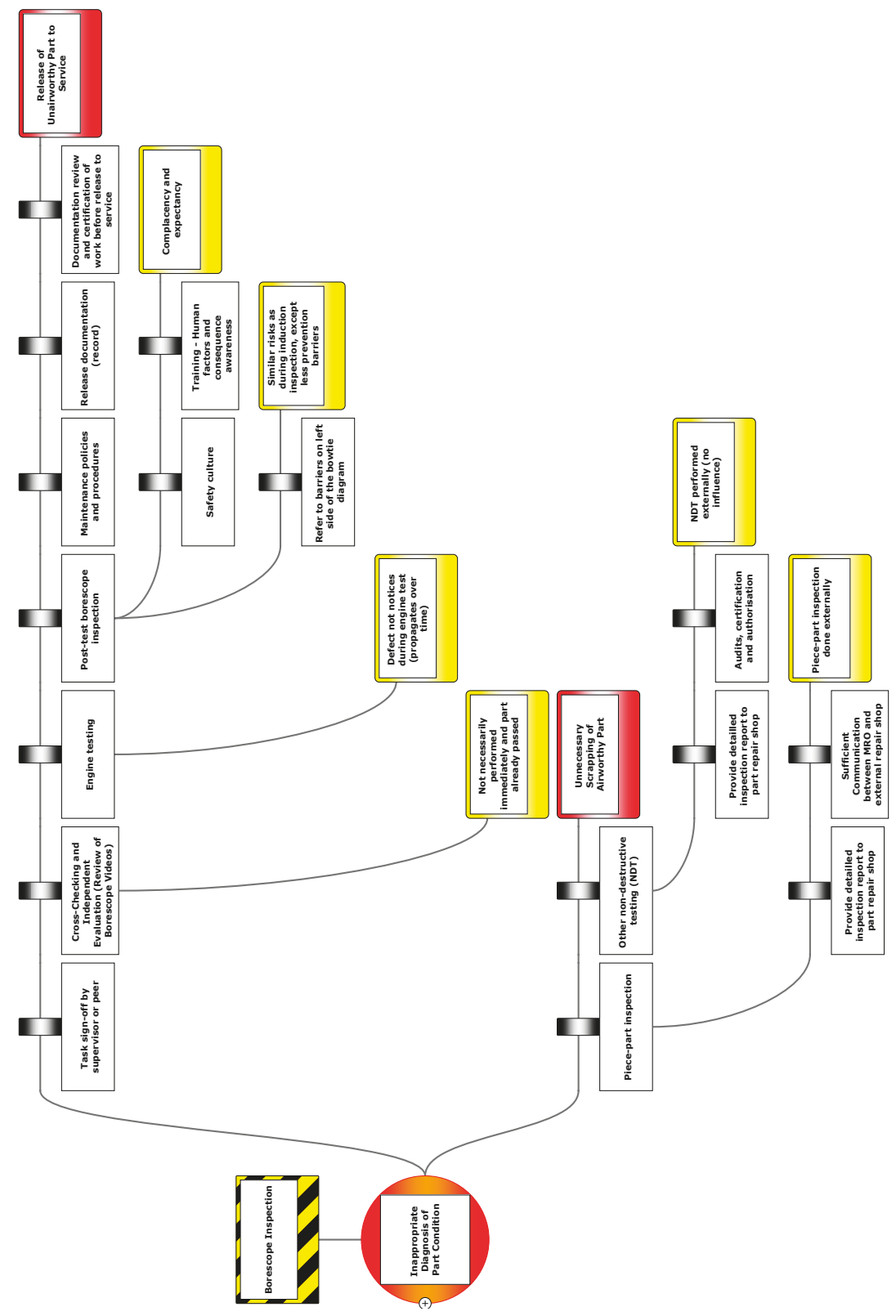

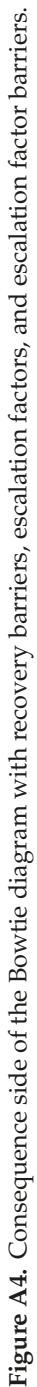




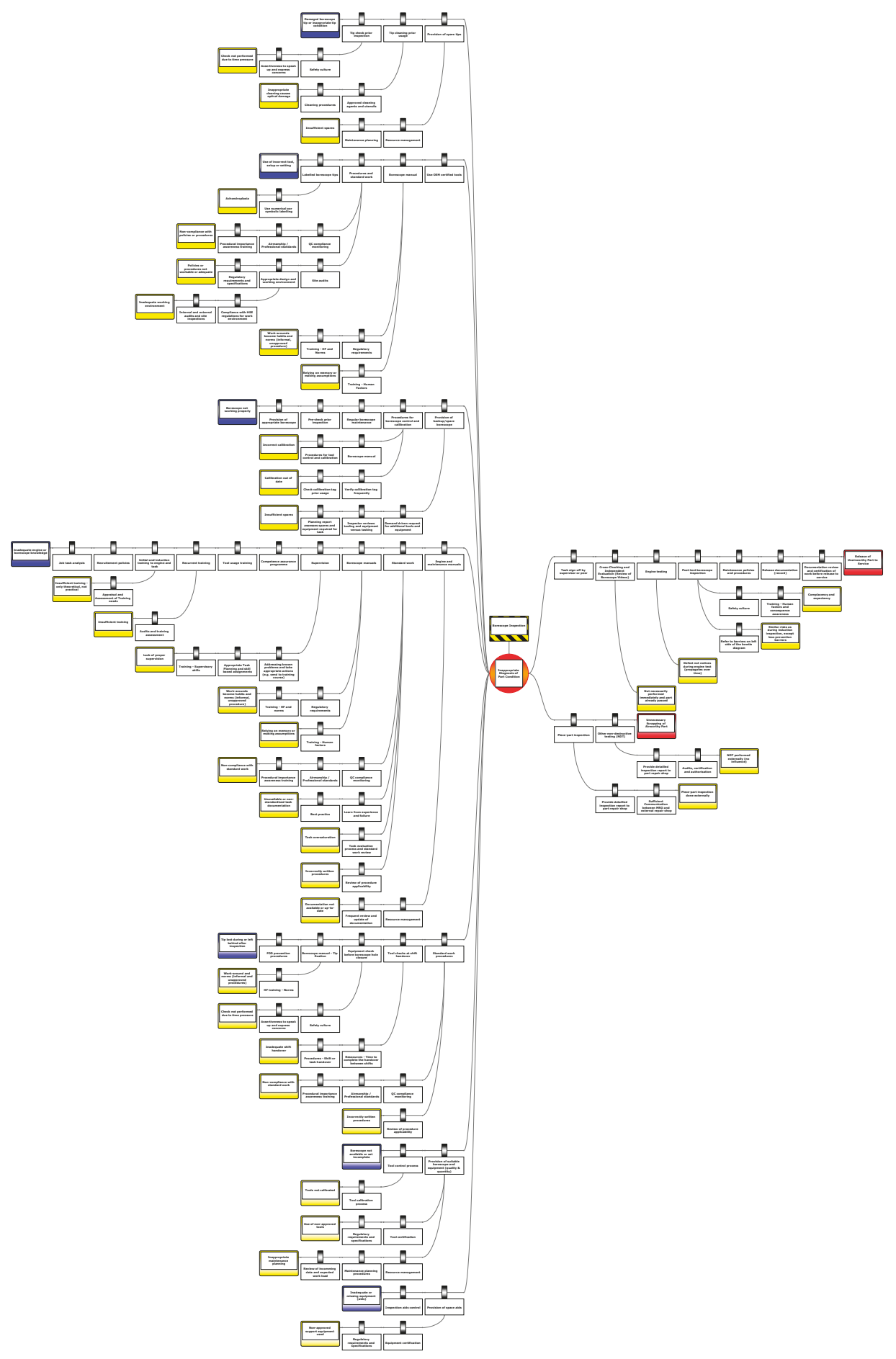

Figure A5. Complete Bowtie result with all elements. 


\section{References}

1. De Ruijter, A.; Guldenmund, F. The bowtie method: A review. Saf. Sci. 2016, 88, 211-218. [CrossRef]

2. Culwick, M.D.; Merry, A.F.; Clarke, D.M.; Taraporewalla, K.J.; Gibbs, N.M. Bow-Tie Diagrams for Risk Management in Anaesthesia. Anaesth. Intensive Care 2016, 44, 712-718. [CrossRef] [PubMed]

3. Tang, Y.; Jing, J.; Zhang, Z.; Yang, Y. A Quantitative Risk Analysis Method for the High Hazard Mechanical System in Petroleum and Petrochemical Industry. Energies 2017, 11, 14. [CrossRef]

4. Shahriar, A.; Sadiq, R.; Tesfamariam, S. Risk analysis for oil \& gas pipelines: A sustainability assessment approach using fuzzy based bow-tie analysis. J. Loss Prev. Process Ind. 2012, 25, 505-523.

5. Federal Aviation Administration (FAA). Bow-Tie Analysis. Available online: http://www.hf.faa.gov/ workbenchtools/default.aspx?rPage=Tooldetails\&subCatId=43\&toolID=21 (accessed on 1 October 2018).

6. Civil Aviation Authority (CAA). Bowtie Risk Assessment Models. Available online: https://www.caa.co.uk/ Safety-Initiatives-and-Resources/Working-with-industry/Bowtie/ (accessed on 23 January 2019).

7. European Aviation Safety Agency (EASA). The European Plan for Aviation Safety (EBAS) 2018-2022. Available online: https:/www.easa.europa.eu/sites/default/files/dfu/EPAS_2018-2022\%20v2.2.8\%20for\%20MB.pdf (accessed on 23 January 2019).

8. Civil Aviation Authority (CAA) of New Zealand. Making Safe Aviation Even Safer. Civil Aviation Authority Sector Risk Profile of Medium and Large Aircraft Air Transport. Available online: https: //www.caa.govt.nz/assets/legacy/Safety_Reports/srp-large.pdf (accessed on 25 September 2018).

9. Papazoglou, I.A.; Bellamy, L.J.; Hale, A.R.; Aneziris, O.N.; Ale, B.J.M.; Post, J.G.; Oh, J.I.H. I-Risk: Development of an integrated technical and management risk methodology for chemical installations. J. Loss Prev. Process Ind. 2003, 16, 575-591. [CrossRef]

10. De Dianous, V.; Fiévez, C. ARAMIS project: A more explicit demonstration of risk control through the use of bow-tie diagrams and the evaluation of safety barrier performance. J. Hazard. Mater. 2006, 130, 220-233. [CrossRef] [PubMed]

11. Gifford, M.; Gilbert, S.; Barnes, I. The Use of Bow-tie Analysis in OME Safety Cases. In Proceedings of the Equipment Safety Assurance Symposium (ESAS), Bristol, UK, 2003.

12. Patrick, M.C.; Martin, D. Safety First-Scenario Analysis under Basel II. 2006, Volume 29, p. 2010. Available online: https://www.researchgate.net/publication/228882614_Safety_first-scenario_analysis_under_Basel_II (accessed on 23 January 2019).

13. Abdi, Z.; Ravaghi, H.; Abbasi, M.; Delgoshaei, B.; Esfandiari, S. Application of Bow-tie methodology to improve patient safety. Int. J. Health Care Qual. Assur. 2016, 29, 425-440. [CrossRef]

14. Cormier, R.; Elliott, M.; Rice, J. Putting on a bow-tie to sort out who does what hy in the complex arena of marine policy and management. Sci. Total Environ. 2019, 648, 293-305. [CrossRef]

15. Burgess-Limerick, R.; Horberry, T.; Steiner, L. Bow-tie analysis of a fatal underground coal mine collision. Ergon. Aust. 2014, 10, 1-5.

16. Khakzad, N.; Khan, F.; Paltrinieri, N. On the application of near accident data to risk analysis of major accidents. Reliab. Eng. Syst. Saf. 2014, 126, 116-125. [CrossRef]

17. Delmotte, F. A sociotechnical framework for the integration of human and organizational factors in project management and risk analysis. Master's Thesis, Virginia Tech, Blacksburg, VA, USA, September 2003.

18. Van Scyoc, K.; Hughes, G. Rail ruminations for process safety improvement. J. Loss Prev. Process Ind. 2009, 22, 689-694. [CrossRef]

19. Brown, K. Review of the South Island Rail Coal Route-MET351-X-REP-001. Available online: www.ltsa. govt.nz/rail/coal-route (accessed on 25 January 2019).

20. Reason, J. Human Error; Cambridge University Press: Cambridge, UK, 1990.

21. Aust, J.; Pons, D. Taxonomy of Gas Turbine Blade Defects; MDPI Aerospace: Basel, Switzerland, 2019.

22. Joy, J.; Griffiths, D. National Minerals Industry Safety and Health Risk Assessment Guide; Minerals Industry Safety and Health Centre, University of Queensland: St Lucia, Australia, 1979.

23. Primrose, M.J.; Bentley, P.D.; van der Graaf, G.C.; Sykes, R.M. The HSE Management System in Practice-lmplementation. Presented at the SPE Health, Safety and Environment in Oil and Gas Exploration and Production Conference, New Orleans, Louisiana, 1 January 1996; Available online: https://doi.org/10.2118/35826-MS (accessed on 25 January 2019). 
24. Gower-Jones, A.D.; van der Graaf, G.C.; Milne, D.J. Application of Hazard and Effects Management Tools and links to the HSE Case. Presented at the SPE Health, Safety and Environment in Oil and Gas Exploration and Production Conference, New Orleans, Louisiana, 1 January 1996; Available online: https://doi.org/10.2118/36031-MS (accessed on 24 January 2019).

25. Zuijderduijn, C.J. Risk management by shell refinery/chemicals at Pernis. Available online: http://www. microkat.gr/microrisk2001/paper_Zuijderduijn.html (accessed on 24 January 2019).

26. Seveso II Directive-Council of the European Union. Council Directive 96/82/EC on the Control of Major-Accident Hazards Involving Dangerous Substances. Available online: http://ec.europa.eu/ environment/seveso/index.htm (accessed on 11 October 2018).

27. Delvosalle, C.; Fiévez, C.; Pipart, A. ARAMIS Project: Reference Accident Scenarios Definition in SEVESO Establishment. J. Risk Res. 2006, 9, 583-600. [CrossRef]

28. De Souza, G.F.M. Thermal Power Plant Performance Analysis; Springer: Berlin, Germany, 2012.

29. Crawley, F.; Tyler, B. Hazard Identification Methods; Inst of Chemical Engineers (IChemE): London, UK, 2003.

30. Ericson, C.A. Fault tree analysis. In Proceedings of the 17th International System Safety Conference, Orlando, FL, USA, 16-21 August 1999.

31. Watson, H.A. Launch Control Safety Study; Bell Telephone Laboratories: Murray Hill, NJ, USA, 1961.

32. Xing, L.; Amari, S.V. Fault Tree Analysis. In Handbook of Performability Engineering; Misra, K.B., Ed.; Springer: London, UK, 2008; pp. 595-620.

33. Ericson, C.A. Hazard Analysis Techniques for System Safety; Wiley: Hoboken, NJ, USA, 2005.

34. Fouladvand, S.; Ghiaci, P.; Shahriari, M. Fault Tree Analysis, Strengths and Weaknesses. In Proceedings of the Inbternational Symposium on Occupational Safety and Hygiene, Guimarães, Portugal, 11-12 February 2010.

35. Rasmussen, N.C. Reactor Safety Study: An Assessment of Accident Risks in US Commercial Nuclear Power Plants; U.S. Nuclear Regulatory Commission: Washington, DC, USA, 1975.

36. Rubin, O.; Dahlberg, R. A Dictionary of Disaster Management; Oxford University Press: Oxford, UK, 2017.

37. Clemens, P.L.; Simmons, R.J.; Cincinnati, O. System Safety and Risk Management: A Guide for Engineering Educators. In Lesson II Risk Assessment Matrix. NIOSH Instructional Module; US Department of Health and Human Services: Cincinnati, OH, USA, 1998.

38. Rausand, M.; Høyland, A. System Reliability Theory: Models, Statistical Methods, and Applications; John Wiley \& Sons: Hoboken, NJ, USA, 2004.

39. Nielsen, D.S. The Cause/Consequence Diagram Method as a Basis for Quantitative Accident Analysis; Risø National Laboratory: Roskilde, Denmark, 1971.

40. Cardwell, G. The application of the Four Essentials Bow Tie Diagram to enhance business success. Total Qual. Manag. Bus. Excell. 2008, 19,37-45. [CrossRef]

41. Harms-Ringdahl, L. Guide to Safety Analysis for Accident Prevention; IRS Riskhantering: Stockholm, Sweden, 2013.

42. Haddon, W., Jr. Energy damage and the ten countermeasure strategies. Hum. Factors 1973, 15, 355-366. [CrossRef]

43. Marvin, R. Risk Assessment: Theory, Methods, and Applications; John Wiley \& Sons, Inc.: Hoboken, NJ, USA, 2011.

44. Sklet, S. Safety barriers: Definition, classification, and performance. J. Loss Prev. Process Ind. 2006, 19, 494-506. [CrossRef]

45. Duijm, N.J.; Goossens, L. Quantifying the influence of safety management on the reliability of safety barriers. J. Hazard. Mater. 2006, 130, 284-292. [CrossRef]

46. Ericson, C.A. System Safety Terms and Concepts. In Concise Encyclopedia of System Safety; John Wiley \& Sons: Hoboken, NJ, USA, 2011; pp. 16-455.

47. Visser, J.P. Developments in HSE management in oil and gas exploration and production. In Safety Management: The Challenge of Change; Hale, A., Baram, M., Eds.; Pergamon: Amsterdam, The Netherlands, 1998; pp. 43-66.

48. Manton, M.; Moat, A.; Ali, W.; Johnson, M.; Cowley, C. Representing Human Factors in Bowties as per the new CCPS/EI Book. In Proceedings of the CCPS Middle East Conference on Process Safety, Sanabis, Bahrain, 9-11 October 2017.

49. Trbojevic, V.M.J.H.; Report, S.E.R. Optimising hazard management by workforce engagement and supervision. Health Safety Exec. 2008, 637, 2008. 
50. SAE International. Aerospace Standard AS 9100 Quality Management Systems-Requirements for Aviation Maintenance Organizations; SAE International: Warrendale, PA, USA, 2012.

51. Lewis, S. Lessons Learned from Real World Application of the Bow-tie Method. In Proceedings of the 6th Global Congress on Process Safety, San Antonio, TX, USA, 22-24 March 2010; Available online: https://www.aiche.org/academy/videos/conference-presentations/lessons-learned-realworld-application-bow-tie-method (accessed on 15 February 2019).

52. CGE Risk BowtieXP.Software; Version 9.2.13; CGE Risk: Leidschendam, The Netherlands, 2019.

53. Civil Aviation Authority (CAA). CAA 'Significant Seven' Task Force Reports. In CAA PAPER 2011/03. 2011. Available online: https://publicapps.caa.co.uk/docs/33/2011_03.pdf (accessed on 28 January 2019).

54. Van Sciver, G.R. Quantitative risk analysis in the chemical process industry. Reliab. Eng. Syst. Saf. 1990, 29, 55-68. [CrossRef]

55. McCulloch, P. Learning from incidents-Linking incident analysis with BowTie based risk assessments. In Proceedings of the Hazards 27, Birmingham, UK, 10-12 May 2017.

56. Moore, C.; Coleman, G.C.; Chang, J.; Nagle, M.; Sten, M.-B. Using Safety Barrier Analysis to Facilitate Quality Improvement in Health Care: Improving Venous Thromboembolism Prophylaxis as a Proof of Concept. Am. J. Med Qual. 2019, 357. [CrossRef]

57. Ferdous, R.; Khan, F.; Sadiq, R.; Amyotte, P.; Veitch, B. Analyzing system safety and risks under uncertainty using a bow-tie diagram: An innovative approach. Process Saf. Environ. Prot. 2013, 91, 1-18. [CrossRef]

58. Khakzad, N.; Khan, F.; Amyotte, P. Dynamic Safety analysis of process systems by mapping bow-tie into Bayesian network. Process Saf. Environ. Prot. 2013, 91, 46-53. [CrossRef]

(C) 2019 by the authors. Licensee MDPI, Basel, Switzerland. This article is an open access article distributed under the terms and conditions of the Creative Commons Attribution (CC BY) license (http://creativecommons.org/licenses/by/4.0/). 


\title{
Use of Cost-Adjusted Importance Measures for Aircraft System Maintenance Optimization
}

\author{
Michail Bozoudis ${ }^{1,+}$, Ilias Lappas ${ }^{2, *,+}$ and Angelos Kottas ${ }^{1,+}$ \\ 1 Hellenic Ministry of National Defense, 15451 Athens, Greece; m.bozoudis@gdaee.mil.gr (M.B.); \\ angelos.kottas@haf.gr (A.K.) \\ 2 Department of Mechanical and Aeronautical Engineering, School of Engineering, University of South Wales, \\ Treforest Campus, Treforest CF37 1DL, UK \\ * Correspondence: ilias.lappas@southwales.ac.uk; Tel.: +44-01443-482565 \\ + These authors contributed equally to this work.
}

Received: 28 May 2018; Accepted: 21 June 2018; Published: 24 June 2018

\begin{abstract}
The development of an aircraft maintenance planning optimization tool and its application to an aircraft component is presented. Various reliability concepts and approaches have been analyzed, together with objective criteria which can be used to optimize the maintenance planning of an aircraft system, subsystem or component. Wolfram ${ }^{\circledR}$ Mathematica v10.3 9 (Witney, UK) has been used to develop the novel optimization tool, the application of which is expected to yield significant benefits in selecting the most appropriate maintenance intervention based on objective criteria, in estimating the probability of nonscheduled maintenance and in estimating the required number of spare components for both scheduled and nonscheduled maintenance. As such, the results of the application of the tool can be used to assist the risk planning process for future system malfunctions, providing safe projections to facilitate the supply chain of the end user of the system, resulting in higher aircraft fleet operational availability.
\end{abstract}

Keywords: aircraft system; reliability; life cycle cost; maintenance planning optimization; reliability centered maintenance; importance measures

\section{Introduction}

Maintaining a fleet of aircraft poses significant challenges for any organization in the aircraft operations business, as multiple and, many times, conflicting requirements are set regarding to the maintenance and operation costs and the desired service levels. Existing approaches to aircraft maintenance planning and scheduling are limited in their capacity to deal with contingencies arising out of tasks carried out during the implementation of maintenance projects [1].

At the aircraft system level, recent methods have been proposed [2-4] that aim to optimize the outcome of an aircraft maintenance plan with respect to various aircraft operational requirements. These studies are based on deterministic mathematical models describing flight and maintenance procedures, without taking into account failures and corrective maintenance requirements. An attempt to incorporate effects of stochastic events in optimizing the maintenance scheduling of an aircraft's main system (engine) to achieve robust flight maintenance planning solutions, has employed Monte Carlo simulations [5]. Further studies have extended the scope to include modelling unscheduled event consequences [6] and up to using a fuzzy analytic hierarchy process (AHP) to improve staff allocation, as well as the support of decision-making process within the aircraft maintenance industry [7].

At the aircraft subsystem and multicomponent subsystem level (a Low Pressure Turbine-LPT of an aircraft jet engine for example), there is an increasing interest on maintenance optimization that would address preventive maintenance scheduling under various constraints [8], minimize the maintenance cost and the unexpected maintenance stop occasions [9], or would minimize the operational costs [10]. 
Maintaining an aircraft system is necessary for achieving sustained performance levels during its operational life. The maintenance should be implemented with the minimum possible cost, while adhering to the highest possible quality standards to guarantee the uninterrupted operation of the systems, minimizing their downtime and the cost-efficient operation of the systems, by careful allocation of the available resources.

The life cycle cost (LCC) of a system can be classified as [11]:

- Research, development, test and evaluation (RDT\&E) cost.

- Investment cost, which is related to production, procurement, manufacture, and infrastructure maintenance activities among others.

- Operating and support (O\&S) cost, which also includes the maintenance cost.

- Disposal cost.

The outcome of the cost assessment and program evaluation of the Department of Defense of the United States of America [11] has shown that the operating and support cost has the biggest share at the life cycle cost (nearly $60 \%$ ). This indicates that the maintenance of a system not only influences its operational capabilities, but it also determines significantly its life cycle cost.

This is why nowadays an immense pressure is applied to the aerospace industry for developing systems with very high maintainability levels throughout their operational life. The maintainability indicates first and foremost how easy it is for a system to be maintained, and secondly how costly it is.

The desired maintainability levels shall be part of the specifications of the system from the development and production stages, aiming at reducing the cost and the complexity of the maintenance procedures which are going to be implemented during the system's operational life. The achieved maintainability levels can be positively influenced by the following characteristics and design philosophies:

- Modular design architecture, which facilitates the removal and installation process for the subsystems and components of the system, which can then be forwarded to the respective repair shops, thus eliminating the need for 'on-board' repair work.

- Interoperability of subsystems and components with the use of standard interface protocols, which facilitates the prompt repair or upgrade of the system simply by installing a new and/or upgraded subsystem or component.

- Prognostics, which enables the monitoring, tracking and recording of the operational data, a feature which helps the user to identify operational limit exceedances and potential failures, while suggesting preventive actions.

- 'Fail-safe' design, which isolates the subsystems and components in case of a system failure, protecting them from further failures and malfunctions.

- Accessibility, especially for subsystems and components that need to be inspected in frequent intervals.

- Commonality with other systems.

- Standardization of subsystems, components and support tools and equipment.

- Opportunistic maintenance and maintenance-free operating periods.

- Commercial off-the-shelf (COTS) support.

Various exogenous factors can also play an important role to the maintainability of a system, such as:

- Low probability of diminishing manufacturing sources (DMS), material shortage, intellectual property rights and monopolies.

- Use of technical orders and digital training of the maintenance personnel.

- Centralized and automated analysis and reporting of the operational and support data, using appropriate key performance indicators (KPIs). 
- Network-centric management of the supply chain.

- Appropriate packaging, handling, storage and transportation.

- Spares optimization as well as personnel allocation optimization.

- Follow-on support programs.

\subsection{Basic Terminology}

The maintenance practice has evolved throughout the ages and various philosophies and approaches have been introduced mainly due to the increasing complexity and technological enhancement of the aircraft systems. The most fundamental philosophies/approaches are the following:

- Run-to-Failure or Breakdown Maintenance. It is implemented on a nonscheduled basis, following the failure of a system/subsystem/component. Its objective is the identification, isolation and rectification of a failure to return the system/subsystem/component within its established operating limits [12].

- Preventive Maintenance. Its objective is to reduce the probability of a nonscheduled maintenance, which typically incurs high costs and considerably lengthy times to return the system to service. Preventive maintenance is implemented through a variety of tools, such as non-destructive inspections (NDI) and planned component replacement (PCR) [12].

- Opportunistic Maintenance. It is a combination of breakdown and preventive maintenance philosophies. Its objective is to reduce the maintenance cost, by taking advantage of any failure and its subsequent downtime, so as to intervene and implement preventive maintenance of subsystems/components which have not failed yet, aiming to reduce the probability of future failure [13].

- Upgrade or Modification. It aims to upgrade the system to enhance its performance and maintainability. It might be required as a solution to a design or manufacturing problem.

- Predictive or Condition Based Maintenance (CBM). It is based on continuous condition and operational data monitoring of a system with an objective to predict its future failure [14].

- Reliability Centered Maintenance (RCM). It is a structured process that aims to optimize the management of the failures of a system [12]. Its objective is to sustain the operation of the system within the desired performance levels, to manage the consequences of the failures and to define the optimum and applicable maintenance policy, by taking into account existing constraints with regard to resources, environmental, health and safety legislation [15].

- $\quad$ Risk Based Maintenance (RBM). It focuses on the management of the risk of active and potential damage mechanisms and its effects to the health, safety and the environment. Severity and probability are assessed for each identified risk, with an objective to define the maintenance schedule which minimizes the overall risk [16].

- Design-Out Maintenance. Its aim is to detect possible defects during the design phase of a system, thus avoiding future system failures. It focuses on possible critical failures which should incur costs which are higher than certain affordable levels.

\subsection{Reliability}

Reliability is an expression of the ability of a system/subsystem/component to operate according to its specification and within the established operating limits, without being subjected to nonscheduled inspection. In other words, it is the probability to operate without failures within a defined period [17]. In analytical form, the reliability or survival function $R(t)$ expresses the probability that a system is operating beyond time $t$ :

$$
R(t)=\operatorname{Prob}(T>t)=1-F(t),
$$


where $F(t)$ is the cumulative distribution function (CDF) that describes the intervals between successive failures?

The mean time to/between failure (MTTF or MTBF) serves as an indicator for the reliability of a system/subsystem or component. High MTTF values indicate high reliability levels. If a system begins to operate at time $t_{0}$ and fails $n$ times at temporal points $t_{1}, t_{2}, \ldots, t_{n}$, where Times To Failure (TTF) are defined as the intervals $T T F_{1}=t_{1}-t_{0}, T T F_{2}=t_{2}-t_{1}, \ldots, T T F_{n}=t_{n}-t_{n-1}$, then MTTF is given by:

$$
M T T F=\frac{1}{n} \sum_{i=1}^{n} \operatorname{TTF}_{i} .
$$

MTTF derives from the reliability function, as follows:

$$
\text { MTTF }=\int_{0}^{+\infty} R(t) d t .
$$

Reliability is an intrinsic qualitative characteristic of a system or component, forged during the design, development, test, and production phases. However, reliability can be affected from extrinsic factors, such as environment, operations, maintenance and support, etc. It is therefore important that these factors correspond to the technical and operational specifications of the system and its components.

\subsection{An Overview of the 'Component Importance Measures'}

Importance measures are objective criteria that classify the significance of the components within the structure of a system, depending on the purpose of the analysis. These measures may serve as resource allocation factors for scheduled maintenance and can help to estimate the spare parts required for both scheduled and unscheduled component replacements. Not all existing importance measures are utilized within the context of the analysis of this study. However, because the selection of the importance measure is subjective and might serve different purpose of analysis, it is believed that an overview of existing importance measures is beneficial for the reader and may trigger ideas on how to expand the applicability of this study. The overview is based on existing literature on ideas and developments in importance measures for reliability and risk analysis [18-24].

In order to describe the importance measures that follow, the notations of Table 1 are used.

Table 1. Notations for the basic functions.

\begin{tabular}{cc}
\hline Notation & Description \\
\hline$R(t)$ & System reliability function \\
$Q(t)$ & System unreliability function \\
$r_{i}(t)$ & Component $i$ reliability function \\
$q_{i}(t)$ & Component $i$ unreliability function \\
$R_{i, 1}(t)$ & System reliability function, whereas $r_{i}(t)=1$ (perfect component $i$ ) \\
$R_{i, 0}(t)$ & System reliability function, whereas $r_{i}(t)=0$ (failed component $i$ ) \\
$Q_{i, 1}(t)$ & System unreliability function, whereas $r_{i}(t)=1$ (perfect component $i$ ) \\
$Q_{i, 0}(t)$ & System unreliability function, whereas $r_{i}(t)=0$ (failed component $i$ ) \\
\hline
\end{tabular}

\subsubsection{Importance Measures Based Solely on System Structure}

These importance measures depend solely on the system structure and are independent of time.

\section{- Structural Importance (Str) or Birnbaum's Structural Importance}

Structural importance (also known as Birnbaum's structural importance) for component $i$ is the fraction of the system states in which component $i$ is working, where a failure of component $i$ will result in a failure of the system. 


\section{- Barlow-Proschan Importance (BP)}

The Barlow-Proschan importance for component $i$ is the probability that the failure of component $i$ coincides with the failure of the system.

\subsubsection{Importance Measures Based on System Structure and Component's Reliability}

These importance measures depend on the system structure and time, because they take into consideration both the system structure and the components reliability functions.

\section{- Birnbaum Importance (B) or Reliability Importance}

Birnbaum importance (also known as reliability importance) at time $t$ for component $i$ is the improvement in the system reliability that would be gained by replacing a failed component $i$ with a perfect component $i$ :

$$
B_{i}(t)=R_{i, 1}(t)-R_{i, 0}(t)
$$

The Birnbaum importance measure does not take into consideration the reliability for component $i$ at time $t$.

\section{- Improvement Importance (Imp) or Improvement Potential}

Improvement importance (also known as improvement potential) at time $t$ for component $i$ is the increase of the system reliability if component $i$ is replaced with a perfect component:

$$
\operatorname{Imp}_{i}(t)=R_{i, 1}(t)-R(t)
$$

For the purpose of this study, whenever a planned component replacement (PCR) is required, we use the improvement importance measure after a 'cost adjustment'. As such, the decision which is being made upon scheduled maintenance is to replace the component for which the highest value of 'benefit/cost' is achieved. More specifically, if the value of the improvement importance measure for component $i$ is $\operatorname{Imp}_{i}(t)$, and the cost of scheduled replacement for component $i$ is $C S_{i}$, we define the cost-adjusted improvement importance measure as: $C A \operatorname{Im} p_{i}(t)=\operatorname{Imp}_{i}(t) / C S_{i}$.

\section{- Risk Achievement Importance or Risk Achievement Worth (RAW)}

Risk achievement importance (also known as risk achievement worth) at time $t$ for component $i$ expresses the relative increase of the system unreliability, if component $i$ failed:

$$
R A W_{i}(t)=\frac{Q_{i, 0}(t)}{Q(t)} .
$$

\section{- Risk Reduction Importance or Risk Reduction Worth (RRW)}

Risk reduction importance (also known as risk reduction worth) at time $t$ for component $i$ expresses the relative decrease of the system unreliability, if component $i$ were perfect:

$$
R W_{i}(t)=\frac{Q_{i, 1}(t)}{Q(t)} .
$$

\section{- Failure-Based Criticality Importance (FBC)}

Failure-based criticality importance (also known as criticality failure importance or failure criticality or criticality importance factor) at time $t$ for component $i$ is the probability that component $i$ has caused system failure, when the system has failed at time $t$ :

$$
F B C_{i}(t)=\frac{B_{i}(t) q_{i}(t)}{Q(t)} .
$$


Proposition 1. The improvement importance and failure-based criticality importance measures obtain analogous weights. Specifically, for any given component, the improvement importance measure equals the system unreliability times the failure-based criticality importance measure.

\section{Proof of Proposition 1.}

$$
\begin{aligned}
B_{i}(t) q_{i}(t) \underset{(\mathrm{eq} .(4))}{=} & {\left[R_{i, 1}(t)-R_{i, 0}(t)\right] q_{i}(t)=R_{i, 1}(t) q_{i}(t)-R_{i, 0}(t) q_{i}(t) } \\
& =R_{i, 1}(t)\left[1-r_{i}(t)\right]-R_{i, 0}(t) q_{i}(t) \\
& =R_{i, 1}(t)-\left[R_{i, 1}(t) r_{i}(t)+R_{i, 0}(t) q_{i}(t)\right] \\
& =R_{i, 1}(t)-R(t) \underset{(\mathrm{eq} \cdot(5))}{=} \operatorname{Imp}_{i}(t) .
\end{aligned}
$$

Hence, Equation (8) becomes:

$$
\operatorname{Imp}_{i}(t)=Q(t) F B C_{i}(t)
$$

\section{- Success-Based Criticality Importance (SBC)}

Success-based criticality importance (also known as criticality success importance or criticality importance factor) at time $t$ for component $i$ is the probability that component $i$ contributes to system success, given that the system is operating:

$$
S B C_{i}(t)=\frac{B_{i}(t) r_{i}(t)}{R(t)} .
$$

\section{- Fussell-Vesely Importance (FV)}

The Fussell-Vesely importance at time $t$ for component $i$ is given by:

$$
F V_{i}(t)=\frac{p_{i}(t)}{Q(t)}
$$

where $p_{i}(t)$ is the probability that at least one minimal cut set containing component $i$ has failed at time $t$. A minimal cut set is a minimal set of components which, if failed, causes the system to fail.

\section{- Partial Derivative Importance (PD)}

The partial derivative importance at time $t$ for component $i$ expresses the sensitivity of the system reliability on a marginal change of the component $i$ reliability [25]:

$$
P D_{i}(t)=\frac{\partial R(t)}{\partial r_{i}(t)} .
$$

An advantage of this importance measure is that it may consider marginal changes in a component's reliability, whereas the previous importance measures consider either a failed or a perfect component.

\section{Materials and Methods}

The developed optimization software tool is demonstrated as applied to the maintenance planning of a fuel pump of an aircraft jet engine. The fuel pump consists of two subsystems (subsystem 1, subsystem 2) which operate in parallel, hence for the pump to operate at least one subsystem must operate. 
Subsystem 1 consists of an electrical valve (a) and a mechanical fuel regulator (b). For subsystem 1 to operate, both (a) and (b) must operate. Subsystem 2 consists of an electronic fuel regulator (c), an electrical compressor (d) and a hydraulic valve (e). For Subsystem 2 to operate, all (c), (d), and (e) must operate. In case of a failure of the electronic fuel regulator (c), Subsystem 2 can use the mechanical fuel regulator (b), which belongs to Subsystem 1 .

\subsection{Basic Assumptions}

The fuel pump is represented by the schematic of Figure 1.

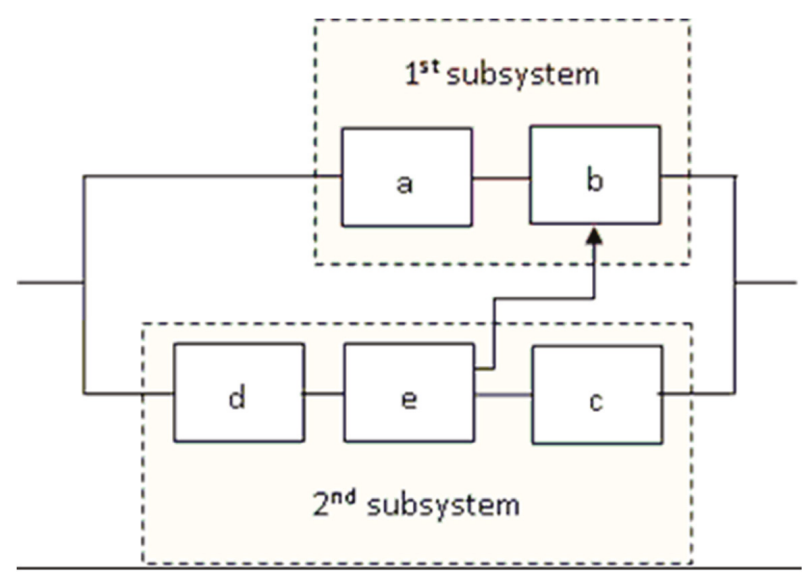

Figure 1. Schematic of the fuel pump.

All its components operate independently and a failure of one or more components is not going to affect the operation of the rest. Furthermore, the pump can operate even when one or more of its components have failed. The first assumption here is that a component failure cannot be detected if the pump keeps operating, as such, corrective maintenance will be implemented only in case that the pump stops operating.

\subsection{System Structure Function}

The fuel pump structure function is:

$$
\varphi\left(x_{\mathrm{a}}, x_{\mathrm{b}}, x_{\mathrm{c}}, x_{\mathrm{d}}, x_{\mathrm{e}}\right)=x_{\mathrm{a}} \cdot x_{\mathrm{b}}+x_{\mathrm{b}} \cdot x_{\mathrm{d}} \cdot x_{\mathrm{e}}-x_{\mathrm{a}} \cdot x_{\mathrm{b}} \cdot x_{\mathrm{d}} \cdot x_{\mathrm{e}}+x_{\mathrm{c}} \cdot x_{\mathrm{d}} \cdot x_{\mathrm{e}}-x_{\mathrm{b}} \cdot x_{\mathrm{c}} \cdot x_{\mathrm{d}} \cdot x_{\mathrm{e}}
$$

\subsection{Minimal Cut Sets}

The fuel pump minimal cut sets are: $\{a, d\},\{a, e\},\{b, c\},\{b, d\},\{b, e\}$

\subsection{Components Reliability Functions}

We accept that every component $i$, with $i \in\{\mathrm{a}, \mathrm{b}, \mathrm{c}, \mathrm{d}, \mathrm{e}\}$, is going through its useful life, hence its failure rate is constant and the respective failure intervals follow the exponential distribution with parameter $\lambda_{i}=1 / M_{T T F}$. In other words, each component $i$ fails randomly and its failures follow the Poisson distribution with parameter $\lambda_{i}$. The reliability function $r_{i}(t)$ of component $i$ is given by:

$$
r_{i}(t)=e^{-\lambda_{i} t}
$$

The component reliability information is shown in Table 2. 
Table 2. Component reliability and cost information.

\begin{tabular}{ccccc}
\hline $\begin{array}{c}\text { Component } \\
M T T F \text { (Hours) }\end{array}$ & $\begin{array}{c}\text { Component } \\
\text { Failure Rate } \\
\text { (Constant) }\end{array}$ & $\begin{array}{c}\text { Component } \\
\text { Reliability } \\
\text { Function }\end{array}$ & $\begin{array}{c}\text { Cost of Scheduled } \\
\text { Replacement of a Single } \\
\text { Component (Euros) }\end{array}$ & $\begin{array}{c}\text { Cost of Unscheduled } \\
\text { Replacement of a Single } \\
\text { Component (Euros) }\end{array}$ \\
\hline$M T T F_{\mathrm{a}}=500$ & $\lambda_{\mathrm{a}}=0.002$ & $r_{\mathrm{a}}(t)=e^{-0.002 t}$ & $C S_{\mathrm{a}}=2000$ & $C U_{\mathrm{a}}=4000$ \\
$M T T F_{\mathrm{b}}=1000$ & $\lambda_{\mathrm{b}}=0.001$ & $r_{\mathrm{b}}(t)=e^{-0.001 t}$ & $C S_{\mathrm{b}}=3000$ & $C U_{\mathrm{b}}=6000$ \\
$M T T F_{\mathrm{c}}=667$ & $\lambda_{\mathrm{c}}=0.0015$ & $r_{\mathrm{c}}(t)=e^{-0.0015 t}$ & $C S_{\mathrm{c}}=4000$ & $C U_{\mathrm{c}}=8000$ \\
$M T T F_{\mathrm{d}}=400$ & $\lambda_{\mathrm{d}}=0.0025$ & $r_{\mathrm{d}}(t)=e^{-0.0025 t}$ & $C S_{\mathrm{d}}=6000$ & $C U_{\mathrm{d}}=12,000$ \\
$M T T F_{\mathrm{e}}=2000$ & $\lambda_{\mathrm{e}}=0.0005$ & $r_{\mathrm{e}}(t)=e^{-0.0005 t}$ & $C S_{\mathrm{e}}=7000$ & $C U_{\mathrm{e}}=14,000$ \\
\hline
\end{tabular}

\subsection{System Reliability Function}

The reliability function $R(t)$ of the fuel pump for $t \leq 1.000$ is shown at the Figure 2 below.

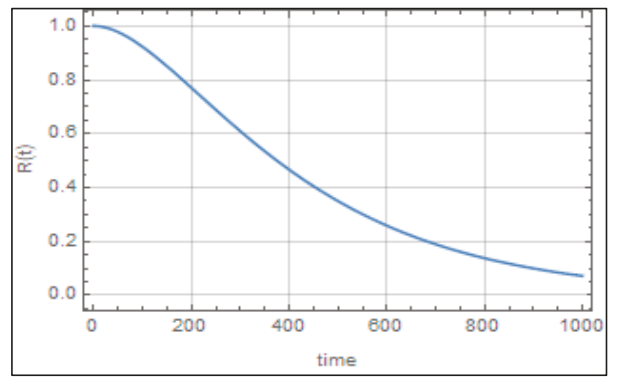

Figure 2. Reliability function $R(t)$ of the fuel pump for $t \leq 1.000$.

At $t=0$ all components are assumed to be new ('perfect'). Following Equations (13) and (14) the fuel pump reliability function is given by:

$$
R(t)=r_{\mathrm{a}}(t) \cdot r_{\mathrm{b}}(t)+r_{\mathrm{b}}(t) \cdot r_{\mathrm{d}}(t) \cdot r_{\mathrm{e}}(t)-r_{\mathrm{a}}(t) \cdot r_{\mathrm{b}}(t) \cdot r_{\mathrm{d}}(t) \cdot r_{\mathrm{e}}(t)+r_{\mathrm{c}}(t) \cdot r_{\mathrm{d}}(t) \cdot r_{\mathrm{e}}(t)-r_{\mathrm{b}}(t) \cdot r_{\mathrm{c}}(t) \cdot r_{\mathrm{d}}(t) \cdot r_{\mathrm{e}}(t)
$$

\subsection{Calculation of the Components' Importance Measures}

As an example, Figure 3 shows the components' importance measures percentages at $t=40$.

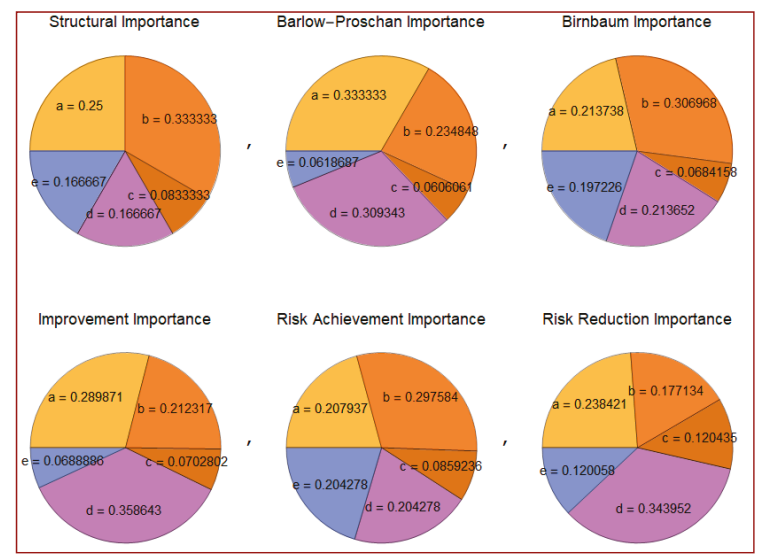

Figure 3. Cont. 


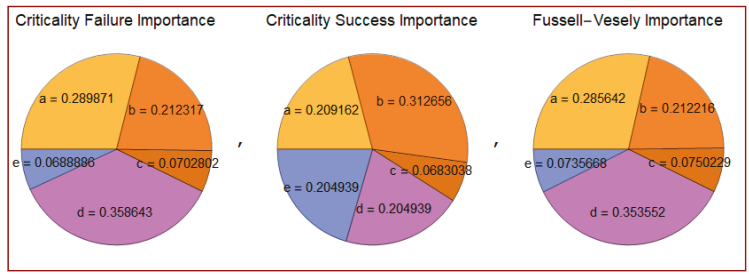

Figure 3. Components' importance measures percentages at $t=40$.

Notably, the percentages of the failure-based criticality and the improvement importance measures are equal (see Proposition 1).

\subsection{Estimation of the Optimum Maintenance Plan}

Importance measures can be used as objective criteria to make the optimum decision regarding the maintenance planning of the fuel pump. However, since the importance measures do not consider the associated cost of components, we introduce a cost adjustment. Thus, we expand the applicability of the importance measures as a 'benefit over cost' criterion for decision making, while trying to determine the optimum maintenance scenario.

\subsubsection{Inputs}

The proposed software tool uses the following inputs:

- The structure of the system.

- The life cycle of the system, more specifically the timeframe of the maintenance plan of the system.

- The reliability distribution of each component.

- The importance measure which is going to be used as an objective criterion to determine the component which will be replaced on a preventive basis during the implementation of the scheduled maintenance of the system. The specified importance measure will be cost-adjusted according to the cost inputs that follow.

- The cost of the scheduled preventive replacement of each component with a brand new one. In other words, the cost of scheduled preventive maintenance for each component after which the cumulative time of operation of the component is zero.

- The cost of the nonscheduled replacement of each component with a brand new one. In other words, the cost of nonscheduled maintenance for each component after which the cumulative time of operation of the component is zero.

- The cost of scheduled preventive replacement of all the components, at once, with brand new ones. In other words, the cost of scheduled preventive maintenance for all components simultaneously, after which the cumulative time of operation of the components is zero.

- The confidence level for the fulfilment of the nonscheduled maintenance requirements, in case of system failures.

\subsubsection{Processing}

The software tool will use an algorithm to assess all the potential scheduled maintenance scenarios; for each scenario it will calculate the value of the criterion 'lowest total maintenance cost/average reliability outcome'. The lowest value of the criterion will determine the optimum scheduled maintenance scenario. Specifically, the structure of the algorithm is: 
Estimate system structure function

For $N=0$ to 98 :

Set $R \_$lower limit $=0.99-0.01 N$

While $t \leq T$ :

Estimate $t_{j}$ for next scheduled maintenance, solving $R(t)=R \_$lower limit

Estimate components cost-adjusted improvement importance measures at $t_{j}$

Replace component with highest cost-adjusted improvement importance measure

Estimate $\boldsymbol{R}(\boldsymbol{t})$ for $\boldsymbol{t}>\boldsymbol{t}_{j}$, given the component replacement at $\boldsymbol{t}_{j}$

Estimate cost of scheduled component replacements

Estimate $\overline{\boldsymbol{R}(\boldsymbol{t})}, \lambda(\boldsymbol{t}), \overline{\lambda(t)}$, MTTF, and system failures at desired confidence level

Estimate components improvement importance measure integrals, from $t=0$ to $T$

Allocate the system failures to each component according to the above integrals

Estimate the cost of unscheduled component replacements

Estimate the total cost of replacements (scheduled + unscheduled)

Estimate the value of the optimization criterion: total cost of replacements $\overline{R(t)}$

Display the maintenance scenario with the lowest value of the optimization criterion

\subsubsection{Outputs}

The outputs of the tool are the following:

- The diagram of the procedure for which the lowest value of the criterion 'cost/benefit' is achieved.

- The reliability function diagram of the system for the optimum scheduled maintenance scenario.

- The average reliability of the system.

- The lowest value of the reliability of the system, at which the system has to be grounded for scheduled maintenance.

- $\quad$ The MTTF of the system.

- The replacement schedule for the system's components.

- The required number of spare parts for each component, for both scheduled and nonscheduled maintenance (at the determined confidence level).

- The cost analysis for both scheduled and nonscheduled replacement of the components.

\section{Exemplified Example/Results}

The following is an exemplified example of an optimization process that uses the proposed software tool.

\subsection{Task}

The optimum maintenance plan for the fuel pump needs to be established for its first $3000 \mathrm{~h}$ of operation with the following constraints: Only one component will be replaced by a new one (or its cumulative time of operation will be considered as zero following an inspection/rectification) during the implementation of the scheduled maintenance of the system. The criterion that will determine the component to be replaced is the 'cost-adjusted improvement importance measure', which corresponds to the cost of the scheduled replacement of each individual component, as illustrated in Table 2.

\subsection{Components Replacement Cost}

The replacement cost of the components is estimated for three different cases:

- Scheduled replacement of a unique component (preventive maintenance)

- Nonscheduled replacement of a unique component (corrective maintenance)

- Scheduled replacement of all the components simultaneously (preventive maintenance) 
The estimation of the scheduled replacement cost for each component takes into account the purchase price of the component and of all the consumables required for its replacement, as well as the total cost of the required maintenance work, such as depreciation of special tools and equipment, energy cost, man-hours cost, the system down-time and its effect on the operational availability, as well as any other associated cost (safe maintenance procedures cost, accessibility cost, operational checks cost, transportation cost for involved staff and materiel).

The cost of the nonscheduled replacement of each component in case of a pump failure should be considered higher than the respective scheduled replacement cost. Further to the cost categories which have been mentioned previously, the risk of unintended damage and/or failures of other jet engine subsystems due to the failure of the pump, should also be considered. It is also possible that the fuel pump fails in a location at a distance from the maintenance base station, a situation that will potentially incur higher costs and disruption to the aircraft fleet operations, due to the nonscheduled grounding of the jet engine and, consequently, the aircraft.

The information regarding the replacement cost (scheduled and nonscheduled) of each component of the fuel pump is presented at the Table 2.

The estimation of the replacement cost, at once, of more than one components, should consider the fact that the total replacement cost should be less than the sum of the scheduled replacement cost for each component (Table 2). This is due to the economies of scale, which materialize due to maintenance work which is common for some or all the components. For example, when all the components are replaced at once, safe maintenance procedures and the operational check of the fuel pump take place only once. In addition, the total downtime of the pump is less and the cumulative effect to the operational availability of the jet engines/aircraft fleet is less severe.

\subsection{Optimization Criterion}

As optimum maintenance plan is considered the one with the lowest possible total maintenance cost (for both scheduled and nonscheduled maintenance) for the average reliability, which is achieved during the first $3000 \mathrm{~h}$ of operation of the fuel pump. In other words, the optimization criterion is the lowest possible value of 'cost over benefit'. The optimization of the preventive maintenance plan is shown in Figure 4.

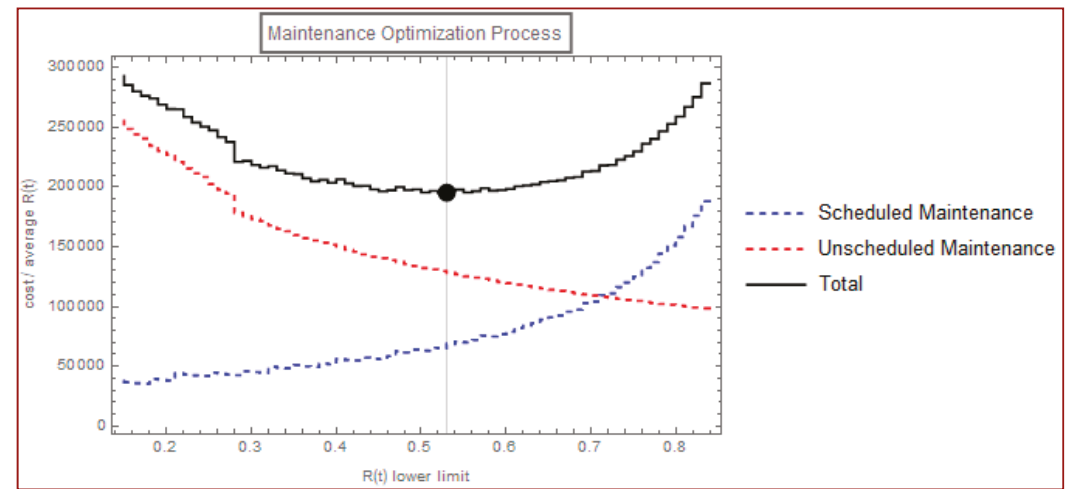

Figure 4. Optimization of the preventive maintenance plan for the fuel pump for the first $3000 \mathrm{~h}$ of its operation.

\subsection{Optimum Number of Spare Components for Scheduled Maintenance}

Every time that the reliability of the fuel pump approaches the lowest acceptable limit, the pump is grounded for scheduled maintenance. In that case, a preventive replacement will take place for the component for which it is estimated to achieve the highest possible improvement of the reliability of 
the pump for the associated cost of the improvement. The importance measure of the improvement is actually 'cost adjusted' and as such the decision which has been made is to replace the component for which the lowest value of 'cost/benefit' is achieved.

More specifically, if at the time $t_{k}$ of the scheduled downtime, the value of the improvement importance measure for the component $i$ is $\operatorname{Imp}_{i}\left(t_{k}\right)$, with $i \in\{\mathrm{a}, \mathrm{b}, \mathrm{c}, \mathrm{d}, \mathrm{e}\}$, and the replacement cost of each component is $C S_{i}$, then, as shown in Table 2, the component replaced is not the one with the highest value of $\operatorname{Im} p_{i}\left(t_{k}\right)$, but the one with the highest value of $\operatorname{Im} p_{i}\left(t_{k}\right) / C S_{i}$. This is how an estimation can be made for the complete list of the components which are going to be replaced during the first $3000 \mathrm{~h}$ of operation of the pump. Having assessed that, an estimation can be made as well for the number of spare components which will be needed for the scheduled maintenance of the pump.

\subsection{Optimum Number of Spare Components for Non-Scheduled Maintenance}

The mean time between two successive occurrences of nonscheduled maintenance for the first $3000 \mathrm{~h}$ of operation of the fuel pump can be estimated by Equation (3) as MTTF $=2040.3 \mathrm{~h}$. The number of failures is: $\mu=8.26$.

The number of failures, for a certain confidence level, and the respective number of spare components needed for the nonscheduled maintenance for the first $3000 \mathrm{~h}$ of operation can be estimated by using Poisson distribution with parameter $\mu=8.26$. As per the results presented at the Table 3 (for a $95 \%$ confidence level), a number of 13 nonscheduled component replacements will be needed for a single fuel pump.

Table 3. Spare components required to fulfil the nonscheduled maintenance requirements (95\% confidence level).

\begin{tabular}{ccc}
\hline Part Type & Items & Cost \\
\hline A & 5.02131 & $20,085.20$ \\
B & 4.36118 & $26,167.10$ \\
C & 0.462472 & 3699.78 \\
D & 2.6525 & $31,830.00$ \\
E & 0.502543 & 7035.60 \\
Fails & & \\
$(95.7391 \%)$ & $\mathbf{1 3}$ & $\mathbf{8 8 , 8 1 7 . 7 0}$ \\
\hline
\end{tabular}

Having estimated this, the quantity of each specific type of spare part for the corrective maintenance can now be estimated. This time, the failure-based criticality importance measure is considered to better express the contribution of each type of spare component to the occurrence of a fuel pump failure. This importance measure represents the probability of a fuel pump failure due to a component failure. Equivalently, according to the Proposition 1, the (more conveniently estimated) improvement importance measure can be used as well.

For the occasion of unscheduled maintenance requirements, cost adjustment on the improvement importance measure is not required. Indeed, cost does not affect the probability of fuel pump failure due to a specific component failure. However, since the improvement importance measure is now applied through the whole 3000 operational hours timeframe, and not to a specific instance in time (such as in the case of scheduled maintenance temporal points), the integral of the improvement importance measure for every component is calculated, from 0 to $3000 \mathrm{~h}$ of the pump's operation. The integration of the improvement importance measures serves as the allocation base for the previously estimated total 13 spare components (unscheduled maintenance), in order to determine the quantity for each component type.

After the allocation of the 13 system failures to each spare part, it is strongly recommended that no rounding should be performed for a single fuel pump's spares (as seen in Table 3). Such an analysis normally aims at making provisions for a relatively large population of fuel pumps, hence it 
is suggested that any rounding should be performed after the calculation of the total number of each spare part type.

Table 3 shows that a confidence level of $95 \%$ to fulfill the nonscheduled maintenance requirements of the pump for the first $3000 \mathrm{~h}$ of operation, is going to require 13 spare components. Using the integral of the improvement importance measure as an allocation basis for the 13 spare components, it is concluded that five nonscheduled replacements of component (a) are going to take place), 4.4 nonscheduled replacements of the component (b), 0.5 nonscheduled replacements of the component (c), 2.7 nonscheduled replacements of the component (d) and 0.5 nonscheduled replacements of the component (e). The total cost of all the above nonscheduled replacements is $88,817.70 €$, and this is the total cost of the nonscheduled maintenance of the pump for the first $3000 \mathrm{~h}$ of operation.

\subsection{Results}

The optimum maintenance plan is shown in Figure 5 and in Tables 3-5.

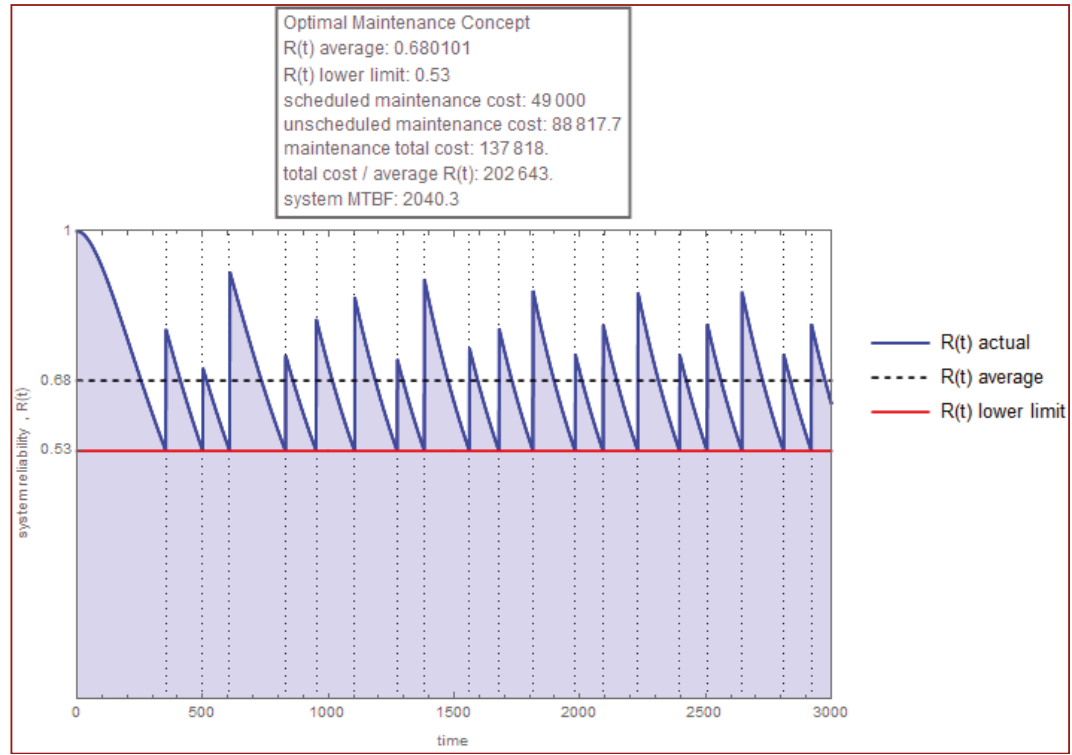

Figure 5. The reliability function under the optimum maintenance plan for the fuel pump for its first $3000 \mathrm{~h}$ of operation.

The reliability function of the first $3000 \mathrm{~h}$ of operation of the fuel pump is presented in Figure 5. The local maxima of the curve represent the improvement of the reliability of the fuel pump following the scheduled down time during which a preventive replacement of a component has taken place. It is reminded that the decision to replace a component has been made based to the lowest value of the cost/benefit optimization criterion, using the cost-adjusted improvement importance measure.

The horizontal red line shows the lowest acceptable reliability limit for the fuel pump, which is $53 \%$. Whenever the limit is reached, the pump is grounded for preventive maintenance or replacement of a specific component. The horizontal dotted black line shows the mean reliability of $68 \%$, which is achieved during the $3000 \mathrm{~h}$ of operation. 
Table 4. Components replacement plan for the scheduled maintenance of the fuel pump for its first $3000 \mathrm{~h}$ of operation.

\begin{tabular}{cc}
\hline Part Type & Replace at \\
\hline d & 353.653 \\
b & 500.406 \\
a & 607.353 \\
a & 829.207 \\
b & 951.600 \\
a & 1104.010 \\
b & 1273.250 \\
a & 1381.720 \\
a & 1560.730 \\
b & 1678.180 \\
a & 1813.860 \\
a & 1981.150 \\
b & 2092.210 \\
a & 2230.450 \\
a & 2396.240 \\
b & 2506.640 \\
a & 2644.860 \\
a & 2810.480 \\
b & 2920.860 \\
\hline
\end{tabular}

Table 5. Total replacement cost breakdown for the scheduled maintenance of the fuel pump for its first $3000 \mathrm{~h}$ of operation.

\begin{tabular}{ccc}
\hline Part Type & Items & Cost \\
\hline a & 11 & 22,000 \\
b & 7 & 21,000 \\
c & 0 & 0 \\
d & 1 & 6000 \\
e & 0 & 0 \\
Total sched. & 19 & 49,000 \\
\hline
\end{tabular}

The results shown in Tables 4 and 5 indicate that fulfilling the scheduled maintenance requirements of the first $3000 \mathrm{~h}$ of operation, is going to require 11 stand-alone replacements of the component (a), seven stand-alone replacements of the component (b) and one stand-alone replacement of the component (d). The total cost of all the above replacements is $49,000 €$ and this is the total cost of the scheduled maintenance of the pump for the first $3000 \mathrm{~h}$ of operation. Notably, no PCRs for components (c) and (e) are required, because any potential replacement of these components would have brought relatively poor improvement in the fuel pump's reliability, given the associated replacement cost. On the other hand, Table 5 shows that the components (a) and (b) PCRs usually have the highest impact on the fuel pump's reliability improvement, compared to the associated replacement cost.

The total maintenance cost (scheduled and nonscheduled) can now be calculated for the first 3000 operation hours of the pump:

$49,000+88,817.7=137,817.7 €$ and the mean reliability for the same timeframe is $68 \%$. As such, the optimization criterion of (cost/benefit) takes its optimum value of $137,817.7 / 0.68=202,673$.

Figure 6 shows the failure rate $\lambda(t)$ and the mean failure rate $\overline{\lambda(t)}$ of the fuel pump. 


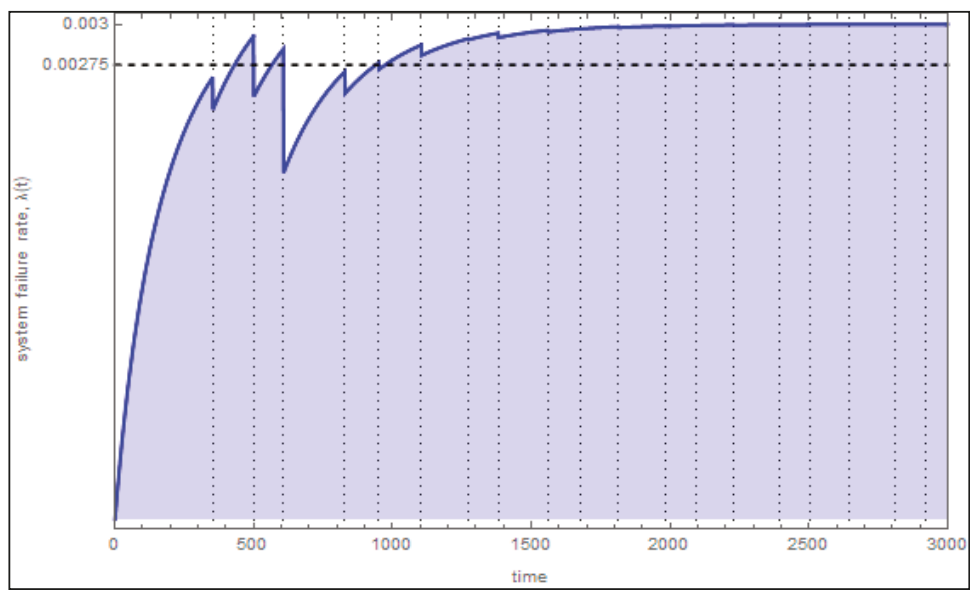

Figure 6. Failure rate $\lambda(t)$ (blue curve) and the mean failure rate $\overline{\lambda(t)}$ (horizontal dotted line) of the fuel pump for its first $3000 \mathrm{~h}$ of operation.

It is observed that after the first $1500 \mathrm{~h}$ of operation, which seems as a 'warm-up period', the failure rate of the pump converges to a constant value $\lambda \approx 0.003$ (CFR period).

\subsection{An Alternative Scenario: All Components Are Replaced Simultaneously}

At this scenario, all the components are replaced simultaneously at any time the pump is subjected to scheduled maintenance. Still, the timing of the scheduled maintenance is determined by the lowest reliability limit which has been set for the pump. After each time the pump is subjected to scheduled maintenance, the pump is considered as brand new and, as such, the time interval between two subsequent scheduled maintenance occurrences is considered as constant.

The optimization of the maintenance plan for this alternative scenario is shown at the Figure 7.

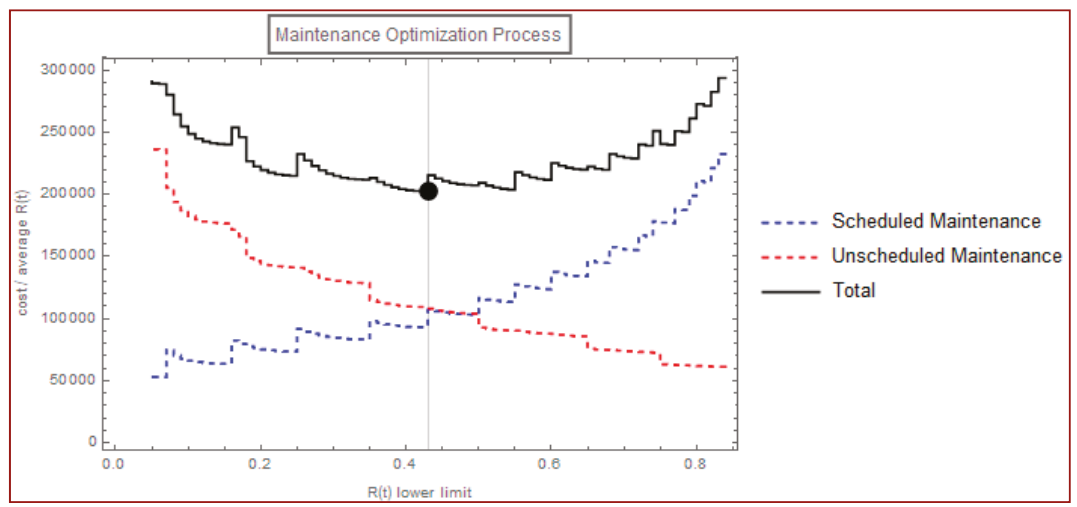

Figure 7. Optimization of the preventive maintenance plan for the fuel pump for the first $3000 \mathrm{~h}$ of its operation (alternative scenario).

Following this, the developed software tool investigates thoroughly the optimum maintenance plan and returns to Figure 8 as well as Tables 6-8. 


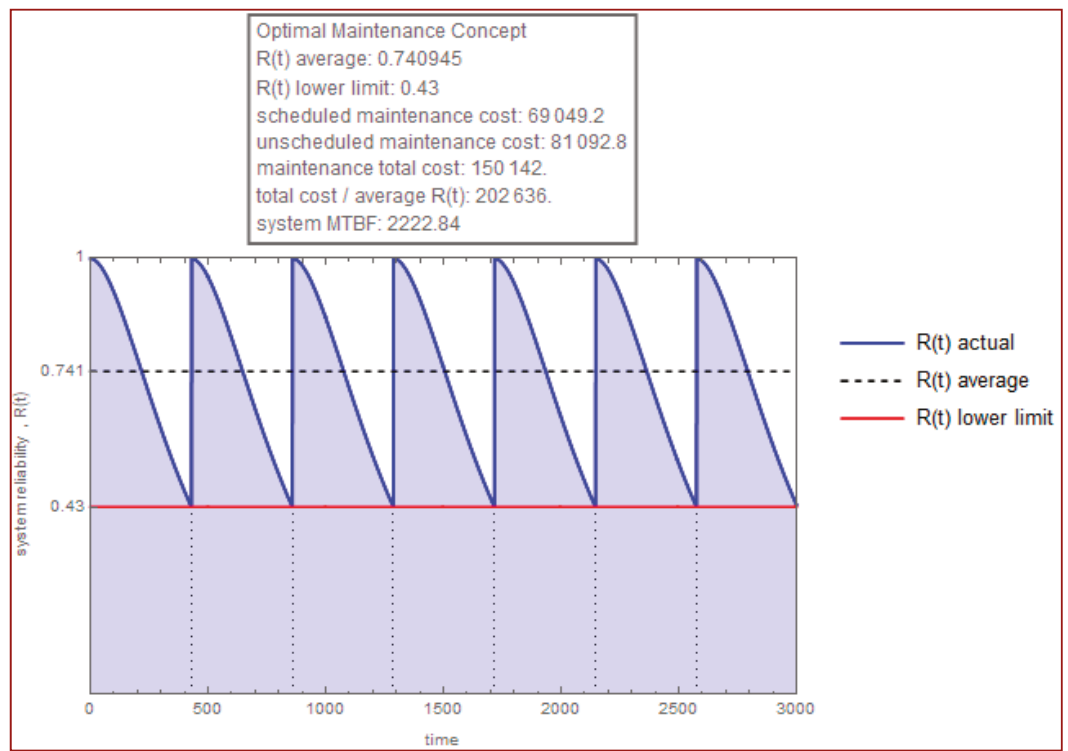

Figure 8. Fuel pump reliability for the first $3000 \mathrm{~h}$ of its operation (alternative scenario).

Table 6. Components replacement plan (alternative scenario).

\begin{tabular}{cc}
\hline Part Types & Replace at \\
\hline a, b, c, d, e & 429.21 \\
a, b, c, d, e & 858.42 \\
a, b, c, d, e & 1287.64 \\
a, b, c, d, e & 1716.85 \\
a, b, c, d, e & 2146.06 \\
a, b, c, d, e & 2575.27 \\
\hline
\end{tabular}

Table 7. Total replacement cost breakdown (alternative scenario).

\begin{tabular}{ccc}
\hline Part Type & Items & Cost \\
\hline a & 6 & \\
b & 6 & \\
c & 6 & \\
d & 6 & \\
e & 6 & $69,049.20$ \\
Total sched. & 30 & \\
\hline
\end{tabular}

Table 8. Total replacement cost breakdown (alternative scenario, confidence level 95\%).

\begin{tabular}{ccc}
\hline Part Type & Items & Cost \\
\hline a & 3.200540 & $12,802.10$ \\
b & 1.983480 & $11,900.90$ \\
c & 0.618516 & 4948.13 \\
d & 3.661420 & $43,937.10$ \\
e & 0.536043 & 7504.60 \\
Fails. & $\mathbf{1 0}$ & $\mathbf{8 1 , 0 9 2 . 8 0}$ \\
\hline
\end{tabular}


According to the assumption of Section 3.2, the cost of the scheduled replacement of more than one components simultaneously, is going to be less than the sum of the costs of each stand-alone scheduled replacement as shown in Table 2. More specifically, it is deducted that since the cost of the preventive simultaneous replacement of all the components is less than the $52.31 \%$ of the sum of the costs of each stand-alone preventive replacement, then the scenario of the preventive replacement of all the components simultaneously is more efficient. In case the scheduled simultaneous replacement of all the components maintains the cost at $52.31 \%$, as compared with the original scenario, then the two scenarios are almost equivalent with regards to the optimization criterion being used. Of note, the case under examination serves as an example for the application of the software tool; no actual data were used, including the system structure, components reliability functions, and component replacement costs. The equivalence threshold is sensitive to structure, reliability, and cost inputs-hence the above-estimated $52.31 \%$ threshold should not be generalized.

Table 6 results indicate that the optimum maintenance is achieved when the pump is grounded every $429.21 \mathrm{~h}$ of operation and all its components are replaced at once, with reliability approaching the lowest acceptable limit of $43 \%$.

Table 7 shows that to fulfil the preventive maintenance requirements of the pump during its first $3000 \mathrm{~h}$ of operation, six components of each type need to be scheduled to be replaced. In that case, the total replacement cost of the 30 involved components is $69,049.2 €$. For this alternative scenario, this is the total cost of the preventive maintenance of the pump for the first $3000 \mathrm{~h}$ of operation.

Table 8 shows that, a confidence level of $95 \%$ to fulfil the nonscheduled maintenance requirements for the first $3000 \mathrm{~h}$ of operation of the fuel pump, is going to require a nonscheduled replacement of 10 components. In more detail, the alternative scenario is going to require the nonscheduled replacement of 3.2 (a) components, 1.98 (b) components, 0.62 (c) components, 3.66 (d) components and 0.54 (e) components. The total cost of all the above nonscheduled replacements is $81,092.8 €$, and this is the total cost of the nonscheduled maintenance of the pump for the first $3000 \mathrm{~h}$ of operation.

Figure 9 shows the failure rate $\lambda(t)$ and the mean failure rate $\overline{\lambda(t)}$. The failure rate takes its highest value (0.00284) just before the scheduled grounding of the pump. Another observation is that between two successive groundings, the pump is always at IFR period.

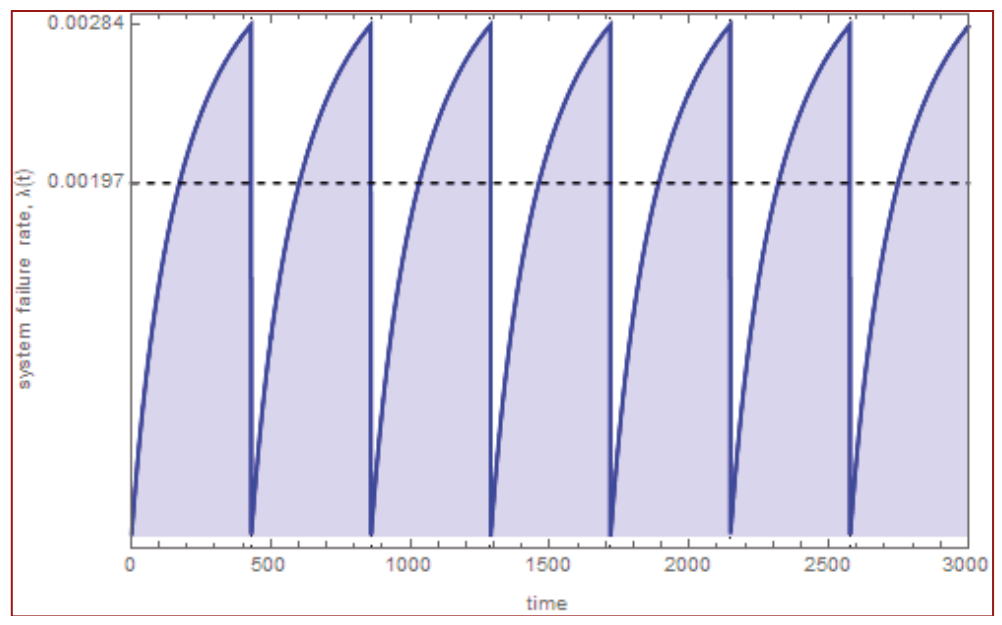

Figure 9. Failure rate $\lambda(t)$ (blue curve) and the mean failure rate $\overline{\lambda(t)}$ (horizontal dotted line) of the pump for its first $3000 \mathrm{~h}$ of its operation (alternative scenario). 
The total maintenance cost (scheduled and nonscheduled) can now be calculated for the first 3000 operation hours of the pump:

$69,049.2+81,092.8=150,142 €$ and the mean reliability for the same timeframe is $74.1 \%$. As such, the optimization criterion of cost/benefit takes its optimum value of $150,142 / 0.741=202,636$. The value is almost equivalent to the value of the optimization criterion of the first scenario.

The outputs of the two maintenance concepts are summarized in Table 9.

Table 9. Summary of the two maintenance concepts.

\begin{tabular}{|c|c|c|c|c|c|c|}
\hline & \multicolumn{3}{|c|}{ Initial Scenario } & \multicolumn{3}{|c|}{ Alternative Scenario } \\
\hline Average reliability & \multicolumn{3}{|c|}{0.68} & \multicolumn{3}{|c|}{0.74} \\
\hline Reliability lower limit & \multicolumn{3}{|c|}{0.53} & \multicolumn{3}{|c|}{0.43} \\
\hline Cost of scheduled maintenance & \multicolumn{3}{|c|}{49,000} & \multicolumn{3}{|c|}{69,049} \\
\hline Cost of unscheduled maintenance & \multicolumn{3}{|c|}{88,817} & \multicolumn{3}{|c|}{81,093} \\
\hline Total maintenance cost & \multicolumn{3}{|c|}{137,818} & \multicolumn{3}{|c|}{150,142} \\
\hline Total maintenance cost/average reliability & \multicolumn{3}{|c|}{202,643} & \multicolumn{3}{|c|}{202,636} \\
\hline Average failure rate per $1000 \mathrm{~h}$ of operation & \multicolumn{3}{|c|}{2.75} & \multicolumn{3}{|c|}{1.97} \\
\hline MTTF & \multicolumn{3}{|c|}{2040} & \multicolumn{3}{|c|}{2223} \\
\hline Component Types & Sched. & Unsched. & Total & Sched. & Unsched. & Total \\
\hline $\mathrm{A}$ & 11 & 5.0 & 16.0 & 6 & 3.2 & 9.2 \\
\hline B & 7 & 4.4 & 11.4 & 6 & 2.0 & 8.0 \\
\hline c & & 0.5 & 0.5 & 6 & 0.6 & 6.6 \\
\hline $\mathrm{d}$ & 1 & 2.7 & 3.7 & 6 & 3.7 & 9.7 \\
\hline $\mathrm{e}$ & & 0.5 & 0.5 & 6 & 0.5 & 6.5 \\
\hline Total & 19 & 13 & 32 & 30 & 10 & 40 \\
\hline
\end{tabular}

\section{Discussion}

Combination of dependencies and simulation optimization have been considered as promising areas for future work for optimal maintenance of multicomponent systems [26]. On the other hand, most optimal maintenance models in the literature use as optimization criterion the system maintenance cost rate, but they ignore the reliability performance [27]. Minimizing the system maintenance cost rate does not necessarily imply that the system reliability performance is optimized with regards to the cost, especially for multicomponent systems, and sometimes minimal maintenance cost is associated with very low system reliability measures. This is one of the effects of having various components in the system which may have different maintenance costs and different importance for the system [28]. As such, the optimal maintenance should always take into account both the maintenance cost and reliability and this is the rationale of introducing the cost adjusted importance measure to determine the optimal maintenance plan.

In the specific example of the fuel pump, it is noticeable that the first scenario (replacement of one component at a time) essentially brings the fuel pump at a state of a constant failure rate, after a 'warmup' period. On the contrary, the alternative scenario (simultaneous replacement of all components) does not have the same effect on the failure rate. Further investigation is needed, in order to assess the mechanism behind the convergence of the failure rate of the first scenario.

Other preventive maintenance scenarios may be examined as well, for example the simultaneous replacement of two or more components, at each time the pump is grounded for scheduled maintenance. In such cases, the calculation of combined importance measures is required.

Furthermore, the required confidence level for the number of components spare parts, which are required for the nonscheduled maintenance, affects the respective maintenance cost. This is a key cost driver for the maintenance optimization process; it is also a risk source for potential availability shortfalls, therefore careful attention should be paid to determine an appropriate confidence level. 
Author Contributions: M.B. contributed to the data curation and all authors contributed to the conceptualization, project administration, formal analysis, writing, editing and reviewing the manuscript.

Funding: This research received no external funding.

Conflicts of Interest: The authors declare no conflicts of interest.

\section{References}

1. Samaranayake, P.; Kiridena, S. Aircraft maintenance planning and scheduling: An integrated framework. J. Qual. Maint. Eng. 2012, 18, 432-453. [CrossRef]

2. Rosenzweig, V.V.; Domitrovic, A.; Bubic, M. Planning of training aircraft flight hours. Croat. Oper. Res. Rev. (CRORR) 2010, 1, 170-179.

3. Kozanidis, G.; Gavranis, A.; Kostarelou, E. Mixed integer least squares optimization for flight and maintenance planning of mission aircraft. Naval Res. Logist. 2012, 59, 212-229. [CrossRef]

4. Gavranis, A.; Kozanidis, G. An exact solution for maximizing the fleet availability of a unit of aircraft subject to flight and maintenance requirements. Eur. J. Oper. Res. 2015, 242, 631-643. [CrossRef]

5. Antonakis, A.S.; Giannakoglou, K.C. Optimization of military aircraft engine maintenance subject to engine part shortages using asynchronous metamodel-assisted particle swarm optimization and Monte-Carlo simulations. Int. J. Syst. Sci. Oper. Logist. 2017. [CrossRef]

6. Papakostas, N.; Papachatzakis, P.; Xanthakis, V.; Mourtzis, D.; Chryssolouris, G. An approach to operational aircraft maintenance planning. Decis. Support Syst. 2010, 48, 604-612. [CrossRef]

7. Cheung, A.; Ip, W.H.; Lu, D. Expert system for aircraft maintenance services industry. J. Qual. Maint. Eng. 2005, 11, 348-358. [CrossRef]

8. Joo, S.J. Scheduling preventive maintenance for modular designed components: A dynamic approach. Eur. J. Oper. Res. 2009, 192, 512-520. [CrossRef]

9. Gustavsson, M.P.; Patriksson, M.; Stomberg, A.B.; Wojciechowski, A.; Onnheim, M. Preventive maintenance scheduling of multi-component systems with interval costs. Comput. Ind. Eng. 2014, 76, 390-400. [CrossRef]

10. Vianna, W.O.L.; Yoneyama, T. Predictive maintenance optimization for aircraft redundant systems subjected to multiple wear profiles. IEEE Syst. J. 2018, 12, 1170-1181. [CrossRef]

11. Office of the Secretary of Defense. Cost Assessment and Program Evaluation; Office of the Secretary of Defense: Washington, DC, USA, 2014.

12. Department of Defense. MIL-STD-3034 'Reliability-Centered Maintenance (RCM) Process'; Department of Defense: Washington, DC, USA, 2011.

13. Wojciechowski, A. On the Optimization of Opportunistic Maintenance. Thesis for the Degree of Licentiate of Engineering, Chalmers University of Gothenburg, Gothenburg, Sweden, 2010.

14. Deputy under Secretary for Logistics and Materiel Readiness. Memorandum 'Condition Based Maintenance Plus; Deputy under Secretary for Logistics and Materiel Readiness: Washington, DC, USA, 2002.

15. SAE JA1011 'Evaluation criteria for Reliability-Centered Maintenance Processes; SAE International: Warrendale, PA, USA, 2009.

16. API Recommended Practice 580 'Risk Based Inspection; American Petroleum Institute: Washington, DC, USA, 2016.

17. Chairman of the Joint Chiefs of Staff Manual. CJCSM 3170.01C 'Operation of the Joint Capabilities Integration and Development System'; Chairman of the Joint Chiefs of Staff Manual: Washington, DC, USA, 2017.

18. Cheok, M.C.; Parry, G.W.; Sherry, R.R. Use of importance measures in risk-informed regulatory applications. Reliab. Eng. Syst. Saf. 1998, 60, 213-226. [CrossRef]

19. Vasseur, D.; Llory, M. International survey on PSA figures of merit. Reliab. Eng. Syst. Saf. 1999, 66, 261-274. [CrossRef]

20. Van Der Borst, M.; Schoonakker, H. An overview of PSA importance measures. Reliab. Eng. Syst. Saf. 2001, 72, 241-245. [CrossRef]

21. Vaurio, J.K. Ideas and developments in importance measures and fault-tree techniques for reliability and risk analysis. Reliab. Eng. Syst. Saf. 2010, 95, 99-107. [CrossRef]

22. Vaurio, J.K. Importance measures in risk-informed decision making: Ranking, optimization and configuration control. Reliab. Eng. Syst. Saf. 2011, 96, 1426-1436. [CrossRef] 
23. Rocco, C.M.; Ramirez-Marquez, J.E. Innovative approaches for addressing old challenges in component importance measures. Reliab. Eng. Syst. Saf. 2012, 108, 123-130. [CrossRef]

24. Wolfram Language and System Documentation Center. Available online: http://reference.wolfram.com/ language/ (accessed on 25 May 2018).

25. Leemis, L.M. Reliability: Probabilistic Models and Statistical Methods; Prentice Hall, Inc.: Englewood Clifs, NJ, USA, 1995; ISBN 9780137205172.

26. Nicolai, R.P.; Dekker, R. Optimal Maintenance of Multi-Component Systems: A Review; Erasmus University Rotterdam, Erasmus School of Economics: Rotterdam, The Netherlands, 2006.

27. Wang, H. A survey of maintenance policies of deteriorating systems. Eur. J. Oper. Res. 2002, 139, 469-489. [CrossRef]

28. Wang, H.; Pham, H. Availability and optimal maintenance of series systems subject to imperfect repair and correlated failure and repair. Eur. J. Oper. Res. 2006, 17, 1706-1722. [CrossRef]

(C) 2018 by the authors. Licensee MDPI, Basel, Switzerland. This article is an open access article distributed under the terms and conditions of the Creative Commons Attribution (CC BY) license (http:// creativecommons.org/licenses/by/4.0/). 


\title{
Differences in Risk Perception Factors and Behaviours amongst and within Professionals and Trainees in the Aviation Engineering Domain
}

\author{
Dimitrios Chionis ${ }^{1, *,+}$ and Nektarios Karanikas ${ }^{2,+}$ \\ 1 Department of Psychology, University of Bolton, Bolton BL3 5AB, UK \\ 2 Aviation Academy, Amsterdam University of Applied Sciences, 1097 DZ Amsterdam, The Netherlands; \\ nektkar@gmail.com \\ * Correspondence: dchionis10@yahoo.com; Tel.: +30-698-352-6798 \\ + Both authors contributed equally to writing the paper.
}

Received: 5 April 2018; Accepted: 4 June 2018; Published: 10 June 2018

\begin{abstract}
In the aviation sector, the variability in the appreciation of safety risk perception factors and responses to risk behaviours has not been sufficiently studied for engineers and technicians. Through a questionnaire survey, this study investigated differences amongst professionals and trainees across eleven risk perception factors and five indicative risk behaviour scenarios. The findings indicated significant differences between the two groups in four factors and three scenarios as well as within groups. Moreover, age, years of work and study and educational level were other factors accounting for such differences within each group of professionals and trainees. The results showing these significant differences are aligned with relevant research about pilots and indicate that the appreciation of risk perception factors by aviation engineers and the development of their risk behaviours deserves more attention. Our findings cannot be generalised due to the small sample and its distribution across the demographic variables. However, the results of this study suggest the need tailoring risk communication and training to address the different degrees to which influences of risk perception factors are comprehended, and risk behaviours emerge in aviation engineering trainees and professionals. Further research could focus on the development of a respective uniform framework and tool for the specific workforce group and could administer surveys to more extensive and more representative samples by including open-ended questions and broader social, organisational and systemic factors.
\end{abstract}

Keywords: risk perception factors; risk behaviours; aviation engineering; professionals; trainees

\section{Introduction}

Risk is widely viewed as a product of exposure to hazard, the probability of hazard's manifestation and severity of its impact, and risk acceptance or rejection is linked to the respective anticipated benefits (e.g., [1]). According to Sjöberg et al. [2], risk perception is a subjective assessment of an action plan and encapsulates the probability of adverse outcomes and the awareness of the magnitude of their respective consequences. For example, there might be a case of an emergency aircraft turn-around under extreme heat to transport a patient. The exposure to extreme heat might lead to health implications and performance degradation of the technical team, but the duty to service the aircraft might be undertaken depending on the effects of a flight delay on the condition of the patient. Risk perception has been considered to mediate between locus of control and safety behaviours during operations [3]. Weber $[4,5]$ suggested the psychological risk-return modelling which treats risk as diverse across individuals and a function of content and context: [Preference $(X)=$ Expected Benefit $(X)$ + Perceived Risk $(\mathrm{X})+$ content/context)]. 
Risk perception is related to deviances from formal procedures when the latter are unclear or irrelevant to the context they target [6]. When formal policies fail to deliver the desired message or do not match the real-world conditions, employees will create agendas of their own. However, even under cases of disregarding established rules, risk perception still plays a role in the decision of workers to voluntarily report hazards and safety occurrences (e.g., [7]). The unclarity of rules does not mean that workers do not perceive and report conditions that can threaten safety. Moreover, due to effects of emotional and cognitive factors, risk perception is linked to the subjective "perceived dread" of an accident rather than "objective risk" [8]. According to Dobbie and Brown [9], the mixture of affective reactions and cognitive processes influencing risk perception involves consequential and ethical evaluations of risk associated with four emotional types: retrospective (i.e., regret) and prospective (i.e., fear) consequential emotions, and self-oriented (i.e., guilt) and externally-focused (i.e., anger) ethical emotions. This argument of Dobbie and Brown [9] underlines the importance of emotion types which determine the basis on which one prioritises risks and may lead to diverse risk perceptions.

In general, researchers view risk perception as a complex construct that regulates behaviour and is affected by cognitive processes (e.g., decision making), emotional attitudes (e.g., fear and guilt), and social projections (e.g., social trust) (e.g., [9,10]). Workers within an organisation may present differences in risk perception [11] which may prove inaccurate due to the desensitisation caused by prolonged exposure to high risks [11,12]. Other factors which contribute to diverse risk perceptions are age [13-15], personality type [16], knowledge or experience of past incidents/accidents and individual beliefs [17]. Additional contributing factors are the motivation level $[17,18]$, the degree of subject knowledge [19,20], and the educational level $[13,21]$.

Apart from factors related to individuals, risk perception has also been linked to the overall safety climate within the organisation and the available safety controls (e.g., personal protective equipment and training) [22]. The National Research Council [1] and Morrow [23] associated risk perception with safety culture and climate. The European Commercial Aviation Safety Team (ECAST) defined safety culture as the "set of enduring values and attitudes regarding safety issues, shared by every member of every level of an organisation. Safety culture refers to the extent to which every individual and every group of the organization is: aware of the risks and unknown hazards induced by its activities; continuously behaving so as to preserve and enhance safety; willing and able to adapt itself when facing safety issues; willing to communicate safety issues; and consistently evaluating safety-related behaviour" [24]. Furthermore, safety climate has been partially connected with occupational risk perception [25,26]. As Sjoberg et al. [2] and Pauley et al. [27] articulated, although risk perception acts unanimously no matter the context for an individual, social factors and ideologies may influence it.

Risk perception has been studied across various industry sectors and professional groups such as oil and gas industry where risk perceptions of experts and non-experts judged overall riskiness almost equally [28]. Research on high-risk industry sectors [29,30] suggested nine parameters at the level of individuals (i.e., excluding the effects of wider organisational and social factors) which are linked to risk perception. According to Slovic, Fischhoff and Lichtenstein [29], experts employ a greater ability to discriminate among the hazards. In addition, the higher the perceived risk of technology, the higher the risk-averse behaviour. Additionally, the results of Slovic, Fischhoff and Lichtenstein [29] showed that experts' judgements of risk factors differed systematically from those of non-experts. The parameters suggested by the particular authors as predictors of perceived and desired risk were voluntariness, controllability, dreadfulness, and lack of knowledge. According to Fischhoff, Hayakawa and Fischbech [30], additional risk perception factors were overconfidence, infliction of damages or injuries, responsibility undertaking and environmental conditions.

Another study by Thomson et al. [31], who investigated the risk perceptions of experts and novice helicopter pilots, suggested 15 factors linked to risk perception in the aviation context. Only five out of the 15 ratings of factors by novices were consistently higher than the ones of experts, suggesting that perceived risk declines with experience and that experts were better at identifying extremely low risks. Thomson et al. [31] also noted that apart from the probability estimation that affects risk 
perception, there were additional influential parameters such as the dreadfulness of the consequences. The particular authors found a positive association of experience with a set of five scenarios with risk-seeking and risk-aversive choices whereas age was not linked to the choices made across these scenarios. Thomson et al. [31] also revealed that increased experience guides to risk-seeking behaviour as it was shown through the positive correlation of an "index of risk-taking tendency-IRT" with flight hours for experts and novices. Moreover, Morrow [23], based on the work of Slovic, Fischhoff and Lichtenstein [29] and Fischhoff, Hayakawa and Fischbech [30], proposed a list of the effects of risk characteristics on risk perception. The parameters proposed by the studies mentioned above are summarised in Appendix A (Tables A1 and A2).

Professionals and trainees, which are the groups of interest for this study, view risks differently, and the judgements of the former group are more veridical than the ones of trainees [32]. As Wright, Pearman and Yardley [28] and Hobbs and Williamson [14] claimed, professionals possess a different prospect; when they define risks regarding consequences, they tend to give higher risk ratings. A setback is that professionals are not a homogeneous group, and they frequently disagree. On the other hand, they coincide when evaluating trainees, portraying the potential of events to cause widespread disastrous consequences, assessing risks affecting personal safety, deciding to accept or reject risks, and estimating the degree to which risks could be reduced [28]. In addition, professionals might view risks as less significant than trainees [28] and the former group recognises that feelings influence risk perception [33]. Wright, Pearman and Yardley [28] concluded that professionals conceive that risks are more familiar to those who are responsible for managing them and the particular group believes that risks are relatively controllable.

Contradictory to professionals, trainees view risks as higher compared to professionals $[28,34]$, are influenced more by public opinion when they develop their risk perception [32], tend to have less real-world based judgements and evaluate circumstances in a more qualitative manner $[28,34]$. Older and more recent studies [34,35] showed that trainees obtain limited to complex, higher-order perceptual and cognitive skills required to interact safely with their occupational environment. The possible variations in risk perception amongst professionals and trainees are attributable to a different ecological orientation, dissimilar awareness of the consequences of specific actions, and unlike environmental obligations [9].

Most of risk perception studies in aviation discuss differences amongst flight crews and air traffic control staff. In addition to Thomson et al. [31] who studied differences in risk perceptions between expert and novice helicopter pilots as mentioned earlier, Hunter [7] studied risk perception and tolerance in general aviation pilots. He revealed that differences in personality traits had a lower effect on risk tolerance than differences in cognitive skills had on accurate risk perception. Pauley et al. [27] through a set of 36 written flight scenarios and an adverse weather flight simulation showed that risk is governed more by sensitivity to opportunities for gain than sensitivity to possible losses. The findings of the particular study highlighted that the higher the risk tolerance, the higher the possibilities of risk-taking, hence the former construct could function as a medium to predict potential accident involvement amongst general aviation pilots.

Hunter and Stewart [36] tested the transfer of general aviation pilots' scales to the military aviation context and through four scenario-based online surveys confirmed that all scales demonstrated adequate psychometric reliability and several of the sub-scales were significantly correlated with self-reported accident involvement. Drinkwater and Molesworth [10] sought to determine if risk perception, among other indicators, and personal traits could predict risk decision-making under uncertainty. The results showed that perception of imminent high risks and higher levels of self-confidence were related to risk-mitigating behaviours, while the higher the age, the higher the will of the subjects to engage in risk-seeking behaviours.

Research has shown that maintenance personnel in various fields possess common traits regarding risk perception [37]. Concerning the group of aviation engineers and technicians, the engineering community has expressed the necessity to handle low-frequency hazards with severely negative 
consequences [38]. According to Shyur [39], particular focus should be given to improper maintenance to prevent the initiation of chains of adverse events, and aviation maintenance error has been viewed as a significant and continuous threat to aviation safety [40]. Drury [41] argued that research in aviation maintenance has focused on a human-centred approach to design new systems and mitigate issues in current system designs, based on human reliability. As Johnson and Hackworth [42] communicated, although there are human factors programs since the 80 s, such programs are not mandated universally, and those that exist are not standardised. However, a study on a sample of maintenance personnel coming from more than 50 countries and respective regulatory bodies showed that maintenance human factor programs facilitate safety and control of human error in maintenance [43]. The implication deriving from such approaches is that the human being is a potentially unreliable component of a system, whose underperformance leads to poor risk assessments [43].

Errors of perception are first of a set of six types of psychological errors related to maintenance are, in which one fails to detect an item he/she should have noticed [43]. What is more, risk perception is mainly managed from the aspect of the individual as part of the well-known SHELL model [44]. Literature regarding pro-active risk management methods (e.g., [45,46]) has focused mainly on error management, reporting systems, automation, effective training, and fatigue risk management through various risk assessment tools and techniques (e.g., [47]). Risk perception is related to time pressure and high workload in maintenance ground operations as well as inadequate training and management that in combination lead to misperceptions of actual risks [48,49]. For example, ramp events are increasing due to time pressure, traffic congestion, technology and change management, ineffective training and education of ground personnel, and human factors [49]. According to Sellers [50], technical training institutions cannot still influence human factors issues of maintenance personnel that drive the latter to errors of omission.

The literature cited above shows that although research and studies mention the effects of various factors affecting decision-making and the commission of errors regarding aviation engineers and technicians, it seems that there has been a lack of focus on the variability across risk perception factors and risk behaviour types. Taking into account this gap in the literature, this research was targeted to the specific workforce group, and through a questionnaire survey, we investigated whether professionals and trainees equally appreciate the effects of various risk perception factors mentioned in literature and whether they similarly choose to reject/accept risk in different contexts. Moreover, potential differences were evaluated against age, educational level and years of experience/study within each of the workforce groups.

\section{Materials and Methods}

An online, voluntary and anonymous questionnaire was used to collect data. The survey instrument was administered via e-mail to aviation engineers/technicians who were professionals or trainees. The participants working as maintenance personnel and engineers and being fully licenced according to the respective local or regional regulations were categorised as professionals. Our target group of professionals regarded personnel working either in line maintenance or for an Approved Maintenance Organization. This group of employees has completed on-job-training (OJT) and can perform their tasks without supervision. Trainees were the subjects who had not worked for the industry, and they were undergoing OJT or studying for at least one year at an aviation engineering institution (e.g., college, academy, or approved training organisation). Thus, professionals attending development courses and undergoing conversion or refresh training were not included in the group of trainees. It is also clarified that, due to the exploratory nature of the study, which to the best of the knowledge of the authors was the first of its kind, we followed the strategy of Hackworth et al. [43] and did not aim at a specific region. Therefore, we did not administer the questionnaire to populations under specific regulatory oversight.

The survey tool was developed in two phases. First, an initial questionnaire was composed and aimed at eleven risk perception factors listed below: 
1. centrality of the incident for safety;

2. controllability the user has over the situation;

3. importance of team coordination;

4. familiarity with the incident;

5. effects of stress;

6. effects of fatigue;

7. level of confidence in own abilities;

8. effects of the night shift;

9. effects of technological complexity;

10. consequences on humans (i.e., injuries); and

11. material consequences (i.e., damages).

These factors were based on the literature mentioned in Section 1 above $[21,29,31]$. The mentioned literature was used due to its specific focus on risk perception factors in aviation employees. Additionally, the selection and formulation of the particular factors along with the respective items of the questionnaire were made in consultation with twelve subject matter experts (SMEs). This approach is in line with the suggestions of Bolger and Wright [51] and was employed to ensure relativeness of the survey topics with the context of the target population. The SMEs had on average more than 30 years of experience, including managerial and training duties.

The first version of the questionnaire was sent to SMEs to ensure relevance to the language and terms used in the industry and achieve its face validity. According to the comments received by the experts, some statements were adjusted to avoid biases towards answers or because the terminology used was not suitable for the target research population. The final version of the questionnaire included two main parts and an introductory text explaining the aim of the study, the target group of the survey and the protection of the participants' identity. The main parts referred to scenarios used in training briefings and every-day practice as a means to present risk domains and response modes familiar to the subjects, as proposed by Rowe and Wright [32] and increase veracity of the answers. The first part of the instrument regarded demographic data (i.e., age, years of experience/study, educational level, and job status), and included a description of possible incidents each of which the participants would rate across the eleven risk characteristics/sub-categories mentioned above by using a 7-point Likert scale with labelled points. To avoid respondent fatigue [52,53], eight simply formulated incidents were used as follows:

1. Temporary transmission system failures during a leak check.

2. Temporary blinking instruments during a pre-flight inspection.

3. Slight oscillation of engine power right after starting the engines.

4. Recoverable braking system failures while parking the aircraft.

5. Short distraction while working on a shaft under the aircraft.

6. Minor hydraulic leakage during turnaround under high time pressure.

7. Temporary high engine temperature indications during engine tests.

8. Minor fuel leakage from the bowser during a delayed turnaround.

The selection of 5-point and 7-point Likert scales is an on-going debate. Studies comparing 5-point and 7-point scales showed that the latter superseded the former in accuracy and respondent feedback $[54,55]$. Specifically, 7 -point scales seemed more sensitive to capturing veridical evaluations of participants, better suited for electronically collected data, less vulnerable to interpolation without jeopardising accuracy, and better in obtaining higher variation in responses. On the other hand, there are claims that 5-point scales are more effective than 7-point scales because they yield better data quality on larger samples [56]. We preferred a 7-point scale over a 5-point one because we could not predict the sample size and we aimed at a wider distribution of answers [57]. In addition, we minimized the arbitrary interpretation of the scale points by labelling them: the lowest scale point 
"1" corresponded to the choice "Not important/Not at all controllable/Not at all likely/Not at all Familiar" and the highest scale point "7" corresponded to the answer "Extremely important/Extremely controllable/Extremely likely/Extremely Familiar", as applicable per question.

Through the design explained above, the appreciation of the particular risk perception factors could be assessed [58] and differences within and between groups could be estimated [29]. Table 1 presents the risk factors and the corresponding questions addressed to the subjects for each of the incidents.

Table 1. Questions Corresponding to the Eleven Risk Perception Factors.

\begin{tabular}{|c|c|c|}
\hline Risk Factors & Shortcode & Question \\
\hline Centrality of the incident for safety & Centrality & To what extent is the incident essential for flight safety? \\
\hline $\begin{array}{l}\text { Controllability the user has over } \\
\text { the situation }\end{array}$ & Controllability & $\begin{array}{l}\text { How much control does an engineer/technician have } \\
\text { over such an incident? }\end{array}$ \\
\hline Importance of team coordination & Team coordination & $\begin{array}{l}\text { To what extent is team coordination likely to affect the } \\
\text { confrontation with such an incident? }\end{array}$ \\
\hline Familiarity with the incident & Familiarity & $\begin{array}{l}\text { To what extent are engineers familiar with this kind } \\
\text { of incident? }\end{array}$ \\
\hline Effect of stress & Stress & $\begin{array}{l}\text { To what extent is stress likely to affect the } \\
\text { engineer/technician in dealing with such an incident? }\end{array}$ \\
\hline Effects of fatigue & Fatigue & $\begin{array}{l}\text { To what extent is fatigue likely to affect the } \\
\text { engineer/technician in dealing with such an incident? }\end{array}$ \\
\hline $\begin{array}{l}\text { Level of confidence in } \\
\text { own abilities }\end{array}$ & Self-confidence & $\begin{array}{l}\text { To what extent is the level of self-confidence likely to } \\
\text { affect the decision about the incident in question? }\end{array}$ \\
\hline Effects of night shift & Night shift & $\begin{array}{l}\text { To what extent is working at night likely to affect } \\
\text { decision making about such an incident? }\end{array}$ \\
\hline Effects of technological complexity & Technology & $\begin{array}{l}\text { To what extent is the complexity of technology used in } \\
\text { aircraft essential for dealing with such an incident? }\end{array}$ \\
\hline Consequences on humans & Injuries & $\begin{array}{l}\text { How likely is that such an incident would } \\
\text { cause injuries? }\end{array}$ \\
\hline Material consequences & Damages & $\begin{array}{l}\text { How likely is that such an incident would cause } \\
\text { equipment/property damage? }\end{array}$ \\
\hline
\end{tabular}

In the second part of the questionnaire, each participant was prompted to choose a probable course of action that he/she would follow regarding five scenarios. The scenarios were based on the concept of Line Oriented Flight Training (LOFT) [59] and on the premise that a "low-risk aversion or a low perception of risk can drive risky behavior" [60]. The scenario-based training method is common in the aviation context [61], and LOFT constitutes a type of scenario-based training method [62]. Scenarios are connected to risk perception because they reflect the estimation of the quality of risk and offer a chance for its manipulation [63]. It is clarified that in our study we did not aim at connecting risk perception factors with behaviours but to examine them separately.

An adapted version of the part of the questionnaire that included the five scenarios is shown in Appendix B. Each of these scenarios reflected social constructs that may interact with risk perception since knowledge may be arbitrary and a matter of social construction and risk perception reflects various thoughts, beliefs and constructs $[64,65]$. Scenario 1 regarded the construct of trust to the capabilities and expertise of others; trust is a key aspect of amplification and attenuation efforts [23]. Scenario 2 was linked to the construct of self-sacrifice and ignorance of self-interest based on the premise that individuals tend to ignore self-interest and they put themselves at risk even when their commitments are at stake [66]; commitment is highly influential on decision-making [67]. Scenario 3 examined the preference to compliance with procedures over the breach of the latter when the stakes are high [6,27]. Scenario 4 regarded the stance of responsibility undertaking when one has committed a mistake/error [11,68]. Scenario 5 targeted to the prioritisation of safety over other task objectives [69].

A pilot test was conducted to test the reliability of the survey instrument. Due to limited access to subjects, the pilot tool was administered only to eight professionals and six trainees. Taking into 
account that the reliability test for an eleven variables survey requires 110 responses (e.g., [70-72]), we presumed that the fourteen participants by the eight incidents the risk perception factors were assessed (i.e., $14 \times 8=112$ subjects) would satisfy adequately the required condition adequately. The pilot test resulted in a Cronbach's alpha a $=0.913$ across all risk factors and the post hoc Cronbach's alpha for the whole sample was calculated to $\mathrm{a}=0.818$. Taking into account the literature suggesting that the specific reliability scores are satisfactory $[73,74]$ and that the reliability scores for the studies of Hunter $[7,75]$, whose work we adapted, were 0.937 and 0.810 correspondingly, we believe that the reliability of the particular part of the questionnaire was adequate.

Regarding the scenarios, a reliability test was not applicable because they represented different cases that were not linked to a single construct. In addition, as part of the pilot study, we performed correlations per participant for all eleven questions across the eight incidents. We found significant correlations only partially between the incidents, and the correlated pairs of incidents differed per participant. These correlations indicated that the employment in the study of various incidents which represented different contexts led to more representative measurements of the risk perception factors. The average time spent by the pilot study participants to complete the survey was $20 \mathrm{~min}$.

To collect data, we used a snowball sampling strategy because there was no definitive list available to form a sampling frame. The specific research was executed as part of an MSc course, and at the time of the study there was no contact list immediately available at any accessible directory of the university. Therefore, taking also into account time limitations and that this was a first exploratory study on the particular topic, no specific organisation or region were targeted. Although possible samples from the same organisation could have increased the likelihood of correlated answers in both parts of the questionnaire, taking into account the snowball sampling strategy and the diversity of contacts the invitation emails were sent, we assume that the observations were independent. Considering that the sample size in the similar study of Thomson et al. [31] was $N=64$, the minimum accepted sample size for the current study was set to $N=50$.

Based on an expected response rate of 30\%, 167 emails were sent out with the web link directing to the online questionnaire. In total 70 questionnaires were returned, but the authors cannot estimate the actual response rate because they had no information about the number of respondents who accessed the respective link and/or read the invitation emails. All questionnaires returned were complete and included in the data analysis. Table 2 reports the sample size along with the grouping of demographic data which were used as independent variables. The particular grouping was decided to achieve almost equal sizes where possible and allow the execution of statistics without validating their assumptions related to the distribution of the sample. The age and education level of trainees fell only in one category, and the spread of trainees' age data was not sufficient to perform their clustering into groups; hence, no statistics were performed within trainees regarding the particular variables.

The data were processed with the SPSS 22 software [76]. To gain an overall picture, the medians per risk perception factor were calculated for each group of participants across the eight incidents, and Friedman tests were used to evaluate significant differences amongst the eleven risk perception factors. Then, we calculated per participant the medians of each risk perception factor across the eight incidents; these scores comprised the dependent variables for the statistical tests. Mann-Whitney tests were conducted to evaluate significant differences in the medians between professionals and trainees and between the age, years of experience and educational level variables for professionals. Kruskal-Wallis tests were performed to evaluate significant differences in risk perception factors among completed years of studies of trainees. To examine any differences between specific pairs of risk perception factors within each of the professionals' and trainees' groups, we performed pair comparisons with the Wilcoxon test. 
Table 2. Research Sample.

\begin{tabular}{|c|c|c|c|}
\hline $\begin{array}{l}\text { Group of Independent } \\
\text { Variables }\end{array}$ & Values & Sample Size $(N)$ & Percentage $(\%)$ \\
\hline \multirow{2}{*}{ Job status } & Professional & 35 & 50.0 \\
\hline & Trainee & 35 & 50.0 \\
\hline \multirow{2}{*}{ Age professionals } & $<36$ & 18 & 51.4 \\
\hline & $\geq 36$ & 17 & 48.6 \\
\hline Age trainees & $<36$ & 35 & 100 \\
\hline \multirow{2}{*}{$\begin{array}{l}\text { Working experience of } \\
\text { professionals (years) }\end{array}$} & $\leq 10$ & 17 & 48.6 \\
\hline & $\geq 11$ & 18 & 51.4 \\
\hline \multirow{3}{*}{$\begin{array}{c}\text { Completes years of studies of } \\
\text { trainees (years) }\end{array}$} & 1 & 8 & 22.9 \\
\hline & $2-4$ & 23 & 65.7 \\
\hline & $4-5$ & 4 & 11.4 \\
\hline \multirow{2}{*}{$\begin{array}{l}\text { Educational level } \\
\text { (Professionals) }\end{array}$} & $\leq$ Graduate & 13 & 37.1 \\
\hline & $\geq$ Post-Graduate & 22 & 62.9 \\
\hline Educational level (Trainees) & $\leq$ Graduate & 35 & 100 \\
\hline
\end{tabular}

Regarding the second part of the questionnaire, Chi-square tests were conducted to evaluate significant differences between professionals and trainees as well as regarding differences across the independent variables per group. When the assumptions of Chi-square tests data were not met due to the distribution of the sample, we consulted the results of the Fisher's exact tests $[77,78]$. The execution of non-parametric statistics was chosen due to the collection of ordinal and nominal data $[79,80]$. The level of statistical significance was set at $p<0.05$ for all tests.

\section{Results}

Overall, Friedman tests showed that the eleven risk perception factors were rated differently within both groups of professionals $\left(N=35, \chi^{2}=47.750, \mathrm{DF}=10, p=0.000\right)$ and trainees $(N=35$, $\chi^{2}=157.251, \mathrm{DF}=10, p=0.000$ ). Table 3 depicts the results regarding the differences between professionals and trainees. Professionals were significantly more appreciative than trainees in the risk factors of Familiarity, Fatigue, Self-confidence, and Injuries. In addition, professionals were significantly more risk-averse than trainees in three out of the five scenarios where professionals appeared more ignorant of self-interest, keener on adhering to procedures and more eager to undertake responsibilities.

Tables A3 and A4 in Appendix C depict the results for the rest of the demographic variables. Regarding the professionals' age groups, the fatigue factor medians were significantly higher for group " $\geq 36$ ", and no significant differences emerged from the scenarios. Concerning the years of professional experience, the group " $\geq 11$ years" was noted as the most appreciative of the controllability factor and the most risk-averse for Scenario 4 (i.e., responsibility undertaking). Concerning the academic level, no significant differences were revealed in the eleven risk factors, and the " $\leq$ Graduate" group was significantly more risk-averse for Scenario 1 (i.e., trust). When considering the differences among the groups of years of studies for trainees, it was indicated that the fewer the years, the higher the rating of the Night Shift factor. No significant differences across the years of study groups were noted for the five scenarios.

Table A5 in Appendix C depicts the differences of risk perception factors within the professionals' group. The results showed that the Technology factor was appreciated less than Centrality, Controllability, Team coordination and Familiarity. In addition, the Injuries factor scored lower than the rest of the factors apart from Technology and Damages. In Table A6 (Appendix C), where the 
differences in risk perception factors within the Trainees group are presented, the results revealed several differences in the rating across the factors, without though showing any consistent pattern or concentration of the significant differences around specific risk perception factors.

Table 3. Differences between Professionals and Trainees.

\begin{tabular}{|c|c|c|c|}
\hline \multirow[t]{2}{*}{ Risk Perception Factors } & \multicolumn{2}{|c|}{$\begin{array}{c}\text { Medians } \\
\text { (across All Participants and Incidents) }\end{array}$} & \multirow{2}{*}{$\begin{array}{l}\text { Mann-Whitney Test Results } \\
\text { (significant results in bold) }\end{array}$} \\
\hline & Professionals & Trainees & \\
\hline Centrality & 5 & 5.5 & $p=0.262$ \\
\hline Controllability & 5.5 & 6 & $p=0.156$ \\
\hline Team coordination & 5 & 5 & $p=0.624$ \\
\hline Familiarity & 5.5 & 3.5 & $p=0.000$ \\
\hline Stress & 5 & 5 & $p=0.342$ \\
\hline Fatigue & 5 & 3 & $p=0.000$ \\
\hline Self-confidence & 5 & 3.5 & $p=0.000$ \\
\hline Night Shift & 5.5 & 5 & $p=0.578$ \\
\hline Technology & 3.5 & 3 & $p=0.286$ \\
\hline Injuries & 3.5 & 2 & $p=0.027$ \\
\hline Damages & 4.5 & 5 & $p=0.530$ \\
\hline \multirow{2}{*}{ Scenarios } & \multicolumn{2}{|c|}{ Percentage for Choice B-Risk Aversion } & Chi-Square Test Results \\
\hline & Professionals & Trainees & (significant results in bold) \\
\hline $\begin{array}{c}\text { Scenario } 1 \\
\text { (trust) }\end{array}$ & $51.4 \%$ & $40 \%$ & $p=0.337$ \\
\hline $\begin{array}{c}\text { Scenario } 2 \\
\text { (ignorance of self-interest) }\end{array}$ & $54.3 \%$ & $28.6 \%$ & $p=0.029$ \\
\hline $\begin{array}{c}\text { Scenario } 3 \\
\text { (compliance with procedures) }\end{array}$ & $80 \%$ & $37.1 \%$ & $p=0.000$ \\
\hline $\begin{array}{c}\text { Scenario } 4 \\
\text { (responsibility undertaking) }\end{array}$ & $88.6 \%$ & $42.9 \%$ & $p=0.000$ \\
\hline $\begin{array}{c}\text { Scenario } 5 \\
\text { (prioritisation of safety) }\end{array}$ & $62.9 \%$ & $52.9 \%$ & $p=0.094$ \\
\hline
\end{tabular}

\section{Discussion}

In general, the findings of this research suggested that there are significant differences among professionals and trainees, but these were not evident across all risk perception factors and behaviours included in this study. Notably, the minimum scores assigned by professionals to all risk factors were at the median of the measurement scale (3.5), whereas trainees rated three out of the eleven factors (i.e., Fatigue, Technology and Injuries), with values lower than the scale's median. The overall results as well as the statistically significant differences found in four out of the eleven risk factors seem contrary to the results of Thomson et al. [31] and Hunter [7] who, based on a probability estimation of risks, found that experts' risk perceptions in overall were lower than those of novices. This contrast can be explained from the fact that in our study we did not include wider environmental, organisational and social factors that can directly affect risk perception or moderate the perception of the parameters studied in the current research. However, based on our findings above, it can be claimed that a mere measurement of risk perceptions might mask important information that a more in-depth examination of different influential parameters can reveal. Thus, although the rating of some of the risk factors employed in this research might be statistically higher in professionals than trainees, the opposite can happen for other factors, leading to counteracting and combined effects that shape final risk perception levels.

Professionals rated the risk of reoccurrences (i.e., Familiarity factor) and the Fatigue factor higher than trainees. These differences might be attributed to the minimal exposure of the latter group to real-world conditions during their training. Moreover, the lack of working experience of trainees might also be a valid explanation about the higher scores professionals attributed to the effects of self-confidence and the probability of adverse implications on people. According to Von der Heyde [17], 
trainees are in the phase of developing their knowledge and experience while they might underestimate some of the factors related to incidents and accidents.

Regarding age, the higher perception of older professionals regarding the fatigue risk factor might be attributed to the effect of prolonged personal fatigue due to a decrease of mental and physical capacity over time [81,82]. Concerning the years of job experience, the fact that the group of professional participants with more working experience assigned higher scores to the controllability factor confirms that the degree of subject knowledge $[19,20]$ and knowledge or experience of past incidents/accidents [17] might lead to such differences. This finding seems contrary to the literature suggesting that risk perception might be falsified due to desensitisation resulting from prolonged exposure to hazards in the working environment $[11,12]$. Thus, although higher experience, built-in corporate knowledge and in-depth knowledge about existing controls may predispose professionals to assume control, invulnerability and high compensatory skills, the particular group might have interfaced with reoccurring safety events that provided learning experiences when hazards were not managed timely or effectively.

The results regarding Scenario 4 (i.e., responsibility undertaking) showed that more experienced professionals seemed more risk-averse, which can be attributed to their increased exposure to teamwork that develops values that are oriented to the benefit of others, creates a sense of responsibility, and fosters an ethos of mutual support [83]. In addition, it is expected that professionals with more working experience have undertaken supervisory and managerial roles that are typically followed by a sense of accountability $[84,85]$. Concerning the educational level, professionals holding a bachelor's degree or lower qualification were more risk averse at Scenario 1 (i.e., trust on others). Trust is earned through exhibitions of competence and character [86]. Based on that premise, respondents holding a post-graduate degree may have developed a questioning and demanding attitude, this possibly leading to a decreased trust in others' judgements. However, individuals with higher education attainment show higher levels of generalised trust due to residual effects of personality traits and non-cognitive skills [87]. Therefore, our interpretation of the particular finding is that professionals with higher education qualifications might not trust everyone in a working environment that dictates high responsibilities and accountabilities but they might confide in colleagues who exhibit similar competencies.

Regarding the years of study, interestingly the group with " 1 year of study" appeared as the most appreciative of the effects of the night shift, whereas the participants belonging in the group " $4-5$ years of study" were the least perceptive of the same factor. Although researchers are not knowledgeable about the training and educational programmes followed by the participants, the specific difference might be attributed to the point that, typically, fatigue is discussed as a risk factor early in the studies when general physiological and psychological aspects of human performance are addressed. The lack of working experience during the studies might contribute over time to a lower appreciation of fatigue as an adverse factor.

The results regarding the differences across all risk perception factors within each group of professionals and trainees were also stimulating. Concerning the professionals, the Injuries factor was underrated against the rest of the factors. Our interpretation of this attitude is two-fold: (a) the heuristic of "small numbers" [88]; and (b) safety illiteracy. Specifically, an expert motivated from a belief of "small numbers" built with experience may fall victim to complacency regarding the actual possibility that his/her decisions will result in injuries. For example, according to To70's Civil Aviation Safety Review [89], the year 2017 was recorded as the safest one since 2010. However, as it is highlighted in the particular review "With so few fatal accidents to examine, it is worth remembering that there were also several quite serious non-fatal accidents in 2017". Nevertheless, we are not in a position to argue if our sample has attributed injuries of any level with the probability of fatality since this was out of the scope of this study. Regarding safety literacy, the abundance and plethora of safety information and safety policies may be challenging to comprehend even for a professional 
recognised as an "expert" [90]. Hence, safety illiteracy can be attributed to the ineffective conveyance of information related to communication and management of risks within an organisation.

In addition, in the professionals' group, the technological complexity was underperceived in comparison with centrality, controllability, team coordination, and familiarity. In addition to the explanations above about the group in the higher age cluster, a probable explanation of this finding could be the fact that automation has been found partially improving team coordination and performance [91-93], thus technology possibly seen as a positive element and less as a risk factor. Moreover, the indication that professionals are more perceptive to the influence of "familiarity" potentially indicates that they possess a level of awareness in the context of out-of-the-loop unfamiliarity problem [94] that might render them less capable of handling risks when automation fails. This indication could also explain the increased perception of professionals regarding centrality and controllability.

Concerning the trainees, there was a high inconsistency among the risk perception factors. However, taking into account the main objective of this research to compare appreciations of factors between professionals and trainees, we focused on the factors of injuries and technological complexity discussed above for the group of professionals. The "injuries" factor was consistently underscored in comparison with eight out of the eleven factors, while technological complexity was underrated compared to five out of the eleven factors. Our interpretation for the "injuries" factor relies on the common bias among young adults of invincibility which may lead to the perception that the consequences of risky behaviour will not occur to them [95], and the "bubble of overconfidence" effect [96]. As Sanchez and Dunning [96] indicated more precisely, this situation could be described as the Dunning-Kruger effect where individuals lack the insight to recognise their shortcomings. Regarding technological complexity, we believe that familiarity and trust of new generations on technology could be a plausible explanation of the corresponding finding. Younger engineers have been exposed to modern technology as early as during their elementary education in some cases. As such, younger engineers rely more on modern technology and possess a positive attitude towards it $[97,98]$.

Regarding the scenarios, professionals chose the risk-averse option more frequently than trainees across all cases, three of which were found significantly different. When examining the frequencies per group, it seems that the views of professionals were almost evenly distributed regarding Scenario 1 (i.e., trust on others) and Scenario 2 (i.e., ignorance of self-interest), and the same group was considerably risk adverse for Scenario 3 (i.e., compliance with procedures) and Scenario 4 (i.e., responsibility undertaking). On the other hand, the choices of trainees were almost evenly distributed only in Scenario 5 (i.e., prioritisation of safety), whereas the risk-averse options regarding the rest of the scenarios were selected by less than half of the participants of the specific group. The differences within groups across the five scenarios included in this study confirm Wright, Pearman and Yardley [28] and Rowe and Wright [32] who found that experts and non-expert groups are not homogeneous. Although the behaviours examined through the five scenarios are not inclusive of the whole list of risky behaviours, we believe that the particular findings are interesting and worth to consider.

The differences between professionals and trainees regarding Scenarios 2-4 indicate thoughtprovoking implications. These differences can be explained from the fact that professionals have a broader horizon during their decision-making, accounting not only for the probable short-term harm but also for the long-term [99]. Professionals due to possibly additional managerial experience are also able to plan at a strategic level and demonstrate a proactive behaviour [99]. Furthermore, professionals might have acquired the capacity to handle safety priority conflicts and discrepancies between organisational and personals goals [100]. In addition, working experience might lead to the development of a positive attitude towards compliance due to the involvement in audits, safety events attributed to the breaching of rules and much more valued experience. It is typical for trainees and students to attribute successes or failures to luck or task difficulty (e.g., [101]) whereas professionals 
comprehend more the concept of risk management and appear more risk averse [102]. Additionally, professionals may conform with safety rules or even internalise them over years of employment [103], leading to a gradual replacement of their self-interest by a priority to the interests of their teams and organisations [104,105].

\section{Conclusions}

This research examined differences in risk perception factors and behaviours among professionals and trainees in the aviation maintenance/engineering sector. Whereas most risk studies in aviation focus on differences within flight crews and air traffic control staff, this paper offers insights into an under-researched workforce group within engineering. Overall, the results suggested that professionals and trainees presented statistically significant differences in four out of the eleven risk perception factors and three out of the five risk behaviours examined by the authors. The findings were mostly in congruence with past research regarding other groups of end-users in the aviation sector but with a few exceptions. Although older studies claimed an overall difference in risk perceptions between experts and novices, in our research such differences were found only in particular risk perception factors.

Although this research was exploratory as a means to examine potential differences and did not aim at collecting explanations of the results, our interpretation of the findings converged on the effects of the accumulation of working experience over time and the effectiveness of initial, recurrent and professional training, especially regarding adaptability, flexibility and literacy. Risk perception factors might be influenced by the lack of progressive adaptability to new working requirements which are naturally dynamic. This potential lack indicates the need to adjust training to enable aviation engineers to develop and maintain appreciations of risk perception factors according to the context of their duties. To realise individual initiatives, we suggest establishing and enhancing the effectiveness of risk related training by customising it through context-tailored coaching (e.g., [106]) and utilisation of augmented/virtual reality technologies [107]. Within an effective Safety Management System, competency training through methods such as Hands-On and Virtual Reality simulations can be tailored to the nature of tasks and associated hazards [108,109].

In addition, training could be provided to professionals and trainees separately regarding risk perception factors and could be offered commonly for risk behaviours. Engineering and maintenance teams are often composed of trainees and professionals with diverse working experience. Hence, a standard approach to hazardous conditions could minimise possible conflicts amongst team members and would boost effective risk communication. Concerning the professionals, our results indicated that training could focus on enhancing cognitive adaptability to hazardous situations associated with new technologies, night shift effects, influences of stress, team coordination challenges, and building of self-management skills. Regarding trainees, education and training could emphasise on increasing familiarity with more or less probable hazards and risks, understanding and experience the effects of fatigue, and managing self-confidence.

Moreover, training could be enriched with scenarios similar to Scenario 2 (i.e., ignorance of self-interest), Scenario 3 (i.e., preference of compliance with procedures over the breach of the latter when the stakes are high) and Scenario 4 (i.e., the stance of responsibility undertaking when one has committed a mistake/error) tested in this research and found significantly different between professionals and trainees. Under the proposed approach, on the one hand, aviation engineering professionals and trainees would become gradually able to appreciate the effects of risk perception factors in correspondence with their status. On the other hand, the effectiveness of risk perception training could be assessed through real-world and context-specific scenarios (e.g., case studies, serious games combining frequently experienced conditions with improbable but yet possible adverse situations).

Although this research employed a valid context-tailored tool, the small sample size employed does not allow the generalisation of the findings. Therefore, the results are indicative and limited to the 
survey participants. In addition, the interpretation of the results was performed against the literature reviewed and not according to the perspectives of the participants. However, to the knowledge of the authors, this study was the first to explore possible differences in the appreciation of risk perception factors and risk behaviours among professionals and trainees in the aviation maintenance/engineering sector. In addition, determining actual risk and indicating its gap from perceptual risk was not feasible in the context of this study because we did not measure risk perception. Such an approach would, for example, necessitate an observational study with standard participants and a validated risk perception measurement instrument, meaning a completely different research design and scope. We envisage that this study could function as a trigger to develop a uniform framework and tool for assessing risk perceptions and behaviours along with associated factors for the specific workforce group by considering the suggestions stated above.

For future research, similar studies could be executed with additional groupings of the aviation maintenance population (e.g., airframe vs. electrical/avionics specialties) and probably include additional social, organisational and systemic factors (e.g., national and organisational culture, leadership, oversight, management structure and type, and task complexity). Another possibility worth examining is the level of risk tolerance level of on-the-job trainees due to the security feeling that can stem from their "protection" when working with experienced professionals. In addition, research is suggested to be conducted with larger samples by including open-ended questions to allow participants to state reasons for their choices. Moreover, the assessment of variations in the appreciation of particular risk factors could be considered as supplementary to the evaluations of overall risk perceptions performed within and outside the aviation sector with the scope to examine the necessity for adjustments to existing risk training and communication programmes.

Author Contributions: Conceptualization, D.C.; Methodology, D.C.; Formal Analysis, D.C. and N.K.; Investigation, D.C.; Writing-Original Draft Preparation, D.C. and N.K.; Writing-Review and Editing, D.C. and N.K.; Visualization, D.C. and N.K.

Acknowledgments: This paper is based on an MSc Thesis for the MSc Human Factors in Aviation conducted at Coventry University under the supervision of Rebecca Grant.

Conflicts of Interest: The authors declare no conflicts of interest. 


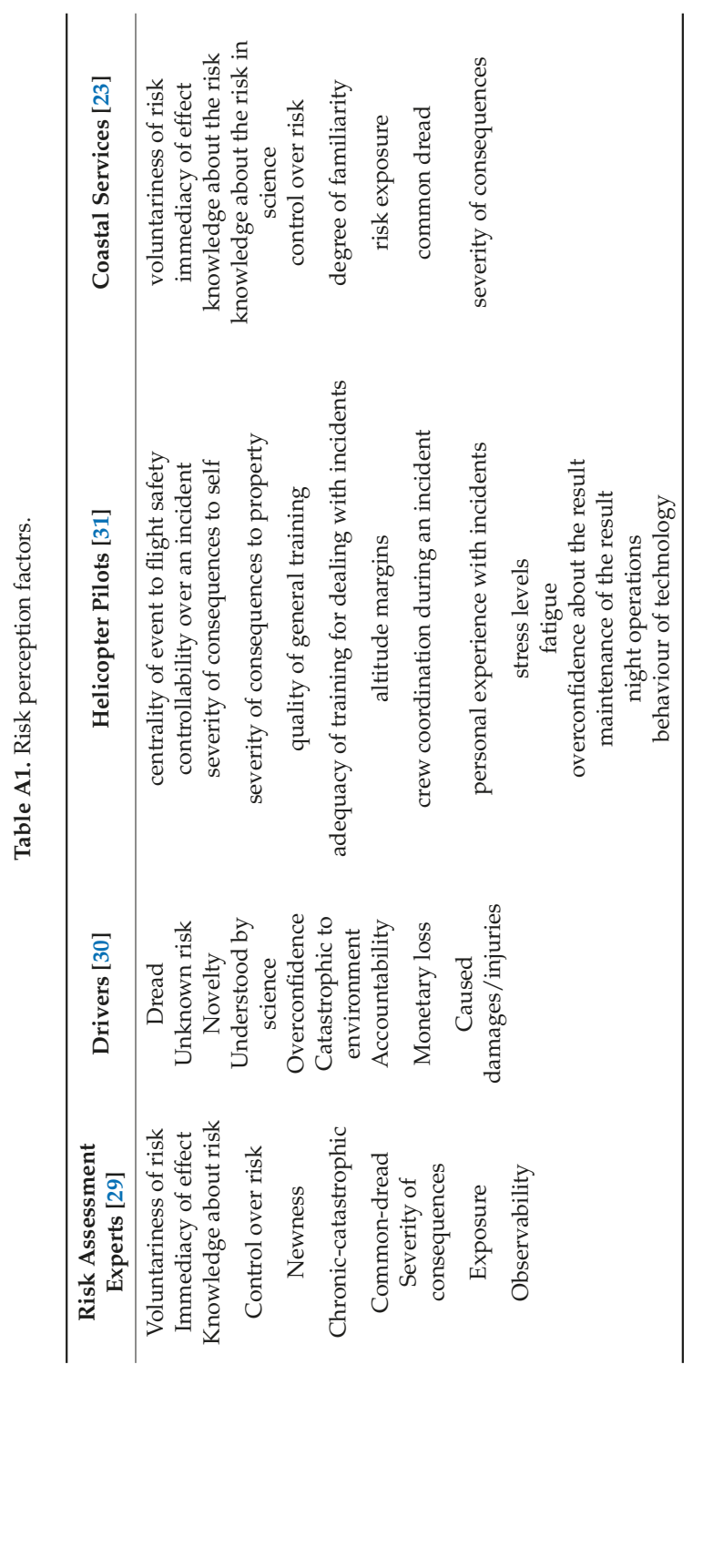


Aerospace 2018, 5, 62

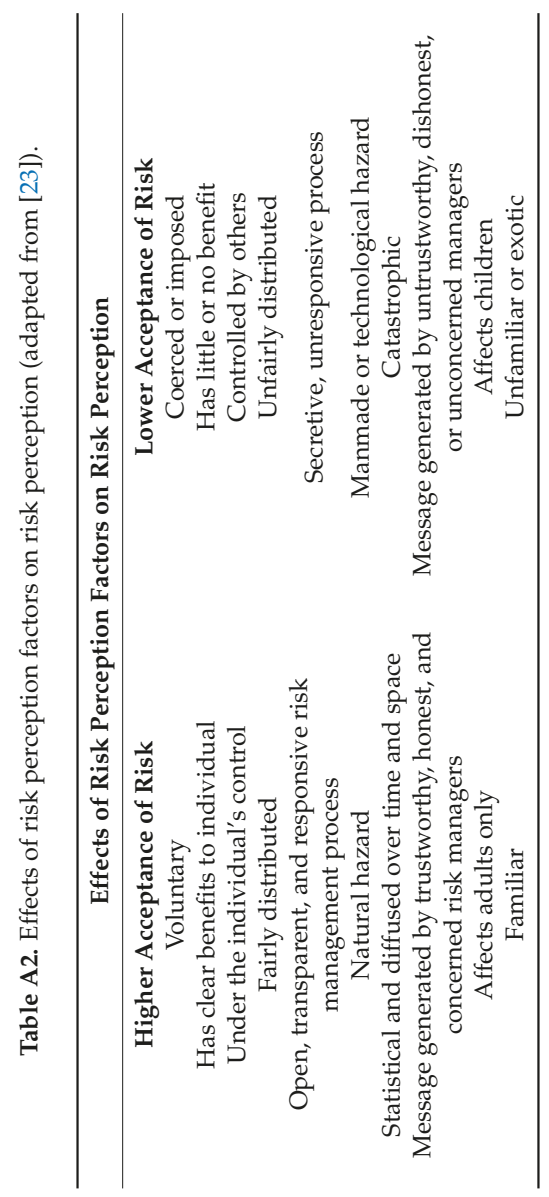




\section{Appendix B}

\section{Scenarios (Second Part of Questionnaire)}

Please consider each of the following scenarios and select the action alternative ( $a$ or $b$ ) that best describes your probable reaction in such circumstances.

\section{$\underline{\text { Scenario } 1}$}

You are handling a 2000lt mini-bowser carrying aviation fuel during a turnaround. The pump was essentially designed for water but the engineering department approved its installation. What would be your probable action?

a. I use it to finish my tasks ASAP, and I will inspect the pump later for any issues. I trust the judgment of the engineering department.

b. I ask for another bowser, even if the turnaround will be delayed. The engineering department could have underestimated the dangers in such situation.

\section{$\underline{\text { Scenario } 2}$}

The condition of runway/taxiway markings and lights, lack of vertical signage and frequent failures of the ground radar affect the ground operation at the airport. You are charged to replace some of the lights during the night because further flights are expected to operate. What would be your probable action?

a. I am heading to replace the lights even if I do not have the whole set of personal protective equipment foreseen. The runway is dangerous for landing.

b. I postpone the task for the next morning and inform the control tower. I do not have a flashlight, and it is dangerous for me.

\section{$\underline{\text { Scenario } 3}$}

You are checking hydraulics during a Cessna-172's turnaround which has to depart ASAP to transfer a sick child in critical condition but stable. You notice some suction screens plugged from degradation deposits. What would be your probable action?

a. I replace the suction screens and run the minimum checks. The patient is in critical condition, and there is no warranty that will remain stable.

b. I replace the suction screens, replace the fluid, check for supplementary contamination sources, and test the engine. The patient is stable and delaying the flight will not have detrimental effects.

\section{$\underline{\text { Scenario } 4}$}

Just before you deliver an aircraft after its post-flight maintenance, you notice that you are missing a tool. What would be your first probable action?

a. I won't tell anyone. I will try to find it myself.

b. I will immediately ask for help from a colleague.

\section{Scenario 5}

You have just completed a two days' maintenance with limited resources, limited help and you miss home and your new-born baby. You need to drive $35 \mathrm{Km}$ to return home, but meteorological conditions are already heavily adverse. There must be little traffic, and the road is quite safe. What would be your probable action?

a. I would drive carefully and get home. The family is above all.

b. I would get some sleep at work and wait for better weather conditions 


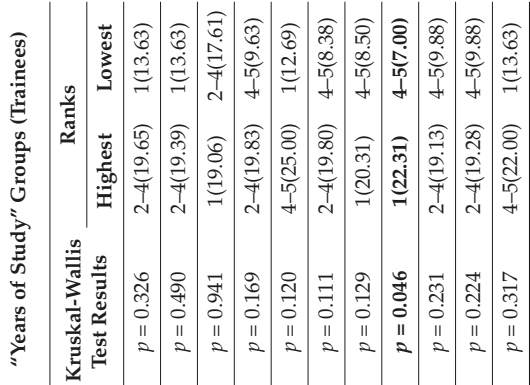

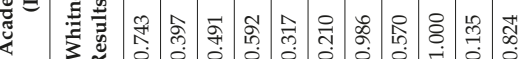

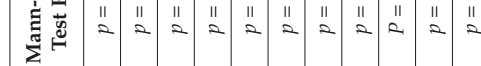

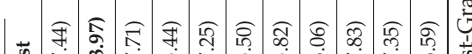

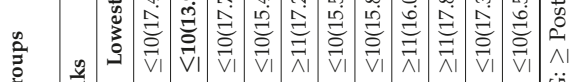

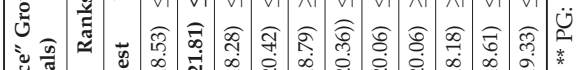

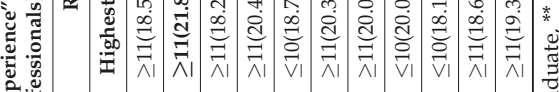

\section{畜嵒}

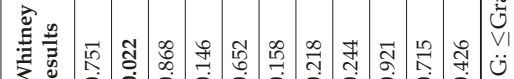

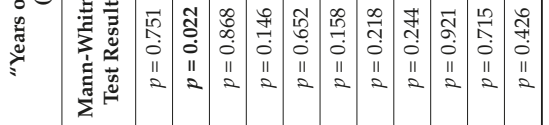

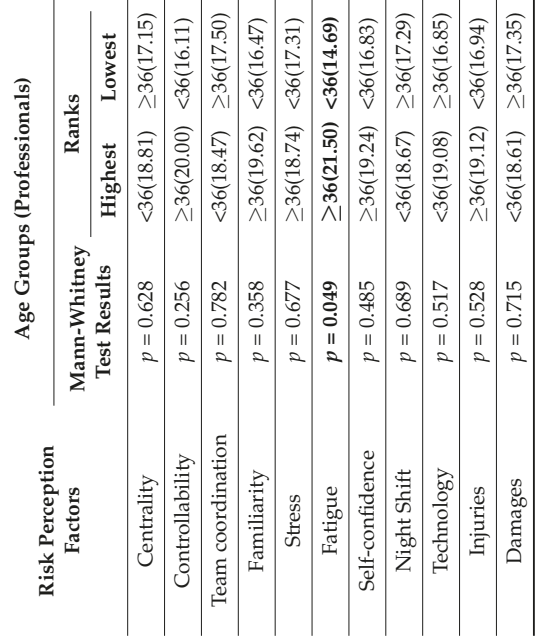




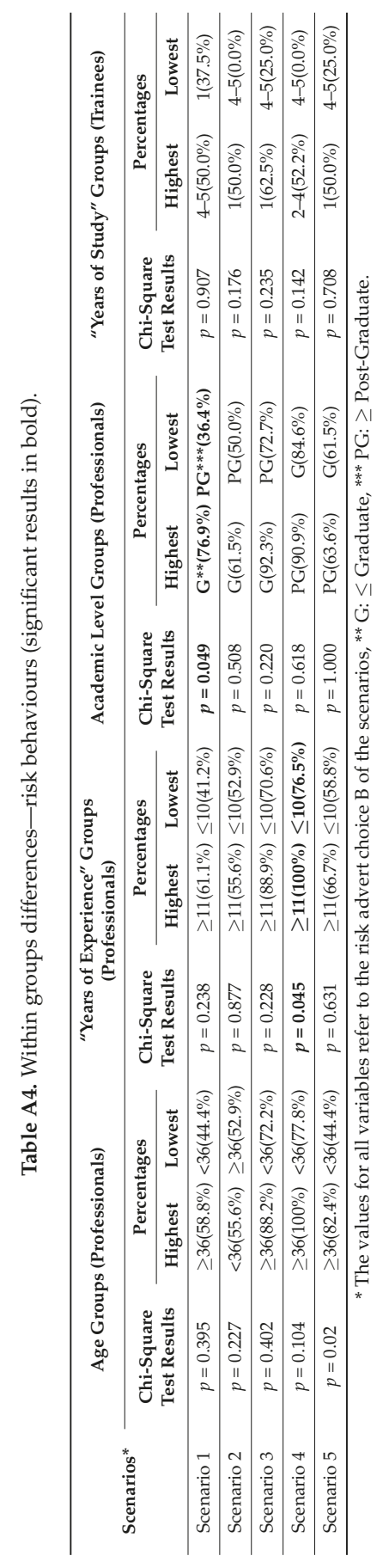




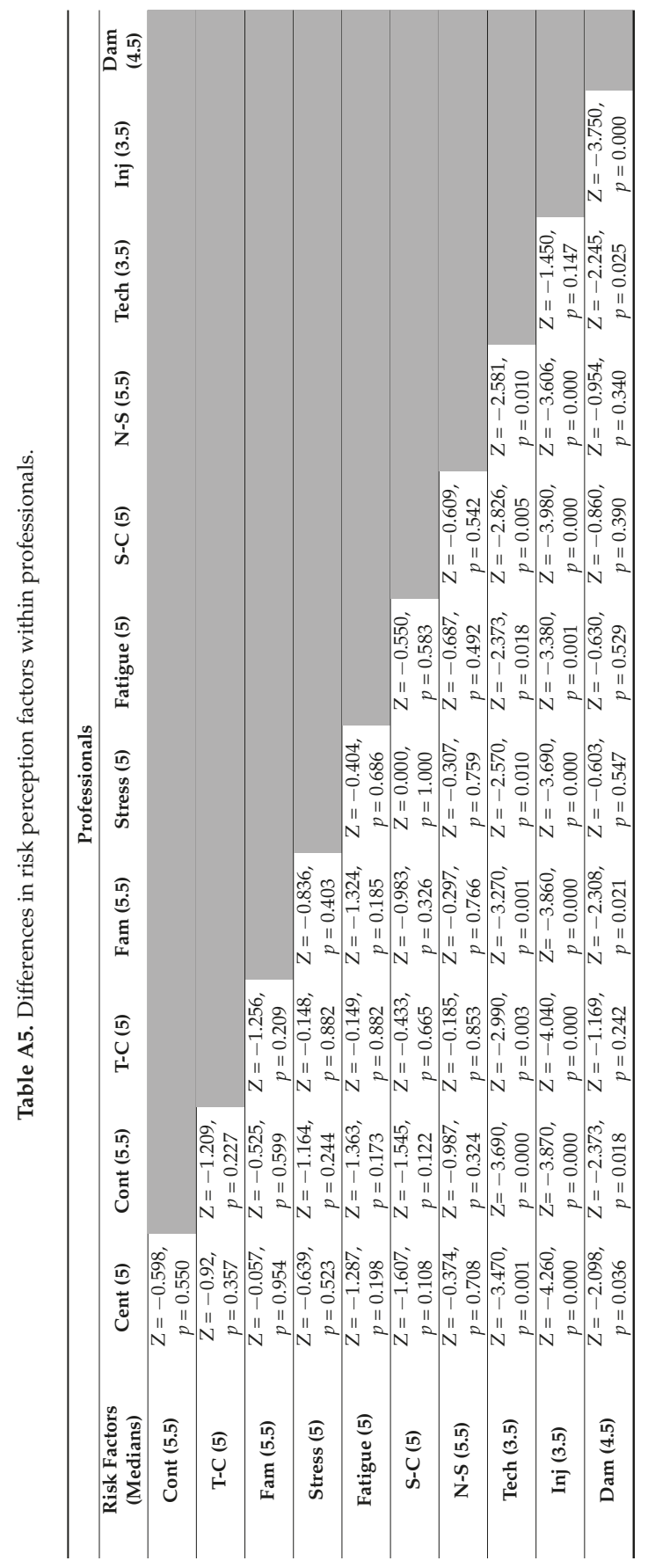




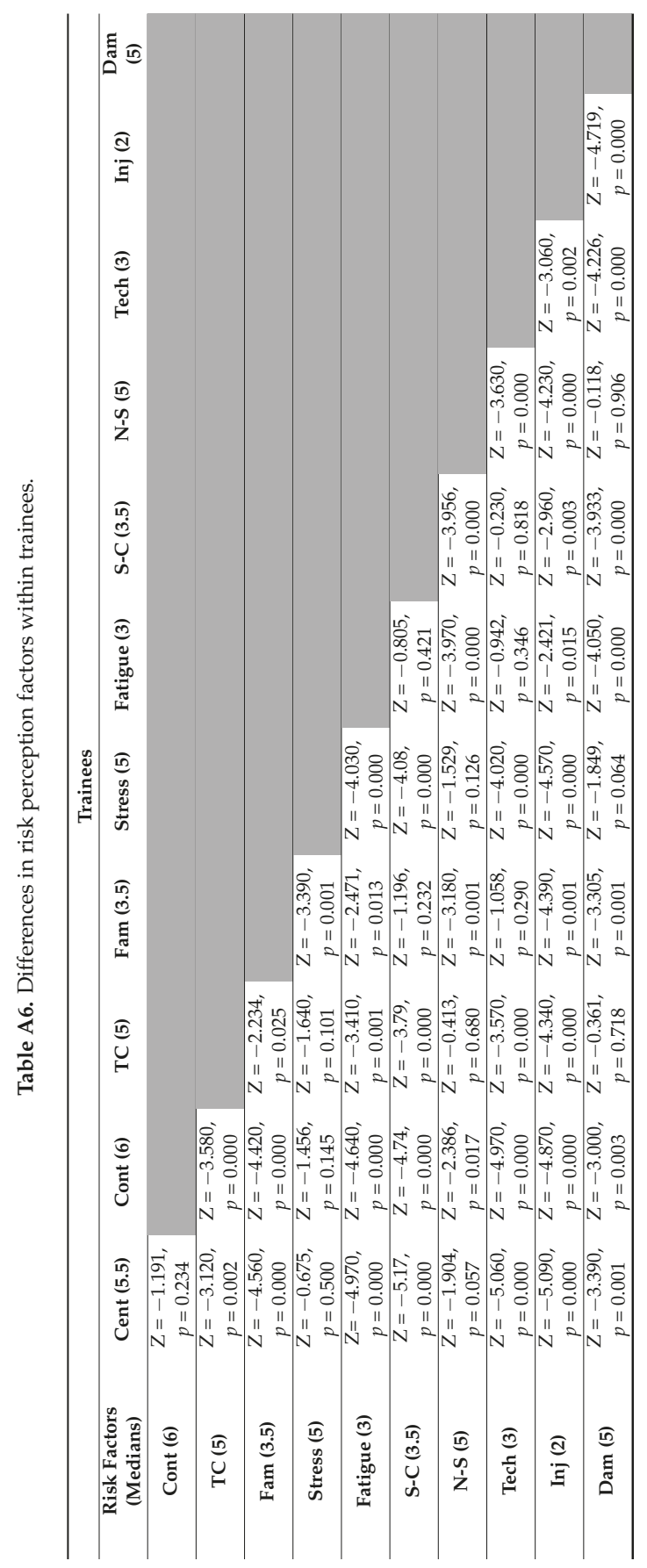




\section{References}

1. National Research Counsil. Improving Risk Communication: National Research Council; National Research Council: Washington, DC, USA, 1989.

2. Sjoberg, L.; Moen, B.; Rundmo, T. Explaining Risk Perception: An Evaluation of the Psychometric Paradigm in Risk Perception Research; Norwegian University of Science and Technology Department of Psychology: Trondheim, Norway, 2004.

3. You, X.; Ji, M.; Han, H. The effects of risk perception and flight experience on airline pilots' locus of control with regard to safety operation behaviors. Accid. Anal. Prev. 2013, 57, 131-139. [CrossRef] [PubMed]

4. Weber, E.U. The Utility of Measuring and Modeling Perceived Risk. In Decision and Measurement: Essays in Honor of R. Duncan Luce; Marley, A., Ed.; Erlbaum: Mahwah, NJ, USA, 1997; pp. 45-97.

5. Weber, E.U. Who's afraid of a little risk? New evidence for general risk aversion. In Decision Research from Bayesian Approach to Normative Systems: Reflections on the Contributions of Ward Edwards; Shanteau, J., Mellers, B.A., Schum, D., Eds.; Kluwer Academic Press: Norwell, MA, USA, 1998.

6. McDonald, N.; Corrigan, S.; Daly, C.; Cromie, S. Safety management systems and safety culture in aircraft maintenance organizations. Saf. Sci. 2000, 34, 151-176. [CrossRef]

7. Hunter, D.R. Risk Perception and Risk Tolerance in Aircraft Pilots; Office of Aerospace Medicine: Washington, DC, USA, 2002.

8. Bohn, J.; Harris, D. Risk Perception and Risk-Taking Behavior of Construction Site Dumper Drivers. Int. J. Occup. Saf. Ergon. 2010, 16, 55-67. [CrossRef] [PubMed]

9. Dobbie, M.; Brown, R. A Framework for Understanding Risk Perception, Explored from the Perspective of the Water Practionioner. Risk Anal. 2014, 34, 294-308. [CrossRef] [PubMed]

10. Drinkwater, J.L.; Molesworth, B. Pilot see, pilot do: Examining the predictors of pilots' risk management behavior. Saf. Sci. 2010, 48, 1445-1451. [CrossRef]

11. Health and Safety Executive (HSE). Research into the Behavioral Aspects of Slips and Trip Accidents and Incidents Research REPORT 396; MCA Limited: Rossmore, UK, 2005.

12. Brink, T.L. Unit 6: Learning. In Psychology; Unit 6: Learning-218; Spielman, R.M., Ed.; Rice University: Houston, TX, USA, 2014.

13. Cooper, D. Safety Culture: A model for understanding \& quantifying a difficult concept. Prof. Saf. 2002, 32, 30-36.

14. Hobbs, A.; Williamson, A. Associations between Errors and Contributing Factors in Aircraft Maintenance. Hum. Factors 2003, 45, 186-201. [CrossRef] [PubMed]

15. Hobbs, A. An Overview of Human Factors in Aviation Maintenance; Australian Transport Safety Bureau: Canberra, Australia, 2008.

16. Beus, J.; Dhanani, L.; McCord, M. A Meta-Analysis of Personality and Workplace Safety. J. Appl. Psychol. 2015, 100, 481-498. Available online: http:/ / openurl.ebscohost.com/linksvc/linking.aspx?sid=pdh\&volume= $100 \&$ date $=2015 \&$ spage $=481 \&$ issn $=0021-9010 \&$ stitle $=\&$ genre $=$ article $\&$ issue $=2 \&$ title $=$ Journal + of + Applied + Psychology\&epage $=498$ (accessed on 1 March 2016). [CrossRef] [PubMed]

17. Von der Heyde, A. Understanding the Determinants of Safety-Related Rule Deviations. University of Duisburg-Essen, 2015. Available online: http://d-nb.info/1067055193/34 (accessed on 17 February 2016).

18. Diefendorff, J.; Mehta, K. The Relations of Motivational Traits with Workplace Deviance. J. Appl. Psychol. 2007, 92, 967-977. [CrossRef] [PubMed]

19. Griffin, M.; Neal, A. Perceptions of Safety at Work: A Framework for Linking Safety Climate to Safety Performance, Knowledge, and Motivation. J. Occup. Health Psychol. 2000, 5, 347-358. [CrossRef] [PubMed]

20. Christian, M.; Bradley, J.; Wallace, C.; Burke, M. Workplace Safety: A Meta-Analysis of the Roles of Person and Situation Factors. J. Appl. Psychol. 2009, 94, 1103-1127. [CrossRef] [PubMed]

21. Oltendal, S.; Moen, B.; Klempe, H.; Rundmo, T. (Eds.) Explaining Risk Perception: An Evaluation of Cultural Theory; Norwegian University of Science \& Technology Department of Psychology: Trondheim, Norway, 2004.

22. Rundmo, T. Safety climate, attitudes and risk perception in Norsk Hydro. Saf. Sci. 2000, 34, 47-59. [CrossRef]

23. Morrow, B.H. Risk Behavior and Risk Communication: Synthesis and Expert Interviews; SocResearch: Miami, FL, USA, 2009. 
24. Maragakis, I.; Clark, S.; Piers, M.; Prior, D.; Tripaldi, C.; Masson, M.; Audard, C. Safety Management System and Safety Culture Working Group: Guidance on Hazard Identification. ESSI/ECAST. 2009. Available online: https:/ / www.icao.int/SAM/Documents /2017-SSP-GUY/ECAST\%20SMS\%20WG\%20-\%20Guidance\% 20on\%20Hazard\%20Identification\%201.pdf (accessed on 15 April 2018).

25. Vinodkumar, M.N.; Bhasi, M. Safety management practices and safety behavior: Assessing the mediating role of safety knowledge and motivation. Accid. Anal. Prev. 2010, 42, 2082-2093. [CrossRef] [PubMed]

26. National Transportation Safety Board (NTSB). Procedural Compliance. Edited by NTSBgov. 3 December 2015. Available online: https://www.youtube.com/watch?v=M4NL4m5cnhs (accessed on 16 March 2016).

27. Pauley, K.; O'Hare, D.; Wiggins, M. Risk tolerance and pilot involvement in hazardous events and flight into adverse weather. J. Saf. Res. 2008, 39, 403-411. [CrossRef] [PubMed]

28. Wright, G.; Pearman, A.; Yardley, K. Risk Perception in the UK Oil and Gas Production Industry: Are Expert Loss-Prevention Managers' Perceptions Different from those of Members of the Public? Risk Anal. 2000, 20, 681-690. [CrossRef] [PubMed]

29. Slovic, P.; Fischhoff, B.; Lichetenstein, S. Characterizing Perceived Risk. In Perilous Progress: Managing the Hazards of Technology; Kates, C.H., Kasperson, J.X., Eds.; Westview Press: Boulder, CO, USA, 1985.

30. Fischhoff, B.; Hayakawa, H.; Fischbech, P.S. Traffic accident statistics and risk perceptions in Japan and the United States. Accid. Anal. Prev. 2000, 32, 827-835.

31. Thomson, M.E.; Onkal, D.; Avcioglu, A.; Goodwin, P. Aviation Risk Perception: A Comparison between Experts and Novices. Risk Anal. 2004, 24, 1585-1595. [CrossRef] [PubMed]

32. Rowe, G.; Wright, G. Differences in Experts and Lay Judgements of Risk: Myth or Reality? Risk Anal. 2001, 21, 341-356. [CrossRef] [PubMed]

33. Marx, S.M.; Weber, E.U.; Orlove, B.S.; Leiserowitz, A.; Krantz, D.H.; Roncoli, C.; Phillips, J. Communication and Mental Processes: Experiential and Analytic Processing of Uncertain Climate Information. Glob. Environ. Chang. 2007, 17, 47-58. [CrossRef]

34. Grote, G. How We Perceive and Live with Risk and Uncertainty. 2011. Available online: https://www. youtube.com/watch?v=xLbU_AVIzzk (accessed on 17 April 2016).

35. Deery, H.A. Hazard and Risk Perception among young novice Drivers. J. Saf. Res. 1999, 30, 225-236. [CrossRef]

36. Hunter, D.R.; Stewart, J.L. Locus of Control, Risk Orientation, and Decision Making Among U.S. Army Aviators; United States Army Research Intitute for the Behavior and Social Sciences: Arlington, VA, USA, 2009.

37. GadBall. Airframe-and-Power-Plant Mechanics Job Description. 2007. Available online: https://www. youtube.com/watch?v=cTEm9yPK_KQ\&index=1\&list=PLF8BB110B33A9B32A (accessed on 17 March 2016).

38. Pidgeon, N.F. Safety Culture and Risk Management in Organizations. J. Cross-Cult. Psychol. 1991, 22, 129-140. [CrossRef]

39. Shyur, H.-J. A quantitative model for aviation safety risk assessment. Comput. Ind. Eng. 2008, 54, 34-44. [CrossRef]

40. Werfelman, L. Error Management; Aerosafety World: Alexandria, VA, USA, 2009; pp. 26-31.

41. Drury, C.G. Human Factors in Aircraft Maintenance. In Aging Aircraft Fleets: Structural and Other Subsystem Aspects; Human Factors in Aircraft Maintenance-1-15-9; Defense Technical Information Center: Fort Belvoir, VA, USA, 2000.

42. Johnson, W.B.; Hackworth, C. Human Factors in Maintenance; Aerosafety World: Alexandria, VA, USA, 2008.

43. Hackworth, C.; Holcomb, K.; Banks, J.; Schroeder, D. A Survey of Maintenance Human Factors Programs across the World. Int. J. Appl. Aviat. Stud. 2007, 7, 212-231.

44. Safety Regulation Group. CAP 716: Aviation Maintenance Human Factors (EASA/JAR145 Approved Organisations); TSO/UK Civil Aviation Authority: Norwich, UK, 2003.

45. Latorella, K.A.; Prabhu, P.V. A review of human error in aviation maintenance and inspection. Int. J. Ind. Ergon. 2000, 26, 133-161. [CrossRef]

46. Hobbs, A.; Avers, K.B.; Hiles, J.J. Fatigue Risk Management in Aviation Maintenance: Current Best Practices and Potential Future Countermeasures; Technical; FAA Civil Aerospace Medical Institute: Oklahoma City, OK, USA, 2011.

47. Bailey, M. Nuts, Bolts, and Electrons Avoiding Risky Business. FAA Aviat. News 2009, 48, 30-31. Available online: https:/ /www.faa.gov/news/safety_briefing/2009/media/janfeb2009.pdf (accessed on 25 May 2018).

48. Safety Regulation Group. CAP 715: An Introduction to Aircraft Maintenance Engineering Human Factors for JAR 66; TSO/UK Civil Aviation Authority: Norwich, UK, 2002. 
49. Pierobon, M. Covering the Ground; Aerosafety World: Alexandria, VA, USA, 2012; pp. 44-48.

50. Sellers, R. Managing the risks of interruptions and distractions during safety critical maintenance. Focused Maint. Environ. 2013. Available online: https://www.casa.gov.au/files/hf-engineers-res-ch6pdf (accessed on 19 May 2018).

51. Bolger, F.; Wright, G. Assessing the quality of expert judgement. Decis. Support Syst. 1994, 11, 1-24. [CrossRef]

52. Krosnick, J.A.; Presser, S. Question and Questionnaire Design. In Handbook of Survey Research; Marsden, P.V., Wright, J.D., Eds.; Emerald Group Publishing Limited: Bingley, UK, 2010; p. 313.

53. Karlberg, C. The Survey Fatigue Challenge: Understanding Young PEOPLE'S motivation to Participate in Survey Research Studies. Master's Thesis, Lund University, Lund, Sweden, 2015.

54. Peterson, R.A. A Quantitative Analysis of Rating-scale Response Variability. Mark. Lett. 1997, 8, 9-21. [CrossRef]

55. Finstad, K. Response Interpolation and Scale Sensitivity: Evidence against 5-point Scales. J. Usabil. Stud. 2010, 5, 104-110.

56. Revilla, M.; Saris, W.E.; Krosnick, J.A. Choosing the Number of Categories in Agree-Disagree Scales. Soc. Methods Res. 2014, 43, 73-97. [CrossRef]

57. Leung, S.-O. A Comparison of Psychometric Properties and Normality in 4-, 5-, 6-, and 11-Point Likert Scales. J. Soc. Serv. Res. 2011, 37, 412-421. [CrossRef]

58. Slovic, P. Perception of risk: Reflections on the psychometric paradigm. In Social Theories of Risk; Krimsky, S., Golding, D., Eds.; Praeger: Westport, CT, USA, 1992; pp. 117-152.

59. Lauber, J.K.; Foushee, H.C. Guidelines for Line-Oriented Flight Training (NASA Rep. CP-2184); NASA Ames Research Center, Scientific and Technical Information Branch: Moffett Field, CA, USA, 1981.

60. Eisenbach, T.M.; Schmalz, M.C. Anxiety, Overconfidence, and Excessive Risk-Taking; Federal Reserve Bank of New York Staff: New York, NY, USA, 2015. Available online: https://www.newyorkfed.org/medialibrary/ media/research/staff_reports/sr711.pdf (accessed on 18 May 2018).

61. Federal Aviation Administration (FAA). Aviation Instructor's Handbook; U.S Government Printing Office: Washington, DC, USA, 2008.

62. Cox, B. Scenario Based Training in an Aviation Training Environment (A Research Project Presented in Partial Fulfillment of the Requirements for the Degree Master of Education); Regis University: Denver, CO, USA, 2010.

63. Kuhberger, A. The Influence of Framing on Risky Decisions: A Meta-Analysis. Org. Behav. Hum. Decis. Process. 1998, 75, 23-55. [CrossRef]

64. Sjöberg, L. Strength of belief and risk. Policy Sci. 1979, 11, 39-57. [CrossRef]

65. Sjöberg, L. The Methodology of Risk Perception Research. Qual. Quant. 2000, 34, 407-418. [CrossRef]

66. Appleby, P.R.; Miller, L.C.; Rothspan, S. The paradox of trust for male couples: When risking is part of loving. Personal Relatsh. 1999, 6, 81-93. [CrossRef]

67. Godin, G.; Conner, M.; Sheeran, P. Bridging the intention-behaviour 'gap': The role of moral norm. Br. J. Soc. Psychol. 2005, 44, 497-512. [CrossRef] [PubMed]

68. Sellers, R. A professional culture of safety-The influence, measurement and development of organisational safety culture. In Proceedings of the ISASI Seminar, Adelaide, Australia, 13-16 October 2014; International Society of Air Safety Investigators: Adelaide, Australia, 2014; pp. 1-11.

69. Industry Safety Strategy Group. Global Aviation Safety Roadmap. Flight Safety Foundation. Available online: https: / / flightsafety.org/files/roadmap1.pdf (accessed on 29 August 2017).

70. Bonett, D.G. Sample Size Requirements for Testing and Estimating Coefficient Alpha. J. Educ. Behav. Stat. 2002, 27, 335-340. [CrossRef]

71. Javali, S.B.; Gudaganavar, N.V.; Raj, S.M. Effect of Varying Sample Size in Estimation of Coefficients of Internal Consistency; WMC001649; Webmed Central Biostatistics 2; Webmed Limited: Durham, UK, 2011.

72. Samuels, P. Statistical Methods—Scale Reliability Analysis with Small Samples; Worksheet; Birmingham City University, Centre for Academic Success: Birmingham, UK, 2015.

73. George, D.; Mallery, P. SPSS for Windows Step by Step: A Simple Guide and Reference. 11.0 Update; Allyn \& Bacon: Boston, MA, USA, 2003.

74. Coolican, H. Research Methods and Statistics in Psychology, 6th ed.; Psychology Press: Sussex, UK, 2014.

75. Hunter, D.R. Risk Perception among General Aviation Pilots. Int. J. Aviat. Psychol. 2006, 16, 135-144. [CrossRef]

76. IBM. IBM SPSS Statistics for Windows version 22; IBM Corp: Armonk, NY, USA, 2013. 
77. Montgomery, D.C.; Runger, G.C. Applied Statistics and Probability for Engineers, 2nd ed.; John Wiley and Sons: Hoboken, NJ, USA, 1999.

78. Armitage, P.; Berry, P.J.; Matthews, J.N.S. Statistical Methods in Medical Research, 4th ed.; Blackwell Publishing: Oxford, UK, 2002.

79. Kuzon, W.M.; Urbanchek, M.G.; McCabe, S. The Seven Deadly Sins of Statistical Analysis. Ann. Plast. Surg. 1996, 37, 265-272. [CrossRef] [PubMed]

80. Egboro, F.O. The Implications of Parametric and Non-Parametric Statistics in Data Analysis in Marketing Research. Int. J. Hum. Soc. Sci. 2015, 5, 74-83.

81. Afari, N.; Buchwald, D. Chronic Fatigue Syndrome: A Review. Am. J. Psychiatry 2003, 160, 221-236. [CrossRef] [PubMed]

82. Marcora, S.M.; Staiano, W.; Manning, V. Mental fatigue impairs physical performance in humans. J. Appl. Physiol. 2009, 106, 857-864. [CrossRef] [PubMed]

83. Bridges, S.J. Professional identity development: Learning and journeying together. Res. Soc. Adm. Pharm. 2018, 14, 290-294. [CrossRef] [PubMed]

84. Ilias, N.; Abdulatiff, N.K.; Mohamed, N. Management Control System and Performance: Accountability Attributes in Local Authorities. Int. J. Econ. Financ. Issues 2016, 6, 26-35.

85. Regional School of Public Administration-ReSPA. Managerial Accountability and Risk Management: Concept and Practical Implementation; Discussion Paper; Regional School of Public Administration-ReSPA: Danilovgrad, Montenegro, 2017.

86. Doty, J.; Fenlason, J. It's not about trust; It's about thinking and judgement. Mil. Rev. 2015. Available online: http:/ /www.armyupress.army.mil/Portals/7/military-review/Archives/English/MilitaryReview_ 20150630_art016.pdf (accessed on 28 May 2018).

87. Kan, K.; Lai, T. Does Education Affect Trust Attitude? Evidence from Europe. 29 May 2018. Available online: https://editorialexpress.com/cgi-bin/conference/download.cgi?db_name=EEAMannheim2015\& paper_id=74229 (accessed on 18 May 2015).

88. Tversky, A.; Kahneman, D. Belief in the law of small numbers. Psychol. Bull. 1971, 76, 105-110. [CrossRef]

89. To70. Civil Aviation Safety Review 2017. Available online: http://to70.com/to70s-civil-aviation-safetyreview-2017/ (accessed on 13 January 2018).

90. AERIC Inc. All Signs Point to Yes: Literacy's Impact on Workplace Health and Safety; AERIC Inc.: Ottawa, ON, Canada, 2008.

91. Wright, M.C.; Kaber, B. Effects of Automation of Information-Processing Functions on Teamwork. Hum. Factors 2005, 47, 50-66. [CrossRef] [PubMed]

92. Metzger, U.; Parasuraman, R. Automation in Future Air Traffic Management: Effects of Decision Aid Reliability on Controller Performance and Mental Workload. Hum. Factors 2005, 47, 35-49. [CrossRef] [PubMed]

93. Rovira, E.; McGarry, K.; Parasuraman, R. Effects of Imperfect Automation on Decision Making in a Simulated Command and Control Task. Hum. Factors 2007, 49, 76-87. [CrossRef] [PubMed]

94. Wickens, C.D. Engineering Psychology and Human Performance, 2nd ed.; Harper Collins: Scranton, PA, USA, 1992.

95. Wickman, M.; Greenberg, C.; Boren, D. The Relationship of Perception of Invincibility, Demographics, and Risk Behaviours in Adolescents of Military Parents. J. Pediatric Health Care 2010, 24, 25-33. [CrossRef] [PubMed]

96. Sanchez, C.; Dunning, D. Overconfidence Among Beginners: Is a Little Learning a Dangerous Thing? J. Personal. Soc. Psychol. 2018, 114, 10-28. [CrossRef] [PubMed]

97. Morris, M.G.; Venkatesh, V. Age Differences in Technology Adoption Decisions: Implications for a Changing Work Force. Personnel Psychol. 2000, 53, 375-403. [CrossRef]

98. Hulse, L.M.; Xie, H.; Galea, E.R. Perceptions of autonomous vehicles: Relationships with road users, risk, gender and age. Saf. Sci. 2018, 102, 1-13. [CrossRef]

99. Thunström, L.; Nordström, J.; Shogren, J.F.; Ehmke, M.; van't Veld, K. Strategic Self-Ignorance; Working Paper; Lund University: Lund, Sweden, 2016.

100. Gonzalez, J.J.; Sawicka, A. The Role of Learning and Risk Perception in Compliance. In Proceedings of the 21st International Conference of the System Dynamics Society, New York, NY, USA, 20-24 July 2003. 
101. Agung, I. How Student Understand of Success and Failure: Internal or External Factor? SSRN 2017. [CrossRef]

102. Martin, W.E.; Martin, I.M.; Kent, B. The role of risk perceptions in the risk mitigation process: The case of wildfire in high risk communities. J. Environ. Manag. 2009, 91, 489-498. [CrossRef] [PubMed]

103. Van Tonder, C.L.; Lessing, B.C. From Identity to Organisation Identity: The Evolution of a Concept. J. Ind. Psychol. 2003, 29, 20-28. [CrossRef]

104. Miller, D.T. The norm of self-interest. Am. Psychol. 1999, 54, 1053-1060. [CrossRef] [PubMed]

105. De Dreu, C.; Nauta, A. Self-Interest and Other-Orientation in Organizational Behavior: Implications for Job Performance, Prosocial Behavior, and Personal Initiative. J. Appl. Psychol. 2009, 94, 913-926. [CrossRef] [PubMed]

106. Kurtz, S.; Silverman, J.; Draper, J. Teaching and Learning Communication Skills in Medicine, 2nd ed.; Taylor \& Francis Group, LLC: Boca Raton, FL, USA, 2004.

107. Higgins, V. Augmented \& Virtual Reality: The Future of Work, Not Just Play. Prof. Saf. 2017, 62, 86-87.

108. International Civil Aviation Organisation (ICAO). Safety Management Manual Doc 9859; International Civil Aviation Organization: Montreal, QC, Canada, 2013.

109. SKYbrary. Safety Management System. 22 September 2017. Available online: https://www.skybrary.aero/ index.php/Safety_Management_System\#Definition (accessed on 7 May 2018).

(C) 2018 by the authors. Licensee MDPI, Basel, Switzerland. This article is an open access article distributed under the terms and conditions of the Creative Commons Attribution (CC BY) license (http:/ / creativecommons.org/licenses/by/4.0/). 


\title{
Review \\ The Unexplored Link between Communication and Trust in Aviation Maintenance Practice
}

\author{
Anna V. Chatzi *, Wayne Martin, Paul Bates and Patrick Murray \\ School of Commerce, University of Southern Queensland, Brisbane QLD4300, Australia; \\ waynem999@gmail.com (W.M.); paul.bates@usq.edu.au (P.B.); patrick.murray@usq.edu.au (P.M.) \\ * Correspondence: anna.chatzi@usq.edu.au; Tel.: +61-7-4631-2285
}

Received: 30 April 2019; Accepted: 30 May 2019; Published: 3 June 2019

\begin{abstract}
Communication and trust are fundamental factors in the operation of complex and highly regulated industries like aviation maintenance. This article reviews two preconditions of human error: communication and trust, as well as the way these are linked as aviation researchers have only recently started to study factors not individually, but rather by combining their effects. Communication is essential in the exchange of information and knowledge in aviation maintenance. The conditions that make communication effective and miscommunication avoidable are explored. Next, ways of communication, like aircraft maintenance documentation, are discussed along with appreciation of how communication is valued in aviation maintenance. Trust within different aspects of maintenance practice (interpersonal trust, trust towards technology, initial levels of trust) is presented and analysed, as well as examined as a prerequisite of effective communication. The characteristics of trust, its forms and results are identified in the literature with limited sources from the aviation bibliography, as it is a domain barely explored. Therefore, a gap has been identified in the study of trust and the exploration of the combined traits of communication and trust in aviation maintenance. Recommendations for additional research in this field are provided.
\end{abstract}

Keywords: human factors; communication; trust; safety; aviation maintenance; error

\section{Introduction}

To err is within human nature. However, it is primarily over the last 50 years that human error has become a field of scientific research, as errors started to have a great global impact in the economy, health, environment and communities. In the US alone, from over $\$ 300$ billion spent on maintenance and operations every year, $80 \%$ was spent repairing damage caused by human error in equipment, systems and dealing with harm caused to people [1,2]. In 2014 alone, there were 648 fatalities in 14 fatal accidents caused by human error. This number was $1.5 \%$ higher than the previous 10 years average. This increase was the result of larger airplanes, with larger passenger capacity which has led to an increase of fatalities in the occurrence of an accident [3], therefore, since human error led to higher numbers of human loss, there is a necessity within the aviation community to address this issue even more urgently.

A greater understanding of human factors became imperative within aviation, and a large number of models and systems have been introduced and implemented in the continuous attempt to predict and reduce human error. In aviation maintenance, there are twelve principal preconditions or conditions that contribute to human errors, widely known as the Dupont's Dirty Dozen [4-9]. These elements (shown in Figure 1) are dissimilar in nature and appear either on personal, group or organizational performance levels [10].

The Dirty Dozen is still used in training, accident, and human error analysis in aviation maintenance worldwide $[4,5,7,8,11]$. These 12 factors are of a different nature and quantifiability, nevertheless 
each one of them represents a precondition/condition to failure in the user's judgement and as such they are treated either individually or in groups of similar items [8]. As shown in Figure 1 lack of communication is among these 12 most frequent conditions/preconditions of human error.

Researchers still investigate elements similar to the ones of the Dirty Dozen, but also consider mutual interactions. As a most recent example, the Joint Research Program in the European Union (EU) 'Future Sky Safety', aims to study the concept of the Human Performance Envelope (HPE) in aviation. This research is investigating the interactions between nine human factors (stress, attention, situation awareness (SA), vigilance, teamwork, workload, communication, trust, fatigue) and the pilot's human performance, how they work individually or in combination, and how they affect or decline human performance [12].

Communication has been indicated by past research to have a strong association with trust [13]. Trust is an important element in human social life and therefore, has been researched extensively in the past by many different disciplines of science such as marketing, psychology, sociology, political science, economics, etc. [14]. Many researchers agree that trust is a very important element in employees' relations and it is associated with the quality of their communication [15-22]. Trust is under-investigated in aviation [19] and its association with communication is an unexplored area, especially in aviation maintenance.
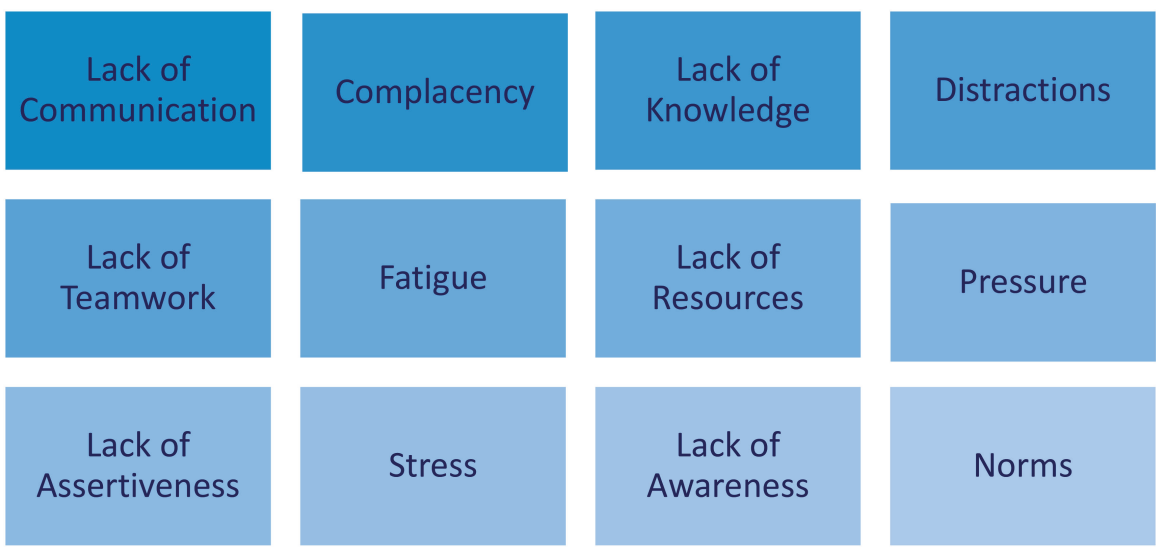

Figure 1. The Dirty Dozen [16].

\section{Basic Communication Theory}

Communication is a field of study that is of interest for many disciplines, such as marketing or computer science. Communication is a process that everyone uses in their everyday life. However, defining communication has proven to be challenging. There have been many definitions of communication in textbooks and different approaches through the years since Shannon and Weaver [23] saw communication as the transmission of messages [24].

There are various definitions of communication depending on the different approaches and discipline of each researcher. In some definitions there is emphasis on the significance of symbols, as in "the transmission of information, ideas, emotions and skills ... by the use of symbols" (Page 527 in [25]), while others examine communication as a product, e.g., "We use the word 'communication' sometimes to refer to what is so transferred, sometimes to the means by which it is transferred, sometimes to the whole process" (Page 13 in [26]). In the study of communication there are two main streams. One stream considers communication as the transmission of messages and the other as the production and exchange of meaning [24].

At the transmission of the message stream, the member that sends the message is the sender, and the one who accepts it is the receiver. Communication, to be effective, must be an active process where both 
the sender and the receiver/s assure that the intended objectives are met. To achieve that, both the coding and the decoding process of the message along with the channel and/or medium of communication, are very important to success. If the result is not the anticipated, then the communication process is characterized as failed and the communication steps are investigated to identify the causes of this failure [24]. The second stream, the production and exchange of meanings deals with the interaction between messages and people and the meaning that comes out of this interaction. In this stream, connotation is a term that is usually met. Additionally, misunderstandings, besides being a result of failure in communication, may occur due to cultural differences between the sender and the receiver [24].

According to Schramm [27] important elements that should be added to the communication process are the sender's and receiver's experiences. The mode of communication chosen should be the appropriate one to meet the circumstances of both the sender and the receiver. The sender proceeds with the message coding based on his/her experience while the receiver understands the message by connecting it to his/her prior knowledge/cognitive level. Then the sender needs to ensure that the message has been transmitted correctly by evaluating the receiver's feedback [27] as shown in Figure 2.

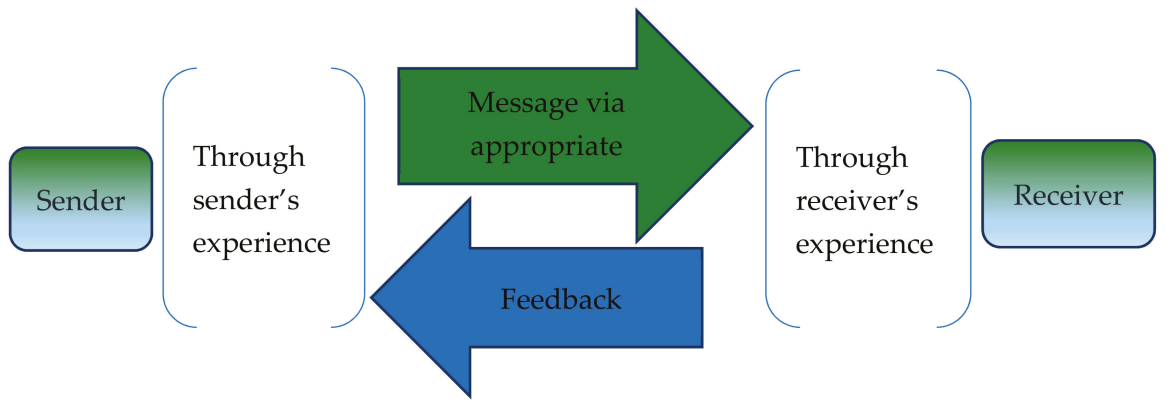

Figure 2. Schramm's [18] communication model with feedback.

To understand the communication theories fully the definitions of the terms: channel, code, and medium are necessary. Channel is the means through which information flows [28]. Examples of channels are: light waves, sound waves, radio waves. Medium is the material or mechanical way of transforming the message into a signal capable of being passed on along the channel. Coding is the sharing of mutual meaning between members of the same culture [24].

The basic features of the chosen channel determine the nature of the medium that will be selected. Next, this medium will determine the characteristics and the range of the codes that will be used to transmit the message. Fiske [24] further suggests that media can be divided into three categories as shown in Figure 3:

a. The presentational media. The body language, the oral speech, the facial expressions are providing communication. This requires the physical presence of the communicator as he/she is the medium and communication happens in real-time.

b. The representational media. Any medium that represents the above by the production of a text, picture, painting, piece of art. These media do not require the presence of the communicator as they can act independently.

c. The mechanical media. These media utilize technologically developed channels; therefore, they are transmitters of the presentation and representation media. Examples are: radio, television, computers, and telephones.

Given that communication is effective and complete it can (a) be beneficial to staff's interpersonal and group relationships; (b) guarantee that attitudes and expectations will be clear with no hidden agendas; (c) retain focus on the task and situational awareness; and (d) act as a managing tool [29]. 


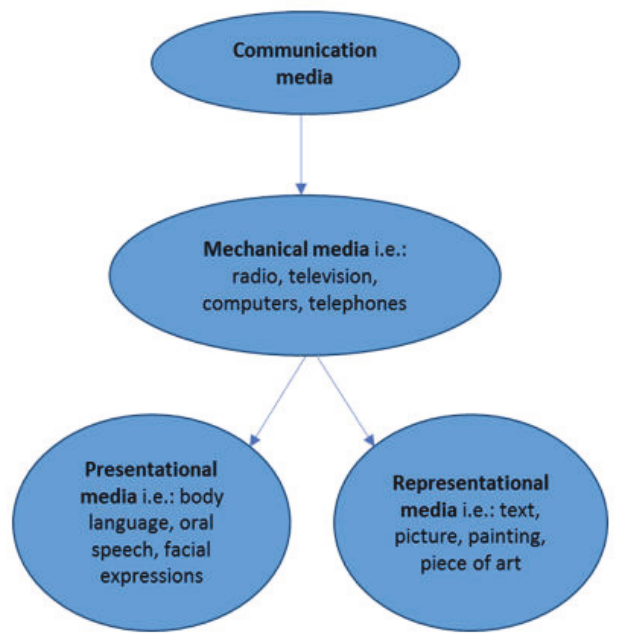

Figure 3. Concept map of communication media.

\subsection{Miscommunication}

To understand and define communication, researchers needed to clarify miscommunication as well. Communication and miscommunication are strongly interrelated, and they present a difficulty in investigating them separately. Miscommunication is treated as a kind of communication with its own distinct patterns and characteristics [30]. In this context miscommunication can be defined as 'the dark side of interpersonal communication' [31] not being too far from its standard meaning of missing, flawed, and disrupted rules of communication [32].

Furthermore, miscommunication includes 'mismatching interpretation' and distortion of message [30]. This definition also includes the potential cultural differences between the sender and the receiver which are responsible for possible alternative interpretative models. Miscommunication, in the condition that if it is noticed and attempted to be repaired, has positive outcome to the communication process as well as it provides a chance for further interaction between the communicators. Miscommunication has been included in several communication theories, e.g., Shannon and Weaver [23], through the years as a deviation or a disruption, either important or less important, at any stage of the communication process [30].

In the aircraft maintenance environment, a model of communication fault was developed by Shukri, Millar, Gratton and Garner [33] that was inspired by Cushing's [34] detailed overview of communication failures between pilot and a traffic controller. In this model there are six message characterisations: “(a) A message that is unavailable; (b) A message that is available but incomplete; (c) A message that is available, complete but incorrect; (d) A message that is available, complete, correct but not clear; (e) A message that is available, complete, correct, clear but not understood; and (f) A message that is available, complete, correct, clear, understood but mistakes still happen due to human factors" [33].

From this model, it is evident that even if the message is free from all the failure prone factors, there is still the possibility of mistakes. Subsequently, all the specialists' efforts lead to the direction of the elimination of the known or predictable factors that can lead to fault and the constant attempt to identify and eliminate the uncharted ones. Therefore, in the case that communication for one or more reasons does not result in the correct exchange of the message, the beneficial effects are not fully realised.

The contribution of communication to the occurrence of human errors has been recorded in various reports. Human error can be tagged as the human causal factor associated with aviation 
accidents' [35] or 'the failure of planned actions to achieve their desired ends-without the intervention of some unforeseeable events' [2]. A study commissioned by the Dutch Aerospace Research Centre (NLR), identified various contributory factors to aircraft accidents, incidents, and errors. In seven ground service providers in the Netherlands both management and operational personnel named the ten most frequent factors that are involved in the cause of mistakes on the ramp (see Figure 4). Poor communication is the second most prevalent factor on that list [36].

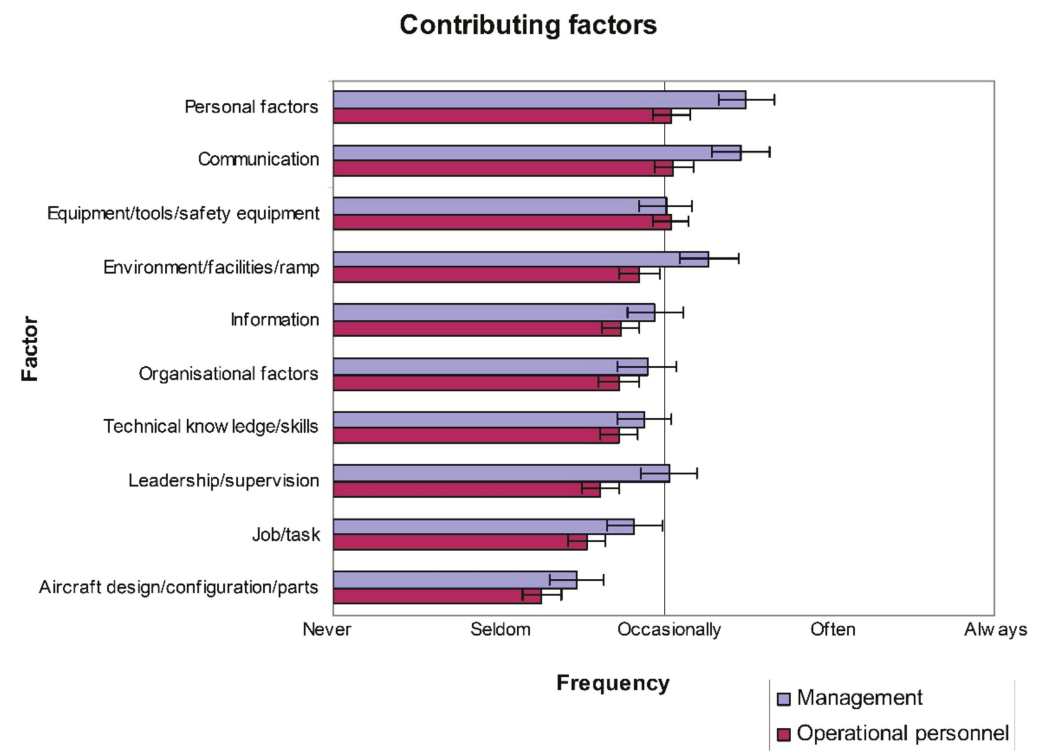

Figure 4. The most frequent causal factors involved in mistakes on the ramp [36].

Ineffective communication is a precondition for human error in all highly complex and regulated industries worldwide [34]. Extended research in aviation has shown that human factors cause $70-80 \%$ of aviation incidents and $15-20 \%$ of them relate to maintenance procedures [37,38]. The aviation sector was the first to identify that the implementation of standardised procedures has contributed to safety and teamwork efficiency, following the realisation that $70 \%$ of commercial flight accidents were caused due to communication errors between crew members [39].

Another large study in the aviation industry found that $70 \%$ of all accidents were caused due to crew coordination and communication issues [40]. These findings are supported by Wiegmann and Shappell [41] and Yacavone [42], as they have recognized crew coordination to be a major contributing factor in military aviation (as cited by Wiegmann and Shappell [43]). Failed communication has also been reported to be among the most frequent local factor in airworthiness events along with tools and equipment, perceived pressure or haste, environment and knowledge, skill, and experience [44]. As a comparison, in railway maintenance, it has been shown that $92 \%$ of incidents occurred due to communication failures $[44,45]$. In the healthcare industry communication is an extremely common element prone to flaws as well [39]. Subsequently, healthcare also had the need for standardization of the communication tools due to its complexity, the limitations of the human performance, and the different training among the medical professionals. For that purpose, tools like SBAR (Situation, Background, Assessment, and Recommendation) were introduced for all medical personnel as a means to establish common terminology and methodology to avoid communication failures [39].

In Figure 4 it is indicated that the management's awareness is at higher levels than the line personnel's, suggesting that the administration has recognised these factors to be preconditions of human errors. The European Commercial Aviation Safety Team (ECAST) has acknowledged the 
awareness of the potential risk of ineffective communication as a human factor and that further research is necessary towards that direction [36]. Moreover, various researchers have highlighted the problem of ineffective communication between maintenance staff, cabin crew, and flight crew, proposing different ways to mitigate this issue $[46,47]$. It is evident from the above that communication is a very important element within complex industries like aviation.

An example, in which maintenance communication was involved in an airplane accident, is the Atlantic Southeast Airlines flight 529 in August 1995. The aircraft crashed in Georgia, USA, during an emergency landing, after the loss of a propeller blade, resulting in 9 fatalities and 20 injuries. The National Transportation Safety Board (NTSB) determined that "the probable cause of this accident was the in-flight fatigue fracture and separation of a propeller blade resulting in distortion of the left engine nacelle, causing excessive drag, loss of wing lift, and reduced directional control of the airplane. The fracture was caused by a fatigue crack from multiple corrosion pits that were not discovered by Hamilton Standard because of inadequate and ineffective corporate inspection and repair techniques, training, documentation, and communications." [48]. The NTSB in this report highlighted as a contributing factor the internal inadequate communication and documentation systems of the airplane parts' manufacturer that led maintenance personnel to confusion and faulty procedures.

Even though aviation was the first industry to regulate and implement human factors policies and guidelines, the need for further research and procedural improvement is continuous and arduous. In the occurrence of any new procedure introduced, new research over the possible reasons for failure of the system or its human element towards its failure must be conducted. Moreover, the continuous effort to make communication in aviation effective has led to the observation and understanding of all aspects of human expressions. Different modes of expression, such as politeness [49], are under review by human factors specialists, in their attempt to promote clarity and minimize miscommunication at all levels.

\subsection{Areas in Aviation Maintenance Prone to Communication Failure}

In aviation maintenance one critical aspect is documentation. The most common reason for accidents in aviation maintenance is insufficient documentation and procedures [50-52]. More recent studies indicate that written communication can be more prone to mistakes than oral communication during critical maintenance tasks. The reason is that in oral communication any clarification is easier to obtain, so more human errors, that affect aircraft safety, are detected [33].

The improvement of maintenance documentation can establish communication as an important factor that could have a positive contribution to the execution of maintenance tasks safely $[50,53]$. Written procedures govern every action in aircraft maintenance. These are manufacturers' Instructions for Continued Airworthiness (ICA's), Fault Isolation Manuals and all supporting documentation that are continually updated. Additionally, as aircraft design is evolving fast and becoming more sophisticated, maintenance-related information is expanding in volume. This immense amount of documentation amendments and novelty has to be adopted simultaneously by maintenance personnel around the world, even if their first language is not the one the documentation was produced in $[54,55]$.

Moreover, there is extended research in the development and improvement of online platforms, that aim to replace workcards, targeting lower cost along with a positive impact on the engineers' situational awareness, error probability, job satisfaction, and adaptability [56,57]. Another example is that of a Federal Aviation Administration (FAA) three-phase sponsored study that dealt with an improved design of the manufacturer's maintenance documentation enabling the transfer of information to the maintenance personnel at a satisfactory level [58].

Many researchers have produced instructions and guidelines, following human factors principles, to help maintenance staff avoid mistakes. Their research has been successful in reducing human errors [55,59]. However, the people in charge do not always acknowledge this work by implementing it in the field [60]. They usually persist in following their own former good experience and the employees' perspective rather than adopt guidelines and instructions that stem from research [58]. 
Moreover, shift turnover is of great significance in highly complex and regulated business environments, such as aviation maintenance, the oil industry, and medicine. According to Parke and Kanki, from the $8 \%$ of the aircraft maintenance failures that were due to communication factors, $51 \%$ were related to the shift turnover while $41 \%$ had no relation to it [61]. The turnover related maintenance occurrences were classified, by the reporting system used for this research, to have more severe and dangerous consequences [61] whereas debriefs that are conducted according to human factors principles can enhance productivity by $20-25 \%$ [62]. While debriefs may appear to be cost effective and produce quick results in the organizations' improvement of performance, the study of such processes over the years is scattered across different disciplines, such as healthcare, education, psychology, and organizational fields with no conclusive results [62].

The literature highlights that communication in the aircraft maintenance environment provides several considerations: first, it is an element that underlies every phase of the aircraft maintenance process; next, it is a primary element of the maintenance process, as it is the framework upon which information transmission takes place; finally, the research community and the industry need to proceed with further investigation on documentation structure and shift turnover procedures.

\subsection{Communication in Aviation Training}

The training framework in aviation is designed to enhance communication skills and techniques, promote teamwork, accommodate human performance tools and develop situational awareness (SA) among maintenance personnel. This indicates of the way that the aviation industry values communication, acknowledges it as an important contributing factor of human performance and takes actions towards its successful application within the aviation various activities. This training is either called Crew Resource Management (CRM), Maintenance Resource Management (MRM), or Team Resource Management (TRM) [63-65].

As the literature indicates: (a) training is essential in enhancing elements such as successful communication and indeed has good results, and (b) the design of training, the delivery and its implementation is of great importance in achieving the required results in areas such as communication $[50,66,67]$. To define the success of training in promoting factors such as communication, more 'on the job' observation of the participants is needed, given that most of the research has been conducted in simulation $[64,68,69]$.

In the European Union, there is a 30 mil. Euro program (Future Sky Safety 2015-2019) that explores all new tools and approaches to aviation safety. This research, among other issues, indicates that a significant gap has been recognized between the quality of the students' oral and written communication skills gained during their studies (especially in the aeronautical area) and the skills required by the aeronautical industry to perform the tasks safely [70]. Industry and academia do not work together as the communication between them is ineffective and discontinued [71,72]. This indicates that since there is no wide human factors training within the tertiary education curricula, there is a great need for it in newly recruited personnel.

\section{Trust}

First, trust is the belief of somebody else's benignant intentions. Second, none can impose these beliefs to come true, in other words trust means to be prepared for the possibility that the anticipated benignant outcome will not happen. Third, the meaning of trust includes a degree of interdependency as somebody's situation is linked to somebody else's actions [13]. Based on these three elements, trust is the attitude someone or a party adopts (trustor) towards somebody else or another party (trustee) [73]. This attitude, or even both parties' relationship, is influenced by the trustee's behaviour and it will form the trustor's understanding and receptiveness towards the trustee [13]. It is noted in the literature that the competence, benevolence and integrity of the trustee are the characteristics that trustor takes into consideration for the formation of his/her trust $[74,75]$. 
Trust, while it has been extensively researched by organizational researchers and more specifically by certain industries (e.g., web commerce) is understudied in high-reliability organisations, such as the aviation industry [76]. Trust usually stands in combination with other human characteristics and is difficult to be isolated and quantified. However, there is growing research indicating that trust and professionalism are fundamental factors in maintaining safety in the aviation industry. On the one hand, professionalism is the basis to exercise all the necessary steps towards safety, but on the other hand, personal trust is essential in the communication that is required $[19,20,22,77,78]$.

Additionally, personal trust is associated with performance and cooperation [79-82], citizenship behavior [83], problem solving [84], and confidence in the skills and capabilities of aviation experts (trust in competence), to achieve the desired level of safety [85]. Maintenance personnel need to trust that their colleagues will act as safely as themselves. This is a process that needs to be inspired and enhanced rather than taken for granted [86].

Trust towards people, and especially towards individuals in the case of a risky situation, where an individual will do anything within his/her power to overcome the risk, aspires to be a solid factor in ensuring safety management [85]. However, Harvey and Stanton [85] and Reason [87] argue that this statement contradicts the modern systems approach to risk and human error, according to the human factors principles, as human error has been considered so far to be a systemic rather than an individual consequence $[88,89]$. Adaptation is inevitable where models include the social system and human error while organizations put pressure on their systems on the benefit of their cost effectiveness-productivity balance [90].

Apart from the trust between colleagues, there is the trust between maintenance personnel and management that has been rather low and makes staff feel sceptic and pessimistic whether positive results in safety can be achievable [65]. Management is responsible for building (establishing/taking the initiative towards the employees) and maintaining trust [13]. Apart from the interpersonal trust, there is the confidence towards technology and procedures. Additionally, another characteristic of trust is that it is bipolar: lingering between the two edges of trust and distrust [91,92].

Procedures are clusters of partial steps that, to be successful, need to meet different criteria and conditions (e.g., environment). Due to different reasons (e.g., lack of knowledge, norms) maintenance employees might not take these conditions under consideration in the case of failure. Situations like these might lead these professionals to lose trust in procedures, in the case of a failure, or show overreliance in the instance that the procedures were effective even if the right conditions were not met [92].

The benefits of trust have been well understood for some decades now since Zand proved in 1972 [84] that employees with higher levels of trust compared to the ones with lower levels: (a) make information processing more cost-effective to the company; (b) seem to have more contentment among them; and (c) show certainty towards other counterparts [84]. Research has also shown that trust towards familiar individuals is far more easily achieved, especially when positive feedback indicates this person to be trustworthy. Obviously, the level of trust tends to differ amongst various organizations, depending on their size. In small organizations, the interpersonal trust seems to be at a higher level than in larger organizations and the army [93].

Technology, on the other hand, is a human construction and, as a product, it lacks human characteristics [94]. To focus on the technology, one should isolate it from the human element (users, developers) and examine the technology artifact itself. This approach enables the investigation of trust towards technology without being influenced by other surrounding human structures [95].

People depend on technological artifacts and rely on their anticipated abilities and capabilities to perform successfully. In this concept trust means to depend or rely on another [96]. Therefore, if someone believes he/she can depend on technology's performance in a time of need, then trust towards technology is the describing term for it [95].

Trust in technology is divided into initial trust and knowledge-based trust [95]. Initial trust refers to the expectations and beliefs of the anticipated operations of the technological application chosen by 
the user. Knowledge-based trust is the result after interaction and familiarization with a technological system. Trust in technology needs further investigation as limited research has been conducted in this area [95].

Furthermore, in modern times, more organisations have evolved into big impersonal enterprises where trust between groups is difficult to achieve [15]. To overcome this issue, organisations have to agree, adopt and utilise similar social rules to gain familiarity and work together efficiently [97]. Even though these sets of rules seem to prevent distrust among enterprises, some researchers insist that interpersonal relations are the ones that guarantee the formation of trust. This means that specific people need to represent organisations to form the needed familiarity [98].

Within business relations, trust is a fundamental factor that takes part in the orchestration of their expectations and mode of collaboration [99]. It appears to have an assistive role in establishing business relationships and it is crucial to re-establish the theory behind the organisational influences on the business behaviour. This will be of major help in attempts at building trust in interorganisational interactions [15]; "The more complex and dynamic social and economic relations and exchange arrangements are today, the more trust is needed as a lubricant to keep the motor running" [100].

Overreliance or excessive trust may have negative effects on interpersonal and organizational relations and there is no current research to describe it adequately [101]. To unfold the role that trust plays in organizations, one must explore the macrolevel and microlevel of theory and analysis. In the macro level, trust is studied regarding its interaction with the industry structure while in micro level trust is examined among people as seen in Figure 5 [102].

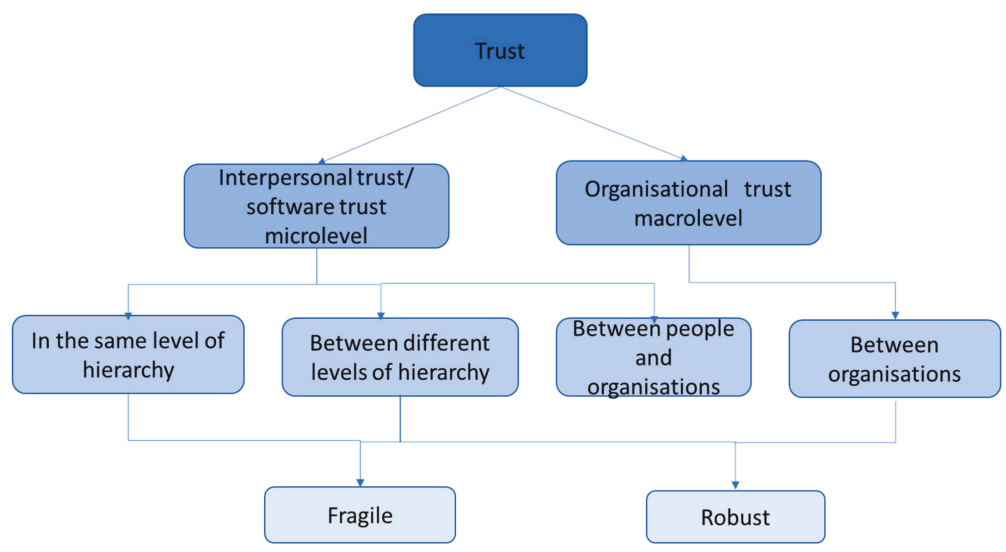

Figure 5. Schematic representation of the concept of trust [102].

\subsection{Trust Dynamics within the Organization}

When systems in organizations promote open and free communication (knowledge sharing, uninhibited information disclosure) their employees are more likely to develop trust towards the organization and each other $[13,74,101]$. From the very beginning, trust has been linked to safety in the aviation industry and there has been a significant effort through MRM training (5th generation) to implement and enhance safety culture and engage all personnel in that direction.

In the case that an organization proceeds with implementing all necessary actions to reduce human errors then learning from their mistakes would be one of them. In this case, it is crucial to the people involved to have sufficient trust that they will not be blamed if they report mistakes and that they can speak openly about them (commonly called a just culture $[103,104])$. Although there are mechanisms available to maintenance personnel to avoid or reduce human errors, they must trust their managers mutually to achieve that. 
Studies have revealed that a big proportion of engineers do not trust that their managers' actions will be solely aimed at enhancing safety [105]. The lack of trust, or distrust, acts as an obstacle to the formation and implementation of programs, such as the FAA's Aviation Safety Action Program (ASAP), that provides maintenance personnel with a system to report failures and thereby contribute to the continuous effort to improve aviation safety.

\subsection{Characteristics of Trust}

Other extended research on trust indicates that trust is at high levels at the beginning of a professional relationship "high initial trust levels" [106]. New employees begin their employment with an intrinsic level of trust towards their colleagues and their organizations. Thereafter, it is the culture of each organization that will be responsible for maintaining or altering this level. Trust is also a multidimensional area that is highly influenced by other social features. As proposed in the Model of Trust by Mayer, Davis, and Schoorman (as cited by Mayer et.al. [75]) trustworthiness is perceived by factors like ability, benevolence and integrity. In a society that is trained to believe and rely on others, it is most probable that people will trust their organization initially at a high level [106,107].

Depending on the circumstances, trust levels can appear to develop as fragile or robust. Fragile is when it is subject to sudden changes during a given period either to a higher level, when the initial level is low or vice versa. Robust, on the other hand, is the opposite of fragile. It is used when the level of trust remains stable over a specified period [106]. Since the existence of the "high initial trust levels" is observed, it is of primary importance in the aviation industry to maintain it at those levels. It will only be successful by keeping in mind that the elements that make trust robust are: (a) adequate precedent support, that is former good experience which forms a present behaviour in a similar manner; (b) belief-confirming cognitive mechanisms, in which people's remarks that oppose their beliefs are overlooked; and (c) social mechanisms, the personal contact among people enhances the positive attitude between them [106]. Moreover, research has identified legislative procedures, conflicts of power, stress, and liability to be factors that reduce trust within organisations [108,109].

Furthermore, research has confirmed the relationship between ASAPs and trust since organizations with ASAPs in place have demonstrated higher scores in trust than other companies in which ASAPs were not in their structure [110]. To evaluate the personal perception of maintenance personnel regarding human factors and safety in the workplace, specific tools had to be introduced. One tool that has been extensively used by FAA is the Maintenance Resource Management Technical Operations Questionnaire (MRM/TOQ). Among other questions that were used to measure different human factors, the following questions were used to measure the level of trust:

- "My supervisor can be trusted".

- "My safety ideas would be acted on if reported to supervisor".

- "My supervisor protects confidential information."

- "I know proper channels to report safety issues" [86,110].

These types of questionnaires evolve and adapt over time, and new data is accumulating through continuous research. The optimum result would be to obtain a large amount of data from the full range of aviation activities, which would enable researchers to analyse results comparatively, inferentially, and longitudinally [86].

\section{The Relation between Trust and Communication}

Literature has indicated that personal trust is an essential element that is associated with successful communication (see, for example, $[15,16,18-20,22,77,78]$ ). Experimental research has proven that face-to-face communication has been highly successful due to, among other reasons, the lifting of anonymity and the trust that the communicators show to each other. Face-to-face communication enhances verbal communication where trust elements, such as commitment and promises, are used along with body language, facial expressions, and visual cues to ensure a successful outcome [82]. 
Experimental evidence, regarding the relation between trust and communication, is scarce and more research in that field is needed [82].

When it comes to group communication, the group should establish common ground for the members to agree upon some basic ideas/concepts. This process depends on trust development among the members, towards their incentives and attitudes, for the group to create a functioning communication ([30] as adapted by [111,112]).

At the organizational level, when organizational culture supports open and free communication among all levels of employees, it is expected from them to enhance their trust levels towards each other and their organization $[13,74,101]$. Recent research in the aviation maintenance field indicated that communication and trust are two major factors that both can be used as tools for maintenance failure detection [113]. Additionally, according to the FAA, trust is an essential element for a successful safety program in the aviation industry. The different safety programs base their effectiveness on the successful communication among the different business partners and mutual trust or distrust can affect this communication.

\section{Discussion and Conclusions}

This review aimed to include mainly aviation maintenance literature relevant to communication and trust and this literature was found to be scarce. This suggests that, the factors of communication and trust, either individually or in combination, are understudied in aviation maintenance. To unfold this critical issue, communication and trust were explored in multidisciplinary literature and they were considered within the aviation maintenance framework. Some of the most important findings of the review are presented in Figure 6.

Most researchers have concluded that aviation has recognised miscommunication as a paramount human factor contributing to errors [36,114], but there is still much work to be done to eliminate this risk and provide the industry with error free communication. A gap has been identified in the issues that arise from the communication among different areas within aviation, and there is research underway mitigating these issues [46,47]. Every aspect of human nature and personality characteristics should be considered, to eliminate the factors that might lead the message to not be adequately delivered and understood in the communication process. To succeed in this, it is of high importance to place the mechanisms and models of miscommunication in the specific frame of aviation industry [30] as there is a great deal of potential in their implementation and development, especially in aviation maintenance [115].

Several decades ago, it became quite apparent that standard terminology and methodology would help reduce human errors related to aircraft procedures, especially in the written forms of communication, e.g., documentation, manuals, workcards, etc. [55,59]. Due to such endeavours, new technology and improved software are being used in the place of internal communication forms and workcards with encouraging results [56,57]. Extended research has still to be conducted in this direction to make novel technology more appealing and subsequently resolve both managers' and employees' negative attitude to similar platforms [58]. On the other hand, there is a lack of systemic study of maintenance debriefings that does not help in the comprehension and improvement of this crucial step in the maintenance procedure [62].

Training is the only vehicle that will introduce and facilitate all the required communication skills $[63-65,116]$. There has been considerable research during the past few decades in developing systems and the generation of effective programs. There is, however, potential for further research in the long-term effectiveness of these programs as trainees do not seem to acquire the desired level of knowledge and skill [50].

The framework within interorganisational trust has a lot of potential to be restructured, to enhance business interactions, and to achieve further development [15]. The literature found that deals with trust in the aviation industry is scarce. This alone indicates that there is a great deal of work that could be done in identifying and associating trust with other traits in the actual working environment in 
aviation maintenance [19]. The interesting element in trust is that the initial levels of trust (the levels of trust an individual or a company indicates at the beginning of a collaboration) are high, so human factors researchers could focus their research towards the direction of the mechanisms which will contribute to maintaining these levels high over time [106].

\section{Communication and Trust}

Experimental evidence, regarding the relation between trust and communication, is scarce and more research on that field is needed [82].

More specifically the relationship between trust and communication (how they interact with each other) among colleagues, between subordinates and managers/supervisors and between maintenance staff and technology.

\section{Communication}

Most researchers have concluded that aviation has recognised miscommunication as a paramount human factor contributing to errors [36, 114], but there is still much work to be done to eliminate this risk and provide the industry with an error free communication

To succeed in this, it is of high importance to place the mechanisms and models of miscommunication in the specific frame of aviation industry [30] as there is a lot of potential in their implementation and development there, especially in aviation maintenance [115].

While debriefs may appear to be cost effective and produce quick results in the organizations' improvement of performance, the study of such processes over the years is scattered across different disciplines with no conclusive results [62].

This research, among other issues, indicates that a significant gap has been recognized between the quality of the students' oral and written communication skills gained during their studies (especially in the aeronautical area) and the skills required by the aeronautical industry to perform the tasks safely [71].

Extended research has still to be conducted in using new technologies to make them more appealing and subsequently resolve both managers' and employees' negative attitude to similar platforms [58].

\section{Trust}

Trust, while it has been extensively researched by organizational researchers and more specifically by certain industries (e.g. web commerce) it is understudied in high-reliability organisations, as the aviation industry [76] .

The optimum result would be to obtain a large amount of data from the full range of aviation activities, which would enable researchers to analyze results comparatively, inferentially, and longitudinally [86].

The literature found that is dealing with trust in the aviation industry is scarce. This alone indicates that there is a lot of work that could be done in identifying and associating trust with other traits in the actual working environment in aviation maintenance [19].

The interesting element in trust is that the Initial levels of trust (the levels of trust an individual or a company indicates at the beginning of a collaboration) are high, so human factors researchers could focus their research towards the direction of the mechanisms which will contribute to maintaining these levels high over time [106].

More extensive research is needed to standardize trust measuring methodologies, in analyzing the results, and to enable smaller scale research to be compared safely, which in turn will lead to reliable results and interventions [86]. Only over recent years, have researchers started trying to unveil the causational factors for maintenance errors [117].

Trust in technology and the negative effects of excessive interpersonal or organizational trust can be researched further, as again these are understudied fields, especially in aviation maintenance.

Figure 6. Tabular representation of the recognised future research potentials. 
More extensive research is needed to standardize trust measuring methodologies, analyse results, and enable smaller-scale research to be compared safely, which, in turn, will lead to reliable results and interventions [86]. Only over recent years have researchers started trying to unveil the causal factors for maintenance errors [117].

Following the example of 'Future Sky Safety' and trying to fill in the gap of the human factors research in aviation maintenance, the investigation of the interaction between two factors, such as communication and trust, is pioneering within the aviation maintenance context and of great importance. The research that has been conducted in aviation human factors so far is mainly a single factor research. Therefore, the study of two and more factors and their impact on human performance is a direction more researchers should follow in the future, given that human reaction is the result of different factors and conditions that interact with each other.

Under the scope of the investigation of factors in combinations, it would be interesting to see further combined research in communication and trust in aviation maintenance. More specifically the relationship between trust and communication (how they interact with each other) among colleagues, between subordinates and managers/supervisors, and between maintenance staff and technology. Furthermore, trust among aviation businesses and how they interact with each other would be a domain for further research, as new data could be exposed. Moreover, trust in technology has been under-researched in the aviation maintenance domain, which appears to be bereft of any significant research in this field. Additionally, the negative effects of excessive interpersonal or organizational trust can be researched further as, again, this is an understudied field, especially in aviation maintenance.

Author Contributions: Conceptualization, A.V.C.; Data Curation, A.V.C.; Writing-Original Draft Preparation, A.V.C.; Writing-Review \& Editing, A.V.C., W.M., P.B., P.M.

Funding: This research received no external funding.

Conflicts of Interest: The authors declare no conflict of interest.

\section{References}

1. Dhillon, B.S.; Liu, Y. Human Error in Maintenance: A Review. J. Qual. Maint. Eng. 2006, 12, 21-36. [CrossRef]

2. Reason, J.T. Managing the Risks of Organizational Accidents; Ashgate: Farnham, UK, 1997.

3. European Aviation Safety Agency. Annual Safety Review 2014; European Aviation Safety Agency: Cologne, Germany, 2015.

4. Blaise, J.-C.; Levrat, E.; Iung, B. Process Approach-Based Methodology for Safe Maintenance Operation: From Concepts to SPRIMI Software Prototype. Saf. Sci. 2014, 70, 99-113. [CrossRef]

5. Chang, Y.-H.; Wang, Y.-C. Significant Human Risk Factors in Aircraft Maintenance Technicians. Saf. Sci. 2010, 48, 54-62. [CrossRef]

6. Dupont, G. The Dirty Dozen Errors in Maintenance. In Proceedings of the 11th Symposium on Human Factors in Maintenance and Inspection: Human Error in Aviation Maintenance, Washington, DC, USA, 12-13 March 1997.

7. Flin, R.; O'Connor, P.; Mearns, K. Crew Resource Management: Improving Team Work in High Reliability Industries. Team Perform. Manag. Int. J. 2002, 8, 68-78. [CrossRef]

8. Marquardt, N.; Gades, R.; Robelski, S. Implicit Social Cognition and Safety Culture. Hum. Factors Ergon. Manuf. Serv. Ind. 2012, 22, 213-234. [CrossRef]

9. Wise, J.A.; Hopkin, V.D.; Garland, D.J. Handbook of Aviation Human Factors; CRC Press: Boca Raton, FL, USA, 2010.

10. Reiman, T. Understanding Maintenance Work in Safety-Critical Organisations-Managing the Performance Variability. Theor. Issues Ergon. Sci. 2011, 12, 339-366. [CrossRef]

11. Federal Aviation Administration. Addendum-Chapter 14: Human Factors. In Aviation Maintenance Technical Handbook FAA-H-8083-30; US Department of Transportation: Oklahoma City, OK, USA, 2011.

12. Silvagni, S.; Napoletano, L.; Graziani, I.; Blaye, P.L.; Rognin, L. Concept for Human Performance Envelope; EU Horizon 2020 Research and Innovation Programme: Brussels, Belgium, 2015. 
13. Whitener, E.M.; Brodt, S.E.; Korsgaard, M.A.; Werner, J.M. Managers as Initiators of Trust: An Exchange Relationship Framework for Understanding Managerial Trustworthy Behavior. Acad. Manag. Rev. 1998, 23, 513-530. [CrossRef]

14. Hernandez, J.M.d.C.; Santos, C.C.d. Development-Based Trust: Proposing and Validating a New Trust Measurement Model for Buyer-Seller Relationships. BAR Braz. Adm. Rev. 2010, 7, 172-197. [CrossRef]

15. Bachmann, R. The Coordination of Relations Across Organizational Boundaries. Int. Stud. Manag. Org. 2003, 33, 7-21. [CrossRef]

16. Carrière, J.; Bourque, C. The Effects of Organizational Communication on Job Satisfaction and Organizational Commitment in a Land Ambulance Service and the Mediating Role of Communication Satisfaction. Career Dev. Int. 2009, 14, 29-49. [CrossRef]

17. Cascio, W.F. Managing a Virtual Workplace. Acad. Manag. Exec. 2000, 14, 81-90. [CrossRef]

18. Cho, Y.J.; Park, H. Exploring the Relationships Among Trust, Employee Satisfaction, and Organizational Commitment. Public Manag. Rev. 2011, 13, 551-573. [CrossRef]

19. Flin, R. Measuring Safety Culture in Healthcare: A Case for Accurate Diagnosis. Saf. Sci. 2007, 45, 653-667. [CrossRef]

20. Muchinsky, P.M. An Intraorganizational Analysis of the Roberts and O'Reilly Organizational Communication Questionnaire. J. Appl. Psychol. 1977, 62, 184-188. [CrossRef]

21. Shapiro, D.B.; Sheppard, H.; Cheraskin, L. Business on a Handshake. Negot. J. 1992, 8, 365-377. [CrossRef]

22. Yeager, S.J. Measurement of Independent Variables Which Affect Communication: A Replication of Roberts and O'Reilly. Psychol. Rep. 1978, 43, 1319-1324. [CrossRef]

23. Shannon, C.; Weaver, W. The Mathematical Theory of Communication; University of Illinois Press: Champaign, IL, USA, 1949.

24. Fiske, J. Introduction to Communication Studies (Studies in Culture and Communication); Taylor \& Francis Group/Books: London, UK, 1990.

25. Berelson, B.; Steiner, G. Human Behavior: An Inventory of Scientific Findings; Harcourt, Brace, and World: Oxford, UK, 1964; p. 527.

26. Ayer, A.J. What is Communication? J. Commun. 1955, 9, 13.

27. Schramm, W. How Communication Works. In The Process and Effects of Mass Communication; University of Illinois Press: Champaign, IL, USA, 1954; pp. 3-26.

28. Duncan, T.; Moriarty, S.E. A Communication-Based Marketing Model for Managing Relationships. J. Mark. 1998, 62, 1-13. [CrossRef]

29. Kanki, B.G.; Helmreich, R.L.; Anca, J. Communication and Crew Resource Management. In Crew Resource Management, 2nd ed.; Academic Press: London, UK, 2010; pp. 111-146.

30. Anolli, L.; Ciceri, R.; Riva, G. Say not to Say: New Perspectives on Miscommunication; IOS Press: Washington, DC, USA, 2002; Volume 3.

31. Parret, H. Indirection, Manipulation and Seduction in Discourse. In Pretending to Communicate; Walter De Gruyter GmbH: Berlin, Germany, 1994.

32. Mortensen, C.D. Miscommunication, 1st ed.; Oaks, T., Ed.; Sage Publications: London, UK, 1997.

33. Shukri, S.A.; Millar, R.M.; Gratton, G.; Garner, M. The Potential Risk of Communication Media in Conveying Critical Information in the Aircraft Maintenance Organisation: A Case Study. IOP Conf. Ser. Mater. Sci. Eng. 2016, 152, 012044. [CrossRef]

34. Cushing, S. Fatal Words: Communication Clashes and Aircraft Crashes; University of Chicago Press: Chicago, IL, USA, 1994.

35. Dismukes, R.K. (Ed.) Human Error in Aviation; Routledge: London, UK, 2009.

36. Balk, A.D.; Bossenbroek, J.W. Aircraft Ground Handling and Human Factors. A Comparative Study of the Perceptions by Ramp Staff and Management; NLR Air Transport Safety Institute: Amsterdam, The Netherlands, 2010.

37. Drury, C.G. Human Factors in Aircraft Maintenance; RTO AVT Lecture Series: Sofia, Boulgaria, 2000; pp. 15-1-15-9.

38. McFadden, K.L.; Towell, E.R. Aviation Human Factors: A Framework for the New Millennium. J. Air Transp. Manag. 1999, 5, 177-184. [CrossRef]

39. Graham, S.; Bonacum, D.; Leonard, M. The Human Factor: The Critical Importance of Effective Teamwork and Communication in Providing Safe Care. Qual. Saf. Health Care 2004, 13, 85-90. 
40. Lautman, L.; Gallimore, P. Control Caused Accident: Results of a 12-Operator Survey; Boeing Commercial Airplane Co.: Seattle, WA, USA, 1987.

41. Wiegmann, D.A.; Shappell, S.A. Human Error and Crew Resource Management Failures in Naval Aviation Mishaps: A Review of US Naval Safety Cetre Data, 1990-1996. Aviat. Space Environ. Med. 1999, 70, 1147-1151. [PubMed]

42. Yacavone, D.W. Mishap Trends and Cause Factors in Naval Aviation: A Review of Naval Safety Center data. Aviat. Space Environ. Med. 1993, 64, 392-395.

43. Wiegmann, D.A.; Shappell, S.A. A Human Error Approach to Aviation Accident Analysis: The Human Factors Analysis and Classification System; Burlington, V.T., Ed.; Ashgate: Aldershot, UK, 2003.

44. Murphy, P. The Role of Communications in Accidents and Incidents during Rail Possessions. In Engineering Psychology and Cognitive Ergonomics Volume Five Aerospace and Transportation Systems; Harris, D., Ed.; Ashgate: Aldershot, UK, 2001.

45. Rail Safety Standards Board. Railway Group Safety Plan; Rail Safety Standards Board: London, UK, 2003.

46. Caldwell, J.A. Fatigue in Aviation. Trav. Med. Infect. Dis. 2005, 3, 85-96. [CrossRef] [PubMed]

47. Mattson, M.; Petrin, D.A.; Young, J.P. Integrating Safety in the Aviation System: Interdepartmental Training for Pilots and Maintenance Technicians. J. Air Transp. World Wide 2001, 6, 37-64.

48. National Transportation Safety Board (NTSB). Aircraft Accident Report-In-Flight Loss of Propeller Blade Forced Landing and Collision with Terrain, Atlantic Southeast Airlines, Inc., Flight 529, Embraer EMB-120RT, N256AS; NTSB: Washington, DC, USA, 1996.

49. Bonnefon, J.F.; Feeney, A.; De Neys, W. The Risk of Polite Misunderstandings. Curr. Dir. Psychol. Sci. 2011, 20, 321-324. [CrossRef]

50. Taylor, J.C.; Thomas, R.L., III. Written Communication Practices as Impacted by a Maintenance Resource Management Training Intervention. J. Air Transp. 2003, 8, 69-90.

51. Von Thaden, T.L.; Wiegmann, D.A.; Shappell, S.A. Organizational Factors in Commercial Aviation Accidents. Int. J. Aviat. Psychol. 2006, 16, 239-261. [CrossRef]

52. Ward, M.E.; McDonald, N.; Morrison, R.; Gaynor, D.; Nugent, T. A Performance Improvement Case Study in Aircraft Maintenance and Its Implications for Hazard Identification. Ergonomics 2010, 53, 247-267. [CrossRef]

53. Sogg, S. An Integrated Systems Approach to Human Factors in Commercial Aviation Maintenance Systems; Aviation Maintenance Symposium: San Francisco, CA, USA, 2002.

54. Drury, C.G.; Guy, K.P.; Wenner, C.A. Outsourcing Aviation Maintenance: Human Factors Implications, Specifically for Communications. Int. J. Aviat. Psychol. 2010, 20, 124-143. [CrossRef]

55. Drury, C.G.; Johnson, W.B. Writing Aviation Maintenance Procedures That People Can/Will Follow. In Proceedings of the Human Factors and Ergonomics Soiety 57th Annual Meeting, San Diego, CA, USA, 3 October 2013.

56. Kraus, D.C.; Gramopadhye, A.K. Effect of Team Training on Aircraft Maintenance Technicians: Computer-Based Training Versus Instructor-Based Training. Int. J. Ind. Ergon. 2001, 27, 141-157. [CrossRef]

57. Liang, G.-F.; Lin, J.-T.; Hwang, S.-L.; Wang, E.M.-Y.; Patterson, P. Preventing Human Errors in Aviation Maintenance Using an On-Line Maintenance Assistance Platform. Int. J. Ind. Ergon. 2010, 40, 356-367. [CrossRef]

58. Chaparro, A.; Groff, L.S. Human Factors Survey of Aviation Maintenance Technical Manuals. In 16th Human Factors in Aviation Maintenance Symposium; Embry-Riddle Aeronautical University Scholarly Commons: San Francisco, CA, USA, 2002.

59. Chervak, S.; Drury, C.G.; Ouellette, J.P. Simplified English for Aircraft Workcards. Hum. Factors Ergon. Soc. Annu. Meet. Proc. 1996, 40, 303-307. [CrossRef]

60. Karanikas, N.; Soltani, P.; Boer, R.J.; Roelen, A.L.C. Safety Culture Development: The Gap Between Industry Guidelines and Literature, and the Differences Amongst Industry Sectors. In Advances in Safety Management and Human Factors: Proceedings of the AHFE 2016 International Conference on Safety Management and Human Factors; Springer International Publishing: Orlando, FL, USA, 2016.

61. Parke, B.; Kanki, B.G. Best Practices in Shift Turnovers: Implications for Reducing Aviation Maintenance Turnover Errors as Revealed in ASRS Reports. Int. J. Aviat. Psychol. 2008, 18, 72-85. [CrossRef]

62. Tannenbaum, S.I.; Cerasoli, C.P. Do Team and Individual Debriefs Enhance Performance? A Meta-Analysis. Hum. Factors 2013, 55, 231-245. [CrossRef] [PubMed] 
63. Patankar, M.S.; Taylor, J.C. MRM Training, Evaluation, and Safety Management. Int. J. Aviat. Psychol. 2008, 18, 61-71. [CrossRef]

64. Salas, E.; Burke, C.S.; Bowers, C.A.; Wilson, K.A. Team Training in the Skies: Does Crew Resource Management (CRM) Training Work? Hum. Factors 2001, 43, 641-674. [CrossRef]

65. Taylor, J.C.; Patankar, M.S. Four Generations of MRM: Evolution of Human Error Management Programs in the United States. J. Air Transp. World Wide 2001, 6, 3-32.

66. Lappas, I.; Kourousis, K.I. Anticipating the Need for New Skills for the Future Aerospace and Aviation Professionals. J. Aerosp. Technol. Manag. 2016, 8, 232-241. [CrossRef]

67. Salas, E.; Tannenbaum, S.I.; Kraiger, K.; Smith-Jentsch, A.K. The Science of Training and Development in Organizations: What Matters in Practice. Psychol. Sci. Public Interest Suppl. 2012, 13, 74-101. [CrossRef]

68. Karanikas, N. Using Reliability Indicators to Explore Human Factors Issues in Maintenance Databases. Int. J. Qual. Reliab. Manag. 2013, 30, 116-128. [CrossRef]

69. Kirkpatrick, D. Evaluating Training Programs: The Four Levels; Berrett-Koehler: San Francisco, CA, USA, 1998.

70. Ribeiro, B.; Filipe, P. Dissemination, Exploitation and Communication; EU's Horizon 2020 Research and Innovation Programme: Brussels, Belgium, 2016.

71. Karanikas, N. Human Error Views: A Framework for Benchmarking Organizations and Measuring the Distance between Academia and Industry. In Proceedings of the 49th ESReDA Seminar, Brussels, Belgium, 29-30 October 2015.

72. Malagas, K.; Fragoudaki, A.; Kourousis, K.I.; Nikitakos, N. The Prospects of the Higher Education Aviation Programs in Greece: A Missed Opportunity or a Challenge to Meet? J. Aerosp. Technol. Manag. 2017, 9, 510-518. [CrossRef]

73. Robinson, S.L. Trust and Breach of the Psychological Contract. Adm. Sci. Q. 1996, 41, 574-599. [CrossRef]

74. Butler, J.K.J. Towards Understanding and Measuring Conditions of Trust: Evolution of a Conditions of Trust Inventory. J. Manag. 1991, 17, 643-663. [CrossRef]

75. Mayer, R.C.; Davis, J.H.; Schoorman, F.D. An Integrative Model of Organizational Trust. Acad. Manag. Rev. 1995, 20, 709-734. [CrossRef]

76. Cox, S.; Jones, B.; Collinson, D. Trust Relations in High-Reliability Organizations. Risk Anal. 2006, 26, 1123-1138. [CrossRef]

77. O'Reilly, C.A. Supervisors and Peers as Information Sources, Group Supportiveness, and Individual Decision-Making Performance. J. Appl. Psychol. 1977, 62, 632-635. [CrossRef]

78. O'Reilly, C.A.; Roberts, K.H. Task Group Structure, Communication, and Effectiveness in Three Organizations. J. Appl. Psychol. 1977, 62, 674-681. [CrossRef]

79. Axelrod, R. The Evolution of Cooperation; Basic Books: New York, NY, USA, 1984.

80. Deutsch, M. Cooperation and Trust: Some Theoretical Notes. In Nebraska Symposium on Motivation; University of Nebraska Press: Lincoln, NE, USA, 1962.

81. Earley, P.C. Trust, Perceived Importance of Praise and Criticism, and Work Performance: An Examination of Feedback in the United States and England. J. Manag. 1986, 12, 457-473. [CrossRef]

82. Ben-Ner, A.; Putterman, L. Trust, Communication and Contracts: An Experiment. J. Econ. Behav. Organ. 2009, 70, 106-121. [CrossRef]

83. McAllister, D.J. Affect-And Cognition-Based Trust as Foundations for Interpersonal Cooperation in Organizations. Acad. Manag. J. 1995, 38, 24-59.

84. Zand, D.E. Trust and Managerial Problem Solving. Adm. Sci. Q. 1972, 17, 229-239. [CrossRef]

85. Harvey, C.; Stanton, N.A. Safety in System-Of-Systems: Ten Key Challenges. Saf. Sci. 2014, 70, 358-366. [CrossRef]

86. Taylor, J.C.; Thomas, R.L., III. Toward Measuring Safety Culture in Aviation Maintenance: The Structure of Trust and Professionalism. Int. J. Aviat. Psychol. 2003, 13, 321-343. [CrossRef]

87. Reason, J.T. Organizational Accidents Revisited; CRC Press: Boca Raton, FL, USA; London, UK, 2016.

88. Dekker, S. Drift into Failure: From Hunting Broken Components to Understanding Complex Systems; Ashgate: Farnham, UK; Burlington, VT, USA, 2011.

89. Rasmussen, J. Risk Management in a Dynamic Society: A Modelling Problem. Saf. Sci. 1997, 27, 183-213. [CrossRef]

90. Leveson, N. A New Accident Model for Engineering Safer Systems. Saf. Sci. 2004, 42, 237-270. [CrossRef] 
91. Jian, J.-Y.; Bisantz, A.M.; Drury, C.G. Towards an Empirically Determined Scale of Trust in Computerized Systems: Distinguishing Concepts and Types of Trust. Proc. Hum. Factors Ergon. Soc. 1998, 1, 501-505. [CrossRef]

92. Ockerman, J.; Pritchett, A. A Review and Reappraisal of Task Guidance: Aiding Workers in Procedure Following. Int. J. Cogn. Ergon. 2000, 4, 191-212. [CrossRef]

93. Patankar, M.S.; Gomez, M. Maintenance ASAP Programs: Barriers and Opportunities; Federal Aviation Agency (FAA): Washington, DC, USA, 2004.

94. McKnight, D.H.; Thatcher, J.B. Trust in Technology: Development of a Set of Constructs and Measures. In Handbook of Trust Research; Zaheer, A., Bachmann, R., Eds.; American Psychological Association: Washington, DC, USA, 2004.

95. McKnight, D.H.; Carter, M.; Thatcher, J.B.; Clay, P. Trust in a Specific Technology: An Investigation of Its Components and Measures. ACM Trans. Manag. Inf. Syst. 2011, 2, 1-25. [CrossRef]

96. McKnight, D.H.; Chervany, N.L. The Meanings of Trust. In MIS Research Center Working Paper Series; University of Minnesota: Minneapolis, MN, USA, 1996.

97. Powell, W.W.; DiMaggio, P.J. The New Institutionalism in Organizational Analysis; University of Chicago Press: Chicago, IL, USA, 1991.

98. Giddens, A. The Consequences of Modernity; John Wiley \& Sons: New Jersey, NJ, USA, 1990.

99. Salam, M.A. The Mediating Role of Supply Chain Collaboration on the Relationship between Technology, Trust and Operational Performance. Benchmarking Int. J. 2017, 24, 298-317. [CrossRef]

100. Arrow, K. The Limits of Organization; Norton: New York, NY, USA, 1974.

101. Zaheer, A.; Bachmann, R. Handbook of Trust Research. Elgar Original Reference; Edward Elgar Publishing: Cheltenham, UK, 2006.

102. Kramer, R.M.; Tyler, T.R. Whither Trust? In Trust in Organizations; Kramer, R.M., Tyler, T.R., Eds.; Sage: Thousand Oaks, CA, USA, 1996.

103. Catino, M. A Review of Literature: Individual Blame vs. Organizational Function Logics in Accident Analysis. J. Conting. Crisis Manag. 2008, 16, 53-62. [CrossRef]

104. Dekker, S.W.A. Just Culture:Who Gets to Draw the Line? Cogn. Technol. Work 2009, 11, 177-185. [CrossRef]

105. Goglia, J.; Patankar, M.S.; Taylor, J.C. Lack of Error Mitigation Tools: The Weakest Link in Maintaining Airworthiness? In Proceedings of the 55th Annual International Air Safety Seminar, Dublin, Ireland, 4-7 November 2002.

106. McKnight, D.H.; Cummings, L.L.; Chervany, N.L. Initial Trust Formation in New Organizational Relationships. Acad. Manag. 1998, 23, 473.

107. Rotter, J.B. A New Scale for the Measurement of Interpersonal Trust. J. Pers. 1967, 35, 651-665. [CrossRef] [PubMed]

108. Hovden, J.; Størseth, F.; Tinmannsvik, R.K. Multilevel Learning from Accidents-Case Studies in Transport. Saf. Sci. 2011, 49, 98-105. [CrossRef]

109. Naevestad, T.O. Safety Cultural Preconditions for Organizational Learning in High-Risk Organizations. J. Conting. Crisis Manag. 2008, 16, 154-163. [CrossRef]

110. Patankar, M.; Driscoll, D. Factors Affecting the Success or Failure of Aviation Safety Action Programs in Aviation Maintenance Organizations; Federal Aviation Administration: Washington, DC, USA, 2005.

111. Donath, J.S. Identity and Deception in the Virtual Community. In Communities in Cyberspace; Smith, M.A., Kollock, P., Eds.; Routledge: London, UK, 1999.

112. Bachmann, R. Trust, Power and Control in Trans-Organizational Relations. Organ. Stud. 2001, 22, 337-365. [CrossRef]

113. Langer, M.; Braithwaite, G.R. The Development and Deployment of a Maintenance Operations Safety Survey. Hum. Factors 2016, 58, 986-1006. [CrossRef]

114. Bureau of Air Safety Investigation Australia. Human Factors in Airline Maintenance: A Study of Incident Reports; Department of Transport and Regional Development Bureau of Air Safety Investigation Australia: Canberra, Australia, 1997.

115. McRoy, S. Preface: Detecting, Repairing and Preventing Human-Machine Miscommunication. Int. J. Hum. Comput. Stud. 1998, 48, 547-552. [CrossRef] 
116. Robertson, M. Maintenance Resource Management. In Human Factors Guide for Aviation Maintenance; Authority, F.A., Ed.; Federal Aviation Administration: Washington, DC, USA, 2005.

117. Hobbs, A.; Williamson, A. Associations Between Errors and Contributing Factors in Aircraft Maintenance. Hum. Factors 2003, 45, 186-201. [CrossRef]

(C) 2019 by the authors. Licensee MDPI, Basel, Switzerland. This article is an open access article distributed under the terms and conditions of the Creative Commons Attribution (CC BY) license (http://creativecommons.org/licenses/by/4.0/). 


\title{
The Regulatory Framework for Safety Management Systems in Airworthiness Organisations
}

\author{
Eranga Batuwangala ${ }^{*}{ }^{\dagger}$, Jose Silva $^{\dagger}$ and Graham Wild ${ }^{*}+$ \\ School of Engineering, Aerospace and Aviation Discipline, RMIT University, Melbourne, VIC 3000, Australia; \\ jose.silva@rmit.edu.au \\ * Correspondence: s3576656@student.rmit.edu.au (E.B.); graham.wild@rmit.edu.au (G.W.); \\ Tel.: +61-422-123-938 (E.B.) \\ + These authors contributed equally to this work.
}

Received: 31 August 2018; Accepted: 1 November 2018; Published: 7 November 2018

\begin{abstract}
In recent years, a growing emphasis on safety has driven various industries, both in manufacturing and service, to implement a Safety Management System (SMS) in their organisations. SMSs have also been widely implemented in aviation due to both regulatory requirements and voluntary implementation with the aim of decreasing incidents and accidents whilst reducing inefficiencies and costs stemming from the repercussions of safety failures. The aviation industry involves various players for the provision of services ranging from airline operations, maintenance, aerodrome operations, air traffic services, aircraft and component design, manufacturing, and training. Not all organisations in the aviation industry have implemented SMSs. Furthermore, SMS is currently not regulated for all aviation organisations. Whilst technology has played a key role in driving down the number of accidents and incidents in aviation, the growth in air traffic demands having programs in place to further drive down accident rates. In this context, this article provides an investigation to the regulatory framework for the implementation of SMSs in aviation, including the requirements stipulated by the International Civil Aviation Organisation (ICAO) and the status of SMS regulation of key National Aviation Authorities (NAA) and Military Aviation Authorities (MAA), with a focus on organisations involved in airworthiness including initial and continuing airworthiness. This article also investigates the challenges of implementing SMSs in organisations involved in Airworthiness, as well as the benefits that could be gained by service providers as well as NAA's or MAA's through SMSs.
\end{abstract}

Keywords: safety management system; human error; airworthiness; design organization

\section{Introduction to Safety and Safety Management Systems in Aviation}

Air transport is growing rapidly with the 2017 statistics of 4 billion air travellers expected to nearly double in the next 15 years [1]. The forecasted traffic of nearly 60 million scheduled passenger flights expected in 2030 compared to 35 million in 2016 will result in over two commercial air transport accidents per week if the same accident rate of 2016 [2] prevails in 2030. This strongly suggests that growth in air traffic requires a parallel effort in aviation safety to reduce accident rates. Air transport is considered the safest way to travel, even with rapid growth in air traffic demands, and technological developments which have resulted in complex aircraft systems. To maintain safety into the future, novel programs and tools will play an increasingly important role in enhancing aviation safety and reducing safety occurrences. In aviation an incident is defined as a safety occurrence, less severe than an accident, associated with the operation of an aircraft which affects or could affect the safety of operation. An accident is defined as an occurrence associated with the operation of an aircraft in which a person is either fatally or seriously injured, or the aircraft sustains damage, experiences structural 
failure, or is lost/missing/completely inaccessible. A more detailed definition is provided in ICAO Annex 19 [3].

The meaning of the word "safety" varies based on the context of its usage and has different definitions in various industries. In aviation, safety means the state in which risks associated with aviation activities, related to, or in direct support of the operation of aircraft, are reduced and controlled to an acceptable level [3]. There are many notable academics and industry experts who have contributed to the evolution of safety in many industries and environments. Jens Rasmussen was a pioneer in the field of safety science for the last quarter of the 20th century specialising in the study of human factors [4]. In the 1980s, Rasmussen proposed a framework with three levels of human performance: skill-based, rule-based, and knowledge-based [5]. James Reason, a research psychologist who has published multiple books and papers, has produced ground-breaking work discussing human error. His book Human Error [6], dedicated to Jens Rasmussen, is said to be a masterpiece in phycological writing [7]. The famous "Swiss-Cheese" model, developed by Reason to illustrate how accidents involve successive breaches of multiple system defences, is widely used by safety specialists as an accident causation model. Since the first flight by the Wright brothers in 1903, aviation safety has progressed through three main eras [8]:

1. the technical era (from the early days of aviation until the 1960s) where safety deficiencies were mainly attributed to technological failures,

2. the human factors era (from the 1970s to the 1990s) when the focus of safety extended to include human factors issues, most notably human-human and human-machine interfaces, and

3. the organisational era (from the 1990s to the present), encompassing organisational factors in addition to human and technical factors.

More recently, and resulting from an increasing level of maturity in aviation safety, an emerging era of "Total Aviation System Approach" requires all aviation stakeholders and their interfaces to be understood and managed for the purpose of safety performance [8]. In addition, this concept of implementation of safety management by various stakeholders and service providers offers a more proactive approach to safety compared to the traditionally reactive approaches to aviation safety adopted in the past.

A Safety Management System (SMS) is a systematic approach to managing safety, including the necessary organisational structures, accountabilities, policies, and procedures [3]. SMSs have evolved from a combination of concepts in system safety, quality management systems, and other inputs [9]. Implementation and maintenance of an SMS have been either voluntary due to its recognition as an industry best practice for safety or due to regulatory compliance. Whilst SMS is widely applied in various industries especially those with high safety risks or complex operations such as oil and gas, construction, electricity generation, highways etc., it has also been actively implemented in aviation in the last decade. The main contributor to this is the standardisation of SMS requirements for aviation by the International Civil Aviation Organisation (ICAO), and the obligation of member States to comply with ICAO standards and recommended practices. SMS provides a framework of methodologies, tools and requirements that help organisations to understand the safety concepts, to construct and customise a management system that is best suited to achieve the required safety outcomes for each organisation. Whilst safety management was previously used as a tool to improve occupational health and safety [9], it has evolved into a much broader system encompassing technological, organisational, social, and psychological approaches to safety and systems thinking. The latest approach taken by ICAO is a total systems approach which considers the entire aviation industry as a system and all entities as sub-systems [8].

Though accidents were mainly attributed to technical failures in the early days of aviation, developments in technology have progressively led to more reliable systems, therefore shifting the interest of safety experts from the 1990s towards the role of human factors as contributory factors to accidents [7]. In fact, human error still holds the largest share of accident causal factors with 
a contribution of about $70 \%$ [10], therefore stressing the need to include adequate human factors training as a key component of current SMSs. Human factors affect aviation safety during various stages of the aircraft or system life cycle, from design, manufacture, operation, and maintenance to disposal [11]. Due to the safety of flights largely depending on the pilots operating the aircraft, there is an abundance of research into human factors and human error mainly in the context of aircraft flight operations [12-16]. Research has also been conducted on human error during air traffic control operations [17-19], aircraft maintenance [20,21], and the aerodrome operational environment [22]. Human error management tools, maintenance error decision tools, and human factor related accident investigation tools are actively used by aviation service providers as part of their safety management systems. An example of these tools is the Human Factors Analysis and Classification System (HFACS), which was developed for investigating and analysing the human causes of aviation accidents in both the military and civil domains [23-25]. In addition to this, the PEAR model considers people, environment, actions, and resources in relation to human factors in aviation maintenance [26], while the SHELL model provides a conceptual tool to analyse the interaction of multiple system components including software, hardware, environment, and liveware [27]. Another widely used tool is the Maintenance Error Decision Aid (MEDA) introduced by Boeing [28]. It is observed, however, that there is less research on management tools that may be more applicable to organisations involved in initial and continuing airworthiness functions including aircraft design, manufacture, and continuing airworthiness management.

This article presents an investigation of the aviation regulatory framework for the implementation of SMSs in organisations involved in various functions of aviation. Whilst previous research has been conducted on the comparison of military airworthiness regulatory frameworks [29], there is no published research found specifically on the adequacy and scope of aviation regulatory frameworks for the implementation of SMS covering different types of service providers. This paper presents a review of the SMS regulations of key aviation stakeholders with reference to the ICAO framework for SMSs, together with the challenges and benefits of implementing SMSs by aviation service providers involved in airworthiness functions.

\section{An Overview of the ICAO Framework for SMS}

The ICAO Annexes provide Standards and Recommended Practices (SARPS) to be enforced or adopted by States' National Aviation Authorities (NAA) as regulations or as industry best practices for civil aviation. While signatory States are required to regulate aviation in accordance with ICAO SARPS for Civil Aviation, Military Aviation Authorities (MAA) are also aligning their regulations in accordance with ICAO SARPS wherever practicable. ICAO Annex 19, first published in July 2013 (which became applicable in November 2013) [30], is dedicated to Safety Management. Annex 19 provides standards for the implementation and maintenance of a State Safety Program (SSP) by States, as well as for the provisioning of a Safety Management System (SMS) by applicable service providers involved in the various services and industries in aviation. Service providers will be regulated by the NAA or other nominated authority within each State. Prior to the publication of the first edition of Annex 19, SMS requirements existed across various ICAO Annexes and documents. The provisions to the 1st edition of Annex 19 were developed in accordance with recommendations provided by the Directors General of Civil Aviation Conference on a Global Strategy for Aviation Safety (Montréal, 20 to 22 March 2006) (DGCA/06) and the High-level Safety Conference (Montréal, 29 March to 1 April 2010) (HLSC/2010) regarding the need for an Annex dedicated to safety management. ICAO recognises that effective implementation of an SSP and implementation of an SMS by the service providers is a gradual process and is dependent on the complexity of air transportation and the level of maturity of the oversight capabilities of each State. The degree and method of implementation of ICAO Annexes vary in each State. A study conducted on aerodromes in EASA member States (2008-2010) indicated that the implementation of SMS requirements represented challenging demands on the authorities as well as the aerodromes [31]. However, under article 38 of the Convention [32], contracting States are 
required to notify ICAO of any differences between their national regulations and practices and the standards contained in a given Annex and any amendments thereto.

Edition 2 to ICAO Annex 19 was published in 2016, the provisions of which will become applicable by November 2019 [3]. Edition 2 provides amendments mainly capturing further developments of safety management provisions and the extension of safety management system (SMS) provisions to organisations responsible for the type design and/or manufacture of engines and propellers. Safety management under the provisions of Annex 19 complements ICAO's Global Aviation Safety Plan (GASP), Doc 10004 [33] and is supported by the Safety Management Manual, Doc 9589 [27] which provides guidance for the development, implementation, and maintenance of an SSP by the State and an SMS by individual organisations operating as aviation service providers.

Annex 19 is applicable to safety management functions related to, or in direct support of, the safe operation of aircraft [3]. It provides a generic list of requirements that is not specific to any particular aviation function or service provider or organisation.

In accordance with ICAO Annex 19, Edition 2, Chapter 3, through the SSP, States are required to ensure that the following service providers implement an SMS within their organisations [3]:

1. Approved Training Organisations that operate in accordance with Annex 1.

2. Operators of airplanes or helicopters authorized to conduct international commercial air transport in accordance with Annex 6, Part I or Part III (section II).

3. Approved Maintenance Organisations, providing services to operators of airplanes or helicopters engaged in international air transport in accordance with Annex 6, Part I or Part III (section II).

4. Organisations responsible for the type design or manufacture of aircraft, engines or propellers in accordance with Annex 8.

5. Air Traffic Services (ATS) providers in accordance with Annex 11.

6. Operators of certified aerodromes in accordance with Annex 14, Volume I.

It should be noted that the SMS framework was applicable to organisations responsible for type design and manufacture of aircraft with edition 1 of ICAO Annex 19. Edition 2 of the said Annex which becomes applicable by November 2019, has broadened this scope to organisations responsible for the design and manufacture of engines and propellers. The operators of aircraft (airplanes or helicopters) authorised to conduct international commercial air transport services in accordance with Annex 6 are required to ensure continuing airworthiness of aircraft. Furthermore, the State of Registry and State of Operator are responsible for ensuring that the operators develop or adopt requirements for continuing airworthiness. Thereby the operators' obligations for SMS implementation are extended to continuing airworthiness functions.

The ICAO specified framework for the implementation and maintenance of an SMS comprises of four main components and twelve elements as the minimum requirement. The framework can be used for the implementation of an SSP by the State, as well as for the implementation of an SMS by a State's aviation service providers by tailoring in accordance with the complexity and nature of the business of each organisation. These four main components and elements are [3]:

1. Safety policy and objectives

1.1. Management commitment

1.2. Safety accountability and responsibilities

1.3. Appointment of key safety personnel

1.4. Coordination of emergency response planning

1.5. SMS documentation

2. Safety risk management

2.1. Hazard identification 


\subsection{Safety risk assessment and mitigation}

3. Safety assurance

3.1. Safety performance monitoring and measurement

3.2. The management of change

3.3. Continuous improvement of the SMS

4. Safety promotion

\subsection{Training and education \\ 4.2. Safety communication}

Sharing and exchange of safety information is encouraged for global safety improvements, incident and accident prevention and safety standardization; this also forms a fundamental component of ICAO's GASP [33]. An equally important requirement is the protection of safety data and safety information, without which sharing and exchange of information cannot be promoted, and the continued availability of data and information cannot be expected. Whilst this is an industry concern, it is broadly addressed by the "Code of Conduct on the Sharing and Use of Safety Information" documented in the GASP [33] and supplemented by the "Principles for the protection of safety data, safety information and related sources" in Annex 19 [3]. However, the adequacy of Annex 19 and Doc $9859[3,33]$ addressing the concerns on the protection of safety data and safety information has been questioned by the aviation industry [34].

\section{Safety Management International Collaboration Group (SM-ICG)}

With the purpose of promoting a common understanding of SMS and facilitating its implementation across aviation internationally, the SM-ICG has been formed and comprises of many aviation authorities including the Federal Aviation Administration (FAA) of the United States, the European Aviation Safety Agency (EASA) of the European Union, the Civil Aviation Safety Authority (CASA) of Australia, the Transport Canada Civil Aviation (TCCA), the Civil Aviation Authority of United Kingdom (UK CAA), the Civil Aviation Authority of New Zealand (CAA NZ), the Aviation Safety and Security Agency (AESA) of Spain, the National Civil Aviation Agency (ANAC) of Brazil, the Civil Aviation Authority of the Netherlands (CAA NL), the Civil Aviation Authority of Singapore (CAAS), the Civil Aviation Department of Hong Kong (CAD HK), the Direction Générale de l'Aviation Civile (DGAC) of France, the Ente Nazionale per l'Aviazione Civile (ENAC) of Italy, the Federal Office of Civil Aviation (FOCA) of Switzerland, the Finnish Transport Safety Agency (Trafi), the Irish Aviation Authority (IAA), Japan Civil Aviation Bureau (JCAB), and the United Arab Emirates General Civil Aviation Authority (UAE GCAA), together with ICAO as an observer to the group [35]. Members of the group collaborate on common SMS/SSP topics of interest, whilst sharing products and lessons learnt in the implementation of SMS/SSP, which encourage the progression of a harmonized SMS across the international aviation community.

\section{Status of Regulation and Implementation of SMS-A Global Review}

Some States or countries have implemented an SSP and other States are in the process of implementation. Under the SSP, a nominated national authority which in most States is the NAA will have oversight on SMS implementation and maintenance by aviation service providers that are required to have an SMS as per the regulations of each State. SMS implementation varies worldwide in terms of regulatory enforcement as well as maturity. It is up to each NAA to determine the regulatory requirements and the timings of applicability of SMS for each aviation function. In most States, SMSs are mandated mainly for service providers that are in operational functions of aviation. Most States are yet to regulate SMSs explicitly for organisations engaged in airworthiness including initial and continuing airworthiness, whilst a few States are in the process of rulemaking for this 
sector, and some have taken the approach of promoting voluntary implementation of SMSs ahead of regulation. Continuing airworthiness may be considered as part of the operator's responsibilities, thereby in certain cases may be implicitly covered by the SMS requirements for an operator of commercial air transport. However, the Defence Aviation Safety Authority (DASA) of Australia has explicitly mandated SMSs for organisations engaged in initial and continuing airworthiness [36].

Some States have regulations specifically for SMSs, whilst some capture this as part of advisory publications or have embedded within individual regulations applicable for various aviation service providers. In most cases, a degree of flexibility prevails within the regulation for the implementation of SMSs, allowing organisations to implement SMSs by integrating already existing and proposed programs, policies or procedures including components of existing System Safety Programs (SSP) and management systems such as quality management systems (QMS) and Security Management Systems (SeMS). This may be the preferred option for some organisations to avoid duplication of processes and resources. Furthermore, organisations that provide multiple services under sub-entities within the parent organisation such as commercial air transport, aircraft maintenance, component maintenance, and aviation design may implement a common SMS across various sub-entities. Thereby in these cases, the SMSs implemented mainly for the requirement of the organisation's commercial air transportation would cover initial and continuing airworthiness organisations as well. Most NAAs would allow the service providers to tailor the SMSs in accordance with the nature of the business, the complexity of operations, activities and size of the organisations, within the broad framework of SMS components and elements provided in ICAO Annex 19.

Table 1 provides a comparison of the status of SMS regulations of the following key aviation authorities, including civil and military sectors. Specifically:

- Civil Aviation Safety Authority (CASA), Australia [37],

- Defence Aviation Safety Authority (DASA), Australia [36],

- European Aviation Safety Agency (EASA), European Union [38],

- European Defence Agency (EDA), European Union [39],

- Federal Aviation Administration (FAA), United States [40],

- US Air Force (USAF) [41,42], and

- $\quad$ Transport Canada (TC), Canada [43]

The scope of the review has been limited to the above-mentioned aviation authorities due to limitations in accessibility to data in the public domain and language constraints.

A comparison of SMS regulation status by key aviation authorities, considering only the fully regulated status for each service provider category is given in Figure 1. This indicates that all authorities listed, both civil and military, have regulated SMSs for operators engaged in regular public transport (or commercial air transport) and military air operations. A further review of regulations reveals this is applicable for both domestic and international operations. ICAO Annex 19 requires that those operators who conduct international commercial air transport in accordance with Annex 6, Part I or Part III (section II) to implement an SMS, and this requirement is well addressed through regulation by the aviation authorities. There are also considerable regulations on SMSs for maintenance organisations as well as air navigation service providers and aerodrome operators, which is also in line with the requirements of Annex 19. Therefore, it is evident that most authorities have focused more on SMS regulations for organisations involved in the operational environments of aviation. 


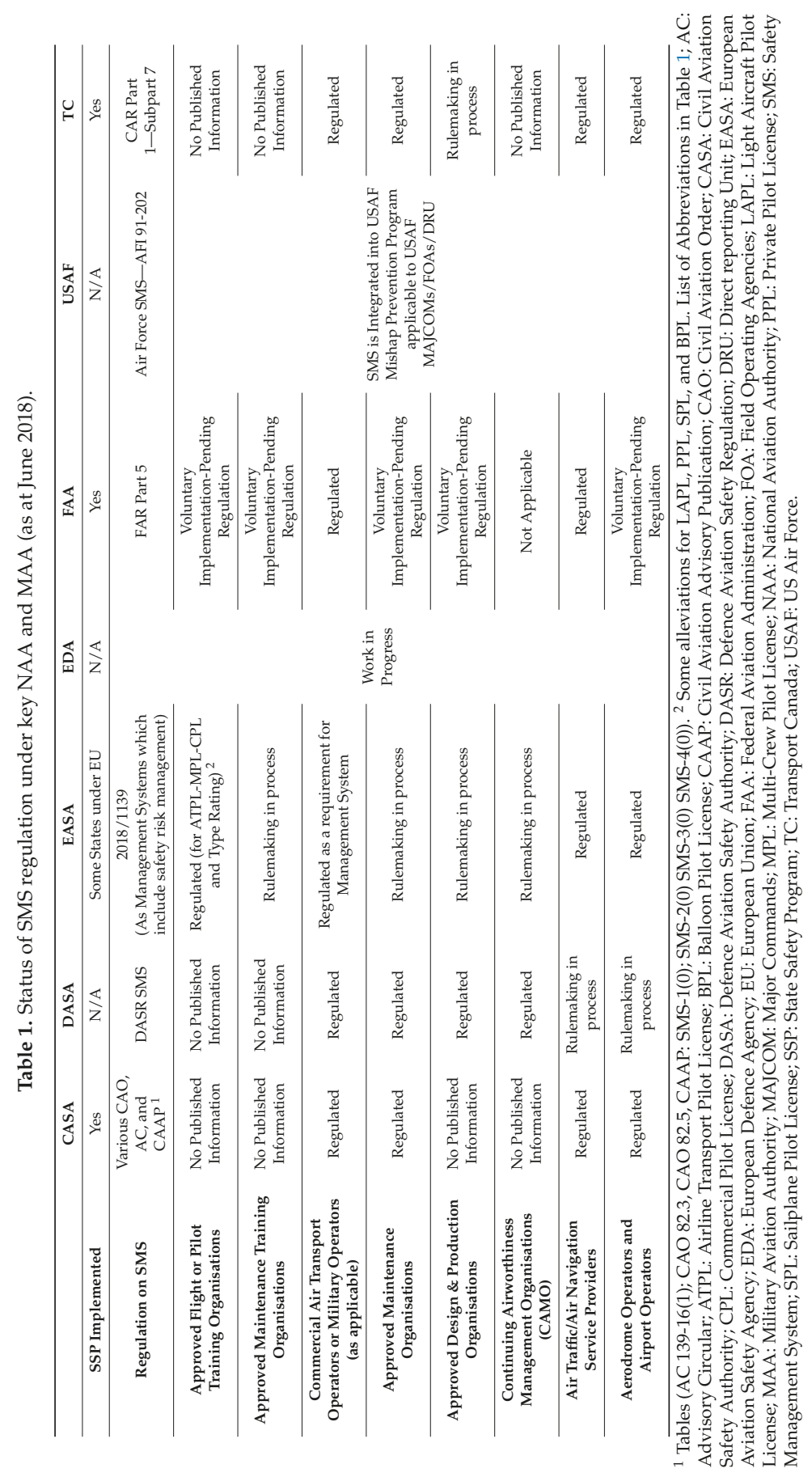




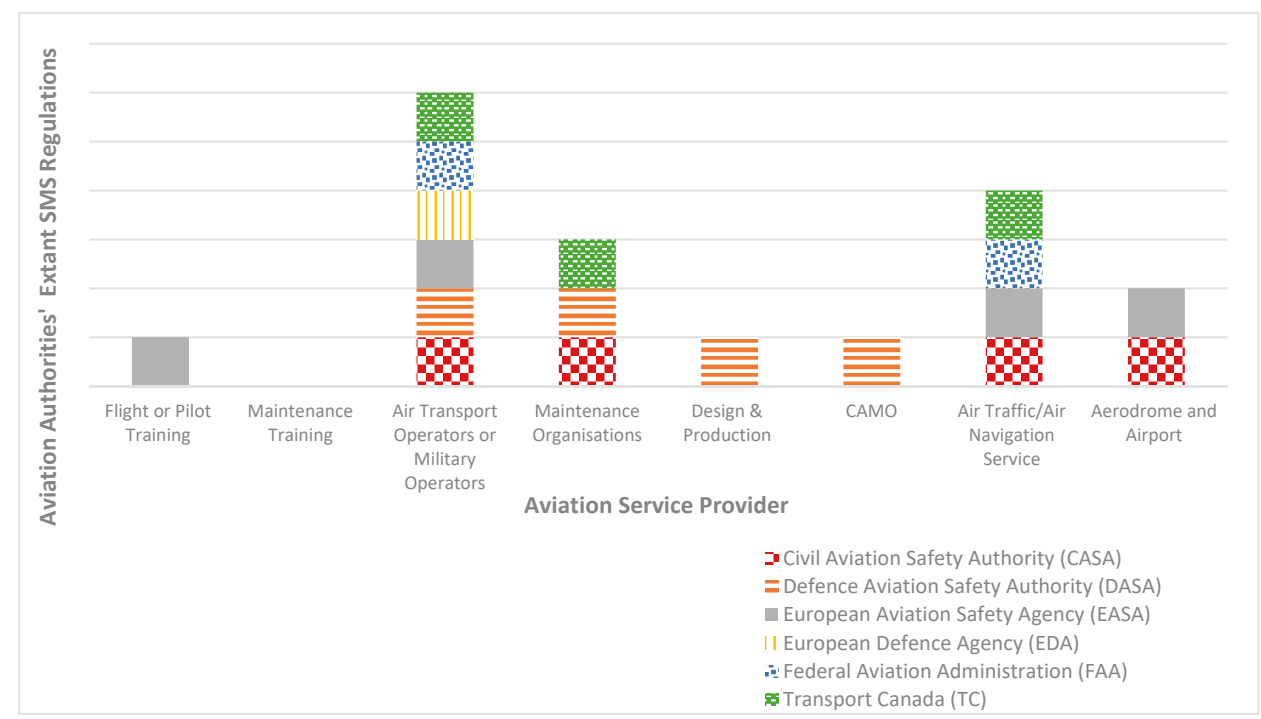

Figure 1. A comparison of Safety Management System regulations under key Aviation Authorities (as at June 2018).

Regulations on SMSs for approved design and production organisations as well as for those involved in continuing airworthiness management (CAMO) are in the process of being regulated, or not yet regulated, with DASA being the only authority to have regulated SMS in CAMO and design organisations out of those considered for comparison in Table 1. The main factor for this inconsistency in SMS regulation for various service providers would be the difference in each organisation's operational context. For those organisations involved in highly complex and hazardous operational environments, the impact of non-compliance with safety requirements or human error might have a direct or immediate consequence, whereas any safety non-compliance or human error has a more latent nature in initial or continuing airworthiness organisations. Furthermore, system certification provides a process of assuring system safety. Regulations pertaining to aircraft and system design, airworthiness codes, industry standards, and system safety engineering methods that govern the system certification process mainly consider the aspect of "design product" or "design output". Examples of existing standards include:

- Aviation regulations, such as Federal Aviation Regulation (FAR) 25 [44] or EASA Certification Specification (CS) 25 [45],

- $\quad$ System safety engineering practices and standards, such as Society of Automotive Engineers Aerospace Recommended Practice (SAE ARP) 4754 [46] or ARP 4761 [47], and United States Military (MIL) standard 882 [48].

However, these do not address organisational management systems for safety including organisational processes and human behavioural aspects of employees of initial and continuing airworthiness organisations. In this regard, implementation of SMSs in these organisations will play a vital role in filling these gaps of safety management, which ultimately affect product safety during various stages of its life cycle.

Responsibilities for continuing airworthiness of aircraft lie with the aircraft operator as well as the design organisation. Although Continuing Airworthiness Management Organisations (CAMO) are not specifically listed in Annex 19, most aviation authorities have regulated continuing airworthiness management functions and the requirement of a CAMO for this purpose. Some authorities are also considering SMS implementation in CAMOs in their current or proposed regulations. Furthermore, 
Annex 19 requires SMSs for design organisations only if they are responsible for the type design or manufacture of aircraft, engines or propellers. However, some authorities have already regulated or considering regulations that require all approved design organisations to implement an SMS.

A detailed review of SMS implementation regulations or instructions and those specific to airworthiness organisations are discussed below for EASA, FAA, CASA, and DASA. Aviation authorities of many countries are currently quite active with regards to regulating and promoting SMS. Further to their notable role in the development and implementation of SMS, the scope of this review is limited to the above-mentioned aviation authorities due to limitations in the availability of data in the public domain and language constraints.

\subsection{EASA}

EASA has recently repealed Basic Regulation EC No. 216/2008 with the issuance of Basic Regulation EC No. 2018/1139 which includes the authority requirement for EU member States to have an SSP as per ICAO Annex 19. Prior to this, some member States had voluntarily implemented an SSP [49]. The new Basic Regulation also emphasises key aspects of SMSs but frames it as management systems in a more general sense [45].

SMS rulemaking for initial and continuing airworthiness, under rulemaking tasks RMT.0251 and RMT.0251(b) $[50,51]$ are in progress for the introduction of SMS into the requirements of design, production, and maintenance organisations by 2020. EASA is also intending to introduce a new Part-CAMO to align with SMS requirements for continuing airworthiness management. This part would be an Annex to Commission Regulation (EU) No. 1321/2014, regulating CAMOs which are managing the aircraft of licensed air carriers or operators of complex motor-powered aircraft (CMPA). Furthermore, subsequent to the approval of Opinion 07/2016, EASA will also adopt a risk-based approach to EASA's determination to the Level of Involvement (LOI) in product certification based on each organisation's performance in airworthiness and environmental certification of aircraft and related products, parts and appliances together with design changes and repairs. The intention here is that the level of oversight on the design organisation by EASA be 'performance-based' (Ref Opinion 07/2016 and NPA 2017-20). These requirements of SMSs will be updated within the respective regulation (EU) No. 748/2012 for organisations involved in initial airworthiness.

EASA is adopting a two-phased approach for SMS rulemaking for airworthiness organisations:

- $\quad$ Phase I-Introduction of SMS requirements in Part-M Continuing Airworthiness Management Organisation,

- $\quad$ Phase II-Introduction of SMS requirements in Part-145 Maintenance Organisations and Part-21 Design and Production Organisation.

Phase I, under RMT.0251 (MDM.055) will primarily focus on SMSs in CAMO and adapt EC No. 1321/2014 to include SMSs. During Phase II under RMT.0251(b) (MDM.055-MDM.060), SMSs in CAMO would be already regulated and implemented by Phase I and the primary focus would move to implementing SMS in Part-145 and Part-21 organisations.

The European Plan for Aviation Safety (EPAS) is a regional program at European level, which aligns the safety priorities with EASA's strategic plan and integrates the input received from stakeholders and aviation service providers in the region.

\subsection{FAA}

FAA 14 CFR Part 5 details the requirements for SMSs. In accordance with FAR Part 5, SMSs are currently applicable to commercial air carriers that conduct domestic, flag, and supplemental operations under FAR Part 121. FAA has been working to implement SMSs in other sectors of aviation, and in the interim promote voluntary implementation. These include Part 135 operators, Part 21 Design and Manufacturing Organisations, Part 141 pilot schools, Part 142 training schools, and Part 145 maintenance, repair, and overhaul (MRO) facilities. Guidance material and standards have 
been made available for use by the aviation industry. FAA's national policy on SMSs is documented in several FAA Orders and Advisory Circulars.

Under current FAA 14 CFR Part 21 regulations (Certification procedures for products and articles) the terminology Type Certificate Holder is used rather than Design Organisation. SMS rule-making for 14 CFR Part 21 was launched in 2014, led by the Aircraft Engineering Division's System Performance and Development Branch (AIR-150), which has taken the feedback received through the Manufacturers SMS (MSMS) Pilot Project and the Part 21/SMS Aviation Rulemaking Committee (ARC) to help develop the rulemaking package. Currently FAA, is in the process of developing a Notice of Proposed Rule Making (NRPRM) for Part 21 that will include requirements for SMSs in design and manufacturing organisations in the US. In the interim, a voluntary SMS program has been instituted by the FAA for design and manufacturing organisations in accordance with an industry standard (NAS 9927) [52] developed by Aerospace Industries Association (AIA) and General Aviation Manufacturers Association (GAMA). This standard uses FAA 14 CFR Part 5 as the basis for SMS requirements. The FAA has recognised this standard as meeting the intent of ICAO Annex 19 and 14 CFR Part 5. The Voluntary SMS Program will further allow the FAA to assess applicant voluntary SMS programs in accordance with the Standard or 14 CFR Part 5.

\subsection{CASA}

Although a separate regulation on SMSs has not yet been published by CASA, individual regulations for various service providers require the implementation of an SMS in their organisations. SMS requirements for Air Transport Operators are detailed in CAO 82.3 for low-capacity regular public transport (LCRPT) and in CAO 82.5 for high-capacity regular public transport (HCRPT), together with CAAP SMS-1, CAAP SMS-2, CAAP SMS-3 and CAAP SMS-4 providing guidance on SMSs, Human Factors (HF), Non-Technical Skills (NTS) training, and assessment and Flight Data Analysis Programs. Regulation on Aerodrome operation on CASR Part 139 and Approved Maintenance Organisations on CASR Part 145 also regulate SMSs in the respective industry sector.

CASA intends to extend the SMS implementation into other aviation service providers including those involved in initial and continuing airworthiness. However, an official notice of the proposed rulemaking has not been published to date.

\subsection{DASA}

With the introduction of the new Defence Aviation Safety Regulations (DASR) by DASA in 2016, a new regulation aligned with the requirements of ICAO Annex 19 has been published as DASR SMS. Other DASR cross refer to the DASR SMS for the purpose of SMS implementation and maintenance by various service providers in the Australian Defence Aviation (ADF) industry. In accordance with DASR SMS, the implementation of SMS is required for holders of Military Air Operator Certificate, DASR Part 21 approved design organisations, DASR Part M Continuing Airworthiness Management Organisations and DASR Part 145 Approved Maintenance Organisations. In comparison with EASA, CASA and FAA, regulations specifically require SMS implementation in initial and continuing airworthiness organisations under the DASR.

\section{Challenges of SMS Implementation in Organisations Involved in Airworthiness}

The main organisations involved in initial and continuing airworthiness functions are the design organisations, the manufacturing (or production) organisations, and continuing airworthiness management organisations. There are common challenges to all aviation organisations and challenges which may be specific to organisations involved in initial and continuing airworthiness functions. These include:

a. Existing research on human error management techniques, tools and error investigation decision aids are mainly in the context of functions related to operational environments [13]. 
Further research needs to be conducted to develop techniques and tools that are more appropriate for airworthiness organisations and specifically applicable for design organisations.

b. Protection of safety data, safety information and related sources, considering the sensitivity of data has not been adequately addressed by all regulators. SMS data could be made public or be required to be produced in civil litigation. ICAO standing is broadly addressed by the "Code of Conduct on the Sharing and Use of Safety Information" documented in the GASP and supplemented by the "Principles for the protection of safety data, safety information and related sources" in Annex 19. Sharing of data should consider the balance between the benefit of sharing versus any adverse effects such as loss of reputation of the organisation, and reduced marketability of services and products.

c. Lack of sufficient safety reports or feedback that affect safety due to various reasons including lack of just culture or reporting culture within either own organisation, or external interfacing organisations.

d. Deficiencies in reporting processes, data management systems, and data analysis tools to make optimal use of safety data.

e. The need to have an integrated approach, with flexibility to integrate existing and proposed programs on safety, quality, security management, and systems engineering to avoid duplication but still ensuring the framework of SMSs are maintained within the context of the airworthiness organisation.

f. Service providers interface with other organisations, and the interface management requirements.

g. The cost burden of additional resources to be allocated to implement SMSs and related activities such as SMS gap analysis, SMS implementation plans, development of organisational procedures, interface management procedures, human resources for new roles, and responsibilities under the SMS and for the provision of SMS training to all staff involved in the processes that affect safety. Cost is dependent on the size and complexity of the organisation and the types of operations and functions carried out by the organisation.

h. Lack of guidance material available for establishing safety targets and safety performance indicators specific for each organisation and operating context.

\section{Benefits of SMS Implementation in Airworthiness Organisations}

In addition to achieving the objective of complying with ICAO Annex 19, implementing SMSs provide various benefits not only to those in operational environments but also to design and production organisations as well as CAMO. SMS as an organised approach to managing safety provides the necessary foundation through organisational structures, accountabilities, policies and procedures, and senior management commitment which is essential for resource allocation [53]. An effective SMS must allocate resources against risk [54], with feedback from the systematic monitoring of key safety performance indicators. Airworthiness organisations will be able to improve on safety performance using the SMS framework correctly. Whilst system safety engineering provides a proven method to ensure the safety of the "design product", SMS enables this to be extended into managing safety through improved organisational structure, processes, procedures, culture, and human error management within the airworthiness organisation. Thus, the safety management of the "product" and "process" as well as the "people" or "human behaviour" are all integrated through SMSs. SMSs also promote scientifically based risk management methods which can be used for product based risks, organisational or process-based risks, and human factor based risks. Costly safety consequences, failures, incidents and accidents can be reduced with proactive risk management and related resource allocation.

In addition to the benefits that can be gained by organisations implementing SMSs, the benefits also extend to aviation authorities. Organisations with a positive safety culture will be more open to safety audits by the regulatory authorities as an external source of information on the safety performance of the organisation [53]. Authorities may have fewer audit findings to administer thereby 
resulting in less time and resources required for follow up on corrective actions. Further to these benefits, EASA Opinion No. 07/2016 [55] discusses the additional benefit of a performance-based approach that can be practiced by design organisations implementing SMS, which would enable EASA to apply a risk-based level of involvement (LOI) in product certification. This is expected to allow EASA to focus its certification resources mainly on areas that need direct and high LOI to more thoroughly verify compliance, while in other certification areas where the risk to safety is assessed to be lower, EASA may rely on approved design organisations, thus optimising the allocation of the agency's resources.

\section{Conclusions}

Review of the regulatory framework for the implementation of SMSs has revealed that the scope of ICAO Annex 19 [3] has recently evolved by recommending the implementation of SMSs in various organisations involved in providing aviation services including organisations responsible for the type design or manufacture of aircraft, engines or propellers. Of the aviation authorities considered in the review, DASA (in its current regulations) and EASA (in its proposed regulations) require SMSs in CAMO, while FAA and Transport Canada do not yet specify SMSs in CAMO. DASA has regulated SMSs for all approved design organisation, while EASA, FAA, and Transport Canada are also in the process of rule-making on this.

ICAO Annex 19 provides a broad framework for implementing SMSs which must be tailored depending on the size and complexity of the organisation and its operations. Furthermore, the context of implementing SMSs and related SMS implementation tools in CAMO and design organisations is different from that in operational environments such as aircraft flying and maintenance. Available techniques and tools for human error management would need to be reviewed for their suitability of application in organisations involved in design and CAMO where further research must be conducted.

Author Contributions: E.B. conceived the study and contributed to all aspects of the paper; J.S. contributed to the introduction, the data analysis, discussion and conclusion; G.W. contributed to the introduction, research design, discussion, and conclusion.

Funding: This research received no external funding.

Conflicts of Interest: The authors declare no conflict of interest.

\section{References}

1. International Civil Aviation Organization. Global Air Transport Outlook to 2030 and Trends to 2040; International Civil Aviation Organization: Montreal, QC, Canada, 2013.

2. International Civil Aviation Organization. Safety Report; International Civil Aviation Organization: Montreal, QC, Canada, 2017.

3. International Civil Aviation Organisation. Annex 19-Safety Management, 2nd ed.; International Civil Aviation Organization: Montreal, QC, Canada, 2016.

4. Coze, L.; Christophe, J. Reflecting on Jens Rasmussen's legacy. A strong program for a hard problem. Saf. Sci. 2015, 71, 123-141. [CrossRef]

5. Rasmussen, J. Skills, rules, and knowledge; signals, signs, and symbols, and other distinctions in human performance models. IEEE Trans. Syst. Man Cybern. 1983, 3, 257-266. [CrossRef]

6. Reason, J. Human Error; Cambridge University Press: Cambridge, UK, 1990.

7. Moriarty, C.D. Practical Human Factors for Pilots; Academic Press: Cambridge, MA, USA, 2014.

8. International Civil Aviation Organization. Doc 9859-Safety Management Manual (DRAFT), 4th ed.; International Civil Aviation Organization: Montreal, QC, Canada, 2017.

9. Stolzer, A.J. Safety Management Systems in Aviation; Routledge: Abingdon, UK, 2017.

10. Allianz. Global Aviation Safety Study; Allianz: Munich, Germany, 2014.

11. Szabo, S.; Koblen, I. Aviation Technology Life Cycle Management: Importance for Aviation Companies, Aerospace Industry Organizations and Relevant Stakeholders. MAD-Mag. Aviat. Dev. 2017, 5, $15-24$. [CrossRef] 
12. Kantowitz, B.H.; Casper, P.A. Human workload in aviation. In Human Error in Aviation; Routledge: Abingdon, UK, 2017; pp. 123-153.

13. Dismukes, R.K. Human Error in Aviation; Routledge: Abingdon, UK, 2017.

14. Sarter, N.B.; Mumaw, R.J.; Wickens, C.D. Pilots' monitoring strategies and performance on automated flight decks: An empirical study combining behavioral and eye-tracking data. Hum. Factors 2007, 49, 347-357. [CrossRef] [PubMed]

15. Sarter, N.B.; Woods, D.D. Pilot interaction with cockpit automation II: An experimental study of pilots' model and awareness of the flight management system. Int. J. Aviat. Psychol. 1994, 4, 1-28. [CrossRef]

16. Wickens, C.D.; Goh, J.; Helleberg, J.; Horrey, W.J.; Talleur, D.A. Attentional models of multitask pilot performance using advanced display technology. In Human Error in Aviation; Routledge: Abingdon, UK, 2017; pp. 155-175.

17. Hopkin, V.D. Human Factors in Air Traffic Control; CRC Press: Boca Raton, FL, USA, 2017.

18. Isaac, A.; Shorrock, S.T.; Kirwan, B. Human error in European air traffic management: The HERA project. Reliab. Eng. Syst. Saf. 2002, 75, 257-272. [CrossRef]

19. Kontogiannis, T.; Malakis, S. A proactive approach to human error detection and identification in aviation and air traffic control. Saf. Sci. 2009, 47, 693-706. [CrossRef]

20. Gramopadhye, A.K.; Drury, C.G. Human Factors in Aviation Maintenance: How We Got to Where We Are; Elsevier: Amsterdam, The Netherlands, 2000.

21. Latorella, K.A.; Prabhu, P.V. A review of human error in aviation maintenance and inspection. Int. J. Ind. Ergon. 2000, 26, 133-161. [CrossRef]

22. Teperi, A.-M.; Leppänen, A. Managers' conceptions regarding human factors in air traffic management and in airport operations. Saf. Sci. 2011, 49, 438-449. [CrossRef]

23. Wiegmann, D.A.; Shappell, S.A. Applying the human factors analysis and classification system (HFACS) to the analysis of commercial aviation accident data. In Proceedings of the 11th International Symposium on Aviation Psychology, Columbus, OH, USA, 5-8 March 2001.

24. Wiegmann, D.A.; Shappell, S.A. Human error analysis of commercial aviation accidents: Application of the Human Factors Analysis and Classification System (HFACS). Aviat. Space Environ. Med. 2001, 72, 1006-1016. [PubMed]

25. Wiegmann, D.A.; Shappell, S.A. A Human Error Approach to Aviation Accident Analysis: The Human Factors Analysis and Classification System; Routledge: Abingdon, UK, 2003.

26. Johnson, W.B. Industry experience: Implementing technology. In Proceedings of the 15th Symposium on Human Factors in Maintenance and Inspection, London, UK, 27-29 March 2001.

27. International Civil Aviation Organization. Doc 9859-Safety Management Manual, 3rd ed.; International Civil Aviation Organization: Montreal, QC, Canada, 2013.

28. Rankin, W.; Hibit, R.; Allen, J.; Sargent, R. Development and evaluation of the maintenance error decision aid (MEDA) process. Int. J. Ind. Ergon. 2000, 26, 261-276. [CrossRef]

29. Purton, L.; Clothier, R.; Kourousis, K.; Massey, K. The PBP Bow-Tie framework for the systematic representation and comparison of military aviation regulatory frameworks. Aeronaut. J. 2014, 118, 1433-1452. [CrossRef]

30. International Civil Aviation Organisation. Annex 19—Safety Management, 1st ed.; International Civil Aviation Organization: Montreal, QC, Canada, 2013.

31. TUV Nord Airsight Arge. Research Report EASA.2008/9-Studies on the State of Implementation of the Provisions Contained in ICAO Annex 14 on Aerodromes in the EASA Member States; European Aviation Safety Agency: Cologne, Germany, 2010.

32. International Civil Aviation Organisation. Convention on International Civil. Aviation done at Chicago on the 7th Day of December 1944; International Civil Aviation Organization: Montreal, QC, Canada, 1944.

33. International Civil Aviation Organisation. Doc. 10004-Global Aviation Safety Plan, 2nd ed.; International Civil Aviation Organization: Montreal, QC, Canada, 2016.

34. Two Years Later: An SMS Update. Available online: https://condonlaw.com/2017/05/two-years-later-smsupdate/ (accessed on 20 June 2018).

35. Safety Management International Collaboration Group (SM ICG). Available online: https://www. skybrary.aero/index.php/Safety_Management_International_Collaboration_Group_(SM_ICG) (accessed on 20 June 2018). 
36. DASR—Safety Management System. Available online: http://www.defence.gov.au/DASP/DASRRegulations/SafetyManagementSystem.asp (accessed on 20 June 2018).

37. CASA—Safety Management System—Legislation and Guidance. Available online: https://www.casa.gov. au/education/standard-page/legislation-and-guidance (accessed on 20 June 2018).

38. SMS-EASA Rules. Available online: https://www.easa.europa.eu/easa-and-you/safety-management/ safety-management-system/sms-easa-rules (accessed on 20 June 2018).

39. European Defence Agency. Available online: https:/ / www.eda.europa.eu/home (accessed on 20 June 2018).

40. Federal Aviation Administration—Safety Management System (SMS). Available online: https://www.faa. gov/about/initiatives/sms/ (accessed on 20 June 2018).

41. USAF-News Article-Enhancing Air Force Safety Management System. Available online: https:/ / www.safety.af.mil/News / Article-Display/Article/862390/enhancing-air-force-safetymanagement-system-revised-afi-align-mishap-preventio/ (accessed on 20 June 2018).

42. USAF. Air Force Instruction 91-204-Safety Investigation and Hazard. Reporting; USAF: Washington, DC, USA, April 2018.

43. Transport Canada-Safety Management Systems-Implementation Schedule. Available online: http:// www.tc.gc.ca/eng/civilaviation/standards/sms-implementation-617.htm (accessed on 20 June 2018).

44. Federal Aviation Administration (FAA) Regulations. Available online: https://www.faa.gov/regulations_ policies / faa_regulations / (accessed on 20 June 2018).

45. European Aviation Safety Agency (EASA) Regulations. Available online: https://www.easa.europa.eu/ regulations (accessed on 18 October 2018).

46. Society of Automotive Engineers. ARP 4754A Guidelines For. Development of Civil. Aircraft and Systems; SAE: Commonwealth Drive Warrendale, PA, USA, 2010.

47. Society of Automotive Engineers. ARP 4761 Guidelines and Methods for Conducting the Safety Assessment Process on Civil. Airborne Systems and Equipment; SAE: Commonwealth Drive Warrendale, PA, USA, 1996.

48. US Department of Defence. MIL STD 882-E-Standard Practice for System Safety; US Department of Defence: Washington, DC, USA, 2012.

49. EASA. State Safety Program-Phase Implementation Survey Results; EASA: Cologne, Germany, 2014.

50. EASA ToR RMT.0251 (MDM.055) Embodiment of Safety Management Systems (SMS) Requirements into Commission Regulation EU No. 1321/2014-Phase I-SMS in Part M. Available online: https:/ /www.easa. europa.eu/document-library/terms-of-reference/tor-mdm055 (accessed on 20 June 2018).

51. EASA ToR RMT.0251(b) (MDM.055-MDM.060)—Embodiment of Safety Management System Requirements into Commission Regulations (EU) No. 1321/2014 and 748/2012 'Phase II-SMS for EASA Part-21 Design Organisations, EASA Part-21 Production Organisations and EASA Part-145 Maintenance Organisations. Available online: https:/ / www.easa.europa.eu/document-library/terms-of-reference-andgroup-compositions / tor-rmt0251b-mdm055-mdm060 (accessed on 20 June 2018).

52. Aerospace Industries Association. Safety Management System Proactices for Design and Production, NAS9927; Aerospace Industries Association: Arlington County, VA, USA, 2015.

53. CASA. SMS for Aviation-A Practical Guide, 2nd ed.; Civil Aviation Safety Authority: Canberra, Australia, 2014.

54. SMS Reconsidered. Available online: https:/ flightsafety.org/asw-article/sms-reconsidered/ (accessed on 20 June 2018).

55. Opinion 07/2016. Embodiment of Level of Involvement Requirements into Part-21. Available online: https: / / www.easa.europa.eu/document-library/opinions/opinion-072016 (accessed on 20 June 2018).

(c) 2018 by the authors. Licensee MDPI, Basel, Switzerland. This article is an open access article distributed under the terms and conditions of the Creative Commons Attribution (CC BY) license (http:/ / creativecommons.org/licenses/by/4.0/). 


\title{
Cost-Effectiveness of Structural Health Monitoring in Fuselage Maintenance of the Civil Aviation Industry ${ }^{\dagger}$
}

\author{
Ting Dong and Nam H. Kim* \\ Department of Mechanical and Aerospace Engineering, University of Florida, P.O. Box 116250, \\ Gainesville, FL 32611-6250, USA; dting0603@ufl.edu \\ * Correspondence: nkim@ufl.edu; Tel.: +1-352-575-0665; Fax: +1-352-392-7303 \\ + A part of this paper has been published at AIAA/SciTech conference: Ting Dong and Nam H. Kim. \\ Reviews of structural health monitoring technologies in airplane fuselage maintenance perspective. \\ In Proceedings of the AIAA Nondeterministic Conference, Kissimmee, FL, USA, 8-12 January 2018.
}

Received: 6 June 2018; Accepted: 7 August 2018; Published: 13 August 2018

\begin{abstract}
Although structural health monitoring (SHM) technologies using sensors have dramatically been developed recently, their capability should be evaluated from the perspective of the maintenance industry. As a first step toward utilizing sensors, the objective of the paper is to investigate the possibility of using sensors for inspecting the entire fuselage during C-check. First, we reviewed various sensors for their detection range, detectable damage size, and installed weight, which revealed that the piezoelectric wafer active sensor (PWAS) is the most promising sensor for aircraft SHM. Second, we performed a case study of inspecting the fuselage of Boeing-737NG using PWAS. To maintain the same detecting capability of manual inspection in C-check, we estimated the total number of sensors required. It turned out that utilizing sensors can reduce the maintenance downtime and thus, maintenance cost. However, even with a very conservative estimate, the lifetime cost was significantly increased due to the weight of sensor systems. The cost due to the weight increase was an order of magnitude higher than the cost saved by using SHM. We found that a large number of sensors were required to detect damage at unknown locations, which was the main cause of the weight increase. We concluded that to make SHM cost-effective, it would be necessary either to improve the current sensor technologies so that a less number of sensors are used or to modify the aircraft design concept for SHM.
\end{abstract}

Keywords: structural health monitoring; condition-based maintenance; scheduled maintenance; cost-benefit analysis; sensors; payload

\section{Introduction}

In the damage-tolerant design concept, aircraft are maintained for their safety and reliability using periodic maintenance. Structural maintenance of civil aviation aircraft is currently based on scheduled maintenance, where the maintenance interval is determined based on safety and reliability. However, the current practice of scheduled maintenance is expensive for airlines. The inspection and maintenance cost accounts for more than $27 \%$ of the total lifecycle cost of an aircraft [1]. There are ongoing research efforts to reduce the maintenance cost by utilizing condition-based maintenance (CBM) where the health status of the system is continuously monitored and maintenance is requested when the safety of the system is threatened [2]. The condition of the structure is monitored using structural health monitoring (SHM) techniques. In the literature [3], various sensor technologies have been employed for SHM. However, many technical and economic issues have to be overcome before $\mathrm{CBM}$ can be used for the civil aviation industry.

During scheduled maintenance, aircraft are inspected and repaired at prescribed intervals, such as flight hours or flight cycles. For example, the major maintenance (C-check) of the Boeing 737NG is 
conducted at every 2800 flight cycles. During major maintenance, inspectors perform a detailed visual inspection (DVI) to detect damage. Non-destructive testing (NDT) can also be performed whenever necessary. The major difficulty in the structural maintenance is to access internal structures for DVI, such as frames and stringers. Therefore, internal surrounding structures, such as walls, ceiling panels, and insulation blankets, need to be removed. This process is time-consuming and can cause unexpected damage to the structure.

Recently, condition-based maintenance (CBM) is proposed, aiming to replace the scheduled maintenance. The basic concept of CBM is to utilize sensors installed on the aircraft structure, called structural health monitoring (SHM) system. The SHM system is used to detect damage and to determine the size and location of damage. Since the SHM system use installed sensors, it is unnecessary to remove internal surrounding structures for inspection. In addition to detecting damage, the SHM can be used to predict the future behavior of detected damage based on damage data at past inspections, which is called prognostics. This makes it possible to predict when the existing damage threaten the safety of the system and repair them before that. Therefore, the scheduled maintenance is often referred to as preventive maintenance, while CBM as predictive maintenance. With prognostics information, it is possible that airlines and MRO (maintenance, repair and overhaul) can schedule and prepare for maintenance in advance. The usage of SHM in CBM can also reduce aircraft downtime by reducing the time of removing and reinstalling surrounding structures, which can increase the availability of aircraft and reduce revenue loss.

In the literature, the safety and lifetime cost-saving by CBM has been discussed. For example, Pattabhiraman et al. [4] showed that the main advantage of CBM is to skip several structural maintenances in early life when there is no severe damage detected. Gerdes et al. [5] showed that it is possible to reduce the maintenance time by $20 \%$ for an air-conditioning system using CBM. It has also been shown that CBM can reduce downtime and make aircraft more available by using the Aircraft Technology and Operation Benchmark System (AIRTOBS) [6]. In addition, Fioriti et al. [7] concluded that prognostics can improve airline profit by making aircraft more available. However, most previous studies assumed that the SHM systems can provide damage inspection data online without explaining details of how they can perform such continuous monitoring. In addition, it is crucially important to consider the effect of weight on the airline's revenue.

The major challenges in applying SHM are the weight increase and continuous monitoring, another important challenge is the change itself. The change from the scheduled maintenance to CBM is too abrupt for the current civil aviation industry to take. In the aviation industry, even slight changes require in-depth safety review and certification, which often takes several months. The changes require approvals from various stakeholders, such as manufacturers, $\mathrm{MRO}$, and the federal aviation administration (FAA). Therefore, it is more likely that a gradual change rather than a radical change might happen in the industry. In this paper, we expect that the first step would be to replace manual inspection with SHM systems while the maintenance interval is still the same as scheduled maintenance. This is also the most probable scenario because non-structural maintenance, such as engine and avionics, can also be performed at the same time. However, even such a simple change requires answering the following concerns: (a) Can the current sensor technologies inspect the entire aircraft structure in the same quality as the current manual inspection? (b) Can the SHM system provide any cost-benefits compared to the current manual inspection? We would like to answer these questions using the case study of fuselage maintenance of the Boeing 737NG, which is the most popular model currently used in civil aviation (based on the number of aircraft in use).

Even if there were prior publications that discussed the cost analysis for CBM [3], this is the first to consider sensor-based inspection of entire fuselage during the conventional C-check. This is a transition state of CBM and can be a near-term implementation of SHM in the civil aviation industry. The uniqueness and contributions of the current paper are as follows: (a) We reviewed and evaluated various sensor technologies from the perspective of aircraft scheduled maintenance, which includes the detection range, detectable damage size, installed weight, and capability to detect closed cracks. 
(b) Based on the best performing sensors, we estimated the total number of sensors for inspecting the entire fuselage of B737. The number and weights of sensor systems are determined such that the same inspection quality with manual inspection in the conventional C-check during the scheduled maintenance. Most previous applications use sensors locally for hotspot monitoring. (c) In the cost-benefit analysis, we incorporated the cost of the weight penalty, an important factor which is normally neglected in previous literature.

The paper is composed of five sections. Section 2 explains the details of scheduled maintenance and CBM. In Section 3, we reviewed three important sensors that are most likely to be used for $\mathrm{SHM}$. We focused on the detection range, detectable damage size, and installed weight. Based on the selected sensor system, we estimated the total number of sensors required to inspect the entire fuselage in Section 4. Section 5 is a cost-benefit analysis when using SHM to replace manual inspection, followed by conclusions in Section 6 .

\section{Scheduled Maintenance versus Condition-Based Maintenance}

\subsection{Scheduled Maintenance}

Scheduled maintenance is preventive maintenance that is performed based on predetermined intervals regardless of the health state of an aircraft. Different types of scheduled maintenance are performed throughout an aircraft's lifecycle. The intensity of scheduled maintenance increases as the intervals increase. These intervals can be either flight hours or flight cycles. For different aircraft models, the maintenance intervals are also different. Scheduled maintenance can be categorized into a transit check-A/B/C/D checks. The transit check is performed after each flight, and only obvious damage is checked by "walking around" inspection, which can be done in half an hour. For B-737, A-check is performed every 100 flight-cycles, and it normally takes about one week. In A-check, only general visual inspection is performed. Since the internal surrounding structures are required to be removed starting from a C-check, only C-check is considered in this paper.

For the Boeing $737 \mathrm{NG}$, the C-check is required at every 2800 flight cycles at a maintenance hangar. During the maintenance, it is required to remove all surrounding structures to make it possible to access internal structures. For accessing fuselage frames and stringers, we need to remove chairs, walls, ceiling and floor panels, and insulation blankets. In addition, the lavatory and galley are also removed. Although internal cables do not need to be removed, they need to be secured to the internal structures using tapes. This removing and preparation process takes about four days by 20 technicians (640 person-hours).

Once the surrounding structures are removed and technicians clean the internal structures, inspectors can easily access the skins, frames, and stringers of the fuselage. C-check utilizes detailed visual inspection (DVI), which is a comprehensive and intensive method of detecting various types of damage, such as dents, corrosions, and cracks. Whenever necessary, inspectors use magnifying lenses and flashlights to assist inspection.

It is known that the DVI can detect cracks in the size of around $0.5 \mathrm{in}$. It is important to measure the size accurately because different repair methods are employed based on the damage size. When the inspector cannot determine the damage size, NDT methods, such as ultrasonic or eddy current, are utilized to determine the accurate damage size. The DVI usually takes about one week by two inspectors. During the inspection, it is required that all detailed information about the damage should be recorded and sent to engineers.

Once the inspection is finished, engineers make detailed repair plans based on the inspector's report. If it is regular damage covered in the repair manual, the damage is repaired according to the manual. If the damage is rare and not covered in the manual, engineers in aircraft manufacture need to make a repair plan for the specific damage.

Most structural repairs are based on the structural repair manual (SRM), which includes repair plans for most damage that can be found in aircraft. It is composed of seven chapters, following the 
same chapter numbering system as Air Transportation Association 100, which includes standard practices and structures-general, doors, fuselage, nacelles/pylons, stabilizers, windows, and wings. It has sections and subjects under each chapter for specific damage at a specific location. Based on the damage location and size in the inspector's report, engineers choose the appropriate repair method from the manual and prepare a job card explaining the step-by-step procedure for repair. The job card also includes required materials and equipment.

Each subject in the SRM includes three contents: identification, allowable damage, and repair general. The first content, identification, includes basic information, such as material, thickness, and heat treatment state of the original material. The second content, allowable damage, categorizes damage into different levels based on its location and size and indicates which repair method should each level of damage refer to. The repair methods change according to the damage size. Also, the same damage size may have different repair methods depending on its locations. The last content, repair general, describes all available repair methods, detailed repair procedures, and required materials for the repair.

When the detected damage is not covered in the SRM — which means that the specific damage rarely happens-engineers in the maintenance company must report the damage to the aircraft manufacturing company because they do not have the authority to determine the repair method. Then, the engineers in the manufacturing company determine the required repair method based on engineering analysis. It is also possible that the maintenance engineers can propose a repair plan, but it needs to be approved by manufacturing engineers. For rare damage, this process takes about a week.

Using the repair plan, technicians can follow the plan for repair. For a small-sized crack in the fuselage skin, the flush repair is commonly used. A large-sized crack is often removed, and a doubler is attached in the removed area using fasteners. The job card should include the type and number of fasteners for the doubler installation. The job card should also include the usage of materials, size, and heat treatment method in details. It is required that technicians strictly follow the instruction on the job card. Once the repair work is done, the work is checked by inspectors to confirm that the repair meets the operation guidelines. The repair job is considered finished when the inspector signs the job card. Once the repair work is finished, all internal surrounding structures are reassembled, and the aircraft goes through a test run.

In the preventive maintenance concept, since the maintenance interval is $2800 \mathrm{flight}$ cycles, it is necessary to repair very small damage so that a high reliability of the aircraft can be maintained until the next maintenance. However, this means that damage that may not threaten the safety of the aircraft also needs to be repaired. In addition, removing and reinstalling surrounding structures for inspection take a long time, which increases aircraft downtime and loses airline revenue. Therefore, it is understood that the cost-inefficient scheduled maintenance is one of the major costs of airlines. The inspection and maintenance cost accounts for more than $27 \%$ of the total lifecycle cost of an aircraft [1]. In addition to the cost, removing and re-installing internal surrounding structures can cause unnecessary damage.

\subsection{Condition-Based Maintenance}

Although condition-based maintenance (CBM) is a still in the research state, it shows a lot of possibilities in the aircraft maintenance industry. While the main purpose of CBM is to replace the manual inspection in the scheduled maintenance, the broader usage of CBM also includes prognostics, which predicts the future behavior of data.

From a diagnostics perspective, the CBM is different from the scheduled maintenance in the damage detection method but has the identical procedure for repair. In general, CBM uses onboard sensors and on-ground equipment for inspection. The ground equipment is connected to the connection ports, which allows access to onboard sensors. Then, the equipment actuates sensors, collects data, and analyzes data to identify the existence of damage (detection) and the size of damage (quantification). Since the raw data in the waveform include noise and bias, various filtering tools are often incorporated to enhance signals. The waveform data are translated into damage 
information using various tools and algorithms $[8,9]$. The types of damage that the CBM can detect are cracks, corrosions, dents in aluminum structures, and delamination and impact damage in composite structures. As mentioned before, the advantage of using SHM sensors is to skip the process of removing surrounding structures to access internal supporting structures.

SHM can also be used for the purpose of prognostics. Since CBM can be conducted more frequently than the scheduled maintenance, it is possible to collect a history of damage growth data and to use them to predict future behavior of the damage. When a physics model that can describe the degradation of damage is available, a physics-based algorithm can be utilized [10]. An et al. [11] used Bayesian inference to identify unknown model parameters of the crack growth model with damage growth data from SHM sensors, from which the future growth of cracks is predicted. Once the model parameters are identified, it is possible to predict when the damage becomes dangerous, and an appropriate maintenance time can be predicted. When the physics model that describes the damage behavior is not available, or when the measured data is indirectly related to damage growth, data-driven approaches can be incorporated. Gaussian process regression and neural network are normally used for that purpose [12].

Instead of the scheduled maintenance at pre-determined intervals, CBM can request maintenance based on prognostics results. Pattabhiraman et al. [4] showed that in its early life CBM can skip several scheduled maintenances because there is no considerable damage detected. In CBM, the maintenance time is determined by considering the detected damage size, the prognostics of damage growth, and the required level of reliability. Normally a damage threshold is determined for a given inspection interval in order to maintain structural reliability. Since the CBM inspection interval is much shorter than that of manual inspection, the threshold is much larger than that of manual inspection. That means that the CBM allows for much larger damage than the manual inspection. Because of this, the CBM can reduce the number of maintenances as well as the number of repairs.

Although the literature has discussed the cost-benefit of CBM [13,14], some fundamental assumptions on CBM may not be practical due to the current level of SHM technology. The first assumption is the real-time health monitoring in CBM, which is the fundamental assumption in most previous cost-benefit analysis research. It is continuous health monitoring using onboard wireless sensors, and damage assessment using the ground station. As will be shown in the following section, however, it is impractical to use wireless sensors to monitor the entire aircraft structure due to the weight penalty and the reliability of batteries. Even if the SHM is performed on the ground after each flight, it is still impractical because the current detection range of sensors requires a large number of sensors to monitor the entire aircraft. The data processing requires operators to actuate each sensor one-by-one, collect all data, and process data to identify damage sizes and location. As will be shown in Section 4, the complete detection procedure may take about three to four days. Considering the time for maintenance between each flight is only half an hour, it is impractical to inspect after each flight.

Even if a lightweight, wireless sensor technology is developed so that continuous monitoring is possible, it takes time to process all collected data. The raw data that are collected in SHM sensors need to be filtered to remove noise and bias, and an appropriate diagnostics algorithm must be used to transform the raw data into useful damage information. Then, prognostics algorithms are employed to predict the future damage growth. Considering we need thousands of sensors to monitor the entire aircraft, it takes a large amount of time to process all data. Therefore, signal processing and computation cost might be much higher than the cost-benefit gained by SHM [3,15].

Different from engine health monitoring, real-time health monitoring might be unnecessary for aircraft structures. For crack growth on fuselage, every flight is one fatigue cycle due to the cyclic pressure increase during the flight and the pressure release on the ground. For an aircraft with 50,000 lifetime flight cycles, crack growth is in its stable crack growth phase in most cases, and crack length increase is infinitesimal in each fatigue cycle. Therefore, inspection after each flight is unnecessary. This is also why the C-check DVI is conducted at every 2800 flight cycles in the scheduled maintenance. The current "damage-tolerant" design concept allows the presence of damage when its 
size is below the allowable threshold. Therefore, it would make more sense to inspect the damage at a certain interval, not real-time monitoring using CBM.

\section{Review of Structural Health Monitoring Sensor Technologies}

In general, the sensors used in SHM systems can be categorized as active or passive sensors. Passive sensors detect signals generated by damage due to the evolution of the damage, which does not require an external excitation. Acoustic emission belongs to this category. If damage is detected during flight, this can be a useful method. As we mentioned earlier, however, since the inspection is performed on the ground, it would be difficult to use passive sensors to detect damage. Therefore, we will not consider passive sensors in this paper. Active sensors detect damage by sending a signal to the damage. The most widely used active sensor is the piezoelectric wafer active sensor (PWAS), which uses ultrasonic waves. Also, fiber Bragg grating (FBG) sensors and comparative vacuum monitoring (CVM) sensors are popular. This section briefly explains how these sensors work for detecting damage. Since the purpose is to use them for SHM, we will focus on the smallest size of detectable damage, detection range, the weight of SHM systems, and the possibility of detecting closed cracks. It would be desirable that the SHM systems can detect at least the same damage size the NDT. The detection range will determine the total number of sensors required to inspect the entire fuselage panels. In order to reduce the payload loss, it is important to reduce the weight of the SHM system. Since the inspection is performed on the ground, it is required to detect closed cracks. We will compare all three sensors in these aspects. In addition, the certification challenges in using SHM system are discussed based on the current regulations. Although only three types of sensors are mainly compared, other emerging sensor technologies are also briefly introduced.

\subsection{Piezoelectric Wafer Active Sensor}

The mechanism of PWAS detecting damage in the material is based on the ultrasonic wave theory. The elastic wave generated by actuators propagates through the material and is reflected when it meets a discontinuity (i.e., damage). The characteristics of the reflected wave, such as time of flight, amplitude, or frequency, are used to identify the location and size of the damage. In the perspective of active sensors, PWAS can be used either as actuator or sensor. For actuation, the PWAS converts an electric voltage to an elastic wave, while an elastic wave induces an electric voltage for sensing.

The mechanism of detecting damage in SHM using PWAS is similar to conventional NDT ultrasonics. Both of them use ultrasonic waves propagating in the structure to detect damage. However, the way that the wave is transmitted from the sensor to structure is different. In SHM, the sensor is permanently attached to the structure by an adhesive layer, which facilitates a strong coupling between the PWAS and the structure. This strong coupling can provide an in-plane strain couple, enabling ultrasonic waves to propagate in the structure parallel to the surface. Therefore, in SHM, permanently installed sensors can detect damage at a certain distance. In conventional NDT, however, the detecting probe is coupled to the structure by gel, which means that the coupling effect is much weaker. The transducer and the structure are displacement coupled. The wave signal is propagated into structure perpendicular to the surface by impinging the structure surface or at some angle if a wedge is used and detects damage in the thickness direction. Thus, conventional NDT requires manually moving the probe on the surface to cover the complete surface area (C-scan).

The usage of sensors to detect damage can be categorized as pulse-echo and pitch-catch [16]. In the former, one PWAS plays for the role of both actuator and sensor. The same PWAS generates pulses and receives signals that are reflected from damage. In the latter, however, one PWAS plays the role of an actuator, while the other is used as a sensor. Phased array $[16,17]$ is a new method based on pulse-echo. It arranges several sensors in a line with a certain space on the structure. Each sensor can work as transmitter and receiver simultaneously. Since the distance from each sensor to target place is different, the time for a wave propagating to that target place is different. By firing this line of sensors sequentially in a specific time delay, it can arrive at the target place at the same time and these 
signals are superposed. By gradually changing the time delay, a virtual beam can sweep from 0 to $180^{\circ}$. After transforming this data from the time domain to the 2D physical plane, damage can be located by plotting the intensity of signal reflection at each point. It is noted that one plot only represents the damage condition at a specific radius. Compared to regular pulse-echo, the phased array method enables the wave signal emitted from each sensor to focus on the damage with a specific time delay and generates larger amplitude reflection, leading to a higher signal-to-noise ratio and resolution. In addition, the whole interrogation can be done with sensors from a single location. This method is good when the radius is large, which means the target is far away from sensors. When the target is close to the sensor, however, the error is large because the assumption in simplified beamforming algorithms is not valid anymore. To solve this problem, a 2D sensor array was developed [18]. It can detect damage both in the near field and far field and achieve full $360^{\circ}$ range detection as well.

Pulse-echo, pitch-catch, and phased array require undamaged structure as pristine information to detect damage. The time reversal method is a baseline-free detection approach [19]. A wave signal received at one point can be time reversed and reconstructed at the source point. If there is damage in between, the reconstructed wave signal will be different because of reflection, refraction, or scatter by the damage. By comparing the different signals, damage can be detected.

Lamb wave is the most common wave for ultrasonic detection on aircraft structures because of its long-distance detection range in thin-wall structures with little amplitude loss. There are two modes of Lamb waves: symmetric mode (S mode) and anti-symmetric mode (A mode). The wave velocity and mode can be calculated from the product of frequency and panel thickness. Only $S_{0}$ and $A_{0}$ modes exist when the product is small. As it increases, higher modes, $A_{k}$ and $S_{k}, k=1, \ldots, n$, are generated [20]. When these multiple modes propagate at different speeds, it would be difficult to analyze the signals reflected from damage. Normally, we only use low-frequency modes as fewer number of lamb modes exist and lower speed modes can give us more time to separate signals generated and received as well. However, the detection is still complicated since at any given frequency, at least two lamb wave modes exist. Single mode wave is crucial for damage detection. Santoni et al. [21] compared the detection results from single mode wave and multimode wave for both phased array method and time reversal method. The results show that single mode wave damage detection has the best image quality. In addition, single mode wave detection can give us the flexibility to use a specific mode to detect a specific damage. For example, $S_{0}$ mode is better at detecting a through-the-thickness crack, while $A_{0}$ mode is used for detecting disbond and delamination. For tuning single mode wave, although we cannot completely separate one mode from the others, we can find a specific frequency that one mode dominates, and others are weak. Of course, this frequency is different for different plate thicknesses, materials, and PWAS dimensions. A detailed lamb wave tuning method can be found in Giurgiutiu [22].

Using PWAS to detect damage has been tested on both metallic and composite structures. Zhao et al. [23] used a wing section from E2 aircraft as a sample and put eight sensors in a circle with a diameter of one foot to test the simulated rivet crack and corrosion. The damage was detected and locations were identified using RAPID (reconstruction algorithm for probabilistic inspection of defects). Kessler et al. [24] simulated damage of holes, fiber fracture, and delamination on both laminates and sandwich composite material, and all damage was successfully detected using piezoelectric sensor patches. Grondel et al. [25] used piezoelectric sensors on an aircraft composite wingbox to detect impact damage and disbonding between skins and stiffeners. First, the impact damage was generated by a drop weight mobile impactor and two transducers, one as signal emitter and one as a signal receiver, were installed near the impact location. The impact damage was detected by the frequency change of signals. Then, disbond was introduced by fatigue bending load, which was detected by analyzing the amplitude change.

As the detection range of a single sensor is limited, for structures like an aircraft fuselage, a large number of sensors are required, thus inevitably leading to a complicated cable system. To reduce the number of cables, PWAS sensors are integrated into a thin dielectric film by printing a circuit on it 
(SMART Layer [26]). This thin film can provide a significant amount of flexibility as it can be attached on a curved surface or even embedded into the composite panel during the layup process. In combination with SMART Layer, a SMART Suitcase can be used for signal processing: generating, receiving, and analyzing signals. It is reported that the SMART Suitcase can connect up to 30 piezo-channels [26].

Ihn and Chang [27] used SMART Layer to detect damage on simulated lap joint of aluminum plates. While the joint is under fatigue loading, two edge cracks are induced near the fastener holes, which were detected using two SMART Layers with 18 piezoelectric sensors each. It was shown that the measured damage index was well correlated with the conventional NDT methods under different loading cycles. It was also proved that cracks in the size of $0.2 \mathrm{in}$. can be detected with the same level of uncertainty as for the conventional NDT.

SMART Layer is not a new type of sensor. It is an integration of PWAS into a network. Therefore, due to the detection capability of each PWAS, SMART Layer have advantages of reasonably high detection accuracy, large detection range. However, the weight penalty is the main problem when they are used on aircraft structures on a large scale, as it needs a metallic cable/circuit.

\subsection{Fiber Bragg Grating Sensors}

Fiber Bragg grating (FBG) sensors shown in Figure 1 has a series of parallel lines, called gratings, with different refractive indices printed on the core of optical fiber [28]. When the sensor is deformed due to damage, the spacing between gratings is changed. When a broadband light passes through the grating, a specific wavelength is reflected depending on the spacing of grating. When the structure experiences a local strain due to a crack, this spacing changes, and the reflected wavelength is shifted. FBG sensors detect damage by measuring the shift of reflected wavelength. Therefore, FBG sensors can measure damage when the damage causes strain.
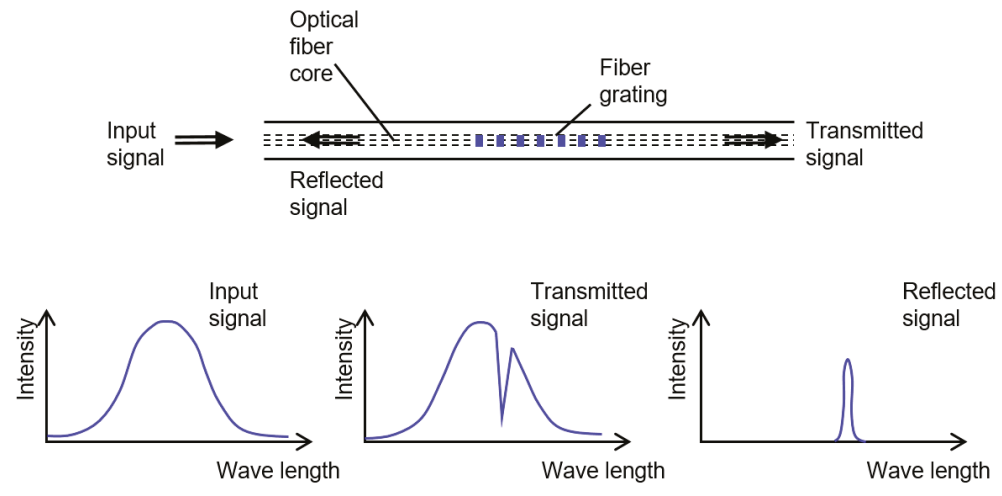

Figure 1. Fiber Bragg grating (FBG) sensor to detect the change in wavelength due to strain.

The FBG sensors are relatively light and safe from electromagnetic interference. Because it is small in size, it can be embedded into composite structures without changing the mechanical performance. By implementing different reflective indices at different locations along the fiber, a single optical fiber can incorporate up to 2000 FGB sensors [29]. This significantly reduces cables and connecting ports. Based on its main usage of strain measurement, it can detect barely visible impact damage (BVID) in composite panels. BVID is often caused by low-velocity impacts and it is the main source of composite delamination. This BVID is very dangerous because it can deteriorate the mechanical strength of the internal structure of composite materials, but it cannot be seen from the surface and easy to be neglected. Takeda et al. [30] conducted fatigue tests for a composite panel, which was initially impacted by a drop-weight to induce BVID and VID. The FBG sensors attached to the backside of the panel detected BVID by comparing the spectrum shift between pristine and damaged states. In addition to 
detecting BVID and VID, there are also other applications of FBG sensors. Baker et al. [31] used FBG sensors to detect the disbond of composite patches on Australian military aircraft. Mieloszyk et al. [32] used FBG sensors to monitor the performance of the aircraft wing made from shape memory alloys by measuring longitudinal strain. Nicolar et al. [33] computed wing shape and measured in-flight loads on a composite aircraft wing using 778 FBG sensors. The dimension of this composite wing is $5.5 \mathrm{~m}$ semi-span and $0.74 \mathrm{~m}$ root chord. The sensors are installed at a spacing of approximately $12.5 \mathrm{~mm}$. Yeager et al. [34] simulated a connection damage by removing a bolt from a composite test panel. They used a finite element model to find out the most effective locations first and place sensors at those locations. In this experiment, FBG sensors successfully extracted damage feature and detected the damage.

FBG sensor has been proved in the literature that it is good for detecting damage in composite materials such as impact damage and disbond as well as monitoring loading condition. For application in this paper, however, several problems might exist. First, we are using B-737 in the case study, and the structure is metallic. The FBG sensor is mainly used on composite structures rather than metallic structures. Even if we do not confine our application to the B-737, we have to admit that most of aircraft in civil aviation are made from metallic structures. Second, damage location (i.e., the impact location) of the experiment by Takeda et al. [30] is known, and the FBG sensors are placed at the same location. Therefore, BVID damage was successfully detected because FBG sensor is in the same location with the damage. Since FBG is based on strain measurement, the detection ability will diminish quickly as the distance increases. Therefore, FBG is appropriate for detecting damage at hotspots but is not appropriate for detecting damage at an unknown location. Third, since strain depends on damage orientation and location, it is necessary to have a fine grid of FBG sensors to detect damage at an unknown location, which can increase the weight of SHM systems as well as data processing time. Fourth, since FBG sensors identify damage by measuring strain change, it works when the airplane is operating, not on the ground, where all strains disappear. That is, FBG is not appropriate to detect closed cracks. Finally, since FBG measures the change in strains, it requires strains at the undamaged (pristine) state. If there is pre-existing damage, it can only measure the change from the previous damage.

\subsection{Comparative Vacuum Monitoring Sensors}

Comparative Vacuum Monitoring (CVM) sensors create a pattern of alternating vacuum and atmospheric pressure galleries, as shown in Figure 2. The concept is that if there is no crack on the surface, the vacuum galleries retain their low pressure. However, if there is crack, it can make a channel between the vacuum and atmospheric galleries, and thus, the air in the atmospheric gallery leaks to the vacuum gallery [35]. Therefore, the low pressure in the vacuum gallery goes up. The level of pressure variation can also indicate the size of cracks [36].

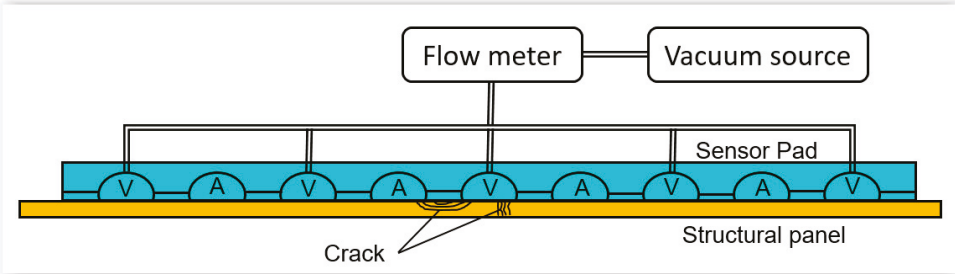

Figure 2. Comparative vacuum monitoring sensor to detect the air leakage due to cracks.

The CVM system is composed of a sensor pad, a flowmeter to measure pressure, and a pump to maintain the low pressure in vacuum galleries. Normally the sensor pad is attached to the surface of a structure, while the flowmeter and pump is a part of a portable system with a data logger. When the 
pump is used to vacuum only the vacuum galleries, the baseline pressure is recorded to the data logger. When there is a crack underneath the sensor, the air can flow from the atmospheric gallery to vacuum gallery, which can raise the pressure in the vacuum gallery. Also, if the sensor pad is disbonded to the structure, the pressure cannot reach the baseline pressure, which means that the system is fail-safe for sensor malfunction. In practice, the sensor pad is permanently attached to the internal supporting structures, while the vacuum lines connect the sensor pad to the inspection port. During the inspection, the inspector connects 16 vacuum galleries with a portable equipment and lowers the pressure in the vacuum galleries.

Sandia National Laboratory tested the CVM on an aircraft panel of thickness $0.1 \mathrm{in.} \mathrm{[37]} \mathrm{under}$ fatigue loading. They showed that the size of $0.02 \mathrm{in}$. cracks can be detected with the probability of $90 \%$ with the confidence level of $95 \%$. Airbus also tested CVM on the lap and welded joints [38]. Delta airline tested CVM on seven Boeing 737 airplanes [39]. Five inspections were conducted every three months with $68 \mathrm{CVM}$ sensors on the wingbox. The tests showed that cracks on the wingbox fittings can be detected successfully using the CVM sensors.

Since the CVM sensor pad is made of polymer, it is lightweight. Also, the gallery size can be manufactured to as small as $10 \mu \mathrm{m}$ [35], which allows to detect very small cracks. The CVM sensors also do not require undamaged (pristine) state information or electrical power and can easily be attached to a curved surface. However, the major difficulty of CVM for SHM is that it can only detect damage underneath the sensor. That is, the detection range is zero. Therefore, this type of sensor is good for detecting damage at a hotspot where the damage location is already well-known. If this sensor is used for the entire fuselage, it requires a sensor layout with a very high density.

\subsection{Comparison of Three Types of Sensors}

As mentioned before, since one of the goals is to choose a sensor technology that is appropriate for detecting damage over the entire fuselage, we compare the three different sensor technologies in the previous section for this application. Also, we consider the situation where the inspection is conducted on the ground at the same time with C-check in the scheduled maintenance, not real-time monitoring as most CBM. Table 1 summarizes the comparison of the three sensor technologies in the above-mentioned scenario. Since the goal is to replace the manual inspection with SHM, the smallest detectable crack size is the most important criterion. Among the three, CVM is the best as it can detect about 0.02 in. cracks. PWAS is almost the same level as conventional NDT, which is around 0.2 in. The FBG is the worst in terms of detectable crack size as it is designed to measure crack indirectly via measuring strain.

Table 1. Comparison of the three types of sensors for structural health monitoring.

\begin{tabular}{cccc}
\hline Performance & CVM Sensor & FBG Sensor & PWAS \\
\hline Smallest detectable damage size & 0.02 in. & N/A & 0.2 in. \\
Weight & Light & Light & Medium \\
Capability of detecting closed crack & Yes & No & Yes \\
Detection range & Low & Medium & High \\
\hline
\end{tabular}

The next important criterion is the weight of SHM systems, which includes not only the weight of the sensor itself but also the weight of cables and connection ports. Both CVM and FBG have advantages in weight as they are composed of polymers, while PWAS is heavier as it requires a metallic wire connection or metallic circuit in SMART Layer.

The detection capability of a closed crack is also an important criterion because the inspection will be performed on the ground, not during the flight. During the flight, the structure experiences tensile loading, which can open the crack and make the crack growth. However, on the ground, the load is removed, and most cracks are closed and do not grow on the ground. Since the inspection is performed on the ground, it is important to detect the cracks when they are closed and they do not 
grow. For CVM, even if the crack is closed, the air can still leak through the existing leakage path. Therefore, it can detect a closed crack. Also, since the closed crack can cause a discontinuity in the material, PWAS can also detect a closed crack. However, since the FBG sensor detects cracks based on strain-induced spectrum shift, it would be difficult to detect the crack on the ground.

Finally, the detection range of the SHM system is important as it determines how many sensors are required to cover the entire fuselage. If a sensor has a long range of detection, a less number of sensors are required, which can reduce the weight of SHM systems. Among the three groups of sensors, it turned out that PWAS shows the longest detection range as the Lamb wave can travel a long distance. On the contrary, CVM has almost zero detection range as it can only detect crack underneath of the sensor pad. FBG sensors can detect damage when the strain caused by the damage is detected by the sensor. However, the strain decays quickly proportional to the distance.

Based on the comparison results shown in Table 1, PWAS turned out to be the most appropriate SHM system for inspecting the entire fuselage of aircraft. This is mostly because of the long detection range of PWAS and the performance of PWAS is almost the same as that of NDT. The CVM sensors would be suitable for monitoring hotspots or pre-determined locations. FBG sensors have advantages for composite material [40] by embedding the fibers during the layup process, which can be used for detecting BVID.

\subsection{Certification Challenges to Implementing SHM on Aircraft}

For any equipment to be used on aircraft, it has to be certified. Federal Aviation Regulations AC-21-16D indicates environmental conditions and test procedures for airborne equipment. The procedures and criteria include testing in temperature variation, fluids susceptibility, combined loading, vibration, etc. [41]. To implement SHM on aircraft, tests have to be performed to prove the capability to endure such environmental conditions. Kessler [1] discussed how SHM system should be certified in detail. Many laboratory tests have been performed by exposing SHM in various environmental conditions.

To test sensor performance under various temperatures, Blackshire et al. [42] used a PWAS bonded to an aluminum panel as a sample. This sample was exposed to low-temperature cycling with $12 \mathrm{~h}$ at $5{ }^{\circ} \mathrm{F}$ and then was thawed to room temperature $\left(75^{\circ} \mathrm{F}\right)$. A total of 40 exposures were performed. Using displacement field images, the vibration level is reduced by approximately $1.8 \%$ after each exposure. Then, a high-temperature cycle with $1 \mathrm{~h}$ at $175^{\circ} \mathrm{F}$ and room temperature was tested. A crack was found after 10 cycles.

Lin et al. [43] also tested the performance of PWAS under different temperatures. Different from the previous experiment, a free PWAS and bonded PWAS were tested at the same time, and the characterization method was electromechanical impedance. Free PWAS can survive up to $500{ }^{\circ} \mathrm{F}$. For bonded PWAS, however, the amplitude of impedance peak dropped above $200^{\circ} \mathrm{F}$. The temperature cycling test was also performed between $100^{\circ} \mathrm{F}$ and $175^{\circ} \mathrm{F}$. Free PWAS showed no obvious change of impedance spectrum up to 1700 cycles, but for bonded PWAS, it failed because of disbond after 1700 cycles. These two experiments suggest that the decreased performance may be caused by degradation of the adhesive layer under high temperatures and the thermal expansion difference between the sensor and the structure.

For a corrosion environment, different solution environments are simulated [43]. They include saline solution, different types of hydraulic fluid, lubricating oil, and kerosene. The result showed no meaningful change in the impedance spectrum except in the case of the saline solution. PWAS only survived in the saline solution around 85 days due to the detachment of soldered connection.

The durability of PWAS under strain as well as fatigue loading is also important. Lin et al. [43] used a PWAS bonded to a 2024-T3 aluminum plate under tensile loading. Significant impedance change was observed after 3000 microstrains and this change became stronger after 6000 microstrains and failed around 7200 microstrains. Under fatigue cyclic loading, PWAS survived before the aluminum plate broke. Moix-Bonet et al. [44] performed a quasi-static test on a composite structure with PWAS 
co-bonded on it. Under tensile stress, the PWAS broke when the strain level reaches $0.54 \%$. While under fatigue loading, its performance decreased between 1000 and 10,000 cycles and failed at 10,000 cycles.

Reliability of PWAS under dynamic motion was tested using a dynamic shaker system [42], which produce a maximum strain of 2093 microstrains at the frequency of $70 \mathrm{~Hz}$. Disbonding with a crack as well as a fracture of PWAS were found in displacement field images.

These experiments indicate that sensor durability to environment conditions still needs to be improved to meet the requirement of certification. In addition, one important aspect for certification is the probability of detection (POD). The POD is crucial for maintaining the required safety level. However, the POD assessment process is very complicated and challenging as it requires a large number of independent tests. It is noted that repeated tests on a few specimens cannot be considered as an independent test. Forsyth [45] explained this in detail and proved that it will lead to unconservative POD estimation. In addition, the real part geometry and loading condition, as well as different defects in morphology, are difficult to simulate in a laboratory environment. These all lead to the lack of SHM POD assessment. Janapati et al. [46] studied SHM sensitivity characterization under the condition that the damage location is known. The results show that sensor location and orientation of damage growth have a significant impact on detection reliability. In our application, the damage location and condition are unknown. This leads to even larger uncertainty in the POD of SHM. Lindgren [47] discussed that, for military aviation, because of the validation constraints, Technology Readiness Level (TRL) remains at 4 or less (out of 10) and this becomes a significant barrier for implementing SHM on USAF aircraft.

\subsection{Emerging Sensor Technologies}

Although only three types of sensors are discussed in this section, there are many new sensor technologies being developed. Although these sensors are developed to overcome the weakness of the conventional sensors, we did not discuss them in this paper because they are still in the developing stage and were not tested in a large scale. However, these sensors are briefly summarized in Appendix A.

Wireless sensors are also popular but are not discussed in this paper. In fact, they should not be considered as a type of sensor, but a sensor network or platform [48]. The main idea is to remove heavy cables and connection ports by replacing them with a wireless connection. Not having cable and connection ports can reduce structural weight significantly, but at the same time, this requires a separate source of power supply, which can penalize weight more. On top of that, adding batteries to the SHM system may require additional maintenance issues. Some researchers have proposed power harvesting [49] for sensors by capturing the required electricity from solar energy or structural vibration. Although it is a promising research area, it is still a challenging research topic to add this technology on the global level of the SHM systems without increasing weight significantly. Therefore, the technology maturity is still low, and it is not included here.

\section{Proposed Inspection Schedule and Estimation of the Number of Sensors}

Although it is impractical and unnecessary for real-time monitoring in CBM, it is obvious that SHM can effectively detect damage. We just need to find a practical way to integrate SHM into maintenance. The questions become what should be the inspection interval using SHM and how many sensors required to inspect entire aircraft fuselage.

Among different scheduled maintenances, the internal surrounding structures need to be removed from C-check, where DVI and conventional NDT are used. Since the performance of SHM sensors is on the same level as NDT, it would be a good choice to replace the manual inspection during the C-check with SHM sensors. That is, the aircraft goes through the same maintenance intervals as C-check, but only the damage detection is replaced by the SHM sensors. We consider this as a transition from the scheduled maintenance to CBM. As the sensor technology can be developed further, the inspection and maintenance may gradually move to the CBM. Since there is no real-time damage information, prognostics would not be applicable to this approach, and it will not be considered in this paper. 
For the sensor layout, it is always a tradeoff between the number of sensors and detection capability. Many optimization approaches have been used to design an optimum sensor layout. Gao and Rose [50] used genetic and evolutionary algorithms to minimize missed-detection probability. Flynn and Todd [51] found out the optimum configuration of actuators and sensors that minimizes Bayes risk using a genetic algorithm with a time-varying mutation rate. Ewald et al. [52] used blob detection algorithm and differential images for a hotspot SHM system. Lee et al. [53] modeled Lamb wave propagation in a $2 \mathrm{D}$ plate interaction with artificial damage and found the sensor location when maximum amplitude change of damage occurs compared to the baseline signals. Thiene et al. [54] found the optimal sensor placement using genetic algorithm by achieving maximum area coverage. Janapati et al. [55] used a model-assisted sensor network optimization to find out the optimal location with the maximum POD. Almost all these studies are based on a sample plate with a known damage location. They are good for hotspot monitoring. For inspecting damage on a whole fuselage, however, it is impractical to do optimization or simulation. Especially in a real situation, the geometry is much more complicated, and the damage location is normally unknown. Since we only need to estimate the total number of sensors required rather than the specific location of each sensor, the optimization and simulation method is unnecessary. Almost all layout optimization processes ended up with either a square or hexagon configuration. Therefore, in this paper, we simply use the square as a basic sensor configuration for our estimation. Our goal is to inspect entire fuselage using a minimum number of sensors/minimum weight and achieving the same detection capability as manual inspection in scheduled maintenance.

In the fuselage area, there are many supporting structures inside the skin. The main structure in the hoop direction is called the frame, and the longitudinal direction is the stringer. The cracks on aircraft structures are mostly originated from fastener holes because of defects generated in manufacturing and maintenance process. Because of stress concentration, these cracks grow faster than other areas. Since most of these fastener holes exist in the stringer and frames, it would be a natural choice to install SHM sensors along the fastener holes. In this paper, SMART Layer is used for SHM system. It is assumed that the SMART Layer installed along the fastener hole can also detect cracks in the skin area between them [27].

Damage detection capability of sensors depends on various factors, such as damage size and orientation, material properties, structure geometry as well as environment condition. In this paper, we use a basic value $10 \mathrm{in}$. as damage detection distance [55]. That means, it is necessary to have one sensor at every $10 \mathrm{in}$. Based on this sensor resolution, Figure 3 shows a representative layout of SMART Layer along fuselage frames and stringers. For estimating the total number of sensors required it is necessary to calculate the total length of stringers and frames in the fuselage. Considering the fuselage is 100 feet long for Boeing $737 \mathrm{NG}$, there are 60 frames since the distance between frames is $20 \mathrm{in}$. Also, considering the diameter of the fuselage is $148 \mathrm{in}$. from SRM and assuming that all frames have the same length, the total length of the frame would be $60 \times 3.14 \times 148 \mathrm{in} .=27,883 \mathrm{in}$. In the same way, there are 60 stringers with each of them having 100 feet length. Therefore, the total length of stringers is $60 \times 1200 \mathrm{in}$. $=72,000 \mathrm{in}$. Therefore, if one sensor is required at every $10 \mathrm{in}$., we need a total of $(27,883+72,000) / 10=9988$ sensors.

It should be mentioned that the above estimation is conservative. First, we only consider the main components of the fuselage area, including skin, stringer and frame. There are also many other small components we did not consider in this paper, such as webs, fittings, splices and angle plates. Second, damage detection capability decreases with a complicated geometry of each component. In the case of frames, the interval between fastener holes is less than an inch. That means, there are about 10 fastener holes in $10 \mathrm{in}$. interval of sensors. Since PWAS uses a Lamb wave to detect damage, it is difficult to detect cracks that are behind a hole. If sensors are located every $10 \mathrm{in.,}$ it is likely that some cracks may not be visible from the sensor. Because of this characteristic, Ihn et al. [27] used the same number of sensors with the number of fastener holes. In this paper, however, it is assumed that $10 \mathrm{in}$. interval of 
sensors can detect damage in the fastener holes as well as the skin between the frames and stringers, as shown in Figure 3. All these lead to a conservative estimation of the total number of sensors required.

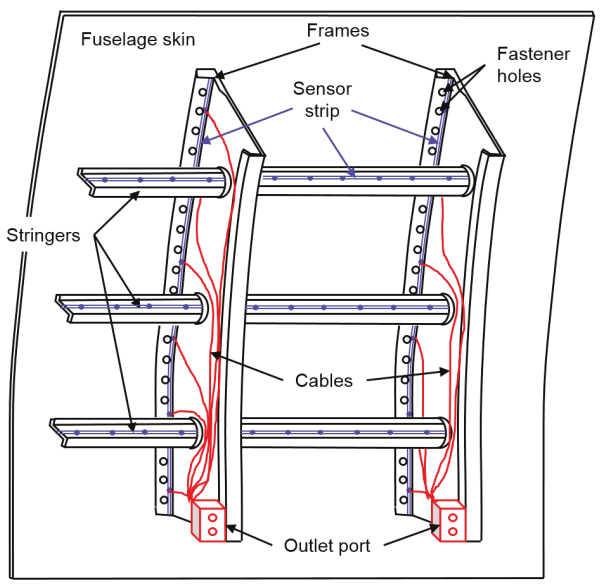

Figure 3. Layout of sensors and cables in fuselage frames and stringers. Blue lines are the sensor strips, while red lines are connection cables.

Once sensors are placed on the structure, the next step is to perform inspection using them. Although there are almost 10,000 sensors installed, it is impractical to connect all of them simultaneously. For each SMART Suitcase, it can connect up to 30 sensors at one time [26]. Therefore, we assume that one connection port in the cabin wall is available for every 30 sensors, which means that with 9988 sensors, 333 connection ports need to be installed for the entire fuselage. Therefore, in this layout, the added weight consists of almost 10,000 sensors, 333 connection ports, and connecting cables between the sensors and connection ports. If more than 30 sensors are connected simultaneously, it is possible to reduce the number of connection ports, but at the same time, longer cables should be used to connect all sensors to the port. Therefore, usage of a larger capacity equipment may not provide any weight savings.

The inspection procedure would be that during the C-check the inspectors connect the portable SMART Suitcase to each port and actuate the sensors one-by-one, collect data from the sensors, and analyze the data to acquire damage information, such as the presence of damage, the location and size of the damage. We estimate that this process may take about $30 \mathrm{~min}$ for each port. Since there are 333 connection ports, it would require about $167 \mathrm{~h}$. It is rather surprising results because it is expected that having SHM sensors can expedite the inspection process, but in practice, it may take almost the same time as manual inspection due to the considerable number of sensors and the time to process a large amount of raw data.

It may be possible to consider SHM as a part of Integrated Vehicle Health Management (IVHM) system, which is already present in most aircraft. The IVHM is used to collect fault signals from many aircraft components and send the information to the ground control station [56]. The collected information includes engine status, avionics, flight control, propulsion, and utilities. It seems promising to integrate the SHM system into IVHM so that data can be automatically collected and sent to the ground station. However, the current IVHM is designed for monitoring faults from operation, engines and avionics, which are targeting completely different systems rather than fuselage structure. This means that there are no pre-existing data buses or electronics blocks on the fuselage, with which SHM system can be shared, to interact with sensors and process. Currently, there is no IVHM system 
that can handle almost 10,000 sensors, and connecting all the SHM sensors to IVHM may penalize the weight significantly.

\section{Cost-Benefit Analysis}

Since the return of investment is an important consideration in the civil aviation industry, introducing a new technology always requires a detailed cost-benefit analysis. It is highly unlikely the industry will adopt a new technology if it failed to bring a significant benefit or safety. As shown in the previous section, since the quality of SHM-based inspection is comparable to manual inspection, it is assumed that SHM can maintain the same level of safety. Therefore, this section discusses the cost-benefit of SHM-based inspection over manual inspection throughout the lifecycle of an aircraft. As we mentioned before, in this paper the SHM system is used for replacing manual inspection. That is, during the C-check, on-board SHM sensors are connected to the ground equipment to detect damage in the entire fuselage skins, frames, and stringers. Therefore, the cost-benefits related to real-time SHM and prognostics are not discussed here.

Since the cost analysis of an aircraft over its lifecycle is really complicated, we limited our cost analysis to those that are affected by replacing SHM sensor-based inspection. In addition, in order to make the cost analysis simple, the following assumptions are made. These assumptions are made in the favor of SHM-based inspection. First, it is assumed that the sensors do not need to be replaced throughout the lifecycle of the aircraft, and all sensors are free of dysfunction. Although this is a significant assumption in cost calculation, it will not change our conclusions because it is a conservative toward the usage of sensors. Boller [15] discussed that in practice the reliability issue of the sensors may overwhelm all the benefits that the sensor technology may bring in.

The second assumption is about the inspection time. It is expected that sensor-based inspection is faster than manual inspection. However, as shown in the previous section, the sensor-based inspection also takes time because almost 10,000 sensors are actuated one-by-one and all raw data are collected and processed to obtain useful damage information. Although the manual inspection requires removing internal surrounding structures, once they are removed, the actual manual inspection time is assumed to be the same as SHM-based inspection.

The last assumption is that the SHM-based maintenance would not require removing surrounding structures to access the internal structures. This is only true when there is no damage detected. However, once the damage is detected, it still needs to remove surrounding structures to access the damage for repair. This process will increase the cost for SHM-based maintenance, but again this assumption will be conservative toward SHM-based maintenance.

In our cost calculation, we will not include those costs that are common for both methods.

\subsection{Added Cost Due to SHM Systems}

In general, the cost can be categorized by one-time cost and recurring cost. The former is related to manufacturing cost, such as installing sensors and connecting cables and making outlet ports, while the latter is related to recurring maintenance during every C-check. Since we limit our interest to the difference between the two inspection methods, we only consider those costs that are related to the inspection. It is noted that the main source of cost in the aviation industry is the weight. Since the take-off weight of an aircraft is fixed, if an extra weight is added to the aircraft, the payload has to be reduced, which was not clearly mentioned in the cost analysis literature $[5-7,13,14]$ for SHM.

Sensor cost: The sensor cost is a one-time cost that occurs during the installation of sensors. Also, off-the-shelf sensors are used instead of research and development of a new sensor. The sensor cost also includes all peripherals to connect the sensor to the structure, cables and connection ports on the cabin wall. Based on Giurgiutiu [22], it is estimated that each sensor with peripherals is about $\$ 10$. Therefore, using the total number of sensors $N_{s}=9988$ calculated in the previous section, the total cost of SHM sensors is

$$
C_{\mathrm{SHM}}=N_{S} \times C_{\text {sensor }}
$$


where $C_{\mathrm{SHM}}$ is the cost of the SHM system, and $C_{\text {sensor }}=\$ 10$ is the cost for each sensor with its peripherals.

Installation cost: In addition to the sensor cost, sensor installation is also a one-time cost. This includes not only attaching sensors to the structure, but also sophisticated cabling and installing outlet ports to the cabin wall. The installation cost is calculated based on the time to install all sensors with the labor rate per person-hour as:

$$
C_{\text {install }}=t_{\text {install }} \times C_{\mathrm{mh}}
$$

where $C_{\text {install }}$ is the installation cost, $t_{\text {install }}$ is the total person-hours required for installing the SHM system, and $C_{m h}$ is the labor rate per person-hour.

Inspection cost: Different from sensor and installation cost, the inspection cost is a recurring cost. Since the inspection will be performed at every C-check, this is proportional to the total number of C-check $N_{C \text {-check }}$ throughout the lifetime of aircraft. The inspection cost can be calculated as

$$
C_{\text {inspec }}=t_{\text {inspec_SHM }} \times C_{\text {mh }} \times N_{\text {C-check }}
$$

where $C_{\text {inspec }}$ is the inspection cost using SHM system, and $t_{\text {inspec_SHM }}$ is the total person-hours required for inspection using SHM system in one C-check. As we mentioned in the assumption, however, since $t_{\text {inspec_SHM }}$ is the same as the time for manual inspection, it is unnecessary to consider the inspection cost for the purpose of comparison.

Cost caused by extra weight: It turned out the weight increase by SHM system is the major issue for the cost. Unfortunately, this issue has been either ignored or inappropriately estimated. For example, the cost due to the extra weight of the SHM system was calculated based on extra fuel cost [57]. Indeed, weight change directly leads to the change in fuel consumption and many airlines benefit from it. To reduce fuel cost, Delta changed the seats five pounds lighter. Lufthansa reduced 506 pounds by removing auxiliary fuel tanks from their A340 aircraft. Northwest put 25\% less water for toilets usage on international flights and they saved $\$ 440,000$ a year for every 25 pounds water removed [58]. However, the calculation of fuel cost change due to weight change is only applicable when the weight is reduced. When weight is increased, we cannot simply calculate the extra fuel cost. To analyze the cost due to the weight increase, it is necessary to consider some aircraft weight conceptions and regulations first. Depending on how the weights are certified, they can be categorized as manufacturer certified weights and operator certified weights [58]. Maximum Zero Fuel Weight (MZFW) is a manufacturer certified weight; that is, the maximum allowable weight before usable fuel is loaded. Operational Empty Weight (OEW) is an operator certified weight; that is, the weight of aircraft equipped for service, including manufacturer's empty weight, standard items, and operator items. Payload, by definition, is the load that can produce revenue, including passenger, baggage and cargo, which can be calculated from

$$
\text { Max. Payload }=\text { MZFW }- \text { OEW }
$$

In the above equation, MZFW is basically a fixed value for a specific aircraft model, whereas OEW can vary in each aircraft depending on its configuration as required by the operator. A payload-range diagram shows the trade-off between flight range and payload an aircraft can carry. To simply put, within the diagram limitation, larger payloads can result in shorter flight range. Excessive weight can also reduce the safety margin in case of emergency and compromise aircraft performance, such as requiring longer takeoff run, higher takeoff speed, and reduced climb angle. In the Aircraft Flight Manual or Pilot Operating Handbook, there are charts indicating allowable flight performance corresponding to a different weight. The pilot needs to check it before the flight to determine whether it is safe to fulfill the proposed flight based on the OEM and how the aircraft is loaded. 
According to FAA regulation, an operator should record any weight changes larger than $5 \mathrm{lbs}$ for medium-cabin aircraft after situations such as structure alteration and modification [59]. If cumulative weight change is more than $0.5 \%$ of the maximum landing weight, the OEW should be reestablished. For the B737-700, the maximum landing weight is $128,000 \mathrm{lbs}$ [60]. This means that when the weight exceeding $640 \mathrm{lbs}$, the OEM has to be reestablished. In our application, as discussed in the previous section, one connection port is installed on the cabin panel for every 30 sensors. The total weight can be calculated as

$$
W_{\text {SHM }}=W_{\text {set }} \times \frac{N_{S}}{30}
$$

where $W_{\text {set }}$ is the weight of each set including 30 sensors and their accessories. If we assume $W_{\text {set }}$ is 3 lbs, the total weight $W_{\mathrm{SHM}}$ is $1000 \mathrm{lbs}$, which means that $\mathrm{OEW}$ should be redefined and the maximum payload is reduced by $1000 \mathrm{lbs}$. For maintaining aircraft performance and safety margin, the only way we can calculate the cost due to extra weight is estimating the revenue loss due to losing payload.

For commercial aircraft in civil aviation, reducing payload means reducing the number of passengers. It is assumed that the weight of one passenger including luggage is 200 pounds, and the ticket price for one passenger is $\$ 200$ for one flight on average. Therefore, for every one pound of weight increase due to the SHM system, the airline lost \$1 in each flight. Then the total life cycle revenue lost due to the weight of the SHM system is

$$
C_{\text {weight }}=W_{\mathrm{SHM}} \times P \times N_{\mathrm{fc}}
$$

where $P$ is the ticket price for each pound in each flight, and $N_{\mathrm{fc}}$ is the total number of flights of B-737NG over its lifecycle.

\subsection{Benefits of SHM Systems}

There are several cost-benefits from using SHM-based inspection. In order to perform a manual inspection, it is required to remove internal surrounding structures so that inspectors can access the internal structures. This process takes person-hours for labor, and airlines lose revenue due to maintenance downtime. The SHM-based inspection can take this as a cost-benefit. In the following analysis, we will calculate the benefit of SHM-based inspection for a single C-check, and then, the total benefits can be calculated by multiplying with the total number of C-checks throughout the lifetime of the aircraft.

Benefit for not removing/reinstalling surrounding structures: As mentioned in Section 3, the process of removing surrounding structures takes about four days by 20 technicians and about the same time to reinstalling them after maintenance. On the other hand, SHM-based inspection does not require removing the surrounding structures. The first benefit can be calculated in terms of person-hours that can be saved using SHM-based inspection. In the case of the Boeing 737NG, a regular $\mathrm{C}$-check takes about a month, among which eight days are used for removing and reinstalling the internal surrounding structures by about 20 technicians. Therefore, the benefit of saving this labor work via an SHM-based inspection can be estimated as

$$
B_{\text {labor }}=t_{\text {manual }} \times C_{\text {mh }} \times N_{\mathrm{C}-\text { check }}
$$

where $B_{\text {labor }}$ is the benefit for saving the labor work of installation and removal internal surrounding structures for manual inspection, $t_{\text {manual }}$ is the total man-hours required for the removal and installation process, and $N_{\mathrm{C}-\text { check }}$ is the total number of C-checks in the lifetime.

Benefit due to reduced maintenance downtime: For every single day the aircraft stays in the hangar for maintenance, it means one day's revenue lost for the airline. The major benefit of the SHM-based inspection method is to reduce the aircraft downtime for the C-check, which can lead to recovered revenue for the airlines. As estimated in the labor calculation, the downtime can be reduced 
by eight days at every C-check. For airlines, net revenue due to downtime is about $\$ 27,428$ per day [61]. Accordingly, the life cost saving can be calculated as

$$
B_{\text {avail }}=t_{\text {downtime }} \times R_{\text {daily }} \times N_{\mathrm{C}-\text { check }}
$$

where $B_{\text {avail }}$ is the benefit of more availability due to reduced maintenance downtime, $t_{\text {downtime }}$ is the reduced downtime in one C-check, and $R_{\text {daily }}$ is the airline daily revenue.

\subsection{Cost-Benefit Analysis Results}

In order to calculate cost-benefit by using SHM-based inspection, Table 2 summarizes the best-estimate values of variables that are used. These parameters are based on the discussions in the previous sections as well as from the literature. As mentioned before, these parameters were selected in the favor of SHM-based inspection. Therefore, the actual cost-benefit might be significantly different from the one calculated in this paper. However, since we took a conservative estimate in the favor of SHM-based inspection, the conclusions remain unchanged.

Table 2. Parameter values used for maintenance cost-benefits analysis.

\begin{tabular}{cc}
\hline Parameter & Value \\
\hline$N_{S}$ & 9988 \\
$C_{\text {sensor }}$ & $\$ 10$ \\
$t_{\text {install }}$ & 2000 \\
$C_{\text {mh }}$ & $\$ 60 /$ man-hour \\
$W_{\text {set }}$ & $3 \mathrm{lbs}$ \\
$P$ & $\$ 1 /$ flight \\
$N_{\text {fc }}$ & 50,000 \\
$t_{\text {manual }}$ & 1280 man-hour \\
$N_{\text {C-check }}$ & 18 \\
$t_{\text {downtime }}$ & 8 days \\
$R_{\text {daily }}$ & $\$ 27,428 /$ day \\
\hline
\end{tabular}

Using these variables, Table 3 showed the cost-benefit analysis results. It showed that the cost due to payload loss is an order of magnitude higher than all other factors combined. This happened because the weight increase was significant due to a large number of sensors to cover the entire fuselage area. With a conservative estimate of $W_{\text {set }}=3 \mathrm{lbs}$ for 30 sensors with all peripherals, the total weight of SHM system would be more than $1000 \mathrm{lbs}$, which is equivalent to losing about five passengers in each flight. Compared to other sensors in IVHM, such as accelerometers or temperature or pressure sensors, the current technology of SHM requires too many sensors, which is the bottleneck of the sensor-based SHM. Therefore, even with a conservative estimate in the favor of SHM-based inspection, it can be concluded that the cost is overwhelmingly higher than benefit by using SHM system, and it is impractical to replace manual inspection with SHM-based inspection for the current aircraft.

Table 3. Cost-benefit analysis final results.

\begin{tabular}{cccc}
\hline \multicolumn{2}{c}{ Cost } & \multicolumn{2}{c}{ Benefit } \\
\hline$C_{\text {SHM }}$ & $\$ 99,880$ & $B_{\text {labor }}$ & $\$ 1,384,400$ \\
$C_{\text {install }}$ & $\$ 120,000$ & $B_{\text {avail }}$ & $\$ 3,949,632$ \\
$C_{\text {weight }}$ & $\$ 50,000,000$ & & \\
$C_{\text {Total }}$ & $\$ 50,219,880$ & $B_{\text {Total }}$ & $\$ 5,334,032$ \\
\hline
\end{tabular}

\subsection{Discussions}

Using cost-benefit study, the main factor to determine the cost-benefit is the payload loss due to the weight of SHM systems. This is because the current sensor technology requires too many sensors 
to replace the manual inspection. The weight of the SHM system is more than $0.5 \%$ of maximum landing weight, which requires reevaluating the Operational Empty Weight, OEW, and leads to losing the payload. The payload loss results in the revenue loss because it limits the maximum number of passengers. It would be necessary that the current SHM technology needs to be developed so that either each sensor assembly is lighter or each sensor can have a larger range of detection.

It is true that we did not fully utilize the capability of the SHM system by incorporating it only with C-check, not real-time monitoring and prognostics. That is, the SHM might be cost-efficient if the scheduled maintenance is completely removed, and the maintenance is conducted only when the damage actually threatens the safety of the aircraft. As presented in the previous section, for stable damage growth, it is unnecessary to have real-time monitoring as damage grows slowly. This is also related to the current concept of "damage-tolerant design", which allows damage to exist on the structures as long as its size is below the threshold. That is, the current aircraft structures are strong enough to keep the aircraft safe even if small-sized cracks exist during scheduled maintenance intervals. However, if real-time monitoring and prognostics are available, it might be possible to reduce the structural weight significantly because the structure does not need to hold the cracks until the next C-check. Such a reduction in weight can compensate for the weight increase due to SHM systems. Our conclusion is that the structural design concept can be optimized with the maintenance approach. In order to achieve a full advantage from SHM-based CBM, a new design concept needs to be developed.

It is noted that we use the Boeing 737NG as an example in the case study because it is the most popular model currently in civil aviation. The conclusion from this case study is applicable for aircraft with metallic structures, such as the A320, A330, B747, B757, B767, and B777. These cover most of the aircraft in current commercial civil aviation. As the size of aircraft increases, the larger the number of sensors required. For new aircraft models with composite structures such as the B787 and A380, it will be a different story. In the case of the Boeing 787, for example, about $50 \%$ of the structure is manufactured using composite materials, while traditional aircraft are composed of $20 \%$. In addition to their lightweight composite materials, they also significantly lower the number of fastener holes by up to $80 \%$. Therefore, it is promising to design SHM systems for new aircraft model with composite materials, which have a lot of potential to reduce the maintenance cost.

\section{Conclusions}

In this paper, various sensor technologies are reviewed in terms of the smallest detectable damage size, detection range, and weight for the perspective of aircraft structural maintenance. It turned out that the Piezoelectric Wafer Active Sensor (PWAS) is the most promising system to replace the current manual inspection during C-check. However, replacing the current manual inspection with an SHM-based inspection anticipates several challenges. Due to the limited detection range of the PWAS, it would require about 10,000 sensors to assess the entire fuselage areas of a Boeing 737NG. The weight increase due to sensors, cables, and connection ports is more than $1000 \mathrm{lbs}$, which can lead to a significant loss of payload.

The cost saving due to reducing maintenance downtime and labor is about $\$ 5 \mathrm{M}$ over the lifetime of the plane, while the revenue loss due to payload is about $\$ 50 \mathrm{M}$. This calculation is based on a conservative estimate in the favor of SHM. Therefore, the aviation industry cannot take advantage of this new technology. In order to make the SHM-based inspection cost-effective, it would be necessary to improve the sensor technology to reduce the weight of the sensor system and to detect damage in a long range. Also, the structural design concept also needs to be integrated/optimized with CBM.

In this study, we did not consider the reliability of sensors, which is an important aspect of a practical point of view. Maintaining about 10,000 sensors in good condition during the lifecycle of the airplane may add additional cost. 
Author Contributions: The first author T.D. reviewed sensor technologies and compared their performances for fuselage inspection. The first author also performed cost-benefit analysis. The second author N.H.K. designed sensor layouts for fuselage inspection.

Funding: This research was supported by Air Force Office of Scientific Research (Contract No. 84796). This support is gratefully acknowledged.

Conflicts of Interest: The authors declare no conflicts of interest.

\section{Appendix A. Summary of Emerging Sensor Technologies}

\section{Appendix A.1. Carbon Nanotube Sensors}

The electrical properties of carbon nanotube vary as the atomic structure changes. When strain in carbon nanotube changes, the resistance changes accordingly. The linear change of resistance with respect to strain has been proved experimentally [62]. This property can be used as a sensor to measure the strain and detect cracks in structures. The idea is to use a grid of carbon nanotubes to cover a large area to detect damage. This sensor can either be sprayed on the surface of the structure or embedded into the composite material as a pre-cured layer with very little weight penalty. However, to put this into practice, problems such as resistance drift and high noise to signal ratio have to be improved.

\section{Appendix A.2. Printed Sensors}

Printed sensors have gain popularity recently because of their low cost. There are several different types of printed sensors. Inject printed sensor uses a moving nozzle to deposit ink on PET substrates. The ink is normally a nanoparticle-based material with electrical function. Using this piezoelectric property of the ink material, resistance change can be measured when the sensor is subjected to strain. Inject printed sensor is proved to have high strain sensitivity and strain tolerance level [63]. However, it has problems such as temperature-dependent resistance, high transverse strain sensitivities, and nozzle clogging as well. To solve the clogging problem, the aerosol printed sensor is developed. The main difference is that ink material is broken into macroscopic particles by ultrasonic vibration of the atomizer. It shows higher flexibility as well as better control on-line width [64]. However, the sensor reliability problem and temperature dependent resistance still exist.

\section{Appendix A.3. Microelectromechanical System (MEMS) Sensors}

Microelectromechanical system (MEMS) is a miniaturization and integration of sensors, actuators and integrated circuit for signal processing and control functions. It can either work in a passive way, by listening to signals generated by damage, or in an active way, by generating signals to interact with structures. In an active way, similar to PWAS, actuators in MEMS can send out wave signal to interrogate the material and the reflected signal is received by sensors. The difference is that MEMS has its own signal processor integrated on the chips. It also incorporates antennas to transmit signals. This powerful multifunctional chip can be manufactured to the submillimeter range [65]. Its small size enables MEMS to be lightweight and non-instructive. This technique is targeting for real-time monitoring application in the future and its whole function requires a power supply.

\section{Appendix A.4. Acoustic Emission}

Acoustic emission is not a specific type of sensor but a detection approach. It can use PWAS or FBGS as sensors to receive signals. However, instead of using wave signals generated by actuators, this approach receives acoustic emission waveform signals generated by the damage itself. For example, when a fatigue crack propagates in the material, it generates acoustic emission signals. By analyzing acoustic emission parameters such as the amplitude and arrival time, damage can be located, and damage size can be measured. An advantage of this technique is that a small number of sensors is required to monitor a large area. However, it cannot be used in our application. Acoustic emission is a typical passive detection approach and it can only be used for real-time monitoring during flight 
because the acoustic emission signals only generated when the damage propagates or is under loading condition [66].

\section{References}

1. Kessler, S.S. Certifying a structural health monitoring system: Characterizing durability, reliability and longevity. In Proceedings of the 1st International Forum on Integrated Systems Health Engineering and Management in Aerospace, Napa, CA, USA, 7-10 November 2005; pp. 7-10.

2. Jardine, A.K.; Lin, D.; Banjevic, D. A review on machinery diagnostics and prognostics implementing condition-based maintenance. Mech. Syst. Signal Process. 2006, 20, 1483-1510. [CrossRef]

3. Boller, C.; Chang, F.; Fujino, Y. Encyclopedia of Structural Health Monitoring; John Wiley \& Sons: Hoboken, NJ, USA, 2009.

4. Pattabhiraman, S.; Gogu, C.; Kim, N.H.; Haftka, R.T.; Bes, C. Skipping unnecessary structural airframe maintenance using an on-board structural health monitoring system. Proc. Inst. Mech. Eng. Part O J. Risk Reliab. 2012, 226, 549-560. [CrossRef]

5. Gerdes, M.; Scholz, D.; Galar, D. Effects of condition-based maintenance on costs caused by unscheduled maintenance of aircraft. J. Qual. Maint. Eng. 2016, 22, 394-417. [CrossRef]

6. Hölzel, N.; Schilling, T.; Gollnick, V. An aircraft lifecycle approach for the cost-benefit analysis of prognostics and condition-based maintenance based on discrete event simulation. In Proceedings of the Annual Conference of the Prognostics and Health Management Society 2014, Fort Worth, TX, USA, 29 September-2 October 2014; pp. 442-457.

7. Fioriti, M.; Pavan, G.; Corpino, S.; Fusaro, R. Impacts of a prognostics and health management system on aircraft fleet operating cost during conceptual design phase by using parametric estimation. In Proceedings of the 5th CEAS Air \& Space Conference, Delft, The Netherlands, 7-11 September 2015.

8. Taha, M.R.; Lucero, J. Damage identification for structural health monitoring using fuzzy pattern recognition. Eng. Struct. 2005, 27, 1774-1783. [CrossRef]

9. Kim, H.; Melhem, H. Damage detection of structures by wavelet analysis. Eng. Struct. 2004, 26, 347-362. [CrossRef]

10. Coppe, A.; Pais, M.J.; Haftka, R.T.; Kim, N.H. Using a simple crack growth model in predicting remaining useful life. J. Aircr. 2012, 49, 1965-1973. [CrossRef]

11. An, D.; Choi, J.H.; Kim, N.H.; Pattabhiraman, S. Fatigue life prediction based on Bayesian approach to incorporate field data into probability model. Struct. Eng. Mech. 2011, 37, 427-442. [CrossRef]

12. Kim, N.H.; An, D.; Choi, J.H. Prognostics and Health Management of Engineering Systems: An Introduction; Springer: Berlin/Heidelberg, Germany, 2016.

13. Leao, B.P.; Fitzgibbon, K.T.; Puttini, L.C.; de Melo, G.P. Cost-benefit analysis methodology for PHM applied to legacy commercial aircraft. In Proceedings of the 2008 IEEE Aerospace Conference, Big Sky, MT, USA, 1-8 March 2008; pp. 1-13.

14. Feldman, K.; Jazouli, T.; Sandborn, P.A. A methodology for determining the return on investment associated with prognostics and health management. IEEE Trans. Reliab. 2009, 58, 305-316. [CrossRef]

15. Boller, C. Next generation structural health monitoring and its integration into aircraft design. Int. J. Syst. Sci. 2000, 31, 1333-1349. [CrossRef]

16. Giurgiutiu, V.; Cuc, A. Embedded non-destructive evaluation for structural health monitoring, damage detection, and failure prevention. Shock Vib. Dig. 2005, 37, 83-105. [CrossRef]

17. Giurgiutiu, V.; Bao, J. Embedded-ultrasonics structural radar for in situ structural health monitoring of thin-wall structures. Struct. Health Monit. 2004, 3, 121-140. [CrossRef]

18. Yu, L.; Giurgiutiu, V. In situ 2-D piezoelectric wafer active sensors arrays for guided wave damage detection. Ultrasonics 2008, 48, 117-134. [CrossRef] [PubMed]

19. Xu, B.; Giurgiutiu, V. Single mode tuning effects on Lamb wave time reversal with piezoelectric wafer active sensors for structural health monitoring. J. Nondestruct. Eval. 2007, 26, 123-134. [CrossRef]

20. Worden, K. Rayleigh and Lamb Waves-Basic Principles. Strain 2001, 37, 167-172. [CrossRef]

21. Santoni, G.B.; Yu, L.; Xu, B.; Giurgiutiu, V. Lamb wave-mode tuning of piezoelectric wafer active sensors for structural health monitoring. J. Vib. Acoust. 2007, 129, 752-762. [CrossRef] 
22. Giurgiutiu, V. Tuned Lamb wave excitation and detection with piezoelectric wafer active sensors for structural health monitoring. J. Intell. Mater. Syst. Struct. 2005, 16, 291-305. [CrossRef]

23. Zhao, X.; Gao, H.; Zhang, G.; Ayhan, B.; Yan, F.; Kwan, C.; Rose, J.L. Active health monitoring of an aircraft wing with embedded piezoelectric sensor/actuator network: I. Defect detection, localization and growth monitoring. Smart Mater. Struct. 2007, 16, 1208. [CrossRef]

24. Kessler, S.S.; Spearing, S.M.; Soutis, C. Damage detection in composite materials using Lamb wave methods. Smart Mater. Struct. 2002, 11, 269. [CrossRef]

25. Grondel, S.; Assaad, J.; Delebarre, C.; Moulin, E. Health monitoring of a composite wingbox structure. Ultrasonics 2004, 42, 819-824. [CrossRef] [PubMed]

26. Lin, M.; Qing, X.; Kumar, A.; Beard, S.J. Smart layer and smart suitcase for structural health monitoring applications. In Proceedings of the Smart Structures and Materials 2001: Industrial and Commercial Applications of Smart Structures Technologies, Newport Beach, CA, USA, 14 June 2001; International Society for Optics and Photonics: Bellingham, WA, USA, 2001; Volume 4332, pp. 98-107.

27. Ihn, J.B.; Chang, F.K. Pitch-catch active sensing methods in structural health monitoring for aircraft structures. Struct. Health Monit. 2008, 7, 5-19. [CrossRef]

28. Staszewski, W.; Boller, C.; Tomlinson, G.R. (Eds.) Health Monitoring of Aerospace Structures: Smart Sensor Technologies and Signal Processing; John Wiley \& Sons: Hoboken, NJ, USA, 2004.

29. Di Sante, R. Fibre optic sensors for structural health monitoring of aircraft composite structures: Recent advances and applications. Sensors 2015, 15, 18666-18713. [CrossRef] [PubMed]

30. Takeda, S.; Aoki, Y.; Ishikawa, T.; Takeda, N.; Kikukawa, H. Structural health monitoring of composite wing structure during durability test. Compos. Struct. 2007, 79, 133-139. [CrossRef]

31. Baker, W.; McKenzie, I.; Jones, R. Development of life extension strategies for Australian military aircraft, using structural health monitoring of composite repairs and joints. Compos. Struct. 2004, 66, 133-143. [CrossRef]

32. Mieloszyk, M.; Krawczuk, M.; Zak, A.; Ostachowicz, W. An adaptive wing for a small-aircraft application with a configuration of fibre Bragg grating sensors. Smart Mater. Struct. 2010, 19, 085009. [CrossRef]

33. Nicolas, M.J.; Sullivan, R.W.; Richards, W.L. Large scale applications using FBG sensors: Determination of in-flight loads and shape of a composite aircraft wing. Aerospace 2016, 3, 18. [CrossRef]

34. Yeager, M.; Todd, M.; Gregory, W.; Key, C. Assessment of embedded fiber Bragg gratings for structural health monitoring of composites. Struct. Health Monit. 2017, 16, 262-275. [CrossRef]

35. Wishaw, M.; Barton, D.P. Comparative vacuum monitoring: A new method of in-situ real-time crack detection and monitoring. In Proceedings of the 10th Asia-Pacific Conference on Nondestructive Testing, Brisbane, Australia, 18-21 September 2001.

36. Choi, C.H. New Vacuum Sensor for Detecting Surface Cracks on Welds; Maritime Platform Division, DSTO: Canberra, Australia, 2002; pp. 1-11.

37. Roach, D. Real time crack detection using mountable comparative vacuum monitoring sensors. Smart Struct. Syst. 2009, 5, 317-328. [CrossRef]

38. Stehmeier, H.; Speckmann, H. Comparative Vacuum Monitoring (CVM). In Proceedings of the 2nd European Workshop on Structural Health Monitoring, Munich, Germany, 7-9 July 2004.

39. Roach, D.P.; Rice, T.M.; Neidigk, S.; Piotrowski, D.; Linn, J. Establishing the Reliability of SHM Systems through the Extrapolation of NDI Probability of Detection Principles; No. SAND2015-4452C; Sandia National Laboratories (SNL-NM): Albuquerque, NM, USA, 2015.

40. Kinet, D.; Mégret, P.; Goossen, K.W.; Qiu, L.; Heider, D.; Caucheteur, C. Fiber Bragg grating sensors toward structural health monitoring in composite materials: Challenges and solutions. Sensors 2014, 14, 7394-7419. [CrossRef] [PubMed]

41. Radio Technical Commission for Aeronautics. Environmental Conditions and Test Procedures for Airborne Equipment; AC21-16G; Federal Aviation Administration: Washington, DC, USA, 1996.

42. Blackshire, J.L.; Cooney, A.T. Characterization of bonded piezoelectric sensor performance and durability in simulated aircraft environments. AIP Conf. Proc. 2006, 820, 1694-1701.

43. Lin, B.; Giurgiutiu, V.; Pollock, P.; Xu, B.; Doane, J. Durability and survivability of piezoelectric wafer active sensors on metallic structure. AIAA J. 2010, 48, 635-643. [CrossRef]

44. Moix-Bonet, M.; Buethe, I.; Bach, M.; Fritzen, C.P.; Wierach, P. Durability of co-bonded piezoelectric transducers. Procedia Technol. 2014, 15, 638-647. [CrossRef] 
45. Forsyth, D.S. Structural health monitoring and probability of detection estimation. AIP Conf. Proc. 2016, 1706, 200004.

46. Janapati, V.; Kopsaftopoulos, F.; Li, F.; Lee, S.J.; Chang, F.K. Damage detection sensitivity characterization of acousto-ultrasound-based structural health monitoring techniques. Struct. Health Monit. 2016, 15, 143-161. [CrossRef]

47. Lindgren, E.A. SHM reliability and implementation-A personal military aviation perspective. AIP Conf. Proc. 2016, 1706, 200001.

48. Lynch, J.P.; Loh, K.J. A summary review of wireless sensors and sensor networks for structural health monitoring. Shock Vib. Dig. 2006, 38, 91-130. [CrossRef]

49. Becker, T.; Kluge, M.; Schalk, J.; Tiplady, K.; Paget, C.; Hilleringmann, U.; Otterpohl, T. Autonomous sensor nodes for aircraft structural health monitoring. IEEE Sens. J. 2009, 9, 1589-1595. [CrossRef]

50. Gao, H.; Rose, J.L. Ultrasonic sensor placement optimization in structural health monitoring using evolutionary strategy. AIP Conf. Proc. 2006, 820, 1687-1693.

51. Flynn, E.B.; Todd, M.D. Optimal placement of piezoelectric actuators and sensors for detecting damage in plate structures. J. Intell. Mater. Syst. Struct. 2010, 21, 265-274. [CrossRef]

52. Ewald, V.; Groves, R.M.; Benedictus, R. Transducer Placement Option of Lamb Wave SHM System for Hotspot Damage Monitoring. Aerospace 2018, 5, 39. [CrossRef]

53. Lee, B.C.; Staszewski, W.J. Sensor location studies for damage detection with Lamb waves. Smart Mater. Struct. 2007, 16, 399. [CrossRef]

54. Thiene, M.; Khodaei, Z.S.; Aliabadi, M.H. Optimal sensor placement for maximum area coverage (MAC) for damage localization in composite structures. Smart Mater. Struct. 2016, 25, 095037. [CrossRef]

55. Janapati, V.; Lonkar, K.; Chang, F.K. Design of Optimal Layout of Active Sensing Diagnostic Network for Achieving Highest Damage Detection Capability in Structures. In Proceedings of the 6th European Workshop on Structural Health Monitoring, Dresden, Germany, 3-6 July 2012.

56. Chang, F.K. Design of integrated SHM system for commercial aircraft applications. In Proceedings of the 5th International Workshop on Structural Health Monitoring, Stanford, CA, USA, 12-14 September 2005; Stanford University Press: Stanford, CA, USA, 2005.

57. Pattabhiraman, S.; Haftka, R.T.; Kim, N.H. Effect of inspection strategies on the weight and lifecycle cost of airplanes. In Proceedings of the 52nd Conference "AIAA/ASME/ASCE/ANS/ASC Structures, Structural Dynamics and Materials", Denver, CO, USA, 4-7 April 2011; Volume 2, pp. 900-913.

58. Ackert, S. Aircraft Payload-Range Analysis for Financiers; Aircraft Monitor: San Francisco, CA, USA, 2013.

59. Flight Standards Service. Aircraft Weight and Balance Control; AC 120-27E; Federal Aviation Administration: Washington, DC, USA, 2005.

60. Boeing. 737 Airplane Characteristics for Airport Planning; D6-58325-6; Boeing: Chicago, IL, USA, 2014.

61. Mcelroy, P. Maintaining a Winner. Available online: https://www.boeing.com/news/frontiers/archive/ 2006/may/i_ca1.html (accessed on 31 May 2006).

62. Kang, I.; Schulz, M.J.; Kim, J.H.; Shanov, V.; Shi, D. A carbon nanotube strain sensor for structural health monitoring. Smart Mater. Struct. 2006, 15, 737. [CrossRef]

63. Zhang, Y.; Anderson, N.; Bland, S.; Nutt, S.; Jursich, G.; Joshi, S. All-printed strain sensors: Building blocks of the aircraft structural health monitoring system. Sens. Actuators A Phys. 2017, 253, 165-172. [CrossRef]

64. Thompson, B.; Yoon, H.S. Aerosol-printed strain sensor using PEDOT: PSS. IEEE Sens. J. 2013, 13, 4256-4263. [CrossRef] 
65. Varadan, V.K.; Varadan, V.V. Microsensors, microelectromechanical systems (MEMS), and electronics for smart structures and systems. Smart Mater. Struct. 2000, 9, 953. [CrossRef]

66. Bhuiyan, M.Y.; Bao, J.; Poddar, B.; Giurgiutiu, V. Toward identifying crack-length-related resonances in acoustic emission waveforms for structural health monitoring applications. Struct. Health Monit. 2018, 17, 577-585. [CrossRef]

(C) 2018 by the authors. Licensee MDPI, Basel, Switzerland. This article is an open access article distributed under the terms and conditions of the Creative Commons Attribution (CC BY) license (http:// creativecommons.org/licenses/by/4.0/). 


\title{
Probabilistic Safety Assessment for UAS Separation Assurance and Collision Avoidance Systems
}

\author{
Asma Tabassum ${ }^{1}$, Roberto Sabatini ${ }^{2, *}$ and Alessandro Gardi ${ }^{2}$ \\ 1 Department of Mechanical Engineering, University of North Dakota, Grand Forks, ND 58202, USA; \\ asma.tabassum.ashraf@gmail.com \\ 2 School of Engineering, Aerospace Engineering and Aviation, RMIT University, Bundoora, VIC 3083, \\ Australia; alessandro.gardi@rmit.edu.au \\ * Correspondence: roberto.sabatini@rmit.edu.au; Tel.: +61-399-258-015
}

Received: 6 September 2018; Accepted: 17 January 2019; Published: 14 February 2019

\begin{abstract}
The airworthiness certification of aerospace cyber-physical systems traditionally relies on the probabilistic safety assessment as a standard engineering methodology to quantify the potential risks associated with faults in system components. This paper presents and discusses the probabilistic safety assessment of detect and avoid (DAA) systems relying on multiple cooperative and non-cooperative tracking technologies to identify the risk of collision of unmanned aircraft systems (UAS) with other flight vehicles. In particular, fault tree analysis (FTA) is utilized to measure the overall system unavailability for each basic component failure. Considering the inter-dependencies of navigation and surveillance systems, the common cause failure (CCF)-beta model is applied to calculate the system risk associated with common failures. Additionally, an importance analysis is conducted to quantify the safety measures and identify the most significant component failures. Results indicate that the failure in traffic detection by cooperative surveillance systems contribute more to the overall DAA system functionality and that the probability of failure for ownship locatability in cooperative surveillance is greater than its traffic detection function. Although all the sensors individually yield $99.9 \%$ operational availability, the implementation of adequate multi-sensor DAA system relying on both cooperative and non-cooperative technologies is shown to be necessary to achieve the desired levels of safety in all possible encounters. These results strongly support the adoption of a unified analytical framework for cooperative/non-cooperative UAS DAA and elicits an evolution of the current certification framework to properly account for artificial intelligence and machine-learning based systems.
\end{abstract}

Keywords: unmanned aircraft systems; sense and avoid; unified analytical framework; ADS-B; surveillance sensor; fault tree analysis; importance measure

\section{Introduction}

While a steady growth of manned aviation has driven the advancement of communication, navigation and sensing (CNS) technologies to support a denser airspace exploitation, various technological and regulatory challenges have affected the development of autonomous separation assurance and collision avoidance (SA\&CA) capabilities for unmanned aircraft systems (UAS). Surveillance systems such as transponders, traffic collision avoidance system (TCAS), and automatic dependent surveillance-broadcast (ADS-B) are conceived to support the in-flight SA\&CA while also incorporating, to the extent possible, the pilot's situational assessment, training, experience, and aircraft capabilities. The detect and avoid (DAA) function in a non-segregated UAS operational context, however, demands transitions from the pilot's decision-making to a fully autonomous decision-making, which is one of the largest challenges faced by the UAS sector today. An accurate performance modelling of current airborne surveillance technologies for maintaining SA\&CA without the pilot 
onboard is critical to evaluate and certify the criteria of equivalent level of safety in the UAS platform. The International Civil Aviation Organization (ICAO) outlined successive steps towards the integration of UAS in controlled airspace as well as into the aerodrome areas, which are identified in the Aviation System Block Upgrades (ASBU) [1]. The United States (US) Federal Aviation Administration (FAA) also provisioned to integrate UAS into the National Airspace System (NAS) in two different phases [2-4]. Phase 1 incorporates rural, Class Golf (G) airspace and is compatible with agricultural, mapping and survey applications, whereas phase 2 comprises controlled airspace that requires technologies to maintain safe separation from cooperative and non-cooperative air traffic [5]. The European Commission's Directorate General for Mobility and Transport (DG MOVE), the European Defence Agency (EDA), the European Aviation Safety Agency (EASA), and the Single European Sky Air Traffic Management (ATM) Research (SESAR) Joint Undertaking (SJU) are also stepping up the efforts to safely accommodate UAS into the European aviation and ATM system [6]. In parallel with these government and industry-led initiatives, the aerospace research community has been continuously working on several challenges of integrating UAS into non-segregated airspaces including separation thresholds and methods for small UAS [7,8], UAS encounter modelling and collision avoidance [9-11], 3D obstacle avoidance strategies for UAS [12-15] dynamic model augmentation [16], Global Navigation Satellite Systems (GNSS) integrity augmentation for UAS [17], surveillance sensor integration in the UAS platform [18,19] and well-clear boundary models for UAS DAA [20-24].

\subsection{Detect and Avoid (DAA) Safety Assessment}

Although adequate performance standards were established for various surveillance equipment, to date the impacts of surveillance system failures in terms of separation degradation, specifically in the UAS platform, have not been defined. Moreover, traditional radar and Mode-A/C transponder technologies show inherent deficiencies in different airspace and equipage scenarios especially in the presence of high air traffic densities [25-33]. The failure modes for different cooperative sensors such as Mode S, TCAS, ADS-B are well defined and safety assessments have been carried out on the individual surveillance sensor considering functions in the manned aircraft. While the availability of ATM deconfliction service provides mitigation to these faults when available, the risk is still notably higher when considering highly autonomous UAS operations. The FAA conducted a safety assessment on the TCAS application in the unmanned platforms [34-36]. A thorough probabilistic safety assessment has been carried out on ADS-B system considering both the ground and airborne segment in [37]. Safety assessment of the surveillance sensor failure in the UAS platform was carried out in [38] with an encounter analysis considering the unmanned aircraft platform only. A simplified model is developed in [39] to assess and predict the risk associated with a given UAS operation. In [40], the authors provided a framework that consists of a target level of safety (TLS) approach using an event tree format to develop specific SAA effectiveness standards based on UAS weight and airspace class combinations. The provision of certified autonomous DAA capabilities is an indispensable milestone for the certification of UAS for safe non-segregated and beyond line of sight (BLOS) operations. This is a widely recognized issue in the aerospace research community but to date, despite the extensive efforts, the various proposed DAA approaches have not satisfactorily addressed the overall safety risks. In this paper, a comprehensive safety assessment is conducted considering the sensitivities, failures and degraded operations of systems and components of the overall DAA architecture. Both qualitative and quantitative analysis are performed to identify and derive the risks of different component failure in both airborne and ground control platform using probabilistic safety assessment.

Probabilistic safety assessment is a technique to quantify risk measures numerically by identifying the specific events that lead to hazards [41]. Fault tree analysis (FTA) relates the logical relationship between component failures which are the basic failures and their contributions to the system failures and the importance analysis provides the importance ranks of the components to the overall risk. Therefore, the combination of these two techniques provides an overall approach to determine the impacts of individual sensor failure as well as the significance of individual risk contributors. 
In particular, a case study for ADS-B as a candidate technology to support DAA is addressed in this paper. The safety analysis indicates the validity of ADS-B for cooperative approach providing a pathway for certification of the unified framework. Section 2 describes the unified analytical framework and overall DAA architecture and Section 3 outlines the assessment methodology. The risk measure and importance analysis are presented in Section 4. A case study of ADS-B as a cooperative surveillance means in specified UAS flight envelope is illustrated in Sections 5 and 6 contains the discussion of overall findings.

\section{Unified Analytical Framework and DAA Architecture}

In recent research [42,43], a unified analytical framework has been proposed, and a novel methodology is demonstrated to integrate the data provided by cooperative systems (reliance on own and intruder aircraft avionics) and non-cooperative sensors (reliance on own aircraft avionics only). Figure 1 illustrates the conceptual top-level architecture of the proposed DAA system, which uses active and passive forward-looking sensors (FLS) in addition to ADS-B and Mode-S transponders. Navigation data is extracted from GNSS, inertial measurement units (IMU) and vision-based sensors.

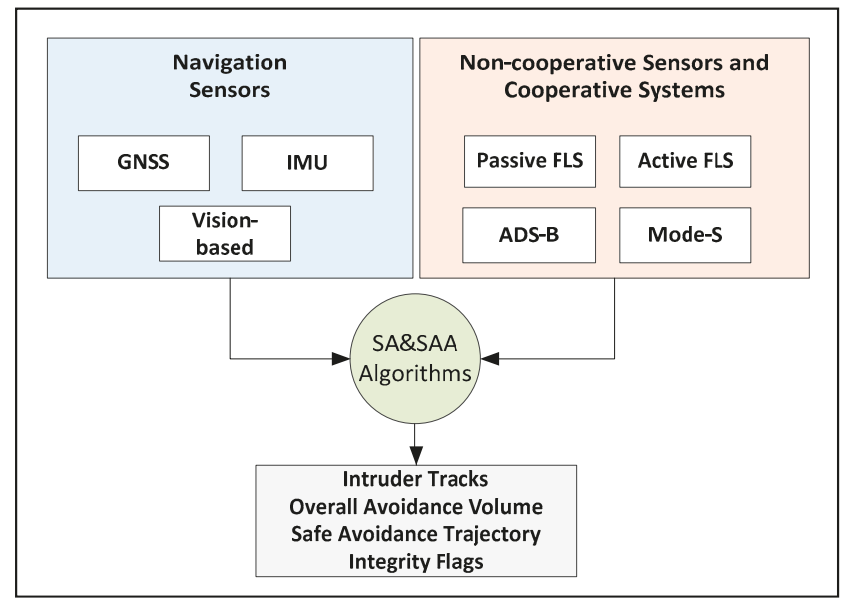

Figure 1. Conceptual high-level detect and avoid (DAA) system architecture adapted from [43].

State-of-the-art active and passive FLS include visual/infrared cameras, RADAR and LIDAR. Mode $S$ transponders are cooperative surveillance employ ground components and an airborne transponder. Mode $S$ has been designed as an evolutionary addition to the Air Traffic Control Radar Beacon System (ATCRBS) [44] for the provision of enhanced surveillance and communication capability which is required for the automation of air traffic control. TCAS was developed as a back-up airborne collision avoidance system (ACAS) which provides vertical maneuvering guidance to the pilot in the event of a possible collision threat [45]. ADS-B is a system that periodically transmits its state vector including horizontal and vertical position, and velocity as well as some other intent information [46]. The system comprises two separate components, ADS-B Out and ADS-B In. ADS-B is called dependent surveillance as it requires that the aircraft state vector and additional information be derived from the on-board navigation equipment. It is automated in the sense that it doesn't need pilot or controller input to transmit information. Cooperative/non-cooperative tracking data and host platform navigation data are processed using a dedicated algorithm within the central DAA processor onboard the UAS to produce avoidance volumes in the airspace surrounding each conflicting intruder/obstacle track. This algorithm ensures the rigorous mathematical treatment of the errors affecting the state measurements (correlated and uncorrelated measurements) and accounts for the 
host-obstacle relative dynamics, with due consideration for the environmental conditions (wind, turbulence, etc.) affecting the aircraft dynamics. A conceptual representation of this approach for the case of a single aerial encounter is depicted in Figure 2.

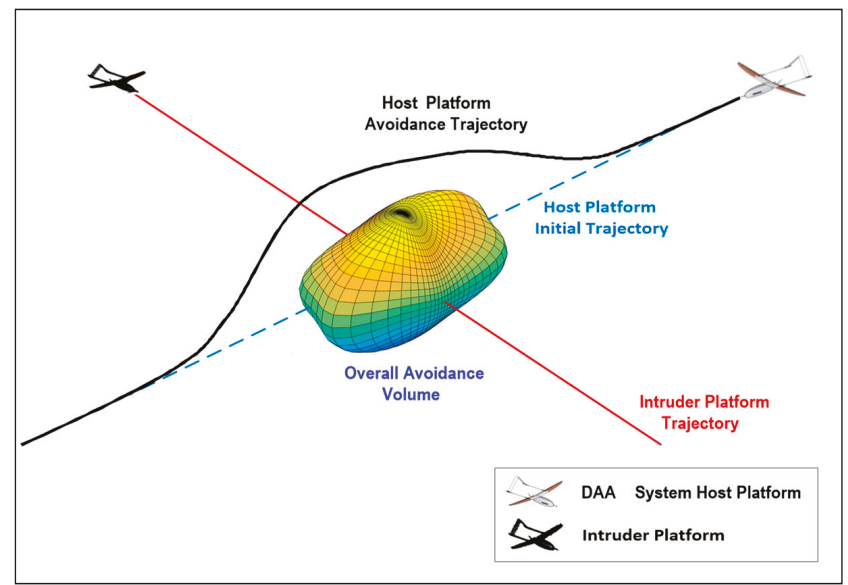

Figure 2. Conceptual depiction of the proposed DAA approach (single aerial encounter).

In particular, the figure shows both the overall avoidance volume and the optimal avoidance trajectory, which is computed by a real-time trajectory optimization algorithm. If the original trajectory of the DAA system host platform intersects the calculated avoidance volume, a risk of collision (RoC) flag is generated $[47,48]$. This RoC flag initiates the real-time trajectory optimization process and the associated steering commands are provided to the aircraft flight controls.

\section{DAA Reference Architecture}

The components of the UAS DAA system are partly located onboard the unmanned aircraft (UA) platform and partly in its ground control station (GCS). In particular, all non-cooperative sensors and cooperative surveillance systems as well as autonomous collision avoidance functions are installed onboard, whereas all the human-machine interfaces (HMI) are integrated in the GCS. Both the UA and the GCS are equipped with Command and Control (C2) data link transceivers to transmit the data from the UA platform to GCS and commands from GCS to UA platform. The UAS pilot-in-command (PIC) manning the GCS is responsible for the safe operation of the UAS and for executing ATM directives unless they pose a hazard to the UAS. Figure 3 provides a simplified schematic diagram of the overall DAA system architecture.

The UA platform includes four major elements namely the surveillance components, DAA processor, onboard navigation system, and the C2 datalink. The state-of-the-art of cooperative surveillance sensors include Active Mode S surveillance, TCAS II, and ADS-B. The non-cooperative surveillance sensors comprise Radar, Light Detection and Ranging (LIDAR), cameras such as thermal camera, infrared cameras etc. Air-to-air radar systems operate in the C, X, or Ku-frequency bands of the aeronautical radio navigation spectrum (ARNS) [49]. Usage of a frequency will be depending on the type of operation. LIDAR is another prominent surveillance sensor which shows great promise for non-cooperative UAS collision avoidance [50]. LIDAR is a remote sensing technology that scans the environment and the 3D image of the environment is constructed from the individual distance points within an aggregate of points gathered during the scanning process. Some different laser scanning techniques are available to steer the beam and achieve very wide fields of vision (FoV). Although current LIDAR systems are still of considerable size, weight, power and cost (SWaP-C), considerable progresses are being made thanks to their extensive usage in the autonomous 
driving domain. The availability of advanced cameras and development of vision-algorithms made them popular for use in the unmanned platform especially in low altitude operation. These non-cooperative sensors complement other on-board airborne surveillance sensors by providing detection of non-cooperative traffic.

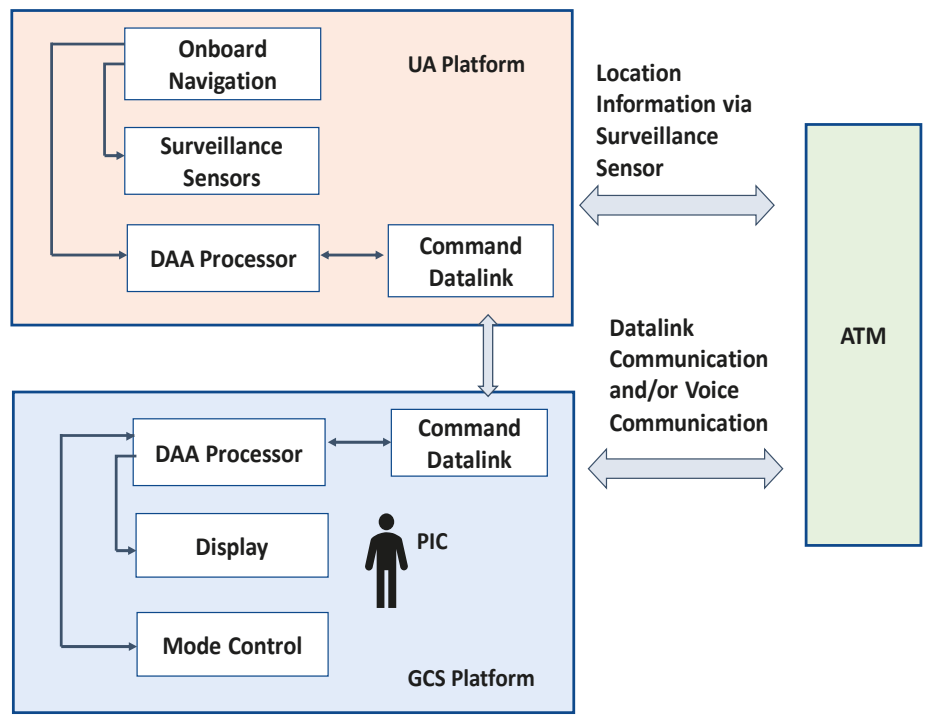

Figure 3. Simplified schematic diagram of the overall DAA system architecture.

The equipage of surveillance sensors depends on the type of unmanned aircraft system, the airspace and the certification. According to DO-365 [49] which was developed by Special Committee-228 [51], UA surveillance equipment will minimally include:

- active Mode $\mathrm{S}$ surveillance that use 1030/1090 MHz frequencies;

- $\quad$ ADS-B In to detect the broadcast directly from the intruder aircraft ADS-B Out or through ADS-R or TIS-B channel;

- $\quad$ air-to-air radar system to detect the non-cooperative traffic.

This equipage is referred to as Class 1 DAA system. The Class 2 DAA system will include TCAS II along with class 1 DAA system. As for the manned aircraft TCAS serves to improve the pilot's awareness of other air traffic, in UAS it would be serving the PIC [35] and no maneuvers will be initiated automatically only on this guidance.

The UA onboard processor receives onboard navigation sensor data, data from onboard active surveillance airborne to detect transponder equipped intruders, ADS-B receiving equipment to detect ADS-B equipped intruders, and radar data to detect non-cooperative intruders. The intruder data received by multiple sensors are then processed by the UA processor. From the intruder state and intent data, the UA processor initially evaluates the intended track of the intruder. The initial track and other information are then sent to the command and non-payload communications datalink for transmission to the GCS. The ATM can locate the UAS via ADS-B out messages and Active Mode S transponder. At all times, PIC can maintain communication with ATM via datalink or voice communication. In the GCS, the processor receives prioritized track data and DAA status data from the UA platform and DAA mode control commands from the GCS control. It then processes the data and forwards the information to the DAA display. The mode control is the interface between the PIC, the UA, and GCS DAA processors. The command functions are executed through this interface 
and then sent to the GCS processors and then via data link to UA platform. The command is then executed by the UA platform. In order to obtain the certification, surveillance sensors need to provide equivalent level of safety as of manned aircraft. This include providing surveillance support suitable for the entire operational flight envelope. The UA operational flight envelope may include five phases; namely takeoff, climb, cruise, descent and landing where the takeoff and landing phase will require low altitude flying and ground roll. The takeoff and landing may take place on airport and a separate launch/recovery zone. Due to the different traffic mix at each altitude, different flight dynamics characteristics and different conflict geometries characterizing each phase, the safety-criticality of DAA sensors and systems will likely change as a function of the flight phase. The unified analytical framework and the associated DAA system safety analysis allows to either define the safely flyable envelope as a function of the available sensors and their reliability or to identify the sensors and their required reliability as a function of the desired safe envelope.

\section{Safety Assessment Methodology}

As already mentioned in Section 1.1, the qualitative analysis involved in the FTA methodology lists all the possible combinations of factors, normal events and component failures resulting in a top event, whereas the quantitative evaluation allows to determine the probability of failure of the top event from the failure probability values of basic events that propagated up through the fault tree. The reliability data or the failure rate of the components is crucial for FTA and is obtained from component manufacturers (typically in the form of mean time between failures-MTBF) and/or from the literature, including among others Aviation Standard Documents by RTCA, FAA and Eurocontrol [37,49,52-56]. The basic events represent component failures and the logic gates dictate how faults of the particular component within the system can combine to result in the failure in the top event.

In this study, FaultTree++ from isograph [57] is utilized to carry out the safety assessment and calculate the top-level event probabilities. Before constructing the fault tree, based on the system overview provided in Section 2, intermediate events leading to failure in onboard DAA capability are identified. We note that the navigation and guidance functionality failures have not been presented in detail as this would be beyond the scope of the article, except for the subsystems on which DAA components directly depend such as onboard Global Positioning System (GPS) and barometric altimeter. The symbols that are used to create the fault tree are illustrated in Table 1.

Table 1. Fault tree symbols used in this study and their significance.

\begin{tabular}{|c|c|c|}
\hline Symbol & Name & Significance \\
\hline & Basic Event & $\begin{array}{l}\text { An initiating event to which reliability model } \\
\text { is associated. }\end{array}$ \\
\hline & Undeveloped Event & $\begin{array}{l}\text { An event that cannot be developed further or for } \\
\text { which the reliability data cannot be found. }\end{array}$ \\
\hline & Transfer & Indicates a transfer continuation to a subtree. \\
\hline & AND Gate & $\begin{array}{l}\text { Indicates the occurrence of all the input events cause } \\
\text { the output event to occur. }\end{array}$ \\
\hline & OR Gate & $\begin{array}{l}\text { Indicates the occurrence of either input event causes } \\
\text { the output event to occur. }\end{array}$ \\
\hline k out of $n$ & VOTING OR Gate & $\begin{array}{l}\text { Indicates the output event occurs if a certain number } \\
\text { of the input events occur. }\end{array}$ \\
\hline
\end{tabular}

In order to identify the basic events that lead to the failure of the onboard surveillance sensors, complete knowledge of the complex architecture of each of the sensors along with the understanding of integrated navigation and communication system components is required. This is because some onboard state data are fed into multiple surveillance sensors and some of them share same transponder datalink. For example, barometric altimeter data is used by both Active Mode S and the ADS-B Out 
system. Hence, error in the barometric altimeter will affect both systems. Figure 4 illustrates the dependency between onboard navigation and surveillance systems in a high-level architecture.

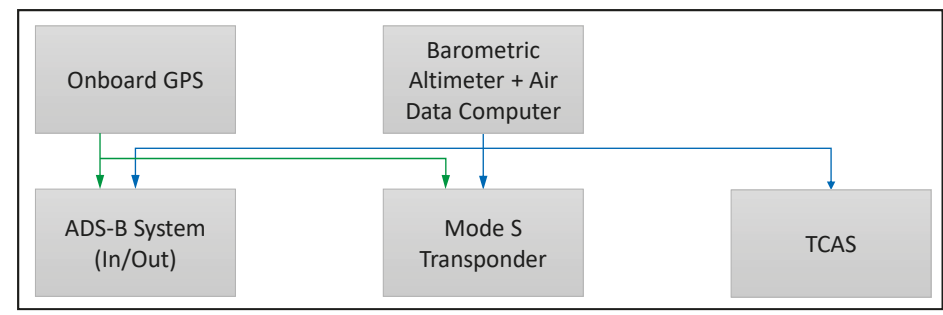

Figure 4. Top-level data flow diagram showing the dependencies between onboard navigation and surveillance systems.

To properly capture failures that affect multiple systems, the common cause failure (CCF) analysis is utilized. The CCF is a failure event that affects multiple components or functions [58]. In CCF analysis, there are two relevant factors: the root cause, which is a single failure event, and the coupling factor. The coupling factor describes the dependency of multiple systems on a common data source. While calculating the overall risk for surveillance system failure, it is crucial to take care of the CCF because, as shown in the architecture in Figure 4, some of the basic events affect a multiple surveillance system at the same time. The most commonly-used method to account for CCF is the beta factor method $[59,60]$. To calculate the failure rate due to common causes, the beta factor is simply multiplied by the component failure rate. In essence, the beta factor simply represents the percentage of component failures that are due to common causes. A beta factor of 0.05 is chosen for this analysis based on the literature and the International Electrotechnical Commission (IEC) method checklist.

In this work, the contribution of individual failure events to their related system failure are determined based on the specific functional dependencies. For example, while in the event of ADS-B out failure, the ownship is not locatable by other platforms through ADS-B, it still can detect intruder traffic with a working ADS-B In. Hence, the detection capability will not be compromised due to the failure of ADS-B out system and can still avoid intruders. Therefore, only the failure in traffic detection capability is considered in the DAA functionality. The ownship surveillance function failure, referred to as a failure in ownship locatability function, is deduced in a different tree. Figures 5-7 illustrate the DAA capability failure considering the function of traffic detection and avoid capability and Figures 8-12 demonstrate the failure in ownship locatability function.

As depicted in Figure 5, the failure in DAA capability onboard can be the result of five alternative events. Three of them are intermediate events: DAA 1A-failure in traffic detection function by cooperative sensors, DAA 2-failure on non-cooperative sensors and DAA 3-evaluation function failure. DAA 1A and DAA 2 are transferred to separate trees and illustrated in Figures 6 and 7. The evaluation function failure traces the data processing function failure which indicates the failure in multi-sensor data fusion and the track evaluation failure indicates the failure probability of intruder track evaluation. The execute function failure is the failure probability to execute appropriate maneuvers as commanded. DAA 5 is the failure of the data link that is used to transfer data and receive command from the ground control station.

Figure 6 outline the intermediate events DAA 1A. As stated earlier, this subtree specifies the failure probability of traffic detection function by cooperative surveillance. In this work, a voting OR gate is utilized to calculate the failure probability of DAA 1. VOTING OR indicates that the event will occur of $k$ out of $n$ events occur. In the fault tree presented in Figure 6, the DAA occurs if two out of three surveillance sensors failed to detect a traffic. VOTING OR gate is considered to account the current equipage scenario for unmanned as well as manned aircraft system. Using a universal AND gate would give a lower failure rate whereas using a universal OR gate would provide a higher failure 
rate than in an actual encounter scenario. For example, if onboard active surveillance system and TCAS system fails and the intruder which can be manned or unmanned, is not equipped with ADS-B, in spite of having a working ADS-B In ownship will fail to detect the intruder. Also, it is considered that without any catastrophic power failure onboard or without any external attack three systems will not be down at the same time. Thus, VOTING OR encompasses all the scenarios.

Figure 7 presents the intermediate event DAA 2-failure in non-cooperative sensor which is the result of two alternatives sensors failure: one is air-to-air radar failure, and another is vision-based sensor failure. While tracing the events for vision-based sensor, a component wise failure probability is adopted as the component is assumed to be acquired off the shelf with a specified MTBF.

As stated earlier, a separate fault tree is constructed to determine the failure in ownship locatability function due to failure of cooperative surveillance system. Figures 8-12 illustrate the faults trees of main event and intermediate events. As detailed in Figure 8, the failure in cooperative surveillance function occurs if either Mode $\mathrm{S}$ or ADS-B out failed. This is a conservative choice that assumes mixed equipage requirements. The ownship ADS-B out system depends on the onboard satellite navigation and pressure altimeter. Figures 9 and 10 present the transferred trees from the ADS-B out; Figure 10 outlines the failure in ADS-B due to onboard satellite navigation loss and Figure 11 outlines the failure due to corrupted data from navigation sources. Finally, Figure 12 shows the fault tree for Mode S surveillance only.

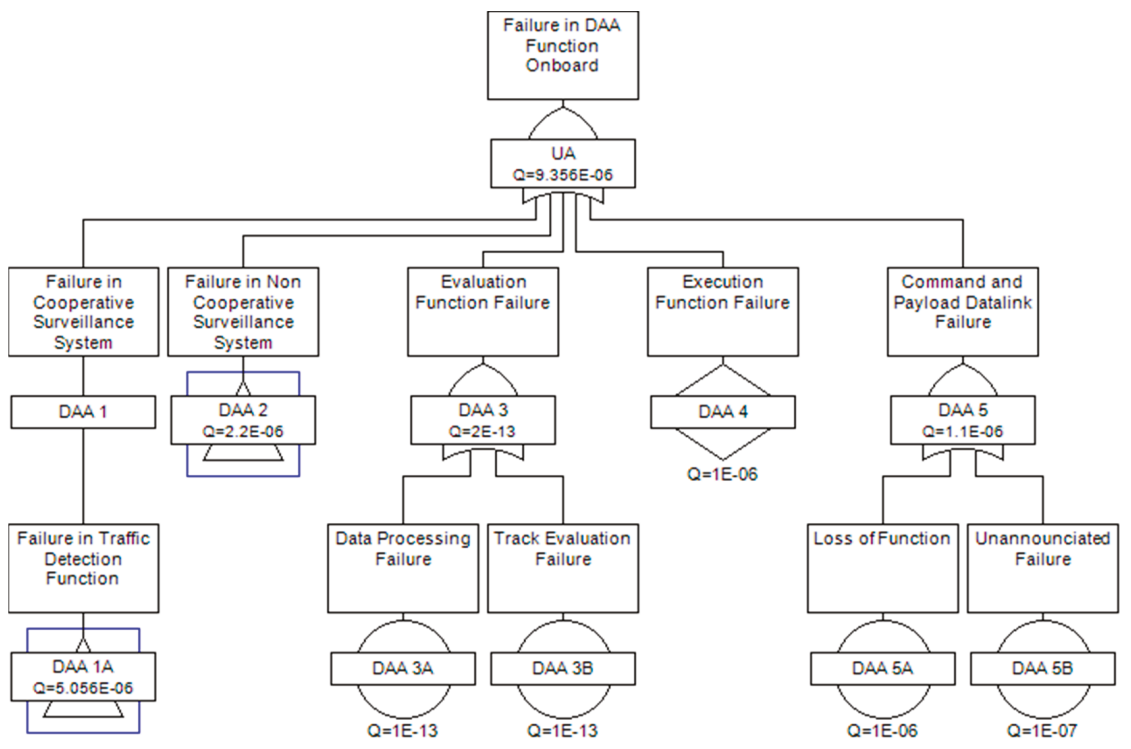

Figure 5. Fault tree for failure in DAA capability. The failure subtrees for DAA 1A and DAA 2 are detailed in the following figures. 


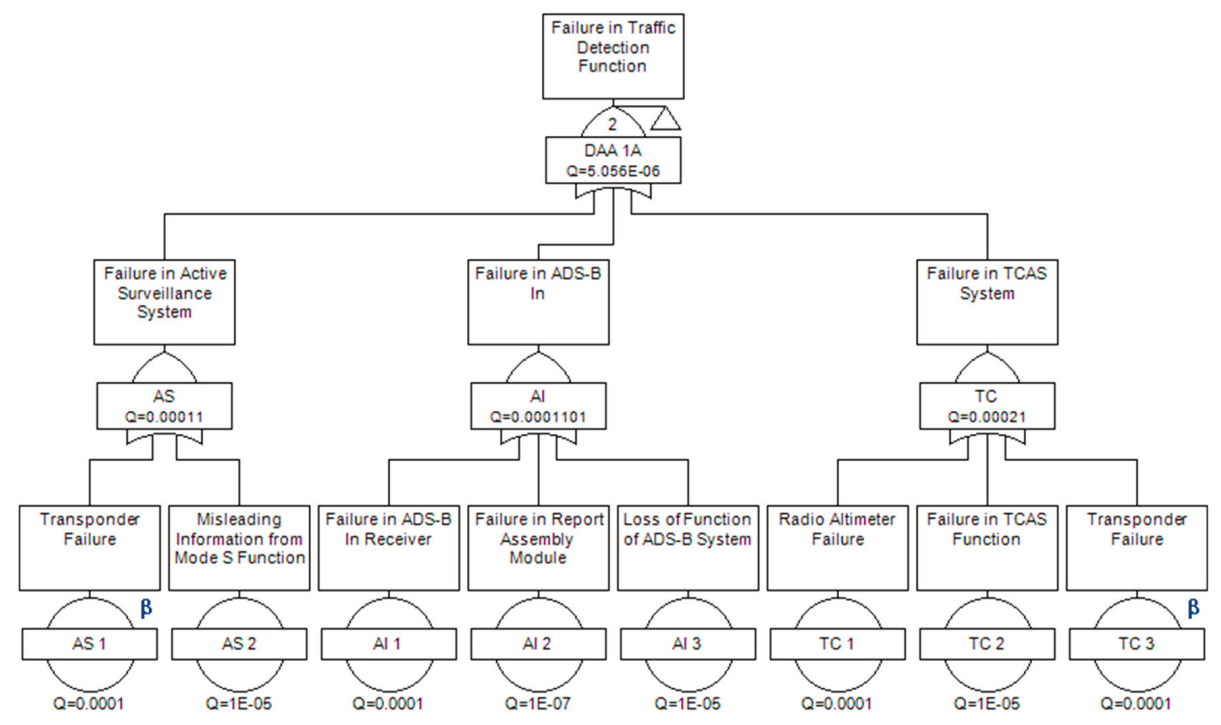

Figure 6. Fault subtree for cooperative surveillance (traffic detection).

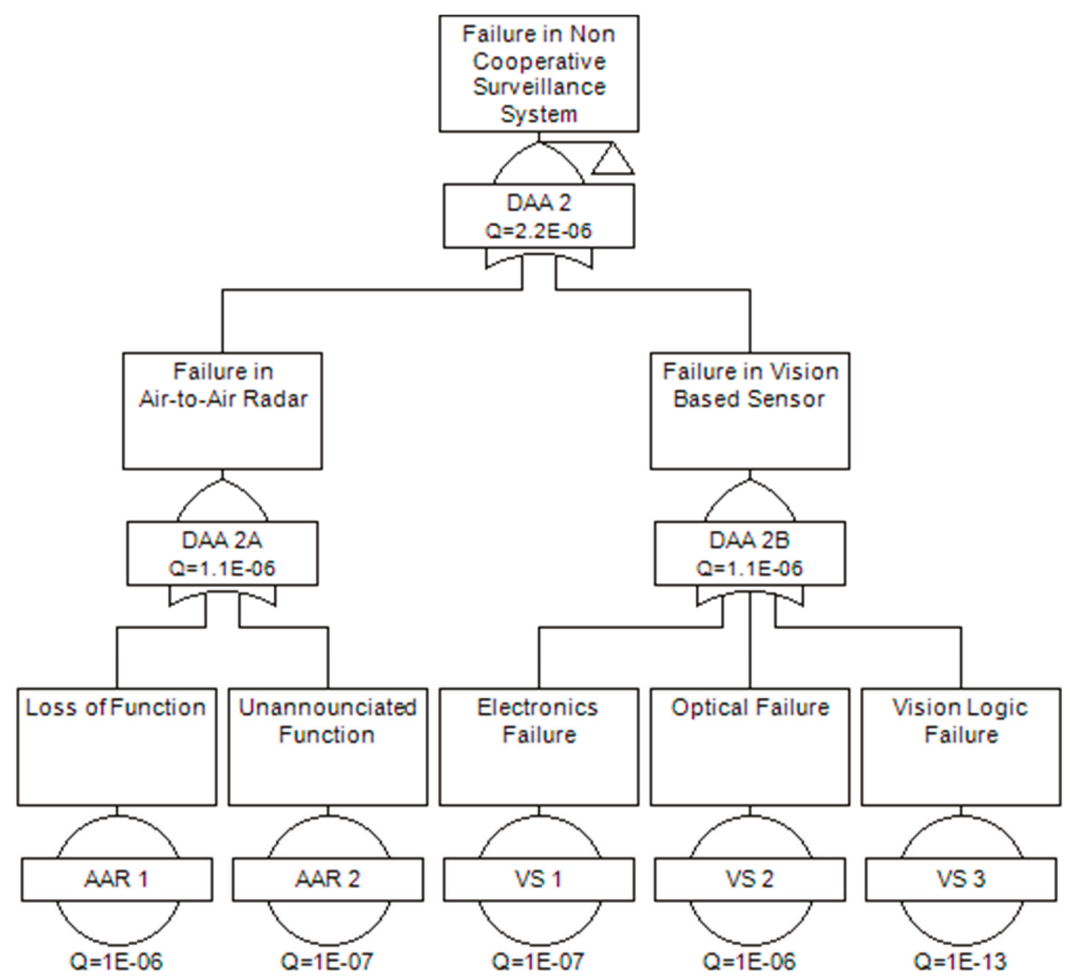

Figure 7. Fault subtree for non-cooperative surveillance. 


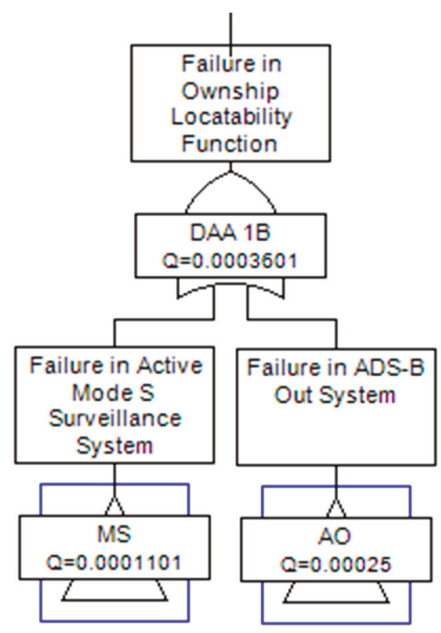

Figure 8. Fault subtree for cooperative surveillance (ownship locatability). The subtrees for failure in automatic dependent surveillance-broadcast (ADS-B) Out and failure in Mode S surveillance are presented in the following figures.

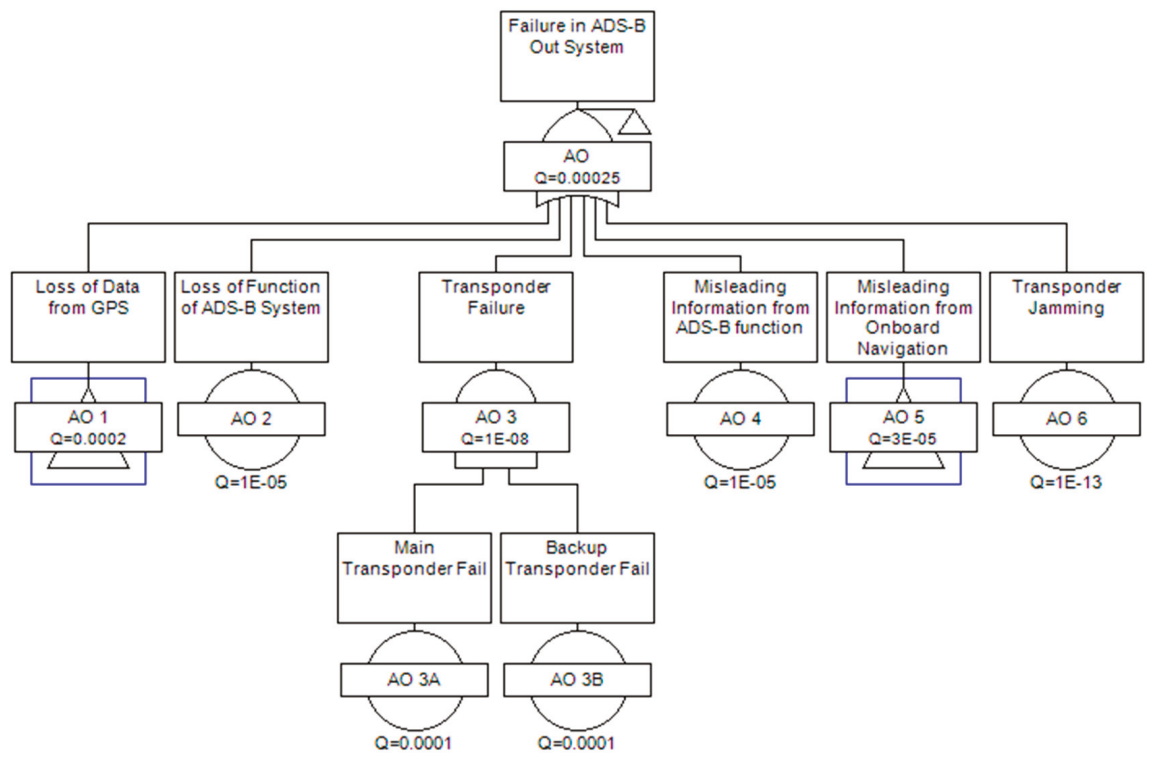

Figure 9. Fault subtree for ADS-B Out system. 


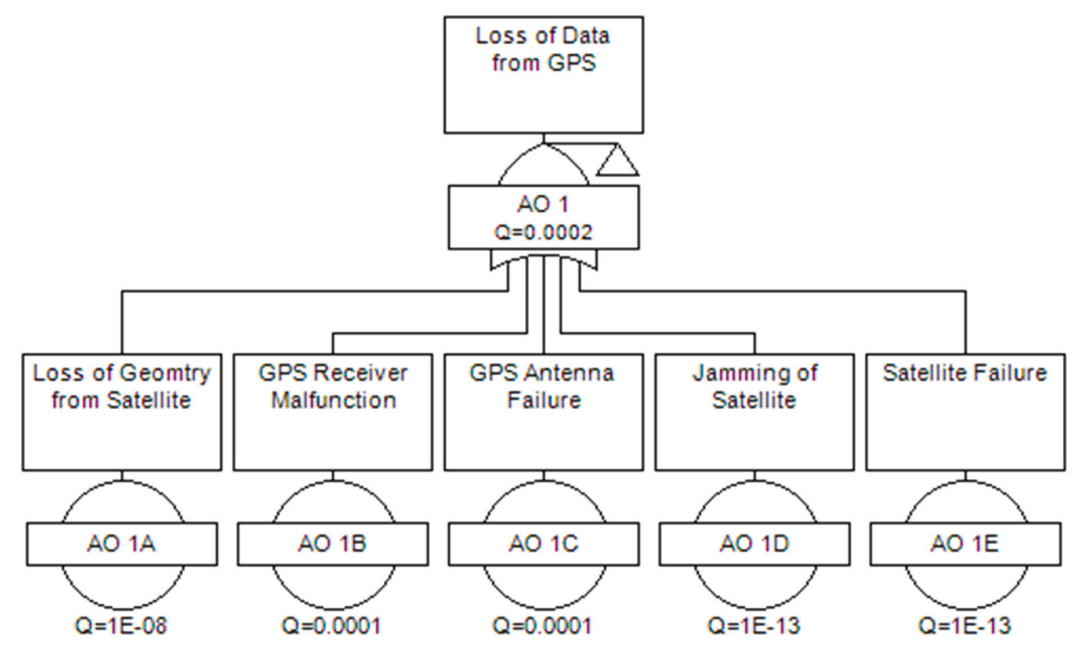

Figure 10. Fault subtree for the loss of Global Positioning System (GPS) data, partially adopted from [37].

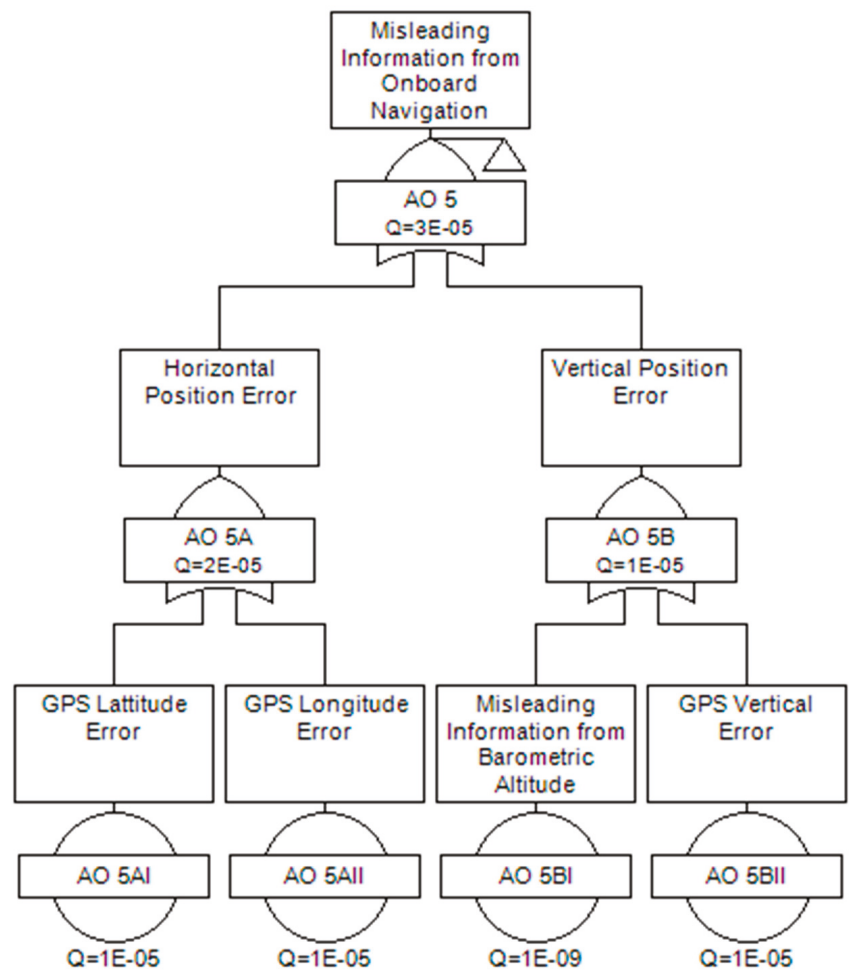

Figure 11. Fault subtree for misleading navigation information. 


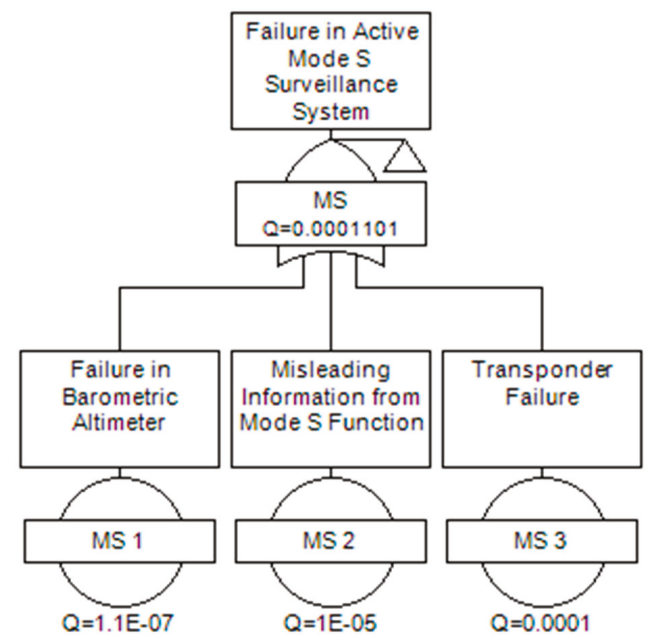

Figure 12. Fault subtree for Mode $S$ failure.

The reliability data for the basic events used in the fault tree are extracted from the literature, aviation standard documents and Original Equipment Manufacturer (OEM) and presented in Table 2.

Table 2. Failure probability associated to the basic events.

\begin{tabular}{lll}
\hline Basic Events & Description & Failure Probability, q \\
\hline DAA 3A & Data Processing Failure & $1 \times 10^{-13}$ as in [61] \\
DAA 3B & Track Evaluation Failure & $1 \times 10^{-13}$ as in [61] \\
DAA 4 & Execution Function Failure & $1 \times 10^{-6}$ as in [49] \\
DAA 5A & Command Datalink Failure (Loss of Function) & $1 \times 10^{-6}$ as in [49] \\
DAA 5B & Command Datalink Failure (Unannounciated Failure) & $1 \times 10^{-7}$ as in [49] \\
AS 1/TC-3/AO 3A /AO 3B/MS-3 & Transponder Failure (Main/Backup) & $1 \times 10^{-4}$ as in [61] \\
AS 2/MS-2 & Misleading Information from Mode S Function & $1 \times 10^{-5}$ as in [38] \\
AI 1 & Failure in ADS-B In Receiver & $1 \times 10^{-4}$ as in [37] \\
AI 2 & Failure in Report Assembly Module & $1 \times 10^{-7}$ as in [37] \\
AI 3/AO 2 & Loss of Function of ADS-B System & $1 \times 10^{-5}$ as in [38] \\
TC 1 & Failure in Radio Altimeter & $1 \times 10^{-4}$ as in [38] \\
TC 2 & Failure in Traffic Collison Avoidance System & $1 \times 10^{-5}$ as in [36] \\
AAR 1 & (TCAS) Function & $1 \times 10^{-7}$ as in [62] \\
AAR 2 & Air-to-Air Radar (Loss of Function) & $1 \times 10^{-6}$ as in [62] \\
VS 1 & Air-to-Air Radar (Unannounciated Function) & $1 \times 10^{-7}$ as in [63] \\
VS 2 & Electronics Failure & $1 \times 10^{-6}$ as in [64] \\
VS 3 & Optical Failure & $1 \times 10^{-13}$ as in [61] \\
AO 4 & Vision Logic Failure (Data processing failure) & $1 \times 10^{-5}$ as in [38] \\
AO 6 & Misleading Information from ADS-B Function & $1 \times 10^{-13}$ as in [37] \\
AO 1A & Transponder Jamming & $1 \times 10^{-8}$ as in [37] \\
AO 1B & Loss of Geometry from Satellite & $1 \times 10^{-4}$ as in [37] \\
AO 1C & GPS Receiver Malfunction & $1 \times 10^{-4}$ as in [37] \\
AO 1D & GPS Antenna Failure & $1 \times 10^{-13}$ as in [37] \\
AO 1E & Jamming of Satellite & $1 \times 10^{-13}$ as in [37] \\
AO 5AI/AO 5AII & Satellite Failure & $1 \times 10^{-5}$ as in [38] \\
AO 5BI & Horizontal Position Error (Latitude/Longitude) & $1 \times 10^{-9}$ as in [63] \\
AO 5BII & Misleading Information from Barometric Altimeter & $1 \times 10^{-5}$ as in [38] \\
MS 1 & GPS Vertical Error & $1.1 \times 10^{-7}$ as in [63] \\
\hline & Failure in Barometric Altimeter &
\end{tabular}

Note: the acronyms used in the Basic Events column are defined in Figures 5-12.

For the failure probability value of command datalink and air to air radar, the value is taken from technical standard orders, which state the loss of function (air to air radar and command datalink) 
cannot be greater than $1 \times 10^{-6}$ per fight hour and unannounciated failure can be greater than $1 \times 10^{-7}$ per flight hour. Although vision-based sensors are widely accepted as a means of UAS non-cooperative surveillance, so far, no specific technical standard defined the reliability requirements for DAA-grade vision sensors. Hence, the vision sensor failure is deduced considering its main component and the reliability data for airborne electronics / optical instruments during nominal condition is considered in the study.

\section{Result and Analysis}

Based on the FTA presented in Section 3, two different further analyses have been carried out in this study. In Section 4.1, we present the results related to the top events failure and the system availability that can be calculated from it. In the second analysis, the results of which are presented in Section 4.2, the importance measure is discussed, which relates the component significance to the top event failure.

\subsection{System Availability}

For the safety assessment in this study, a general model is used, which considers the failure probability as constant across the lifespan of the component. Denoting basic failure probability as $Q_{i}$ with $\mathrm{i}=1 \ldots n$ and the top event failure as $Q$, assuming all basic events are independent, the model can be expressed as:

$$
Q(t)=f\left(Q_{1}(t), Q_{2}(t), \ldots Q_{n}(t)\right)
$$

This implies that if the state of each component in the fault tree is known at time $t$, then the state of the top event can also be determined regardless of what has happened up to time t. The top event probability is calculated by logically tracing the failure of basic events. $Q(t)$, the probability of the hazard/top event occurrence is also known as the risk measure or unavailability [52]. Thus, the availability of the system can be obtained as:

$$
\text { Operational Availability }=1-Q(t)
$$

The failure in the DAA capability onboard deduced in Figure 5 is $9.356 \times 10^{-6}$, which implies operational availability of higher than $99.99 \%$. For the fault tree presented in Figure 5, two most important intermediate events are failure in cooperative and non-cooperative surveillance sensor failure. Tables 3-5 summarize the results of intermediate events fault trees.

Table 3. Result summary for DAA capability fault tree analysis (FTA) as per Figure 5.

\begin{tabular}{lcc}
\hline Function & Failure Probability & Operational Availability \\
\hline $\begin{array}{l}\text { Failure in Cooperative System } \\
\text { (Traffic Detection Function), DAA 1 }\end{array}$ & $5.056 \times 10^{-6}$ & 0.999994944 \\
Failure in Non-cooperative & $2.2 \times 10^{-6}$ & 0.9999978 \\
Surveillance System, DAA 2 & $1.1 \times 10^{-6}$ & 0.9999989 \\
Command Datalink Failure, DAA 5 & $1 \times 10^{-6}$ & 0.999999 \\
Execution Function Failure, DAA 4 & $2 \times 10^{-13}$ & $\sim 1$ \\
Evaluation Function Failure, DAA 3 & & \\
\hline
\end{tabular}

Table 4. Result summary for the cooperative surveillance (traffic detection function) FTA as per Figure 6.

\begin{tabular}{lcc}
\hline Function & Failure Probability & Operational Availability \\
\hline Failure in Active Surveillance System, AS & 0.00011 & 0.99989 \\
Failure in ADS-B In, AS & 0.0001101 & 0.9998899 \\
Failure in TCAS system, TC & 0.00021 & 0.99979 \\
\hline
\end{tabular}


Table 5. Result summary for the non-cooperative surveillance FTA as per Figure 7.

\begin{tabular}{lcc}
\hline Function & Failure Probability & Operational Availability \\
\hline Failure in Air-to-Air Radar, DAA 2A & $1.1 \times 10^{-6}$ & 0.9999989 \\
Failure in Vision Based Sensor, DAA 2B & $1.1 \times 10^{-6}$ & 0.9999989 \\
\hline
\end{tabular}

From the results presented in Table 4, the probability of cooperative surveillance system traffic detection capability is in order of $10^{-6}$ which can be referred to as remote [65]. From Figure 12 it can be seen that Mode $S$ has the lowest failure probability where TCAS has most likely to failure (referred to Figure 6). Also, in Figure 6 it is also illustrated that ADS-B In failure probability is intermediate between Mode S and TCAS system. For all of three systems, the operational availability is higher than $99.9 \%$. The failure in non-cooperative surveillance is also in the order of $10^{-6}$ as detailed in Table 5, but the value is lower than that of surveillance sensor failure. The lower level fault trees are generated based on the very basic reliability data and need future work to incorporate system specific information.

The failure of the cooperative surveillance to successfully locate ownship to intruder as well as ATM is deduced in a separate tree. This way the impact of particular system failure does not affect the failure of certain functionality. Table 6 summarizes the results.

Table 6. Result summary for ADS-B Out system FTA as per Figure 8.

\begin{tabular}{lcc}
\hline Function & Failure Probability & Operational Availability \\
\hline Failure in Active Surveillance, MS & 0.0003601 & 0.9996399 \\
Failure in ADS-B Out, AO & 0.00025 & 0.99975 \\
\hline
\end{tabular}

Note: the acronyms MS and AO are consistent with Figures 5-12 and Table 2.

Comparing Tables 4 and 6, it can be noted that the surveillance system may fail to locate ownship more than it may fail to detect the intruder. This may occur because any misleading information or loss of data from intruder aircraft was not considered, while the ownship surveillance sensor are bound to corrupted data error from onboard navigation.

\subsection{Importance Measure}

A component or cut set's contribution to the top event occurrence is termed as importance [66]. Importance measures of the basic events are associated with the risk-significance and safety-significance of the related components. They are normally used to rank the system's components with respect to their contribution to the reliability and availability of the overall system. In this study, three different importance measures are used to quantify the risks. The first one is the Fussell-Vessely factor (F-V). The Fussell-Vessely factor measures the overall percent contribution of cut sets containing a basic event of interest to the total risk.

$$
F V=\frac{\text { (Probability of top event due only to cutsets of interest) }}{\text { (Probability of top event) }}
$$

The second one is Risk Reduction Worth (RRW), a measure of the change in risk of the system when the system component is perfect, or failure probability is zero. This measure helps to identify the components that are the best candidates to improve for overall safety.

$$
R R W=\frac{(\text { Probability of top event })}{(\text { Probability of top event with component failure probability }=0)}
$$


The third factor is risk achievement worth (RAW) measure of the increase in risk when a system is unavailable. Mathematically,

$$
R A W=\frac{(\text { probability of top event with component failure probability }=1)}{(\text { probability of top event })}
$$

Table 7 summarizes the importance analysis for each of platform failure and ranked them according to their significance on the total failure.

Table 7. Risk measure and importance analysis for the DAA capability FTA as per Figure 5.

\begin{tabular}{cccc}
\hline Events & F-V & RRW & RAW \\
\hline DAA 1 & 0.5404 & 2.176 & $1.069 \times 10^{4}$ \\
DAA 2 & 0.2351 & 1.307 & $1.069 \times 10^{4}$ \\
DAA 3 & $2.683 \times 10^{-8}$ & 1 & $1.069 \times 10^{4}$ \\
DAA 4 & 0.1069 & 1.12 & $1.069 \times 10^{4}$ \\
DAA 5 & 0.11 & 1.133 & $1.069 \times 10^{4}$ \\
\hline
\end{tabular}

The F-V value for DAA 1 failure in cooperative surveillance system is higher than all the events indicating that it contributes most to the system failure. Any improvement in the reliability of DAA 1 will decrease the risk with $\mathrm{RRW}=2.176$. Failure in non-cooperative surveillance system is the second highest effect on the DAA failure. The ability of airborne processor is rigid, and the failure of processor is considered extremely improbable, therefore its contribution is minimal to the DAA failure. Table 8 summarize the importance measure value for the fault tree presented in Figure 8.

Table 8. Risk measure and importance analysis for the ADS-B Out System FTA as per Figure 8.

\begin{tabular}{cccc}
\hline Events & F-V & RRW & RAW \\
\hline MS & 0.6942 & 3.12 & $1.341 \times 10^{4}$ \\
AO & 0.3058 & 2.211 & $1.341 \times 10^{4}$ \\
\hline
\end{tabular}

Note: the acronyms MS and AO are consistent with Figures 5-12 and Table 2.

The results summarize in Table 8, depicts that Mode S failure affects and contribute more to the overall system failure. This can also be concluded from the failure probability value of each system. The failure probability was higher for mode $S$ surveillance than the ADS-B Out system.

\section{Pathway to DAA Certification: ADS-B Suitability}

DAA systems capable of consistently and reliably performing equally or exceed the see-and-avoid performance of a human pilot are indispensable to mitigate the risks associated with possible errors/failures in the command and control (C2) loops involving the remote pilot and to support safe autonomous operations. Previous undertakings in the domain only managed to establish the safety cases for UAS operating within the line-of-sight (LOS) of their pilots or segregated from other traffic and well clear of public infrastructure and major urban settlements. For BLOS operation and safe integration of UAS in non-segregated airspace, the provision of certified autonomous DAA capabilities is an indispensable milestone. The current LOS operations/segregated airspace constraints are preventing further exploitations of UAS technology and impeding many practical uses. For instance, the use of UAS to survey large areas, to deliver essential goods in remote locations and to provide communication services over wide geographic regions, to name a few, all require non-segregated BLOS operational capabilities. From the FTA carried out in this study, the system availability is greater than $99.98 \%$ for both ADS-B Out and ADS-B In systems. The availability of ADS-B In system is solely based on the host platform and any failure or malfunction from the intruder platform is not considered. The Minimum Aviation System Performance Standards for ADS-B [67] specify the availability of 
ADS-B to be greater than $99.9 \%$ if used as primary means of surveillance and greater than $95 \%$ if used as supplementary means of surveillance. The Civil Aviation Certification Authority (CASA) in Australia has mandated using ADS-B for aircraft flying above FL285 and also for Instrument Flight Rule (IFR) traffic as specified in CAO 20.18. The FAA also mandated all the general aviation aircraft to be equipped with ADS-B within 2020 [68]. Although the failure of the ADS-B system $\left(1.2 \times 10^{-3}\right)$ is lower comparative to other surveillance sensors, researcher working on DAA capability concluded that only an adequate exploitation of multi-sensor architecture will potentially meet the safety requirements in all flight phases. Therefore, depending on the operational flight envelope ADS-B data shall be fused with other cooperative and non-cooperative surveillance data. Therefore, ADS-B systems can be used as a cooperative sensor especially in the airspace with IFR traffic allowing the safe operation of unmanned platforms in non-segregated airspace. The mathematical approach proposed in the unified framework allows us to determine the safe-to-fly portions of the host UAS operational flight envelope based on the avionics sensors/systems available onboard or, alternatively, to identify the required sensors/systems required for operating in a certain predefined portion of the host UAS operational flight envelope. Figure 13 conceptually depicts the two-way certification approach.

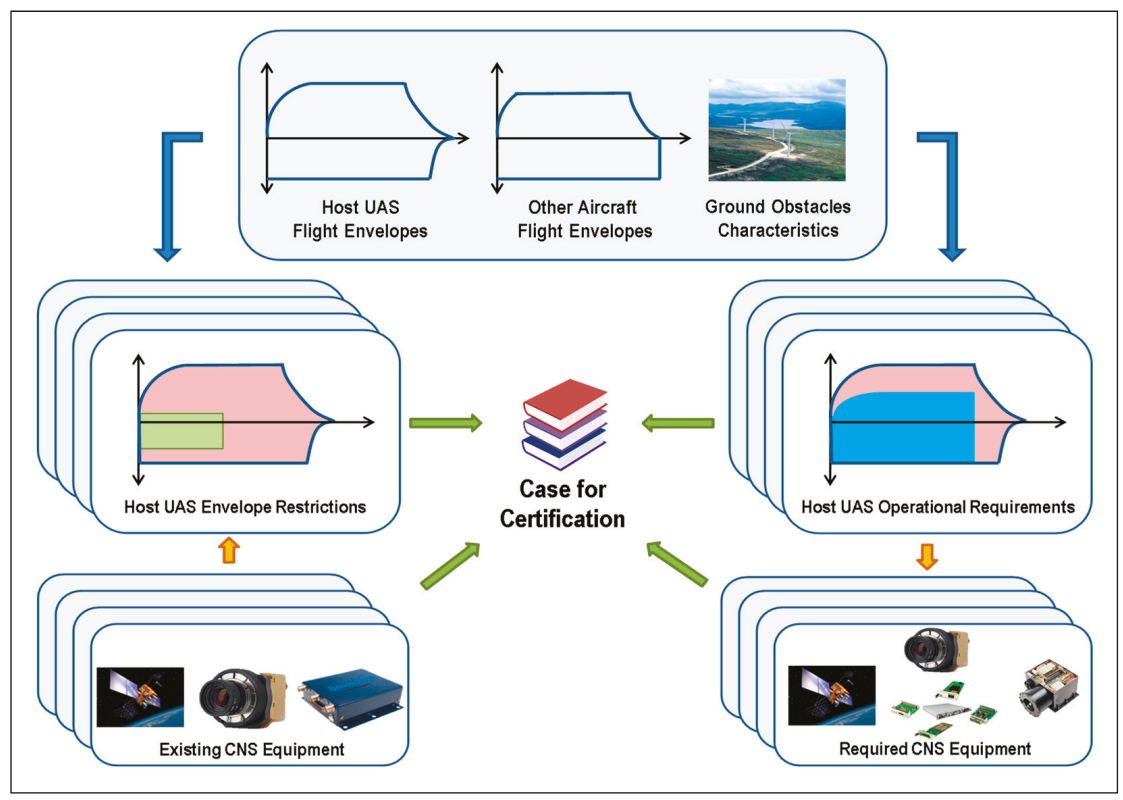

Figure 13. Two-way approach to certification.

In particular, considering the nominal flight envelopes of the host UAS/intruders and the characteristics of the on-board sensors/systems, the algorithms will determine the applicable safety envelope restrictions. Conversely, based on a predefined (required) flight envelope and on the intruder dynamics, the algorithms will allow an identification of the specific avionics sensors/systems that must be integrated in the UAS. This approach will lay the foundations for the development of an airworthy DAA capability and a pathway for manned/unmanned aircraft coexistence in all classes of airspace.

Moreover, the research community determined that only the exploitation of machine learning and artificial intelligence technologies will allow to develop a DAA capability that can perform reliably with the predicted levels of traffic density and the infinite combination of possible encounter characteristics, which already exceed the cognitive capabilities of human operators. This has been the chosen path, for 
instance, in the development of the ACAS-Xa variant. However, the current regulatory framework does not cater for the certification of non-deterministic behavior avionics systems, hence significant evolutions will be required to the framework [69], which shall also account for the ever-increasing air-ground functional integration as part of the so-called CNS+A (i.e., CNS/ATM and Avionics) paradigm, which demands that cohesive safety certification requirements are adopted for both airborne and ground-based systems $[69,70]$.

\section{Conclusions}

The reliability of UAS DAA systems based on ADS-B and other cooperative/non-cooperative sensors was analyzed in this paper. The unified analytical framework has been utilised for the mathematical fusion of navigation and tracking errors, supporting the development of low SWaP-C DAA systems exploiting cooperative and non-cooperative surveillance technologies. The paper also briefly discussed the need for an evolution of the certification framework to accommodate the adoption of non-deterministic systems and to encompass the ever-increasing functional integration between airborne and ground-based systems. The analysis highlighted the safety significance and importance of the onboard surveillance equipment. The cooperative surveillance system failure contributes most to the DAA capability failure. Another important finding is that for the cooperative surveillance system, the failure in ownship surveillance capability is higher than the failure in traffic detection capability. The adequacy of ADS-B as a cooperative surveillance system for conventional one-to-one encounters was also discussed. The calculated failure probability is in the order of $10^{-6}$, which is remote. Although the severity analysis has not been included in this study, the implications of the failure will depend on the airspace characteristics. In particular, in uncontrolled airspace, where ATM deconfliction service is not available or limited, the consequences will be likely more severe than in controlled airspace. Additionally, the severity also depends on the intruder equipage, as inadequate maneuvers can be initiated due to CNS performance limitations in the intruder platform. Hence, depending on airspace and UAS performance characteristics, specific avionics sensors/systems will have to be integrated. In conclusion, ADS-B has a good potential to be utilized as the main cooperative system especially in airspace with IFR traffic. Further evaluation will have to consider intruder equipage failures as well as different airspace and conflict scenarios. This future work will prompt an evolution of the conventional probabilistic safety assessment methodology.

Author Contributions: Conceptualization, R.S. and A.T.; Methodology and Formal Analysis, A.T.; Investigation, R.S. and A.T.; Writing-Original Draft Preparation, A.T. and A.G.; Writing-Review and Editing, R.S. and A.G.; Supervision, R.S.

Funding: This research received no external funding.

Conflicts of Interest: The authors declare no conflict of interest.

\section{References}

1. 2016-2030 Global Air Navigation Plan. Available online: https:/ /www.icao.int/airnavigation/documents / ganp-2016-interactive.pdf (accessed on 18 July 2018).

2. U.S. Army Unmanned Aircraft System Roadmap 2010-2035. Available online: https://www.army.mil/ article/37470/us_army_roadmap_for_unmanned_aircraft_systems_2010_2035 (accessed on 18 July 2018).

3. Unmanned Aircraft Systems Integration in the National Airspace System. Available online: https://www. nasa.gov/centers/armstrong/news/FactSheets/FS-075-DFRC.html (accessed on 18 July 2018).

4. Ribeiro, L.; Giles, S.; Katkin, R.; Topiwala, T.; Minnix, M. Challenges and opportunities to integrate UAS in the National Airspace System. In Proceedings of the IEEE 2017 Integrated Communications, Navigation and Surveillance Conference (ICNS), Herndon, VA, USA, 18-20 April 2017; pp. 6C3-1-6C3-13.

5. Avionics. Integrating UAS in the NAS. Available online: https://www.aviationtoday.com/2013/08/01/ integrating-uas-in-the-nas/ (accessed on 18 July 2018). 
6. EASA. Partners Step Up Efforts to Address the Integration of Drones into European Airspace. Available online: https: / www.easa.europa.eu/newsroom-and-events/news/partners-step-efforts-address-integrationdrones-european-airspace (accessed on 18 July 2018).

7. Wood, D. Collision Avoidance System and Method Utilizing Variable Surveillance Envelope. U.S. Patent 10,125,918, 17 April 2002.

8. Mullins, M.; Holman, M.W.; Foerster, K.M.; Kaabouch, N.; Semke, W. Dynamic Separation Thresholds for a Small Airborne Sense and Avoid System. In AIAA Infotech @ Aerospace Conference; American Institute of Aeronautics and Astronautics: Reston, VA, USA, 2013. [CrossRef]

9. Smith, A.; Coulter, D.; Jones, C. UAS Collision Encounter Modeling and Avoidance Algorithm Development for Simulating Collision Avoidance. In AIAA Modeling and Simulation Technologies Conference and Exhibit; American Institute of Aeronautics and Astronautics: Reston, VA, USA, 2008.

10. Smith, A.; Harmon, F. UAS Collision Avoidance Algorithm Minimizing Impact on Route Surveillance. In AIAA Guidance, Navigation, and Control Conference; American Institute of Aeronautics and Astronautics: Reston, VA, USA, 2009.

11. Seo, J.; Kim, Y.; Kim, S.; Tsourdos, A. Collision Avoidance Strategies for Unmanned Aerial Vehicles in Formation Flight. IEEE Trans. Aerosp. Electron. Syst. 2017, 53, 2718-2734. [CrossRef]

12. De Crescenzio, F.; Persiani, F.; Miranda, G.; Bombardi, T. 3D Obstacle Avoidance Strategies for UASs (Uninhabited Aerial Systems) Mission Planning and Re-Planning. In The 26th Congress of ICAS and 8th AIAA ATIO; American Institute of Aeronautics and Astronautics: Reston, VA, USA, 2008.

13. Yang, X.; Alvarez, L.M.; Bruggemann, T. A 3D Collision avoidance strategy for UAVs in a non-cooperative environment. J. Intell. Robot. Syst. 2013, 70, 315-327. [CrossRef]

14. Sabatini, R.; Richardson, M.; Bartel, C.; Shaid, T.; Ramasamy, S. A Low-cost vision based navigation system for small size unmanned aerial vehicle applications. J. Aeronaut. Aerosp. Eng. 2013, 2. [CrossRef]

15. Sanfourche, M.; Delaune, J.; Besnerais, G. Perception for UAV: Vision-based navigation and environment modeling. Aerosp. Lab J. 2012, 1-19. Available online: http:/ /www.aerospacelab-journal.org/sites/www. aerospacelab-journal.org/files/AL04-04_1.pdf (accessed on 18 July 2018).

16. Cappello, F.; Bijjahalli, S.; Ramasamy, S.; Sabatini, R. Aircraft dynamics model augmentation for RPAS navigation and guidance. J. Intell. Robot. Syst. 2017, 1-15. [CrossRef]

17. Sabatini, R.; Moore, T.; Hill, C. GNSS avionics-based integrity augmentation for RPAS detect-and-avoid applications. In Proceedings of the Fourth Australasian Unmanned Systems Conference (ACUS 2014), Melbourne, Australia, 15-16 December 2014. [CrossRef]

18. Sabatini, R.; Rodríguez, L.; Kaharkar, A.; Bartel, C.; Shaid, T.; Zammit-Mangion, D. Low-cost navigation and guidance systems for unmanned aerial vehicles-Part 2: Attitude determination and control. Annu. Navig. 2013, 20. [CrossRef]

19. Cappello, F.; Ramasamy, S.; Sabatini, R. A low-cost and high performance navigation system for small RPAS applications. Aerosp. Sci. Technol. 2016, 58, 529-545. [CrossRef]

20. Stephen, P.; Cook, S.P.; Brooks, D.; Cole, R.; Hackenberg, D.; Raska, V. Defining Well Clear for Unmanned Aircraft Systems. In AIAA Infotech@Aerospace; American Institute of Aeronautics and Astronautics: Reston, VA, USA, 2015. [CrossRef]

21. Walker, D. FAA Position on Building Consensus Around the SaRP Well-Clear Definition; RTCA Inc.: Washington, DC, USA, 2014.

22. Johnson, M.; Mueller, E.R.; Santiago, C. Characteristics of a well clear definition and alerting criteria for encounters between UAS and manned aircraft in class E airspace. In Proceedings of the 11th USA/Europe Air Traffic Management Research and Development Seminar (ATM2015), Lisbon, Portugal, 23-26 June 2015.

23. Cone, A.C.; Thipphavong, D.P.; Lee, S.M.; Santiago, C.; Langley, N.; Jack, D.P.; Group, A.A.; Vincent, M.J.; Group, A.A.; Myer, R.R. UAS Well Clear Recovery against Non-Cooperative Intruders using Vertical Maneuvers. In Proceedings of the 17th AIAA Aviation Technology, Integration, and Operations Conference, Denver, CO, USA, 5-9 June 2017; pp. 1-17. [CrossRef]

24. Monk, K.J.; Roberts, Z. Maintain and Regain Well Clear: Maneuver Guidance Designs for Pilots Performing the Detect-and-Avoid Task. In Proceedings of the 8th International Conference on Applied Human Factors and Ergonomics (AHFE 2017), Los Angeles, CA, USA, 17-21 July 2017. 
25. Syd Ali, B.; Majumdar, A.; Ochieng, W.Y.; Schuster, W.; Chiew, T.K. A causal factors analysis of aircraft incidents due to radar limitations: The Norway case study. J. Air Transp. Manag. 2015, 44-45, 103-109. [CrossRef]

26. Hammer, J.; Calgaris, G.; Llobet, M. Safety analysis methodology for ADS-B based surveillance applications. In Proceedings of the 7th USA/Europe Air Traffic Management Research and Development Seminar, Barcelona, Spain, 2-5 July 2007; pp. 1-11.

27. Ali, B.S.; Ochieng, W.Y.; Zainudin, R. An analysis and model for Automatic Dependent Surveillance Broadcast (ADS-B) continuity. GPS Solut. 2017, 1-14. [CrossRef]

28. Ali, B.S.; Ochieng, W.; Majumdar, A.; Schuster, W.; Kian Chiew, T. ADS-B system failure modes and models. J. Navig. 2014, 67, 995-1017. [CrossRef]

29. Syd Ali, B.; Schuster, W.; Ochieng, W.; Majumdar, A. Analysis of anomalies in ADS-B and its GPS data. GPS Solut. 2016, 20, 429-438. [CrossRef]

30. Semke, W.; Allen, N.; Tabassum, A.; McCrink, M.; Moallemi, M.; Snyder, K.; Arnold, E.; Stott, D.; Wing, M. Analysis of radar and ADS-B influences on aircraft detect and avoid (DAA) systems. Aerospace 2017, 4, 49. [CrossRef]

31. Allen, N.; Tabassum, A.; Semke, W. Data abnormalities and drop outs in North Dakota air traffic control radar. In Proceedings of the 2017 IEEE/AIAA 36th Digital Avionics Systems Conference (DASC), St. Petersburg, FL, USA, 16-21 September 2017; pp. 1-9.

32. Tabassum, A.; Allen, N.; Semke, W. ADS-B message contents evaluation and breakdown of anomalies. In Proceedings of the 2017 IEEE/AIAA 36th Digital Avionics Systems Conference (DASC), St. Petersburg, FL, USA, 16-21 September 2017; pp. 1-8.

33. Tabassum, A.; Semke, W. UAT ADS-B data anomalies and the effect of flight parameters on dropout occurrences. Data 2018, 3, 19. [CrossRef]

34. Billingsley, T.B. Safety Analysis of TCAS on Global Hawk Using Airspace Encounter Models; Massachusetts Institute of Technology: Cambridge, MA, USA, 2006.

35. Federal Aviation Administration (FAA). Evaluation of Candidate Functions for Traffic Alert and Collision Avoidance System II (TCAS II) On Unmanned Aircraft System (UAS); FAA: Washington, DC, USA, 2011.

36. MITRE System Safety Study of Minimum TCAS II; Federal Aviation Administration: Washington, DC, USA, $1983 ; 376 \mathrm{p}$

37. Ali, B.S.; Ochieng, W.Y.; Majumdar, A. ADS-B: Probabilistic safety assessment. J. Navig. 2017, 70, 887-906. [CrossRef]

38. Snyder, K. UAS Surveillance Criticality Final Report; Federal Aviation Administration: Washington, DC, USA, 2016.

39. Lum, C.W.; Waggoner, B. A Risk Based Paradigm and Model for Unmanned Aerial Systems in the National Airspace. In Proceedings of the 2011 Infotech@Aerospace Conference, St. Louis, MI, USA, 29-31 March 2011.

40. Melnyk, R.; Schrage, D.; Volovoi, V.; Jimenez, H. Sense and avoid requirements for unmanned aircraft systems using a target level of safety approach. Risk Anal. 2014, 34, 1894-1906. [CrossRef] [PubMed]

41. Nusbaumer, O. Introduction to Probabilistic Safety Assessments (PSA); Leibstadt NPP: Leibstadt, Switzerland, 2017.

42. Ramasamy, S.; Sabatini, R.; Gardi, A. A unified approach to separation assurance and collision avoidance for flight management systems. In Proceedings of the 2016 IEEE/AIAA 35th Digital Avionics Systems Conference (DASC), Sacramento, CA, USA, 25-29 September 2016; pp. 1-8.

43. Ramasamy, S.; Sabatini, R.; Gardi, A. A unified analytical framework for aircraft separation assurance and UAS sense-and-avoid. J. Intell. Robot. Syst. Theory Appl. 2017, 1-20. [CrossRef]

44. Orlando, V.A. The Mode S Beacon Radar System. Linc. Lab. J. 1989, 2, 345-362.

45. International Civil Aviation Organization (ICAO). Airborne Collision Avoidance System (ACAS) Manual; ICAO: Montreal, QC, Canada, 2006.

46. Guidance Material on Comparison of Surveillance Technologies (GMST); International Civil Aviation Organization Asia and Pacific: Bangkok, Thailand, 2007.

47. Sabatini, R.; Moore, T.; Hill, C. A New Avionics-Based GNSS Integrity Augmentation System: Part 1Fundamentals. J. Navig. 2013, 66, 363-384. [CrossRef]

48. Sabatini, R.; Moore, T.; Hill, C. A New Avionics-Based GNSS Integrity Augmentation System: Part 2Integrity flags. J. Navig. 2013, 66, 501-522. [CrossRef] 
49. RTCA-SC-228 Draft Detect and Avoid (DAA) Minimum Operational Performance Standards for Verification and Validation; NASA: Washington, DC, USA, 2015.

50. Sabatini, R.; Gardi, A.; Richardson, M.A. LIDAR Obstacle Warning and Avoidance System for Unmanned Aircraft. Aerosp. Sci. Technol. 2016, 55, 344-358.

51. RTCA. SC-228, Minimum Operational Performance Standards for Unmanned Aircraft Systems. Available online: https:/ / www.rtca.org/content/sc-228 (accessed on 22 July 2018).

52. Wide Area Multilateration Report on EATMP TRS 131/04 Version 1.1; National Aerospace Laboratory (NLR): Amsterdam, The Netherlands, 2005.

53. Bromberg, B.G.; Hill, R.D. Reliability of airborne electronic components. Proc. IRE 1953, 41, 513-516. [CrossRef]

54. Final Report for Software Service History and Airborne Electronic Hardware Service Experience in Airborne Systems; Federal Aviation Administration: Washington, DC, USA, 2016.

55. Kornecki, A.; Liu, M. Fault tree analysis for safety/security verification in aviation software. Electronics 2013, 2, 41-56. [CrossRef]

56. Technical Standard Order: Detect and Avoid (DAA) Systems; FAA TSO-C211; Federal Aviation Administration: Washington, DC, USA, 2017.

57. Isograph. Fault Tree Analysis Software. Available online: https://www.isograph.com/software/reliabilityworkbench/fault-tree-analysis-software/ (accessed on 18 July 2018).

58. Stott, J.E.; Britton, P.T.; Ring, R.W.; Hark, F.; Hatfield, G.S. Common Cause Failure Modeling: Aerospace vs. Nuclear. Available online: https://ntrs.nasa.gov/archive/nasa/casi.ntrs.nasa.gov/20100025991.pdf (accessed on 18 July 2018).

59. Sun, W. Determination of Beta-factors for Safety Instrumented Systems. Master's Thesis, Norwegian University of Science and Technology, Trondheim, Norway, June 2013.

60. Amjad, Q.M.N.; Zubair, M.; Heo, G. Modeling of common cause failures (CCFs) by using beta factor parametric model. In Proceedings of the 2014 International Conference on Energy Systems and Policies (ICESP), Islamabad, Pakistan, 24-26 November 2014. [CrossRef]

61. European Organisation for the Safety of Air Navigation. Generic Safety Assessment for ATC Surveillance Using Wide Area Multilateration; Edition Number: 5.0; EUROCONTROL: Brussels, Belgium, 2008.

62. Technical Standard Order; TSO-C212; Federal Aviation Administration: Washington, DC, USA, 2017.

63. Kritzinger, D. Aircraft System Safety: Assessments for Initial Airworthiness Certification; Woodhead Publishing: Cambridge, UK, 2016; ISBN 0081009321.

64. Martin Marietta Aerospace. Laser Reliability Prediction; National Technical Information Service: Springfield, VA, USA, 1975.

65. Federal Aviation Administration (FAA). FAA System Safety Handbook, Chapter 3: Principles of System Safety; FAA: Washington, DC, USA, 2000.

66. Gomez Cobo, A. Importance Measures. In Proceedings of the Workshop on "PSA Applications", Sofia, Bulgaria, 7-11 October 1996; pp. 17-27.

67. RTCA Minimum Aviation System Performance Standards for Automatic Dependent Surveillance Broadcast (ADS-B); RTCA, Inc: Washington, DC, USA, 2006.

68. Federal Aviation Administration. General Aviation ADS-B Rebate Program-Frequently Asked Questions. Available online: https://www.faa.gov/nextgen/equipadsb/rebate/faq/ (accessed on 18 May 2018).

69. Kistan, T.; Gardi, A.; Sabatini, R. Machine learning and cognitive ergonomics in air traffic management: Recent developments and considerations for certification. Aerospace 2018, 5, 103. [CrossRef]

70. Batuwangala, E.; Kistan, T.; Gardi, A.; Sabatini, R. Feature article: Certification challenges for next-generation avionics and air traffic management systems. IEEE Aerosp. Electron. Syst. Mag. 2018, 33, 44-53. [CrossRef] 
Article

\title{
The Development of an Ordinary Least Squares Parametric Model to Estimate the Cost Per Flying Hour of 'Unknown' Aircraft Types and a Comparative Application ${ }^{\dagger}$
}

\author{
Ilias Lappas ${ }^{1, *} \ddagger$ and Michail Bozoudis $2, \ddagger$ \\ 1 Department of Mechanical and Aeronautical Engineering, School of Engineering, University of South Wales, \\ Treforest Campus, Treforest CF37 1DL, UK \\ 2 Hellenic Ministry of National Defence, 15451 Athens, Greece; m.bozoudis@gdaee.mil.gr \\ * Correspondence: ilias.lappas@southwales.ac.uk; Tel.: +44-01443-482565 \\ $+\quad$ This paper is an extended version of Mr Bozoudis's paper published in the Proceedings of the ICEAA \\ International Training Symposium, Bristol, UK, 17-20 October 2016. \\ $\ddagger$ These authors contributed equally to this work.
}

Received: 19 August 2018; Accepted: 29 September 2018; Published: 3 October 2018

\begin{abstract}
The development of a parametric model for the variable portion of the Cost Per Flying Hour (CPFH) of an 'unknown' aircraft platform and its application to diverse types of fixed and rotary wing aircraft development programs (F-35A, Su-57, Dassault Rafale, T-X candidates, AW189, Airbus RACER among others) is presented. The novelty of this paper lies in the utilization of a diverse sample of aircraft types, aiming to obtain a 'universal' Cost Estimating Relationship (CER) applicable to a wide range of platforms. Moreover, the model does not produce absolute cost figures but rather analogy ratios versus the F-16's CPFH, broadening the model's applicability. The model will enable an analyst to carry out timely and reliable Operational and Support (O\&S) cost estimates for a wide range of 'unknown' aircraft platforms at their early stages of conceptual design, despite the lack of actual data from the utilization and support life cycle stages. The statistical analysis is based on Ordinary Least Squares (OLS) regression, conducted with R software (v5.3.1, released on 2 July 2018). The model's output is validated against officially published CPFH data of several existing 'mature' aircraft platforms, including one of the most prolific fighter jet types all over the world, the F-16C/D, which is also used as a reference to compare CPFH estimates of various next generation aircraft platforms. Actual CPFH data of the Hellenic Air Force (HAF) have been used to develop the parametric model, the application of which is expected to significantly inform high level decision making regarding aircraft procurement, budgeting and future force structure planning, including decisions related to large scale aircraft modifications and upgrades.
\end{abstract}

Keywords: Cost Per Flying Hour; parametric model; Life Cycle Cost; F-35A; F-16C/D; operating and support cost

\section{Introduction}

At the present environment of decreasing defence budgets, obtaining the right balance among the components of force structure, modernization, readiness and sustainability of an Air Force is extremely challenging and requires careful analysis of the cost data. Cost Per Flying Hour (CPFH) is the main metric that many Air Forces are using to develop operating and support budgets and is defined as [1]:

$$
\mathrm{CPFH}=\frac{\text { Total O\&S Costs }}{\text { Total Flying Hours }}
$$


Air Forces and aircraft operation organizations across the world use CPFH estimates mainly to budget resources to achieve aircrew proficiency. Other potential uses of CPFH estimates are for flying hour reimbursable billing rates, in other words estimating how much other governmental agencies, foreign militaries and any other customer should be charged on a per-flying-hour basis, given the variety of services an Air Force owned fleet can offer (search and rescue for civilians, aerial fire-fighting, provision of air patrol and flight training to allied nations, participation in flight displays, to name a few). Last but not least, CPFH estimates are essential in comparing the Operational and Support (O\&S) costs of different aircraft programs. CPFH estimates are then multiplied by projected flying hours and the projected budget requirements feed the decision-making process of the organization. However, actual costs do not always change to the extent predicted by this multiplicative application of the $\mathrm{CPFH}$ estimates. Selected prior work which deals with the complexities, the challenges, the strengths and the weaknesses of the CPFH method is discussed below.

Hildebrandt and Sze [2] have conducted regression studies, which relate multiple system's flying hours to several different elements of $O \& S$ cost and they found, in general, that $O \& S$ costs increase less than proportionally with flying hours. Their study has developed Cost Estimating Relationships (CERs), which relate the O\&S cost with aircraft design features and operating tempo variables and as such, these relationships might be useful for estimating the O\&S cost of an acquisition program during the early stages of the planning, programming and budgeting cycle. Using data from 1993 to 1996, Sherbrooke [3] has challenged the hypothesis that higher flying hour numbers lead to higher aircraft spares demand. By linking data from the supply database with the United States Air Force (USAF) core automated maintenance database, he has concluded that higher aircraft utilization rates tend to require less maintenance. Another significant finding of his work was that short training missions in which the pilots pulled as many as eight G's had three times as many depot-level reparable 'demands' per sortie as long cross-country sorties.

Wallace et al. [4] have analysed C-5B fleet data during the Operation Desert Storm and C-17, KC-135 and F-16C fleet data during the 90's operations in Kosovo and they have concluded that:

- The proportional CPFH model works: When nothing changes in the way an aircraft fleet flies (and rests) from one period to the next. It is then perfectly reasonable to use flying hours as a predictor for removal-causing failures. When fight behaviour does not change, the failure rate from each potential cause of failures remains constant.

- The proportional CPFH model fails: When a fleet of aircraft significantly changes its flight behaviour from one time interval to the next. An example of this is the wartime surge (flying hours increase dramatically but landings remain the same) and this is a typical case in which flying hours and the other factors that affect failures begin to diverge.

In a similar work which was carried out by Lee [5], a physics-based model has been developed that considered the ground equipment, flying hours and take-off/landing cycles to predict removals. The model has been applied to the Gulf War C-5B fleet data and it has provided more accurate results than the proportional CPFH model for the Gulf War surge.

Laubacher [6] has researched forecasting techniques for various helicopter types of the USAF, with an objective to reduce the differences between forecasted budgets and actual expenses. A similar study for various helicopter types of the United States Army has been conducted by Hawkins [7]. Armstrong [8] has analysed F-15 fleet data to estimate an incremental, rather than average CPFH. Hess [9] has evaluated the method used by the USAF to estimate the Flying Hour Program costs and introduced new methods to forecast future costs. His findings suggest that the assumption of a linear relationship between cost and flying hours is not appropriate.

Knowing the possible factors that cause operational and maintenance costs to fluctuate may allow for better predictions of the cost of the Flying Hour Program of an Air Force. Hawkes and White [10] investigated the predictive ability of many diverse variables such as aircraft age, average sortie duration, base location, utilization rate and engine type among others. Utilization rate, base location, block and 
engine type appeared to accurately predict an F-16 C/D fighter wing CPFH. Both regression models of their study are sensitive to utilization rates and that they inversely affect the $\mathrm{CPFH}$, which is in good agreement with previous studies [3-5]. The modern F-16 blocks also decrease the cost of flying, generally older technology is more expensive to maintain. Hawkes and White [11] have also investigated the relationship between the aircraft age and ownership CPFH cost growth from seventy-four different airframes in the USAF inventory. Their findings suggest that very young and very old aircraft platforms exhibit higher levels of cost growth and variability, the magnitude though of the cost growth and variability for old aircraft platforms is almost equal to that of young aircraft. By examining the empirical relationship between multiple USAF system's expenditures, flying hours and fleet sizes, Unger's [12] research has suggested a more sophisticated way to think about USAF costs than is currently used. A fixed-plus-variable cost structure has been proposed in which the expenditures do not increase nor decrease in proportion to flying hours. Unger concludes with the policy implications of his research findings, noting that current USAF budgeting methods likely overestimate funding requirements when flying hours increase and underestimate requirements when flying hours decrease.

The discussion above highlights that the accuracy of a CPFH estimate is of paramount importance, given its use as a main decision-making tool at the upper echelons of the hierarchy of the organization. Error in the cost estimates has been identified as a causal factor in cost overruns and as studies have shown, cost overruns challenge fiscal management in the United States Department of Defense (US DoD) $[13,14]$. As a knock-on effect, they may also lead to funding instability in those programs that did not experience cost overruns but were affected by re-programming of funds. This instability in funding only further exacerbates cost overruns [15].

\section{Materials and Methods}

During the procurement process of an aircraft platform, there is an emphasis in affordability and cost management issues. Potential buyers can be always offered reliable estimates for the O\&S costs of an aircraft platform which has been in operation and has reached its 'fleet maturity' stage. This is not possible though in the case of comparing and evaluating new ('unknown') aircraft platforms, therefore the decisions should be based, if possible, to cost estimates the variables of which are known at the time of the procurement process. This is one of the main objectives of the paper, to develop a CER which will enable an analyst to carry out a timely and reliable O\&S cost forecast, despite the lack of actual data from the utilization and support life cycle stages of the platform, during which the largest portion of the Life Cycle Cost (LCC), nearly $60 \%$, is incurred [16]. As such, aircraft's physical and performance characteristics and parameters which are known very well in advance at the aircraft's conceptual design phase, are being researched on the present work as potential variables of an O\&S parametric cost estimation model. An introductory demonstration of this concept has been presented by one of the authors at the 2016 International Training Symposium of the ICEAA [17].

\subsection{The Parametric Estimation Technique}

The parametric or 'top-down' technique is a relatively fast and inexpensive estimating tool. Properly applied, it may provide reliable predictions and, most important, timely estimates. According to ISPA/SCEA Parametric Handbook [18]:

Parametric estimating is a technique that develops cost estimates based upon the examination and validation of the relationships which exist between a project's technical, programmatic and cost characteristics as well as the resources consumed during its development, manufacture, maintenance, and/or modification. Parametric models can be classified as simple or complex. Simple models are cost estimating relationships (CERs) consisting of one cost driver. Complex models, on the other hand, are models consisting of multiple CERs, or algorithms, to derive cost estimates.

The parametric technique is applicable during the early stages of a system's life cycle, amidst analogy and engineering estimating techniques (Figure 1) [19]: 


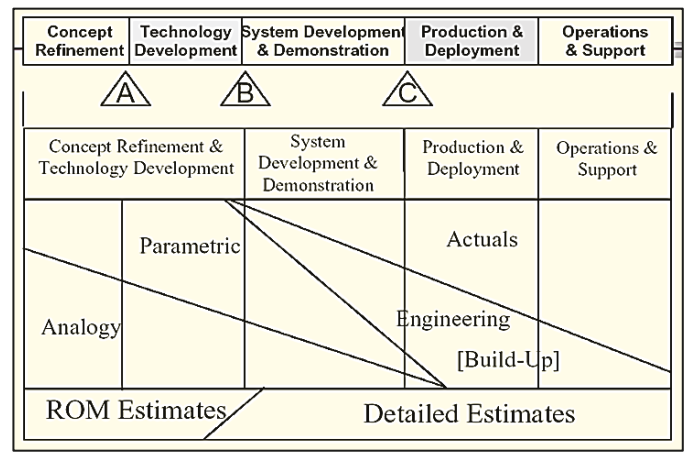

Figure 1. Typical application of estimating techniques through a system's life cycle stages [19].

The parametric technique uses regression analysis for estimating the relationships among variables. Regression analysis helps an analyst to understand how the typical value of the dependent variable (response or criterion variable) changes when any one of the independent variables (predictors or explanatory variables) is varied, while the other independent variables are held fixed.

\subsection{The Strengths and Weaknesses of the Parametric Estimation Technique}

The implementation of the parametric technique is a blended process and the interpretation of the results has to be done with extreme caution. An analyst should always consider the following strengths and weaknesses of the parametric technique:

Strengths:

- It does not require actual and detailed cost information about a new system. Compared to the engineering or 'bottom-up' cost estimating technique, it requires less data, time and resources.

- It may reveal strong CERs between cost and Reliability-Maintainability-Supportability (RMS) metrics [20], thus helping to optimize maintenance and logistic procedures.

- A parametric model can be easily adjusted when the main cost drivers change. The CERs may be easily updated and sensitivity analysis may be applied.

- It is a sound statistical process and can be objectively validated.

- The uncertainty of the estimate can be quantified, allowing cost risk analysis.

- There are many available COTS parametric tools. Additionally, general-purpose statistical packages support the parametric technique.

Weaknesses:

- It is a rigorous statistical technique (uses regression analysis).

- CERs are often considered 'black boxes,' especially if they derive from COTS tools with unknown data libraries, and/or if the CER mathematical expression cannot be logically explained.

- Appropriate data adjustments might be required before the analysis, depending on the selected regression method (OLS, OLS-Log space, MUPE, ZMPE). Also, standard error adjustments for sample size and relevance might be required [21].

- CERs must be frequently updated to ensure validity.

- The validity of the PI and CI heavily depends on the residuals diagnostics.

- The decision makers may feel uncomfortable to base their final decision on a parametric estimate (probably they will not be statisticians).

- Wide-ranging PI or CI may render the estimate useless; why not use the 'rule of thumb' instead? 


\subsection{The Development of the Parametric Model}

The relationship between historical $\mathrm{CPFH}$ and specific aircraft characteristics is investigated with an objective to identify a strong CER that will be used to estimate the hypothetical CPFH for an 'unknown' aircraft. Typically, the CPFH includes the following six main cost categories [16] according to the O\&S cost element structure: Unit-level manpower, unit operations, maintenance, sustaining support, continuing system improvements and indirect support. Since the purpose of the presented parametric model is the assessment of the relationship between cost and technical or performance characteristics, the 'indirect support' cost category is excluded from the analysis.

The Fiscal Year (FY) 2013 CPFH data from the Hellenic Air Force (HAF) aircraft fleet have been used as input for the developed parametric model (Table 1). The Ministry of National Defence of Greece restricts the publication of the CPFH data for the fighter jet fleet, CPFH data though for other than fighter jet aircraft types are publicly available without any restriction. CPFH data of Table 1 includes the contribution of the 'indirect support' cost category which, as mentioned previously, was excluded from the present study.

Table 1. HAF fixed and rotary wing aircraft types used for the development of the parametric model and related CPFH data for FY 2012, 2013 and 2018. (CPFH data for fighter aircraft is classified-publication is restricted. It includes the contribution of the 'indirect support' cost category. Data retrieved by various published issues of the Official Governmental Gazette of Greece (OGGG)).

\begin{tabular}{cccc}
\hline Aircraft/Helicopter Type & CPFH (FY 2012, $\boldsymbol{\epsilon})$ & CPFH (FY 2013, $\boldsymbol{\epsilon})$ & CPFH (FY 2018, $\boldsymbol{\epsilon}$ ) \\
\hline Helicopters & & & \\
B-212 & $10,089.9$ & 3133.63 & 2297.00 \\
AS-322C1 & 3142.43 & 3352.00 & 3583.64 \\
AB-205 & 3790.32 & 3505.24 & 2479.77 \\
A-109E & 2800.21 & 2678.12 & 1788.13 \\
Transport aircraft & & & \\
C-130H/B & 7370.88 & 7312.81 & 5887.34 \\
C-27J & 3174.90 & 4088.80 & 9114.23 \\
Airborne Early Warning \& Control aircraft & & & \\
EMB-145H & 9226.77 & 7570.15 & 4292.80 \\
VIP aircraft & & & \\
EMB-135 & 3545.58 & 4904.08 & 3162.17 \\
Gulfstream V & 3192.92 & 5537.09 & 3514.70 \\
Training aircraft & & & \\
T-41 & 3415.60 & 1449.12 & 1314.07 \\
T-6A & 1794.40 & 1839.08 & 2127.99 \\
T-2 & 4206.68 & 4240.92 & 5154.07 \\
CL-215 & & & \\
CL-415 & 9807.82 & 8858.95 & 7117.25 \\
PZL & 9508.46 & 6690.70 & $10,696.98$ \\
Fighter aircraft & 2492.69 & 1712.34 & 2884.25 \\
F-16C/D & & & \\
F/RF-4E & Classified & Classified & Classified \\
M2000/-5 & Classified & Classified & Classified \\
A-7H & Classified & Classified & Classified \\
Classified & Classified & Classified \\
\hline
\end{tabular}

In more detail, the $2012 \mathrm{CPFH}$ Issue of the OGGG has been based on O\&S data collected during the FY 2011, the 2013 CPFH Issue of the OGGG has been based on O\&S data collected during the FY 2012 and the 2018 CPFH Issue of the OGGG has been based in analysis of O\&S data collected during the FY 2015. At any point in time, the most recently published at that particular point in time $\mathrm{CPFH}$ Issue of the OGGG is used to feed the decision making of the Ministry of National Defence of Greece.

The 2013 CPFH Issue of the OGGG, which have been used for the development of the parametric model, is considered as having more reliable data than that of 2012, as the Ministry has transitioned from 2012 to a more GAO-streamlined [22] procedure for categorizing and analysing the cost input data. It was deemed necessary to exclude the contribution of the 'indirect support' cost category 
when developing the parametric model, as this category is influenced by extrinsic factors (institutional framework, organizational structure, integrated logistic support policies to name a few). As a matter of fact, the 'indirect support' cost category portion in HAF aircraft types ranges from $5 \%$ up to $50 \%$ of the $\mathrm{CPFH}$, depending on these extrinsic factors.

The HAF fire-fighting fleet (CL-215, CL-415) case can provide some evidence to support our decision to exclude the 'indirect support' cost category. As observed from Table 1 (data including 'indirect support' cost), column 'CPFH FY 2018,' the CPFH of the CL-415 seems to be considerably higher than the CL-215 CPFH. It is worth noting that the CL-415, as opposed to CL-215, is a contemporary aircraft with enhanced reliability and maintainability provisions, equipped with very fuel efficient, latest technology turboprop engines. The paradox in the CPFH difference has to do with the fact that the CL-415 squadron experiences a higher 'indirect support' cost than the CL-215 squadron does. Almost the entire structure of 113th Wing supports the CL-415 squadron; on the contrary, the CL-215 squadron belongs in the organizational chart of 112th Wing, which supports other squadrons as well. Thus, in the case of 112th Wing, the 'indirect support' cost is allocated to multiple aircraft types (generally, each HAF Wing supports multiple aircraft squadrons and/or aircraft types [23]). Nevertheless, if the 'indirect support' cost is excluded, CL-415 experiences lower CPFH than the CL-215, which makes more sense for the comparative purpose of the development of the parametric model.

A generic view of the constraints/requirements and the parametric model performance is presented at the Table 2 . The variables used for the analysis are shown at the Table 3.

Table 2. Generic view of the constraints/requirements and the parametric model performance.

\begin{tabular}{|c|c|}
\hline Constraints and Requirements & Model Performance \\
\hline Use the appropriate cost information. & $\begin{array}{l}\text { Satisfactory: Official FY } 2013 \text { CPFH data was used, excluding the } \\
\text { 'indirect support' cost category. }\end{array}$ \\
\hline $\begin{array}{l}\text { Use cost drivers (independent variables) that are easily } \\
\text { accessible and quantifiable. }\end{array}$ & $\begin{array}{l}\text { Satisfactory: The cost drivers are aircraft physical and } \\
\text { performance characteristics. }\end{array}$ \\
\hline The model should be statistically significant at the $5 \%$ level. & Satisfactory: $p-$ value $<0.01$ \\
\hline The model should capture at least $75 \%$ of the $\mathrm{CPFH}$ variance. & Satisfactory: $R_{a d j}^{2}=0.82$ \\
\hline The model's confidence and prediction intervals must be valid. & Satisfactory: The residuals do pass all the appropriate tests. \\
\hline The model's mathematical expression should make sense. & $\begin{array}{l}\text { Satisfactory: The model suggests that the aircraft empty weight } \\
\text { and the engine SFC correlate positively with the CPFH. }\end{array}$ \\
\hline
\end{tabular}

The variables used for the analysis are shown at the Table 3.

Table 3. The variables used for the analysis. In most cases, the log-transformations contributed to the creation of linear simple CERs versus the LogCPFH (Figure 2).

\begin{tabular}{|c|c|c|c|c|c|c|c|}
\hline \multirow{2}{*}{ Variables } & \multirow{2}{*}{$\begin{array}{c}\text { Variable } \\
\text { Trans-Formation }\end{array}$} & \multirow{2}{*}{$\begin{array}{c}\text { Transformed } \\
\text { Variable } \\
\text { Notation }\end{array}$} & \multicolumn{5}{|c|}{$\begin{array}{c}\text { Assessment Tests * for Linearity among Variable and } \\
\left.\text { LogCPFH (' } \varnothing^{\prime} \text { Indicates } p \text {-Value }<0.05\right)\end{array}$} \\
\hline & & & Test $1^{a}$ & Test $2^{b}$ & Test $3^{c}$ & Test $4^{d}$ & Test $5^{\mathrm{e}}$ \\
\hline \multicolumn{8}{|l|}{ Dependent } \\
\hline $\mathrm{CPFH}, € / \mathrm{h}$ & $\log$ & LogCPFH & & & & & \\
\hline \multicolumn{8}{|l|}{ Independent } \\
\hline Length (longitudinal axis), $\mathrm{ft}$ & $\log$ & LogLENGTH & $\varnothing$ & & & $\varnothing$ & \\
\hline Empty weight, $\mathrm{lb}$ & $\log$ & LogEMPTY & & & & & \\
\hline MTOW, lb & $\log$ & LogMTOW & & & & & \\
\hline Max SFC, lb/(lbf $\cdot h)$ or lb/(hp·h) & Log & LogSFC & & & & & \\
\hline Max speed, $\mathrm{km} / \mathrm{h}$ & $\log$ & LogSPEED & & & & & \\
\hline Ceiling, $\mathrm{ft}$ & $\times 10^{-4}$ & AdjCEIL & & & & & \\
\hline
\end{tabular}




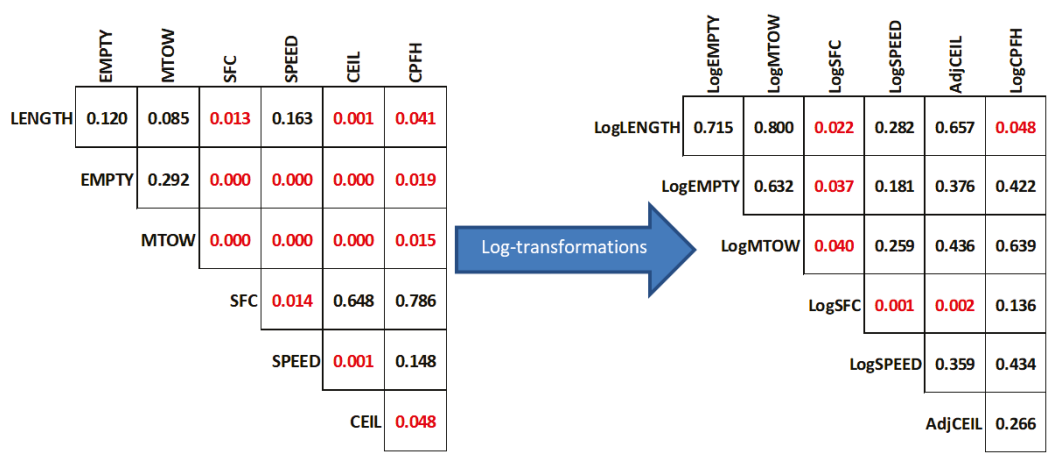

Figure 2. Assessment of the linear model assumptions among the selected variables, using the global test on 4 degrees of freedom. The $p$-values lower than 0.05 (in red) indicate the rejection of linear model assumptions at the $5 \%$ significance level. It is evident that log-transformations enhanced linear relationships among variables.

Work done by Bryant ([24], Table 2, page 10) offers an overview of independent variables used in previous $\mathrm{CPFH}$ research. The variables are grouped in four distinct groups, namely 'aircraft characteristics,' 'operational factors,' 'economic factors' and 'environmental factors.' The most frequently used independent variables by the researchers are 'average aircraft age' (belonging to the 'aircraft characteristics' group) and 'utilization rate' (belonging to the 'operational factors' group), which also reflect the fact that the CPFH research efforts are mainly channelled to find answers to policy hypotheses which are questioning the effects of the aircraft fleet aging and utilization. Instead, the present study aims to provide a 'universal' CER applicable to a wide range of platforms, which can be used at the very early development stages of the 'new' aircraft design and, as such, the independent variables are concentrated to aircraft design and performance characteristics. Moreover, in most cases, the values of the variables are unclassified and they are readily available online, something that enhances the usability of the developed model.

Figure 3 offers an overview of the way that the systems are being classified, based on the selected independent variables and depending on the desired systems similarity level. Because the selected independent variables serve as system identifiers, it is important to examine if the systems are perceptible in a realistic way and identified as 'different' or 'similar' through the regression process. The vertical axis of the cluster dendrogram in Figure 3 corresponds to the level of 'resolution' of the sample's 'image.' The 'resolution' is tied to the independent variables, which serve as system identifiers.

For example, the red horizontal dashed line in Figure 3 corresponds to the selection of a low difference level (high 'resolution'). This line cuts 8 branches of the dendrogram, meaning that the 22 different systems are identified and classified as 8 different entities (clusters), at the selected difference level. Specifically, the systems are grouped as follows: The 1st cluster includes two training aircraft (T-2E, T-6A II); the 2nd cluster includes the rotary wing platforms (AB-205, A-109E, AS-332C1, B-212) plus two light fixed-wing, single reciprocating engine, aircraft (T-41D, PZL); the 3rd cluster includes the four-engine transporter $\mathrm{C}-130 \mathrm{H} / \mathrm{B}$; the 4 th cluster includes the lighter, two-engine transporter C-27J; the 5th cluster includes the two fire-fighting aircraft (CL-215, CL-415); the 6th cluster includes the two-engine supersonic jet fighter (F/RF-4E); the 7th cluster includes the single-engine supersonic jet fighters (F-16 blocks 30/50/52+, M2000/-5); the 8th cluster includes the VIP and early warning subsonic jet aircraft (ERJ-135BJ/LR, ERJ-145H, GV) plus the A-7H single-engine subsonic jet fighter. Apart from a few pitfalls, the classification of the systems according to the aforementioned clusters seems quite realistic.

Prior to the CPFH Log-transformation, the sample's actual CPFH was multiplied by a positive real $c$, such that the selected model will estimate CPFH $=1$ for the F-16C/D Block 52+. The F-16's $\mathrm{CPFH}$ was chosen as the reference point for relative comparisons against other system's $\mathrm{CPFH}$. As a 
result, the model estimates the $\mathrm{CPFH}$ of any aircraft type times the F-16 mean $\mathrm{CPFH}$. Analysts may use analogy to turn the model's outputs into absolute CPFH estimates, by choosing a known system as their reference and multiplying its actual CPFH by the model's output.

\section{Cluster Dendrogram}

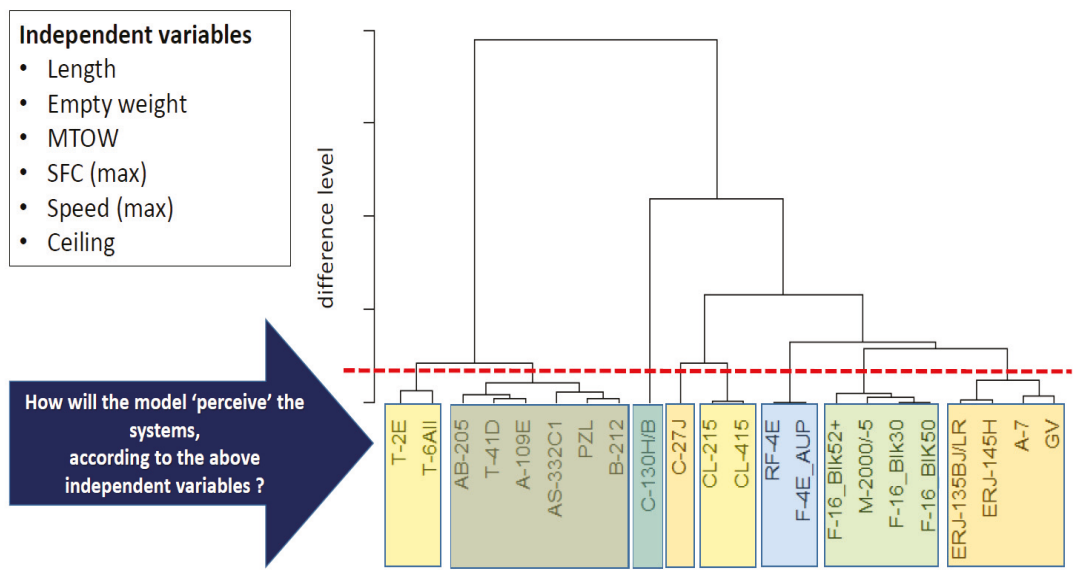

Figure 3. The cluster dendrogram of the 22 systems.

The pairwise assessment of the selected independent variables reveals multicollinearity issues. Two or more independent variables may be highly correlated, for example LogEMPTY and LogMTOW, meaning that one can be linearly estimated from the others with a substantial degree of accuracy. A parametric model should not include strongly correlated independent variables, because its predictive ability will decrease. The Pearson correlation matrix (Figure 4) offers an overview of the existing correlations among the transformed variables. Figure 5 shows examples of multicollinearity amongst various variables.

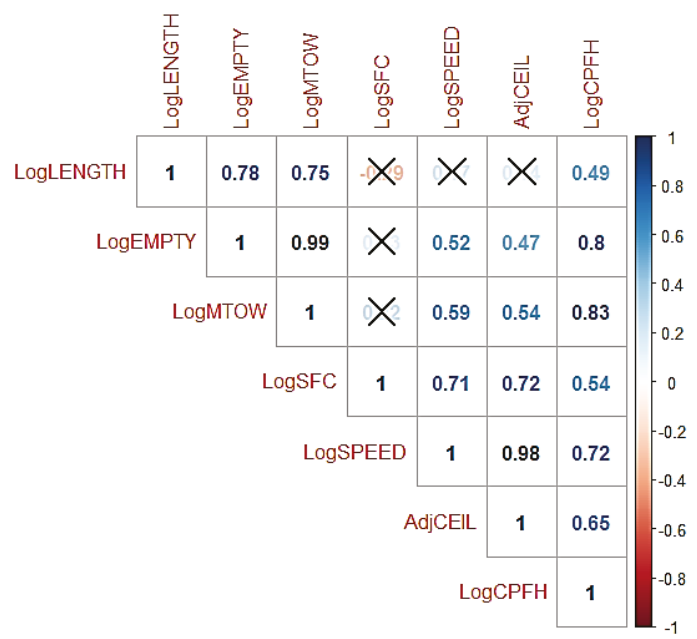

Figure 4. The variables correlation (Pearson) matrix. The symbol " $x$ " indicates the insignificant correlations at the $5 \%$ significance level. Multicollinearity is evident among several independent variables. 

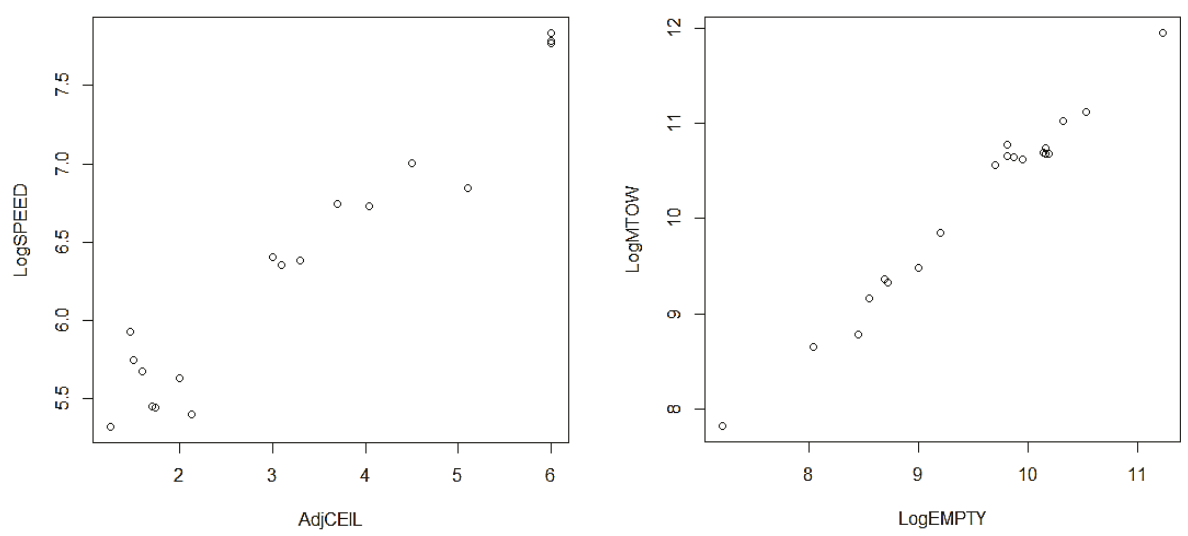

Figure 5. Visualization of the existing strong linear relationships between LogSPEED $\sim$ AdjCEIL and LogMTOW LogEMPTY.

\subsection{Selection of the Optimal CER}

As seen in Figure 4, the highest correlation coefficient between $\log \mathrm{CPFH}$ and the independent variables is $r=0.83$. Therefore, LogMTOW would be the best choice for developing a simple CER. Unluckily, this model does not comply at least with one of the requirements in Table 2, which is: $R_{\text {adj }}^{2} \geq 0.75$ (indeed, $r^{2}=0.83^{2}=0.69<0.75$ ).

The next step is to investigate all possible complex CERs with two independent variables, including their interaction, of the form:

$$
Y=\beta_{0}+\beta_{1} X_{i}+\beta_{2} X_{j}+\beta_{3} X_{i} X_{j}
$$

where $\beta_{0}, \beta_{1}, \beta_{2}, \beta_{3}$ are the model's coefficients and $i, j \in\{1,2, \ldots, 6\}, i \neq j$. After performing stepwise regression on all possible ( 2 out of $6=15)$ models with two independent variables, as shown in Equation (2), the following model is chosen, according to the AIC as the measure of the CERs relative quality:

$$
\log C P F H=-4.95006+0.4751 \log E M P T Y+0.42793 \log S F C
$$

Notably, the two selected independent variables do not correlate significantly (Figures 4 and 6), so there is no multicollinearity in the selected model. Also, the interaction of the two independent variables is not significant, hence the term $\beta_{3} X_{i} X_{j}$ is omitted from the right hand of the equation.

The selected model explains a remarkable $82.15 \%$ of the $\mathrm{LogCPFH}$ variance, while the intercept, LogEMPTY and LogSFC have significant explanatory power at the 5\% significance level. The assumptions of model's linearity are not rejected at the $5 \%$ significance level. Moreover, there is a statistically strong indication that no power transformation is required on $\log \mathrm{CPFH}$. Table 4 shows the regression analysis details obtained from R software (v5.3.1, released on 2 July 2018) and Figure 6 shows a 2D density plot (log-scale) for the model's independent variables.

\subsection{Residuals Diagnostics}

Getting valid prediction or confidence intervals relies on the assumptions that the residuals are normal with mean zero, have constant variance and no autocorrelations. The residuals of the selected model pass all the necessary tests (Table 5). 
Table 4. Model summary and ANOVA.

\begin{tabular}{|c|c|c|c|c|c|}
\hline \multicolumn{6}{|c|}{ Model Selection } \\
\hline \multicolumn{6}{|l|}{$\begin{array}{l}\text { Start: AIC }=-56.02 \\
\text { LogCPFH } \sim \operatorname{LogEMPTY~} * \operatorname{LogSFC}\end{array}$} \\
\hline & \multirow{3}{*}{$\begin{array}{c}\text { Df } \\
1\end{array}$} & Sum of $\mathrm{Sq}$ & RSS & \multicolumn{2}{|l|}{ AIC } \\
\hline & & 0.040019 & 1.2384 & \multirow{2}{*}{\multicolumn{2}{|c|}{$\begin{array}{l}-57.298 \\
-56.021\end{array}$}} \\
\hline$<$ none $>$ & & & 1.1984 & & \\
\hline \multicolumn{6}{|l|}{ Step: $\mathrm{AIC}=-57.3$} \\
\hline \multicolumn{6}{|l|}{ LogCPFH $\sim \operatorname{LogEMPTY~+~LogSFC~}$} \\
\hline & Df & Sum of Sq & RSS & \multicolumn{2}{|l|}{ AIC } \\
\hline$<$ none $>$ & & & 1.2384 & \multicolumn{2}{|l|}{-57.298} \\
\hline -LogSFC & 1 & 1.5185 & 2.7569 & \multicolumn{2}{|l|}{-41.692} \\
\hline -LogEMPTY & 1 & 4.1550 & 5.3934 & \multicolumn{2}{|l|}{-26.929} \\
\hline \multicolumn{6}{|c|}{ Residuals } \\
\hline Min & $1 Q$ & Median & $3 Q$ & \multirow{2}{*}{\multicolumn{2}{|c|}{$\begin{array}{c}\operatorname{Max} \\
0.50650\end{array}$}} \\
\hline-0.42125 & -0.08515 & -0.02154 & 0.09199 & & \\
\hline \multicolumn{6}{|c|}{ Coefficients } \\
\hline & Estimate & Std. Error & $t$ value & \multirow{4}{*}{\multicolumn{2}{|c|}{$\begin{array}{l}\operatorname{Pr}(>|\mathrm{t}|) \\
5.48 \times 10^{-8} \\
1.73 \times 10^{-7} \\
0.000117\end{array}$}} \\
\hline (Intercept) & -4.95006 & 0.57456 & -8.615 & & \\
\hline LogEMPTY & 0.47510 & 0.05951 & 7.984 & & \\
\hline LogSFC & 0.42793 & 0.08866 & 4.827 & & \\
\hline \multicolumn{6}{|c|}{$\begin{array}{l}\text { Residual standard error: } 0.2553 \text { on } 19 \text { degrees of freedom } \\
\text { Multiple R-squared: } 0.8385 \text {, Adjusted R-squared: } 0.8215 \\
\text { F-statistic: } 49.31 \text { on } 2 \text { and } 19 \mathrm{DF}, p \text {-value: } 3.009 \times 10^{-8}\end{array}$} \\
\hline \multicolumn{6}{|c|}{ Correlation of Coefficients } \\
\hline & \multirow{3}{*}{\multicolumn{2}{|c|}{$\begin{array}{l}\text { (Intercept) } \\
-0.99 \\
0.17\end{array}$}} & \multirow{2}{*}{\multicolumn{2}{|c|}{ LogEMPTY }} & \\
\hline LogEMPTY & & & & & \\
\hline LogSFC & & & \multicolumn{2}{|c|}{-0.13} & \\
\hline \multicolumn{6}{|c|}{ Analysis of Variance Table } \\
\hline Response: LogCPFH & & & & & \\
\hline & Df & Sum Sq & Mean Sq & F value & $\operatorname{Pr}(>\mathrm{F})$ \\
\hline LogEMPTY & 1 & 4.9099 & 4.9099 & 75.327 & $4.895 \times 10^{-8}$ \\
\hline LogSFC & 1 & 1.5185 & 1.5185 & 23.296 & 0.0001172 \\
\hline Residuals & 19 & 1.2384 & 0.0652 & & \\
\hline - & & & & & \\
\hline & cnPower Tra & formation to & Jormality & & \\
\hline Estimated power, lambda & & & & & \\
\hline & Est Power & $\begin{array}{l}\text { Rounded } \\
\text { Pwr }\end{array}$ & $\begin{array}{l}\text { Wald Lwr } \\
\text { Bnd }\end{array}$ & Wald & Upr Bnd \\
\hline $\mathrm{Y} 1$ & -1.2543 & 1 & -5.4661 & & 574 \\
\hline Location gamma was fixed at its low & er bound & & & & \\
\hline & Est gamma & Std Err. & $\begin{array}{l}\text { Wald Lower } \\
\text { Bound }\end{array}$ & Wald U & per Bound \\
\hline $\mathrm{Y} 1$ & 0.1 & NA & NA & & NA \\
\hline Likelihood ratio tests about transfor & nation parar & ers & & & \\
\hline & & LRT & Df & & val \\
\hline LR test, lambda $=(0)$ & & 0.3258308 & 1 & & 81244 \\
\hline LR test, lambda $=(1)$ & & 1.0123004 & 1 & & 43524 \\
\hline Asse & ssment of th & inear Mode & Assumptions & & \\
\hline & & Value & $p$-value & & cision \\
\hline Global Stat & & 0.776499 & 0.9416 & Assumpti & ns acceptable. \\
\hline Skewness & & 0.593439 & 0.4411 & Assumpti & ns acceptable. \\
\hline Kurtosis & & 0.001988 & 0.9644 & Assumpti & ns acceptable. \\
\hline Link Function & & 0.177909 & 0.6732 & Assumpti & ns acceptable. \\
\hline Heteroscedasticity & & 0.003163 & 0.9552 & Assumpti & ns acceptable. \\
\hline
\end{tabular}




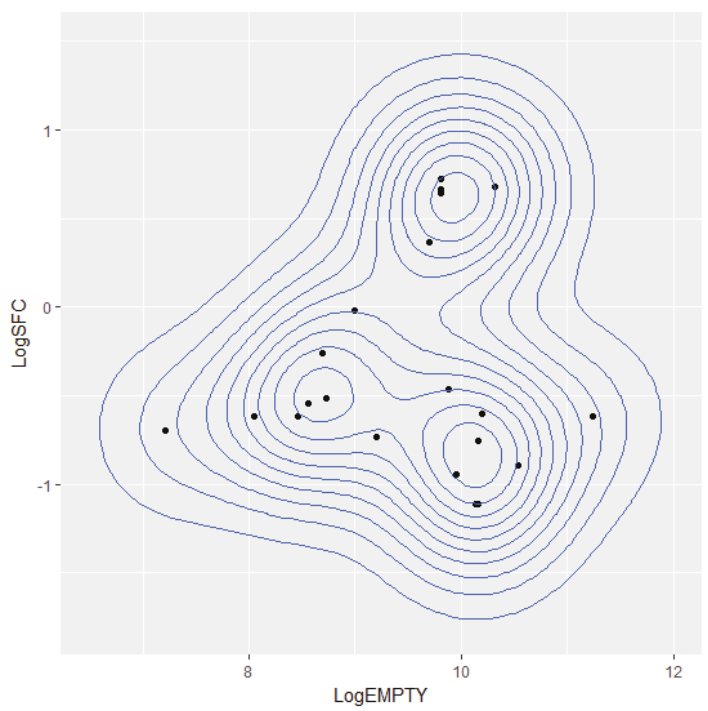

Figure 6. 2D density plot (log-scale) for the model's independent variables.

Table 5. Summary of residuals diagnostics.

\begin{tabular}{lccc}
\hline \multicolumn{1}{c}{ Test } & Null Hypothesis & $\boldsymbol{p}$-Value & $\begin{array}{c}\text { Reject the Null Hypothesis at } \\
\text { the 5\% Significance Level? }\end{array}$ \\
\hline Shapiro-Wilk normality test & Normality & 0.161 & NO \\
Breusch-Pagan test for heteroscedasticity & Constant variance & 0.332 & NO \\
Durbin-Watson test for autocorrelation & Randomness & 0.302 & NO \\
Two-sided $t$-test with Bonferroni adjustment & No outliers & 0.714 & NO \\
\hline
\end{tabular}

The residual plots (Figure 7) offer some additional insight, following the tests in Table 5 . The histogram indicates normality for the residuals; there are a few high-discrepancy observations (candidate outliers) shown in the boxplot, however the respective test in Table 5 supports the null hypothesis that there are no outliers. The residual plots versus the fitted values indicate absence of curvature pattern and presence of constant variance, supported by the minor slope in the spread-level plot; furthermore, no significant autocorrelation is evident in the respective plots. There are also a few high-leverage observations, however no hat value exceeds the empirical limit for small samples ( 3 times the hat values mean). The studentized residuals seem to follow the theoretical student- $t$ distribution, as shown in the Q-Q plot.

Observation no.14 needs further attention as being influential for the model, since its Cook's distance exceeds the empirical cut-off limit. This data point corresponds to the $\mathrm{C}-130 \mathrm{H} / \mathrm{B}$, which is the heaviest aircraft within the sample (high-leverage observation); additionally, the model overestimates to a great degree the $\mathrm{C}-130 \mathrm{H} / \mathrm{B}^{\prime} \mathrm{s}$ actual $\mathrm{CPFH}$ (high discrepancy observation). Excluding observation no.14 from the analysis would trigger a vicious cycle of consecutive exclusions, diminishing the size of the sample. Because the sample size is small, we decided not to exclude any observation from the regression analysis.

The construction of prediction or confidence intervals requires the residuals standard error and degrees of freedom (provided in Table 4), as well as the hat matrix. For any given input $\mathbf{X}_{0}^{\mathrm{T}}=$ $\left[1, \log E M P T Y_{0}, \log S F C_{0}\right]$, the hat matrix $\mathbf{P} \equiv \mathbf{X}_{0}^{\mathrm{T}}\left(\mathbf{X}^{\mathrm{T}} \mathbf{X}\right)^{-1} \mathbf{X}_{0}$ can be calculated using the following information obtained from the sample: 


$$
\left(\mathbf{X}^{\mathrm{T}} \mathbf{X}\right)^{-1}=\left[\begin{array}{ccc}
5.0647305 & -0.5216059 & 0.1365213 \\
-0.5216059 & 0.0543257 & -0.0104403 \\
0.1365213 & -0.0104403 & 0.1205977
\end{array}\right]
$$

Figure 8 shows the standard deviation map for the construction of LogCPFH confidence intervals. The highest precision for mean CPFH predictions is obtained when $\mathrm{SFC} \approx 0.75 \mathrm{lb} /(\mathrm{lbf} \cdot \mathrm{h})$ or lb/(hp.h) and empty weight $\approx 15000 \mathrm{lb}$.
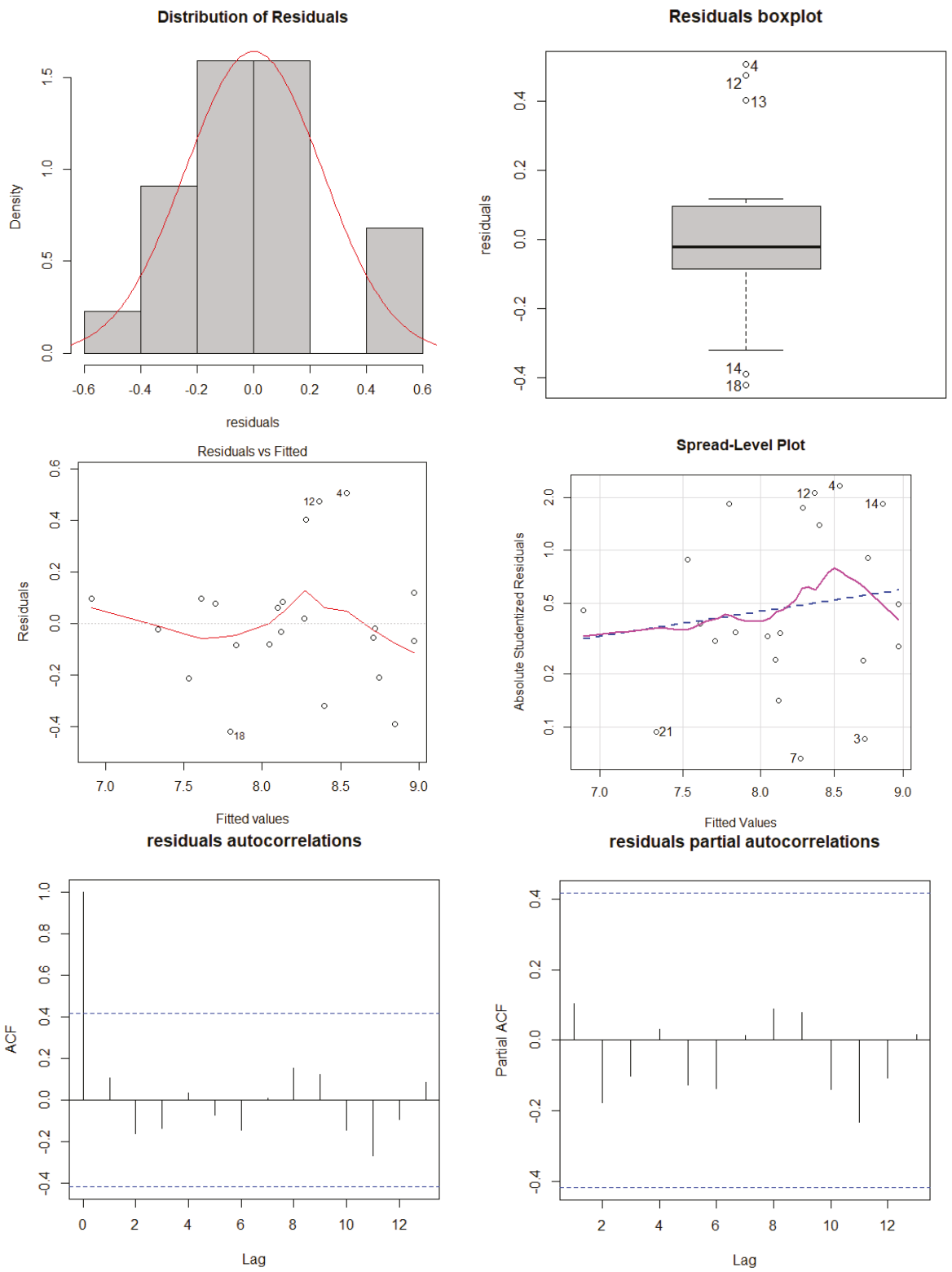

Figure 7. Cont. 


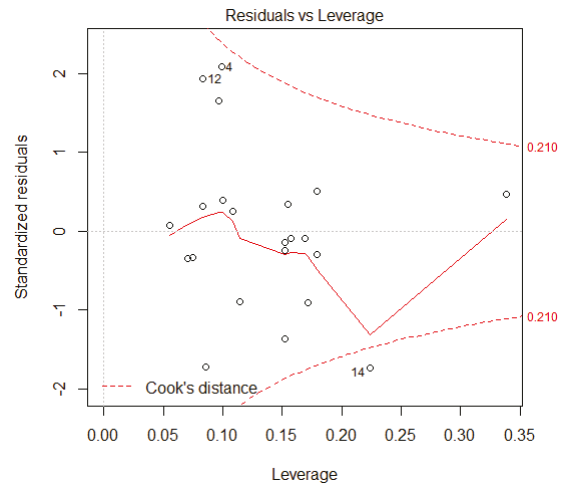

Hat values

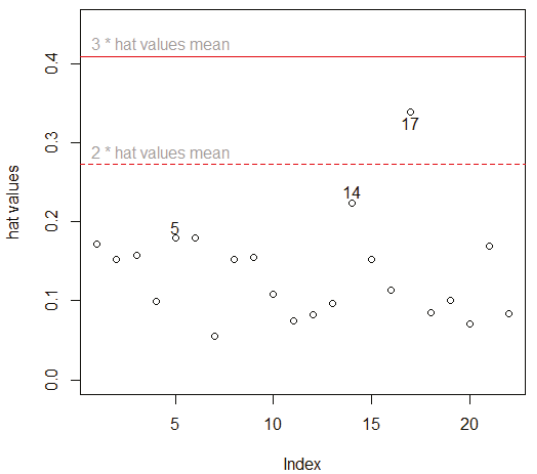

Q-Q plot for studentized residuals

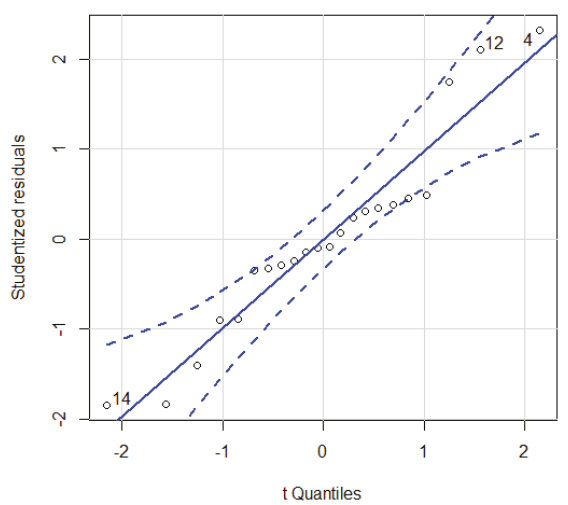

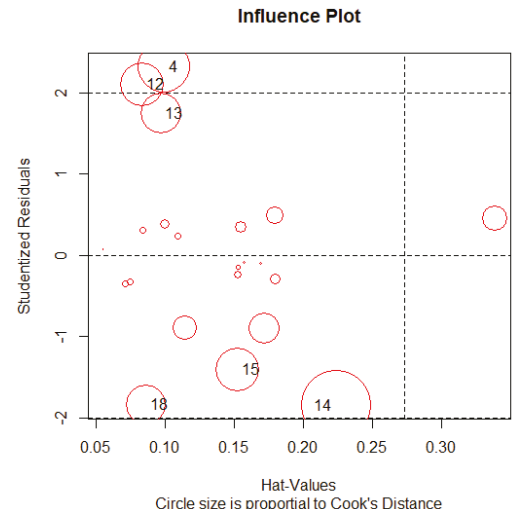

Circle size is prop Cook's distance

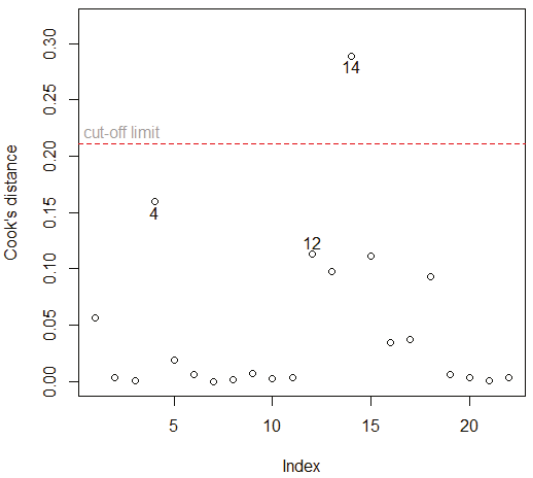

Leverage Plots
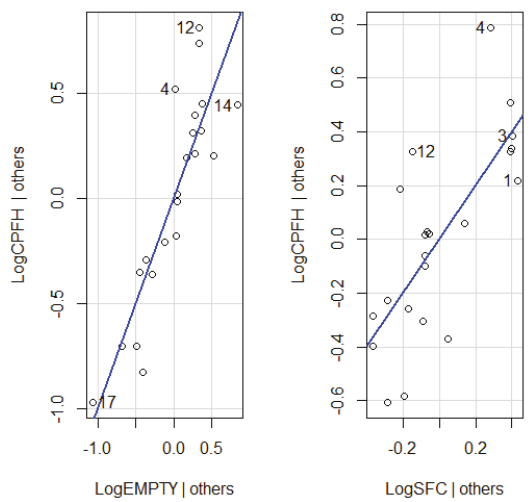

Figure 7. Typical residual plots. 


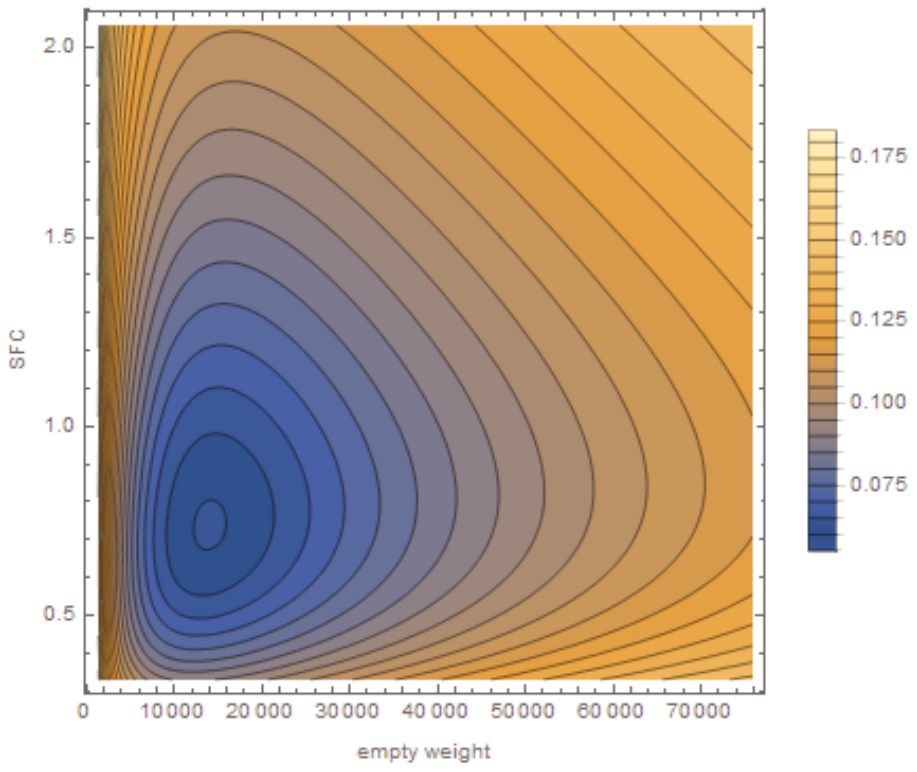

Figure 8. The standard deviation map for the construction of LogCPFH confidence intervals.

\section{Parametric Model Predictions for 'Known' and 'Unknown' Aircraft Types}

3.1. Model Comparative Predictions for Various Types

\subsubsection{Predictions on the Training Sample}

Results from the comparison of mean CPFH and 95\% CI for the training sample are shown at Figure 9 and Table 6.

\section{Comparison of CPFH means and $95 \%$ confidence intervals}

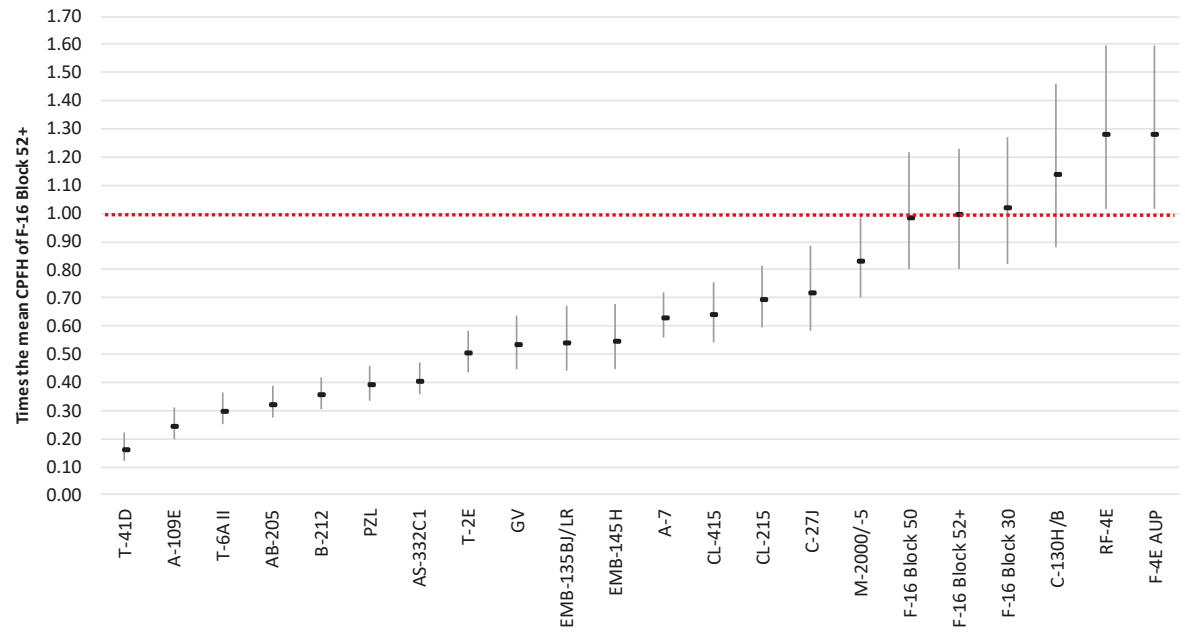

Figure 9. Comparison of mean $\mathrm{CPFH}$ and $95 \% \mathrm{CI}$ for the training sample. 
Table 6. Comparison of mean CPFH and 95\% CI for the training sample. The figures indicate 'times the mean CPFH of F-16 Block 52+.'

\begin{tabular}{cccc}
\hline Aircraft & CPFH Lower Bound & CPFH Expected & CPFH Upper Bound \\
\hline T-41D & 0.11901211 & 0.16420763 & 0.22162284 \\
A-109E & 0.19990530 & 0.25036102 & 0.31012026 \\
T-6A II & 0.25249018 & 0.30355962 & 0.36225471 \\
AB-205 & 0.27634370 & 0.32830309 & 0.38749658 \\
B-212 & 0.30764429 & 0.35999624 & 0.41896993 \\
PZL & 0.33723845 & 0.39536636 & 0.46093791 \\
AS-332C1 & 0.35547705 & 0.41073767 & 0.47240366 \\
T-2E & 0.43697559 & 0.50679004 & 0.58491362 \\
GV & 0.44894272 & 0.53734944 & 0.63862291 \\
EMB-135BJ/LR & 0.44230344 & 0.54767037 & 0.67142878 \\
EMB-145H & 0.44643551 & 0.55351426 & 0.67940476 \\
A-7 & 0.55941742 & 0.63567511 & 0.71971577 \\
CL-415 & 0.54352594 & 0.64380037 & 0.75778338 \\
CL-215 & 0.59726742 & 0.69851969 & 0.81253214 \\
C-27J & 0.58484956 & 0.72391072 & 0.88720093 \\
M-2000/-5 & 0.70287959 & 0.83413491 & 0.98354446 \\
F-16 Block 50 & 0.80040814 & 0.99097233 & 1.21478042 \\
F-16 Block 52+ & 0.80500314 & 1.00000000 & 1.22957677 \\
F-16 Block 30 & 0.81828962 & 1.02648845 & 1.27337004 \\
C-130H/B & 0.87955200 & 1.14080188 & 1.45822407 \\
RF-4E & 1.01709601 & 1.28261782 & 1.59868855 \\
F-4E AUP & 1.01709601 & 1.28261782 & 1.59868855 \\
\hline
\end{tabular}

3.1.2. Predictions on a Set of 'Unknown' Aircraft Types

A comparative application of mean CPFH predictions with 95\% CI for a set of 'unknown' aircraft types is shown at Figure 10 and Table 7.

\section{Comparison of CPFH means and $95 \%$ confidence intervals}

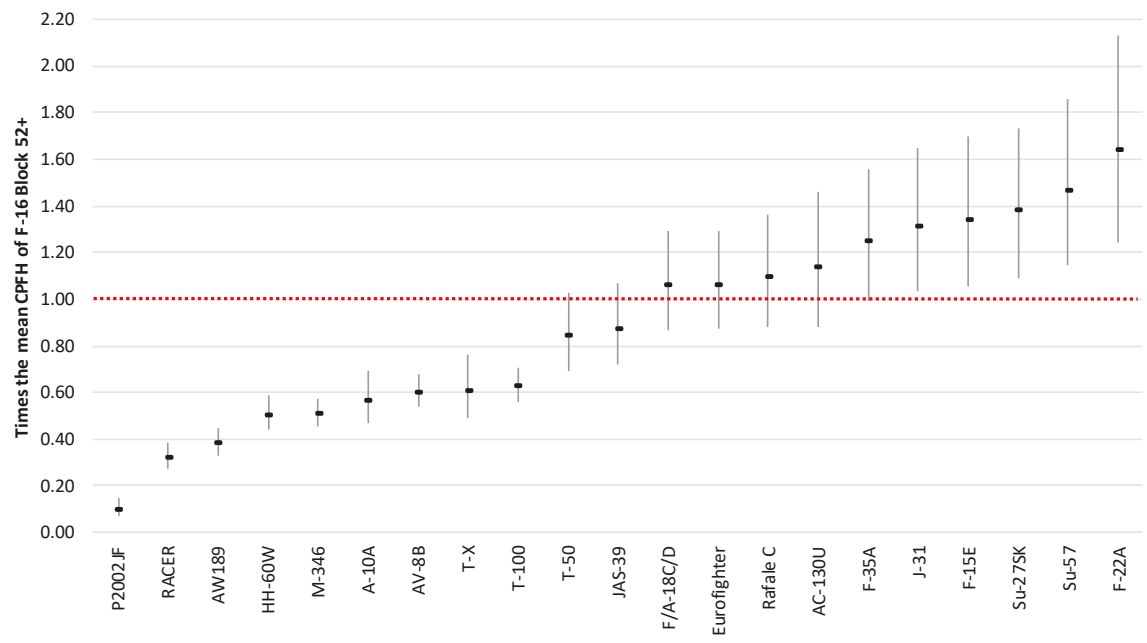

Figure 10. A comparative application of mean CPFH predictions with 95\% CI for a set of 'unknown' aircraft types. 
Table 7. A comparative application of mean CPFH predictions with $95 \%$ CI for a set of 'unknown' aircraft types. The figures indicate 'times the mean CPFH of F-16 Block 52+.'

\begin{tabular}{cccc}
\hline Aircraft & CPFH Lower Bound & CPFH Expected & CPFH Upper Bound \\
\hline P2002JF & 0.06753461 & 0.10155222 & 0.14747995 \\
RACER & 0.27574280 & 0.32714039 & 0.38563437 \\
AW189 & 0.33099377 & 0.38469385 & 0.44488060 \\
HH-60W & 0.43900130 & 0.50855135 & 0.58631201 \\
M-346 & 0.45194200 & 0.51116159 & 0.57619763 \\
A-10A & 0.46891536 & 0.57069196 & 0.68872595 \\
AV-8B & 0.53926887 & 0.60547233 & 0.67777883 \\
T-X & 0.48855572 & 0.61262218 & 0.75969810 \\
T-100 & 0.56187968 & 0.63154563 & 0.70769602 \\
T-50 & 0.69523642 & 0.84927503 & 1.02840736 \\
JAS-39 & 0.71724836 & 0.87968786 & 1.06914862 \\
F/A-18C/D & 0.86861590 & 1.06510753 & 1.29424863 \\
Eurofighter & 0.87437845 & 1.06688394 & 1.29056054 \\
Rafale C & 0.88019674 & 1.10117609 & 1.36269648 \\
AC-130U & 0.87930885 & 1.14038891 & 1.45758505 \\
F-35A & 0.99567786 & 1.25154867 & 1.55541068 \\
J-31 & 1.03666736 & 1.31599161 & 1.65010582 \\
F-15E & 1.05604359 & 1.34694738 & 1.69611550 \\
Su-27SK & 1.09117401 & 1.38460952 & 1.73549656 \\
Su-57 & 1.14592428 & 1.46794227 & 1.85568007 \\
F-22A & 1.24714749 & 1.64265811 & 2.12859570 \\
\hline
\end{tabular}

\subsection{Model Predictions for the F-35A}

The Lockheed Martin F-35 Lightning II is a family of fifth generation, single-seat, single engine, stealth multirole fighters undergoing final development and testing. It is intended to replace a plethora of existing aircraft types in the US Air Force, Navy and Marine Corps, while offering the most technologically advanced, effective and survivable fighter aircraft to date. The F-35 program, also known as the Joint Strike Fighter (JSF), is the most expensive weapon system in history with a projected service life up to 2070 and estimated sustainment costs of about $\$ 1$ trillion [25]. The F-35 is designed and built by an industrial consortium led by Lockheed Martin. Besides the USA, many NATO members and close USA allied nations participate in the funding of the F-35 development. The US DoD plans to procure nearly 2500 aircraft [25] and several other countries have ordered, or are considering ordering the F-35.

Initial O\&S cost estimates for the JSF date back to 2001 [26]. The focus of that study was to estimate the effect of changes in the reliability to the competition-sensitive O\&S costs. As such, at the initial phases of the JSF development program it has been considered that reliability improvements have a strong effect on reducing O\&S costs but not enough to recover initial investment. After the selection of the contractor has been made and the program has entered the production phase, the US DoD has moved on (2012) to establish affordability targets for the program, stating that the CPFH for the USAF, Marine Corps and US Navy could not exceed $\$ 35,200, \$ 38,400$ and $\$ 36,300$ respectively [25].

The credibility of the O\&S cost estimates and affordability targets made by the US DoD seem to have always been questionable though, not only for the F-35 [25] but for mature aircraft types as well [27]. As a general theme, the Government Accountability Office (GAO) recommends that the USAF and the Navy should follow all best practices $[22,28]$ to improve the credibility of the CERs, including an investigation of the potential range of costs and, perhaps most importantly, seeking independent cost estimates. Research by GAO has shown that 19 out of 20 independent estimates developed by the Office of Secretary of Defence office of the Director of Cost Assessment and Program Evaluation were higher than the service (US Air Force, Navy) estimate. Past work of GAO has also shown that an independent estimate is usually higher and more accurate than an estimate, which has been made by the Program Office [29]. The present work also aims to serve the purpose of providing an independent estimate for various aircraft types and to constructively contribute to the current 
world-wide debate regarding the F-35 projected O\&S costs. The developed parametric model predicts that the ratio of the mean CPFH of F-35A to the mean CPFH of the F-16C/D is 1.25. Figure 11 shows the cumulative distributions of the $\mathrm{CPFH}$ for the two systems.

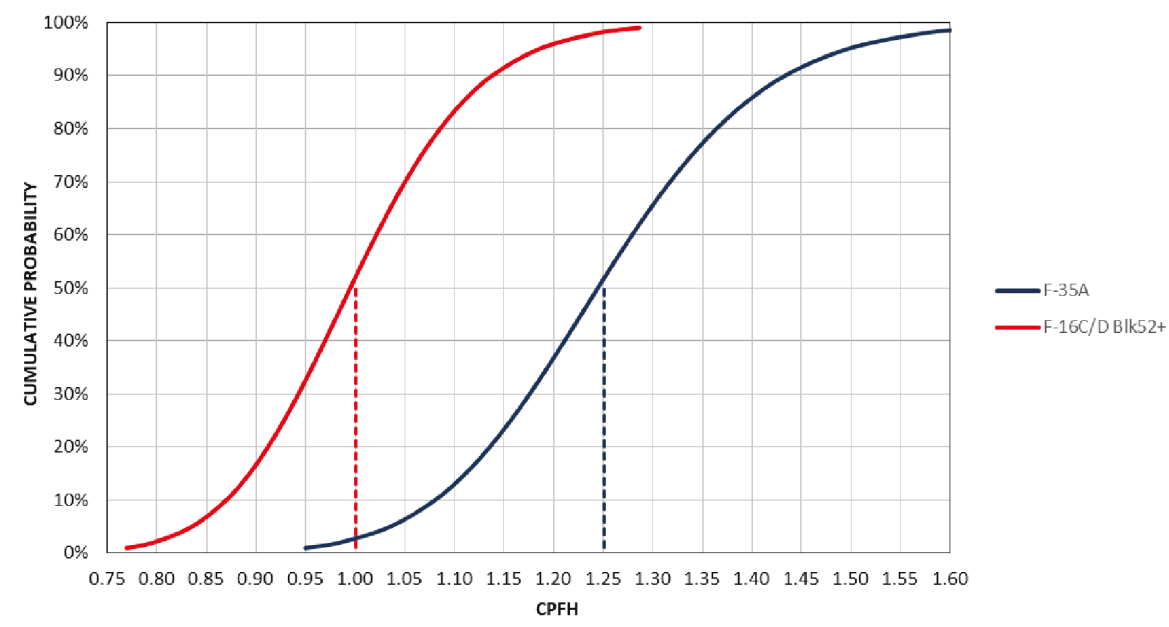

Figure 11. The cumulative distribution for the F-35A CPFH compared to the F-16C/D Block52+, according to the developed parametric model.

\section{Discussion}

Developing sound O\&S cost estimates for a new aircraft platform without data from its operational phase is a very demanding and complex process and possess significant, mainly non-systematic challenges for the aircraft operators, given that the $\mathrm{CPFH}$ estimates are affected by:

- Various operational variables and most importantly by the fleet utilization rates $[2-4,10,11]$. Many of those variables are often beyond the control of the aircraft operators, especially during situations (crisis, war conflicts) which require a sudden surge in aircraft flying hours.

- Reliability and maintainability improvements [2,30]. As above, the improvements are often beyond the control of the operators, they are mainly implemented during the production phase of the aircraft program and they are mainly based on best practices identified by analysing O\&S data from historical aircraft projects. As such, there is uncertainty on the potential effect of a reliability and/or maintainability improvement to the O\&S cost of a new aircraft program. The authors' professional experience indicates, especially for aircraft types which are operated by many different users across the world (F-16C/D for example), that the implementation of an improvement at the aircraft production line or even later as a modification/upgrade, might not get necessarily translated into O\&S cost savings, as different users develop different operational profiles for their fleets, to suit their specific operational needs.

- The 'maturity' of the fleet. In other words, by when the fleets are at their maximum size. This is because the ramp-up, steady-state and ramp-down phases tend to affect aircraft fleet cost [1].

- Inflation predictions, which are very difficult to estimate $[13,14]$.

With regards to the developed parametric model, it is believed that it incorporates important features which enhance its ability to accurately predict the CPFH of an 'unknown' aircraft type:

- $\quad$ The aircraft sample is comprised by a well-balanced mix of fixed and rotary wing aircraft types which perform a plethora of different missions, from typical military nature (air defence and superiority, interception, aerial support to land and sea military operations) to public service 
nature ones (fire-fighting, search and rescue, air transportation of VIPs and equipment, medical evacuations). Despite the fact that a high degree of diversification exists in the training sample, a statistically significant CER was obtained consisting of the empty weight and the SFC. This CER seems realistic since both the SFC and aircraft weight are expected to be positively related with the energy consumed during a flying hour.

- The aircraft sample has reached maturity in terms of maximum fleet numbers and this is considered a very crucial condition for sound cost estimates, especially in case of comparing $\mathrm{CPFH}$ of different aircraft types [1]. Most of the aircraft sample types are legacy ones with stabilized CPFH, with the newest type (F-16C/D Block 52+Adv) approaching already ten years of operational life within the HAF.

- There is no significant variation of the utilization rates of the sample, mainly because of the fact that the engagement of HAF aircraft to war conflicts outside its national borders, conditions which require unpredictable aircraft utilization rate 'spikes' for prolonged periods of time, is minimal. The analysis of fleet data during the Operation Desert Storm and the operations at Kosovo [4,5] suggests that the $\mathrm{CPFH}$ proportional model fails when a fleet of aircraft significantly changes its flight behaviour from one time interval to the next (wartime surge for example). Furthermore, Boito et al. [1] suggest that the cost of fleets should be compared using stable annual flying hours required for crew proficiency, excluding flying hours for contingency operations. Of course, as many other NATO Air Forces, HAF actively conducts and participates in large scale military exercises within the country and abroad and there might be occasions in which the utilization rates would fluctuate but overall, they are considered as stable on an annual basis.

\section{Conclusions}

The accuracy of the cost estimates is also challenged by the variety and the complexity of the missions flown by the military operators. Commercial airline 'cost per available seat mile' is a widely used, simple and effective metric of cost and effectiveness, since fleets at the commercial industry are flown for a common and simple purpose which is easily measured. At the military field, there is a variety of missions and even within a given mission area, a military aircraft often provides many different capabilities. Hence, a 'cost per capability' shall be considered by the military operators as an additional metric for the $O \& S$ cost considerations of a military air platform. In such a metric, various capabilities and respective capability levels shall be defined for the fleet, which can then get adjusted on a cost basis. An application of the proposed methodology has been developed to optimize the maintenance of an aircraft system [31]. Recent evidence [25] has identified F-35 CPFH as being significantly higher than the legacy aircraft, with an F-35 Joint Program Office member of staff stating that 'this was deemed reasonable taking into the account the complexity of the next-generation aircraft and the additional capability offered by the F-35'. The application of the parametric model for many 'mature' aircraft types for which there exists officially published $\mathrm{CPFH}$ data yields very promising results $[10,11]$. The calculated, by the parametric model, ratio (mean CPFH F-35A)/ (mean CPFH F-16 C/D) of 1.25 compares very well with the respective ratio of 'normalized' (CPFH F-35A)/ (CPFH F-16 C/D) of 1.27 (32,554/25,541 (2012\$)) reported at the Selected Acquisition Reports (SARs) which have been submitted to the US Congress in 2013 [1]. Furthermore, the most recent available SAR estimate for the CPFH F-35 [32], which excludes the 'indirect support' contribution for both F-35 and F-16 C/D, calculates the ratio (CPFH F-35A)/ (CPFH F-16 C/D) as 1.17 (29,806/25,541 (2012\$)).

In general, it is believed that one of the key conclusions of the present work is that, not only the F-35A but also the majority of the new generation of the advanced fighter jets will not be significantly more costly to sustain than the F-16 C/D, when they will reach their 'fleet maturity status.' It is expected that the present work will inform the decision making and policy considerations of current F-16 C/D users who are considering acquiring a new generation advanced fighter jet fleet, especially in terms of financial forecasting, budgeting and planning of the optimum future force structure. It should also 
channel the existing debate to issues which relate to 'cost per capability,' given the promised enhanced capabilities which the F-35A is expected to offer as compared to previous generation fighter jet types.

Author Contributions: The authors contributed equally to the preparation of the article.

Funding: This research received no external funding.

Conflicts of Interest: The authors declare no conflicts of interest.

\section{Acronyms}

$\begin{array}{ll}\text { AIC } & \text { Akaike Information Criterion } \\ \text { ANOVA } & \text { Analysis of Variance } \\ \text { CER } & \text { Cost Estimating Relationship } \\ \text { CI } & \text { Confidence Interval } \\ \text { COTS } & \text { Commercial-Off-The-Shelf } \\ \text { CPFH } & \text { Cost Per Flight Hour } \\ \text { DoD } & \text { Department of Defense (US) } \\ \text { FY } & \text { Fiscal Year } \\ \text { GAO } & \text { Government Accountability Office (US) } \\ \text { HAF } & \text { Hellenic Air Force } \\ \text { ICEAA } & \text { International Cost Estimating and Analysis Association (merger of SCEA and ISPA) } \\ \text { ISPA } & \text { International Society of Parametric Analysts } \\ \text { JSF } & \text { Joint Strike Fighter } \\ \text { LCC } & \text { Life Cycle Cost } \\ \text { MTOW } & \text { Maximum Take-Off Weight } \\ \text { MUPE } & \text { Minimum Unbiased Percentage Error } \\ \text { NATO } & \text { North Atlantic Treaty Organization } \\ \text { OGGG } & \text { Official Governmental Gazette of Greece } \\ \text { OLS } & \text { Ordinary Least Squares } \\ \text { O\&S } & \text { Operating and Support } \\ \text { OSD } & \text { Office of the Secretary of Defense (US) } \\ \text { PI } & \text { Prediction Interval } \\ \text { RMS } & \text { Reliability-Maintainability-Supportability } \\ \text { ROM } & \text { Rough Order of Magnitude } \\ \text { SAR } & \text { Selected Acquisition Report } \\ \text { SCEA } & \text { Society of Cost Estimating and Analysis } \\ \text { SFC } & \text { Specific Fuel Consumption } \\ \text { USAF } & \text { United States Air Force } \\ \text { US DoD } & \text { United States Department of Defence } \\ \text { ZMPE } & \text { Zero Bias Minimum Percent Error } \\ \end{array}$

\section{References}

1. Boito, M.; Keating, E.G.; Wallace, J.; DeBlois, B.; Blum, I. Metrics to Compare Aircraft Operating and Support Costs in the Department of Defense; Report number RR-1178-OSD; RAND Corporation: Santa Monica, CA, USA, 2015.

2. Hildebrandt, G.G.; Sze, M.B. An Estimation of USAF Aircraft Operating and Support Cost Relations; Report number N-2499-AF; RAND Corporation: Santa Monica, CA, USA, 1990.

3. Sherbrooke, C.C. Using Sorties vs Flying Hours to Predict Aircraft Spares Demand; Report number LMI-AF501LN1; Logistics Management Institute: McLean, VA, USA, 1997.

4. Wallace, J.M.; Houser, S.A.; Lee, D.A. A Physics-Based Alternative to Cost-Per-Flight-Hour Models of Aircraft Consumption Costs; Report number LMI-AF909T1; Logistics Management Institute: McLean, VA, USA, 2000.

5. Lee, D.A. The Cost Analyst's Companion; Logistics Management Institute: McLean, VA, USA, 1997; ISBN 9780985396504. 
6. Laubacher, M.E. Analysis and Forecasting of Air Force Operating and Support Cost for Rotary Aircraft; Biblioscholar. 2012. ISBN1 9781288286126. Available online: https://www.bookdepository.com/Analysis-Forecasting-AirForce-Operating-Support-Cost-for-Rotary-Aircraft-Matthew-E-Laubacher/9781288286126 (accessed on 2 October 2018).

7. Hawkins, J.C. Analysis and Forecasting of Army Operating and Support Cost for Rotary Aircraft. Master's Thesis, Air Force Institute of Technology, Wright-Patterson Air Force Base, Dayton, OH, USA, 2004.

8. Armstrong, P.D. Developing an Aggregate Marginal Cost Per Flying Hour Model for the U.S. Air Force's F-15 Fighter Aircraft; Biblioscholar. 2012. ISBN 9781288335183. Available online: https:/ / www.bookdepository.com/Developing-an-Aggregate-Marginal-Cost-Per-Flying-HourModel-for-the-US-Air-Forces-F-15-Fighter-Aircraft-Patrick-D-Armstrong/9781288335183 (accessed on 2 October 2018).

9. Hess, T.J. Cost Forecasting Models for the Air Force Flying Hour Program. Master's Thesis, Air Force Institute of Technology, Wright-Patterson Air Force Base, Dayton, OH, USA, 2009.

10. Hawkes, E.M.; White, E.D. Predicting the cost per flying hour for the F-16 using programmatic and operational data. J. Cost Anal. Manag. 2007, 9, 15-27. [CrossRef]

11. Hawkes, E.M.; White, E.D. Empirical evidence relating aircraft age and operating and support cost growth. J. Cost Anal. Parametr. 2008, 1, 31-43.

12. Unger, E.J. An Examination of the Relationship between Usage and Operating-and-Support Costs of U.S. Air Force Aircraft; Document number TR-594-AF; RAND Corporation: Santa Monica, CA, USA, 2009.

13. Smirnoff, J.P.; Hicks, M.J. The impact of economic factors and acquisition reforms on the cost of defense weapon systems. Rev. Financ. Econ. 2008, 17, 3-13. [CrossRef]

14. Christensen, D.S.; Searle, D.A.; Vickery, C. The Impact of the Packard Commission's Recommendations on Reducing Cost Overruns on Defense Acquisition Contracts; Department of the Air Force: Washington, DC, USA, 1999.

15. McNutt, R. Reducing DoD Product Development Time: The Role of the Schedule Development Process. Ph.D. Thesis, Massachusetts Institute of Technology, Cambridge, MA, USA, 1998.

16. Office of the Secretary of Defense, Cost Assessment and Program Evaluation (OSD CAPE). Operating and Support Cost-Estimating Guide; Office of the Secretary of Defense: Washington, DC, USA, 2014.

17. Bozoudis, M. Case study: A parametric model for the Cost Per Flying Hour. In Proceedings of the ICEAA International Training Symposium, Bristol, UK, 17-20 October 2016.

18. International Society of Parametric Analysts. Parametric Estimating Handbook, 4th ed.; International Society of Parametric Analysts: Vienna, VA, USA, 2008.

19. Defense Acquisition University. Integrated Defense Acquisition, Technology, and Logistics Life Cycle Management Framework Chart, v5.2; Defense Acquisition University: Fort Belvoir, VA, USA, 2008.

20. Office of the Secretary of the Air Force. Technical Order 00-20-2: Maintenance Data Documentation, (Change 2-2007), Appendix L: "Air Force Standard Algorithms; Office of the Secretary of Defense: Washington, DC, USA, 2016.

21. Office of the Secretary of the Air Force. United States Air Force Cost Risk and Uncertainty Analysis Handbook (2007), par. 2.2.2.1 and 2.2.2.3.; Office of the Secretary of Defense: Washington, DC, USA, 2007.

22. United States Government Accountability Office. Cost Estimating and Assessment Guide: Best Practices for Developing and Managing Capital Program Costs; GAO-09-3SP; United States Government Accountability Office: Washington, DC, USA, 2009.

23. Hellenic Air Force (HAF) Official Web Site. Available online: www.haf.gr (accessed on 19 August 2018).

24. Bryant, M.T. Forecasting the KC-135 Cost per Flying Hour: A Panel Data Analysis. Master's Thesis, Air Force Institute of Technology, Wright-Patterson Air Force Base, Dayton, OH, USA, 2007.

25. United States Government Accountability Office. F-35 Sustainment: Need for Affordable Strategy, Greater Attention to Risks, and Improved Cost Estimates; Report GAO-14-778; United States Government Accountability Office: Washington, DC, USA, 2014.

26. Birkler, J.; Graser, J.C.; Arena, M.V.; Cook, C.R.; Lee, G.; Lorell, M.; Smith, G.; Timson, F.; Younossi, O. Assessing Competitive Strategies for the Joint Strike Fighter: Opportunities and Options; Report number MR-1362.0-OSD/JSF; RAND Corporation: Santa Monica, CA, USA, 2001.

27. United States Government Accountability Office. Fighter Aircraft: Better Cost Estimates Needed for Extending the Service Life of Selected F-16s and F/A-18s; Report GAO-13-51; United States Government Accountability Office: Washington, DC, USA, 2012. 
28. United States Government Accountability Office. Improvements Needed to Enhance Oversight of Estimated Long-Term Costs for Operating and Supporting Major Weapon Systems; GAO-12-340; United States Government Accountability Office: Washington, DC, USA, 2012.

29. United States Government Accountability Office. Defense Acquisitions: A Knowledge-Based Funding Approach Could Improve Major Weapon System Program Outcomes; Report GAO-08-619; United States Government Accountability Office: Washington, DC, USA, 2008.

30. Abell, J.B.; Kirkwood, T.F.; Petruschell, R.L.; Smith, G.K. The Cost and Performance Implications of Reliability Improvements in the F-16A/B Aircraft; Report number N-3062-ACQ; RAND Corporation: Santa Monica, CA, USA, 1988.

31. Bozoudis, M.; Lappas, I.; Kottas, A. Use of cost-adjusted importance measures for aircraft maintenance system maintenance optimization. Aerospace 2018, 5, 68. [CrossRef]

32. F-35 Lightning II Program Office. F-35 Lightning II Joint Strike Fighter (JSF) Program Selected Acquisition Report 2016; RCS: DD-A\&T (Q\&A) 823-198; F-35 Lightning II Program Office: Arlington, VA, USA, 2017.

(C) 2018 by the authors. Licensee MDPI, Basel, Switzerland. This article is an open access article distributed under the terms and conditions of the Creative Commons Attribution (CC BY) license (http:/ / creativecommons.org/licenses/by/4.0/). 


\title{
Crack Growth in a Range of Additively Manufactured Aerospace Structural Materials
}

\author{
Athanasios Iliopoulos ${ }^{1}$, Rhys Jones ${ }^{2, *}$, John Michopoulos ${ }^{1}$, Nam Phan ${ }^{3}$ and \\ R. K. Singh Raman ${ }^{2}$ \\ 1 Computational Multiphysics Systems Laboratory, Code 6394, Center for Materials Physics and Technology, \\ US Naval Research Laboratory, Washington, DC 20375, USA; athanasios.iliopoulos@nrl.navy.mil (A.I.); \\ john.michopoulos@nrl.navy.mil (J.M.) \\ 2 Centre of Expertise for Structural Mechanics, Department of Mechanical and Aerospace Engineering, \\ Monash University, Clayton, VIC 3800, Australia; raman.singh@monash.edu \\ 3 Structures Division, Naval Air Systems Command, Patuxent River, MD 20670, USA; nam.phan@navy.mil \\ * Correspondence: rhys.jones@monash.edu; Tel.: +61-487753232
}

Received: 26 September 2018; Accepted: 2 November 2018; Published: 9 November 2018

\begin{abstract}
The aerospace industry is now beginning to adopt Additive Manufacturing (AM), both for new aircraft design and to help improve aircraft availability (aircraft sustainment). However, MIL-STD 1530 highlights that to certify airworthiness, the operational life of the airframe must be determined by a damage tolerance analysis. MIL-STD 1530 also states that in this process, the role of testing is merely to validate or correct the analysis. Consequently, if AM-produced parts are to be used as load-carrying members, it is important that the $d a / d N$ versus $\Delta K$ curves be determined and, if possible, a valid mathematical representation determined. The present paper demonstrates that for AM Ti-6Al-4V, AM 316L stainless steel, and AM AerMet 100 steel, the $d a / d N$ versus $\Delta K$ curves can be represented reasonably well by the Hartman-Schijve variant of the NASGRO crack growth equation. It is also shown that the variability in the various $\mathrm{AM} d a / d N$ versus $\Delta K$ curves is captured reasonably well by using the curve determined for conventionally manufactured materials and allowing for changes in the threshold and the cyclic fracture toughness terms.
\end{abstract}

Keywords: additive manufacturing; Ti-6Al-4V; 316L stainless steel; AerMet100 steel; crack growth; NASGRO

\section{Introduction}

Structural issues that have arisen because of aging aircraft have motivated a focus on the analytical tools needed to assess the growth of small naturally occurring material discontinuities and methods for extending the fatigue life of operational aircraft [1-5]. In this context, Appendix X3 of the ASTM fatigue test standard E647-13a and [6-10] indicate that the fatigue life of an operational aircraft is largely governed by the growth of cracks that nucleate and grow from small sub-mm material discontinuities. The NASGRO crack growth, expressed by Equation [11], viz:

$$
d a / d N=D \Delta K^{(m-p)}\left(\Delta K-\Delta K_{t h r}\right)^{p} /\left(1-K_{\max } / A\right)^{q}
$$

where $D, m, p$ and $q$ are constants, $A$ is the cyclic fracture toughness, and $\Delta K_{t h r}$ is defined as an apparent fatigue threshold which is dependent on the crack length and the $R$ ratio, is perhaps the most widely used crack growth equation. A problem with Equation (1) is that the constants $D, m, p$ and $q$ are not unique, i.e., they are a function of the crack length. Consequently, in order to assess the crack growth in operational aircraft the challenge is to obtain a form of the NASGRO equation where this "artificial" crack length dependency vanishes. In this context, Ritchie, Yu, Blom and Holm [12], 
and subsequently [4], explained that the $d a / d N$ versus $\Delta K$ relationship associated with the growth of cracks from small naturally occurring defects follows from long crack data by removing the effect of crack closure and other crack tip shielding effects. This is achieved by adopting the Hartman-Schijve variant of the NASGRO crack growth equation $[2-5,10,13-16]$ by setting $m=p$ and $q=p / 2$. This yields

$$
d a / d N=D\left(\Delta K-\Delta K_{t h r}\right)^{p} /\left(1-K_{\max } / A\right)^{p / 2}
$$

When expressed in this form, the Hartman-Schijve variant of the NASGRO equation not only captures the long crack $d a / d N$ versus $\Delta K$ relationship but the same formulation with the same values of $D$ and $p$ and $q$ and with, as per Appendix X3 of the ASTM fatigue test standard E647-13a, $\Delta K_{t h r}$ set to a small value (for small cracks, Appendix X3 questions the existence of a fatigue threshold) also captures the small crack $d a / d N$ versus $\Delta K$ relationship, and can be used to accurately predict the growth of small naturally occurring cracks under operational (variable amplitude) flight load spectra [2-5,10,13-16]. As such, Equation (2) represents a form of the NASGRO equation that, with the values of $D, m(=p), p$ and $q(=p / 2)$ held constant, can be used to compute the growth of both long cracks and also naturally occurring cracks under operational flight loads. To the best of the authors' knowledge, Equation (2) is the only form of the NASGRO equation that both fulfils the Ritchie, Yu, Blom and Holm requirement and has also been shown to capture the growth of small sub mm cracks under a large number of operational flight load spectra, viz: combat aircraft, civil aircraft, maritime aircraft, etc. $[2,5,10,13,16]$. Furthermore, to the best of the authors' knowledge, Equation (2) is the only form of the NASGRO equation that has been shown to capture crack growth in AM Ti-6Al-4V fabricated in a wide range of AM processes [17]. With this in mind, and since if AM is to be used for replacement parts on operational aircraft the ability to assess the parts' performance under operational flight loads is essential, this paper focuses on the use of Equation (2) to represent crack growth in a range of AM materials.

An additional feature of the Hartman-Schijve equation [18], i.e., Equation (2), is that, for traditionally manufactured structures and for structures repaired using either externally bonded composite patches or using additively metal deposition, the scatter in the $d a / d N$ versus $\Delta K$ curves is captured by allowing for the variability in the term $\Delta K_{t h r}[3,4,10,13-16]$. Furthermore, as discussed in $[4,10,16]$, the $d a / d N$ versus $\Delta K$ curve needed to assess the growth of small naturally occurring cracks often can be determined from the corresponding $d a / d N$ versus $\Delta K$ long crack curve by setting the term $\Delta K_{t h r}$ to a small value, typically of the order of $0.1-0.2 \mathrm{MPa} \sqrt{\mathrm{m}}$.

Reference [16] also indicated that while it is commonly believed that two materials with different microstructures will have different (long crack) $d a / d N$ versus $\Delta K$ curves, the experimental data suggest that this is not necessarily true. Furthermore, as shown in [16], even if the growth of long cracks in two materials with different microstructures have different $d a / d N$ versus $\Delta K$ curves, the corresponding small crack curves can be similar [16].

We also know [19-23] that the Hartman-Schijve equation, i.e., Equation (2) with the term $\Delta K$ replaced by $\Delta \sqrt{G}$ and $K_{\max }$ replaced by $\sqrt{G_{\max }}$ where $G$ is the energy release rate (for metals, $\sqrt{G}$ is linearly proportional to $K$ ), also holds for cracking in adhesives and delamination growth in both composites and nano-composites. It is also known $[20,21]$ that the large scatter seen in the delamination growth curves is also captured by allowing for the variability in the term $\left.\Delta \sqrt{G}\right|_{t h r}$ and the effect of the test protocol on the cyclic fracture toughness term $A$.

With these in mind, and noting that the US Navy has announced [24] that the US Navy aircraft carrier John C. Stennis will become the first US Navy ship to have an advanced manufacturing lab, which will have four 3D printers, the present paper focuses on the topic of the use of AM to ensure continued aircraft availability. There are several ways for this to be achieved, viz:

1. The repair of damage using additive metal technologies [25-28], or by utilizing multiplicative manufacturing [29], which involves the combination of both additive and subtractive manufacturing.

2. The replacement of damaged components with additively manufactured parts [30]. 
In this context, References [25-28] have shown how additive metal technology can be used to:

a. Restore the load-carrying capacity of corroded wing skins;

b. Restore the load-carrying capacity of rib-stiffened wing skins with stress corrosion cracking in the ribs;

c. Seal fasteners and thereby help alleviate the effect of environmental damage;

d. Help alleviate the effect of multi-site damage in fuselage lap joints;

e. Increase the fatigue life of wing skins with intergranular cracking at fastener holes; and

f. Withstand approximately three lifetimes, without cracking or delamination from the airframe, when applied to an F/A-18 center barrel fatigue test article subjected to a measured (operational) flight load spectra.

We have also shown [5] that crack growth in structures repaired using additive metal technology can be accurately modelled using the Hartman-Schijve crack growth equation, i.e., Equation (2). Consequently, the present paper focuses on the ability of Equation (2) to model crack growth in AM Ti-6Al-4V, AM 316L stainless steel and AM AerMet100 steel. To this end, the present paper builds on the authors' prior work [17] where it was shown that, regardless of whether the AM process is:

i. $\quad$ Electron Beam Melting (EBM);

ii. Direct Metal Laser Sintering (DMLS);

iii. Selective Laser Melt (SLM);

iv. Hot Isostatic Pressing (HIP);

v. Laser engineered Net Shaping (LENS);

vi. whether the LENS process is low- or high-power;

vii. whether the build direction was horizontal or vertical.

The $d a / d N$ versus $\Delta K$ curves, obtained using tests performed as described in the main body of the ASTM E-64-13a fatigue test standard, can be represented reasonably well by the Hartman-Schijve variant of the NASGRO crack growth equation, i.e., Equation (2), with allowance made for changes in the terms $\Delta K_{t h r}$ and $A$. This finding mimics that discussed above for modelling the variability in the crack growth curves seen in conventionally manufactured metallic structures, structures repaired using additive metal deposition and for modelling the variability of delamination/disbond growth in composite and bonded structures.

The experimental data presented in this paper indicate that for the materials studied (namely AM Ti-6Al-4V, AM 316L stainless steel, and AM AerMet100 steel) the corresponding $d a / d N$ versus $\Delta K$ curves can be represented reasonably well by the Hartman-Schijve variant of the NASGRO crack growth equation. It is also shown that the variability in the various $\mathrm{AM} d a / d N$ versus $\Delta K$ curves is captured reasonably well by using the curve determined for conventionally manufactured materials and allowing for changes in the threshold and the cyclic fracture toughness terms.

\section{Crack Growth in Additively Manufactured Ti-6AL-4V}

While AM offers the potential to economically fabricate customized parts with complex geometries, Reference [31] explained that the mechanical behavior of these materials must be better understood (related statements can be found in the US Federal Aviation Administration review paper [32], as well as in [17,33]) before AM can be utilized for critical load-bearing applications. This is particularly true for aircraft applications where, as detailed in MIL-STD 1530 [34], the design and certification approval requires analytical tools that are capable of modelling crack growth. 
Reference [32] revealed the $d a / d N$ versus $\Delta K$ curves associated with crack growth in 34 different AM Ti-6Al-4V tests, which covered a wide range of AM processes including EBM, DML, SLM, HIP, and LENS, could be represented using the Hartman-Schijve, viz:

$$
\frac{d a}{d N}=2.79 \times 10^{-10}\left(\frac{\Delta K-\Delta K_{t h r}}{\sqrt{\left(1-\frac{K_{\max }}{A}\right)}}\right)^{2.12}
$$

In this study, the constants $\Delta K_{t h r}$ and $A$ were determined using a global optimization scheme that was based on a latin hypercubes approach. The objective function used in the scheme was:

$$
f=\left(\sum_{i=1}^{N} \sum_{k_{i}=1}^{K_{i}}\left|\frac{\log \left(\frac{d a}{d N}\left(D, p, \Delta K_{t h r}, A, R_{i}, \Delta K_{k_{i}}\right)\right)-\log \left(\left.\frac{d a}{d N}\right|_{k_{i}}\right)}{K_{i}}\right|\right) / N,
$$

where $N$ is the number of tests, $i=1, \ldots, N$ is an index representing the $i$ th test, $R_{i}$ is the value of $R$ for test $i, K_{i}$ is the number of data points of test $i, k_{i}=1, \ldots, K_{i}$ is an index representing the $k_{i}$ th data point of test $i, \Delta K_{k_{i}}$ is the value of $\Delta K$ for the $i$ th test for the $k_{i}$ th data point and similarly $\left.\frac{d a}{d N}\right|_{k_{i}}$ is the relevant data value of $d a / d N$. The objective function defined in Equation (4) was chosen such that it provides a measure of fit quality. Specifically, this value represents the average absolute error of the exponent base 10 of the fit to the measured $d a / d N$ data. For each data point we can, in addition, establish the exponent error metric, as follows:

$$
e=\left|\log \left(\frac{d a}{d N}\left(D, p, \Delta K_{t h r}, A, R_{i}, \Delta K_{k_{i}}\right)\right)-\log \left(\left.\frac{d a}{d N}\right|_{k_{i}}\right)\right|,
$$

The expression presented by Equation (5) can be plotted to provide a visual depiction of the goodness-of-fit associated with the various instances Equation (2). In this section, we first show that the AM Ti-6Al-4V crack growth data presented in [35-37], which were not studied in [17], also conform to Equation (3).

\subsection{BELL Helicopter Crack Growth Data}

Let us first consider the $R=0.1 \mathrm{da} / \mathrm{dN}$ versus $\Delta K$ curves given by Bell Helicopters [35] for crack growth in AM Ti-6Al-4V samples that were obtained from several different suppliers, see Figure 1a. Although [35] does specifically state what AM process was used to manufacture the test specimens, it states that: "All builds were stress relieved and received Hot Isostatic Pressing (HIP) to ensure optimal mechanical properties". Equation (3) was used to compute the curves associated with these tests. As per [4,10,31], the values of $A$ and $\Delta K_{t h r}$ were chosen to fit the data. The values used are given in Table 1. As can be seen in Figure 1, the resultant computed curves are in excellent agreement with the measured data. Furthermore, the error plots of Figure $1 \mathrm{~b}$ indicate that the exponent error is well below 1.0, further corroborating the excellent agreement of the fitted parameters with the experimental data. It is interesting to note that the range of the threshold terms is similar to that obtained in [31] for fatigue tests performed on a range of other AM Ti-6Al-4V specimens.

Table 1 reveals a large variability in the cyclic fracture toughness parameter A. It is postulated that this may be attributed to either lack of data at Region III that does not allow us to obtain estimates with high certainty, or to the nature of AM processes. Further investigation on this matter will be conducted in follow-up work. 
Table 1. Values of $\Delta K_{t h r}$ and $A$ used in Figure 1 and identified by global optimization of Equation (4).

\begin{tabular}{ccc}
\hline Bell Helicopter Tests [35] & $\boldsymbol{\Delta} \boldsymbol{K}_{t h r}(\mathbf{M P a} \sqrt{\mathbf{m}})$ & $\boldsymbol{A}(\mathbf{M P a} \sqrt{\mathbf{m}})$ \\
\hline Supplier 1 XY & 3.74 & 134.9 \\
Supplier 1 YX & 3.26 & 32.1 \\
Supplier 2 XY & 4.05 & 330 \\
Supplier 2 YX & 4.39 & 71.7 \\
Supplier 4 XY & 3.85 & 75 \\
Supplier 4 YX & 4.08 & 74.7 \\
Supplier 5 XY & 3.92 & 77.4 \\
Supplier 5 YX & 2.64 & 84.6 \\
\hline
\end{tabular}

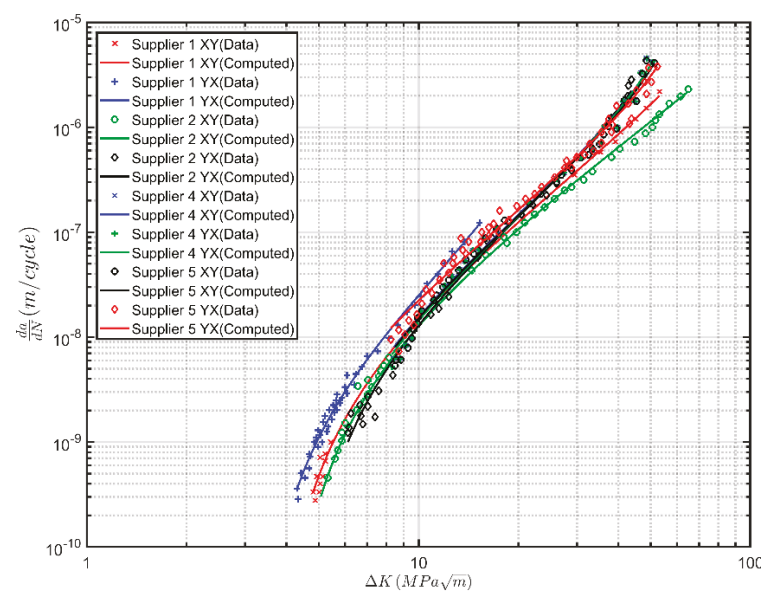

(a)

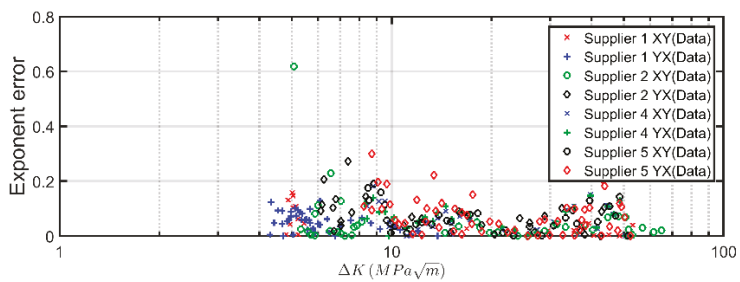

(b)

Figure 1. (a) Measured, from [35], and computed crack growth curves in the various directions (XY and $\mathrm{YX}$ ) of AM and HIPed Ti-6Al-4V; (b) Exponent error of the fitted curves as computed using Equation (5).

\subsection{Laser Metal Wire Deposition (LMwD) Crack Growth Data}

To further illustrate that crack growth in AM Ti-6Al-4V can be represented by Equation (3), consider the crack growth data given in [36] for specimens fabricated using Laser Metal wire Deposition $(\mathrm{LMwD})$. In $\mathrm{LMwD}$, a laser heat source melts a metal wire into the desired shape, and it is, in general, an attractive AM process for larger structures in which a higher deposition rate is required. In these tests, an initial semi-circular fatigue crack, approximately $0.7 \mathrm{~mm}$ in depth (except for specimen (2), where the pre-crack was $1.2 \mathrm{~mm}$ deep), was created from the notch by cyclic loading at a stress ratio $R=0.0$, a frequency $F=10 \mathrm{~Hz}$ and a maximum stress of $500 \mathrm{MPa}$. The tests were stopped at crack lengths around $2.5 \mathrm{~mm}$, and the specimens were subsequently fractured in tension at room temperature. Figure 2 presents the resultant room temperature $d a / d N$ versus $\Delta K$ curves for tests where crack growth was either parallel or perpendicular to the build direction. All specimens were 
post-weld heat-treated and annealed at $704{ }^{\circ} \mathrm{C}$ for $2 \mathrm{~h}$ and cooled in the furnace to $538^{\circ} \mathrm{C}$, after which the samples were taken out of the furnace and air cooled to room temperature. Reference [36] stated that this heat treatment is not expected to introduce any significant changes to the microstructure. The specimen surfaces were not machined.

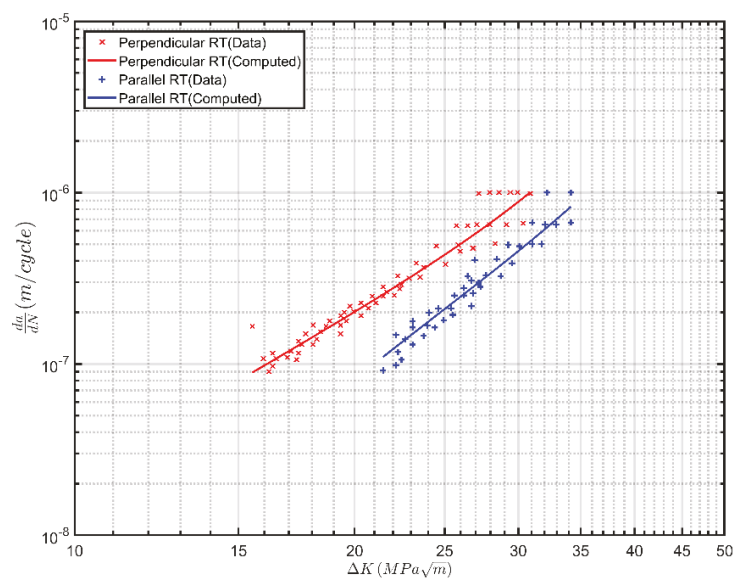

(a)

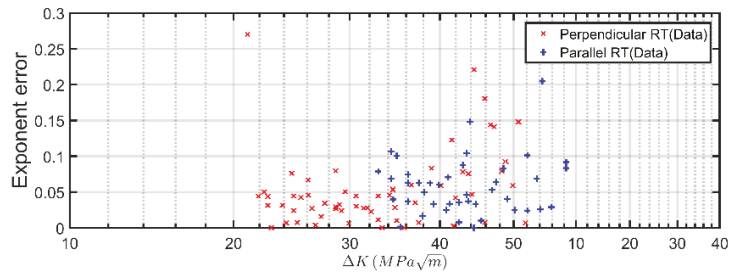

(b)

Figure 2. (a) Measured, from [36], and computed crack growth curves in two directions of laser metal wire deposited Ti-6Al-4V; (b) Exponent error of the fitted curves as computed using Equation (5).

Equation (4) was again used through a global optimization scheme to compute these curves. The identified values of $\Delta K_{t h r}$ and $A$ are given in Table 2. As per References [4,10,17], and as can be seen in the experimental data, the threshold values for these two tests differ. This is a somewhat expected result, since data are available only in the Paris region. As can be seen in Figure 2a, the resultant computed curves are in reasonably good agreement with the measured data, an observation that is also corroborated by the error plots in Figure $2 b$.

Table 2. Values of $\Delta K_{t h r}$ and $A$ used in Figure 2 and identified by global optimization of Equation (4).

\begin{tabular}{ccc}
\hline Laser Metal Wire Deposition Tests [36] & $\boldsymbol{\Delta} \boldsymbol{K}_{\boldsymbol{t} \boldsymbol{r} \boldsymbol{r}}(\mathbf{M P a} \sqrt{\mathbf{m}})$ & $\boldsymbol{A}(\mathbf{M P a} \sqrt{\mathbf{m}})$ \\
\hline Perpendicular RT & 3.11 & 46.9 \\
Parallel RT & 8.59 & 52.3 \\
\hline
\end{tabular}

\subsection{Boeing India Crack Growth Data}

Next consider crack growth data presented by the Boeing India Research Centre [37] for crack growth in SLM Ti-6AL-4V specimens B3090 and S3090, where growth was parallel to and perpendicular to the build direction, respectively. In these tests, the samples were stress relieved by annealing them at $650{ }^{\circ} \mathrm{C}$ for $3 \mathrm{~h}$. The surfaces were not machined. Figure 3 presents the measured growth data together 
with those presented in the Bell Helicopter and in the LMwD tests [35,36]. Here we see that these three different studies yielded similar $d a / d N$ versus $\Delta K$ data. It would therefore be expected that the Boeing India $d a / d N$ versus $\Delta K$ curves could again be represented as per [4,17] by Equation (3), albeit with similar values of $\Delta K_{t h r}$ and $A$. To confirm this, the measured and predicted curves, using the values of $A$ and $\Delta K_{\text {thr }}$ given in Table 3, are shown in Figure 4.

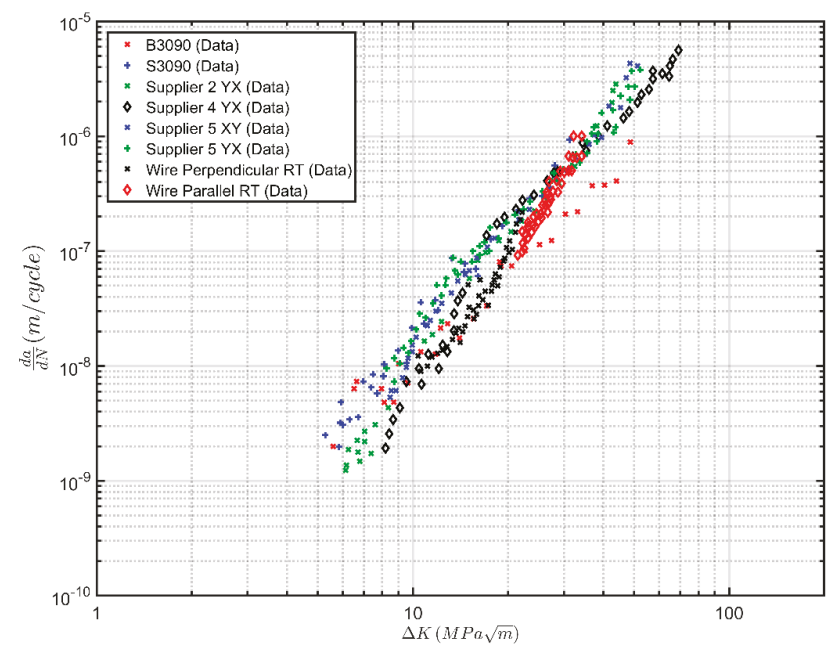

Figure 3. Measured crack growth in the Boeing India SLM specimens [37] compared with crack growth in the Bell Helicopter [35] and the LMwD [36] tests.

Table 3. Values of $\Delta K_{t h r}$ and $A$ used in Figure 1 and identified by global optimization of Equation (4).

\begin{tabular}{ccc}
\hline Boeing India SLM Tests [37] & $\Delta K_{t h r}(\mathbf{M P a} \sqrt{\mathbf{m}})$ & $A(\mathbf{M P a} \sqrt{\mathbf{m}})$ \\
\hline B3090 & 4.12 & 200 \\
S3090 & 3.07 & 60.4 \\
\hline
\end{tabular}

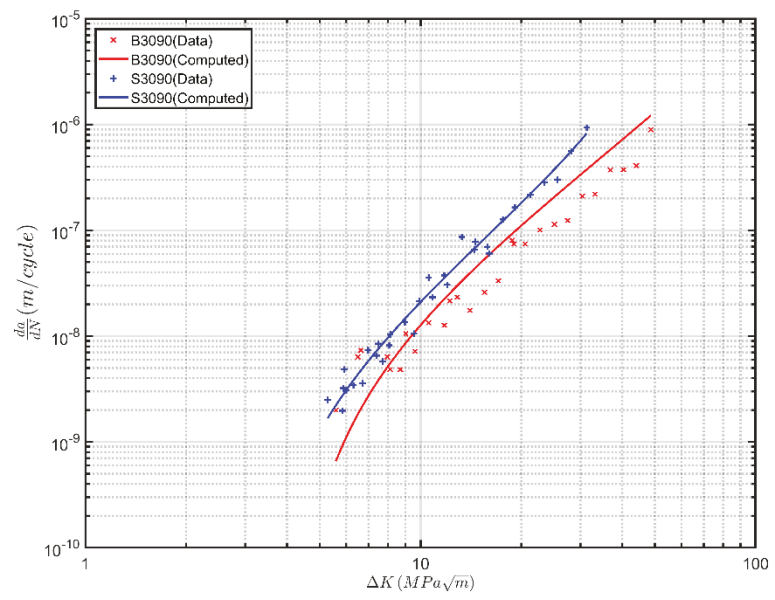

(a)

Figure 4. Cont. 


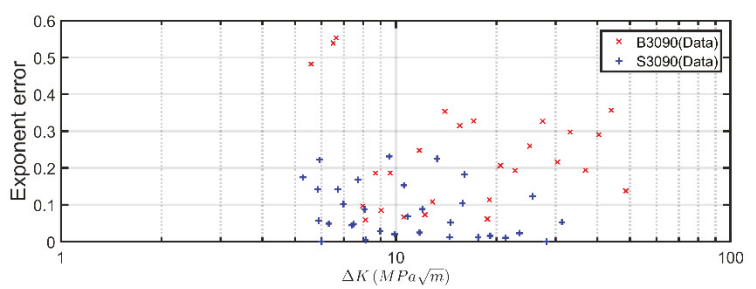

(b)

Figure 4. (a) Measured, from [37], and computed crack growth curves in the perpendicular (B3090) and parallel (S3090) directions of SLM-manufactured specimens; (b) Exponent error of the fitted curves as computed using Equation (4).

\subsection{Small Crack Growth in LENS Ti-6Al-4V}

The paper by Zhai et al. [38] noted that the use of long crack growth $d a / d N$ versus $\Delta K$ curves to estimate the fatigue life of AM components may be non-conservative (Figure 5, from [39], illustrates how cracks can initiate and grow from small sub-mm material discontinuities, in this case a lack of fusion).

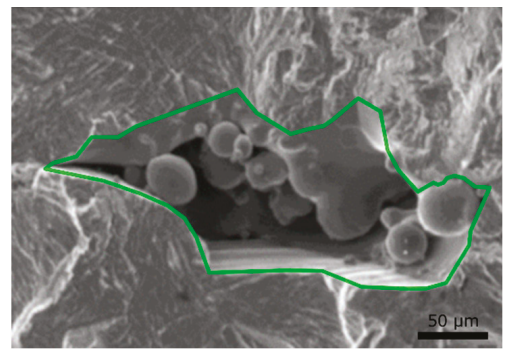

Figure 5. SEM image of the fatigue crack origin, a lack of fusion defect, in the SLM Ti-64, from [39] with its outline (in green) superimposed. Image Courtesy of Dr. Milan Brandt.

As such, let us next consider the growth of sub mm cracks in AM Ti-6Al-4V. As previously noted [2-4,10,13-16], it has been shown that the growth of small cracks under both constant amplitude and operational flight load spectra can often be estimated from the Hartman-Schijve long crack representation, i.e., Equation (3), by setting the threshold term $\Delta K_{t h r}$ to a small value, typically of the order of $0.1(\mathrm{MPa} \sqrt{\mathrm{m}})$. As such, the results presented in [17] suggest that small crack growth in Mil Annealed Ti-6Al-4V should (approximately) conform to Equation (6):

$$
\frac{d a}{d N}=2.79 \times 10^{-10}\left(\frac{\Delta K-0.1}{\sqrt{\left(1-\frac{K_{\max }}{128}\right)}}\right)^{2.12}
$$

To this end, Figure 6 presents the $d a / d N$ versus $\Delta K$ curves associated with the growth of small cracks given in [40] for post-heat-treated LENS Ti-6Al-4V where the surfaces were not machined. For comparison, Figure 6 also presents:

1. The LENS Ti-6Al-4V small crack $d a / d N$ versus $\Delta K$ curve predicted by Equation (6).

2. The small crack curve for Ti-17 [41]. In Reference [41], this curve was shown to be essentially $R$ ratio-independent.

3. The $R=0.1$ small crack curve for Ti-6246 [42].

4. The $R=0.1$ short crack curve for Mil Annealed Ti-6Al-4V [43]. 
5. The $R$ ratio-independent small crack curve for D6ac steel [4].

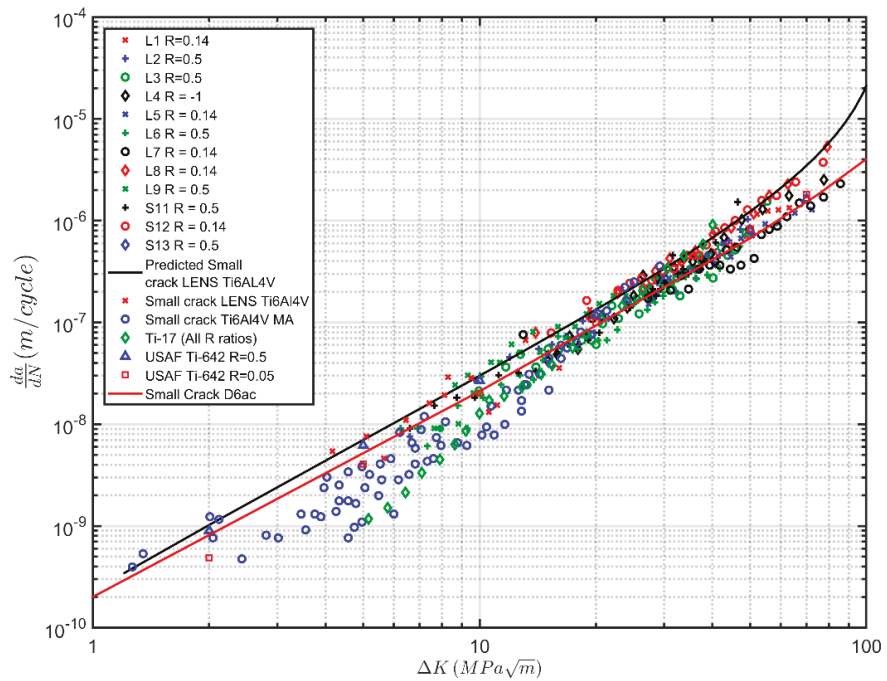

Figure 6. Comparison of small crack growth in LENS Ti-6Al-4V, Ti-6Al-4V MA, Ti-17, Ti-642, and a $350 \mathrm{MPa}$ locomotive mild steel, which were tested at a range of $\mathrm{R}$ ratios, with the predicted small crack growth in small crack growth in LENS Ti-6Al-4V.

At this point, it should be noted that the review paper [16] revealed that the short crack $d a / d N$ versus $\Delta K$ curves for the two different aerospace quality Titanium alloys Ti-17 and Ti-6246 were similar to that of a $350 \mathrm{MPa}$-grade locomotive mild steel. Consequently, Figure 6 also presents the $d a / d N$ versus $\Delta K$ small curves associated with a $350 \mathrm{MPa}$-grade locomotive (mild) steel tested at a range of $R$ ratios [44], see Table 4 .

Figure 6 reveals that the $d a / d N$ versus $\Delta K$ curve associated with the growth of small cracks in LENS Ti-6Al-4V is very similar to that seen for small crack $d a / d N$ versus $\Delta K$ curves of Mil Annealed Ti-6Al-4V, Ti-6246, and Ti-17, and also to the small crack $d a / d N$ versus $\Delta K$ curves seen by both D6ac steel and a $350 \mathrm{MPa}$-grade locomotive steel. We also see that the growth of small cracks in LENS Ti-6Al-4V can be reasonably well represented by Equation (6), which has the value of the fatigue threshold $\Delta K_{\text {thr }}$ set to a small value.

Table 4. Test envelope, from [16], for small cracks growth in a locomotive steel.

\begin{tabular}{cccccc}
\hline Specimen Number & $\boldsymbol{R}$ & $\boldsymbol{\sigma}_{\max }(\mathbf{M P a})$ & $\boldsymbol{\sigma}_{\text {min }}(\mathbf{M P a})$ & $\boldsymbol{\Delta} \boldsymbol{\sigma}(\mathbf{M P a})$ & $\boldsymbol{\sigma}_{\text {mean }}(\mathbf{M P a})$ \\
\hline L1 & 0.14 & 330.0 & 46.2 & 283.8 & 188.1 \\
L2 & 0.50 & 330.0 & 165.0 & 165.0 & 247.5 \\
L3 & 0.50 & 330.0 & 165.0 & 165.0 & 247.5 \\
L4 & -1.0 & 240.0 & -240.0 & 240.0 & 0.0 \\
L5 & 0.14 & 330.0 & 46.2 & 283.8 & 188.1 \\
L6 & 0.50 & 330.0 & 165.0 & 165.0 & 247.5 \\
L7 & 0.14 & 330.0 & 46.2 & 283.8 & 188.1 \\
L8 & 0.14 & 330.0 & 46.2 & 283.8 & 188.1 \\
L9 & 0.50 & 330.0 & 165.0 & 165.0 & 247.5 \\
S11 & 0.50 & 330.0 & 165.0 & 165.0 & 247.5 \\
S12 & 0.14 & 330.0 & 46.2 & 283.8 & 188.1 \\
S13 & 0.50 & 330.0 & 165.0 & 165.0 & 247.5 \\
\hline
\end{tabular}

As such, Figure 6 supports the findings presented in [16] that, while the growth of specimens containing cracks that have been grown from artificially induced notches, as per E647-13a [6], can show 
significant microstructural effects, such effects may be not significant in the growth of small cracks. We also see that the small crack growth curve associated with LENS Ti-6Al-4V is similar to that of small cracks in MA Ti-6Al-4V, Ti-17 and Ti-642.

\subsection{Discussion}

The $d a / d N$ versus $\Delta K_{t h r}$ curves associated with each of these studies are consistent with Equation (3), and hence with the 34 different AM Ti-6Al-4V specimen test results (previously) analyzed in [17]. It is also clear that, as per [17], the cyclic fracture toughness $(A)$ can vary significantly. The variation in the fatigue threshold $\left(\Delta K_{t h r}\right)$ is also similar to that seen in [17], and as discussed in [17], is consistent, albeit in these tests slightly larger, with the variation seen in traditionally manufactured materials. However, according to the statements in Appendix X3 of the tests standard E647-13a [6]:

1. "Fatigue cracks of relevance to many structural applications are often small or short for a significant fraction of the structural life."

2. "The growth rates of such cracks usually cannot be measured with the standard procedures described in the main body of Test Method E647, which emphasizes the use of large, traditional fracture mechanics specimen geometries."

3. "Of greater importance, the growth behavior of these small cracks is sometimes significantly different from what would be expected based on large-crack growth rate data and standard fatigue crack growth analysis techniques. Direct measurement of small-crack growth rates may be desirable in these situations."

4. "It is not clear if a measurable threshold exists".

It follows that the fatigue threshold $\left(\Delta K_{t h r}\right)$ associated with naturally occurring cracks in operational AM parts (this assumes that the parts will be annealed) will (in all likelihood) be small. Hence, the variation in the threshold, associated with the fastest growing (lead) cracks in these parts will (likely) be correspondingly small. This now leads us to the question: What is the effect of the variability in the cyclic fracture toughness $(A)$ on the fatigue life of AM parts. In this context, E647-13a notes that for conventionally manufactured materials, the majority of the operational life of a structure is consumed in the short/small crack regime and that for such naturally occurring cracks the fatigue threshold is small. Consequently, for conventionally manufactured materials the effect on total life of the variability of the apparent toughness term $A$ is generally small. In contrast, for AM materials, the variability in $A$ can be quite large. As such, the effect of this (large) variability in the cyclic fracture toughness $(A)$ on the fatigue lives of AM replacement parts needs further investigation.

\section{Crack Growth in Two AM Steels}

\subsection{AM 316L Stainless Steel}

In the previous analysis, we presented a method to identify the coefficients of the Hartman-Schijve variant of the NASGRO crack growth equation using a global optimization scheme. In cases were the availability of optimization or computational tools is limited, an alternative approach based on regular spreadsheet software can be used. Such a methodology for determining the constants in the Harman-Schijve variant of the Nasgro equation, i.e., Equation (2), from the measured $d a / d N$ versus $\Delta K$ data was outlined in $[16,44]$ and will be described in this section. The process outlined in $[16,44]$ was: for a given $R$ ratio, plot $d a / d N$ against $\frac{\Delta K-\Delta K_{t h r}}{\sqrt{1-K_{\max } / A}}$ using $\log -\log$ scales. Here, the value of $A$ is chosen to be a typical value for the given material and thickness. In the near-threshold region, the effect of any errors in the assumed value of $A$ in the term $K_{\max } / A$ in the denominator will generally be small. As such, the value of $\Delta K_{t h r}$ is now chosen such that plot of the $d a / d N$ versus $\frac{\Delta K-\Delta K_{t h r}}{\sqrt{1-K_{\max } / A}}$ data in the near-threshold region, i.e., the low- $d a / d N$ region, appears as a (nearly) straight line. The value of $A$ is then fine-tuned to improve linearity in the high- $\Delta K$ region. This process is repeated for each of the $R$ ratio data sets, with the $A$ value used being kept the same for each $R$ ratio. This process will generally 
result in $d a / d N$ versus $\frac{\Delta K-\Delta K_{t h r}}{\sqrt{1-K_{\max } / A}}$ plots that differ slightly in the high- $\Delta K$ region. The value of $A$ is then adjusted slightly, keeping the (adjusted) $A$ the same for each $R$ ratio, to minimize this difference, i.e., to better collapse the curves in the high- $\Delta K$ region. This process will sometimes result in the various $d a / d N$ versus $\frac{\Delta K-\Delta K_{t h r}}{\sqrt{1-K_{\max } / A}}$ curves associated with different $R$ ratio's slightly diverging in the near-threshold region. This can be alleviated by slightly tweaking the values of $\Delta K_{t h r}$ until the various curves now essentially coincide, while allowing for experimental error. At this stage, the values of $\Delta K_{t h r}$ for each $R$ ratio and the value of $A$ have been obtained. The values of $D$ and $p$ are then obtained directly from a linear fit to the data.

To illustrate this, let us first consider the $R=0.1,0.3$ and $0.5 \mathrm{da} / \mathrm{dN}$ versus $\Delta K$ presented in [45] for Annealed 316L stainless steel data. The resultant $d a / d N$ versus $\frac{\Delta K-\Delta K_{t h r}}{\sqrt{1-K_{\max } / A}}$ curves are shown in Figure 7. This yields $D=1.49 \times 10^{-10}$ and $p=1.99$ with the values of $A$ and $\Delta K_{t h r}$ listed in Table 5, and the associated crack growth equation is:

$$
\frac{d a}{d N}=1.49 \times 10^{-10}\left(\frac{\Delta K-0.1}{\sqrt{\left(1-\frac{K_{\max }}{A}\right)}}\right)^{1.99}
$$

These constants were then used to predict the $d a / d N$ versus $\Delta K$ curves presented in [46] for AM 316L steels. The specific manufacturing processes studied in [46] were Selective Laser Melting (SLM) without post-processing and SLM followed by Hot Isostatic Pressing (HIP). In [46], tests were performed on specimens where crack growth was parallel to the build direction, in Figure 8, these specimens are labelled "SLM 1" and "SLM, HIP 1". Tests were also performed on specimens where crack growth was parallel to the build direction, in Figure 8 these curves are labeled "SLM 2" and "SLM, HIP 2". The corresponding computed crack growth curves are also shown in Figure 8.

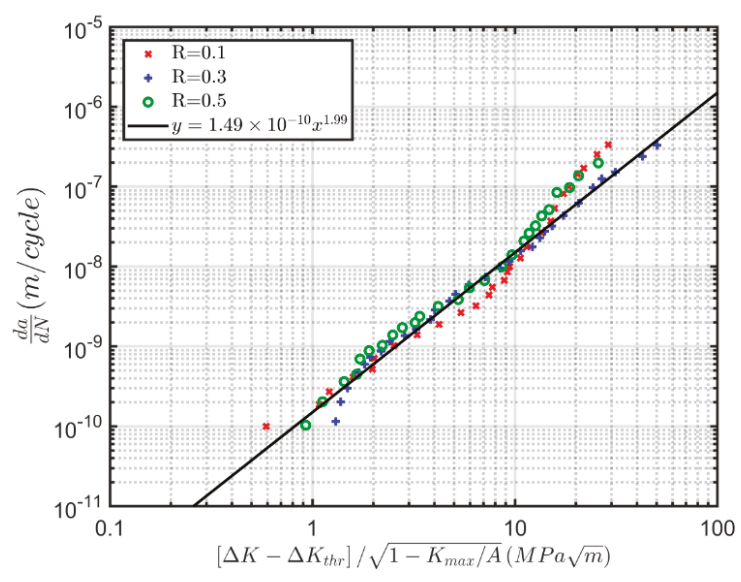

Figure 7. Plot of $d a / d N$ versus $\frac{\Delta K-\Delta K_{t h r}}{\sqrt{1-K_{\max } / A}}$ for $R=0.1,0.3$ and 0.5 . 


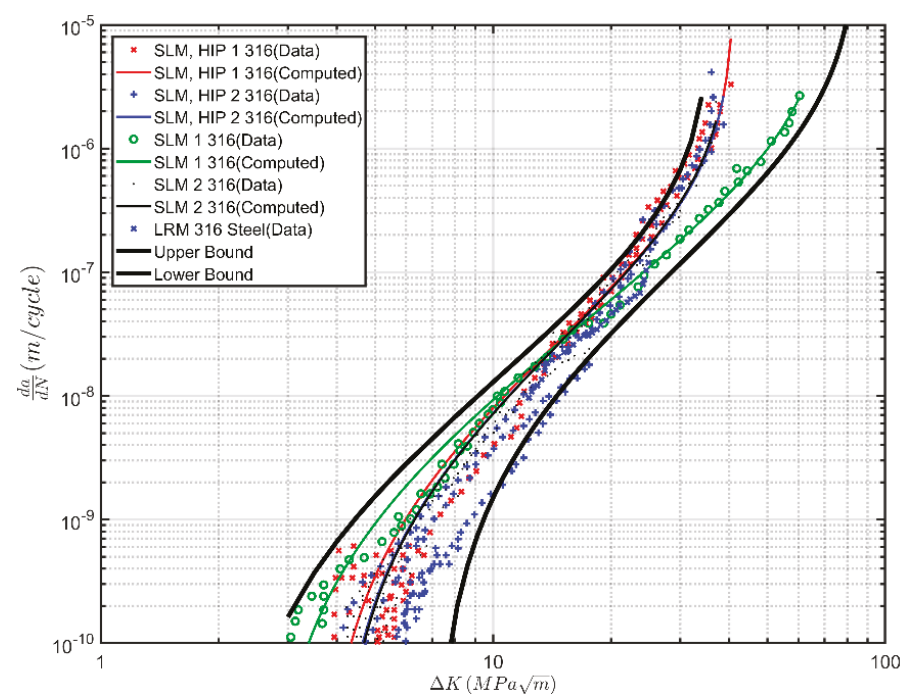

(a)

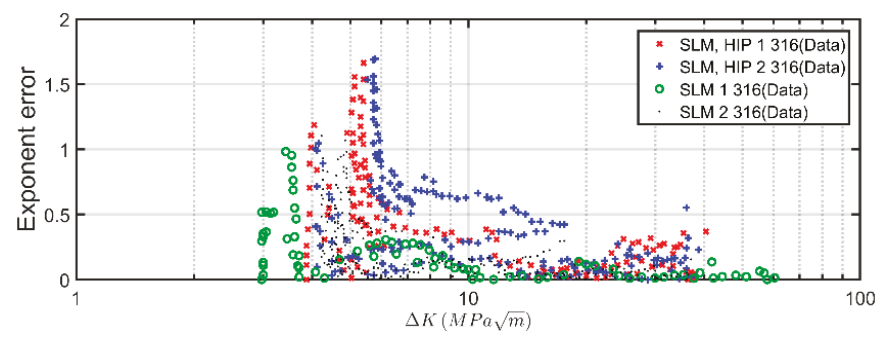

(b)

Figure 8. (a) Comparison of measured and computed curves for AM 316L; (b) Exponent error of the fitted curves as computed using Equation (5). Index "1" indicates crack growth parallel to the build direction, while index " 2 " indicates crack growth perpendicular to the build direction.

Table 5. Values of $\Delta K_{t h r}$ and $A$ used in Figure 7.

\begin{tabular}{ccc}
\hline $\boldsymbol{R}$ Ratio & $\boldsymbol{\Delta} \boldsymbol{K}_{\text {thr }}(\mathbf{M P a} \sqrt{\mathbf{m}})$ & $\boldsymbol{A}(\mathbf{M P a} \sqrt{\mathrm{m}})$ \\
\hline 0.1 & 11.1 & 69 \\
0.3 & 8.0 & 69 \\
0.5 & 6.2 & 69 \\
\hline
\end{tabular}

Figure 8 also contains the measured [47] $R=0.3$ tests on AM 316L steel specimens manufactured using laser rapid manufacturing (LRM), which employs a high-power laser beam to melt and deposit the raw material (in the form of wire or powder) in a layer-by-layer manner to build-up a three-dimensional functional component of desired geometry. The corresponding computed curves are also shown. The values of $A$ and $\Delta K_{t h r}$ used in Figure 8 are given in Table 6 . Figure 8 also contains lower and upper bound predictions, and the corresponding values of $A$ and $\Delta K_{t h r}$ are also given in Table 6.

Figure 8 reveals that using the Hartman-Schijve equation for the growth of long cracks in conventionally manufactured 316L and allowing for the changes in $A$ and the threshold captures the experimental data associated with AM 316L reasonably well, as was also noted in [17]. The higher 
values of the exponent error in Figure $8 \mathrm{~b}$ can be attributed to the relative scatter of the experimental data, which is higher than that of the tests presented in the previous figures.

Furthermore, Figure 9 presents:

(a) The crack growth curves given in [47] for the $R=0.3$ tests on AM 316L steel specimens manufactured using laser rapid manufacturing (LRM).

(b) The crack growth curves given in [48] for carburized (CT) and non-treated (NT) 316L.

(c) The $R=0.05 d a / d N$ versus $\Delta K$ curves contained in the NASGRO materials data base for 316L steel in the Annealed and Fully Annealed condition.

(d) A comparison with the (long) crack growth curves presented in [44] for bridge steels, and in [49] for crack growth in the high-strength aerospace steels 4340 and D6ac steel.

(e) The $d a / d N$ versus $\Delta K$ curves associated with a "Puddle steel" that was manufactured in Europe circa 1850 [50].

(f) The predicted crack growth curves for test specimen SLM1 and the predicted upper and lower bound curves shown in Figure 8.

Figure 9 reveals that despite the differences in yield stress and microstructure, the $d a / d N$ versus $\Delta K$ curves associated with these very different steels largely fall between the upper and lower bound predictions.

Table 6. Values of $\Delta K_{t h r}$ and $A$ used in Figure 8.

\begin{tabular}{|c|c|c|}
\hline$R$ Ratio & $\Delta K_{t h r}(\mathrm{MPa} \sqrt{\mathrm{m}})$ & $A(\mathrm{MPa} \sqrt{\mathrm{m}})$ \\
\hline HIP $1, R=-1$ & 3.57 & 20.7 \\
\hline $\mathrm{HIP} 2, R=-1$ & 3.88 & 20.7 \\
\hline $\operatorname{SLM} 1, R=-1$ & 2.59 & 37 \\
\hline $\operatorname{SLM} 2, R=-1$ & 3.92 & 20.4 \\
\hline Upper bound prediction & 2 & 20 \\
\hline Upper bound prediction & 7 & 45 \\
\hline
\end{tabular}

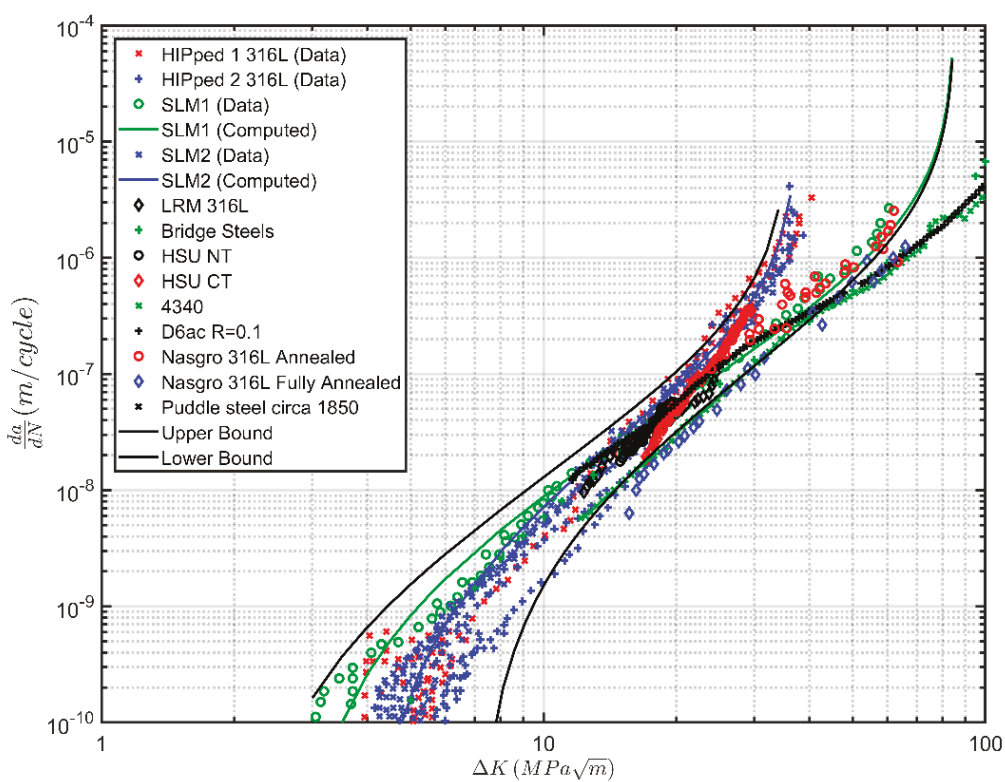

Figure 9. Measured and computed growth in AM 316L specimens. 


\subsection{AM AerMet100 Steel}

AerMet 100 is widely used for landing gear and fasteners. It is an interesting material in that in the Paris region, it shows very little $R$ ratio dependency and is relatively unaffected by the test environment [51]. This is shown in Figure 10, which presents the $R=0.3$ and 0.5 data obtained by the US Navy [51] for tests performed in both dry hydrogen and in a $3.5 \% \mathrm{NaCl}$ environment. For comparison, Figure 10 also reveals that the AerMet $100 \mathrm{da} / \mathrm{dN}$ versus $\Delta K$ curves are quite similar to that of D6ac steel (which as shown in [49] is also essentially $R$ ratio independent), and the bridge steel $d a / d N$ versus $\Delta K$ master curve.

The resultant $d a / d N$ versus $\left[\frac{\Delta K-\Delta K_{t h r}}{\sqrt{ }\left\{1-K_{\max } / A\right\}}\right]$ curves are shown in Figure 11 . This yields $D=5.06 \times$ $10^{-10}$ and $p=1.81$. The values of $A$ and $\Delta K_{t h r}$ used in Figure 11 are listed in Table 7 . The resultant crack growth equation for conventionally manufactured AerMet 100 steel is:

$$
\frac{d a}{d N}=1.49 \times 10^{-10}\left(\frac{\Delta K-0.1}{\sqrt{\left(1-\frac{K_{\max }}{A}\right)}}\right)^{1.99}
$$

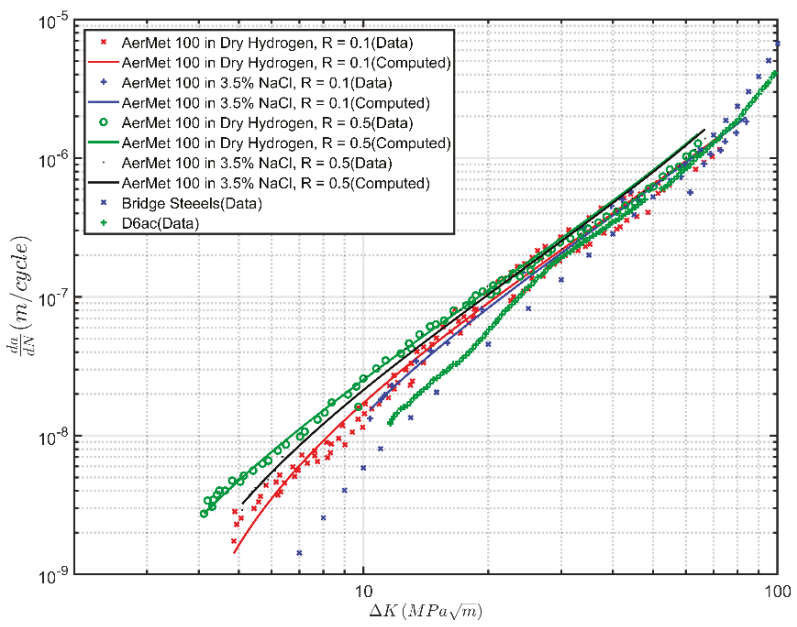

(a)

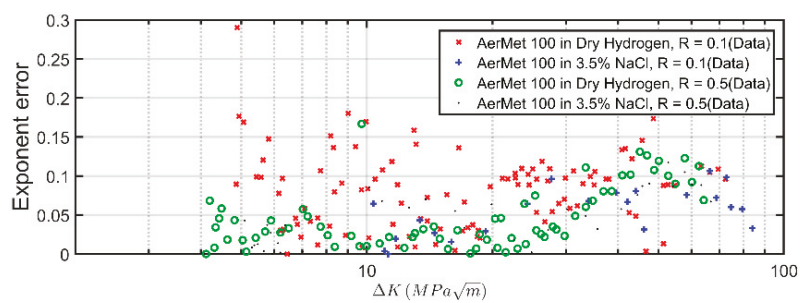

(b)

Figure 10. (a) Measured and computed growth in conventionally manufactured AerMet 100 and comparison with crack growth curves for D6ac steel and bridge steels; (b) Exponent error of the fitted curves as computed using Equation (5). 


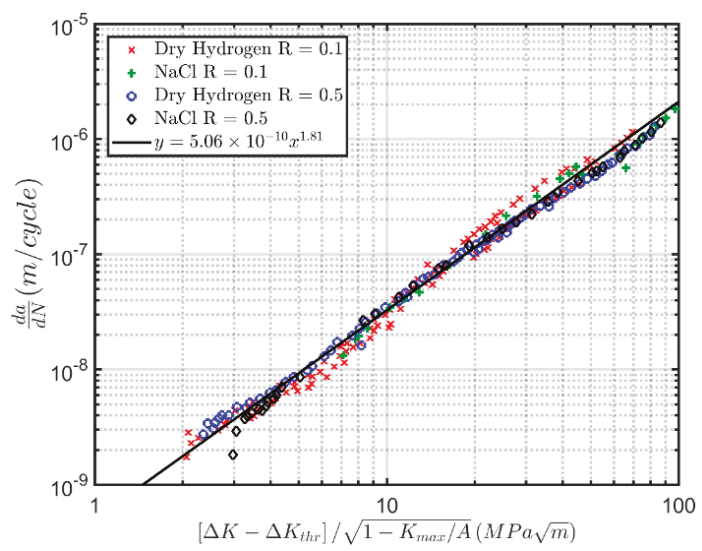

Figure 11. Plot of $d a / d N$ versus $\frac{\Delta K-\Delta K_{\text {thr }}}{\sqrt{1-K_{\max } / A}}$ for $R=0.1$ and 0.5 .

Table 7. Values of $\Delta K_{t h r}$ and $A$ used in Figures 11 and 12.

\begin{tabular}{ccc}
\hline Test & $\Delta K_{t h r}(\mathbf{M P a} \sqrt{\mathbf{m}})$ & $A(\mathbf{M P a} \sqrt{\mathbf{m}})$ \\
\hline US Navy Tests [51]: & & \\
$R=0.1$, dry hydrogen & 3.11 & 300 \\
$R=0.1,3.5 \%$ NaCl & 3.89 & 300 \\
$R=0.5$, dry hydrogen & 1.61 & 300 \\
$R=0.5,3.5 \%$ NaCl & 2.36 & 300 \\
\hline From [52]: & 5 & $300^{*}$ \\
AM AerMet 100, CG-TM [52] & 5 & $300^{*}$ \\
AM AerMet 100, FG-TM & 7.5 & $300^{*}$ \\
AM AerMet 100, FG-TM-HRA & 5
\end{tabular}

\footnotetext{
* Having determined a value of $A=300 \mathrm{MPa} \sqrt{\mathrm{m}}$ for conventionally manufactured AerMet 100, it was logical to first assess if, when using that value, the computed $d a / d N$ versus $\Delta K$ curves associated with AM AerMet 100 were in reasonable agreement with the measured curves. Since they were, see Figure 12, no attempt was made to refine the value of $A$.
}

Figure 10 reveals that, with the values of $A$ and $\Delta K_{\text {thr }}$ given in Table 7, the AerMet $R=0.1$ and 0.5 crack growth curves can be reasonably well represented by Equation (8), and that the variation in the $d a / d N$ versus $\Delta K$ curves is captured reasonably well by allowing the term to vary from 1.6 to 3.9 $\mathrm{MPa} \sqrt{\mathrm{m}}$; see Table 7 .

Having characterized crack growth in conventionally manufactured AerMet 100, let us next examine crack growth in AM AerMet 100 [52]. The $R=0.1 d a / d N$ versus $\Delta K$ curves presented in [52] for Laser additive manufacturing (LAM) AerMet 100 are shown in Figure 12. Three different heat treatments were used. The heat treatment procedures resulted in three kinds of heat-treated microstructures, viz:

1. Coarse Grain Tempered Martensite microstructure (CG-TM);

2. Fine Grain Tempered Martensite microstructure (FG-TM);

3. Fine Grain Tempered Martensite microstructure with High contents of Retained Austenite (FG-TM-HRA).

Figure 11 also presents a comparison of the crack growth curves for conventionally manufactured D6ac steel and bridge steels with the computed curves for the AM AerMet 100 obtained using Equation (8) together with the values of $A$ and $\Delta K_{t h r}$ given in Table 7. Here we see that the coarse and fine grain microstructures essentially exhibit the same performance, and that they are in reasonably good agreement with the computed curves. As a result, Figure 11 only presents the computed curve 
for the FG material. We also see that the AM AerMet $100 d a / d N$ versus $\Delta K$ curves are similar to the $d a / d N$ versus $\Delta K$ curves associated with crack growth in both D6ac and bridge steels.

Figure 12 also indicates that using the Hartman-Schijve representation for the growth of long cracks in conventionally manufactured AerMet 100 and allowing for the changes in $A$ and $\Delta K_{t h r}$ captures the experimental data associated with AM AerMet 100 quite well.

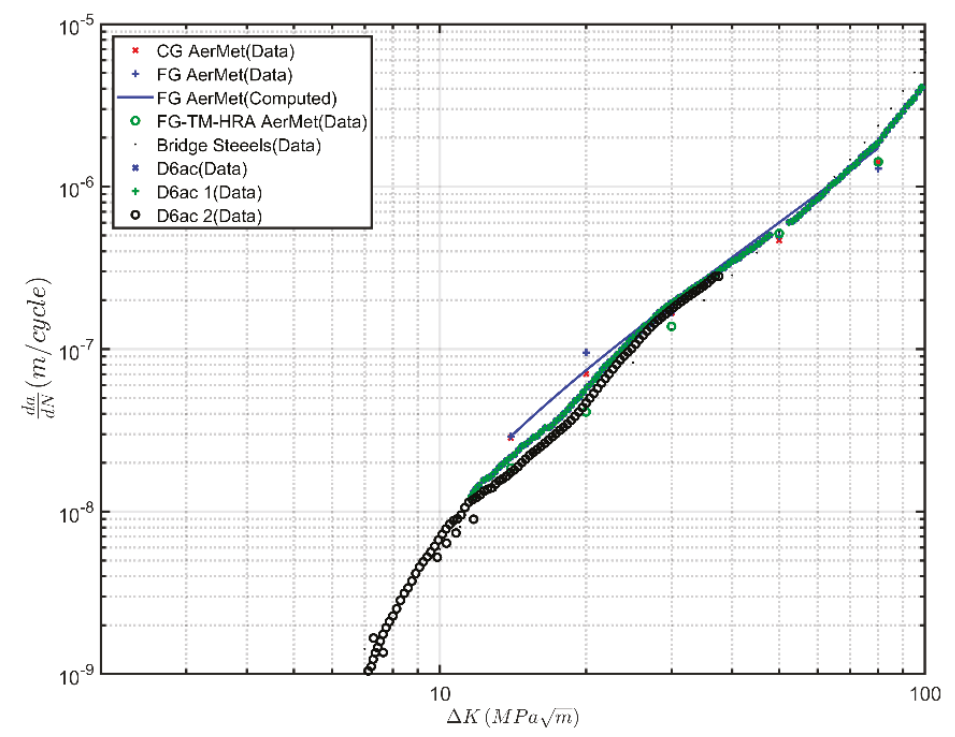

Figure 12. Measured and computed $R=0.1$ crack growth curves for additively manufactured AerMet 100 and comparison with the crack growth curves for conventionally manufactured AerMet 100, D6ac steel and bridge steels.

\section{Conclusions}

This paper has examined crack growth in three different additively manufactured aerospace materials. It is shown that, in each case, the various $d a / d N$ versus $\Delta K$ curves can be represented reasonably well by the Hartman-Schijve variant of the NASGRO crack growth equation. It is also shown that, as first revealed in [17] for crack growth in AM Ti-6Al-4V, the variability in the various $d a / d N$ versus $\Delta K$ curves is captured reasonably well by using the curve determined for conventionally manufactured materials and allowing for changes in the threshold and the cyclic fracture toughness terms.

Consequently, noting that

1. it is now known that the effects of micro-structure on the growth of small sub-mm naturally occurring cracks in conventionally manufactured aerospace materials is often small [16];

2. that crack growth in conventionally manufactured and AM materials appears to be able to be modelled using the Hartman-Schijve crack growth equation, i.e., Equation (1); and

3. that the growth of small cracks in LENS Ti-6Al-4V can be reasonably well predicted using the long crack Hartman-Schijve representation and setting the threshold term $\Delta K_{\text {thr }}$ to a small value.

It is hypothesized that, in Regions I and II, the effect of different microstructures on the growth of naturally occurring sub-mm cracks in AM materials may also be small. This hypothesis needs to be evaluated further via tests on small naturally occurring cracks in AM materials.

If this hypothesis is true, and noting that for small naturally occurring cracks in operational aircraft, the fatigue threshold is likely to be small, then the next question to be addressed is: What is the effect of the variability in the cyclic fracture toughness $A$ on the fatigue life of AM parts in 
operational aircraft. In this context, E647-13a notes that for conventionally manufactured materials, the majority of the operational life of a structure is consumed in the short/small crack regime, and that for such naturally occurring cracks, the fatigue threshold is small. Consequently, for conventionally manufactured materials, the effect on total life of the variability in the apparent toughness term $A$ is generally small. In contrast, for AM materials, the variability in $A$ can be quite large. This realization can result in a significant but informed AM part design process and subsequent maintenance cycle specification. In particular, the stochastic variability of the cyclic fatigue threshold can be determined, and appropriate reliability metrics can be incorporated in the design. The relevant metrics can then be used to establish maintenance specifications that include AM part lifetime predictions and replacement timelines. An additional extension can include studies that correlate the cyclic fatigue fracture toughness and the static fracture toughness. This correlation could lead to a significant reduction in the time needed to perform experimental determination of the fatigue crack life of the AM part. It is thus apparent that the effect of this (large) variability in the cyclic fracture toughness $(A)$ on the fatigue lives of AM replacement parts needs further investigation.

Author Contributions: Conceptualization, R.J.; Methodology, R.J. and A.I.; Software, A.I.; Validation, A.I., R.J., J.M. and R.K.S.R.; Data Curation, R.J.; Writing-Original Draft Preparation, R.J.; Writing-Review \& Editing, All authors.; Visualization, A.I.; Supervision, N.P., J.M. and R.J.; Funding Acquisition, J.M., R.J.

Funding: Support for this work by the Office of Naval Research through the Naval Research Laboratory's core funding was provided to co-authors A.I. and J.M.

Acknowledgments: A.I. and J.M. acknowledge support for this work by the Office of Naval Research through the Naval Research Laboratory's core funding.

Conflicts of Interest: The authors declare no conflict of interest.

\section{References}

1. Tiffany, C.F.; Gallagher, J.P.; Babish, I.V.; Charles, A. Threats to Aircraft Structural Safety, Including a Compendium of Selected Structural Accidents/Incidents; ASC-TR-2010-5002; Aeronautical Systems Center, Engineering Directorate, Wright-Patterson Air Force Base: OH, USA, 2010.

2. Jones, R.; Peng, D.; Singh, R.R.; Huang, P.; Tamboli, D.; Matthews, N. On the growth of fatigue cracks from corrosion pits and manufacturing defects under variable amplitude loading. JOM 2015, 67, 1385-1391. [CrossRef]

3. Jones, R.; Molent, L.; Barter, S. Calculating crack growth from small discontinuities in 7050-T7451 under combat aircraft spectra. Int. J. Fatigue 2013, 55, 178-182. [CrossRef]

4. Jones, R. Fatigue crack growth and damage tolerance. Fatigue Fract. Eng. Mater. Struct. 2014, 37, 463-483. [CrossRef]

5. Jones, R.; Matthews, N.; Baker, A.; Champagne, V. Aircraft Sustainment and Repair; Butterworth-Heinemann Press: Oxford, UK, 2018, ISBN 9780081005408.

6. ASTM Standard E647-13a Standard Test Method for Measurement of Fatigue Crack Growth Rates; ASTM International: West Conshohocken, PA, USA, 2013.

7. Berens, A.P.; Hovey, P.W.; Skinn, D.A. Risk Analysis for Aging Aircraft Fleets-Volume 1: Analysis; WL-TR-91-3066; Flight Dynamics Directorate, Wright Laboratory, Air Force Systems Command, Wright-Patterson Air Force Base: OH, USA, 1991.

8. Barter, S.A.; Molent, L.; Wanhill, R.H. The lead crack lifing framework. Int. J. Fatigue 2012, 41, 1-198.

9. Molent, L.; Jones, R. A Stress versus Crack Growth Rate Investigation (aka Stress-Cubed Rule). Int. J. Fatigue 2016, 87, 435-443. [CrossRef]

10. Jones, R.; Peng, D.; McMillan, A. Crack growth from naturally occurring material discontinuities. In Aircraft Sustainment and Repair; Jones, R., Matthews, N., Baker, A.A., Champagne, V., Jr., Eds.; Butterworth-Heinemann Press: Oxford, UK, 2018; Chapter 5, pp. 129-190. ISBN 9780081005408.

11. Forman, R.G.; Mettu, S.R. Behavior of Surface and Corner Cracks Subjected to Tensile and Bending Loads in Ti-6Al-4V Alloy. In Fracture Mechanics 22nd Symposium, ASTM STP 1131; Ernst, H.A., Saxena, A., McDowell, D.L., Eds.; American Society for Testing and Materials: Philadelphia, PA, USA, 1992. 
12. Ritchie, R.O.; Yu, W.; Blom, A.F.; Holm, D.K. An analysis of crack tip shielding in aluminium alloy 2124: A comparison of large, small through-crack and surface fatigue cracks. Fatigue Fract. Eng. Mater. Struct. 1987, 10, 343-363. [CrossRef]

13. Tamboli, D.; Barter, S.; Jones, R. On the growth of cracks from etch pits and the scatter associated with them under a miniTWIST spectrum. Int. J. Fatigue 2018, 109, 10-16. [CrossRef]

14. Jones, R.; Huang, P.; Peng, D. Crack growth from naturally occurring material discontinuities under constant amplitude and operational loads. Int. J. Fatigue 2016, 91, 434-444. [CrossRef]

15. Molent, L.; Jones, R. The influence of cyclic stress intensity threshold on fatigue life scatter. Int. J. Fatigue 2016, 82, 748-756. [CrossRef]

16. Jones, R.; Singh Raman, R.K.; McMillan, A.J. Crack growth: Does microstructure play a role? Eng. Fract. Mech. 2018, 187, 190-210. [CrossRef]

17. Jones, R.; Michopoulos, J.G.; Iliopoulos, A.P.; Raman, R.S.; Phan, N.; Nguyen, T. Representing Crack Growth in Additively Manufactured TI-6AL-4V. Int. J. Fatigue 2018, 111, 610-622. [CrossRef]

18. Hartman, A.; Schijve, J. The effects of environment and load frequency on the crack propagation law for macro fatigue crack growth in aluminium alloys. Eng. Fract. Mech. 1970, 1, 615-631. [CrossRef]

19. Jones, R.; Hu, W.; Kinloch, A.J. A convenient way to represent fatigue crack growth in structural adhesives. Fatigue Fract. Eng. Mater. Struct. 2015, 38, 379-391. [CrossRef]

20. Jones, R.; Kinloch, A.J.; Michopoulos, J.G.; Brunner, A.J.; Phan, N. Delamination growth in polymer-matrix fibre composites and the use of fracture mechanics data for material characterisation and life prediction. Compos. Struct. 2017, 180, 316-333. [CrossRef]

21. Yao, L.; Alderliesten, R.; Jones, R.; Kinloch, A.J. Delamination Fatigue Growth in Polymer-Matrix Fibre Composites: A Methodology for Determining the Design and Lifing Allowables. Compos. Struct. 2018, 96, 8-20. [CrossRef]

22. Jones, R.; Steltzer, S.; Brunner, A.J. Mode, I., II and mixed mode I/II delamination growth in composites. Compos. Struct. 2014, 110, 317-324. [CrossRef]

23. Jones, R.; Pitt, S.; Brunner, A.J.; Hui, D. Fatigue crack growth in nano-composites. Compos. Struct. 2013, 99, 375-379. [CrossRef]

24. Stennis to Be First Aircraft Carrier with Additive Manufacturing Lab. Available online: https:/ /insidedefense. com/daily-news/stennis-be-first-aircraft-carrier-additive-manufacturing-lab (accessed on 25 August 2018).

25. Jones, R.; Matthews, N.; Peng, D.; Phan, N.; Nguyen, T. Applications of SPD to enhance the structural integrity of corroded airframes. In Aircraft Sustainment and Repair; Jones, R.N., Matthews, A.A.B., Champagne, V., Jr., Eds.; Elsevier Butterworth-Heinemann Press: Oxford, UK, 2018; Chapter 16, pp. 863-906. ISBN 9780081005408.

26. Champagne, V., Jr.; Matthews, N.; Champagne, V., III. Introduction to Supersonic Particle Deposition. In Aircraft Sustainment and Repair; Jones, R., Matthews, N., Baker, A.A., Champagne, V., Jr., Eds.; Butterworth-Heinemann Press: Oxford, UK, 2018; Chapter 14, pp. 799-844. ISBN 9780081005408.

27. Matthews, N. Additive Metal Technologies for Aerospace Sustainment. In Aircraft Sustainment and Repair; Jones, R., Matthews, N., Baker, A.A., Champagne, V., Jr., Eds.; Butterworth-Heinemann Press: Oxford, UK, 2018; Chapter 15, pp. 845-862. ISBN 9780081005408.

28. Matthews, N.; Molent, L.; Barter, S.; Jones, R. Application of SPD to enhance the structural integrity of fuselage skins and centre barrels. In Aircraft Sustainment and Repair; Jones, R., Matthews, N., Baker, A.A., Champagne, V., Jr., Eds.; Elsevier Butterworth-Heinemann Press: Oxford, UK, 2018; Chapter 17, pp. 907-930. ISBN 9780081005408.

29. Jones, R.; Peng, D.; Matthews, N. Multiplicative Manufacturing and Aircraft Sustainment. In Aircraft Sustainment and Repair; Jones, R., Matthews, N., Baker, A.A., Champagne, V., Jr., Eds.; Elsevier Butterworth-Heinemann Press: Oxford, UK, 2018; Chapter 18, pp. 931-938. ISBN 9780081005408.

30. NAVAIR Marks First Flight with 3-D Printed, Safety-Critical Parts. NAVAIR News Release, NAVAIR Headquarters. Patuxent River, MD, USA, July 2016. Available online: http:/ / www.navair.navy.mil/index. cfm?fuseaction=home.printnewsstory\&id=6323 (accessed on 5 August 2018).

31. Li, P.; Warner, D.H.; Fatemi, A.; Phan, N. Critical assessment of the fatigue performance of additively manufactured Ti-6Al-4V and perspective for future research. Int. J. Fatigue 2016, 85, 130-143. [CrossRef]

32. Gorelik, M. Additive manufacturing in the context of structural integrity. Int. J. Fatigue 2017, 94, $168-177$. [CrossRef] 
33. Yadollahi, A.N.; Shamsaei, N. Additive manufacturing of fatigue resistant materials: Challenges and opportunities. Int. J. Fatigue 2017, 98, 14-31. [CrossRef]

34. MIL-STD-1530D; Department of Defense Standard Practice: Washington, DC, USA, 2016.

35. Maxime, L.; Éric, T.; Gilles, R. Comparison of Mechanical Properties of Additively Manufactured Ti-6Al-4V Alloy Made Using Different Manufacturing Processes. In Proceedings of the AHS International 74th Annual Forum \& Technology Display, Phoenix, AZ, USA, 14-17 May 2018.

36. Åkerfeldt, P.; Colliander, M.H.; Pederson, R.; Antti, M.L. Electron backscatter diffraction characterization of fatigue crack growth in laser metal wire deposited Ti-6Al-4V. Mater. Charact. 2018, 135, 245-256. [CrossRef]

37. Kumar, P.; Prakash, O.; Ramamurty, U. Micro-and meso-structures and their influence on mechanical properties of selectively laser melted Ti-6Al-4V. Acta Mater. 2018, 154, 246-260. [CrossRef]

38. Zhai, Y.; Lados, D.A.; Brown, E.J.; Vigilante, G.N. Fatigue crack growth behavior and microstructural mechanisms in Ti-6Al-4V manufactured by laser engineered net shaping. Int. J. Fatigue 2016, 93, 51-63. [CrossRef]

39. Walker, K.F.; Liu, Q.; Brandt, M. Evaluation of fatigue crack propagation behaviour in Ti-6Al-4V manufactured by selective laser melting. Int. J. Fatigue 2018, 104, 302-308. [CrossRef]

40. Sandgren, H.R.; Zhai, Y.; Lados, D.A.; Shade, P.A.; Schuren, J.C.; Groeber, M.A.; Kenesei, P.; Gavras, A.G. Characterization of fatigue crack growth behavior in LENS fabricated Ti-6Al-4V using high-energy synchrotron x-ray microtomography. Addit. Manuf. 2016, 12, 132-141. [CrossRef]

41. Cadario, A.; Alfredsson, B. Fatigue growth of short cracks in Ti-17: Experiments and simulations. Eng. Fract. Mech. 2017, 74, 2293-2310. [CrossRef]

42. Jha, S.K.; John, R.; Larsen, J.M. Incorporating small fatigue crack growth in probabilistic life prediction: Effect of stress ratio in Ti-6Al-2Sn-4Zr-6Mo. Int. J. Fatigue 2013, 51, 83-95. [CrossRef]

43. Wang, K.; Wang, F.W.; Cui, W.; Hayat, T.; Ahmad, B. Prediction of short fatigue crack growth of Ti-6Al-4V. Fatigue Fract. Eng. Mater. Struct. 2014, 37, 1075-1086. [CrossRef]

44. Ali, K.; Peng, D.; Jones, R.; Singh, R.R.K.; Zhao, X.L.; McMillan, A.J.; Berto, F. Crack growth in a naturally corroded bridge steel. Fatigue Fract. Eng. Mater. Struct. 2017, 40, 1117-1127. [CrossRef]

45. Alpas, A.T.; Edwards, L.; Reid, C.N. The effect of R-ratio on near threshold fatigue crack growth in a metallic glass and a stainless steel. Eng. Fract. Mech. 1990, 36, 71-92. [CrossRef]

46. Riemer, A.; Leuders, S.; Thone, M.; Richard, H.A.; Troster, T.; Niendorf, T. On the fatigue crack growth behavior in 316L stainless steel manufactured by selective laser melting. Eng. Fract. Mech. 2014, 120, 15-25. [CrossRef]

47. Ganesh, P.; Kaul, R.; Sasikala, G.; Kumar, H.; Venugopal, S.; Tiwari, P.; Rai, S.; Prasad, R.C.; Kukreja, L.M. Fatigue Crack Propagation and Fracture Toughness of Laser Rapid Manufactured Structures of AISI 316L Stainless Steel. Metallogr. Microstruct. Anal. 2014, 3, 36-45. [CrossRef]

48. Hsu, J.-P.; Wang, D.; Kahn, H.; Ernst, F.; Michal, G.M.; Heuer, A.H. Fatigue crack growth in interstitially hardened AISI 316L stainless steel. Int. J. Fatigue 2013, 47, 100-105. [CrossRef]

49. Forth, S.C.; James, M.A.; Newman, J.A.; Everett, R.A., Jr.; Johnston, W.M., Jr. Mechanical Data for Use in Damage Tolerance Analyses; NASA/TM-2004-213503 and ARL-TR-3375; NASA Technical Reports Server (NTRS): Washington, DC, USA, 2014.

50. Lesiuka, G.; Szatab, M.; Correiac, J.A.F.O.; De Jesus, A.M.P.; Berto, F. Kinetics of fatigue crack growth and crack closure effect in long term operating steel manufactured at the turn of the 19th and 20th centuries. Eng. Fract. Mech. 2017, 185, 160-174. [CrossRef]

51. Lee, E.U. Fatigue Crack Growth in AerMet 100 Steel; Report No. NADC-91111-60; Naval Air Development Center: Warminster, PA, USA, 1991.

52. Ran, X.Z.; Liu, D.; Li, J.; Wang, H.M.; Cheng, X.; Zhang, J.K.; Tang, H.B.; Liu, X. Effects of microstructures on the fatigue crack growth behavior of laser additive manufactured ultrahigh-strength AerMet100 steel. Mater. Sci. Eng. A 2018, 721, 251-262. [CrossRef]

This article is published under the terms of the free Open Government License, which permits unrestricted use, distribution and reproduction in any medium, provided the original author and source are credited. See http:/ / www.nationalarchives.gov.uk/doc/ open-government-licence/open-government-licence.htm. 


\title{
Damage Localization in Composite Structures Using a Guided Waves Based Multi-Parameter Approach
}

\author{
Vittorio Memmolo ${ }^{*}+$, Natalino D. Boffa, Leandro Maio, Ernesto Monaco and Fabrizio Ricci \\ Department of Industrial Engineering-Aerospace Division, Università degli Studi di Napoli Federico II, \\ Via Claudio 21, 80125 Napoli, Italy; natalinodaniele.boffa@unina.it (N.D.B.); leandro.maio@unina.it (L.M.); \\ ermonaco@unina.i (E.M.); fabricci@unina.it (F.R.) \\ * Correspondence: vittorio.memmolo@unina.it; Tel.: +39-081-768-3576 \\ $+\quad$ The author has been awarded the 2017 Aerospace Travel Award for his research on reliable solutions for \\ structural health monitoring of complex composite structures using guided waves.
}

Received: 19 September 2018; Accepted: 16 October 2018; Published: 19 October 2018

\begin{abstract}
Aerospace vehicles are demanded to withstand harsh conditions with a low weight impact. Composites have been increasingly adopted to meet such performances but they are affected by sudden and barely visible failures when subjected to low velocity impacts. The design criteria and the maintenance tasks in a damage tolerant approach are unavoidably compromised. Structural Health Monitoring is expected to avoid typical accommodations employed during design and lifetime management by achieving a cost-effective and on condition maintenance. This paper describes the use of guided ultrasonic waves excited and sensed by permanently attached piezoelectric transducers for detection and localization of unforeseen and hidden flaws in composite structures. A composite stiffened structures designed for real scale components is investigated to test a multi-parameter detection technique capable of predicting different wave features affected by hidden failures to detect any possible change in the structure. Usually, propagation behavior is exploited to detect changes in the waveguide focusing on the analysis of an intrinsic feature of the propagating wave. Numerical simulations and measurements carried out on a real-scale aircraft structure demonstrate that increasing the observed characteristics improves the result making efficient the diagnosis. Furthermore, it is shown that accounting a multi-parameter analysis of ultrasonic data enhances the localization reliability making use of the same reconstruction algorithm with data fusion approach while facing with different kind of damages.
\end{abstract}

Keywords: aerospace structures; composites; impact detection; structural health monitoring; guided waves

\section{Introduction}

Performances are key concerns in the field of transportation engineering where aerospace vehicles require safer structures with as little consumption as possible. To achieve higher performances with lighter components, composite materials replaced classic aluminum alloys even in primary structures. An important aspect consists of the flexible design of the structure according to tailorable properties of composite materials [1], making them even more efficient for load cases and conditions typically withstood by aerostructures [2]. Moreover, aircrafts made of composites require far fewer parts, so there is less to bolt together and the possibility to create structural components with fewer connections possible. Looking for operational efficient aircrafts, the use of composites improves passenger comfort. Furthermore, composites are even tougher than aluminum alloys and the higher durability should allow maintenance costs to be much lower than for aluminum planes.

However, random events such as certain low velocity impacts may induce damages which are typically more severe and even less visible than in metals [3]. The mixed crack-delamination evolution characterizing the impact mechanics of composites results in a very small surface indentation 
even when the through thickness damage is much greater than an emerging flaw. The damage tolerance approach, which usually avoids rough safety factors in favor of inspection procedures and structural design concepts to protect safety [4], introduces a sort of "defect" factor based on degree of detectability for establishing minimum damage tolerance residual strengths for composite structures [5]. Such residual strength is that connected with external visibility, much lower than the material ultimate strength. To accomplish the presence of hidden failures due to barely visible damages, the design strain level is knocked down for both ultimate and limit combined load [6]. According to Boeing design manuals and military handbooks [4], the design limit allowable $s_{\text {d.l.a. }}$ can be calculated for first approximation introducing a scatter to the ultimate material allowable $s_{\text {m.u.a. }}$ as follows:

$$
s_{\text {d.l.a. }}=0.5 \times s_{\text {m.u.a. }}
$$

where the major part of such knockdown factors results from impact induced residual strength.

In addition, stringers are adopted for reinforcing thin walled structures and lightening aeronautical components [2]. When subject to low energy impacts, disbondings may appear; the punctual load leads to complex damage mechanics resulting in the separation between the stringer and the hosting structure which prevents the collaboration between parts with a dangerous drawback for loading absorbing. To avoid separations overcoming the ultimate length of disconnection, ensuring that stiffeners and skin are collaborating properly, such disbonding stoppers are usually included into the design [6]. In fact, connections are indeed necessary where the introduction of composites would avoid or limit any type of connection between different parts to reduce weight as well as manufacturing and maintenance costs.

This rough damage tolerance approach therefore further breaks down the benefits encouraging composites introduction. That is where an integrated structure providing monitoring of critical components can limit the design allowables to the residual stress or strain associated to the minimum detectable instead of minimum visible damage. Although this is a very long-term perspective, the introduction of an effective SHM system may completely change the maintenance strategies which are actually based on different level of inspections targeted to ensure safety according to the damage tolerance design criteria. An integrated on demand inspection allowing condition-based maintenance can increase safety and reduce the aircraft downtime as well [7]. The European Union itself is deeply involved in research programs dedicated to achieving low-weight aircraft configurations in which the continuous monitoring is a key concept [8-10]. In fact, SHM integration would enable the reduction of in-service inspection costs of up to $1 \%$ for defect critical structures.

Using permanently distributed sensors, several approaches may be used to interrogate or extract sensitive data from the integrated structure [11]. Among various techniques, wave propagation or guided ultrasonic waves (GUWs) techniques respond to the requirements for an integrated and self-sensed structure. They exploit the propagation and reflection of elastic ultrasonic waves in solids with the assumption that a hidden flaw in the structure alters their behavior [12]. The pitch-catch techniques allow excitation of elastic waves at one location (pitch), and sensing at a different location (catch) by employing piezoelectric devices. Damage and its severity along the wave propagation path is detected by examining such response in terms of wave characteristics.

It is worth noting that the complex propagation behavior makes reconstructing the real wavefield from limited resources, namely the few single sensing points, quite difficult. Instead, wave parameters (signal responses) likely affected by hidden changes in structural characteristics (i.e., damage scenario) need to be analyzed for damage detection. In addition, propagation complexities introduced by composites [13] do not allow efficiently using model based approaches. A possible failure would be detected directly comparing one or more of such parameters with scheduled intervals towards a "pristine (healthy) configuration". The comparative analysis provides information about hidden flaws by means of damage indicators as assessment metrics. Practically, a damage index close to zero suggests undamaged/healthy structure. Otherwise, a flaw indicator higher than a certain threshold warns such a failure. Namely, damage metrics are used to correlate wave behavior to waveguide anomalies 
because the response of the structure is not predictable while considering impact on composites [14] and different features can be extracted as signal response to track changes within the waveguide [15]. Likewise, many algorithms [16,17] and signal processing techniques [18,19] are tailored to work while varying operative conditions [20] and temperatures [21] are implemented for efficiently monitoring maintenance-critical structures.

Damage diagnosis is quite complex and strongly affects the remaining life of the structure. Detection stage is crucial mostly because its reliability allows the further diagnosis stages including localization and characterization. The target of the system, defined as minimum flaw size detectable with a certain confidence level, is the key application concern. The Probability of detection analysis [22] is usually extended to SHM systems to approach this kind of problems. The system quantification appears mostly affected by the decision level [23] and a threshold identifying technique cannot be demanded to operator expertise. Unsupervised [24,25] or supervised [26] data processing have been proposed and can be addressed to enhance the aircraft lifetime management as well [27]. Likewise, the signal response can be statistically related to the flaw size to assess the severity and size of damage from damage indicator $[22,28]$. Hence, a system efficiently warning hidden failures can simultaneously return the severity of damage. Instead, the flaw localization needs an algorithm opportunely sorting the data to reconstruct the damage risk.

To achieve the comprehensive diagnosis is crucial to: (i) establish a signal response (metric) likely affected by flaw occurrence and directly related to its severity; and (ii) locate the damage estimating at least its coordinates in 2D system. For the first item, the application needs to be known a priori. Aircrafts show typical damage scenario dealing with low velocity impact induced failures, whose characteristics mainly depend upon the the impact location. Typically, delaminations and disbondings are mostly arising, respectively, through multilayered composites at the interface between two adjacent layers with different fiber orientation and between thin stringer and hosting structure. Consequently, a SHM methodology aiming to discover and characterize impact induced damages should be able to monitor both events. To achieve this goal, a guided wave based multi-path damage detection approach with multi-parameter capabilities is presented and validated in this work. The reconstruction algorithm, where different features are simultaneously extracted from the propagating waves, is indeed able to enhance the detectability of several types of damages by using a single detection framework where the detection is operated via statistical approaches.

\section{Materials and Methods}

One of the major concerns in SHM is to define an algorithm to relate one or more wave features (signal response) to damage features (diagnosis) in relation to the desired level of inspection. In this context, the approach proposed is dedicated to detect and localize damages analyzing direct propagating waves resorting to a distributed array of ultrasonic sensors. All relevant aspects are here detailed and a few preliminary results are discussed to highlight critical points, improvements and capabilities of the resulting methodology, which has been widely validated on several real scale structures with different damage scenarios.

\subsection{Flaw Detection Using Direct Propagating Waves}

The detection and localization procedure adopted here requires the ultrasonic interrogation in "pitch-catch" mode in different operative conditions where the main activities involved can be grouped in:

- data acquisition, where the guided waves are recorded during aircraft parking according to the interrogation mode and stored for analysis;

- data processing, which deals with the analysis of stored data to extract features possibly affected by the damage (signal response);

- decision-making process, where the minimum metric associated to a damage with a reasonable confidence is established; and 
- damage reconstruction, which deals with all algorithms aimed at a certain diagnosis, no matter what is the level of the estimation.

Data acquisition and data processing are mostly related to the wave propagation behavior while the decision and reconstruction process is strongly related to the reconstruction algorithm adopted. Discussion about data acquisition is here limited to the description of the measurement setup. However, it is worth noting that the critical issue is the correct sampling of the guided waves related to the acquisition and analog to digital (receivers) and digital to analog (transmitter) conversion. In fact, a poor resolution of time histories reduces the system capabilities. The second item is related to several signal processing techniques to establish characteristic features of propagating wave which reveal the interaction with damage [29]. Instead, the latter items are crucial to select all useful data among those processed and to correctly relate the signal responses to damage features (e.g., occurrence, position, severity, dimension), as described hereinafter.

\subsection{Ultrasonic Metrics}

For the sake of the simplicity, it can be asserted that the propagation is always affected while a detectable damage is encountered. However, non-isotropic media are quite complex waveguides $[13,30]$ making relating time histories caught in a few single sensing points to propagation, interaction with, and scattering from such a hidden flaw challenging. As highlighted in Figure 1 for a pitch-catch approach, the acquired signals are merely a synthesis of the wave propagation, which is reflected in the time history of the high frequency vibration affecting the receiver. Ultrasonic propagation needs the analysis of specific features (signal responses according to [22]) likely affected by unforeseen failure. Data analysis from rough signals is a key step for operating an identification system properly. The appropriate signal processing technique extracts features from the sensor array and translates the information gathered from single points into a diagnosis including location and/or severity of damage [31].

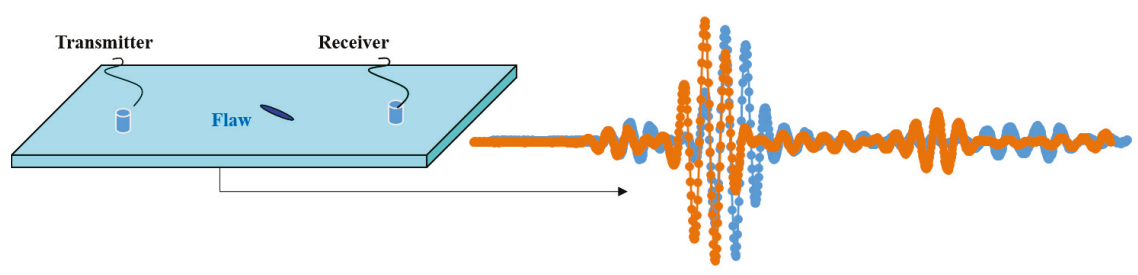

Figure 1. Lamb waves response sensed using pitch-catch approach as a synthesis of wave propagation.

In fact, the accuracy and precision of a GUWs-based damage identification approach depends on the signals captured by several sensors and it is largely subject to their processing and interpretation. Efficient data processing while using limited resources is demanded to catch crucial yet concise features from raw signals which are expected to further provide the damage assessment. While the latter demand deals with the algorithms able to relate signal responses to damage parameters, such parameters have to be correctly addressed. Several signal processing techniques can be exploited in relation to the wave feature selected. Such selection depends primarily upon the type of damage to investigate while interrogating the structure. An impact induced damage can indeed be idealized as a complex discontinuity distributed through the thickness changing the waveguide characteristics [32]. Lamb waves are quite dispersive at certain frequencies and the interaction with local damage can lead to a different arrival time with respect to pristine propagation. The group velocity is strongly affected by those damages which modify the waveguide, while thickness frequency response shows a certain 
gradient. The group velocity results directly from the Time of Flight (ToF) estimating the characteristic time of the sensed $\left(\bar{t}_{s}\right)$ and excited $\left(\bar{t}_{e}\right)$ waves, respectively.

$$
T o F=\bar{t}_{s}-\bar{t}_{e}
$$

Due to the dispersion restriction, the combination of wave modes, interrogation frequency and thickness variation strongly affects the detectability varying the time of flight efficiency. Otherwise, a discontinuity in a waveguide can be modeled as an abrupt change of the local mechanical impedance [33], where the energy propagating in the media is scattered. Transmitted and received portions of the energy content of the propagating wave can be monitored using the pitch-catch approach where such a Transmission Factor (TF) identifies the hidden flaw. To obtain an interrogation-independent metric, the transmission factor is here defined as the ratio between an energy parameter $\bar{E}$ of the sensed and the excited signal, respectively:

$$
T F=\frac{\bar{E}_{s}}{\bar{E}_{e}}
$$

Both energy parameter and characteristic time can be computed by means of Short Time Fourier Transform (STFT) of the digitized signal (see Equation (4))

$$
\operatorname{STFT}\{x(t)\}(t, \omega)=X(\omega, t)=\sum_{t \rightarrow-\infty}^{+\infty} X(t) \omega(t-\tau) e^{j \omega t}
$$

where $x(t)$ is the discrete signal and $\omega(t)$ is the window function, chosen here as Hanning function, used to select a subset of samples to be further processed with Fourier transform using a certain overlap [34]. This function ensures low aliasing a with slightly lower resolution. The amplitude of the Power Spectral Density $P_{S D}$ calculated with Equation (4) identifies the energy content of the selected Lamb wave mode exploited in Equation (3) and the characteristic time exploited in Equation (2). It is worth noting that the ratio between excited and sensed wave in Equation (3) allows neglecting every dependence upon discrete transformation included in Equation (4) (e.g., $\omega(t)$ and $\tau$ ). For arrival time, the STFT approach is usually preferred because of the double feature obtained preventing further processing for cross correlation analysis which has been proven to lead to quite close results.

When the damage occurs, the wave transmitted over the flaw results from a complex interaction which is characterized by the scattering of the incident guided mode into propagating and non-propagating evanescent modes [35], including mode conversion in the case of multi-modal waves (e.g., Lamb waves). In fact, to account for every change in the complex wave packet sensed rather than the interrogating mode selected, the parameter should account for the entire diagnostic signal. For the latter demand, the wave energy $E$ is a key feature and it can be computed in its generalized version [36] analyzing the time or spectral domain following Equation (5).

$$
E=\sum_{-\infty}^{+\infty} x(t)^{2}=\sum_{-\infty}^{+\infty}|X(\omega)|^{2}
$$

Because the primary measurements acquired are time limited signals, it is worth noting that the time analysis is adopted to maximize the accuracy. In addition, sensing the wave from $t_{0}$ (trigger time) to $t_{f i n}$ (observation time), the dependences upon time limited analysis can be neglected using damage indicators as comparative features. 
The damage-related metric can be finally computed following Equation (6), where the extracted feature $f$ (scalar quantity), chosen among Equations (2), (3) and (5) or others, is evaluated on pristine $\left(f_{B}\right)$ and currently operating $\left(f_{C}\right)$ structures separately to assess the damage indicator.

$$
D I(f)=\frac{\left|f_{C}-f_{B}\right|}{f_{B}}
$$

\subsection{Multi-Path Reconstruction Principles}

When the features are extracted from wave signals, a key procedure regards the decision making approach, where the changes detected in the guided waves are defined sufficient enough to identify any damage. The autonomous identification of failure is itself the determination of a threshold level efficiently warning the presence of damage. Hence, a non-arbitrary decision procedure which does not rely on the expertise of any operator is crucial. The results below the decision level are then censured and, when available, those above the threshold are analyzed to further locate and characterize the failure.

In detail, the detection approach is based on a multi-path analysis in which lines of sight between every actuator-receiver pair are exploited to obtain a set of independent interrogations, whose post processing returns the several features described. Using a cluster with a limited number of sources, it is indeed possible to define a discrete number of paths affected by damage emerging at the surrounding area [37]. The same approach can be used also in complex structures as depicted in Figure 2 where a double-line array of sensors is adopted to monitor the stringer in a stiffened structure. If one damage indicator exceeds the threshold, the path is indeed affected by damage and classified as damaged by the system. A few selected paths are classified among all possible propagation paths using the decisional step. Those ones are used for the localization presented in Section 2.5. It is supposed that paths crossing the damages area are affected by stiffness variation which results in a different vibration response reflected within the signals. Otherwise, paths crossing far from damaged area are not affected because no stiffness variation is present. Consequently, the damage index theoretically vanishes when signals are sensed on the same structural condition. However, repeating measurements leads to slightly different results with nonzero value of DI, [38], demanding a specific decision tool using prediction techniques to define the minimum indicator value warning the presence of a damage.

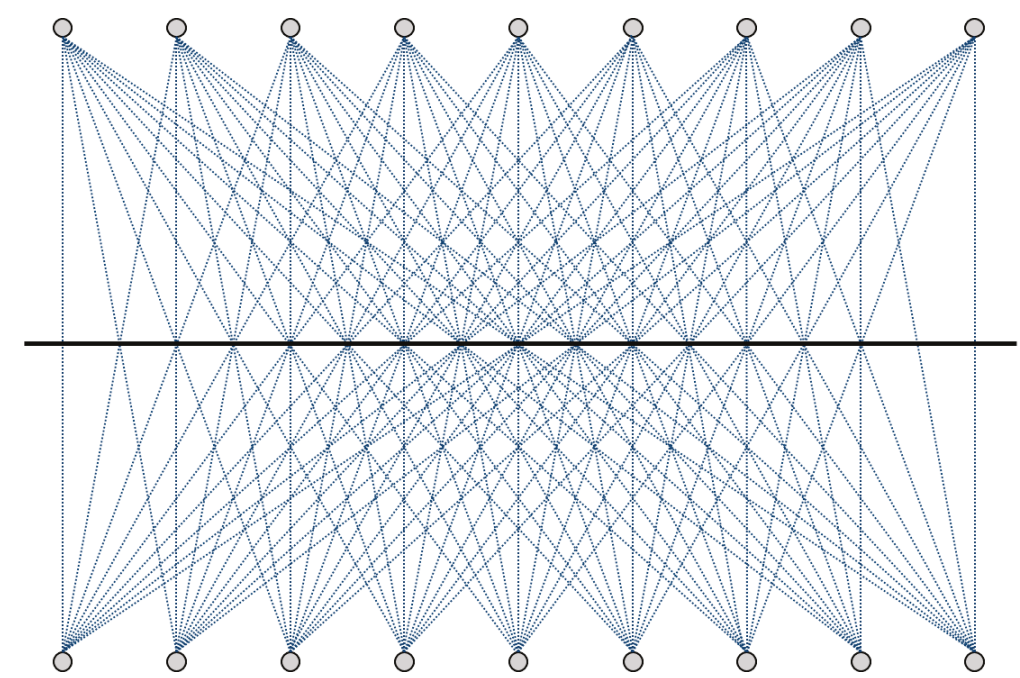

Figure 2. Transmitter-receiver paths for double-line array configuration around stringer in a stiffened structure. 


\subsection{Decision-Making Approach}

The decision-making procedure can be statistically addressed; damage detection is achieved when measurements return damage metrics exceeding the threshold according to a certain confidence level. In fact, decisional phase combines knowledge and uncertainties due to random and systematic variability in measurements. To prevent the misinterpretation of those changes revealed by the dynamic response of the structure, statistics allows the classification of the wave parameters ensuring a certain degree of confidence. Various approaches are available in the literature to define a discriminating threshold by unsupervised learning mode and using central statistics [39] or outliers analysis [24,40-42]. The main issue is to ensure that the extreme values are properly estimated because there the data from pristine and altered condition may be very close. Furthermore, threshold determination can be obtained by supervised approach using previous observations or simulations. In many investigations, disturbances resulting from inputs and environmental variation are introduced numerically to achieve the threshold level estimated in the next measurements $[26,43,44]$ at the cost of analysis which are often too much intensive.

To account such a variability due to the non-repeatability and noise of measurements, a prediction interval can be more simply estimated according to the definition of a normal distribution. In this case, an appropriate hypothesis test is required to classify the feature distribution while no damage is indeed present in the structure. The damage indicator that returns from that analysis measures the noise level instead of the damage level. Then, the Gauss bound is estimated to discern the damaged condition from the noise. When the damage is present, the feature is expected to be above the estimated upper bound level. In this context, an effective discrimination of sensitive signals can be reached even with few samples and less effort using parametric statistics such as a Kolmogorov-Smirnov test [45]. An example of such application is successfully presented in Figure 3 where the energy based metric is parametrically defined together with the threshold level, $I_{t h}$ :

$$
I_{t h}=\mu+k \cdot \sigma
$$

where $\mu$ is the estimated mean value and $\sigma$ is the estimated standard deviation of the noise. The $k$ factor defines the bounds of the prediction interval and it depends on the significance level chosen in accordance with normal distribution. With the probability of $1-\alpha$, every sample $x_{i}$ of the population $X$ (i.e., DS population) is in the range defined by statistical bounds. For the sake of the clarity, for a normally distributed noise, the threshold level fixed as $\mu+1.96 \cdot \sigma$ provides a $97.5 \%$ prediction interval. If the damage indicator lies below that value, there is $97.5 \%$ confidence in stating that no damage is indeed occurring. Likewise, a damage index higher than that limit returns a $97.5 \%$ confidence in stating that the damage is present.

This prediction analysis returns a statistically meaningful threshold only when a certain variability is present in the signal response. However, when a discrete transformation is computed (see Equation (4)), signal processing of experimental data demonstrates that uncertainties are hidden by the time-frequency discretization; the metric is classified in larger ranges whose extremes (discrete metric) prevent the statistical analysis of such data. To overcome this lack of applicability, the Acoustic Reciprocity Theorem is proposed in an unsupervised learning mode to discern noise from signal response when any variability is not identified from statistics. The Betti reciprocal theorem [2] applied to ultrasonic fields suggests that the signal response related to the direct wave should not be dependent upon the direction of wave propagation in pristine condition. Hence, exciting Lamb waves with a transducer located in A and sensing the wave propagation with the sensor located in B (see Figure 4), the system should return some features that are equal to those extracted from signal recorded by a sensor located in A while exciting propagation with a transducer located in B. 


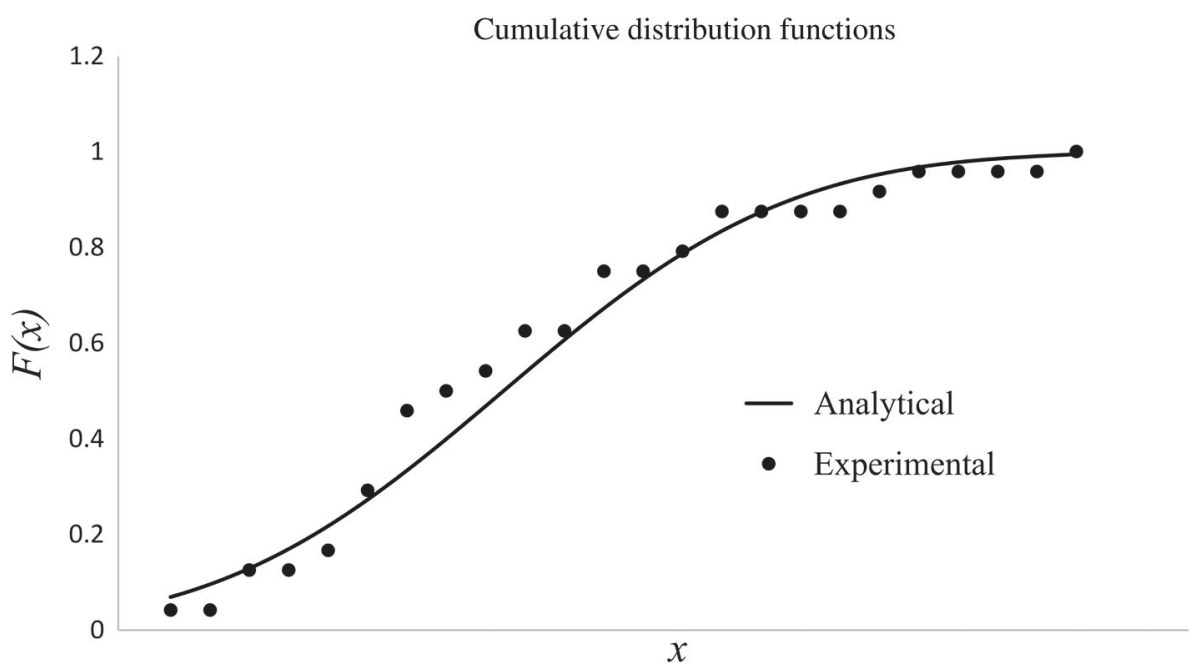

Figure 3. Kolmogorov-Smirnov testing: Comparison between analytical and experimental cumulative distribution functions of the signal response noise in a composite panel without defect [37].

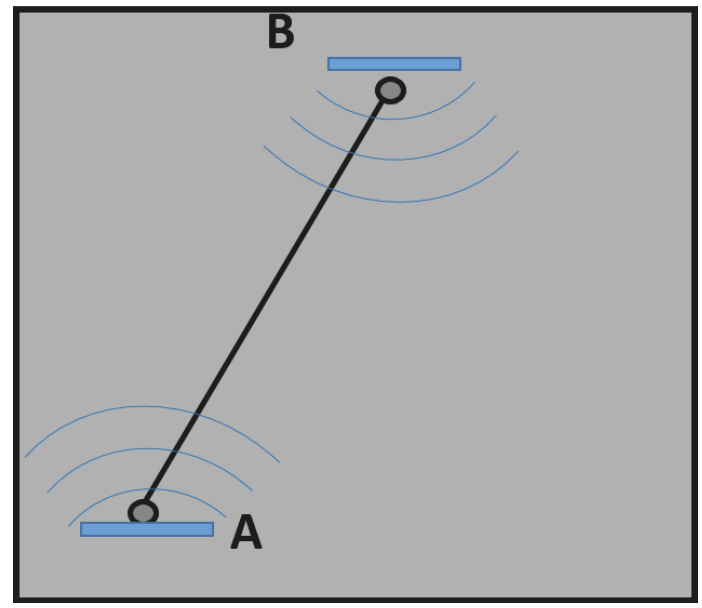

Figure 4. According to Betti reciprocal theorem applied to direct wavefield, the same relative influence is found considering $\mathbf{A}-\mathbf{B}$ and $\mathbf{B}-\mathbf{A}$ pairs.

Measurements and data processing show that this principle is not satisfied even when any damage is not indeed present in the structure [15,38]. In addition, this consideration is applied to different transmitter-sensor couples so that the lack of agreement is still present when a nearly repeatability of extracted features is obtained. Thus, the reciprocity mismatch is considered here due to such uncertainties affecting damage detection. It simply provides the decision value as the maximum difference between the same feature observed along the two propagation directions.

\subsection{Reconstruction Algorithm}

The identification of damage is the first diagnostic output achievable with a SHM system, warning the presence of a damage. With a statistical correlation, the signal response can be related to the severity of damage [22], but it does not provide any information about its location. Using several 
signal processing techniques, the detection approach described in Section 2.4 aims to select those paths affected by such a damage. The last result can be used to locate the damage using an opportune reconstruction scheme aimed to assess the risk to have a damage in a specific location. Since the identification is provided with the threshold definition, the location of damage is estimated as the location with the highest risk. The information contained after data processing is related to the paths and it is necessary to get that knowledge on the structure via developing an image depicting the position of damage. Many image techniques to investigate the region surrounded by an array of transducers have been developed in the past years in this field as reported in [46]. One of such techniques is the guided wave based tomography where certain features of a wave mode or of a sensed signal are used as input to create an image of the area for damage detection. Discretized the structure to be monitored in finite elements (see Figure 5), it is possible to define two different types of mesh: (i) the structural mesh, where the health information is desired; and (ii) the SHM mesh, where that information is primarily known. Depending on the relation between them, it is possible to broadly group several techniques in:

- mesh-based approaches, where SHM data are directly obtained on the structural mesh (i.e., the SHM mesh corresponds to the structural mesh [18]); and

- $\quad$ meshless approaches, where the SHM data are obtained in points not previously known and interpolated on the structural mesh (i.e., the SHM mesh does not match with the structural mesh [47]).

The first approach usually requires a heavy computational effort accounting for each point the effect of all possible paths resorting to a decreasing probability far from their line of sight [16].

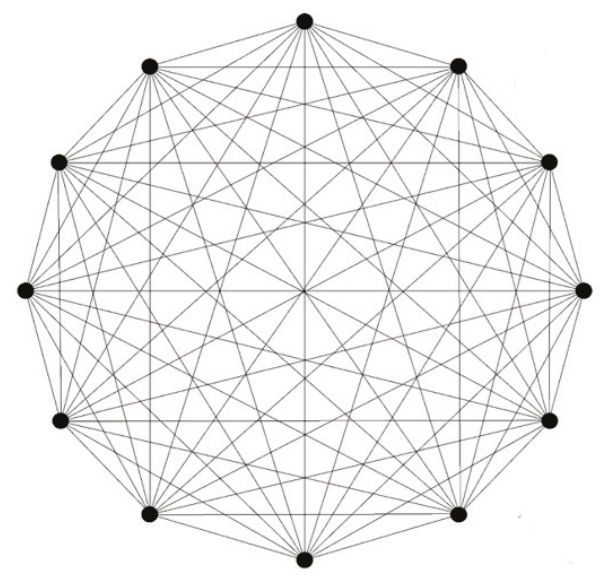

(a)

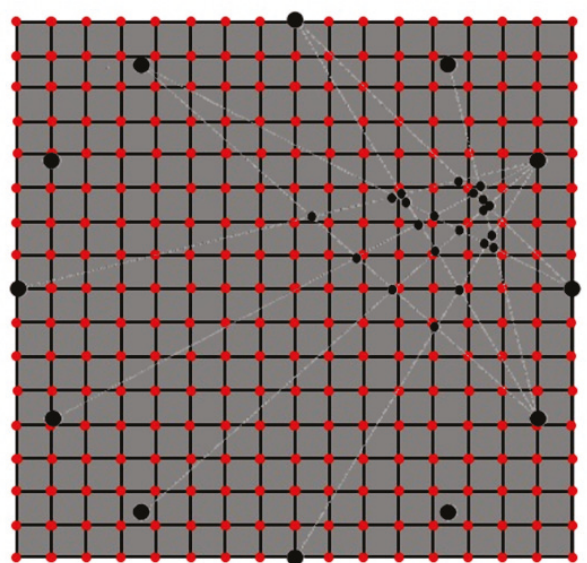

(b)

Figure 5. Circular sensors cluster with all interrogating paths (a). Representation of a typical bi-parametric structural mesh (b). Selected paths (light grey lines) and their intersections (sparse black points) are highlighted in the background.

To reduce the efforts demanded by a mesh-based probabilistic formulation, the effect of selected paths is here considered in a different way. From their intersection, few emerging points create the SHM mesh where structural condition is parameterized according the average value of DI at intersecting lines of sight. The coordinates of such resulting nodes, whose weight is the resulting DI, can be passed on to an algorithm which estimates the the impact point through such a tomographic representation of damaged area. Several image processing techniques can be exploited to portray the health status from scattered data points to the structural mesh and they can broadly classified as: 
- discrete approach;

- spatial interpolation; and

- nodal density.

With the former approach, scattered data formally constitute a discrete system. The damage location is estimated considering the centroid of the SHM mesh where he weight of every discrete point is mainly the DI which returns at the emerging node. The barycentric information is estimated first via weighted averaging algorithms. Accordingly, the damage location is then defined as the point $C G=\left(x_{C G} ; y_{C G}\right)$ in the Cartesian reference. The geometric extrapolation of the coordinates $\left(C G_{G}\right)$ is carried out as follows:

$$
x_{G}=\Sigma_{i=1}^{n} \sqrt[f_{i}]{\prod_{i=1}^{n} x_{i}^{f_{i}}}, \quad y_{G}=\sqrt[\Sigma]{i=1} \sqrt[f_{i}]{\prod_{i=1}^{n} y_{i}^{f_{i}}}
$$

while the arithmetic coordinates $\left(C G_{A}\right)$ are given by:

$$
x_{G}=\frac{\sum_{i=1}^{n} x_{i} \cdot f_{i}}{\sum_{i=1}^{n} f_{i}}, \quad y_{G}=\frac{\sum_{i=1}^{n} y_{i} \cdot f_{i}}{\sum_{i=1}^{n} f_{i}}
$$

where $f_{i}$ is the weight of the $i$ th node, namely the damage indicator.

Otherwise, considering that each node of the SHM mesh contains structural information about the surrounding area according to the emerging damage indicators, the damage can be located fitting a surface on the scattered data. The scattered data are interpolated to smooth the surface on to the supporting (structural) mesh which returns the risk to having a damage in a specific location. The highest risk is thus associated to the impact position. Likewise, the latter approach enables the density of the SHM mesh as the key feature to be interpolated and provides the damage risk. It mainly accounts that the greater is the number of points, the higher the probability is to have damage in the concerned area. Returning a sort of damage risk map, the last two approaches provide such a global reconstruction rather than merely the localization of hidden diagnosed with the first approach. In both cases, the reconstruction returns a rapidly decreasing risk moving away from the SHM mesh whose main criteria are itemized below:

1. The damage risk is estimated on the area enclosed by the sensors which are employed to set boundary conditions for the interpolation.

2. The data below the threshold do not affect the interpolation because are censured by the decision-making approach.

3. Every isolated path which is not intersecting at least another path does not affect the localization.

4. The peak of smoothed function returns the damage position whose coordinates are used to estimate the impact location.

It is worth noting that a node of the SHM mesh affects only the surrounding area according to the specific scheme adopted for the interpolation. Here, the imaging is carried out using spline-based algorithm, typically suited for image processing when few data are supposed to be available.

In the next section, several results are described. A first analysis based on numerical data is presented to demonstrate and overcome a few shortcomings of the proposed methodology. Interpolation is improved weighting the effect of DIs merging the nodal density approach to the images obtained with a single parameter interpolation. The final improvement is obtained resorting to a normalization and further data fusion to obtain the multi-path and multi-parameter approach called $M P^{2}$ and based on meshless reconstruction. The results are finally compared with those obtained using literature mesh based "benchmarks" improved by resorting to the same multi-parameter approach. After validating the reliability and efficiency of the $M P^{2}$ system, real scale structures are monitored with the $M P^{2}$ approach to detect and localize both delamination-like structures and stiffener disbondings. 


\section{Results}

\subsection{Setup}

The structural health monitoring based on guided wave propagation is here operated through several steps, which are the same whether simulations or experiments are considered. The structure is simulated/integrated with several PZTs to constitute the active diagnostic cluster of sensors where multiple datasets are then extracted. To get all data, the multipath guided wave propagation is activated first on the pristine structure and then on the current (damaged) structure. The currently operating structure is obtained by introducing a barely visible damage to simulate the airplane-in-service when cracks can initiate and propagate. The data are thus post processed with the comparative multi-parameter analysis and the damage is reconstructed where any damage indicator is found to overcome the threshold. A 4.5 sine-cycles windowed burst excited at low-ultrasound frequencies is adopted as diagnostic wave to mostly excite the $A_{0}$ mode and extract the described features. That mode is selected as interrogation mode instead of $S_{0}$ or $S H_{0}$ modes because more tuned with the type of sensors employed at low ultrasound frequencies. The sketch of the processes followed during experiments is reported in Figure 6 where the modeling of Structure, PZTs and damage is highlighted with multiple option according to how the datasets are extracted. Those are where the experiments and simulation are indeed different. To achieve a correlation between measurements and simulation, the methodology already developed for this type of damage and validated in [32] is successfully adopted.

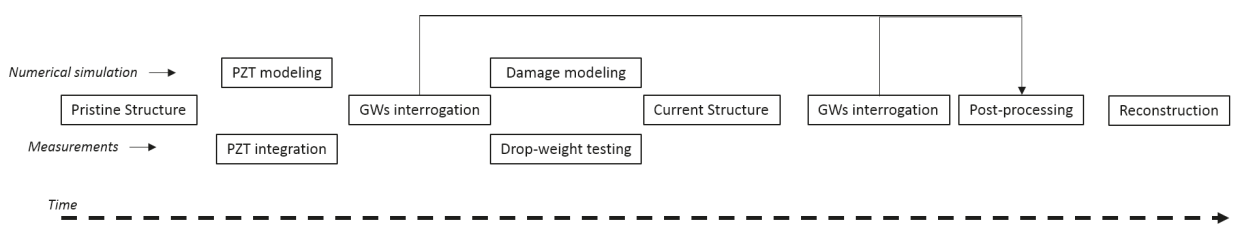

Figure 6. Scheme followed during experiment.

\subsection{Validation of Multi-Parameter Analysis}

While exciting low ultrasound, only the fundamental Lamb wave modes ( $A_{0}$ (antisymmetric) and $S_{0}$ (symmetric)) are excited. Whereas antisymmetric mode appears more tuned, group velocity and transmission factor of the $A_{0}$ mode are typically evaluated by processing recorded signals. Instead, the energy content integrated over time allows accounting for the effect of the damage on several propagating modes. Comparing signals, only a few paths among those defined by all possible sensors pairs are selected as those affected by the damage. Summarizing preliminary results for the sake of conciseness, it is worth noting that impact induced damage can be typically identified and localized using the approach proposed in the previous section even where a minimum number of emerging nodes results from decision-making approach. For several features, only the DIs higher than the respective threshold currently suggest the presence of the damage and the impact location is predicted with a negligible error compared to the size of the damage. Furthermore, the impact location predicted with discrete approach falls exactly in the area with greater probability of damage appearance.

Although a very simple, faster (compared with other image reconstruction algorithms) and effective approach has been obtained including discrete analysis and spatial interpolation to improve hidden flaw localization after the decision-making approach, few criticality aspects have been detected with the aid of numerical simulations as well.

- Phantom damages: Several spots in the image may suggest damage where no failure is present. This event happens when few nodes in the SHM mesh are emerging far from the damage due to the intersection of most affected paths among those selected. The high DI level associated to those paths induces a high risk to a single node which is indeed far from damage location. 
- Feature sensitivity: Due to the complex behavior of wave propagation and the statistical decision-making approach, a few paths that should be affected by the damage show a response suggesting no change in the structure. Otherwise, relevant changes in signal response can be detected even when no such a damage affects the correspondent line of sight. This happens especially when time of flight associated with low dispersivity of $A_{0}$ mode is adopted to detect changes in the waveguide.

About the first item, it is worth noting that the most critical area (damage) corresponds always to the area with the largest number of neighboring nodes in the SHM mesh. This remark suggests to resort to nodal density as damage metric, i.e. the greater is the number of nodes, the higher is the risk to have damage in the neighboring area. Namely, an isolated spot with very high damage indicator may return false alarm. Conversely, the large number of emerging nodes with a damage indicator exceeding threshold returns the damage diagnosis with higher reliability.

The output of a numerical simulation is considered hereinafter to analyze such aspects and to establish a reliable solution to be further validated on real scale components. In detail, the structure considered is a $6 \mathrm{~mm}$-thick bay of a tapered wing panel designed for a lower wing panel discretized resorting to $600 \mathrm{~mm} \times 600 \mathrm{~mm} \times 6 \mathrm{~mm}$ composite plate made of carbon-epoxy material typically adopted in the aeronautical sector on which 12 PZT disks made of soft material PIC 255 by Physik Instrumente are mounted and arranged in a circular network. The plate is laminated using unidirectional laminae with fibers along $0^{\circ}$ (UD) and biaxial laminae with orientation $0^{\circ} / 90^{\circ}$ (B) and $\pm 45^{\circ}$ (B45) which are stacked between 5 Harness $(5 \mathrm{H})$ external plies according to the stacking sequence $[5 H / B 45 / U / B / U / B 45 / U / B]_{s}$. The plies are discretized as single layers modeling the material properties reported in Table 1 and material orientation according to the defined layup.

Table 1. Elastic properties of graphite-epoxy laminae adopted for the $6 \mathrm{~mm}$-thick composite plate.

\begin{tabular}{cccc}
\hline Properties & Biaxial & Uniaxial & 5Harness \\
\hline$\rho\left[\mathrm{kg} / \mathrm{m}^{3}\right]$ & 1790 & 1790 & 1770 \\
$E_{1}[\mathrm{MPa}]$ & 81,000 & 152,000 & 158,420 \\
$E_{2}[\mathrm{MPa}]$ & 81,000 & 8800 & 8800 \\
$E_{3}[\mathrm{MPa}]$ & 8800 & 8800 & 8800 \\
$G_{12}=G_{13}=G_{23}[\mathrm{MPa}]$ & 4100 & 4100 & 3600 \\
$v_{12}=v_{13}=v_{23}$ & 0.31 & 0.31 & 0.31 \\
\hline
\end{tabular}

The wave propagation is simulated by using equivalent single layer approach [13] and the damage is discretized decreasing the mechanical properties around the impact [32]. The noise is then mathematically introduced into the signals to simulate the decision-making approach. As anticipated above, Figure 7a shows that the phantom damages are located in a sparsely populated area. This evidence confirms the hypothesis about the critical role of the nodal density. Furthermore, it can be confirmed as a lack of the reconstruction technique appearing appearing even while resorting to simulations. The SHM mesh indeed consists of nodes emerging from the intersection of those paths affected by the damage occurrence according to the decision-making output. It may happen that two selected paths strongly affected by the hidden failure (i.e., they return a high damage indicator) intersect each other in an area far away from the real damage location. Thus, an isolated spot arises around that location, generating a lack of the reliability. To reduce such a false alarm in damage prediction, the density of the SHM mesh can be calculated for each node resorting to the distance between that node and the others as follows:

$$
\frac{1}{f_{i}}=\frac{\sum_{j=1}^{n} \sqrt{\left(x_{i}-x_{j}\right)^{2}+\left(y_{i}-y_{j}\right)^{2}}}{n-1}, \quad i \neq j \text { and } i, j=1,2, \ldots, n
$$


where $f_{i}$ is the density parameter of the $i$ th node and and $n$ is the number of SHM nodes. Then, the parameter is normalized in order to do not affect the DI scale as follows:

$$
\bar{f}_{i}=\frac{f_{i}}{\left(f_{i}\right)_{\max }}, \quad i=1,2, \ldots, n
$$

Such a densification factor is preferred here rather than a classic density definition because it allows addressing such a weight for each node: the higher is the inverse of the average distance obtained, the greater is the number of nodes in the surrounding area. Instead, to construct another image, a new damage index is formulated as:

$$
D I_{i w}=\bar{f}_{i} \cdot D I_{i}
$$

where $D I_{i}$ is the damage index value assigned to the $i$ th node after decision making phase. The $D I_{i w}$ is thus preferred because it incorporates the severity of damage $\left(D I_{i}\right)$ with the density of emerging nodes in the surrounding area $\left(f_{i}\right)$. The ability to eliminate phantom damages is depicted in Figure $7 \mathrm{~b}$, where any indecision in the damage reconstruction is overcome, without giving up the information about the gravity of damage. In this case, the probability of a false alarm due to the occurrence of phantom damage rapidly decreases.

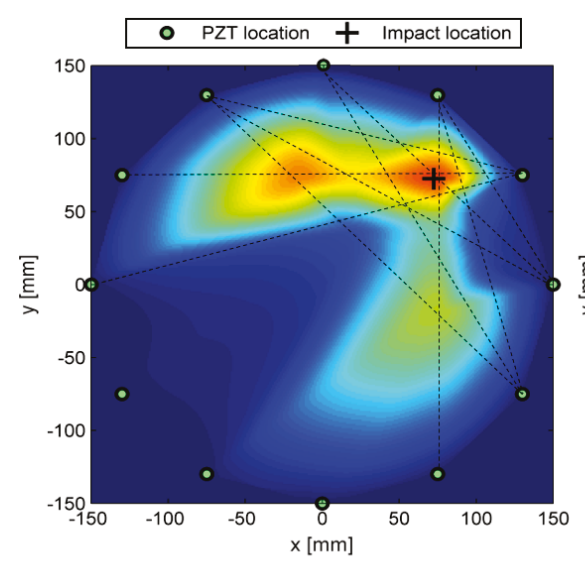

(a)

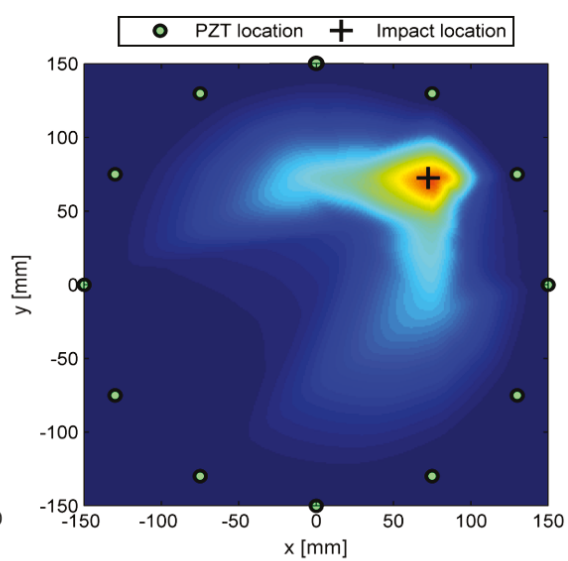

(b)

Figure 7. Tomographic analysis of the numerical test-case: reconstruction of damage based on energy level (a); and reconstruction of damage based on weighted energy level (b).

The second item regards the sensitivity of the specific feature to a specific damage. Due to the wide range of variables involved (frequency, thickness, multimode, dispersion, damage scenarios, etc.), establishing the relation between a classified damage and the effectiveness of a single feature is often complex. Every feature extracted from wave modes has its own detection capability for a specific damage considered. Generally, damage indicators based on wave energy content analysis in time domain are quite effective for detection and localization especially while accounting all modes, echoes and reflections affected by the failure. On the other hand, when the energy based feature accounts the entire wave signal, it strongly reflects the noise and the threshold, which is usually very high, and may censure also useful data. The same discussion can be pointed out for the transmission factor based damage index. Although it is likewise effective, it is affected by those echoes and waves appearing in the signal with the same frequency which introduce distortion in the wave spectrum. Otherwise, a different discussion lies in the time of flight parameter because it is connected to dispersive behavior of selected wave mode which strongly depends upon the frequency thickness. This feature indeed appears effective while decreasing the thickness of the structure and the efficiency is strongly reduced with thicker solids. In addition, its efficiency is related to the ratio between damage dimension 
and path length; the local effect of hidden failure is indeed mitigated by the entire propagation path between the couple of sensors.

Among those explained, the most striking result deals with such dispersive behavior, which affects the localization of damage using ToF single-parameter representation. Figure 8a shows the result obtained with the ToF damage index This lack of agreement while processing wave velocity is due to the fact that the $A_{0}$ mode shows low dispersive behavior around $60 \mathrm{kHz}$, the frequency chosen to optimize the signal response of the antisymmetric mode. Emerging even when propagating waves are simulated, such result is mostly due to the parameter selection rather than to uncertainties in measurements.

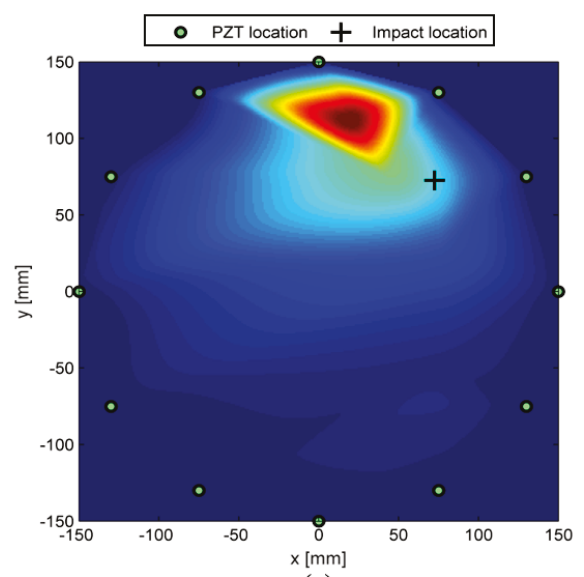

(a)

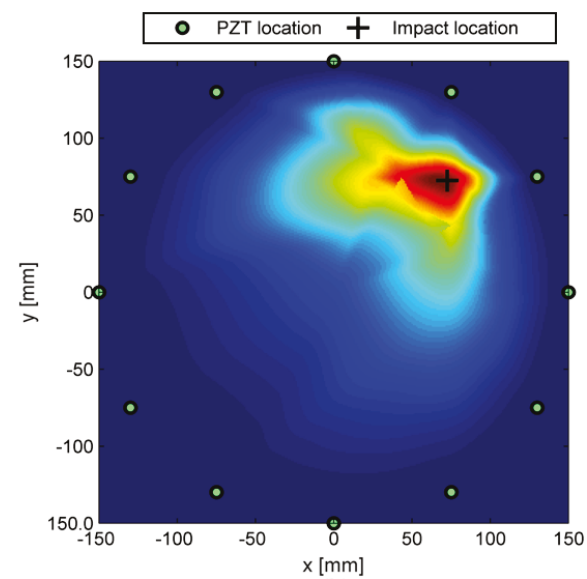

(b)

Figure 8. Tomographic analysis of the numerical test-case: map of damage based on single ToF (a); and multi-parameter (b) approach.

However, a SHM system should be oriented to find the more reliable and general purpose identification rather than the more reliable feature according to the specific case. In addition, an autonomous decision-making approach does not allow improving results by changing the decision level. Decisional procedure indeed affects and tightly correlates probability of false alarm and probability of detection. When defined the system target, the probability of detection (POD) is directly connected with safety and the operative costs due to the downtime decreases according with the probability of false alarm (PFA) [27]. Thus, while increasing the threshold, the PFA decreases (desirable) and the probability of missed detection increases, which means a decreasing POD (undesirable). Otherwise, the system can be enhanced by improving the system response. Several features parameters can be weighted and combined (data fusion) after decision-making to increase the robustness of the system versus the damage characteristics. Although probabilistic reconstruction is a consolidated approach for GUWs-based damage detection [16], there are few studies in which resulting reconstruction images for the same structural state are fused to improve damage localization and background noise [20]. The data fusion here is carried out resorting to the following steps:

- (i) weighting procedure according to Equation (12) for each parameter extracted from traveling waves and selected by decision-making step;

- (ii) interpolation of damage according to each feature on the structural mesh (single parameter approach);

- (iii) normalization of data obtained on that mesh; and

- (iv) data fusion for the multi-parameter representation of damage.

The result obtained with data fusion of normalized weighted DIs is depicted in Figure 8 where the misleading interpretation of the ToF based reconstruction (Figure 8a) is clearly smoothed by introducing the multi-parameter approach (Figure 8b) including all of the three features considered. 
To establish the effectiveness of the $M P^{2}$ meshless methodology, the results obtained are compared with a classic mesh-based approach where the damage index is evaluated in the same way for every path depicted in Figure 9a. Then, the damage probability index (DPI) is calculated in every point of structural mesh shown in Figure $9 \mathrm{~b}$ resorting to a decreasing probability function based on a nonlinear definition of a distance Index $(d I)$, which establishes the effect of the path on its surrounding area. The effect induced by the $i$ th path to the specific point $P$ of the structural mesh is addressed as follows:

$$
D P I_{i}(P)=d I_{i}(P) \cdot D I_{i}
$$

where $D I_{i}$ is the damage index of $i$ th path and $d I_{i}(P)$ is the distance index between that path and point $P$ calculated according to enable a specific decreasing probability. To obtain the classic elliptical reconstruction [18], for each point $P$, the distance $\delta_{i}(P)$ is calculated from the distances between that node and the sensors connected by the $i$ th path. The distance index is then evaluated following Equation (14) where $\beta$ is a scale parameter (i.e., it defines the farther influence of a path) to improve the reconstruction after being calibrated on a well-known condition. Finally, the DPI of the point $P$ is evaluated accounting for the effects of every selected path induced on the point $P$ and normalizing such overall value for further data fusion according to the multi-parameter approach.

$$
d I_{i}(P)=\frac{\beta-\delta_{i}(P)}{\beta-1}, \quad \delta_{i}(P) \leq \beta d I_{i}(P)=0, \quad \delta_{i}(P) \geq \beta
$$

The results obtained with mesh based and meshless multi-parameter $\left(M P^{2}\right)$ approach are reported in Figure 10. Figure 10a shows a mesh-based reconstruction and returns damage identification and localization without uncertainties. Figure $10 \mathrm{~b}$ shows the reconstruction of the meshless-based diagnosis, where the density weight is able to restrict the localization around the damage location. From the comparison, it is worth noting that a similar reasonable result can be obtained with the meshless approach with less computational cost needed.

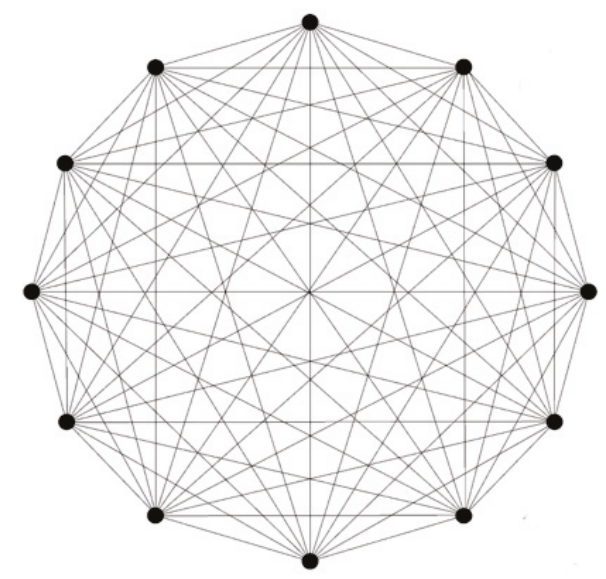

(a)

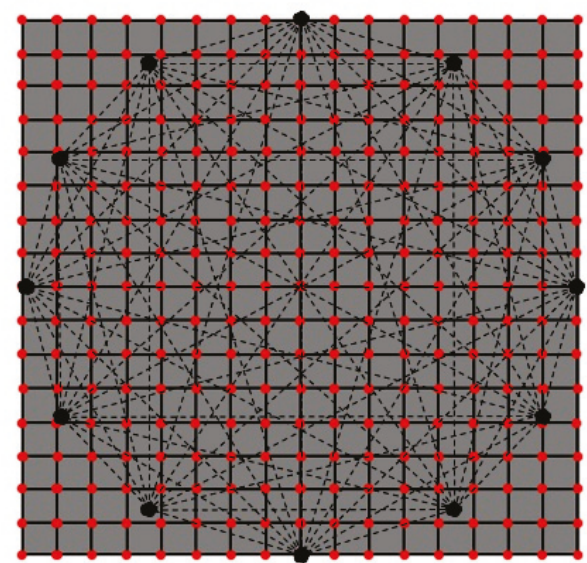

(b)

Figure 9. Cluster of sensor with all passible propagation paths (a); and typical mesh for mesh-based reconstruction approach $(\mathbf{b})$. 


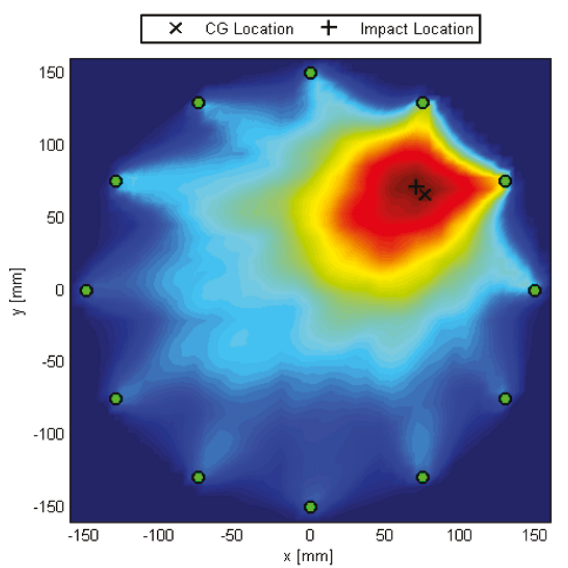

(a)

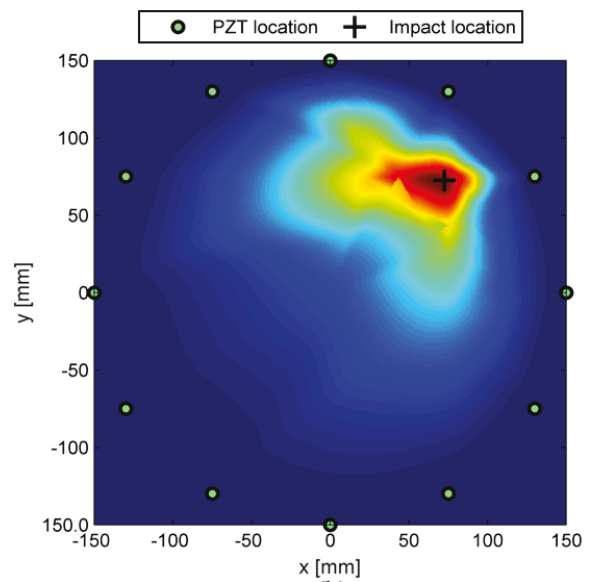

(b)

Figure 10. Tomographic analysis of the numerical test-case: mesh based multi-parameter approach (a); and $M P^{2}$ meshless image reconstruction (b).

\subsection{Delamination Detection in Complex Structures}

The $M P^{2}$ methodology described in the previous section is employed and validated on real scale structures designed for the outer wing box of a commercial aircraft (see Figure 11). For the sake of the conciseness, the effects of several improvements in the $M P^{2}$ system are not further discussed by using measurement datasets. The results obtained through numerical simulations are even confirmed by the experiments, where the multi parameter approach is able to enhance the detectability of the multipath analysis. About the structure, the same material and similar thicknesses of the composite plate discretized in the virtual environment are designed for the wing component. In addition, several stringers are inserted for stiffening the thin walled structure according to the actual aerospace advanced structural design [2].

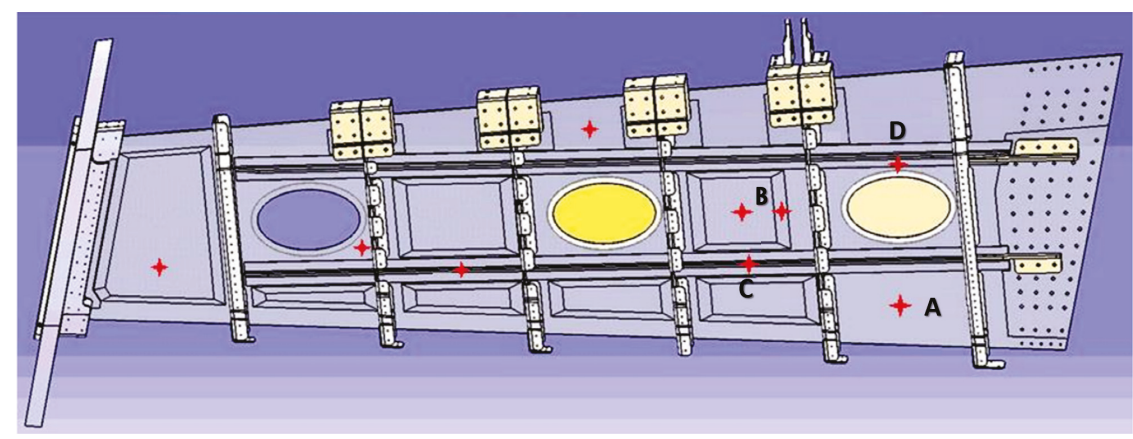

Figure 11. Lower wing panel mounted on the outer wing box of a commercial aircraft. Structural and impacts details used for the design of the SHM configuration. Red crosses represent impact locations while capitalized letters label the monitored area whose SHM analysis is reported afterwards.

Before monitoring the structure, the wave behavior of the $A_{0}$ mode is investigated on a flat area of the lower wing panel where a similar thickness (about $6 \mathrm{~mm}$ ) and stacking sequence is present $\left([5 H / B 45 / U / B / U / B 45 / U / B]_{s}\right)$. The dispersion curves depicted in Figure 12a confirm the low dispersivity discussed in the previous section along principal direction of propagation. Furthermore, there is $\mathrm{n}$ strong dependence of the group velocity upon the direction of propagation. This result is mostly due to the thick plate and the complex stacking sequence which is inclined to a quasi-isotropic 
configuration. Otherwise, the tuning of the anti-symmetric mode is strongly dependent upon the frequency of excitation showing the classic bend bell curve in Figure 12b.

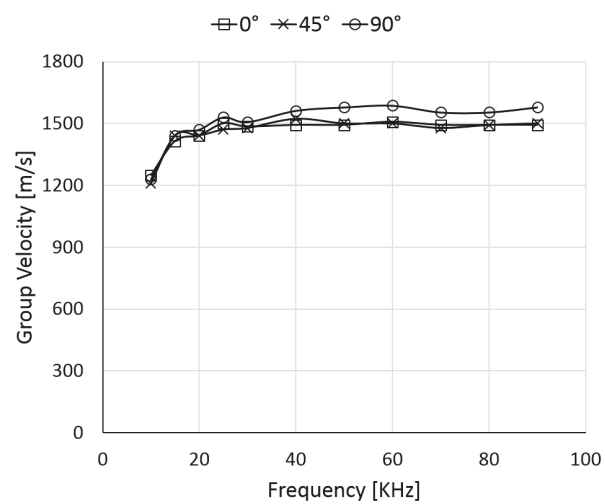

(a)

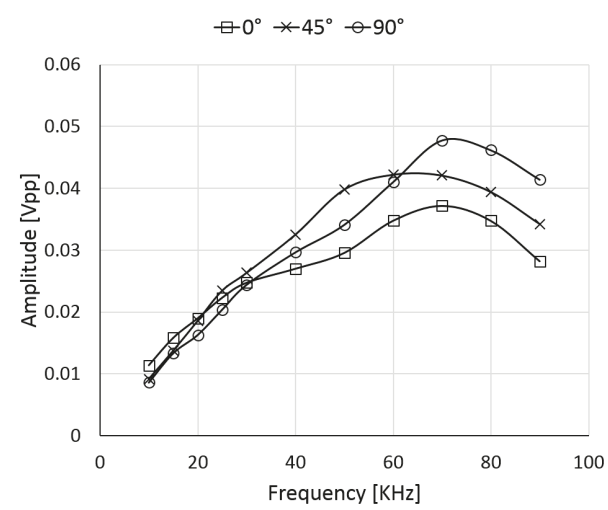

(b)

Figure 12. Dispersion (a); and tuning (b) characteristics of the $A_{0}$ Lamb wave mode travelling through the $6 \mathrm{~mm}$ composite media.

The SHM system is expected to monitor critical components of the entire structure, including thin bays (delamination detection) and stiffened area (disbonding detection). Hence, several bays of the structure are sensorized with clusters of PZTs bonded on the inner surface to perform condition monitoring when the wing box is correctly assembled and mounted on the aircraft. The sensors distribution, for each group and for each bay, is defined according to: (i) the potential critical impact locations during lifetime; and (ii) the wave propagation directionality analysis. Figure 11 shows in detail the critical impact points selected which are reported on the inner side of the lower wing panel. The structure includes three different thicknesses zones and transition areas with an inhomogeneous distribution inside each bay with respect to the nominal value of $8.3 \mathrm{~mm}$. The other identified thickness values are $12.5 \mathrm{~mm}$ below the T-shaped stringers, $10 \mathrm{~mm}$ in the left thin walled bay, and $6.4 \mathrm{~mm}$ in the remaining bays where the ramp is depicted. According to the described setup, the aircraft operative life is simulated through impact tests on the lower wing panel after wing-box assembly stage. The complex test article constraint system (when mounted on the wing-box) and the inhomogeneous distribution of thickness require impact energy calibration tests suggesting the energy level to obtain barely visible damages. The experimental calibrated energies found are:

- $60 \mathrm{~J}$ for $6.4 \mathrm{~mm}$ thickness;

- $90 \mathrm{~J}$ for $8.3 \mathrm{~mm}$ thickness; and

- $\quad 100-110 \mathrm{~J}$ for $10 \mathrm{~mm}$ thickness.

After energy impact calibration, the baseline ultrasonic data are acquired and scheduled impacts are performed through drop weight test. Each impacted area reveals the presence of barely visible damages when inspected with nondestructive ultrasonic phased array tests which are adopted for detailed inspection in the aeronautical sector. Finally, the current ultrasonic data are acquired for further post processing.

Figure 13 shows one of the sensor clusters adopted to monitor delamination-like damages in flat thin walled composite. Several PZT transducers are located on the independent bay delimited by stringer, ribs and corner. The energy released by a low velocity impact occurring at the internal area may lead to a barely visible set of delaminations between several layers which are stacking the flat structure. 


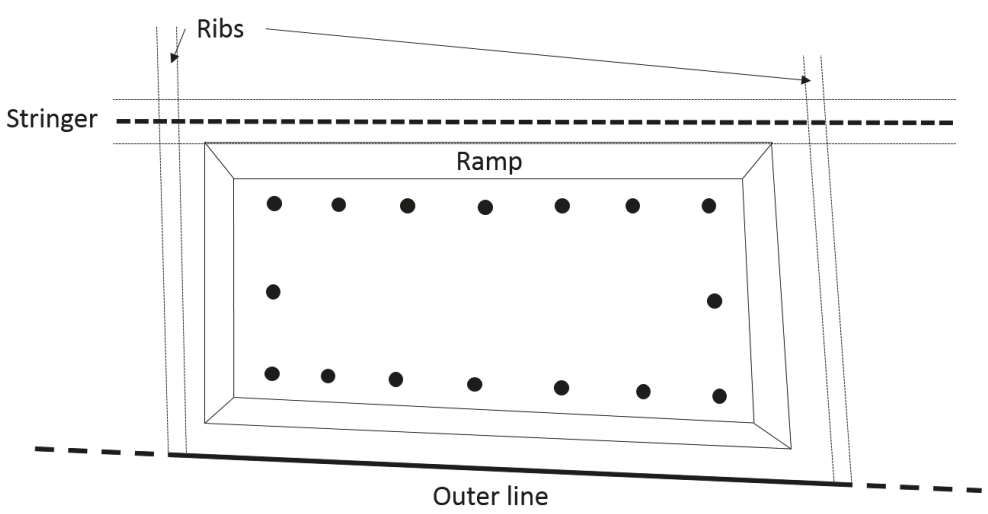

Figure 13. Sensor clusters adopted to monitor delamination-like damages in flat thin walled composite (Area A in Figure 11).

The damage identification is here strongly challenging due to the complex wave propagation behavior in real composite aerostructures characterized by varying thicknesses and layups, stiffeners and holes. Besides the monitored area, the remaining part of the sketched section is quite complex, showing ramp links towards stringer and ribs which strongly affects the wave propagation. In Figure 14, the noise introduced in the signals and the several modes and echoes recorded are quite evident. Different response of pristine and currently damaged structure is even evident while considering time of flight and transmission (amplitude) of $A_{0}$ mode as well as generalized energy of the entire signal.

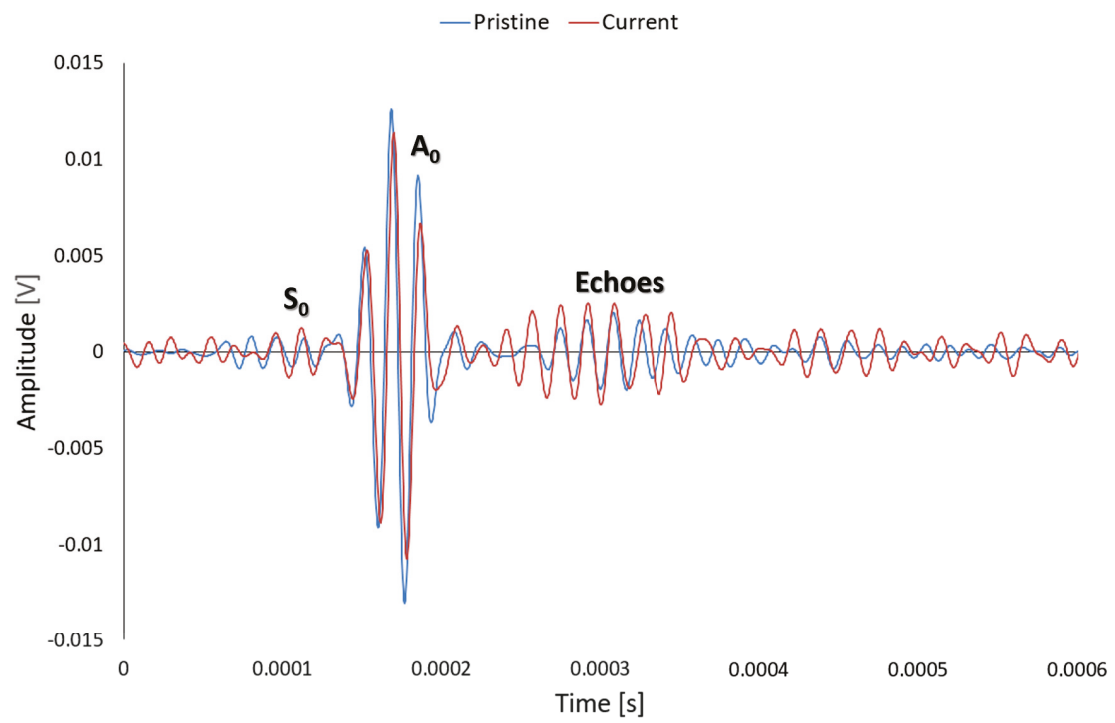

Figure 14. Typical time history of the propagating wave captured at sensor location. Several modes and reflections propagating at frequency of $60 \mathrm{KHz}$.

A 4.5-sine-cycle windowed burst with a frequency of $60 \mathrm{KHz}$ is adopted as diagnostic wave to achieve a trade off between tuning of $A_{0}$ mode and time shift between fundamental modes. The monitoring is operated by interrogating the structure before and after low energy impacts 
simulated on the structure employing a drop weight machine. Despite the complex operative conditions in which the system worked, the damage reconstruction approach appears to be able to determine the damage location, even though some ghost areas (phantom damages) are often present, especially processing a single parameter without accounting the density of emerging nodes in the SHM mesh. However, the introduction of the density parameter to weight damage indicators highly reduces the presence of those areas and increases the reliability of the system. In addition, the results can be enhanced with the multi-parameter analysis by performing the image fusion of the various damage reconstructions using the same supporting mesh grid. It is worth noting that the best results in terms of localization are always achieved by the data fusion of all different damage parameters (i.e., signal energy level, time of flight and transmission factor), as reported in Figure 15, which shows the diagnosis of the flat area (A) depicted in Figure 13.

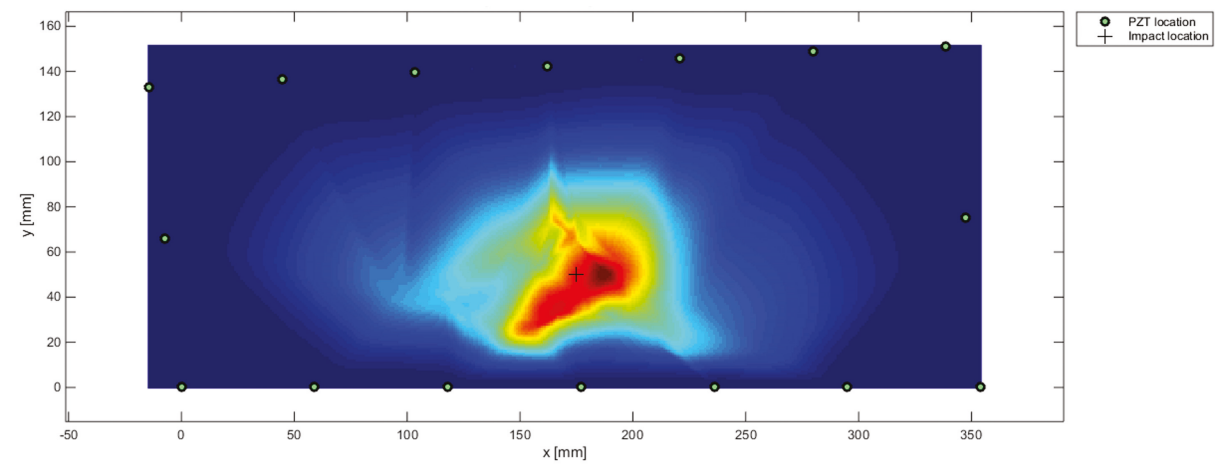

Figure 15. $M P^{2}$ damage detection of flat thin walled composite sketched in Figure 13 (Area A).

Another test case is sketched in Figure 16, where another bay of the wing panel is characterized by thinner inner area connected to a thicker plate on which several stiffeners are bonded. Two different impact damages are investigated in this case: one occurring on the thinner area and the other occurring below the right ramp. Both damages are simulated with a drop weight test and the diagnosis is separately carried out sorting the appropriate sensor configuration as depicted in Figure 16.

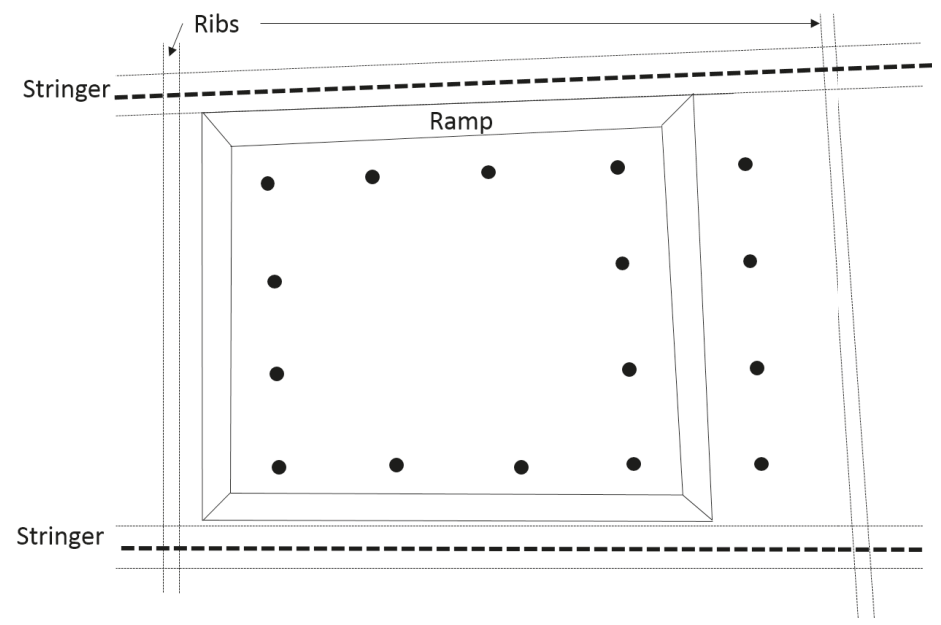

Figure 16. Sensor clusters adopted to monitor delamination-like damages in tapered thin walled composite (Area B in Figure 11). 
In both cases, the $M P^{2}$ approach is able to correctly detect and localize the presence of the damage as reported in Figure 17. Even when the ramp is strongly complicating the wave propagation, the system does not show any indecision in localization while accounting for the density of emerging nodes and data fusion for the final reconstruction. The damage decision approach is indeed able to sort those paths that are mostly affected by the emerging flaw while the multi-parameter approach is able to provide a reliable localization.
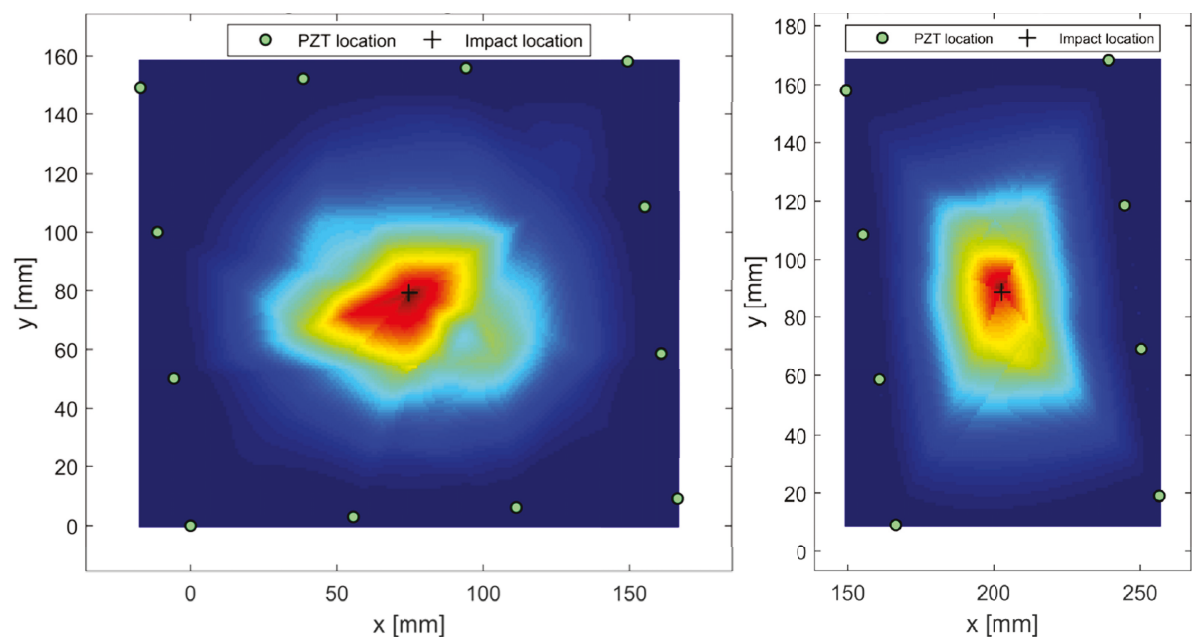

Figure 17. $M P^{2}$ damage detection of tapered thin walled composite sketched in Figure 16 (Area B).

\subsection{Disbonding Detection in Complex Structures}

A distributed cluster of sensors used to detect propagating wave through pitch-catch approach consists of a sensor configuration asclosed pattern or sensor matrix, where the sensors constitute a polygonal geometry. While monitoring a possible disbonding between stringer and thin walled composite structure, the wave propagating directly along transducers path is recorded for all possible pairs located on the opposite sides of the stiffener (see Figure 2). Stringer, structure and their interface are indeed expected to affect the paths crossing the damage. With meshless approach, the SHM mesh is constructed restoring DI datasets on the intersections defined after decisional step. The results are further interpolated to transfer health information to the structural mesh according to required resolution. A damage index approach can be efficiently employed even in this case because the wave propagating over the stringer behaves in completely different manner when the stringer is disconnected rather than bonded to the hosting structure [48]. In the latter, the wave mostly penetrates into the stringer and then is scattered back to the source location. A small amount of the energy is transmitted through the stiffener and reaches the sensors on the other side. When the stringer is completely detached, the wave travels in the thin walled structures without interacting with the stiffener. When a low velocity impact occurs below the stringer feet, usually the load partially disconnects the parts jointed together. While interrogating the structure, a portion of the energy is transmitted behind the stringer due to the wave propagating in the plate and the remaining part of the energy is reflected due to the wave penetrating into the stringer. Hence, the configuration in Figure 2 allows detecting and locating the damage using the decision-making step to select the paths affected by the hidden flaw and the dedicated algorithm to localize the damage from DI datasets, namely exploiting the paradigms of the $M P^{2}$ approaches. Namely, the approach proposed in the previous section for delamination-like damage identification in flat plates is merely extended to stiffened panels for disbonding detection. To demonstrate the feasibility of this global approach for 
further detecting the disbonding, another section of the same structure (Area C) is instrumented as sketched in Figure 18.

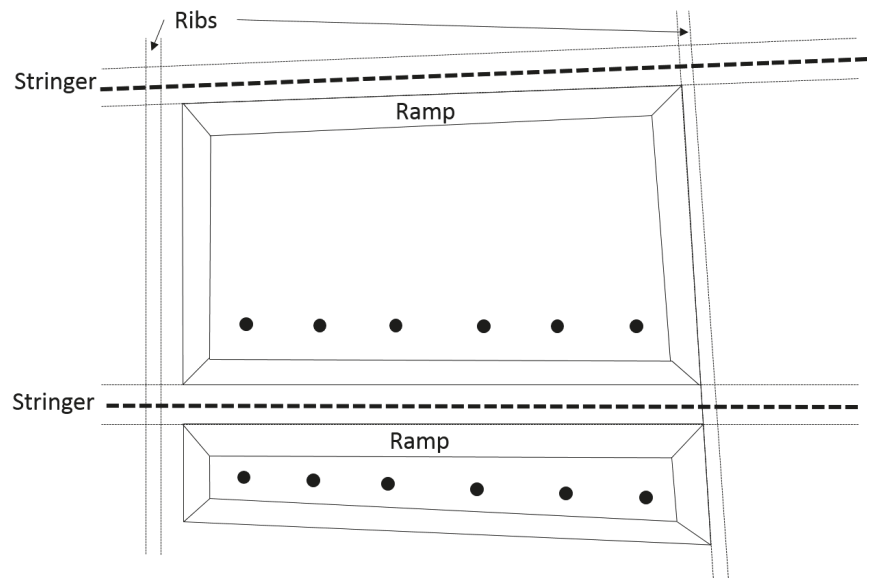

Figure 18. Sensor clusters adopted to monitor disbondings in stiffened thin walled composite (Area C in Figure 11).

The thin walled structure is thick $6 \mathrm{~mm}$ and shows a ramp connecting flat parts to the stringer leg where the hosting structures is thick $8 \mathrm{~mm}$ as the leg and the web. The same interrogation procedure is adopted before and after a low velocity impact calibrated to lead to a disbonding. The $M P^{2}$ diagnosis is reported in Figure 19, showing the disbonding diagnosis of the meshless approach. The reconstruction is based on the multi-parameter approach where the first antisymmetric mode $\left(A_{0}\right)$ of propagating Lamb waves is mostly excited. The impact location is depicted as well, showing the very marginal error obtained. The map shows increasing risk where the structure is disbonded, achieving both its detection and localization. The $M P^{2}$ approach returns a negligible impact localization error when compared with the real disbonding extent. It is indeed about $35 \mathrm{~mm}$, as assessed with classic ultrasonic NDT.

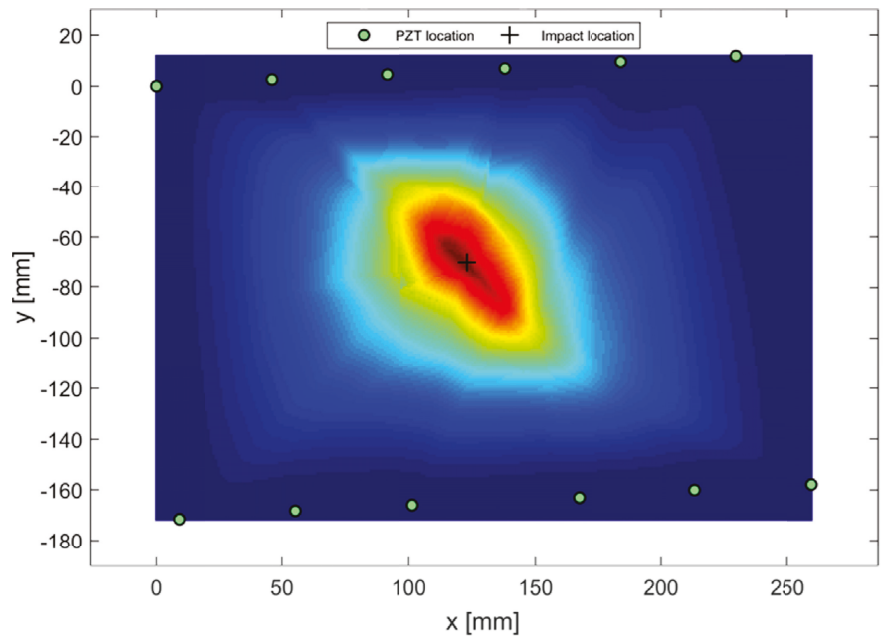

Figure 19. $M P^{2}$ diagnosis of the stringer disbonding occurred below the stringer web depicted in Figure 18 (Area C). 
Another stiffened plate (Area D) is monitored as depicted in Figure 20 by using a non-regular cluster of sensors. In this case, the thin walled structure hosting the stringer has a constant thickness $(8 \mathrm{~mm})$. The stiffened area is characterized by the stringer legs directly connected to the surface without any ramp link. Otherwise, one of the depicted bays shows an hole very close to the stringer which prevents the design of a regular cluster of PZTs and strongly complicates the wave propagation. The damage is here simulated with loading the lower leg of the stringer to localize the damage only lower side of the stringer. No matter what the geometry and complexities are, the $M P^{2}$ approach is able to correctly detect and locate the stringer disbonding. The result depicted in Figure 21 shows the reasonable result obtained in terms of localization even when a very complex geometry is considered. Furthermore, the diagnosis correctly suggests the leg which is currently damaged.

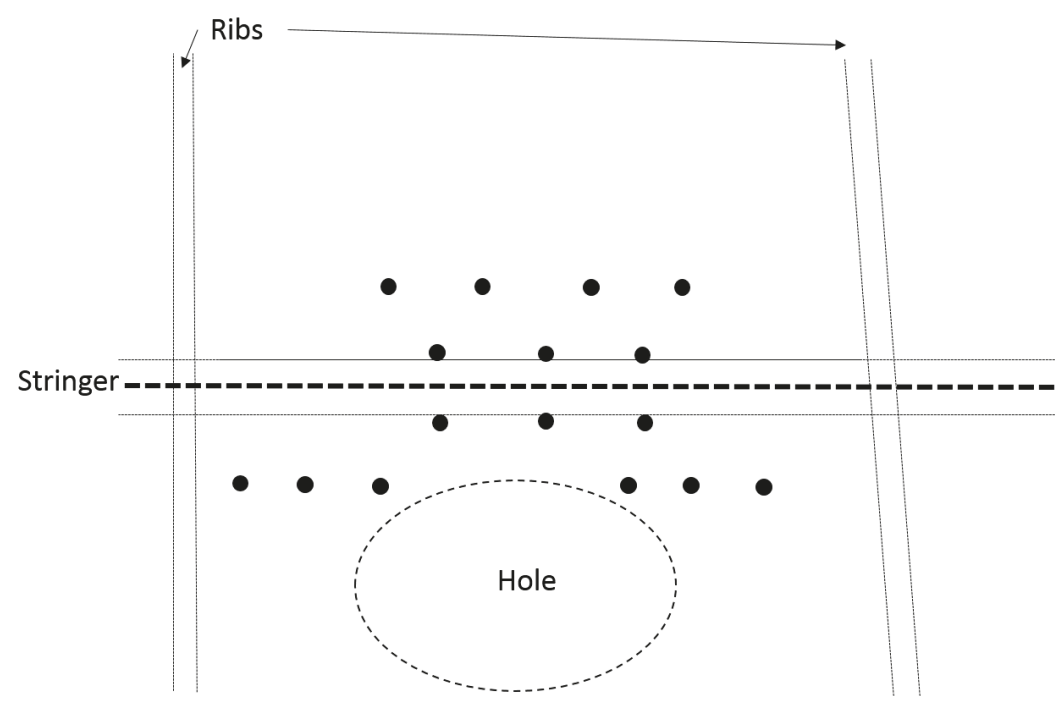

Figure 20. Sensor clusters adopted to monitor disbondings in stiffened thin walled composite ( Area D in Figure 11).

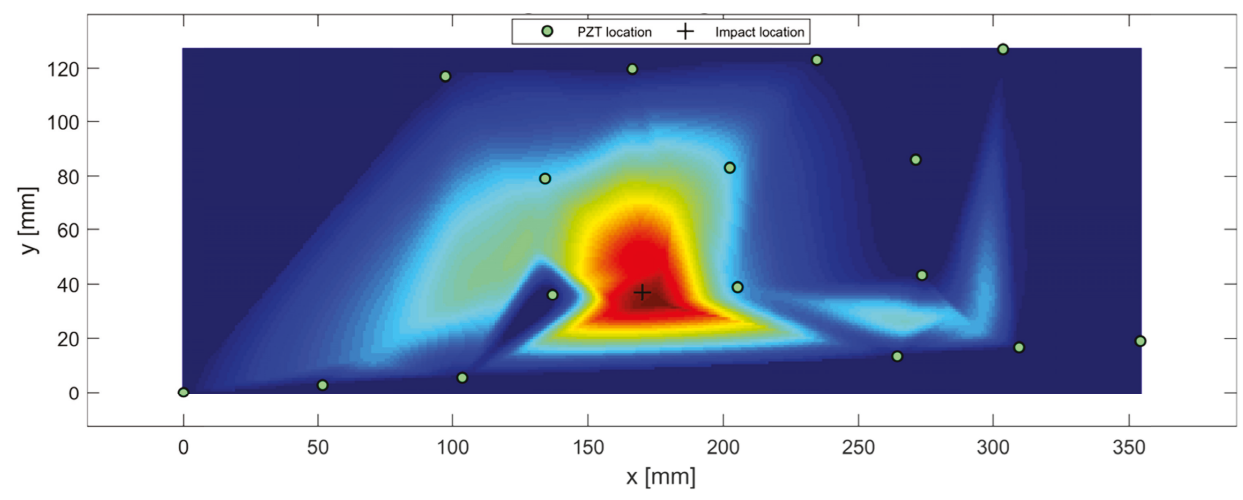

Figure 21. $M P^{2}$ diagnosis of the stringer disbonding occurred below a stringer leg depicted in Figure 20 (Area D). 


\section{Discussion and Concluding Remarks}

The work deals with efficient identification and localization of damage in complex composite structures by allowing a multi-path and multi-parameter approach. Despite the different and less regular geometries involved compared to flat composite plates, the tomographic method based on unsupervised threshold definition and multi-parameter processing does not show any indecision in detecting and locating the impact damages. Good results are obtained even while reconstructing damaged area where thickness ramps are present as well as where holes and stiffeners are located near the monitored area. The results reported show the effectiveness of the implemented approach combining mesh-less reconstruction from statistical selection of propagation paths with multi-parameter analysis and data fusion techniques to provide higher levels of probability of detection for all the investigated damage scenarios. Furthermore, the result is often even more promising than that of conventional mesh-based approaches with fewer computational costs possible. It is worth noting that the methodology proposed is here applied to aeronautical structures, where the SHM has been demonstrated to improve the performances and the operations. However, it can be applied to monitor all types of structures, including isotropic and anisotropic components. The $M P^{2}$ framework presented in this work is indeed general while the features affected by the hidden flaw can be addressed to the appropriate event-induced damage (i.e., impact rather than fatigue-induced damage or others). In addition, although impacts may randomly occur, it is worth noting that the position is a priori established to make more challenging the investigation and the central location is likely chosen because: (i) that area is characterized by less dense mesh; and (ii) the closer the damage is to the sensors, the more accurate is the reconstruction [49].

One of the more challenging aspects is the robustness of the methodology versus number of sensors adopted, which may also varying during the system lifetime. Sensors may fail due to the harsh condition that they have to withstand $[50,51]$ and a self diagnosis approach should be integrated together with a health management strategy continuously pursuing the minimum target to achieve the prescribed POD. This means that the effect of missing sensors has to be addressed a priori to continuously predict the minimum detectable damage. On the other hand, the impact of SHM systems strongly depends upon the weight introduced into the monitored vehicle. Although PZT sensors are much lighter than classic probes, they need connections, wiring and driving hardware to be mounted on the aircraft. This means that a reliability oriented approach is needed to have the minimum detectable damage very close to the system target to minimize the weight by using as few as sensors possible.

Author Contributions: V.M. conceived the proposed multi-parameter methodology, wrote the paper, carried out numerical simulations and measurements and post-processed the whole datasets for diagnosis purpose. N.D.B. designed the experiments and was deeply involved during the measurements campaign on the lower wing panel. L.M. reviewed the article. E. M. and F.R. supervised the activity.

Funding: The research leading to these results has received funding from the European Union's Seventh Framework Programme for research, technological development and demonstration under grant agreement no 284562 (SARISTU Project).

Conflicts of Interest: The authors declare no conflict of interest.

\section{Abbreviations}

The following abbreviations are wisely used in this manuscript:

SHM Structural Health Monitoring

NDT Non destructive Testing

GW Guided Wave

PZT Lead zirconate titanate (piezoelectric material)

POD Probability of detection

PFA Probability of false alarm 


\section{References}

1. Jones, R. Mechanics Of Composite Materials; Materials sclence And Engineering Series; Taylor \& Francis: Abingdon, UK, 1998.

2. Megson, T. Aircraft Structures for Engineering Students, 5th ed.; Butterworth-Heinemann: Boston, MA, USA, 2013; doi:10.1016/B978-0-08-096905-3.00065-6.

3. Maio, L.; Monaco, E.; Ricci, F.; Lecce, L. Simulation of low velocity impact on composite laminates with progressive failure analysis. Compos. Struct. 2013, 103, 75-85, doi:10.1016/j.compstruct.2013.02.027. [CrossRef]

4. USA Department of Defense. MIL-HDBK 17-3F: Composite Materials Handbook; Department of Defense Handbook: Washington, DC, USA, 2002.

5. USA Department of Defense. JSSG-2006, Aircraft Structures; Department of Defense Joint Service Specification Guide: Washington, DC, USA, 1998.

6. US Department of Transportation-Federal Aviation Administration. AC No: 20-107B. Composite Aircraft Structure; US Department of Transportation-Federal Aviation Administration: Washington, DC, USA, 2009.

7. Cot, L.; Wang, Y.; Bes, C.; Gogu, C. Scheduled and SHM structural airframe maintenance applications using a new probabilistic model. In Proceedings of the 7th European Workshop on Structural Health Monitoring, EWSHM 2014-2nd European Conference of the Prognostics and Health Management (PHM) Society, Nantes, France, 8-11 July 2014; pp. 2306-2313.

8. Clean Sky 1 GRA-Green Regional Aircraft. Available online: http://www.cleansky.eu/green-regionalaircraft-gra (accessed on 16 September 2018).

9. Wolcken, P.C.; Papadopoulos, M. SARISTU—Smart Intelligent Aircraft Structures; Springer: Berlin, Germany, 2015.

10. Clean Sky 2 RA-Regional Aircraft. Available online: http:/ / www.cleansky.eu/regional-aircraft (accessed on 16 September 2018).

11. Giurgiutiu, V. Structural Health Monitoring with Piezoelectric Wafer Active Sensors, 2nd ed.; Academic Press: Oxford, UK, 2014; doi:10.1016/B978-0-12-418691-0.00007-1.

12. Viktorov, I. Rayleigh and Lamb Waves: Physical Theory and Applications; Ultrasonic Technology; Springer: New York, NY, USA, 1967.

13. Maio, L.; Memmolo, V.; Ricci, F.; Boffa, N.; Monaco, E. Investigation on fundamental modes of guided waves propagating in symmetric and nonsymmetric composite laminates. Proc. Inst. Mech. Eng. Part C J. Mech. Eng. Sci. 2017, 231, 2988-3000, doi:10.1177/0954406217698721. [CrossRef]

14. Abrate, S. Impact on Composite Structures; Cambridge University Press: Cambridge, UK, 1998, doi:10.1017/CBO9780511574504.

15. Memmolo, V.; Pasquino, N.; Ricci, F. Experimental characterization of a damage detection and localization system for composite structures. Measurement 2018, 129, 381-388. [CrossRef]

16. Hay, T.R.; Royer, R.L.; Gao, H.; Zhao, X.; Rose, J.L. A comparison of embedded sensor Lamb wave ultrasonic tomography approaches for material loss detection. Smart Mater. Struct. 2006, 15, 946. [CrossRef]

17. Testoni, N.; De Marchi, L.; Marzani, A. Detection and characterization of delaminations in composite plates via air-coupled probes and warped-domain filtering. Compos. Struct. 2016, 153, 773-781, doi:10.1016/j.compstruct.2016.07.005. [CrossRef]

18. Zhao, X.; Royer, R.L.; Owens, S.E.; Rose, J.L. Ultrasonic Lamb wave tomography in structural health monitoring. Smart Mater. Struct. 2011, 20, 105002. [CrossRef]

19. De Marchi, L.; Marzani, A.; Moll, J.; Kudela, P.; Radzieński, M.; Ostachowicz, W. A pulse coding and decoding strategy to perform Lamb wave inspections using simultaneously multiple actuators. Mech. Syst. Signal Process. 2017, 91, 111-121, doi:10.1016/j.ymssp.2016.12.014. [CrossRef]

20. Michaels, J.E.; Michaels, T.E. Guided wave signal processing and image fusion for in situ damage localization in plates. Wave Mot. 2007, 44, 482-492, doi:10.1016/j.wavemoti.2007.02.008. [CrossRef]

21. Croxford, A.J.; Moll, J.; Wilcox, P.D.; Michaels, J.E. Efficient temperature compensation strategies for guided wave structural health monitoring. Ultrasonics 2010, 50, 517-528, doi:10.1016/j.ultras.2009.11.002. [CrossRef] [PubMed]

22. US Department of Defence. MIL-HDBK No: 1823A. Non Destructive Evaluation System Reliability Assessment; US Department of Defence: Washington, DC, USA, 2009. 
23. Janapati, V.; Kopsaftopoulos, F.; Li, F.; Lee, S.; Chang, F.K. Damage detection sensitivity characterization of acousto-ultrasound-based structural health monitoring techniques. Struct. Health Monit. 2016, 15, 143-161, doi:10.1177/1475921715627490. [CrossRef]

24. Worden, K.; Allen, D.W.; Sohn, H.; Farrar, C.R. Damage detection in mechanical structures using extreme value statistics. In Smart Structures and Materials 2002: Modeling, Signal Processing, and Control; International Society for Optics and Photonics: Bellingham, WA, USA, 2002; Volume 4693, pp. 289-299, doi:10.1117/12.475226.

25. Monaco, E.; Memmolo, V.; Ricci, F.; Boffa, N.; Maio, L. Guided waves based SHM systems for composites structural elements: Statistical analyses finalized at probability of detection definition and assessment. In Proceedings of the SPIE-The International Society for Optical Engineering, San Diego, CA, USA, 8-12 March 2015 ; Volume 9438, doi:10.1117/12.2084334.

26. Sohn, H.; Farrar, C.; Hunter, N.; Worden, K. Structural health monitoring using statistical pattern recognition techniques. J. Dyn. Syst. Meas. Control 2001, 133, 706-711, doi:10.1115/1.1410933. [CrossRef]

27. Cottone, G.; Gollwitzer, S.; Heckenberger, U.; Straub, D. Reliability-oriented optimization of replacement strategies for monitored composite panels for aircraft structures. In Proceedings of the 9th International Workshop on Structural Health Monitoring: A Roadmap to Intelligent, Stanford, CA, USA, 10-13 September 2013; Volume 2, pp. 2728-2735.

28. Gianneo, A.; Carboni, M.; Giglio, M. Feasibility study of a multi-parameter probability of detection formulation for a Lamb waves based structural health monitoring approach to light alloy aeronautical plates. Struct. Health Monit. 2017, 16, 225-249, doi:10.1177/1475921716670841. [CrossRef]

29. Maio, L.; Ricci, F.; Memmolo, V.; Monaco, E.; Boffa, N. Application of laser Doppler vibrometry for ultrasonic velocity assessment in a composite panel with defect. Compos. Struct. 2018, 184, 1030-1039, doi:10.1016/j.compstruct.2017.10.059. [CrossRef]

30. Maio, L.; Memmolo, V.; Ricci, F.; Boffa, N.; Monaco, E.; Pecora, R. Ultrasonic wave propagation in composite laminates by numerical simulation. Compos. Struct. 2016, 121, doi:10.1016/j.compstruct.2014.10.014. [CrossRef]

31. Staszewski, W.; Boller, C.; Tomlinson, G. Health Monitoring of Aerospace Structures: Smart Sensor Technologies and Signal Processing; John Wiley \& Sons: Hoboken, NJ, USA, 2004.

32. Memmolo, V.; Ricci, F.; Maio, L.; Boffa, N.; Monaco, E. Model assisted probability of detection for a guided waves based SHM technique. In Proceedings of the SPIE-The International Society for Optical Engineering, Las Vegas, NV, USA, 20-24 March 2016; Volume 9805, doi:10.1117/12.2219306.

33. Cremer, L.; Heckl, M.; Petersson, B.A.T. Structure-Borne Sound: Structural Vibrations and Sound Radiation at Audio Frequencies; Springer: Berlin, Germany, 2005; doi:10.1007/b137728.

34. Harris, F.J. On the use of windows for harmonic analysis with the discrete Fourier transform. Proc. IEEE 1978, 66, 51-83, doi:10.1109/PROC.1978.10837. [CrossRef]

35. Auld, B. Acoustic Fields and Waves in Solids; Ripol Classic: Moscow, Russia, 1975, doi:10.1016/0003-682X(75)90008-0.

36. Oppenheim, A.; Verghese, G. Signals, Systems and Inference, Global Edition; Pearson Education: London, UK, 2016.

37. Memmolo, V.; Maio, L.; Boffa, N.D.; Monaco, E.; Ricci, F. Damage detection tomography based on guided waves in composite structures using a distributed sensor network. Opt. Eng. 2015, 55, 011007, doi:10.1117/1.OE.55.1.011007. [CrossRef]

38. Memmolo, V.; Boffa, N.; Maio, L.; Monaco, E.; Ricci, F.; Pasquino, N. Experimental characterization of a composite structures health monitoring methodology. In Proceedings of the 3rd IEEE International Workshop on Metrology for Aerospace, MetroAeroSpace, Florence, Italy, 22-23 June 2016; doi:10.1109/MetroAeroSpace.2016.7573214.

39. Worden, K.; Manson, G.; Fieller, N. Damage detection using oulier analysis. J. Sound Vib. 2000, 229, 647-667, doi:10.1006/jsvi.1999.2514. [CrossRef]

40. Fugate, M.; Sohn, H.; Farrar, C. Vibration-based damage detection using statistical process control. Mech. Syst. Signal Process. 2001, 15, 707-721, doi:10.1006/mssp.2000.1323. [CrossRef]

41. Sohn, H.; Czarnecki, J.A.; Farrar, C.R. Structural health monitoring using statistical process control. J. Struct. Eng. 2000, 126, 1356-1363, doi:10.1061/(ASCE)0733-9445(2000)126:11(1356). [CrossRef]

42. Bornn, L.; Farrar, C.R.; Park, G.; Farinholt, K. Structural health monitoring with autoregressive support vector machines. J. Vib. Acoust. 2009, 131, 021004, doi:10.1115/1.3025827. [CrossRef] 
43. Farrar, C.; Worden, K. Structural Health Monitoring: A Machine Learning Perspective; John Wiley \& Sons: Hoboken, NJ, USA, 2012.

44. Laboratory, L.A.N.; States, U. A Comparison Study of Modal Parameter Confidence Intervals Computed Using the Monte Carlo and Bootstrap Techniques; Department of Energy, Office of the Assistant Secretary, Management and Administration: Washington, DC, USA, 1998.

45. Hazewinkel, M. Encyclopaedia of Mathematics: Volume 3 Heaps and Semi-Heaps-Moments, Method of (in Probability Theory); Encyclopaedia of Mathematics; Springer: New York, NY, USA, 2013.

46. Mitra, M.; Gopalakrishnan, S. Guided wave based structural health monitoring: A review. Smart Mater. Struct. 2016, 25, 053001. [CrossRef]

47. Moll, J.; Schulte, R.; Hartmann, B.; Fritzen, C.P.; Nelles, O. Multi-site damage localization in anisotropic plate-like structures using an active guided wave structural health monitoring system. Smart Mater. Struct. 2010, 19, doi:10.1088/0964-1726/19/4/045022. [CrossRef]

48. Ricci, F.; Monaco, E.; Maio, L.; Boffa, N.; Mal, A. Guided waves in a stiffened composite laminate with a delamination. Struct. Health Monit. 2016, 15, 351-358. [CrossRef]

49. Memmolo, V.; Ricci, F.; Boffa, N.; Maio, L.; Monaco, E. Structural health monitoring in composites based on probabilistic reconstruction techniques. Procedia Eng. 2016, 167, 48-55, doi:10.1016/j.proeng.2016.11.668. [CrossRef]

50. Memmolo, V.; Park, Y.; Lilov, M.; Monaco, E.; Ricci, F. Preliminary acousto-ultrasonic investigation for multi-parameter transducer self-diagnostic system in composites. Compos. Struct. 2018, 202, 1229-1238. [CrossRef]

51. Mueller, I.; Fritzen, C.P. Inspection of piezoceramic transducers used for structural health monitoring. Materials 2017, 10, 71, doi:10.3390/ma10010071. [CrossRef] [PubMed]

(C) 2018 by the authors. Licensee MDPI, Basel, Switzerland. This article is an open access article distributed under the terms and conditions of the Creative Commons Attribution (CC BY) license (http:// creativecommons.org/licenses/by/4.0/). 
Article

\title{
EASA's "Open" Category for Military UAS: Opportunities and Limitations in the Field of Airworthiness
}

\author{
Oliver Hirling * and Florian Holzapfel \\ Institute of Flight System Dynamics, Technische Universität München, 85748 Garching bei München, Germany; \\ florian.holzapfel@tum.de \\ * Correspondence: oliver.hirling@tum.de
}

Received: 31 May 2018; Accepted: 25 June 2018; Published: 1 July 2018

\begin{abstract}
The European Aviation Safety Agency (EASA) plans to establish a sole risk-based set of regulations for drones to grant access to European airspace, thus opening a multibillion-euro market. One part of this new regulation set is the so-called "open" category, imposing only a minimum set of regulations. The EASA's approach presents a strong converse to traditional and prescriptive airworthiness regulations. For decades, unmanned aircraft systems (UAS) have been state-of-the-art assets in military forces. Aiming at the fulfilment of complex missions in extreme environments, in different theatres of operation, and with different partners, military UAS need to be reliable, safe, and interoperable. Therefore, NATO established internationally accepted airworthiness standards. However, these standards might be too severe to be adhered to by small, commercial, off-the-shelf UAS in the up-to- $25 \mathrm{~kg}$ category, preventing the military from benefiting from the now fast-growing civil drone market. Based on a sound literature review, the paper presents the EASA's upcoming regulations for civil UAS and discusses if they are applicable to military UAS. Possible opportunities, challenges, and limitations of applying the approach for the military are shown.
\end{abstract}

Keywords: UAS; airworthiness; military; EASA; “open” category

\section{Introduction}

Unmanned aircraft systems (UAS), remotely piloted aircraft systems (RPAS), or just "drones" have emerged from being a purely military asset to being a sophisticated tool for professional civil applications and model aircraft enthusiasts. The range of UAS is nearly infinite regarding design and performance. Manufacturers already produce millions of UAS for the private sector, causing market prices to drop and therefore making UAS achievable for the broad public. The steady progressive development of the field of UAS, and especially in the field of small UAS, has enabled people with no experience in aviation to fly an aircraft [1,2].

Of course, every person who purchases a UAS wants to fly it, regardless of whether it was bought just for leisure purposes or for professional usage. Flying these machines requires operators and manufacturers to enter the aviation system and the related regulatory framework. The regulatory framework of the aviation system is a highly controlled system in which operational and technical aspects are regulated in every detail in order to ensure the utmost safety of all people involved. UAS are prohibited from endangering existing manned aviation, therefore, they must be integrated into the aviation system in a seamless and appropriate way [3,4].

This development was also acknowledged by the European Union (EU), and therefore, the European Commission tasked the European Aviation Safety Agency (EASA) to facilitate the integration of UAS into the European Airspace in a safe manner and in order to open the market for UAS [4,5]. 
One of the latest results of this task was the publication of a draft regulation for making UAS available on the EU market [6] as well as the publication of a draft regulation for operating UAS in the EU, including an Annex document which specifies the operational regulation $[7,8]$. In addition to the publication of these draft documents, EASA published the related Annex Acceptable Means of Compliance (AMC) and Guidance Material (GM) [9]. In contrast to traditional airworthiness codes, as for example CS-25 or CS-29 [10,11], the UAS regulation approach of EASA is operation and risk based instead of purely product based. The risk to people and property based upon the operation of UAS has been put into focus. In conclusion, one can say that the higher the risk of UAS operation, the more the competent aviation authority must be involved [6-9].

This new regulatory approach is a significant step within European aviation regulations. Up to now, UAS with a maximum take-off mass (MTOM, including fuel, batteries, payload, etc.) below $150 \mathrm{~kg}$ are under the authority of the Member States of the EU [12]. Obviously, putting all UAS under one regulatory framework will overcome the difficulty of different UAS airworthiness and operational regulations in the EU Member States and will greatly advance the harmonization and subsequent operations of UAS in the EU.

Harmonization is also key for interoperability within the regime of military UAS if they are used in allied operations like those of NATO. This fact was recognized by NATO years ago. Consequently, NATO has already published harmonized standards regarding airworthiness and operations of UAS (for example [13-16]). While within the military community, airworthiness standards for UAS comparable to the Certified Category of EASA are now quite common, the military community struggled and still struggles with the harmonization of UAS comparable to the "open" category which do not fulfill traditional airworthiness requirements but are already in use across military nations. To overcome this issue in Europe, the European Defence Agency (EDA) has been ordered to create a harmonized set of regulations similar to the upcoming civil regulations [17].

However, one core question remains: are the upcoming European civil UAS regulations entirely applicable to military UAS? Military UAS are operated quite differently compared to the envisaged usage of civil UAS. Moreover, it must be taken into account that the European civil UAS regulation approach is not limited to UAS operations. The approach also encompasses aspects of the UAS itself and the manufacturing industry as well as requirements of UAS pilots. Additionally, it should be considered that, for the time being, military aviation is always under the sovereignty of the individual state, unlike civil aviation in Europe, which is under the supervision of one authority. Several publications have already shown the applicability of military UAS regulations on civil UAS. However, it is not so obvious that this is also valid vice versa [18-20].

By providing sound insight into the proposed new civil regulations and comparing the different aspects of them to military unmanned aviation, the present paper discusses the core question outlined above. The discussion will show possible impacts and challenges for military unmanned aviation, if those regulations would be applied in exact the same way, and if such an approach is feasible at all. Furthermore, the possible opportunities for aligning civil and military regulations for UAS are shown.

\section{The European UAS Regulation Approach}

At the moment, the European UAS regulation approach consists of four central draft documents. The titles are quoted as written within the draft documents.

- "Draft Delegated Commission Regulation (EU) ... / ... of XXX on making available on the market of unmanned aircraft intended for use in the 'open' category and on third-country UAS operators" [6]. For the purpose of this paper, this regulation will be called "UAS Market Regulation".

- "Draft Commission Regulation laying down rules and procedures (EU) ... / . . of XXX for the operation of unmanned aircraft" [7]. For the purpose of this paper, this regulation will be called "UAS Operations Regulation". 
- "Annex UAS operations in the 'open' and 'specific' categories [PART-UAS]" [8]. For the purpose of this paper, the annex will be called "Part UAS".

- "Draft acceptable means of compliance (AMC) and guidance material (GM) to Regulation ... / ... [IR] laying down rules and procedures for the operation of unmanned aircraft and to the Annex (Part-UAS-UAS operations in the 'open' and 'specific' categories)" [9]. For the purpose of this paper, the document will be called "UAS AMC GM".

The next subsections outline the content of each draft document. In the last subsection, a conclusive overview in relation to traditional airworthiness regulations is provided.

\subsection{UAS Market Regulation}

The UAS Market Regulation [6] is going to become a law of the EU. Member States have to adopt the regulation and to include it into their national laws [21]. The regulation is divided as shown in Table 1.

Table 1. Content of the UAS Market Regulation [6].

\begin{tabular}{|c|c|}
\hline Section & Content \\
\hline & Preamble \\
\hline 1 & General Provisions \\
\hline 2 & Obligations of economic operators \\
\hline 3 & Conformity of the product \\
\hline 4 & Notification of conformity assessment bodies \\
\hline 5 & $\begin{array}{l}\text { Union market surveillance, control of products entering the Union market and Union } \\
\text { safeguard procedure }\end{array}$ \\
\hline 6 & Third-country UAS operators \\
\hline 7 & Final and transitional provisions \\
\hline Appendix 1 & Product requirements for a class CO UAS \\
\hline Appendix 2 & Product requirements for a class C1 UAS \\
\hline Appendix 3 & Product requirements for a class C2 UAS \\
\hline Appendix 4 & Product requirements for a class C3 UAS \\
\hline Appendix 5 & Product requirements for a class C4 UAS \\
\hline Appendix 6 & Electronic identification system \\
\hline Appendix 7 & $\begin{array}{l}\text { Conformity assessment Module A-Internal production control as per Annex II to } \\
\text { Decision No } 768 / 2008 / \text { EC }\end{array}$ \\
\hline Appendix 8 & $\begin{array}{l}\text { Conformity assessment Modules B and C-EU-type examination and conformity to type } \\
\text { based on internal production control as per Annex II to Decision No 768/2008/EC }\end{array}$ \\
\hline Appendix 9 & $\begin{array}{l}\text { Conformity assessment Module } \mathrm{H}-\text { Conformity based on full quality assurance as per } \\
\text { Annex II to Decision No } 768 / 2008 \text { /EC }\end{array}$ \\
\hline Appendix 10 & Contents of technical documentation \\
\hline Appendix 11 & EU declaration of conformity \\
\hline Appendix 12 & Simplified EU declaration of conformity \\
\hline
\end{tabular}

\subsection{UAS Operations Regulation}

Not only will the UAS Market Regulation [6] become EU law, so will the UAS Operations Regulation [7,21].

Table 2 presents the articles and content of the UAS Operations Regulation. In contrast to the UAS Market Regulation, the UAS Operations Regulation is not further divided into sections and appendices. 
Table 2. Content of the UAS Operations Regulation [7].

\begin{tabular}{ll}
\hline Article & Content \\
\hline 1 & Preamble \\
2 & Subject matter and scope \\
3 & Definitions \\
4 & Principles applicable to all UAS operations \\
5 & The 'open' category of UAS operations \\
6 & The 'specific' category of UAS operations \\
7 & UAS operations conducted in the framework of model clubs and associations \\
8 & Registration of UAS operators and their UA \\
9 & Designation of the competent authority \\
10 & Tasks of the competent authority \\
11 & Means of compliance \\
12 & Airspace conditions for UAS operations \\
13 & Safety information \\
14 & Derogations and limitations \\
15 & Conversion of authorisations, declarations and certificates \\
\hline
\end{tabular}

\subsection{Part UAS}

The Part UAS [8] contains specific and detailed requirements on the UAS Operations Regulation [7]. The main content is shown in Table 3. It will become an annex to the UAS Operations Regulation and therefore a law of the EU. A similar structure with regulation and annex can be seen for example in the Implementing Regulation 748/2012 and the included annex Part 21 [22].

Table 3. Content of the Part UAS [8].

\begin{tabular}{ll}
\hline Subpart & Content \\
\hline A & UAS operations in the "open" category \\
B & UAS operations in the "specific" category \\
C & Light UAS Operator Certificate (LUC) \\
\hline
\end{tabular}

\subsection{UAS AMC GM}

The UAS AMC GM [9] contains the Acceptable Means of Compliance and Guidance Material to the UAS Operations Regulation and the Part UAS [7,8]. AMC and GM are the recommended means to show compliance to the requirements in the regulation. For the sake of completeness, it is noteworthy that in contrast to regulations, which become law, the AMC and GM are not mandatory. Therefore, a UAS manufacturer might use alternative means of compliance but only if they are well justified $[9,23]$.

\subsection{Conclusion}

Unlike traditional airworthiness regulations which put the aircraft, the "technical product", in focus, the upcoming UAS regulations put the UAS operation in the centre of all further considerations. However, to reduce the approach only to the UAS Operations Regulation would be a shortfall. Without the UAS Market Regulation, the Part UAS, and the UAS AMC GM, the approach would not work and would not be as comprehensive as it is now [6-9,19].

The UAS Market Regulation, the UAS Operations Regulation, Part UAS, and the UAS AMC GM take into account the special characteristics of UAS. Especially within the "open" category, this can be seen very well. However, because of the necessary interconnections between the documents, the whole set of regulations is complex. These interconnections and other details will be discussed in the next section, in which the "open" category is outlined. 


\section{The "Open" UAS Category}

\subsection{Manned versus Unmanned Aviation Safety}

The technical airworthiness of manned aircraft is achieved by strict regulations on the aircraft and the design and manufacturing organisations. Technical airworthiness regulations may be either product based or performance based, but always with clear expectations of what the machine shall do and/or shall not do.

Besides an airworthy aircraft, the professional on-board human pilot and the environment in which the aircraft is operated (e.g., aerodromes, maintenance facilities, air traffic control and air navigation services, weather forecast services) must guarantee flight safety to the utmost extent. Consequently, this stringent approach primarily protects flight crews, passengers, and ground personnel but also reduces the risk to overflown third parties as far as possible [24-26].

UAS do not have a pilot on-board and do not transport crew and/or passengers yet. On the one hand, this allows a great amount of freedom in designing such vehicles, but on the other hand, it also puts the protection of third parties in the environment where the UAS is operated upfront. In contrast to manned aviation, in which a controlled environment is assumed, UAS in general, but in particular UAS of the "open" category, may be operated in any environment without an airport infrastructure or air traffic control. Furthermore, pilots of "open" category UAS do not need extensive training comparable to pilots of maned aircraft $[2,24,27]$. Therefore, their influence on the environment might be more intense than that of manned aircraft.

Another aspect in this context is the fact that presently available UAS of the "open" category have usually not been built against a solid airworthiness standard. Subsequently, airworthiness of such systems can hardly be verified [19]. Enforcing a strict airworthiness standard now and only allowing UAS that have been built and certified against such a standard to ensure safety to third parties would probably lead to an immense protest from the UAS industry.

Therefore, the focus change from the mainly technical product-certification-driven approach to an operation-driven approach is quite obvious. Nevertheless, this still represents a stark contrast to manned aviation, in which one key driver to achieve safe flight operations is an airworthy aircraft [24]. UAS of the "open" category are seen as a class of UAS operations that pose an acceptably low risk to the public if they are operated in accordance with the UAS Operations Regulation. Because of this fundamental assumption, UAS in the "open" category should not be put under prescriptive airworthiness regulations and procedures comparable to manned aviation $[6,7]$.

However, if the technical product is no longer the primary driver to ensure safety, some apparent questions come up: In which way are the other interacting aspects for ensuring safe UAS flight operations taken into account? How do the upcoming UAS regulations [6-9] encompass the human pilot, the design and/or manufacturing organisation, and the environment?

Figure 1 shows the basic interaction of aspects that influence safe UAS operation. The design/ production organisation with its production processes directly influences the quality of the UAS operated by the pilot. Furthermore, it influences the pilot by the quality of the associated operation manuals. The pilot can only operate a UAS safely if the UAS is of good and safe design and if he or she has the appropriate manuals and sufficient expertise. Both the UAS and the pilot affect the environment directly with their operation, especially in case UA crashes, whereas the designer/producer does this only indirectly but foremost also if the UA crashes because of bad design. The supervision and creation of regulations that enable the safe operation of UAS that are not deemed airworthy but safe enough to fly are obliged to the competent authorities, as was done by EASA and proposed in [6-9]. The entire regulation approach can be summarized into four central requirement aspects:

- UAS operation requirements

- Requirements of the remote pilot

- Requirements of the product

- Requirements of the organisations 
Together, these aspects guarantee safe UAS operations in the "open" and "specific" categories. All four central aspects are highlighted in the next subsections, with the focus on the "open" category because of the scope the present paper.

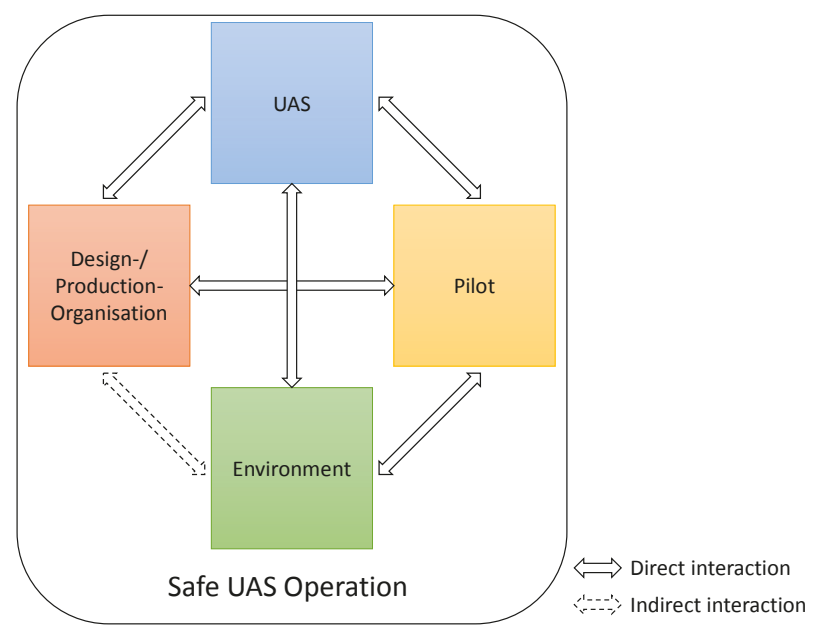

Figure 1. Aspects and their interactions affecting safe UAS operation.

\subsection{UAS Operation Requirements}

The core of the regulation approach is the allowed UAS operations, which are recorded in the UAS Operation Regulation [7] and the Part UAS [8]. These two documents are accompanied by the UAS AMC GM [9], providing guidance and AMC (cf. Section 2.4).

It is proposed by the regulation approach that there are three types of operation: A1, A2, and A3. All operations have the aim to reduce the risk for third parties to the greatest extent possible. Because of this aim and because the "open" category is made especially for UAS which are not airworthy (cf. Section 3.1), the operational limitations are very strict. The fundamental requirements on all three types of operation are [7]:

- $\quad$ All UAS operations must be conducted in the visual line of sight (VLOS) of the remote pilot. VLOS is defined as an entire unaided and unhindered view on the UA by the remote pilot.

- The UA shall not fly higher than $120 \mathrm{~m}$ above the ground, except in close proximity to a fixed object that is higher than $120 \mathrm{~m}$. In this case, the height may be increased up to $50 \mathrm{~m}$ above this object.

These two general limitations are intended to protect other airspace users as well as persons or property on the ground. Besides these general limitations, the operational requirements can be categorized into three further groups:

- $\quad$ Protection of people on the ground

- $\quad$ Required pilot competence

- $\quad$ Required UAS class

In fact, the UAS operation requirements of $[7,8]$ encompass all the central aspects that were outlined in general in Section 3.1 and Figure 1, which affect safe UAS operation. This makes it obvious why the UAS regulation approach of EASA cannot be reduced only to operational limitations. The requirements of each group are summarized in Sections 3.2.1-3.2.3. 


\subsubsection{Protection of People on the Ground}

Regarding protection of people on the ground, the distinctions between the three types of operation are presented in Table 4.

Table 4. Protection of people on the ground [8].

\begin{tabular}{ll}
\hline Operation & Requirement \\
\hline A1 & The UA shall not be flown over an open-air assembly of persons (UAS.OPEN.020). \\
\hline A2 & $\begin{array}{l}\text { The UA shall not be flown over and only in a safe distance to uninvolved persons } \\
\text { (UAS.OPEN.030). }\end{array}$ \\
\hline A3 & $\begin{array}{l}\text { The UA shall only be flown above an area where it can be reasonably expected that } \\
\text { during the entire operation no uninvolved person will be endangered. A safe distance } \\
\text { to congested areas must be maintained (UAS.OPEN.040). }\end{array}$ \\
\hline
\end{tabular}

Looking at Table 4 and at the general limitations makes it obvious that, in fact, only three operational requirements must be fulfilled by an operator who wants to conduct a UAS mission in the "open" category. Although these few requirements per type of operation seem to be clear at first sight, they leave room for interpretation. For example, is it allowed to fly a UA over individual persons in an A1 operation, or what are uninvolved persons with respect to A2 and A3 operations? Such questions can be clarified by the UAS AMC GM [9].

To discuss every single AMC in detail would be out of scope this paper. Therefore, three core aspects will be discussed:

- Open-air assembly of persons vs. individual persons

- Uninvolved persons

- $\quad$ Safe distance

EASA states within the AMC to the requirement UAS.OPEN.020 that the overflight of individual persons is allowed, and also that the overflight of groups is allowed. However, this should be minimized, and the UA should not fly less than $3 \mathrm{~m}$ above ground level. This is remarkable if one takes into account that the "open" category encompasses UA with MTOM up to $25 \mathrm{~kg}$, which could kill people if it crashes on them [28]. Nonetheless, such an interpretation is not correct, as is shown in Sections 3.2.3 and 3.3.

With respect to "uninvolved persons", only guidance is provided and no AMC is provided by the UAS AMC GM because of the vast possibilities for the definition of "uninvolved persons" [9]. In conclusion, the GM to UAS.OPEN030 and UAS.OPEN.040 defines "uninvolved person" as a person who does not occur especially for the UAS operation. An "involved person" is defined as "someone who can reasonably be expected to follow directions and safety precautions given by the person controlling the operation" (GM1 UAS.OPEN.030(1) and UAS.OPEN.040(1) [9]). This definition excludes, for example, spectators who are watching a car race which is filmed by a camera drone. To become an "involved person", the UAS operator should ask each person for an overflight permission. This guidance regarding "uninvolved person" is of special interest for military UAS operations and will be discussed in Section 4 .

Regarding the required "safe distance" for A2 and A3 operations, the UAS AMC GM makes the clear statement that this distance is highly dependent upon the design of the UAS. In case of doubt, the remote pilot has the full responsibility to ensure that a distance is kept which avoids hitting uninvolved persons by a crashing UA. Nevertheless, it is suggested that during an operation, a horizontal distance equal to the altitude of the UA above ground should be maintained. As minima, the AMC defines $5 \mathrm{~m}$ for UA capable of limiting the speed down to $3 \mathrm{~m} / \mathrm{s}$, including balloons and airships, and $50 \mathrm{~m}$ for all other cases (AMC1 UAS.OPEN.30(2) [9]). For example, a fixed-wing UA 
that flies $100 \mathrm{~m}$ above the ground must maintain a safe distance of $50 \mathrm{~m}$ to uninvolved people on the ground, but it should maintain $100 \mathrm{~m}$ distance to uninvolved people on the ground.

The brief outline on the "safe distance" showed again an important factor in order to ensure safe operation-the human pilot in the loop, who must guarantee the protection of the people on the ground affected by the UAS operation. This brings up the question, what are the necessary requirements of the remote pilot? The will be analysed in the next subsection.

\subsubsection{Required Pilot Competence}

It is stated in [7] that, besides the operator of the UAS ensuring the safety of the UAS operation, it is the remote pilot's mandatory duty to conduct every flight of a UA in such a UAS operation safely. As can be seen in Table 5, the required pilot competence is again dependent upon the UAS operation, but there is already dependency to the design of the UA with respect to the MTOM in the A1 operation.

Table 5. Required pilot competence [8].

\begin{tabular}{|c|c|}
\hline Operation & Requirement \\
\hline A1 & $\begin{array}{l}\text { UA MTOM }<0.25 \mathrm{~kg} \text { : } \\
\text { UAS familiarization is sufficient (UAS.OPEN.020(3)(a)). } \\
\text { UA MTOM } \geq 0.25 \mathrm{~kg} \text { : } \\
\text { Remote pilot competence must be demonstrated via an online training and online test } \\
\text { in a format to be defined by EASA, provided by an entity, recognized by the competent } \\
\text { authority (UAS.OPEN.020(3)(b)). }\end{array}$ \\
\hline A2 & $\begin{array}{l}\text { Remote pilot competence must be shown by obtaining a certificate of remote pilot } \\
\text { competency, by passing a theoretical test to be defined by EASA at an entity recognized } \\
\text { by the competent authority (UAS.OPEN.030(3)). }\end{array}$ \\
\hline A3 & $\begin{array}{l}\text { Remote pilot competence must be demonstrated via an online training and online test } \\
\text { in a format to be defined by EASA, provided by an entity, recognized by the competent } \\
\text { authority (UAS.OPEN.040(2)). }\end{array}$ \\
\hline
\end{tabular}

Table 5 shows that the required remote pilot competencies range from a simple familiarization up to a course including an examination. More details can be found in the related AMC to UAS.OPEN.020(3)(b), UAS.OPEN.030(3), UAS.OPEN.040(2), and GM to UAS.OPEN.030(2).

In conclusion, it is envisaged that the remote pilot who conducts A1 operations with a UA that has an $\mathrm{MTOM} \geq 0.25 \mathrm{~kg}$ or who conducts $\mathrm{A} 3$ operations must demonstrate adequate knowledge in the following fields (AMC1 UAS.OPEN.020(3)(b) and UAS.OPEN.040(2) [9]):

- Responsible behaviour, safety measures, basic knowledge of dangerous goods

- Maintaining VLOS, safe distance, and height above the ground

- Awareness regarding recognizing assemblies of persons and air traffic encounters

- Consciousness regarding the environment where the UAS operation takes place, including operational conditions, low airspace structure, prohibited areas, etc. of the Member State

- Profound knowledge of emergency procedures and the UAS operational manual

- Background knowledge with respect to types of UAS operations, related restrictions, as well as privacy and security risks.

The demonstration of these points shall be verified by the competent authority in accordance with specifications to be set up by EASA. In contrast to this, for an A1 operation with a UA of less than $0.25 \mathrm{~kg}$ MTOM, self-study of the UAS and the instructions is seen as appropriate because of the very low risk of such an operation.

Regarding the A2 operation, which poses a higher risk because it is possible to fly above involved persons, it is foreseen that the pilot must prove a deeper knowledge of the points mentioned above plus sufficient flying practice in order to obtain the certificate of remote pilot competency (AMC1 UAS.OPEN.030(3) [9]). 
After this quick look at the required pilot competencies, the "required UAS" will be discussed. This completes all aspects that affect safe UAS operation with respect to the UAS Operations Regulation [7].

\subsubsection{Required UAS Class}

As it has already been seen in the section before, the "open" category includes more than one generic class of UAS. In fact, the UAS Operations Regulation defines five classes of UAS and aligns them to the three types of operation. One could say that, with a specific class of UAS, only certain operations are allowed. In particular, specific equipment which must be part of the UAS is also required to conduct an operation. Table 6 presents the allocation of operation type to UAS class in accordance with [7].

The technical requirements of each class of UAS are discussed in Section 3.3 because they are not as extensive as traditional airworthiness codices, although they do require a more detailed review.

Table 6. Required UAS [8].

\begin{tabular}{ll}
\hline Operation & Requirement \\
A1 & C0 UAS \\
& $\begin{array}{l}\text { C1 UAS with active electronic identification and updated geo-awareness } \\
\text { systemsPrivately build UA }<0.25 \mathrm{~kg} \text { MTOM } \\
\text { (UAS.OPEN.020) }\end{array}$ \\
\hline A2 & $\begin{array}{l}\text { C2 UAS with active electronic identification and updated geo-awareness systems } \\
\text { (UAS.OPEN.030) }\end{array}$ \\
\hline & C2 UAS with active electronic identification and updated geo-awareness systems \\
A3 & $\begin{array}{l}\text { C3 UAS with active electronic identification and updated geo-awareness systems } \\
\text { Privately build UA }<25 \mathrm{~kg} \text { MTOM } \\
\text { (UAS.OPEN.040) }\end{array}$ \\
\hline
\end{tabular}

To summarize the section on UAS operation requirements, the Table 7 provides three theoretical examples for UAS applications and the related operations allowed.

Table 7. Theoretical examples for UAS operations.

\begin{tabular}{|c|c|c|c|c|}
\hline Application & Environment & Operation & UAS Class & Remarks \\
\hline Movie shoot & Old city town & $\mathrm{A} 1$ & $\mathrm{C} 0, \mathrm{C} 1$ & $\begin{array}{l}\text { The area where the movie shoot takes places is cordoned off. } \\
\text { Uninvolved persons cannot enter the area. } \\
\text { An A3 operation is not possible because the requirement to } \\
\text { maintain a safe distance to congested areas cannot be fulfilled }\end{array}$ \\
\hline Cell phone tower inspection & Open field & $\mathrm{A} 3$ & all & $\begin{array}{l}\text { Only persons who are involved with the operation are in the } \\
\text { area where the UA is flown. } \\
\text { No congested areas are close to the operation. }\end{array}$ \\
\hline
\end{tabular}

\subsection{Requirements of the Product}

Despite UAS in the "open" category not being subject to traditional airworthiness requirements, they still have to fulfil certain product or build requirements. This fact became quite obvious when analysing the UAS Operations Regulation [7] in detail. One could expect to find the technical requirements of the five UAS classes, shown in Tables 8-10, also in the UAS Operations Regulation or in the PART UAS, but this expectation is misleading. The five UAS classes and the technical requirements are part of the UAS Market Regulation [6]. Besides the definition of the UAS classes and the related requirements, the technical requirements for the necessary electronic identification and geo-awareness systems are also defined. 
The technical requirements can be found in appendices 1-6 of the UAS Market Regulation [6]. All requirements are written in a performance-based style by clearly outlining what shall be achieved but not outlining how it shall be achieved [29].

Furthermore, the requirements can be split roughly into the following groups:

- Physical characteristics

- Functional characteristics

- Documentation and marking

The number of technical requirements between the UAS classes differs. This variation can be related to the resulting risk of operation combined with UAS class:

- $\quad \mathrm{C} 0-11$ Requirements

- $\quad$ C1-20 Requirements

- $\quad$ C2-21 Requirements

- $\quad$ C3-16 Requirements

- C4-6 Requirements

Even though the number of requirements varies among the five UAS classes, many requirements are identical or almost identical. To get an overview and to compare the requirements of the five classes directly, excerpts have been taken from appendices $1-5$ of [6] and are summarized in Tables 8-10.

Table 8. UAS physical characteristics requirements excerpt [6].

\begin{tabular}{llllll}
\hline UAS Physical Requirement & C0 & C1 & C2 & C3 & C4 \\
\hline MTOM (kg) & $<0.25$ & $<0.9$ & $<4$ & $<25$ & $<25$ \\
Impact Energy (J) & - & $<80$ & - & - & - \\
$v_{\text {Max }}(\mathrm{m} / \mathrm{s})$ & $\leq 19$ & $\leq 19$ & - & - & - \\
Voltage $(\mathrm{V})$ & $\leq 24$ & $\leq 24$ & $\leq 48$ & $\leq 48$ & - \\
Sound pressure (dB(A)) & - & $<60$ & $<60$ & - & - \\
\hline
\end{tabular}

Table 9. UAS functional characteristics requirements excerpt [6].

\begin{tabular}{llllll}
\hline UAS Functional Requirement & C0 & C1 & C2 & C3 & C4 \\
\hline Safely controllable & X & X & X & X & - \\
Safe flight design & X & X & X & X & X \\
Safe work design & - & $X$ & $X$ & $X$ & - \\
Attainable height & $X$ & $X$ & $X$ & $X$ & - \\
C2Link loss procedure & - & $X$ & $X$ & $X$ & - \\
Electronic identification system & - & X & X & X & - \\
Geo-awareness system & - & $X$ & $X$ & $X$ & - \\
\hline
\end{tabular}

Table 10. UAS documentation and marking requirements excerpt [6].

\begin{tabular}{lccccc}
\hline UAS Documentation Requirement & C0 & C1 & C2 & C3 & C4 \\
\hline Manual & $X$ & $X$ & $X$ & $X$ & $X$ \\
Class identification label & $X$ & $X$ & $X$ & $X$ & $X$ \\
Serial number on UA & - & $X$ & $X$ & $X$ & - \\
\hline
\end{tabular}

A sound description on the origin and development of the five UAS classes can be found in [4,30-34]. The present paper takes the classes as given and highlights only some noteworthy aspects.

As can be seen in Table 8, despite the fact that the UAS regulation approach focuses on the operation, the first denominator in the appendices to differentiate the UA classes is the MTOM. A urther primary parameter is the allowed speed. By limiting $\mathrm{C} 0$ and $\mathrm{C} 1 \mathrm{UAS}$ to these low masses 
and respectively low velocities, the risk to people overflown is reduced immensely. In contrast to this, the $\mathrm{C} 2, \mathrm{C} 3$, and $\mathrm{C} 4$ classes do not have limitations regarding velocity. The resulting higher risk is mitigated by very prescriptive operational requirements of A3.

The C2 class has no speed limit but does have an MTOM of $4 \mathrm{~kg}$. Such a UA may fly above involved persons and at a safe distance from uninvolved persons in accordance with an A2 type of operation. Therefore, the C2 class includes the most requirements, and a certified remote pilot is required for an operation in order to compensate the resulting highest risk throughout all combinations of UAS and types of operation [4].

With respect to functional, documentation, and marking requirements, the $\mathrm{C} 1, \mathrm{C} 2$, and $\mathrm{C} 3$ classes are obliged to fulfil the same requirements entirely. Furthermore, all UAS classes fall under the essential functional requirement of "safe flight design" — the UAS must be designed and produced to fly safely. Additionally, fundamental requirements, such as the "safe work design" (a UAS obliged to this requirement can be operated safely if the user follows the instructions) or mandatory lost link procedures, reduce the operational risk by technical requirements [6].

One question might arise with respect to the C4 class, which is treated hereafter. The C4 class has, at first sight, the fewest technical requirements but the same freedom regarding MTOM and velocity as the C3 class. The resolution can be found in one unique technical requirement to this class. For C4, no automatic control modes are allowed [6]. Thus, this class must be seen as a model aircraft and not as a UAS in the common sense.

Even if the technical requirements of [6] are basically not treated as "traditional" prescriptive UAS airworthiness requirements, they ensure a high level of safety. In addition to this, similar technical requirements, for example, on the safety and correct functioning of the UAS on lost link loss procedures, or also on the controllability of the UAS can also be found in common UAS airworthiness standards (e.g., [13]).

Nevertheless, the technical requirements laid down in [6] grant a great amount of flexibility to the designers, manufacturers, distributors, or in other words, the economic operators. Consequently, the question arises of how these organisations, e.g., the economic operators, will be controlled and which processes will be applied. These significant points are the content of the next section.

\subsection{Requirements on Organisations}

It has been shown that the combination and interconnection of the driving aspects to ensure safe UAS operations can grant a sufficient level of safety. Therefore, it is not necessary to put UAS of the "open" category under prescriptive airworthiness requirements. It also allows much flexibility and freedom for the design and/or manufacturing organisations, e.g., the economic operators, because the processes for designing and manufacturing to be applied are not as strict as those in civil manned aviation [22].

However, there are also requirements for the economic operators and their processes in order to ensure that the requirements to grant safe UAS operations in the "open" category can be achieved. They are laid down in UAS Market Regulation [6] and are subdivided into requirements for the manufacturers, importers, and distributors. It can be said that this division will ensure that the UAS to be sold on the European market will comply with the requirements laid down in the market regulation throughout the entire economic chain.

At first, the manufacturer must ensure that the appropriate product complies with the applicable technical requirements and have in place appropriate procedures to prove this (Article 5, [6]).

Second, the importer must take all necessary actions to ensure that the imported product complies with the market regulation (Article 7 [6]). In fact, the importer verifies that the manufacturer has built the product in the right way.

Third, the distributor must recheck again that the UAS obtained from the importer still is in conformity with the market regulation (Article 8 [6]). 
This chain of control is obviously dependent upon how many bodies are involved in the distribution of a UAS. There must not always be the chain manufacturer-importer-distributor. It is reasonably possible that all three entities are encompassed in one company.

Besides this interdependent quality assurance between the different industrial actors, the market regulation foresees a mandatory conformity assessment of the manufacturer by so-called notified authorities and notified bodies to ensure the conformity of the UAS to the regulations already at the production origin in order to guarantee independent quality assurance (preamble, (11), [6]).

Notified authorities shall be designated by each Member State. Notified authorities are obliged to be independent but must not be a governmental body. It is also possible that the Member States designate a national accreditation body (Articles 18 and 19, [6]).

The notified authorities will entitle competent bodies as so-called "notified bodies" after a successful assessment of them with respect to the relevant requirements (Article 21, [6]). Further on, notified authorities shall monitor the notified bodies (Article 18, [6]). The main task of notified bodies is to perform the conformity assessment of the manufacturer regarding the product. If the notified body finds that a manufacturer's product is produced in conformity with the UAS Market Regulation, an EU-type examination will be issued to the manufacturer for the specific product. The individual products shall be built identical to this type. The manufacturer shall document that the product fulfils the applicable requirements in the EU declaration of conformity.

The responsible notified authority must inform the European Commission and the other Member States about the notified bodies, who may raise an objection against the notification (Article 25, [6]). A noteworthy aspect within the system of notified authority and notified body is the fact that both may subcontract other entities to perform the assessment task, although the responsibility remains with the notified authority/body (Articles 18 and 23, [6]). Figure 2 shows the interaction and related articles of the UAS Market Regulation between the European Commission, Member States, notifying authority, notified body, and manufacturer.

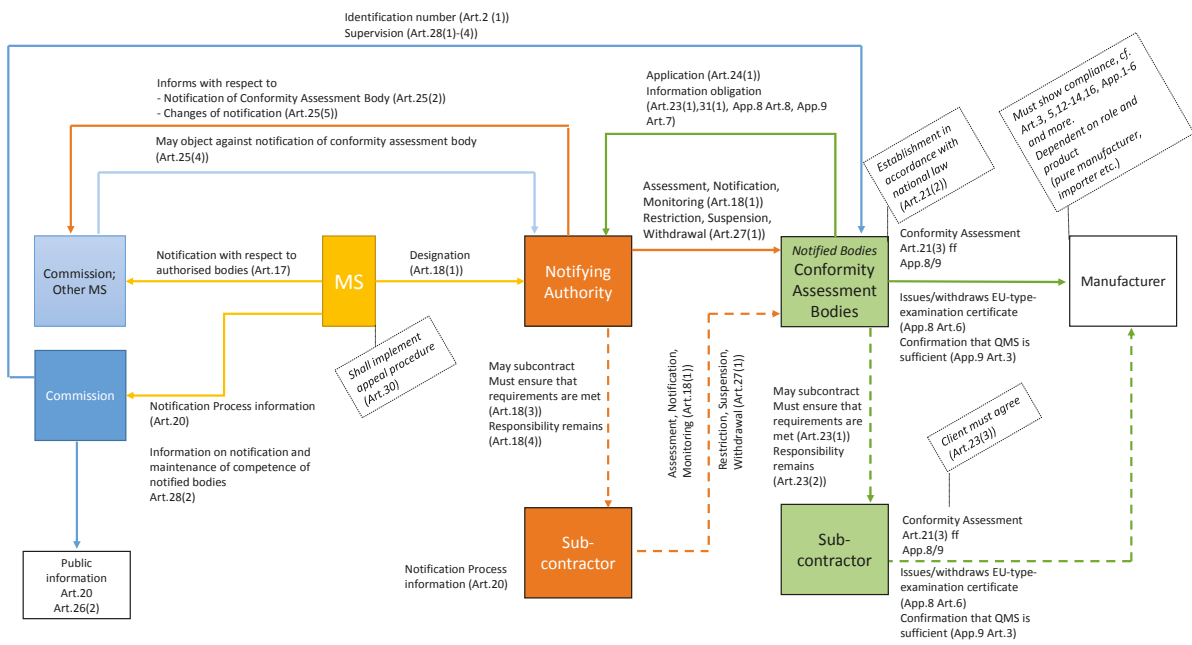

Figure 2. Interaction between stakeholders in accordance with the UAS Market Regulation [6].

At the moment, it cannot be said if the proposed system to control the economic operators in order to ensure the safety of UAS products will work as expected. The designation of the first notified bodies is especially crucial. A pure "industry controls industry" situation without any governmental oversight and control should be avoided. 


\section{Applicability of the "Open" UAS Category to Military UAS Operations}

The proposed regulatory framework for civil UAS operations of the "open" category seems to be very promising and has the potential to ease the usage of UAS in Europe immensely. If the regulations come into force as suggested by EASA, harmonization of UAS operations in Europe would be significantly advanced.

As stated in Section 1, harmonization across military forces is one essential factor. Therefore, it is very reasonable to discuss if such an approach would also be feasible for military forces. Before reviewing military UAS operations itself and if they could be compared, the paper briefly outlines some key differences between civil and military regulations in the field of aviation and airworthiness.

\subsection{Civil vs. Military Aviation}

While civil aviation is organized under the leadership of EASA as the focal point, the military aviation community in Europe does not have a single focal point. Furthermore, military aviation is usually excluded from the fundamental civil aviation agreements and laws, as for example, in the Chicago Convention of the International Civil Aviation Organization (Article 3, [35]) or the Basic Regulation of EASA (Article 2, [12]). In addition to this, military aircraft always need a special permit to fly into a foreign airspace by the state which has sovereignty over that airspace (Article 3, [35]).

Military aviation always has to achieve a balance between safety and mission accomplishment. This is related to the fact that since military aircraft are intended to fly over enemy territory in hostile airspaces, they carry weapons or operate from airfields with no infrastructure. In summary, military aircraft must be as reliable as possible in the worst environmental conditions. Taking these aspects into account, it becomes quite clear that airworthiness certification for military aircraft cannot work in the same manner as civil airworthiness does.

Furthermore, because military aircraft may carry weapons, electronic warfare items, or similar equipment, as well as the fact that these aircraft usually represent the cutting edge of aviation technology, they will probably always remain under the sovereignty of a state. Consequently, airworthiness certification bases are driven usually by the design usage spectrum of the military aircraft and therefore might differ greatly among the states of a military alliance, e.g., NATO. With respect to the above mentioned Article 3 of the Chicago Convention, this might cause many obstacles, especially within the field of UAS in which almost no limitations regarding design exist because of the absence of a human on-board $[17,18,36]$.

In order to overcome these issues and to enable harmonization in the field of military aviation on a broad, international basis, both NATO and EDA have launched several groups, for example, the NATO Flight In Non-Segregated Air Space Group (FINAS) for UAS, the NATO Aviation Committee for or at the EDA, and the so-called Military Airworthiness Authorities Forum (MAWA) for any kind of military aviation among the allies [37-39].

Today, the working groups have made several steps forward. For example, NATO was able to publish and establish harmonized airworthiness standards for UAS several years ago and continues to develop them further [13-15]. MAWA on the European side published the European Military Airworthiness Requirements 21 (EMAR 21) [40], which represents a military version of the civil Part 21 [22]. However, the latest developments have shown that those standards probably are too prescriptive for small military UAS comparable to the new civil UAS classes $[17,41]$.

As it was outlined, the civil European regulatory approach encompasses all aspects that affect the safe operation of UAS. To ensure that this principle is kept, the military community would have to apply the same principles. The next subsections take the four areas outlined in the Sections 3.2, 3.2.2, 3.3, and 3.4 and apply them to the military context.

\subsection{Military UAS Operation Requirements}

One of the biggest obstacles is probably the fact that military UAS operations cannot be limited to VLOS. For example, the UAS "ALADIN" of the German Army could be classified as C2 UAS with 
respect to the MTOM of $3.5 \mathrm{~kg}$. However, the usage quite differs: ALADIN is capable of flying up to $5 \mathrm{~km}$ away from the remote pilot at heights up to $150 \mathrm{~m}$. Such a usage is obviously not in accordance with VLOS as defined by [7]. While in military controlled airspaces this is not an issue, it would not be applicable in the regime of the new civil UAS regulations. ALADIN would automatically fall into the "specific" category, making the advantages of the "open" category obsolete [42,43].

Similar issues would probably arise if the UAS Operations Regulation were applied on the small UAS program of the German Navy. The German Navy intends to purchase several UAS of the type "PUMA AE II". The UA will be flown by the Special Forces of the German Navy at day and night. Even if this UAS is in conformity with the comparable C3 UAS class, the capability of flying up to $20 \mathrm{~km}$ in relation to the tasks of the Special Forces, for example, obtaining intelligence or observe critical evacuations, rejects the application of any of the three types of operation [44,45].

These have been only two examples of military UAS usage. Reality shows that military UAS operations are always of a complex nature, including gathering intelligence, reconnaissance, and surveillance of targets, in all kinds of environments. This also makes flying over individual persons or assemblies indispensable. Persons who are the target of such military UAS missions can probably not be counted as involved persons because they obviously will not be asked for an overflight permission. Furthermore, military forces need to take advantage of the entire capabilities of the UAS regarding range and endurance in particular [27].

\subsection{Competence of Military Remote Pilots}

Military remote pilots are required to obtain an adequate licence. This might range from remote operator certificates for small UAS up to a pilot licence if manned aviation is necessary. Furthermore, military remote pilots are required to obtain a sufficient amount of flight hours per year in order to keep their licence. An example of a national military authority that has the responsibility of oversight regarding military remote pilot licences is the German Military Aviation Authority (GMAA).

To have well-trained remote pilots is also one goal of NATO. Thus, it is not surprising that NATO has also published a standard with respect to the training of UAS operators $[16,46,47]$.

\subsection{Military Requirements of the Product}

The aspect "requirements on the product" does not need to be discussed in detail, because as written in the abstract as well as in the introduction, the military UAS community does not have a similar set of requirements for UAS as those foreseen by EASA for the "open" category and the related UAS classes [6,7].

\subsection{Requirements of Military Forces for Organisations}

National military forces might put requirements on the qualification of the contracting companies. In Europe, for example, this could be EMAR 21. However, at the moment, this also falls under the responsibility of the competent national military authorities. Furthermore, because there is not a military EASA, the national MAAs must recognize each other as competent authorities. This process is slowly on its way, but there is no guarantee that if, for example, the Spanish MAA certifies a company in accordance with EMAR 21, that this company would get the same privileges from the MAA of France. A comparable system of notified authorities, notified bodies, and economic operators, as shown in Figure 2, is not available in the military communities yet $[40,48]$.

\section{Results and Discussion}

Applying the four key areas-UAS operation requirements, requirements for the remote pilot, requirements for the product, requirements for the organisations-has resulted in the major finding that a complete application of EASA's UAS regulation approach on military UAS is not seen as feasible. In order to be consistent with EASA's regulation approach, the same strict operational limitations must be applied also on military UAS operations. It is quite questionable if such restricted operations would enable military forces to reach their mission aims, in particular, for missions abroad or missions of 
Special Forces. Nevertheless, there might be areas where it would be sufficient to perform a military operation in accordance with the civil operational regulations. For example, in training operations in the home country.

Furthermore, it cannot be said that the military community would be able to introduce an international system with respect to the oversight and control of designers, manufactures, etc. as it was described in Section 3.4. It is quite doubtful that the European nations would, for example, establish a military EASA with the power to enact standards, etc. as one single point because this would mean giving up national sovereignty over military aviation.

Regarding the competence of military remote pilots, it can reasonably be said that military remote pilots have a very high level of competence. Based on experience in flying all types of UAS, defined standards and procedures for the training of remote pilots, and the continuing growth of both of these aspects in the military UAS community, one could also say that the military remote pilots are far in advance of the civil world regarding professionalism.

Finally, with respect to the requirements of UAS products, there are already common standards in the field of airworthiness. In the context of airworthiness standards for UAS that receive a type certificate and the related certificates for airworthiness, the community of military aviation authorities was able to create mutually accepted standards. Having this in mind, this community should also be able to create a set of technical requirements for UAS that are in a similar range as the civil $\mathrm{C} 0-\mathrm{C} 4$ UAS classes are. While the requirements could become slightly more prescriptive because of the more complex and risky military operations, it should be feasible to create such a harmonized set of adequate technical requirements that provide enough product safety. In this context, it is worth considering if risk assessment tools for UAS operations could be included in a beneficial way. This topic will be discussed in an upcoming paper by the corresponding author.

In conclusion, if military aviation authorities would generate a UAS standard that carefully takes into account the proposed civil UAS regulation framework as well as the given facts regarding experience and professionalism of military UAS operators and pilots, such a standard would probably ensure an equivalent level of safety as the proposed civil European regulations for UAS.

Author Contributions: Conceptualization, O.H.; Investigation, O.H.; Supervision, F.H.; Writing—original draft, O.H.; Writing-review \& editing, O.H.

Funding: This research was funded by the Institute of Flight System Dynamics, Technische Universität München. No other external funding was received.

Conflicts of Interest: The authors declare no conflict of interest.

\section{References}

1. SESAR Joint Undertaking. European Drones Outlook Study. Unlocking the Value for Europe; SESAR: Brussels, Belgium, 2016.

2. Lowbridge, C. Flying a Drone: How Easy Is It to Fly One Safely? Available online: http://www.bbc.com/ news/uk-england-nottinghamshire-37318584 (accessed on 16 May 2018).

3. ICAO. Manual on Remotely Piloted Aircraft Systems (RPAS)//Manual on Remotely Piloted Aircraft Systems (RPAS), 1st ed.; International Civil Aviation Organization: Montréal, QC, Canada, 2015.

4. EASA. Opinion No 01/2018. Introduction of a Regulatory Framework for the Operation of Unmanned Aircraft Systems in the 'Open' and 'Specific' Categories; Related NPA/CRD: 2017-05-RMT.0230; European Aviation Safety Agency: Cologne, Germany, 2018.

5. European Union. Riga Declaration on Remotely Piloted Aircraft (Drones). "Framing the Future of Aviation"; European Union: Riga, Latvia, 2015.

6. EASA. Draft Commission Delegated Regulation (EU) ... / . . of XXX on Making Available on the Market of Unmanned Aircraft Intended for Use in the 'Open' Category and on Third-Country UAS Operators; European Aviation Safety Agency: Cologne, Germany, 2018.

7. EASA. Draft Commission Regulation (EU) ... / . . of XXX Laying Down Rules and Procedures for the Operation of Unmanned Aircraft; European Aviation Safety Agency: Cologne, Germany, 2018. 
8. EASA. Annex UAS Operations in the 'Open' and 'Specific' Categories [PART-UAS]; European Aviation Safety Agency: Cologne, Germany, 2018.

9. EASA. Draft Acceptable Means of Compliance (AMC) and Guidance Material (GM) to REGULATION ... /... [IR] Laying Down Rules and Procedures for the Operation of Unmanned Aircraft and to the Annex (Part-UAS-UAS Operations in the 'Open' and 'Specific' Categories); European Aviation Safety Agency: Cologne, Germany, 2018.

10. EASA. Certification Specifications and Acceptable Means of Compliance for Large Aeroplanes CS-25; Amendment 21; European Aviation Safety Agency: Cologne, Germany, 2018.

11. EASA. Certification Specifications for Large Rotorcraft CS-29; Amendment 4; European Aviation Safety Agency: Cologne, Germany, 2016.

12. EASA. Regulation (EC) No 216/2008 of the European Parliament and of the Council of 20 February 2008 on Common Rules in the Field of Civil Aviation and Establishing a European Aviation Safety Agency, and Repealing Council Directive 91/670/EEC, Regulation (EC) No 1592/2002 and Directive 2004/36/EC; EC No 216/2008; European Aviation Safety Agency: Cologne, Germany, 2008.

13. NATO. STANAG 4671-Unmanned Aerial Vehicle Systems Airworthiness Requirements (USAR), 1st ed.; North Atlantic Treaty Organization: Brussels, Belgium, 2009.

14. NATO. AEP-80_Rotary Wing UAV Systems Airworthiness Requirements (USAR-RW); Edition A Version 1; North Atlantic Treaty Organization: Brussels, Belgium, 2014.

15. NATO. AEP-83-Light Unmanned Aircraft Systems Airworthiness Requirements (USAR-LIGHT); Edition A Version 1; Ratification Draft 1; North Atlantic Treaty Organization: Brussels, Belgium, 2014.

16. NATO. ATP-3.3.8.1—Guidance for the Training of Unmanned Aircraft Systems (UAS) Operators; Edition A Version 1; North Atlantic Treaty Organization: Brussels, Belgium, 2016.

17. EDA. European Military Airworthiness Authorities Forum (MAWA). Available online: https: //www.eda.europa.eu/what-we-do/activities/activities-search/european-military-airworthiness-authoritiesforum-(mawa) (accessed on 19 May 2018).

18. Hirling, O.; Holzapfel, F. Applicability of Military UAS Airworthiness Regulations to Civil Fixed Wing Light UAS in Germany; Deutsche Gesellschaft für Luft-und Raumfahrt-Lilienthal-Oberth e.V: Bonn, Germany, 2012.

19. Hirling, O.; Holzapfel, F.O.R.C.U.S. risk assessment tool for operations of light UAS above Germany. Int. J. Int. Unmanned Syst. 2017, 5, 2-17. [CrossRef]

20. EASA. Policy Statement Airworthiness Certification of Unmanned Aircraft Systems (UAS); European Aviation Safety Agency: Cologne, Germany, 2009.

21. European Union. Consolidated Version of the Treaty on the Functioning of the European Union; European Union: Brussels, Belgium, 2012.

22. European Union. Commission Regulation (EU) No 748/2012 of 3 August 2012 Laying Down Implementing Rules for the Airworthiness and Environmental Certification of Aircraft and Related Products, Parts and Appliances, As Well As for the Certification of Design and Production Organisations; EU No 748/2012; European Union: Brussels, Belgium, 2012.

23. Hinsch, M. Industrielles Luftfahrtmanagement. Technik und Organisation luftfahrttechnischer Betriebe; Springer: Berlin, Germany, 2010.

24. De Florio, F. Airworthiness. An Introduction to Aircraft Certification, 3rd ed.; Butterworth-Heinemann: Amsterdam, The Netherlands, 2016.

25. NTSB. Loss of Thrust in Both Engines after Encountering a Flock of Birds and Subsequent Ditching on the Hudson River. US Airways Flight 1549 Airbus A320-214, N106US, Weehawken, New Jersey, January 15, 2009; Accident Report NTSB/AAR-10/03 PB2010-910403; National Transportation Safety Board: Washington, DC, USA, 2010.

26. Meyer, H. Oberleutnant Ludger Hölker-Ein Flugunfall. Militärgeschichte 2005, 39; ISSN 0940-4163.

27. Biermann, K.; Wiegold, T. Drohnen. Chancen und Gefahren Einer Neuen Technik; 1. Aufl.; Ch. Links Verlag: Berlin, Germany, 2015.

28. Feinstein, I.; Heugel, W.F.; Kardatzke, M.L.; Weinstock, A. Personnel Casualty Study; IIT Research Institute: Chicago, IL, USA, 1968.

29. EASA. European Plan for Aviation Safety (EPAS) 2018-2022 Including the Rulemaking and Safety Promotion Programme; European Aviation Safety Agency: Cologne, Germany, 2017.

30. EASA. Advance Notice of Proposed Amendment 2015-10. Introduction of a Regulatory Framework for the Operation of Drones; European Aviation Safety Agency: Cologne, Germany, 2015. 
31. EASA. Technical Opinion. Introduction of a Regulatory Framework for the Operation of Unmanned Aircraft; European Aviation Safety Agency: Cologne, Germany, 2015.

32. EASA. 'Prototype' Commission Regulation on Unmanned Aircraft Operations; European Aviation Safety Agency: Cologne, Germany, 2016.

33. EASA. Notice of Proposed Amendment 2017-05 (A). Introduction of a Regulatory Framework for the Operation of Drones Unmanned Aircraft System Operations in the Open and Specific Category; RMT.0230; European Aviation Safety Agency: Cologne, Germany, 2017.

34. EASA. Notice of Proposed Amendment 2017-05 (B). Introduction of a Regulatory Framework for the Operation of Drones Unmanned Aircraft System Operations in the Open and Specific Category; RMT.0230; European Aviation Safety Agency: Cologne, Germany, 2017.

35. ICAO. Convention on International Civil Aviation, 9th ed.; International Civil Aviation Organization: Montréal, QC, Canada, 2006.

36. Schwuchow, S.C. Völkerrecht als Restriktion für das Handeln von Regierungen. Diplomatie Durch Zwang und Internationales Öffentliches Luftrecht; Springer Gabler: Wiesbaden, Germany, 2015.

37. Snow, M. NATO FINAS. Presented at EASA UAV Workshop, Paris, France, 1 February 2008.

38. NATO. Aviation Committee. Available online: https://www.nato.int/cps/en/natohq/topics_69339.htm (accessed on 30 May 2018).

39. EDA. Military Airworthiness Authorities (MAWA) Forum. Available online: https://www.eda.europa.eu/ experts/airworthiness/mawa-forum (accessed on 30 May 2018).

40. Military Airworthiness Authorities Forum. European Military Airworthiness Requirements EMAR 21. Certification of Military Aircraft and Related Products, Parts and Appliances, and Design and Production Organisations; European Defence Agency: Brussels, Belgium, 2014.

41. Kräher, D. Entwicklungen aus dem Bereich der Militärischen Zulassungsvorschriften für Militärische UAV. Presented at SGW-Forum Unmanned Vehicles VI, Bad Godesberg, Germany, 4-5 July 2017.

42. Presse-und Informationszentrum des Heeres. Aufklärungssystem ALADIN. Available online: http:/ / www. deutschesheer.de/portal/a/heer/start/technik/luftfahrzeuge/ (accessed on 30 May 2018).

43. EMT. ALADIN UAV System. Available online: https://www.emt-penzberg.de/en/produkte/aladin/aladin. html (accessed on 30 May 2018).

44. Wiegold, T. DroneWatch: Marine-Spezialkräfte Bekommen Neue Aufklärungsdrohne. Available online: https: / / augengeradeaus.net/2018/05/dronewatch-marine-spezialkraefte-bekommen-neue-aufklaerungsdrohne/ (accessed on 30 May 2018).

45. BAAINBw L5.2. Beschaffungsvertrag für ein Taktisches UAS im Maritimen Umfeld Geschlossen. Available online: http:/ / www.baainbw.de/portal/a/baain/start/aktuell/ (accessed on 30 May 2018).

46. Biermann, K.; Wiegold, T. “Ich bin kein Computerspieler”. Available online: https://www.zeit.de/politik/ deutschland/2014-12/bundeswehr-drohne-heron-pilot-interview/ (accessed on 30 May 2018).

47. BMVg. Das Luftfahrtamt der Bundeswehr als Nationale Militärische Luftfahrtbehörde, 3rd ed.; BMVg: Bonn, Germany, 2018.

48. Oeltjen, B. Berlin Declaration on Recognition-Ein Weiterer Meilenstein der EUMAAC Recognition Initiative: EUMAAC-Partner Bauen Basis Für Gegenseitige Anerkennung Aus. Available online: http: / / www.luftfahrtamt.bundeswehr.de/portal/a/lufabw/start/aktuelles/ (accessed on 30 May 2018).

(C) 2018 by the authors. Licensee MDPI, Basel, Switzerland. This article is an open access article distributed under the terms and conditions of the Creative Commons Attribution (CC BY) license (http:// creativecommons.org/licenses/by/4.0/). 
MDPI

St. Alban-Anlage 66

4052 Basel

Switzerland

Tel. +41616837734

Fax +41 613028918

www.mdpi.com

Aerospace Editorial Office

E-mail: aerospace@mdpi.com

www.mdpi.com/journal/aerospace

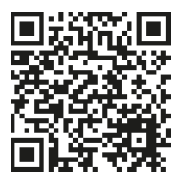



MDPI

St. Alban-Anlage 66

4052 Basel

Switzerland

Tel: +41 616837734

Fax: +41 613028918

www.mdpi.com 